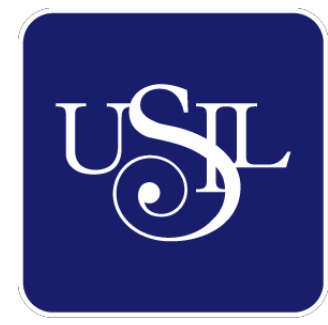

UNIVERSIDAD

SAN IGNACIO

DE LOYOLA

ESCUELA DE POSTGRADO

\title{
PLAN DE NEGOCIO PARA COMBATIR LA OBESIDAD EN EL DISTRITO DE ATE MEDIANTE UN MODELO DE NEGOCIO “CROSSFIT”
}

Trabajo de Investigación para optar el grado de:

GIANCARLO RENÁN CHÁVEZ SUÁREZ

Maestro en Ciencias Empresariales con Mención en Gestión Financiera

ARTURO ELVIDER PALOMINO MENDIOLAZA Maestro en Ciencias Empresariales con Mención en Gestión de Salud Ocupacional y Riesgos Laborales

Asesor:

Niria Marleny Goñi Ávila

Lima - Perú

2019 
Dedicatoria:

A nuestros padres por su constante apoyo durante nuestra formación académica. 
Agradecimientos:

Nuestra gratitud a la Dra. Niria Goñi Ávila por habernos brindado las herramientas necesarias y conocimiento científico durante el desarrollo de la presente investigación. 


\section{Resumen Ejecutivo}

El presente Plan de Negocios sugiere al modelo de negocio 'CrossFit' como mecanismo para combatir en el distrito de Ate para los años 2018 - 2022, mediante la empresa Ate CrossFit. El boom fitness está en su máximo desarrollo; lo cual, crea una oportunidad para el crecimiento del CrossFit dentro del mercado peruano; más aún, en uno de los distritos con mayor porcentaje de obesidad y sobrepeso, y no existe establecimiento alguno que ofrezca dicho servicio. Según la Cámara de Comercio de Lima (2018), en su Informe Especial, recoge la información de la Asociación Internacional de Clubes para la Salud, Juegos de Raqueta y de Deporte (IHRSA, por sus siglas en inglés) la población fitness en el Perú es de $1.5 \%$ a $2 \%$ del total de habitantes.

Ate CrossFit plantea que el cliente viva una experiencia fitness distinta en un Box afiliado, acondicionado y equipado; donde pueda practicar el CrossFit, que, según Glassman (2009) es un régimen de ejercicios que consiste en movimientos funcionales con constante variación y ejecutados a alta intensidad" (CrossFit, Inc., 2014), además de servicios de valor adicionales, que lo diferencian de otras actividades físicas que poseen rutinas y ofrecen servicios complementarios.

De acuerdo con la información de la Asociación Peruana de Empresas de Investigación de Mercados (APEIM, 2018), el distrito de Ate presenta un 66\% de personas que pertenecen a los Niveles Socio Económicos (NSE) A, B y C, siendo la Zona 2 del mismo distrito (ver Figura 52) la que concentra mayor población de dichos NSE; esto último, en razón a la cercanía de los distritos de La Molina y Santa Anita; así como, la profusión de centros comerciales, educativos y financieros.

Se ha determinó una inversión inicial de S/. 205,334.16 nuevos soles, adquiriendo un préstamo bancario bajo la modalidad de Préstamo de trabajo ascendente a S/. 52,000.00 nuevos soles; esto es, un 25\% del total de la inversión. Este préstamo bancario cuenta con una Tasa de Costo Efectivo Anual (TCEA) de $11.50 \%$ y una Tasa Efectiva Mensual (TEM) de $0.91 \%$ a un plazo de 60 meses.

El horizonte de vida para el presente plan de negocio es de 5 años, mismos que al término, se procederá con la liquidación y extinción de la sociedad. Bajo las condiciones expuestas previamente, y al realizar el cálculo del Flujo Económico, se obtiene un VAN ascendente a S/. 79,992.50 nuevos soles y una TIR del 39\%. Con esta información se concluye que el presente plan de negocios es viable, factible y rentable por lo tanto, se recomienda ponerlo en marcha. 


\section{Tabla de Contenido}

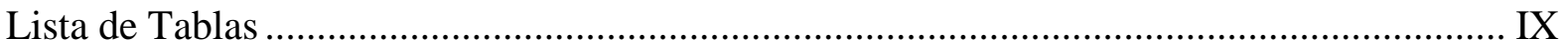

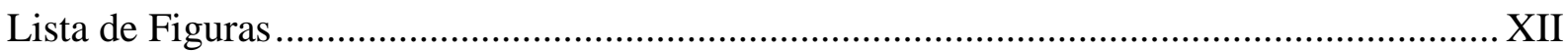

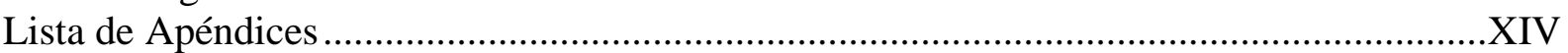

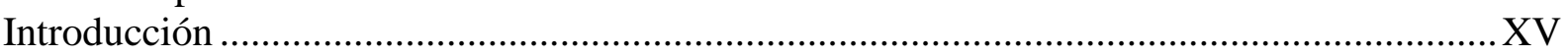

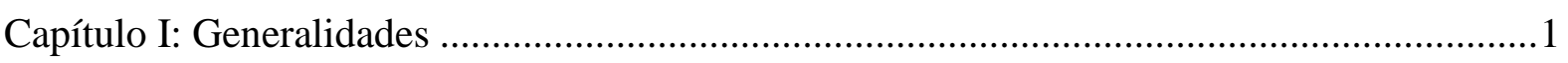

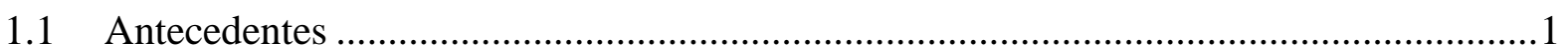

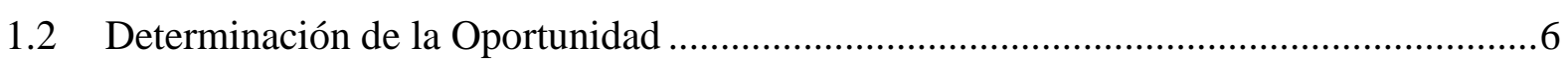

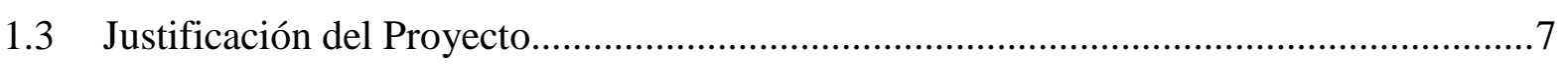

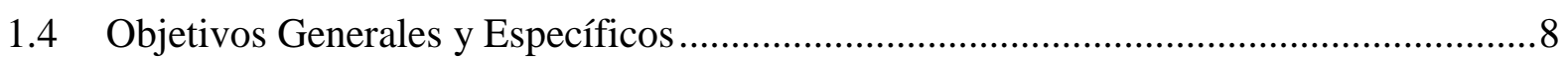

1.5 Alcances y Limitaciones de la Investigación ..........................................................

Capítulo II: Estructura Económica del Sector .................................................................. 10

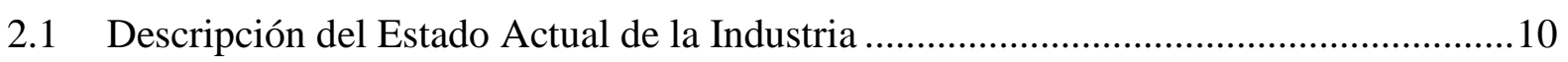

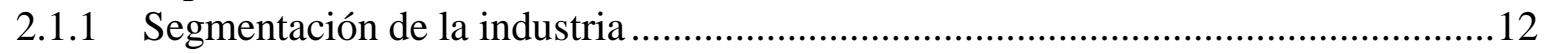

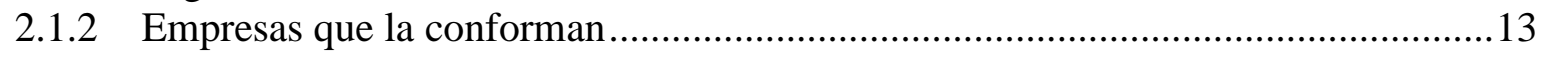

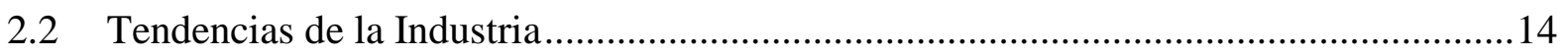

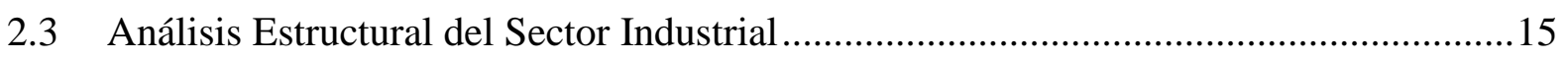

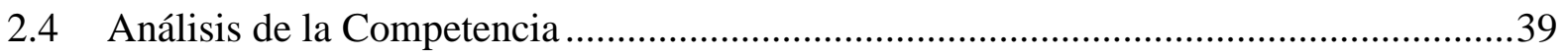

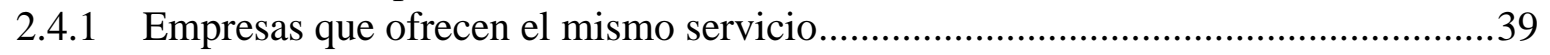

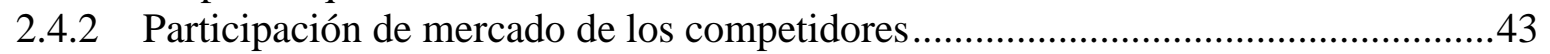

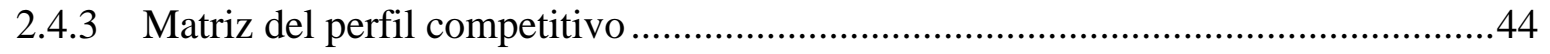

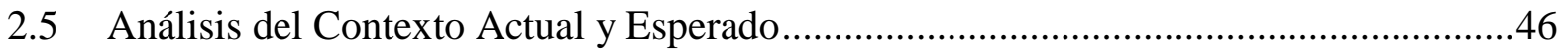

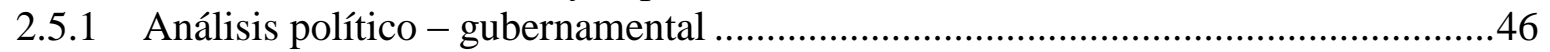

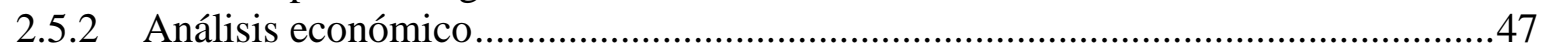

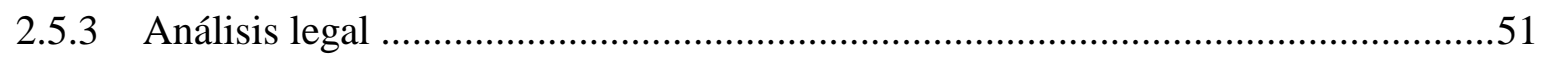

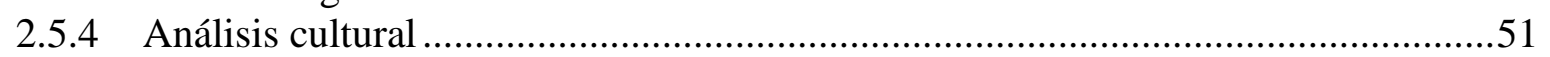

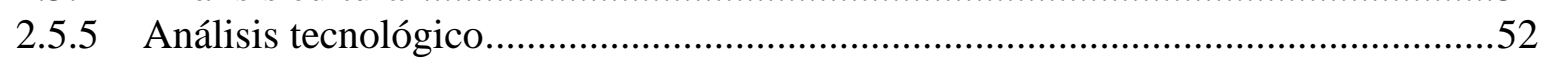

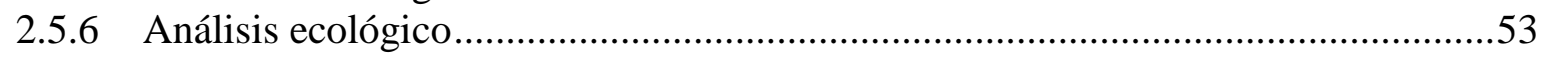

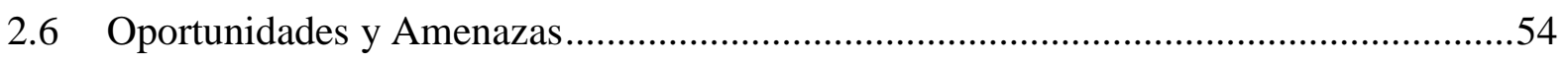

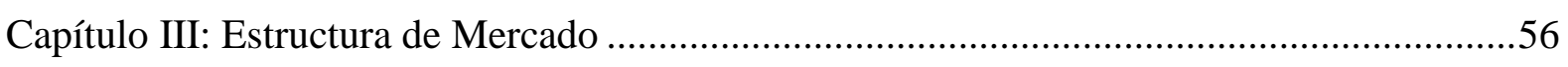

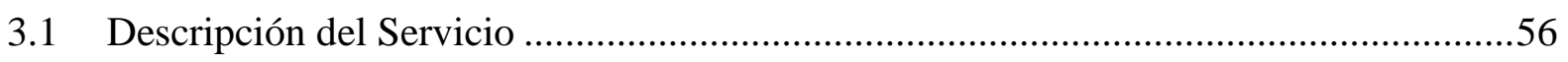

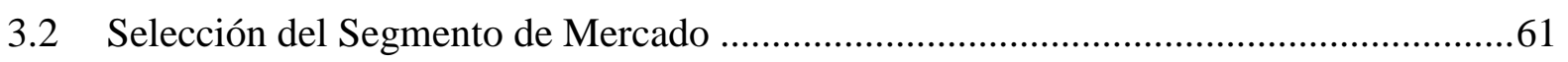

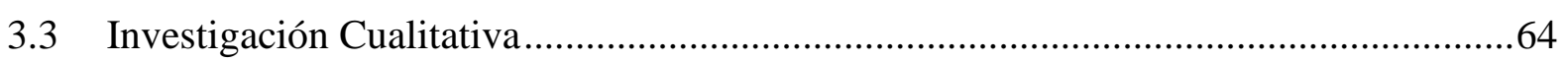

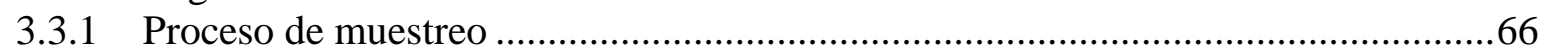

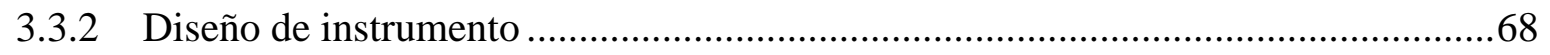

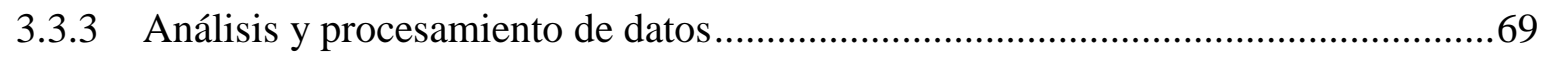

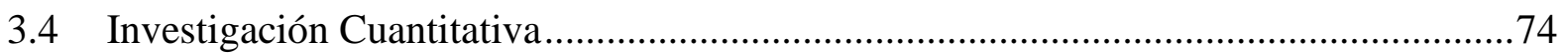

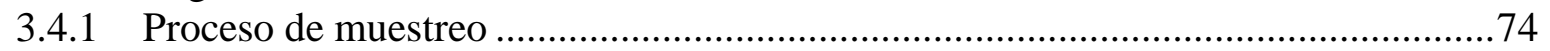

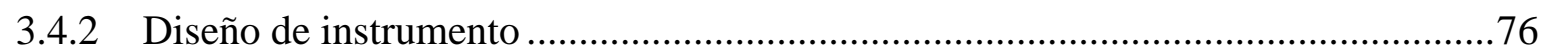

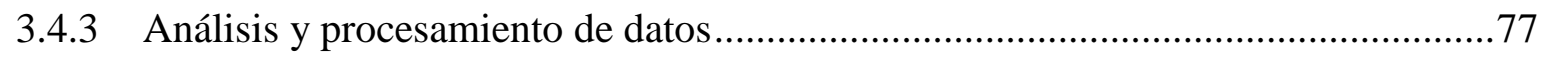

3.5 Conclusiones y Recomendaciones del Estudio Cualitativo y Cuantitativo ...................85 
3.6 Perfil del Consumidor Tipo y sus Variantes .89

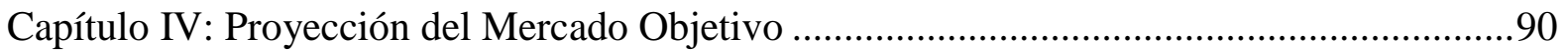

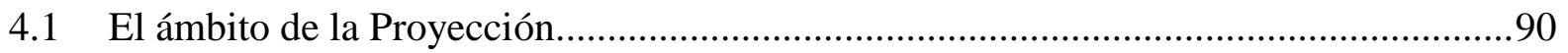

4.2 Selección del Método de Proyección ............................................................................91

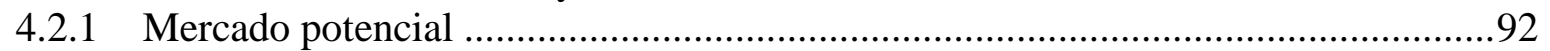

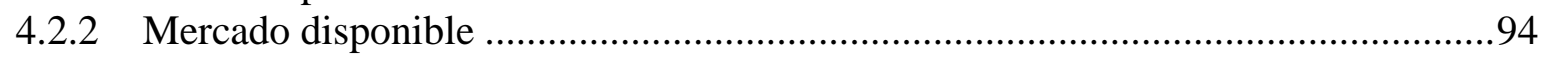

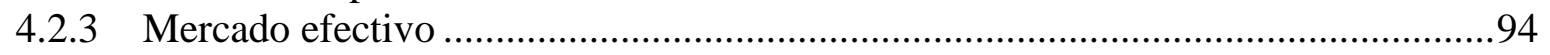

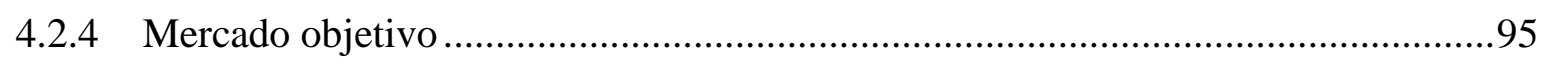

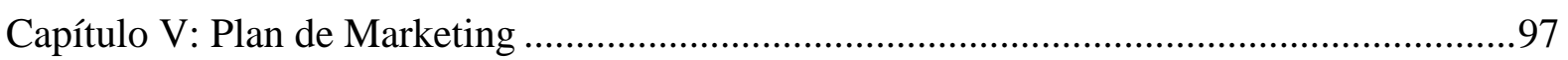

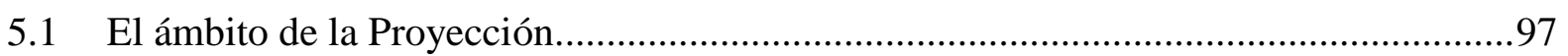

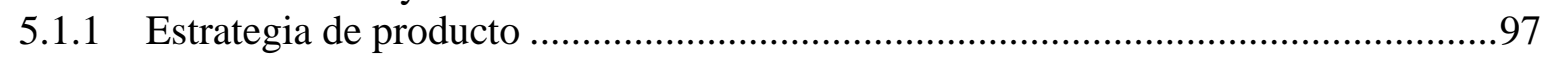

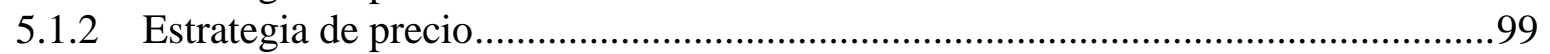

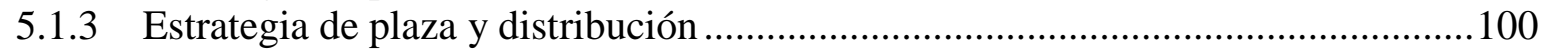

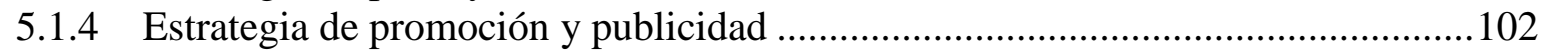

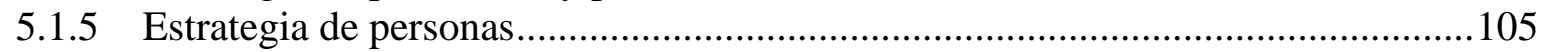

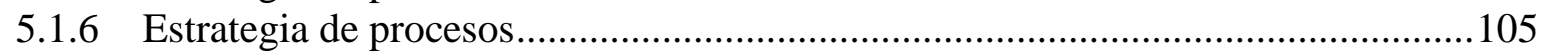

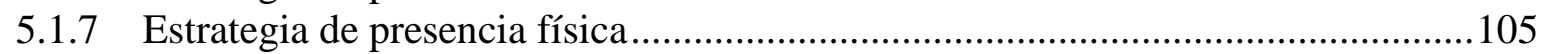

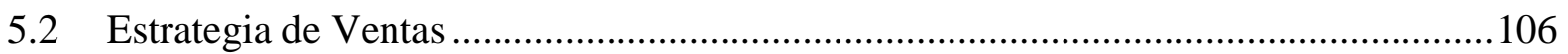

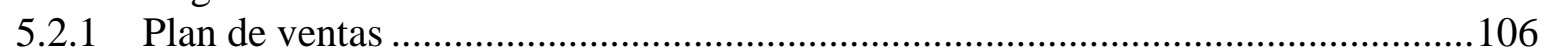

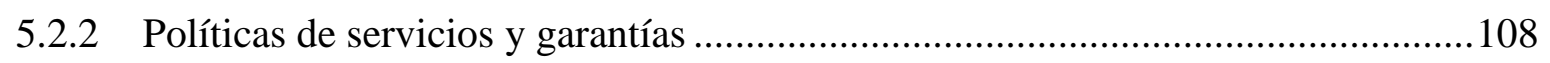

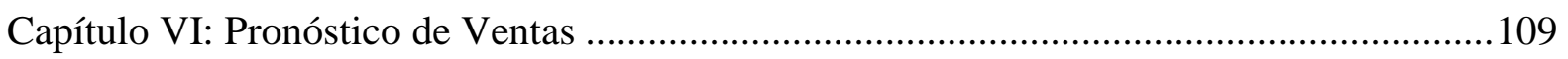

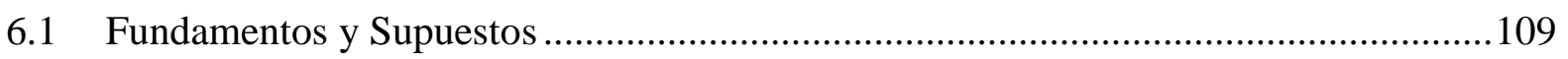

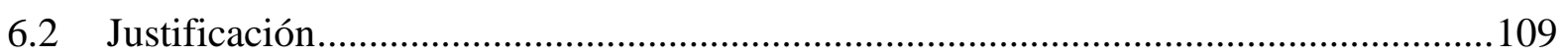

6.3 Análisis de los Riesgos y Aspectos Críticos que Impactan en el Pronóstico ................117

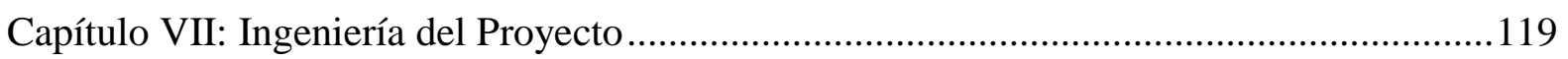

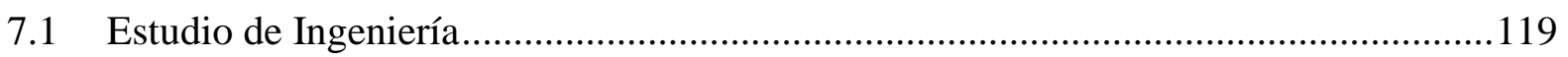

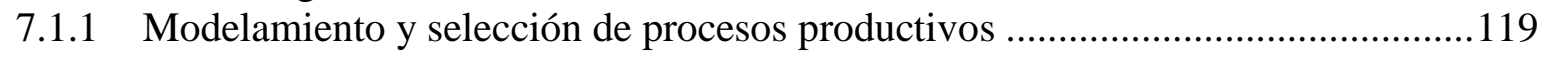

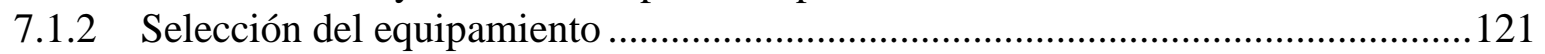

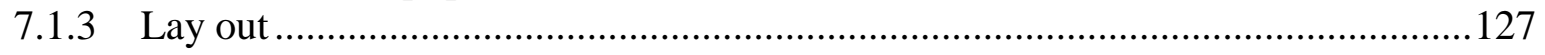

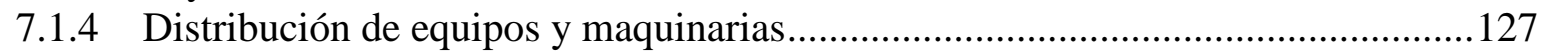

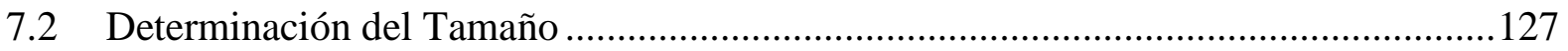

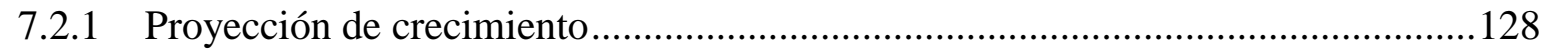

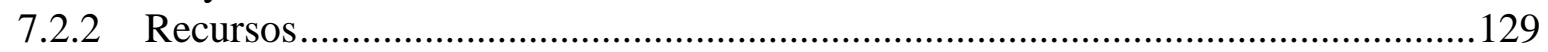

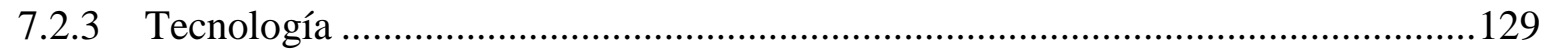

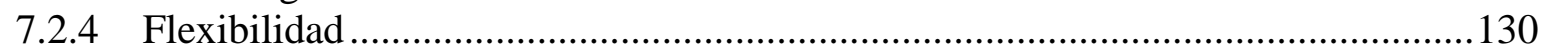

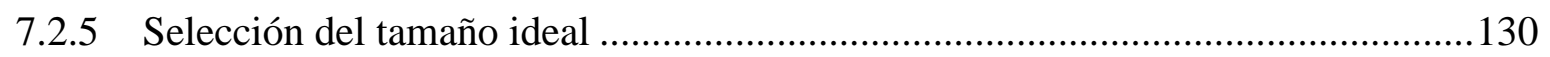

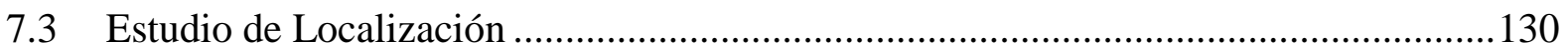

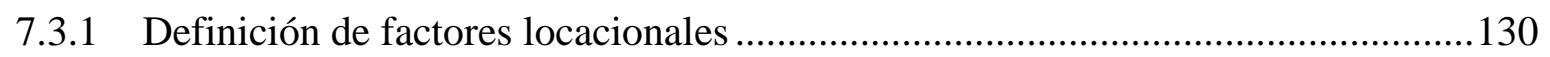

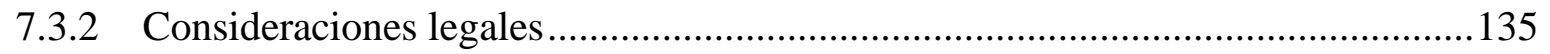

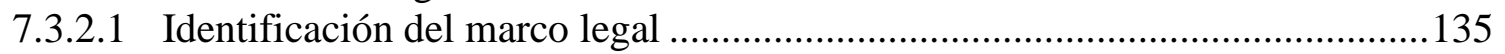

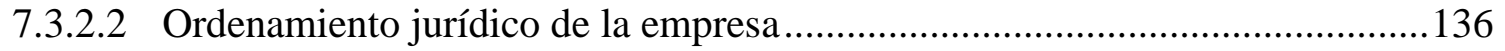

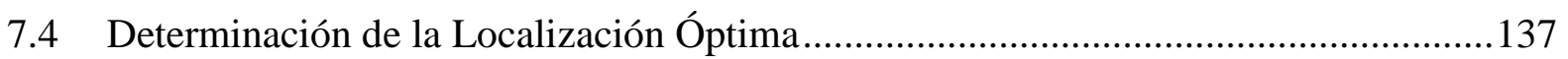

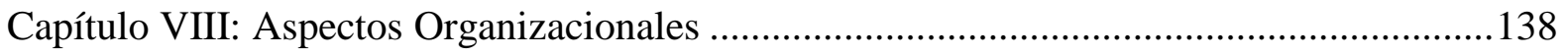


8.1 Caracterización de la Cultura Organizacional Deseada .......................................... 138

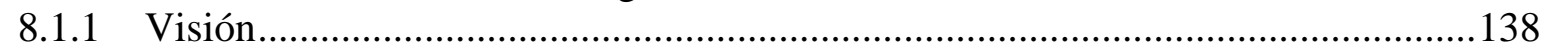

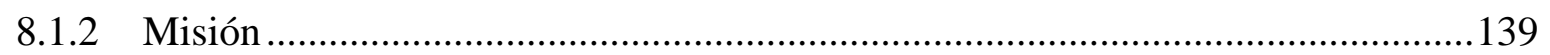

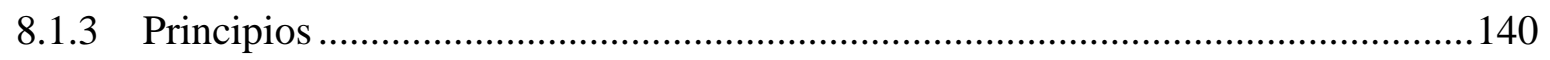

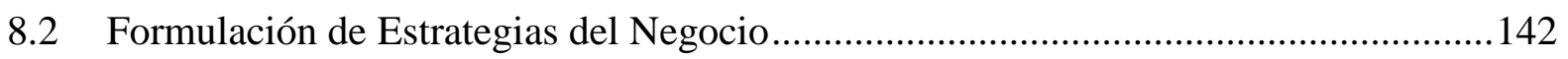

8.3 Determinación de las Ventajas Competitivas Críticas ................................................. 143

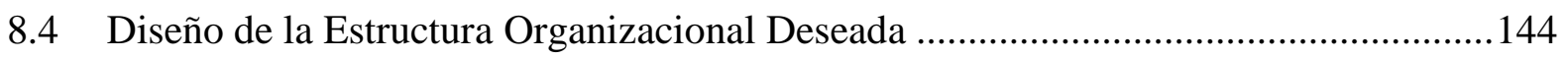

8.5 Diseño de los Perfiles de Puestos Clave..................................................................... 144

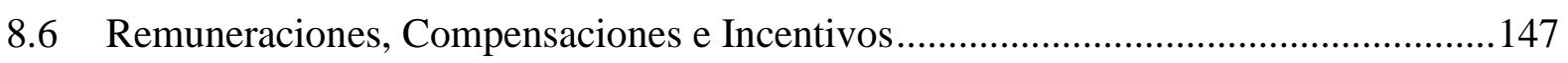

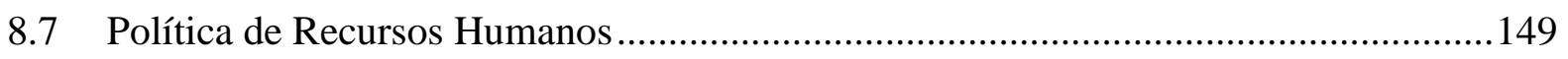

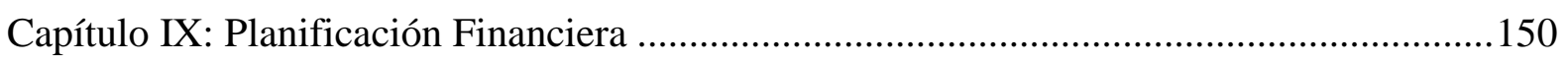

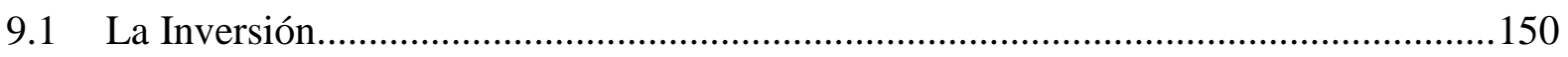

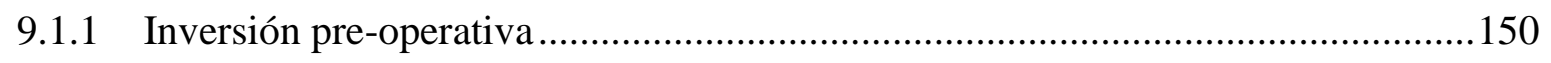

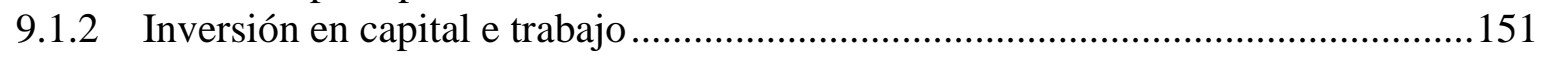

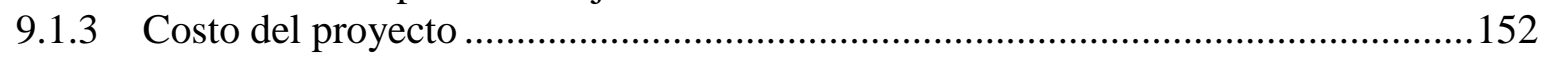

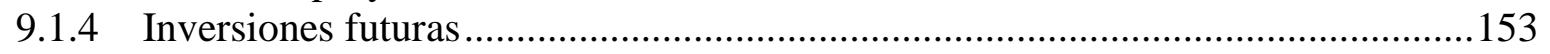

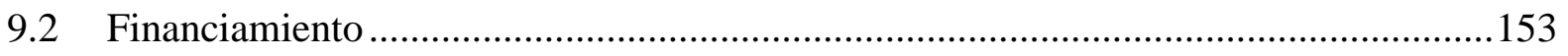

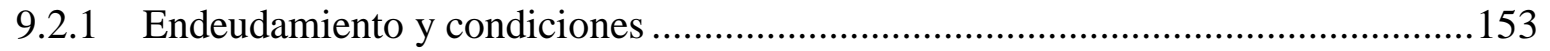

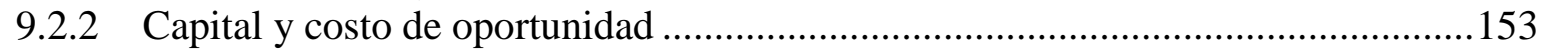

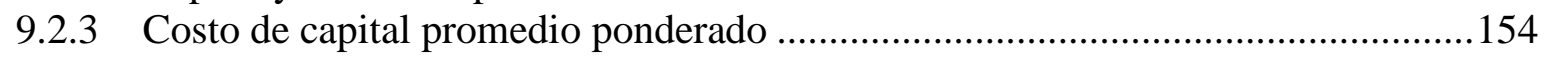

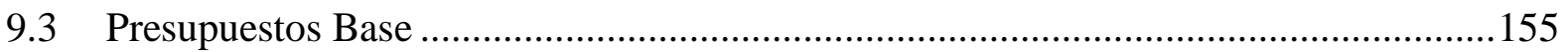

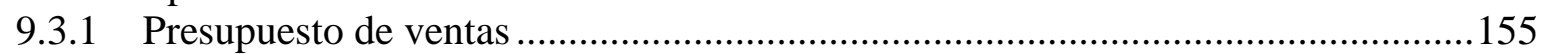

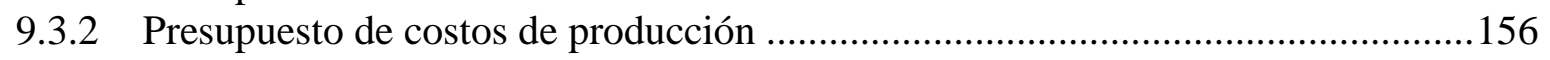

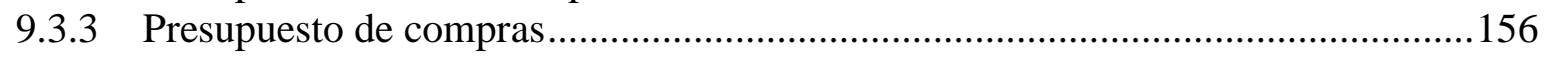

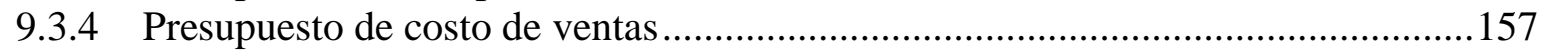

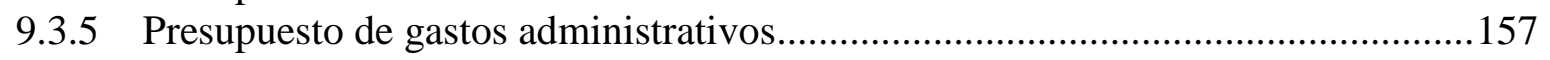

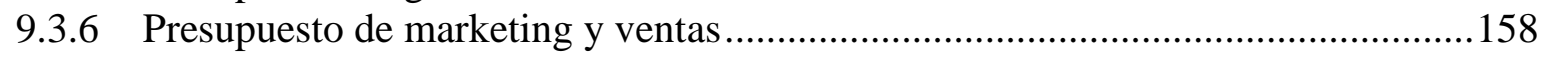

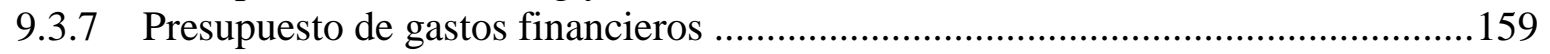

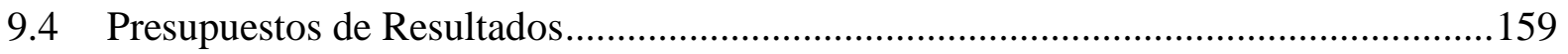

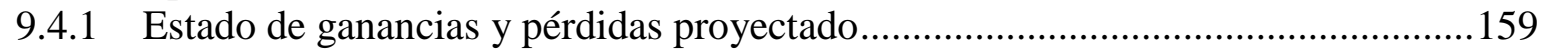

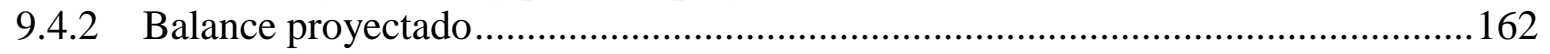

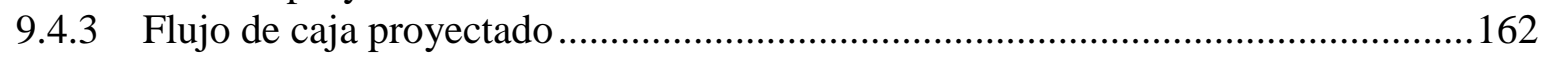

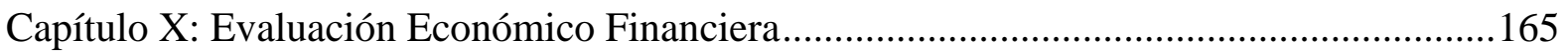

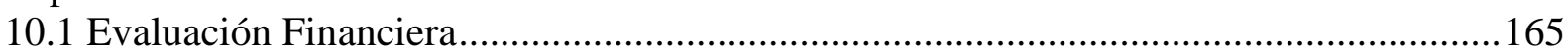

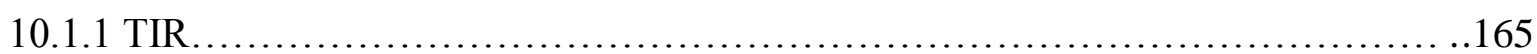

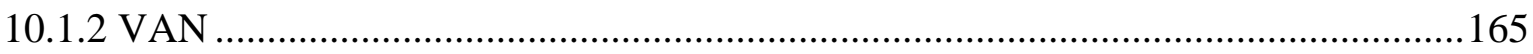

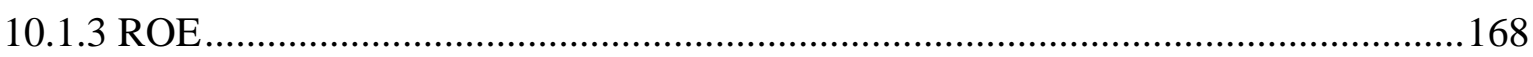

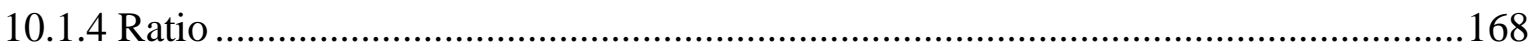

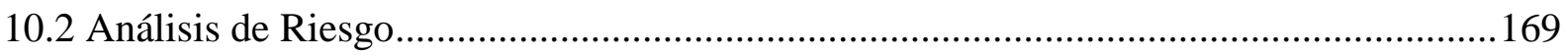

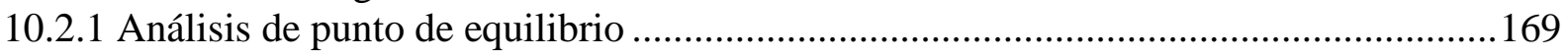

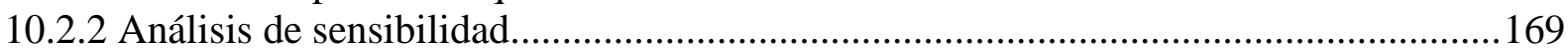

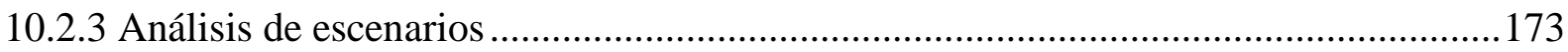

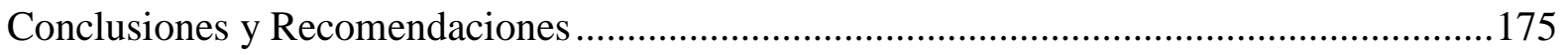

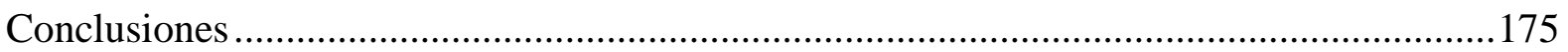


Recomendaciones

175

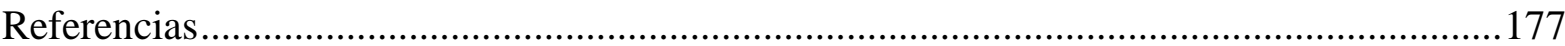




\section{Lista de Tablas}

Tabla 1. Distribución de Boxes de CrossFit Afiliados en el Perú ............................................12

Tabla 2. Boxes de CrossFit Afiliados en Lima ..........................................................................14

Tabla 3. Matriz de Atractividad para la Entrada de Competidores Potenciales ......................21

Tabla 4. Matriz de Atractividad para la Rivalidad entre los Competidores Existentes ............29

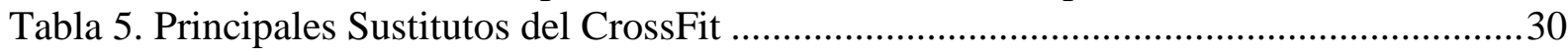

Tabla 6. Matriz de Atractividad de los Productos Sustitutos como Amenaza...........................32

Tabla 7. Matriz de Atractividad para el Poder de Negociación de los Compradores ...............35

Tabla 8. Matriz de Atractividad para el Poder de Negociación de los Proveedores.................38

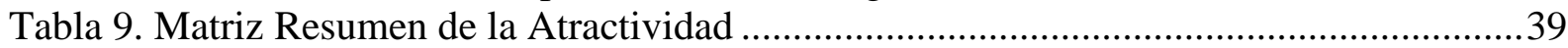

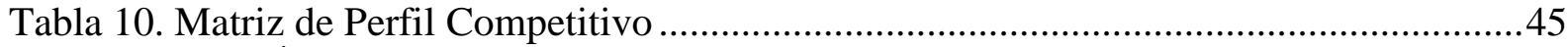

Tabla 11. Perú: Índice de Percepción de la Corrupción 2012-2017 ......................................46

Tabla 12. Matriz de Evaluación de Factores Externos .............................................................55

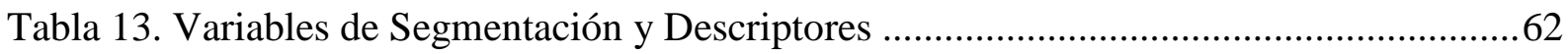

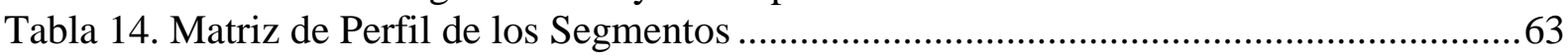

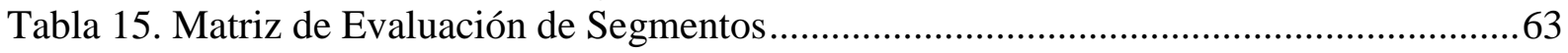

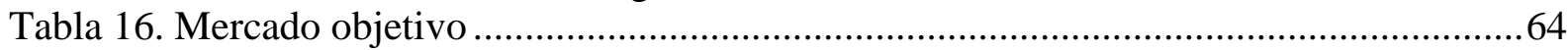

Tabla 17. Relación de Participantes del Focus Group .............................................................66

Tabla 18. Relación de Participantes de las Entrevistas a Profundidad ..................................67

Tabla 19. Relación de Expertos que Participaron en la Entrevista .........................................68

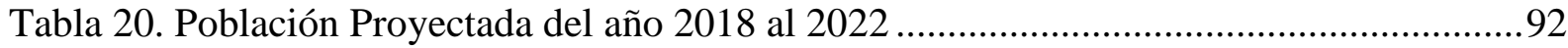

Tabla 21. Proyección de la población total de Ate al 2022 ...............................................93

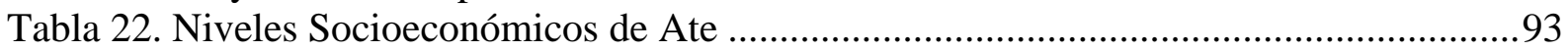

Tabla 23. Porcentaje de Edades en el Distrito de Ate .........................................................93

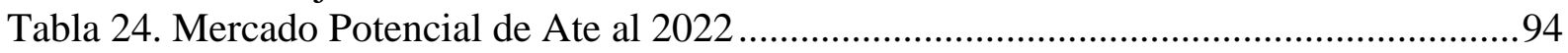

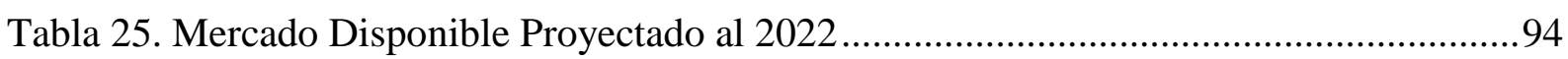

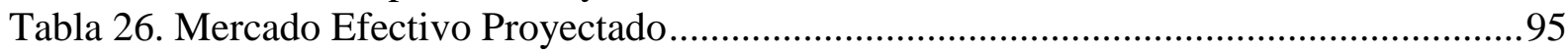

Tabla 27. Porcentaje de Participación Proyectado ....................................................................95

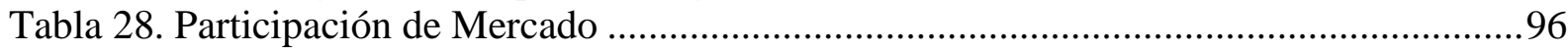

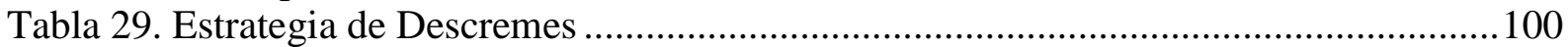

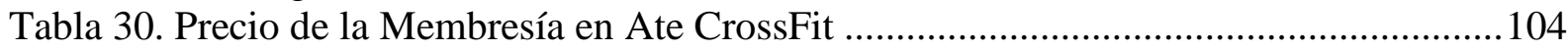

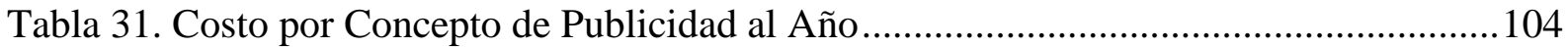

Tabla 32. Variación de Precios por Estacionalidad ............................................................... 107

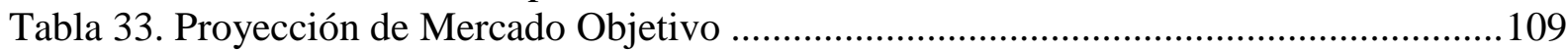

Tabla 34. Pronóstico de Cantidad de Clientes del Año 1 ........................................................110

Tabla 35. Pronóstico de Cantidad de Clientes del Año 2 .....................................................110

Tabla 36. Pronóstico de Cantidad de Clientes del Año 3 .....................................................111

Tabla 37. Pronóstico de Cantidad de Clientes del Año 4 ........................................................111

Tabla 38. Pronóstico de Cantidad de Clientes del Año 5 ....................................................112

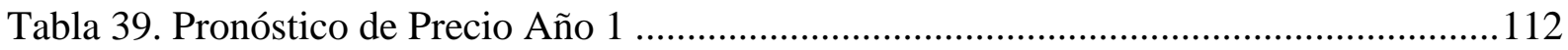

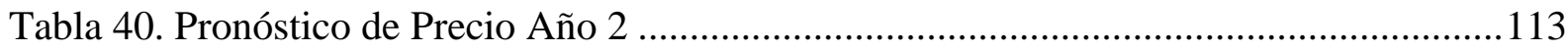

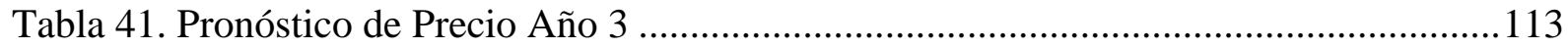

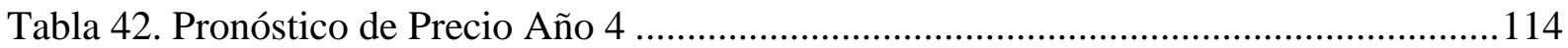

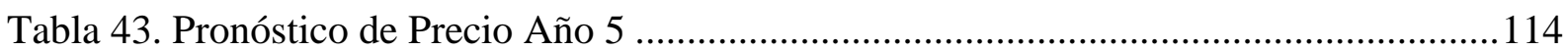

Tabla 44. Proyección del Precio por Cantidad del Año 1 ....................................................115

Tabla 45. Proyección del Precio por Cantidad del Año 2 ....................................................115

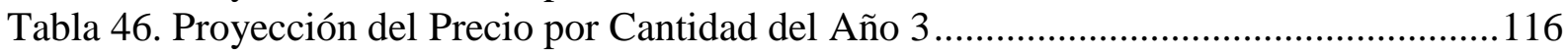

Tabla 47. Proyección del Precio por Cantidad del Año 4 .....................................................116

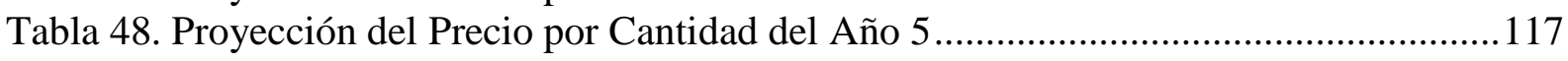

Tabla 49. Muebles y Enseres de Oficina Administrativa ...................................................121 
Tabla 50. Muebles y Enseres de Oficina de Nutrición .........................................................122

Tabla 51. Muebles y Enseres de la Oficina de Fisioterapia ...............................................122

Tabla 52. Muebles y Enseres del Área Común.....................................................................123

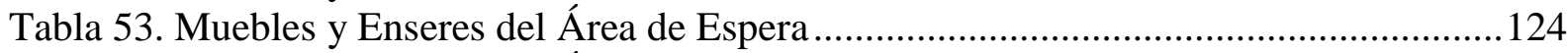

Tabla 54. Muebles y Enseres del Área de Entrenamiento ................................................... 124

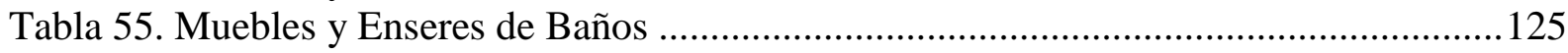

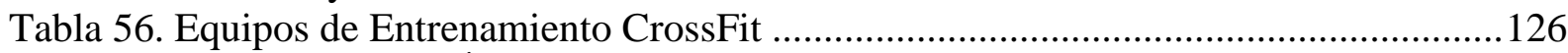

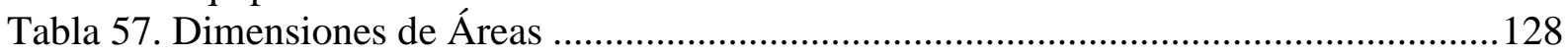

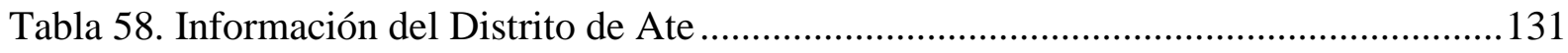

Tabla 59. Ponderación de las Zonas frente a los Factores Locacionales ................................135

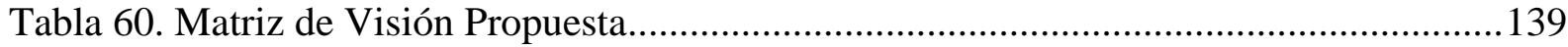

Tabla 61. Matriz de Componente de la Misión Propuesta....................................................140

Tabla 62. Matriz de Valores Propuestos ............................................................................... 142

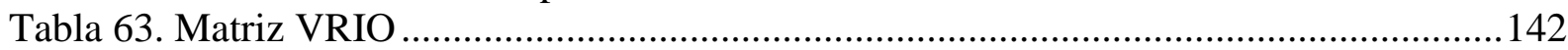

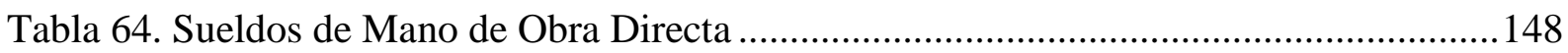

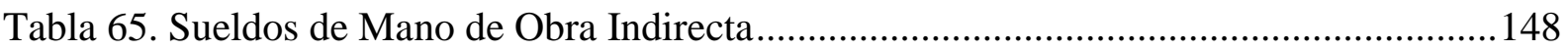

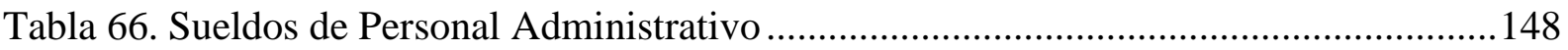

Tabla 67. Inversión en Muebles y Enseres de Ate CrossFit .................................................151

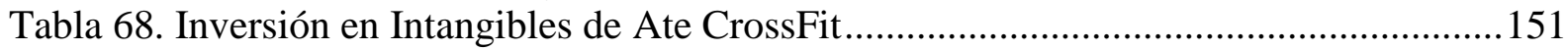

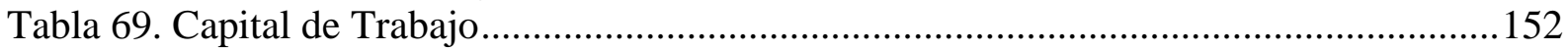

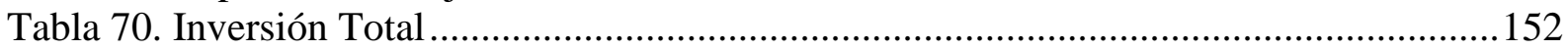

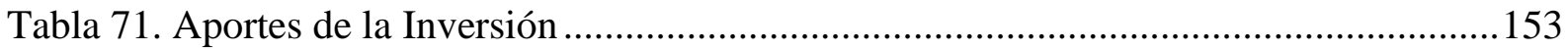

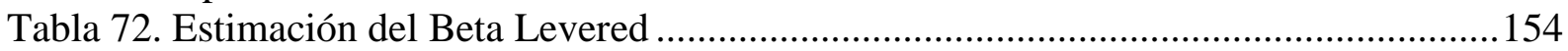

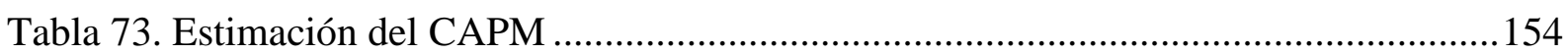

Tabla 74. Presupuesto de Ingreso y Proyección de Ventas del Año 1 al 5.............................155

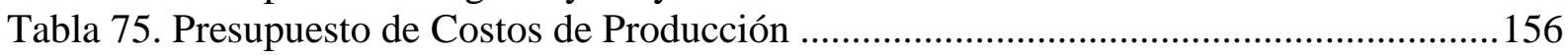

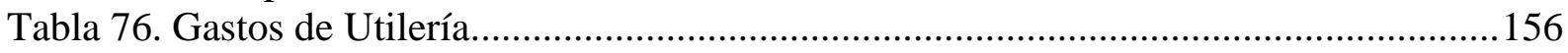

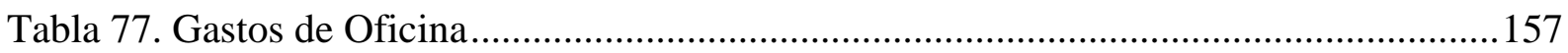

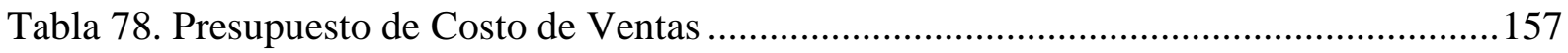

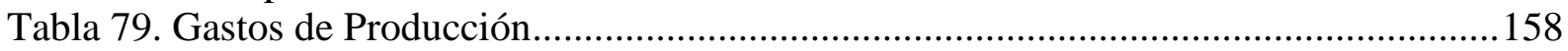

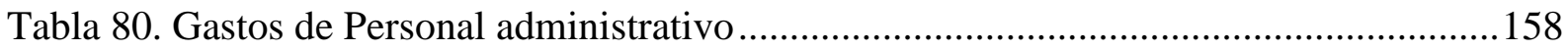

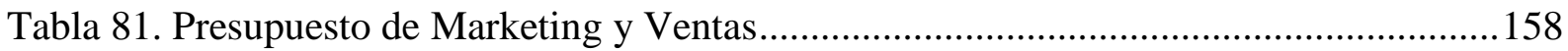

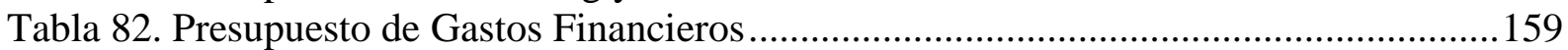

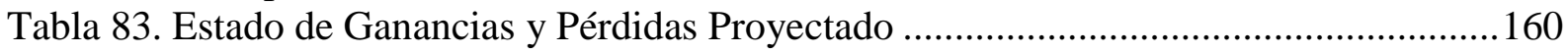

Tabla 84. Estado de Ganancias y Pérdidas Mensual Primer Año..........................................161

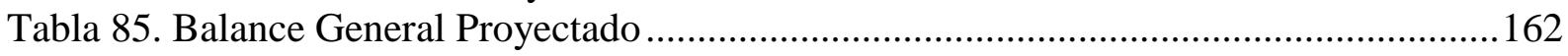

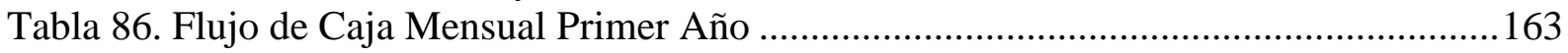

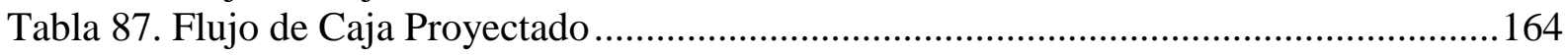

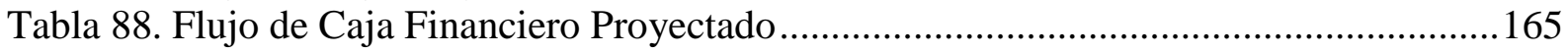

Tabla 89. Flujo de Caja Financiero Proyectado y Déficit Acumulado ...................................166

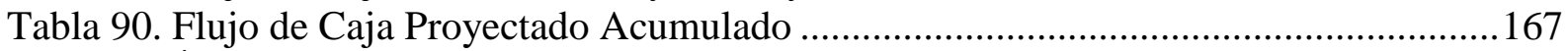

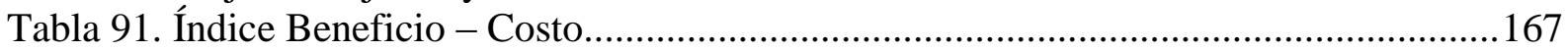

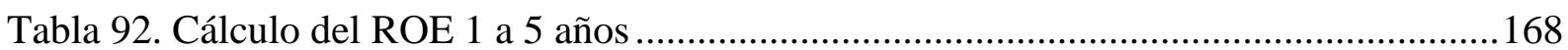

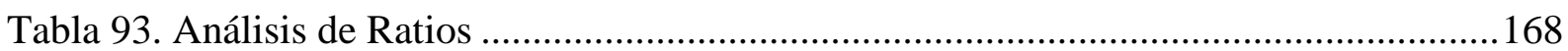

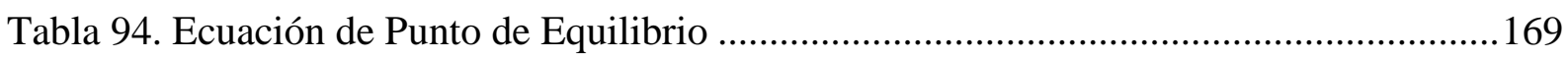

Tabla 95. Análisis de Sensibilidad de la Inversión a Financiarse ........................................170

Tabla 96. Sensibilidad por Precio Mensual de Membresía..................................................170

Tabla 97. Análisis de Sensibilidad a las Ventas ..................................................................171

Tabla 98. Análisis de Sensibilidad por Patente CrossFit .....................................................171

Tabla 99. Análisis de Sensibilidad al Precio Trimestral de Membresía ..................................172 
Tabla 100. Análisis de Sensibilidad Bidimensional Ventas sobre Precio Mensual de Membresía

Tabla 101. Análisis de Sensibilidad Bidimensional Ventas sobre Porcentaje de Endeudamiento

Tabla 102. Análisis de Sensibilidad por Escenarios

Tabla 103. Análisis de Escenarios 


\section{Lista de Figuras}

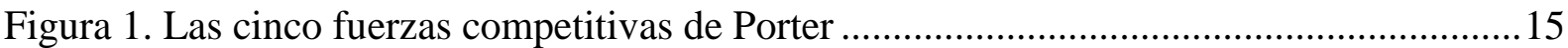

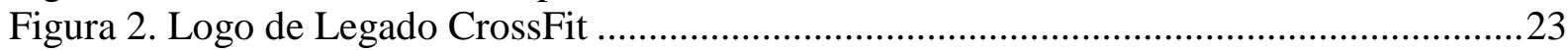

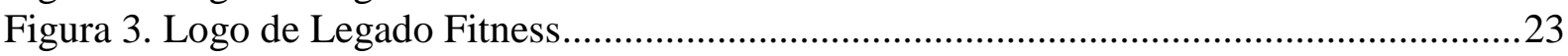

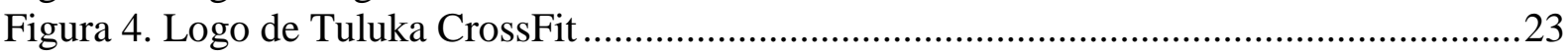

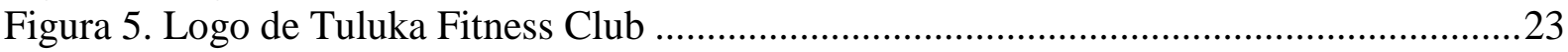

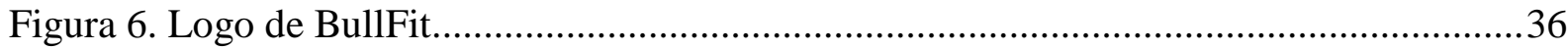

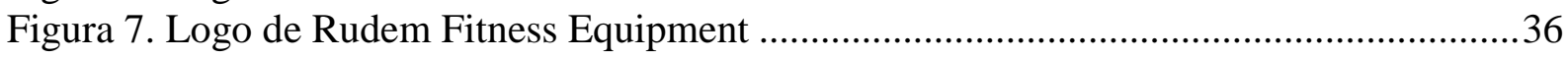

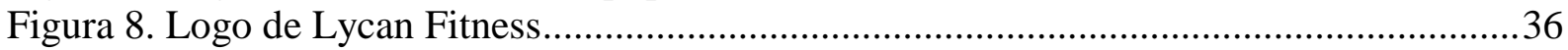

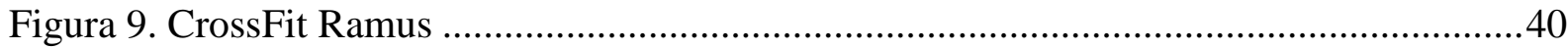

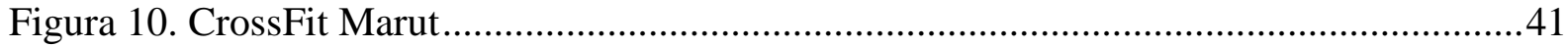

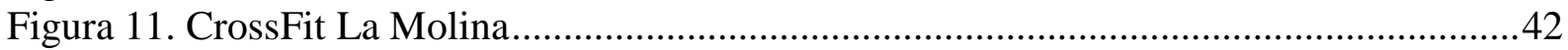

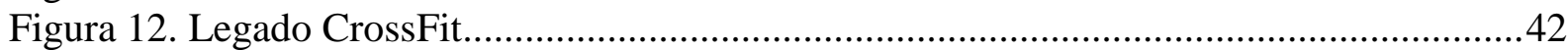

Figura 13. Nivel de Participación de los boxes de CrossFit afiliados en Lima ........................43

Figura 14. Producto bruto interno y demanda interna 2018-I.............................................48

Figura 15. Términos de intercambio. Variación porcentual promedio anual ...........................49

Figura 16. Tasa de Interés de referencia del Banco Central ...............................................49

Figura 17. Evolución del tipo de cambio de Soles por Dólares ...............................................50

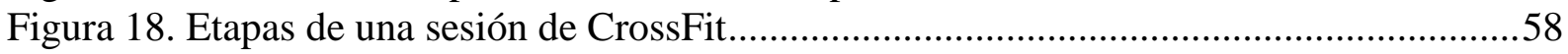

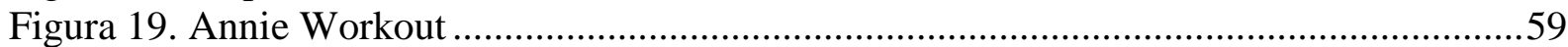

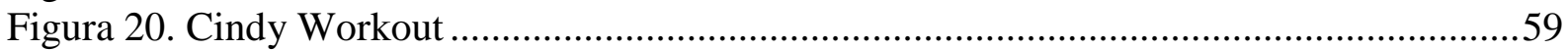

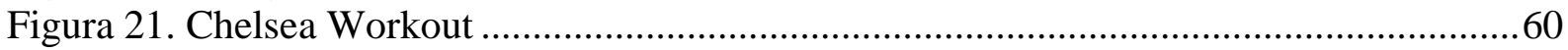

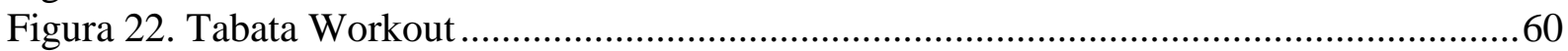

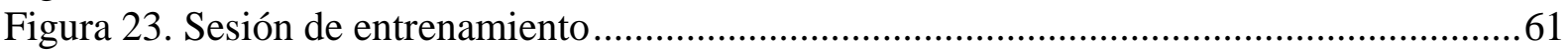

Figura 24. Porcentaje de personas que viven en el distrito de Ate. .......................................78

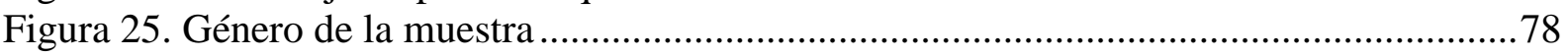

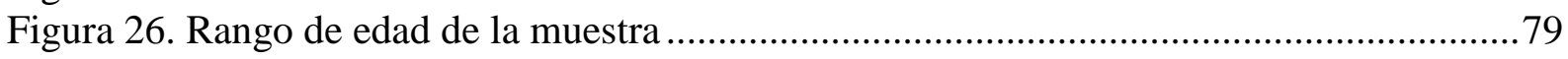

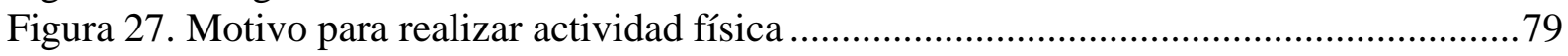

Figura 28. Preferencias de estacionalidad para hacer actividad física ................................... 80

Figura 29. Gasto promedio dispuesto a pagar por servicio CrossFit ......................................8

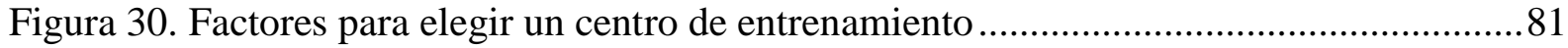

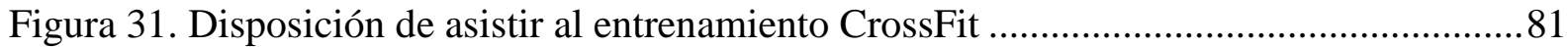

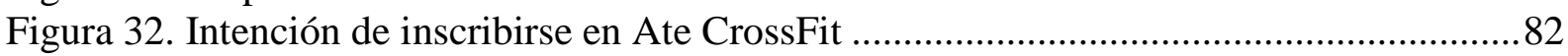

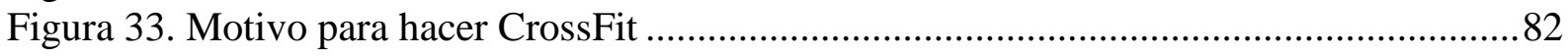

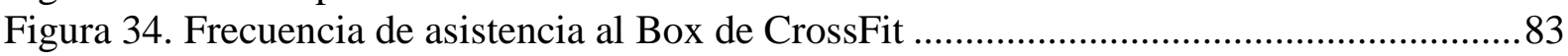

Figura 35. Horario de preferencia para acudir al Box de CrossFit ......................................83

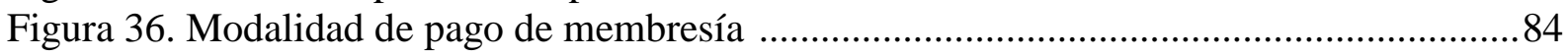

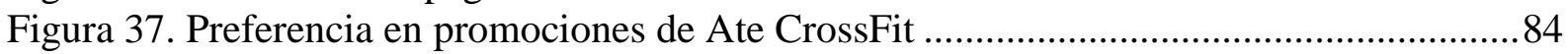

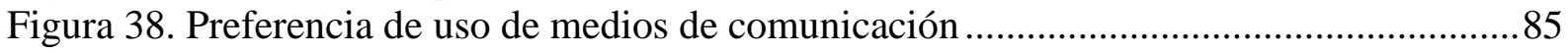

Figura 39. Proyección de la población del distrito de Ate .....................................................91

Figura 40. Regresión Lineal de la población de Ate 2005-2022 ........................................92

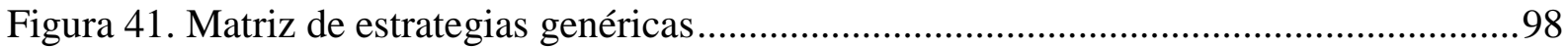

Figura 42. Mapa de ubicación geográfica de Ate .................................................................101

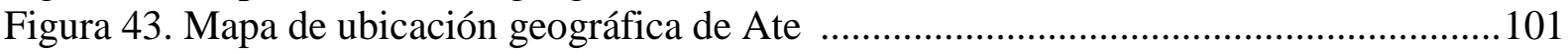

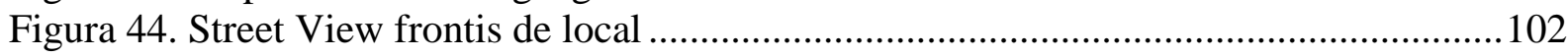

Figura 45. Preferencia de canal de comunicación .............................................................102

Figura 46. Preferencia e canal de comunicación para box de crossfit .................................103

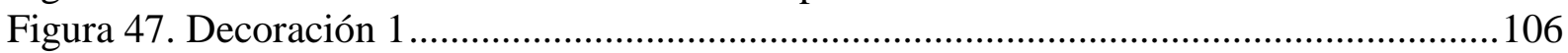

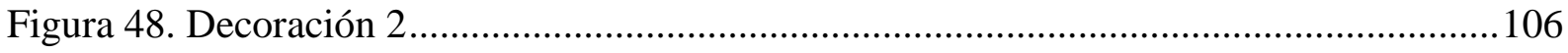

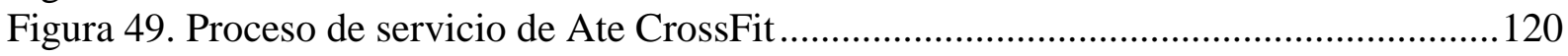




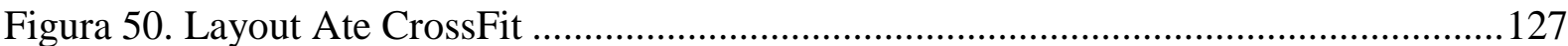

Figura 51. Preferencia de horario para asistir al Box de CrossFit ......................................129

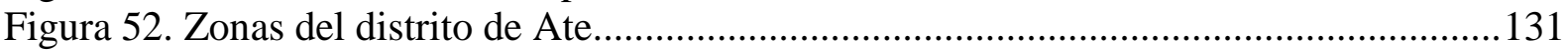

Figura 53. Distrito de Ate: Ubicación del distrito en Lima Metropolitana.............................132

Figura 54. Distrito de Ate: Límites del distrito de Ate ........................................................ 132

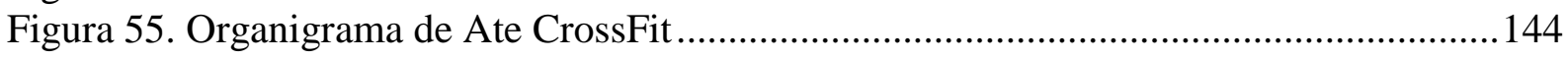




\section{Lista de Apéndices}

Apéndice 1 Resumen de Ficha de Reclutamiento.............................................................180

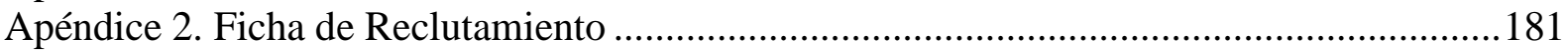

Apéndice 3. Ficha de Reclutamiento de Yaniré Macalopú..................................................186

Apéndice 4. Ficha de Reclutamiento Sandra Parodi ..............................................................191

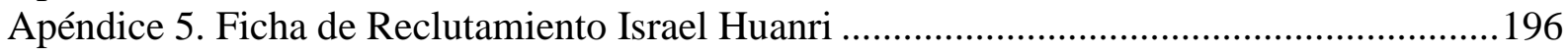

Apéndice 6. Ficha de Reclutamiento Aaron Vargas ............................................................201

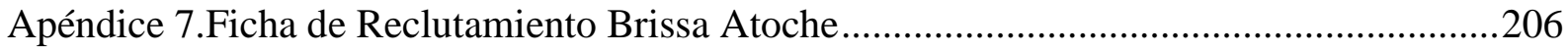

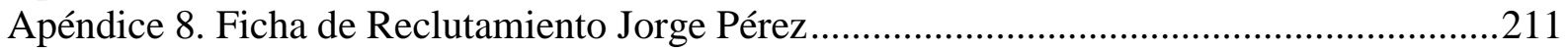

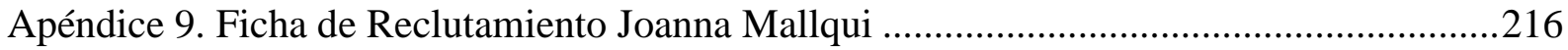

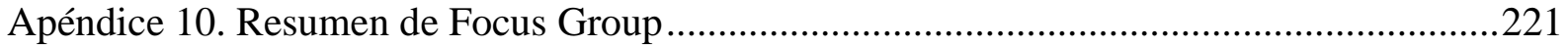

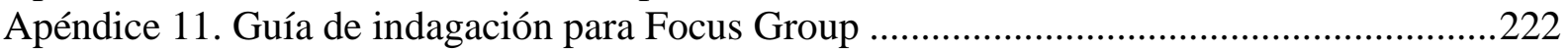

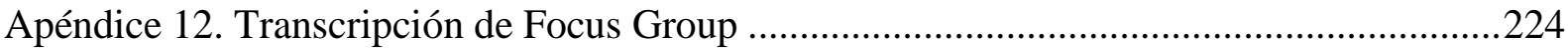

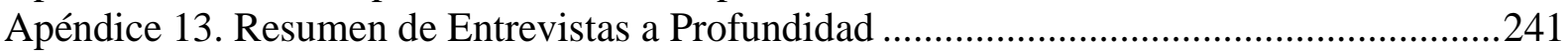

Apéndice 14. Esquema de Entrevista a Profundidad .........................................................242

Apéndice 15. Entrevista a Profundidad Alfonso Uribe León ................................................244

Apéndice 16. Entrevista a Profundidad Pamela Chunga Seminario .......................................248

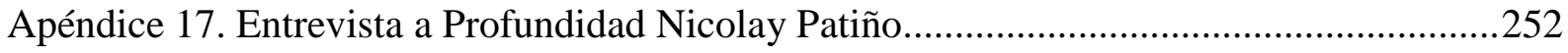

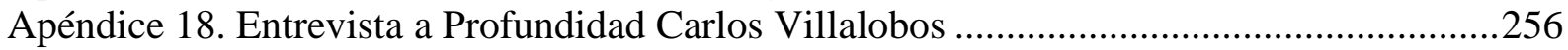

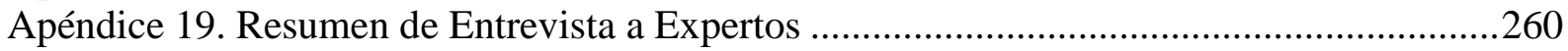

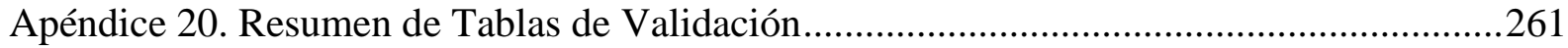

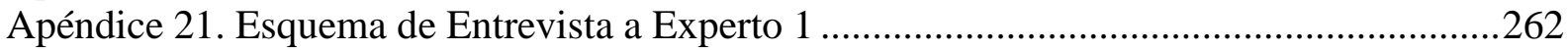

Apéndice 22. Transcripción de Entrevista a Experto 1 ….......................................................264

Apéndice 23. Validación de Factores Externos Claves por Experto 1 ..................................269

Apéndice 24. Ponderación de Factores Externos Claves por Experto 1 ................................270

Apéndice 25. Calificación de Factores Externos Claves por Experto 1 ................................271

Apéndice 26. Validación de Factores Críticos por Experto 1 .............................................2272

Apéndice 27. Ponderación de Factores Críticos por Experto 1 ............................................273

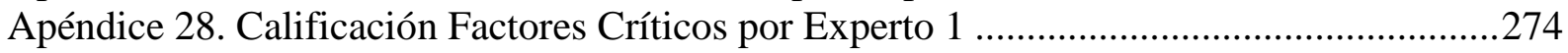

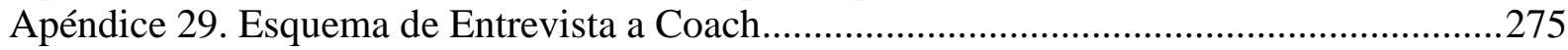

Apéndice 30. Transcripción de Entrevista a Experto 2 ....................................................277

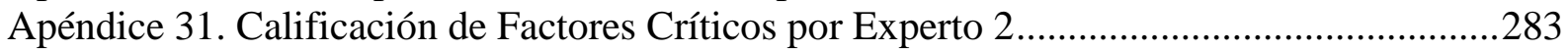

Apéndice 32. Transcripción de Entrevista a Experto 3 ….....................................................2. 284

Apéndice 33. Calificación de Factores Críticos por Experto 3 ...........................................28

Apéndice 34. Síntesis de Calificación de Factores Críticos ................................................289

Apéndice 35. Resultados de Calificación por Expertos ......................................................290

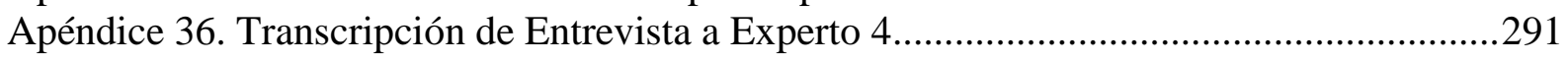

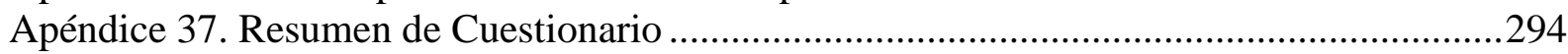

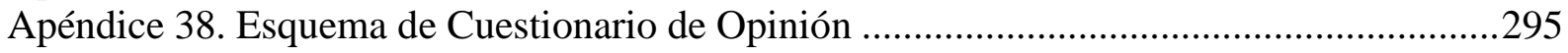

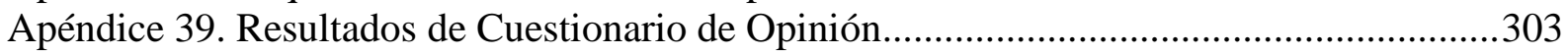

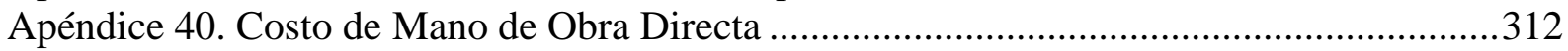

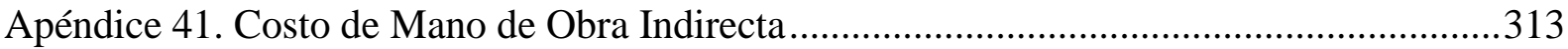

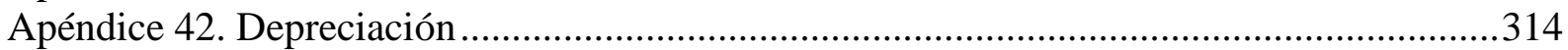




\section{Introducción}

El auge y crecimiento del denominado "Boom Fitness" en el Perú durante los últimos años ha sido sorprendente. Esto último, se debe gracias a la promoción de diversas actividades deportivas que prometen mejorar la calidad de vida de las personas, ya sea desde el aspecto físico, mejora en la salud, generar confianza e inclusive combatir la obesidad; pero todas estas, con el único fin: tener una vida más sana. Un claro ejemplo de esto, se puede apreciar con el aumento de establecimientos que ofrecen distintos tipos de entrenamiento, tales como: gimnasios, sedes de entrenamiento funcional y de alta intensidad; así como, aquellas personas que por iniciativa propia emprenden como Personal Trainer dentro del mercado Fitness, brindando asesoría nutricional y una programación de ejercicios, ya sea desde rutinas diarias mediante correos o mensajes hasta el uso de aplicaciones móviles de entrenamiento personalizado.

A nivel mundial, estas tendencias han crecido de manera extraordinaria; ya sea porque los usuarios están en búsqueda de actividades que sean distintas a las agobiantes rutinas de entrenamiento tradicional que ofrecen los gimnasios, a tal punto que llegan a considerar aquellas actividades cuyo diseño de entrenamiento está basado para atletas de competencia mundial, y así poder superar sus capacidades físicas; llegando incluso a convertirlas en nuevas disciplinas. Un ejemplo claro de ello, es el CrossFit

El presente trabajo de investigación denominado, Plan de Negocio para combatir la obesidad en distrito de Ate mediante un modelo de negocio 'CrossFit' se ha desarrollado para determinar la viabilidad de los centros de entrenamiento CrossFit, así como la rentabilidad de la misma y si es factible aperturar en uno de los distritos con mayor porcentaje de obesidad.

Capítulo I. Generalidades

Se explica los antecedentes que permitieron obtener indicios de la existencia de una problemática y que, en base al presente plan de negocios se busca dar respuesta; así también, se determina la oportunidad para el desarrollo de la presente investigación; así como, la justificación en base a una posible solución de la problemática encontrada. De igual forma, se propone los objetivos generales y específicos a alcanzar; y finalmente, los alcances y limitaciones de la investigación.

\section{Capítulo II. Estructura Económica del Sector}

Se realizó un estudio sobre el estado actual de la industria Fitness dentro del mercado peruano; así como, la segmentación del mercado. De igual forma, se analiza las tendencias de la industria tanto en su crecimiento como el nivel de su inversión; también se analiza a la competencia (competidores fuertes, así como sus sustitutos), ya que todas las empresas de 
este mercado ofrecen la mejora en salud, y sería importante determinar las grandes diferencias que existen entre una y otra; para ello, se ha definido cuanto es la participación en el mercado de cada uno. Se ha realizado una matriz de perfil competitivo, con la finalidad de identificar como se encuentra el Box de CrossFit frente a sus principales competidores; para se determinó los principales factores claves del éxito de los más grandes Box de CrossFit del mercado y como adaptarlas a nuestro Core del negocio, obteniendo una competencia central que con el tiempo será la ventaja competitiva. Asimismo, se identifica las debilidades y fortalezas, para posteriormente otorgar el análisis de los factores externos del mercado, con la finalidad de identificar la oportunidad de desarrollo de Ate CrossFit.

Capítulo III. Estudio de Mercado

Se desarrolla la descripción del servicio que ofrece Ate CrossFit; el mercado hacia donde apunta y sobre todo, se coteja con una investigación cuantitativa y cualitativa, para posteriormente determinar las conclusiones y recomendaciones de la misma; y con ello, determinar el perfil de los consumidores, así como sus variantes.

\section{Capítulo IV. Proyección del mercado Objetivo}

Se realiza una investigación de mercado, recopilando y analizando datos de cualquier aspecto que permita conocer más a los clientes, competidores y mercado que se interpretan de una manera adecuada y así, se concluye que mercado es el adecuado y cómo se puede introducir el servicio de Ate CrossFit.

\section{Capítulo V. Plan de Marketing}

Se elabora la estrategia de marketing y la estrategia de venta. En la primera, se incluye la estrategia de producto, precio, plaza y distribución, promoción y publicidad, personas, procesos y presencia física. Y en la segunda, el plan de ventas y las políticas de servicio y garantías. Todo esto, con el fin de plasmar cómo Ate CrossFit va alcanzar sus objetivos.

Capítulo VI. Pronóstico de ventas

Se estima las ventas del servicio que brindará Ate CrossFit mediante la aplicación de fundamentos y supuestos que el mercado nos brinde; asimismo, se justifica los resultados obtenidos, y se analizan los riesgos y aspectos críticos que impactan en el pronóstico de ventas en el mercado de Fitness peruano.

Capítulo VII. Ingeniería del Proyecto

Se descifra los recursos necesarios para llevar a cabo el proyecto dentro del mercado peruano; ya sea desde el modelamiento y selección de procesos productivos como la determinación del tamaño, recursos, tecnologías y flexibilidad; así como, la localización del 
Box de CrossFit que cumpla con las características esenciales de todo Box afiliado bajo las consideraciones legales que tiene CrossFit, Inc.

Capítulo VIII. Aspectos Organizacionales

Se estudia las características esenciales que hay en cada cultura organizacional; y así decidir la de Ate CrossFit. Se inicia desde la creación de la misión, visión y principios; del mismo modo, se formula las estrategias del negocio, para determinar las ventajas competitivas. Se diseña una estructura organizacional deseable para la empresa, acorde a los fundamentos de CrossFit, Inc. integrando los perfiles de puestos clave; pues, en la industria del fitness es indispensable contar con éstas; con ello, se determina la remuneración, compensación e incentivos que cada trabajador tendrá por el desarrollo de sus funciones. Finalmente, se crea una política de recursos humanos que sirvan de apoyo a todo lo contemplado en el presente capítulo.

Capítulo IX. Planificación Financiera

Se propone el plan financiero como parte importante de las operaciones de la empresa, que brindará la ruta a seguir para lograr los objetivos de la empresa; y ello se dará a través de la inversión, el financiamiento, presupuestos base y presupuestos de resultados. Todo ello, para determinar las decisiones que Ate CrossFit debe realizar; y así lograr, como ya se indica, los objetivos propuestos para conseguir la viabilidad de la empresa.

Capítulo X. Evaluación Económica Financiera

Con la realización de la evaluación económica financiera, se busca identificar, valorar y comparar si por los costos y beneficios obtenidos del proyecto desarrollado logrará generar la rentabilidad financiera esperada o en su defecto la insostenibilidad de la misma en el tiempo. Esto último, se determina con el uso de una evaluación económico-financiera con las herramientas necesarias; esto es, TIR, VAN, ROE, RATIOS FINANCIEROS y finalmente se procede a analizar los riesgos.

Conclusiones y Recomendaciones

En esta sección se dan las conclusiones del plan de negocio, y se determina si es viable o no aperturar un Box de CrossFit en el distrito de Ate. Finalmente, se proponen las recomendaciones del caso para futuras propuestas o un posible plan estratégico a futuro. 


\section{Capítulo I: Generalidades}

\subsection{Antecedentes}

Álvarez, Sánchez, Gómez y Tarqui (2012) señalan que la obesidad es un problema de salud pública tanto en los países desarrollados como en países en vías de desarrollo; a tal punto que, según el último reporte ${ }^{1}$ realizado por la Organización Mundial de la Salud (OMS, 2017) desde 1975 la obesidad se ha triplicado en todo el mundo; siendo catalogada como pandemia.

Conforme a los datos emitidos por la OMS (2017):

En el 2016, a nivel mundial, se registró que más de 1900 millones de adultos de 18 o más años tenían sobrepeso, de los cuales, más de 650 millones eran obesos; siendo el 39\% de las personas adultas de 18 o más años las que tenían sobrepeso, y el 13\% eran obesas. (párr. 3).

De conformidad con este informe emitido, la lista es liderada por Estados Unidos con un $13 \%$ de adultos jóvenes y niños con obesidad. Asimismo, se ha determinado que esta enfermedad no es transmisible; sin embargo, se produce de manera paulatina a cualquier edad. Álvarez et al. (2012) determinan que el sobrepeso y la obesidad son causados por:

La adopción de dietas con alto contenido de grasas saturadas, azúcares, carbohidratos y bajas en gradas poli saturadas y fibras.

El sedentarismo producido por la falta de actividad física; ya sea por exceso de carga laboral o negligencia propia; $y$,

La disponibilidad de alimentos a bajos costos ha permitido que la población pueda acceder a alimentos con alto contenido energético. Esto último, a causa de la alta producción de alimentos industrializados, cuyos componentes son nocivos para la salud.

Es importante resaltar que tanto el sobrepeso y la obesidad aumentan el riesgo de la mortalidad de la población a temprana edad. Álvarez et al. (2012) asocian el sobrepeso y la obesidad con otras enfermedades no transmisibles como: la hipertensión arterial, la diabetes y las enfermedades cardiovasculares; entre otras, que han empezado a ser más frecuentes y comunes en la humanidad tanto en la población adulta como en la más joven.

El Perú no es ajeno a este problema. De conformidad con la última Encuesta Demográfica y de Salud Familiar (ENDES, 2016) ${ }^{2}$ se obtuvieron los siguientes resultados: un $35.4 \%$ de personas de 15 y más años tienen sobrepeso; dicha cifra se ha sostenido proporcionalmente en referencia al año 2015; de otro lado, un $18.3 \%$ de personas de 14 y más años tienen

\footnotetext{
${ }^{1}$ Nota descriptiva actualizada a octubre de 2017 por la Organización Mundial de la Salud en su portal web.

${ }^{2}$ La Encuesta Demográfica y de Salud Familiar (ENDES) está a cargo del Instituto Nacional de Estadística e Informática (INEI).
} 
obesidad; esta cifra ha aumentado en un $0.5 \%$ en referencia al 2015. Asimismo, se identifica que del total de personas con obesidad, el 6,4\% se ubican en Lima; seguidas de Tacna, Arequipa, Cajamarca e Ica con 6,3\%, 6,2\%, 6,1\% y 5,8\% respectivamente. En este mismo orden de ideas, los resultados obtenidos en otros distritos de Lima, se aprecia que San Juan de Lurigancho cuenta con un $11.8 \%$ de personas con obesidad; siendo el distrito con el porcentaje más elevado, seguidas de Villa el Salvador, Ate, Los Olivos y San Martín de Porres con $11,7 \%$ respectivamente.

Con el fin de reducir el considerable crecimiento porcentual del sobrepeso y la obesidad, la OMS (2004) elaboró una estrategia mundial sobre el régimen alimentario, actividad física y salud; determinando que:

La alimentación y la actividad física influyen en la salud ya sea de manera combinada o a cada una por separado. Así pues, mientras que los efectos de la alimentación y la actividad física en la salud suelen interactuar, sobre todo en el caso de la obesidad, la actividad física aporta beneficios nutricionales considerables que no guardan relación con la obesidad. La actividad física es fundamental para mejorar la salud física y mental de las personas. (p. 3).

La OMS (2004) en su estrategia para reducir la obesidad señala que no solo es necesario un buen plan nutricional; sino también, realizar una actividad física de forma constante; la cual, dependiendo de su variación e intensidad, se obtendrán distintos resultados. Ahora bien, dicha estrategia ha sido implementada para que de manera colectiva sea aplicada por todos los estados miembros en cooperación con el sector privado, quiénes son protagonistas importantes en la promoción de una alimentación sana y de la actividad física; y de esta manera, crear programas que las promocionen. Esto ultimo, ha sido ratificado como objetivo específico en el Plan de Acción para la Prevención y el Control de las Enfermedades no Transmisibles en las Américas (2013-2019) para "promover la vida activa a fin de propiciar la salud y el bienestar y prevenir la obesidad" (OMS, 2014, p. 14).

Así pues, diversas empresas han optado por invertir en el mercado más atractivo; esto es, el Fitness; que, según el último reporte global del International Health, Racquet and Sportclub Association (IHRSA, 2017) ${ }^{\mathbf{3}}$ logró alcanzar un estimado de $\$ 81.1$ mil millones de dólares americanos durante el 2016. Por tanto, dichas empresas distinguen un panorama de oportunidades para insertar al mercado nuevas propuestas de negocio o reforzar aquellas que ya ofrecían. Este auge de crecimiento, ha producido un fenómeno denominado como "Boom

\footnotetext{
${ }^{3}$ International Health Racquet and Sportclub Association (IHRSA) emite informes anuales sobre el estado del mercado fitness a nivel mundial. Siendo considerado como un recurso necesario para todos aquellos inversionistas, analistas y demás profesiones involucradas en la industria.
} 
Fitness"; dentro del cual, existen diversas actividades deportivas que ofrecen distintos tipos de entrenamiento; pero que en su conjunto, buscan otorgar una vida más sana a las personas.

Dentro de este mar de ofertas deportivas, existe una tendencia que ha podido destacarse no solo por sus nuevas y alternadas rutinas de ejercicio; sino, por la fuerte influencia de su comunidad dentro y fuera de la actividad física; y esta es, el CrossFit. Greg Glassman (2009) define el CrossFit como "un régimen de ejercicios que consiste en movimientos funcionales con constante variación y ejecutados a alta intensidad" (CrossFit, Inc., 2014); diferenciándose según CrossFit, Inc. (2017) en sus fundamentos, por ser un programa de fuerza central y de acondicionamiento, basado en un método que involucra: nutrición, acondicionamiento metabólico, gimnasia, levantamiento de pesas con lanzamiento y deportes. Una aproximación a la diferenciación del CrossFit frente a otros programas de Fitness, se aprecia en la guía de entrenamiento de CrossFit Level 1; donde se describe que:

El CrossFit no es un programa de fitness especializado, sino un intento deliberado por optimizar la competencia física en cada uno de los diez dominios reconocidos del fitness. Los mismos que comprenden: resistencia cardiovascular y respiratoria, fuerza,

flexibilidad, potencia, velocidad, fortaleza, coordinación, agilidad, equilibrio y precisión. (CrossFit, Inc., 2017, p. 5).

Asimismo, Glassman (2012) concluye que “ ...la enfermedad, el bienestar y el fitness parecen ser diferentes medidas de una sola cualidad: la salud" (párr. 16); asimismo, el mencionado autor señala que "el fitness consiste y debe consistir en un estado de 'superbienestar'. La enfermedad, el bienestar y el fitness son medidas de la misma entidad. Un régimen fitness que no promueve la salud no es CrossFit" (párr. 19) y para ello, es necesario aplicar un fitness amplio, general e integral. En este mismo orden de ideas, como parte de su visión en fitness, Greg Glassman a través de CrossFit, Inc. creó hace más de 10 años, CrossFit Journal, una revista enfocada en la publicación de artículos cuya materia de investigación está centrada en la propagación de una cultura fitness relacionadas a la nutrición, herramientas para mantener la salud en casa, medicina moderna, deportes y condición física de manera legal. Como iniciativa de CrossFit para luchar contra la obesidad, se han publicado diversos artículos basados en experiencias de algunos miembros en razón a su proceso para revertir la obesidad. Un claro ejemplo de ello, es Kai Rainey, quién se ha convertido en una colaboradora de Crossfit Journal y cuya misión es acercarse a otras personas que deseen luchar contra la obesidad, y apoyarlos a dar ese primer paso para intentar y acudir a un box de CrossFit. 
Pues bien, una vez definido el concepto del CrossFit, su importancia para combatir la obesidad y el factor diferenciador frente a otros programas de Fitness; acontece precisar el modelo de negocio CrossFit. En el 2015, en una entrevista para el show de YES Network Forbes SportsMoney, Greg Glassman sostuvo que el CrossFit es un modelo de negocio basado en la licencia para afiliados y programas de entrenamiento (Ozanian, 2015). La primera, por el uso de la marca registrada CrossFit que incluye tanto la apertura de un box de CrossFit con el uso y dominio del nombre comercial, como el permiso de ofrecer las sesiones de entrenamiento bajo la metodología CrossFit, dando libertad absoluta al propietario del box de CrossFit para la implementación de su infraestructura y equipamiento, eliminando así ciertas barreras que se encuentran en las grandes franquicias del mercado fitness (Achauer, 2016); y la segunda, la enseñanza de la metodología CrossFit a entrenadores y atletas. Asimismo, en la Guía de entrenamiento de Nivel 1, CrossFit Level One Certificate Course, se indica que "los objetivos, la prescripción, la metodología, la implementación y las adaptaciones de CrossFit son únicos e individualmente, brindan la definición de CrossFit y resultan instrumentales en el éxito de nuestros programas en diversas aplicaciones" (CrossFit, Inc., 2017).

La mayor interrogante que toda persona ajena al CrossFit se hace: ¿Es para mí? Esto último, en atención a lo percibido en las redes sociales y blogs, que en su mayoría, se enfocan por enseñar a los atletas élite en su preparación física o en plena competencia; generando, gran incertidumbre en razón al grado de dificultad de este deporte y hacia quién va dirigido. Para ello, la guía de entrenamiento de CrossFit Level 1 otorga la siguiente respuesta:

Sus necesidades y las de un atleta olímpico difieren en grado, pero no en tipo. Mayor potencia, fuerza, resistencia cardiovascular y respiratoria, flexibilidad, coordinación, resistencia en general, agilidad y equilibrio son importantes para los mejores deportistas del mundo y para nuestros abuelos. (CrossFit, Inc., 2017, p. 7).

Con respecto a lo descrito, la realidad es que el CrossFit es para todas las personas sin restricción; ello, debido a su principal fundamento, que es el acondicionamiento de los ejercicios; pues, los métodos utilizados forman parte de la progresión de la técnica. Un claro ejemplo de la variación del grado de dificultad de los ejercicios más no de la técnica, se encuentra en el Workout of the Day (WOD) ${ }^{4}$ de los CrossFit Games 5 ; ya sea desde las

\footnotetext{
${ }^{4}$ Workout of the Day (WOD) conocido como el entrenamiento del día que se emplea en el CrossFit.

${ }^{5}$ Los CrossFit Games son las competencias de CrossFit más importantes para encontrar al atleta con mejor estado físico en la tierra, y esta consiste en tres etapas. La primera, el Open, donde se evalúa vía online a los atletas durante cinco semanas con un WOD por semana y con ello, los mejores clasifican a la siguiente etapa; la segunda, los Regionales, donde los atletas clasificados en la primera etapa son evaluados en 6 eventos durante 3
} 
clasificatorias (Open) hasta los Games, de conformidad con las divisiones ${ }^{6}$ en las que se compiten.

En el 2016, la cadena CNBC catalogó al CrossFit por sus cifras de crecimiento en razón al número de boxes ${ }^{7}$ afiliados, como posiblemente la mayor tendencia Fitness en el mundo (Wang, 2016). Según CrossFit Affiliates (2018) en la actualidad hay 13,610 boxes de CrossFit afiliados; creciendo significativamente en comparación al año 2016, donde se registró 13,000 afiliados. Asimismo, se identifica que el número de afiliados en Sudamérica asciende a 1,189 boxes. En el Perú, sólo se encuentran afiliados a CrossFit, Inc. 17 boxes; 15 de ellos ubicados en Lima, uno en cusco y otro en Arequipa. De los afiliados en Lima, la distribución de su ubicación se da de la siguiente manera: un box de CrossFit afiliado en los distritos de San Miguel, Los Olivos, San Juan de Lurigancho, Pueblo Libre, Surquillo, San Borja, Barranco, La Molina, respectivamente; dos boxes de CrossFit afiliados en el distrito de Surco y Lima Cercado, respectivamente; y finalmente, tres boxes de CrossFit afiliados en el distrito de Miraflores.

Cabe resaltar que, en el Perú, existen algunos boxes de CrossFit que no se encuentran afiliados, lo cual es alarmante; puesto que, no garantizan las condiciones básicas que CrossFit, Inc. solicita para la apertura de un box afiliado; ocasionando ciertos inconvenientes para aquellos atletas o usuarios que deseen participar en las clasificatorias de los CrossFit Games: debido a que, al no pertenecer a un box afiliado, no pueden registrarse como competidores. En este mismo orden de ideas, no pueden participar de las competencias tanto nacionales como internacionales que CrossFit, Inc. realiza.

En el Perú, el incremento de boxes de CrossFit se ha producido de manera paulatina; siendo los tres últimos años -2015, 2016 y 2017- los de mejor desempeño. Esto último, se debe al poderoso componente que acompaña al CrossFit, su comunidad; la misma que se encarga de integrar a nuevos miembros cada año, ya sea por recomendación, percepción de resultados, inducción por medios de comunicación, influencia de los atletas élite en la promoción de marcas o redes sociales; entre otros.

\footnotetext{
días consecutivos, clasificando a los Games sólo los cinco primeros por cada región (Atlantic Regional, California Regional, Central Regional, East Regional, Meridian Regional, Pacific Regional, South Regional y West Regional) que hayan conseguido el mayor puntaje; y finalmente, los Games, donde los atletas clasificados en la etapa previa, son puestos a prueba en 13 eventos durante cuatro días consecutivos del fin de semana; y quién obtenga el mayor puntaje en su respectiva división, se coronará como el atleta con mejor estado físico de la tierra.

${ }^{6}$ CrossFit Games Division: Rx (Men \& Women), Teams, Boys \& Girls (14-15 años), Boys \& Girls (16-17 años) y Masters: Men \& Women (35-39 años), Men \& Women (40-44 años), Men \& Women (45-49 años), Men \& Women (50-54 años), Men \& Women (55-59 años), Men \& Women (60 + años).

${ }^{7}$ Gimnasios no convencionales para la práctica del CrossFit, cuya temática está ligada a un garaje de entrenamiento.
} 
Por ello, mediante la presente investigación, se plantea elaborar un plan de negocio basado en un modelo de negocio de alto potencial que viene creciendo a gran escala; instaurándolo en el distrito de Ate, donde el índice de obesidad es elevado; e inculcar el CrossFit como una actividad física que es en realidad.

\subsection{Determinación de la Oportunidad}

En Lima, la apertura de boxes de CrossFit se ha dado, en su mayoría, en distritos con bajo porcentaje de obesidad a excepción de algunos casos como: San Juan de Lurigancho y Los olivos; sin embargo, esta medida no es suficiente para abastecer la demanda de cada distrito. Esta demanda insatisfecha, da la oportunidad de aperturar un box de CrossFit afiliado en el mercado Fitness peruano en uno de los distritos con mayor porcentaje de obesidad, tal como se propone en la presente investigación.

A esto, se le suman las siguientes problemáticas que tiene todo box de CrossFit afiliado peruano: En primer lugar, escasez de Coaches capacitados y debidamente certificados por CrossFit, Inc., lo cual es indispensable para la enseñanza de las técnicas con las respectivas progresiones; caso contrario, pueden ocasionar lesiones en sus alumnos; en segundo lugar, la falta de implementos deportivos necesarios para la ejecución de los ejercicios planteados en el WOD; esto último, se debe a que muchos de los boxes no han calculado el presupuesto adecuado de la inversión inicial; por ello, para subsanar dicho inconveniente, suelen iniciar sus actividades con prontitud para obtener ingresos; y con ello, en un margen de tiempo prolongado de uno a dos años aproximadamente, ir adquiriendo los implementos faltantes. Esto, no será inconveniente para Ate CrossFit; debido a que, contará con el presente plan de negocio; investigación de suma importancia que han obviado la totalidad de boxes de CrossFit aperturados en el Perú. Finalmente, el escaso uso de aplicaciones móviles que permitan evaluar la evolución constante de sus miembros.

Por otro lado, según el Instituto Nacional de Estadística e Informática (INEI, 2009) en el Censo (2007) la población ascendente del distrito de Ate fue de 478,278 habitantes, y la estimada al Censo (2017) será superior a 630,068 habitantes; asimismo, la Asociación Peruana de Empresas de Investigación de Mercados (APEIM, 2017) de conformidad con el INEI (2018) con la data alcanzada de la Encuesta Nacional de Hogares (ENAHO, 2017) en razón a la distribución de personas según Niveles Socioeconómicos (NSE), menciona que el distrito objeto de la presente investigación, se ubica en la Zona cinco, conformada por los distritos de Ate, Chaclacayo, Lurigancho (Chosica), Santa Anita, San Luis y El agustino; en la cual se observa que el 100\% de habitantes de la Zona cinco, el 1.0\% pertenece al NSE A, $17.0 \%$ al NSE B, $47.3 \%$ al NSE C, $27.3 \%$ AL NSE D y 7.4\% al NSE E; sufriendo una 
variación considerable en comparación a los resultados obtenidos del ENAHO (2016); asimismo, y en razón a la población estimada en el distrito de Ate, se obtiene que 6469 habitantes pertenecen al NSE A, 109,973 al NSE B, 305,984 al NSE C, 176,604 al NSE D y 47,871 al NSE E. Por consiguiente, el alcance del público objetivo de Ate CrossFit será en los NSE A, B y C; las mismas que, se ahondaran durante el desarrollo del análisis del contexto actual y esperado.

Finalmente, ante el incremento de apertura de boxes de CrossFit durante los últimos años entre ellos boxes afiliados y no afiliados- la competencia central de Ate CrossFit se basará en inculcar en lo que realmente es el CrossFit; esto es, de acuerdo con los estándares establecidos por CrossFit, Inc.(2017) lograr un Fitness amplio, general e integral; a tal punto de acoplarlo al Core de negocio como estrategia principal para la viabilidad económica de la empresa; así como, un servicio pre venta, donde el consumidor recibirá una atención personalizada de evaluaciones físicas y nutricionales para determinar la progresión del CrossFit en su nuevo estilo de vida.

\subsection{Justificación del Proyecto}

En la actualidad, es conveniente inculcar la actividad física como parte fundamental de un estilo de vida, y que no solo se base en un control nutricional que en varios casos son extremos y poco saludables. Hoy en día, realizar actividad física es la mejor opción de mantenerse saludable en un mundo con un modo de vida acelerado y asediado por la comida rápida cargada de grasas saturadas y demás alimentos tratados químicamente que contribuyen al quebrantamiento de la salud.

Aperturar un box de CrossFit afiliado en el distrito de Ate que permite hacer frente a la problemática de salud pública en razón a la obesidad y el sobrepeso, en uno de los distritos con mayor porcentaje de dicha enfermedad; permitiendo aportar en la mejora de la calidad de vida de las personas. En este mismo orden de ideas, ser en una alternativa para aquella demanda insatisfecha de potenciales clientes del distrito, que se encuentran abrumados con aquellas rutinas de entrenamiento convencionales. Asimismo, reducir el número de potenciales clientes que hasta el momento no han podido experimentar el CrossFit por motivos de ubicación y costos de traslado.

De otro lado, se observa que el precio de alquiler por metro cuadrado de los locales comerciales en el distrito de Ate, oscila entre \$ 7 a \$10 dólares americanos; siendo catalogada como uno de los distritos con mejor ocasión de alquiler. Esto último, conviene a la idea de negocio planteada; puesto que, un box de CrossFit debe tener entre $300 \mathrm{~m}^{2}$ a $500 \mathrm{~m}^{2}$, que permita la correcta instalación de los instrumentos deportivos y la separación de las áreas de 
entrenamiento; por consiguiente, el distrito de Ate es una excelente plaza para poner en marcha el negocio; no solo por la accesibilidad del precio de alquiler; sino también, por su ubicación limitante con los distritos de La Molina y Santa Anita.

Finalmente, en la elaboración de la presente investigación, se pondrá en práctica los conocimientos adquiridos durante la estancia académica de la Maestría en Ciencias Empresariales; tales como, la aplicación de un plan de marketing, la responsabilidad social y ética empresarial, planificación financiera, entre otros; incluso, permitirá contribuir con futuros trabajos de investigación que requieran de un análisis del impacto de las nuevas tendencias Fitness en el mercado o de cómo insertar al mercado un modelo de negocio con gran impacto mundial.

\subsection{Objetivos Generales y Específicos}

Objetivo general:

Desarrollar un plan de negocio para combatir la obesidad en el distrito de Ate mediante un modelo de negocio denominado 'CrossFit'.

Objetivos específicos:

1. Desarrollar un análisis del sector económico, la competencia y del contexto actual y esperado en busca de sustentar el plan de negocio.

2. Realizar un estudio de mercado que proyecte y sustente el presente plan de negocio.

3. Elaborar las estrategias de marketing y de ventas para alcanzar los objetivos.

4. Proyectar el pronóstico de ventas para viabilizar el plan de negocio.

5. Formular la ingeniería del plan de negocio.

6. Planificar los aspectos organizacionales y de valor del plan de negocio.

7. Elaborar la planificación financiera y realizar la evaluación económico financiera correspondiente.

\subsection{Alcances y Limitaciones de la Investigación}

Alcances de la investigación:

- Se priorizará el estudio de la presente investigación en el distrito de Ate.

- Se investigará a los potenciales boxes de CrossFit en el Perú.

- Se realizará un estudio para determinar el monto de inversión para la apertura de un box de CrossFit en Ate.

- Se expone el CrossFit como negocio y la importancia de su comunidad.

Limitaciones de la investigación:

- La presente investigación, no podrá estudiar los potenciales boxes de CrossFit de otros países. 
- La sección financiera y contable se limita al contenido del presente plan de negocio.

- Reserva de información por parte de otros boxes de CrossFit.

- Escaza información estadística del incremento del CrossFit en el mercado fitness peruano. 


\section{Capítulo II: Estructura Económica del Sector}

\subsection{Descripción del Estado Actual de la Industria}

Durante los últimos años - a nivel mundial- el auge y crecimiento del denominado "Boom Fitness" ha sido sorprendente. De conformidad con los resultados del IHRSA (2017) la industria del Fitness logró alcanzar un estimado de \$ 81.1 mil millones de dólares americanos durante el 2016. Este crecimiento, se debe gracias a la inversión realizada por las empresas como parte de su cooperación con los países para reducir la obesidad- en la promoción de novedosas actividades deportivas que prometen mejorar la calidad de vida de las personas; ya sea, desde una mejora en la salud, cambios en el aspecto físico o generar mayor confianza social. Un claro ejemplo de ello, se aprecia en el aumento de establecimientos que ofrecen distintos tipos de entrenamiento, tales como: gimnasios, sedes de entrenamiento funcional y de alta intensidad; así como, aquellas que por iniciativa propia emprenden como personal Trainer, brindando una programación de ejercicios y plan nutricional mediante correos, mensajes de texto y uso de aplicaciones móviles.

Este fenómeno Fitness se asocia con las nuevas tendencias del mercado, tales como: Pilates, yoga, zumba, functional training, Smart Training, calistenia, HidroFit, Boxeo; entre otros, que en la búsqueda del mismo bien común -otorgar una vida más sana para las personas- han logrado fomentar servicios idóneos para la época, diferenciándose de las agobiantes rutinas de entrenamiento tradicional ofertado por las grandes cadenas de gimnasio que en su momento conquistaron el mercado y se posicionaron en la mente del consumidor como la mejor alternativa para reducir tallas y verse físicamente bien.

Sin embargo, de acuerdo con Wang (2016) en el reporte realizado para CNBC (2016); el CrossFit es posiblemente la mayor tendencia de Fitness en el mundo; esto, en razón al incremento del número de boxes afiliados durante los últimos años; las mismas que, de conformidad con CrossFit Affiliates (2018) hay 13,610 boxes de CrossFit afiliados en todo el mundo; creciendo significativamente en comparación a las cifras registradas en el 2016. Convirtiendo al CrossFit en el fenómeno Fitness con mayor impacto durante la última década. Asimismo, el CrossFit ha insertado 6 factores de innovación en la industria del Fitness que, le han otorgado una ventaja competitiva; convirtiéndose en un modelo de negocio de gran escala con altos índices de retorno financiero; según Charles (2014) los factores de innovación del CrossFit son:

1. Una nueva tecnología de entrenamiento en el mercado fitness.

2. Un nuevo modelo empresarial.

3. Una marca reconocida mundialmente. 
4. Una plataforma de conectividad a nivel de cliente en el internet.

5. Combinación de entrenamiento físico con competencias deportivas a nivel local, nacional, regional y mundial.

6. Un énfasis en resultados de fitness medibles y en el corto plazo para $100 \%$ de los practicantes (p. 18).

Para definir la situación actual de la industria del fitness en el Perú, se debe: primero, ubicar en que Clasificación Industrial Internacional Uniforme (CIIU) de todas las actividades económicas se ubica el CrossFit; segundo, identificar el desempeño de la industria del Fitness en el Producto Bruto Interno (PBI) del país; y finalmente, describir la expansión del CrossFit en el país.

En relación con la CIIU de todas las actividades económicas -revisión 4- proporcionada por la ONU (2009) se identifica que, el CrossFit se encuentra en la clase de otras actividades deportivas, donde se refleja la explotación de instalaciones deportivas; a diferencia de la enseñanza deportiva y recreativa, que es estructurada y sólo busca el adiestramiento en la actividad deportiva.

Con respecto a identificar el desempeño de la industria Fitness en el PBI peruano; según el informe técnico $\mathrm{N}^{\circ} 01$ del INEI (2018) se puede determinar que:

El crecimiento del Producto Bruto Interno (PBI) de 2,2\% fue el resultado del desempeño favorable de las actividades: Construcción $(9,1 \%)$; Telecomunicaciones y otros servicios de información (7,8\%); Transporte, almacenamiento, correo y mensajería (4,2\%);

Agricultura, ganadería, caza y silvicultura (4,0\%); Administración pública y defensa (3,7\%); Otros servicios $(3,7 \%)$; Servicios financieros, seguros y pensiones $(2,9 \%)$; Extracción de petróleo, gas y minerales (2,6\%); Servicios prestados a empresas $(1,9 \%)$; Comercio (1,7\%); Alojamiento y restaurantes $(1,7 \%)$; Electricidad, gas y agua $(0,2 \%)$. En cambio, se contrajo la actividad pesca y acuicultura en $(-51,4 \%)$ y la Manufactura en ($5,5 \%)($ p. 9).

Hay que tener en cuenta, que la industria del Fitness se ubica en la actividad de otros servicios, la cual ha contribuido de manera significativa en el desarrollo del PBI en el IV trimestre del 2017; y es aquí, donde el fenómeno CrossFit compite con las grandes cadenas de gimnasio -Gold's Gym, Bodytech, Sportlife Fitness Club; entre otros- frente a otras actividades deportivas con distintos tipos de entrenamiento.

Por último, para describir la expansión del CrossFit en el Perú; se debe analizar el registro ofrecido por CrossFit Affiliates (2018) donde se estima que la cifra de afiliados en el país 
asciende a 17 boxes; las cuales se aprecian en la Tabla 1; superando en 1 box afiliado a la cifra registrada en el 2017 y en 3 durante el 2016.

Tabla 1

Distribución de Boxes de CrossFit Afiliados en el Perú

\begin{tabular}{lcc}
\hline Departamento & Distrito & Cantidad \\
\hline & San Miguel & 1 \\
& Los Olivos & 1 \\
& San Juan de Lurigancho & 1 \\
Lima & Pueblo Libre & 1 \\
& Surquillo & 1 \\
& San Borja & 1 \\
& Barranco & 1 \\
& La Molina & 1 \\
Cusco & Surco & 2 \\
Arequipa & Lima Cercado & 2 \\
Nota: Adaplores & Miraflor & 3 \\
& Cusco & 1 \\
& Cayma & 1
\end{tabular}

Nota: Adaptado de "CrossFit Affiliates", por CrossFit, Inc., 2018, Affiliates. Copyright 2018 por CrossFit, Inc.

Para el análisis de la presente investigación, se considera aquellos boxes de CrossFit afiliados en Lima. En este mismo orden de ideas, del análisis de la Tabla 1, la apertura de la mayoría de los boxes de CrossFit se ha realizado en distritos con bajo porcentaje de obesidad a excepción de San Juan de Lurigancho y Los Olivos; generando la necesidad de aperturar un box de CrossFit en uno de los distritos con mayor porcentaje de obesidad como Ate.

\subsubsection{Segmentación de la industria}

Edwin Llance -socio de CrossFit Marut- en una entrevista realizada por Inga (2017) para el diario El Comercio (2017) hace referencia a la segmentación del CrossFit en la industria del Fitness, indicando que "hoy existe una oferta muy segmentada. Aún no hay una marca que sea el referente del CrossFit actualmente en el país..." (párr. 2). Eso quiere decir, que cada box de CrossFit segmenta su mercado de acuerdo con los objetivos que esta se plantee al iniciar la actividad económica. Por ejemplo, algunos buscan formar atletas de competencia, mejorar el rendimiento físico de las personas, mejorar el aspecto físico de las personas mediante resultados, mantener una comunidad sana y hacer que las personas superen sus propios límites. Como contrapartida a ello, Ate CrossFit contará con una ventaja central, la cual es lograr un Fitness amplio, general e integral; a tal punto, de acoplarlo al Core del negocio como estrategia principal para la viabilidad de la empresa; y con ello, poder segmentar el mercado. 
Para segmentar la industria se debe: primero, definir la segmentación de la industria; y, segundo, elegir las variables de segmentación correspondientes a la actividad del negocio y así seleccionar el público objetivo. Para empezar, Kotler y Armstrong (2013) determinan que:

Los compradores de cualquier mercado difieren en sus deseos, recursos, ubicaciones, actitudes y prácticas de compra. A través de la segmentación del mercado, las empresas dividen los mercados grandes y heterogéneos en segmentos a los que pueden llegar de manera más eficiente y eficaz con productos y servicios que coinciden en sus necesidades únicas... (p. 165).

De conformidad con lo descrito por Kotler y Armstrong (2013), para la presente investigación se utilizará la segmentación de los mercados de consumo; debido a que, se puede contar con las principales variables; esto es, geográficas, demográficas, psicográficas y conductuales. La primera, basada en unidades geográficas, tales como países, ciudades, estados, densidad de población, clima, etc.; la segunda, en descriptores de edad, ciclo de vida, ingresos, ocupación, género, educación, origen étnico, religión, etc.; la tercera, en estilos de vida, clase social y personalidad; y la cuarta, en beneficios de uso, tasa de uso y ocasión de uso.

\subsubsection{Empresas que la conforman}

La industria fitness peruana está compuesta por : (a) gimnasios convencionales, (b) entrenamientos alternativos, y (c) centros deportivos. De acuerdo a los resultados obtenidos por IHRSA (2018) en la actualidad hay más de 1,682 gimnasios; de los cuales más de 50 le pertenecen a las grandes cadenas y el resto a los denominados gimnasio de barrio. Luis Keiser (2017) señala al respecto que "del total de gimnasios de cadenas, el 70\% lo copa Bodytech y Gold's Gym, sin embargo, de ese 70\%, el grueso mayor se lo lleva Bodytech" (Gestión, 2017, párr. 6). En cuanto a la participación de mercado, el $80 \%$ le pertenece a Bodytech y el restante a Gold’s Gym; y en razón a la facturación, Bodytech tiene un $60 \%$ y Gold's Gym un 40\% (Gestión, 2017). Ambas empresas se destacan por ofertar servicios complementarios a sus clientes; tales como clases de baile, pilates, sauna, Bodypump, Functional Training, entre otros.

Y respecto al CrossFit, a nivel nacional, hay 17 boxes de CrossFit (ver Tabla 1). CrossFit, Inc. (2018) señala que en Lima operan 15 boxes de CrossFit, las cuales pueden apreciarse en la Tabla 2. 
Tabla 2

Boxes de CrossFit Afiliados en Lima

\begin{tabular}{lc}
\hline Distrito de Lima & Box de CrossFit \\
\hline San Miguel & CrossFit Ramus II \\
Los Olivos & CrossFit Kronos \\
San Juan de Lurigancho & CrossFit G300 \\
Pueblo Libre & CrossFit Marut \\
Surquillo & Sinchi CrossFit \\
San Borja & CrossFit Perú \\
Barranco & Barranco CrossFit \\
La Molina & CrossFit La Molina \\
Surco & CrossFit Ramus \\
& Altair CrossFit Este \\
Lima Cercado & Caution CrossFit SI \\
& Atoq CrossFit \\
Miraflores & Latido CrossFit \\
& Altair CrossFit \\
& CrossFit La Parada
\end{tabular}

Nota: Adaptado de "CrossFit Affiliates", por CrossFit, Inc., 2018, Affiliates. Copyright 2018 por CrossFit, Inc.

En el listado propuesto se observa que no existe un box de CrossFit afiliado en el distrito de Ate; sin embargo, existe un box de CrossFit no afiliado -dada las circunstancias de la investigación nos reservaremos la confidencialidad del nombre- la cual no garantiza las condiciones básicas de CrossFit, Inc.; y que incluso, estaría usando la denominación de la marca "CrossFit" sin licencia otorgada por la compañía; convirtiéndolo en un box ilegal. En este orden de ideas, cabe precisar que al no contar con el permiso de licencia de la marca, los principales perjudicados son los miembros afiliados; puesto que, no podrían participar como competidores en las clasificatorias de los CrossFit Games y otras competencias tanto nacionales como internacionales.

\subsection{Tendencias de la Industria}

El panorama de la industria Fitness es muy alentador; a tal punto que, diversos expertos como Miguel Blanco, Jesús Lezama, entrenadores de TRX y Vanna Pedraglio en una entrevista al diario Gestión han señalado que "el peruano ahora se preocupa más por llevar un estilo de vida activo" (Gestión, 2018); por lo cual, este está en busca de nuevas alternativas de entrenamiento que le permitan satisfacer dicha necesidad que ha sido obviada por las aburridas sesiones en los gimnasios y otros centros deportivos; de igual forma, ven que la tendencia de dichos entrenamientos aún no ha llegado a su máximo apogeo. 


\subsection{Análisis Estructural del Sector Industrial}

Para analizar la estructura del sector en nuestro país, se ha empleado las 5 fuerzas competitivas que influyen en el desarrollo de todo negocio elaboradas por Porter (1979) con el fin de obtener una radiografía para analizar el entorno en el cual Ate CrossFit va a realizar sus actividades económicas; las cuales se encuentran plasmadas en la Figura 1.

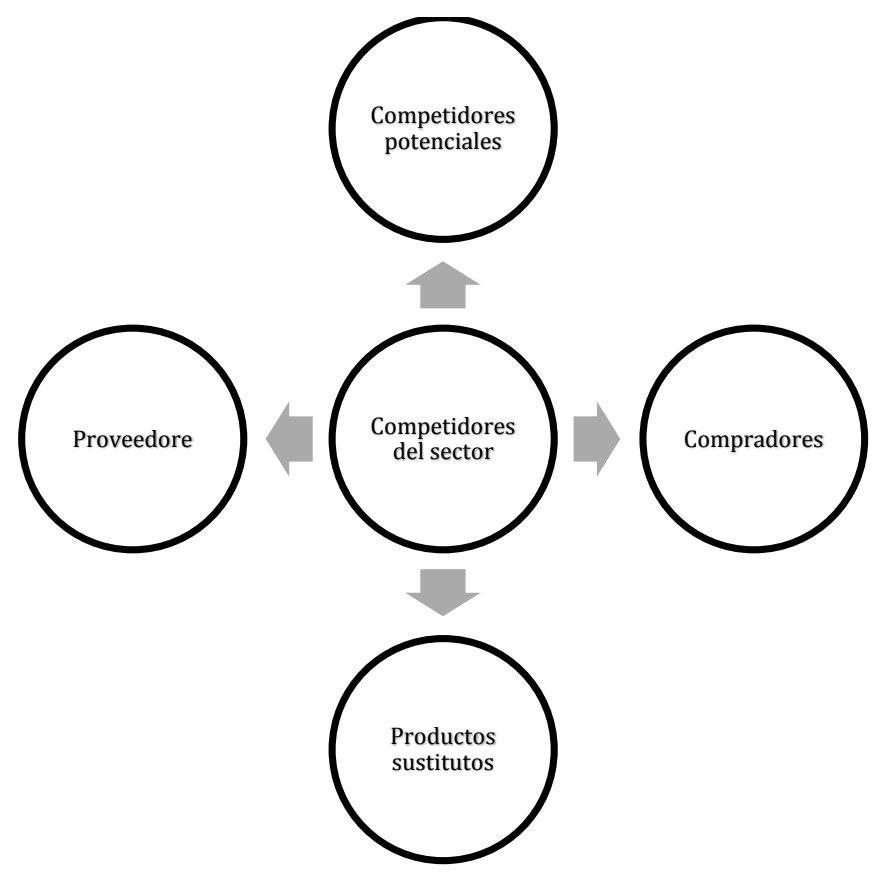

Figura 1. Las cinco fuerzas competitivas de Porter. Adaptado de "Strateigc Management: A Competitive Advantage Approach Concepts" por David, Fred R., 2013, Pearson Education, Inc.,14, p. 76. Copyright 2013 por Pearson.

David (2013) señala que para el análisis de las fuerzas competitivas de Porter (1980) debemos tener en consideración los siguientes tres pasos:

1. Identificar los aspectos o elementos clave de cada una de las fuerzas competitivas que impactan a la empresa.

2. Evaluar qué tan fuerte e importante es cada elemento para la compañía.

3. Tomando en consideración la fuerza conjunta de los elementos, decidir si para la empresa vale la pena entrar o permanecer en la industria (p. 76).

En efecto, la aplicación de los pasos expuestos permite obtener un mejor panorama del entorno en donde estará situada la empresa; y así determinar los beneficios que le puedan producir. Ahora bien, corresponde analizar el grado de cada una de las fuerzas competitivas de la industria a través de la matriz de atractividad. 


\subsubsection{Amenaza de entrada de los competidores potenciales}

Porter (1980) señaló que "los nuevos competidores en una industria aportan más capacidad, el deseo de conquistar participación en el mercado y, a menudo, grandes recursos"(p. 47), provocando una reacción en aquellas empresas ya posicionadas; invitándolas a buscar mejoras o nuevos recursos para producir productos o servicios diferenciados; sin embargo, "el riesgo de que ingresen más competidores en una industria dependerá de las barreras actuales de entrada y también de la reacción previsible por parte de las empresas ya establecidas" (Porter, 1980, p. 47).

Para ello, se debe analizar el tipo de economía que tiene el Perú y posteriormente determinar los elementos claves que influirían en la presente investigación. Álvarez (2014) señala que Alfred Müller-Armack define a la economía social de mercado como "aquel modelo en el que la economía funciona de acuerdo con las reglas del mercado, pero complementada con garantías sociales" (p. 261); por tanto, es común que en una economía social de mercado, el principal ideal de un estado sea impulsar el crecimiento económico de acuerdo con la situación actual de cada industria, bajo una mínima intervención a través de políticas pública que promuevan el bien común; tal como es el caso de nuestro país; donde, durante la última década, la economía ha sido dinámica y con favorables perspectivas hacia el futuro; dejando de ser catalogada como -según el Fondo Monetario Internacional ([FMI], 2006)- una estrella en ascenso; siendo hoy en día un mercado emergente con crecimiento, de bajo riesgo y atractivo para la inversión extranjera

Con respecto al incremento de la obesidad en el país, diversas empresas internacionales han optado como medida para reducirla, insertar al mercado Fitness, sus productos y servicios. Esto último, en concordancia con la estrategia mundial sobre el régimen alimentario, actividad física y salud, elaborado por la OMS. Para ejemplificar tal consideración; se debe observar que, en la industria del Fitness existen diversas empresas con distintos tipos de entrenamiento, partiendo desde lo más convencional -gimnasios- hacia nuevas tendencias que van asomándose; tales como, el CrossFit; la misma que, es materia de estudio de la presente investigación.

A nivel mundial, el CrossFit se ha convertido en un modelo de negocio a gran escala y con alto índice de retorno; a tal punto que, en la actualidad -como ya se ha indicado anteriormente- existen 13,610 boxes de CrossFit afiliados; de los cuales, la mayor parte se ubican en Estados Unidos; donde, predominan las franquicias Reebok, Krypton CrossFit, Tuluka y Mayhem Freedom. Este último, debido al prestigio ganado por el 4 veces campeón en la categoría “Individual Men Élite” (2011, 2012, 2013 y 2014) y 2 veces campeón en la 
categoría "Teams” con Mayhem Freedom CrossFit (2015 y 2016): Rich Froning. Sin embargo, al analizar el informe de CrossFit Affiliates (2018) se observa que, a nivel mundial, Tuluka y Reebok son las franquicias que más boxes de CrossFit han aperturado; quedando evidenciado, el potencial poder del fitness en el mercado.

Contemplado el panorama actual de la industria en relación con la amenaza de entrada de competidores potenciales, corresponde identificar qué elementos clave de esta fuerza competitiva determinadas por Porter (1980) impactan en la empresa y posteriormente, definir el nivel de atractividad para evaluar qué tan fuerte es para la empresa.

1. Desventajas de costes independientes de las economías de escala.

Porter (1980) señala que "las empresas ya establecidas pueden tener ventajas de costes que no están al alcance de los competidores potenciales, sin importar su tamaño ni las economías obtenidas" (p. 51) las cuales se manifiestan en:

Curva de experiencia o aprendizaje. Porter (1980) refiere a este criterio que "en algunos sectores industriales, los costes unitarios tienden a disminuir conforme las compañías van acumulando experiencia en la producción de un bien" (p. 52); esto quiere decir que, toda empresa con el transcurrir con los años desarrollan procesos, mejoran métodos, innovan diseños y equipos que le permiten disminuir costos; a tal punto que, lo convierten como una fortaleza cuyo efecto es una barrera de entrada hacia los nuevos competidores; quienes por lo general, afrontan costes mayores y pérdidas en su adaptación.

Dentro de este concepto, en razón a la apertura de un box de CrossFit en el distrito de Ate; se tiene en cuenta que, no hay un box de CrossFit afiliado; sin embargo, existen diversos centros de entrenamiento, siendo Gold’s Gym y Bodytech los que tienen mayor experiencia en el mercado y que posiblemente utilicen dicho factor como una barrera de entrada; a pesar de ello, en la industria del Fitness, la metodología de CrossFit se encuentra patentada, en comparación a la metodología de los gimnasios y demás centros de entrenamiento; lo cuál, nos daría un elemento que nos permita introducirnos en el mercado peruano.

Acceso preferencial a materias primas. Porter (1980) precisó que "las empresas previamente establecidas posiblemente tengan acceso a las mejores fuentes o tengan asegurado el abastecimiento a precios que reflejan una demanda inferior a la que existe actualmente" (p. 51); más aún, que el poder de negociación con sus proveedores sea tan bueno o incluso, que acaparen a los principales proveedores por completo.

En la actualidad, como ya se ha conceptualizado previamente, el Perú tiene una economía social de mercado que se rige por la libre competencia; si una empresa ya posicionada en el mercado busca ante la posible entrada de un competidor realizar actos que conlleven a 
generar una barrera de mercado mediante el acceso preferencial de materias primas o de abastecimiento; incurriría en actos de competencia desleal, conllevándolo a sanciones impuestas por el INDECOPI. De otro lado, hoy en día en la industria del Fitness, hay una gran variedad de empresas ofertantes que abastezcan las fuentes necesarias, no existiendo empresa alguna con acceso preferencial. En este mismo orden de ideas, para obtener la totalidad de equipos deportivos para un Box de CrossFit resulta neutra; por lo general, se suelen hacer pedidos a los proveedores nacionales con una anticipación de 3 meses y a un precio módico. Sin embargo, cabe precisar que las empresas potenciales extranjeras como: Tuluka, Reebok y Mayhem Freedom cuentan con convenios especiales con la marca Rogue Fitness, quienes poseen el mercado deportivo del CrossFit en la mayoría de países.

Ubicación favorable. Hace referencia al lugar de desempeño de la actividad económica de las empresas ya establecidas en el mercado, cuyo valor se encuentra situado en la accesibilidad de los servicios o productos para el consumidor. Porter (1980) señala que "las compañías bien establecidas se localizan generalmente en los mejores sitios antes de que las fuerzas del mercado incrementen los precios para darles su verdadero valor" (p. 52); esto último, en referencia al cambio constante que suele ofrecer la oferta y demanda de los productos o servicios en el mercado peruano.

En el contexto situado, el box de CrossFit que se desea aperturar se ubicará en uno de los distritos con mayor porcentaje de obesidad; ofreciendo la oportunidad de insertar la metodología CrossFit como actividad física alternativa para combatir la obesidad en el mercado Fitness peruano.

Identificación de la marca. Baena, Sánchez y Suárez (2003) al respecto sostienen que "la imagen, credibilidad, seriedad, fiabilidad, que la empresa tiene en el mercado, como consecuencia de una forma de actuar, que puede llevar al comprador a identificar el producto con la marca..." (p. 63). En el mercado Fitness peruano, muchas empresas han hecho que sus servicios se identifiquen con la marca. Un claro ejemplo de ello, lo podemos apreciar con Bodytech y Gold's Gym que, con la sola apreciación de su logo o nombre comercial, hacen que el comprador pueda enlazarlo con el servicio que brindan.

Igualmente sucede con la marca CrossFit pero con una característica distinta, que es la asociación inherente del nombre comercial con la actividad física permitiéndoles identificarse en cualquier lugar; asimismo, la imagen que CrossFit, Inc. ha logrado posicionar en el mercado fitness a nivel mundial ha sido sorprendente; y esto se puede ver en los CrossFit Games, donde compiten atletas de todos los países; adicional a ello, la vinculación de grupos 
de referencia y otras marcas deportivas comerciales que se han aliado a CrossFit, permiten que ésta se empodere como una gran tendencia deportiva.

2. Diferenciación de productos

Para Porter (1980) el presente elemento:

Significa que las empresas ya establecidas gozan de identificación de marca y lealtad de los consumidores, obtenidas por medio de la publicidad, el servicio al cliente, las diferencias de productos o, simplemente, por el hecho de haber sido las primeras en entrar en la industria (p. 49).

Sobre la base de la idea expuesta por Porter (1980), este elemento obliga a los competidores potenciales a invertir en cantidades fuertes para poder captar la fidelidad de los clientes de la competencia; provocando pérdidas al inicio de las operaciones que conforme vaya aumentado su participación en el mercado o de su capacidad económica, podrá resarcir dicha situación. En la presente investigación, el modelo de negocio CrossFit brinda un servicio Fitness diferenciado, basado como nos señala Greg Glassman (2009) en "un régimen de ejercicios que consiste en movimientos funcionales con constante variación y ejecutados a alta intensidad" (p. 4) adaptado en cada persona mediante progresiones; cuya particularidad se encuentra en la no repetición de las rutinas de ejercicios; buscando un fitness amplio, general e integral.

3. Necesidades de capital

La barrera de entrada con mayor influencia dentro de esta fuerza competitiva es la capacidad económica que tienen aquellas empresas establecidas en el mercado. Porter (1980) dice que "la necesidad de invertir grandes recursos financieros para competir crea una barrera de entrada, sobre todo si se requiere capital para publicidad, investigación o desarrollo anticipados que entrañan riesgo o son irrecuperables" (p. 50); en razón a lo expuesto, si una empresa quiere ingresar a un mercado, deberá tener la capacidad económica para invertir y afrontar cualquier situación que las empresas del mercado interpongan.

Para el ingreso en el mercado peruano de fitness, diversas empresas como Bodytech y Gold’s Gym poseen una capacidad económica dominante; sin embargo, en referencia a la apertura de un box de CrossFit afiliado, se necesita el costo de afiliación, costo para alquilar el box, equipos de entrenamiento, personal calificada, servicios y publicidad que son menores en comparación a dichas empresas que dominan el mercado fitness peruano.

\section{Costes cambiantes}

Porter (1980) señala que "la existencia de costes cambiantes crea una barrera de entrada, es decir, los costes que paga una vez el comprador cuando cambia el producto de un 
proveedor por otro" (p. 50); en otras palabras, es aquel gasto en los que incurre el comprador al adquirir un producto o servicio de una empresa distinta a la que solía comprar. Un claro ejemplo de ello, se aprecia cuando el producto adquirido de otro proveedor genera una inversión en la capacitación del personal que no provocaba el producto del proveedor tradicional o viceversa, si el producto del nuevo proveedor reduce costes que el producto del proveedor frecuente. Por lo cual, la estrategia que deberá emplear el competidor potencial será el ofrecimiento de una mejora en costes que permitan la preferencia del comprador sobre su proveedor tradicional.

En el mercado fitness peruano, las empresas ya posicionadas han elaborado sólo la reducción de sus precios más no de aquellos costes que incurre el comprador por la adquisición de sus servicios; tales como: nutricionistas, fisioterapeutas, masajes e indumentaria deportiva; que en su defecto, ofrecen promociones adicionales al precio del servicio principal. Por el contrario, el modelo de negocio del CrossFit busca ofrecer un fitness amplio, general e integral; cuyo servicio es completo y con una mejora importante de costes. Esto último, se debe a que la metodología del CrossFit incluye aquellos servicios que otras empresas del mercado ofrecen accesoriamente; reduciendo costes al comprador al momento de realizar su cambio de servicio.

5. Acceso a los canales de distribución

Al respecto, Baena et al. (2003) señalan que "es la aceptación de comercializar el producto del nuevo competidor por los canales existentes, con restricciones que disminuyan la capacidad de competencia de la nueva empresa en el mercado" (p. 63); es decir, la nueva empresa busca persuadir a los canales de distribución que promocionen sus productos y servicios; ello, a través de beneficios que le resulten atractivos frente a los que le ofrecen las empresas ya establecidas. Porter (1980) da un claro ejemplo de ello cuando señala que “...el fabricante de un nuevo producto alimenticio debe convencer al distribuidor de que le conceda un espacio en un estante de supermercado muy codiciado prometiéndole a cambio promociones, intensas actividades de venta con él o alguna otra concesión” (p. 51); asimismo, Porter (1980) señala que mientras limitado sean estos canales de distribución, mayor será la barrera de entrada; puesto que, las empresas del sector ya establecidas, buscarán mejorar la relación con dichos canales de distribución; o en su defecto, ejecutar estrategias que le impidan la comercialización de sus productos o servicios a través de los canales tradicionales; generando que el competidor potencial invierta en la propuesta o busque otros canales alternativos. 
Bajo el criterio expuesto, hoy en día, existen nuevos canales de distribución que le permiten a todo negocio ingresar con mayor facilidad, siempre y cuando se invierta en la promoción de la misma; tal es el caso de las redes sociales. En la actualidad, esta tendencia va en aumenta; puesto que, el consumidor busca referencias en tiempo real y sin límites sobre el servicio brindado en base a las experiencias de otros consumidores; más aún, si estos pertenecen a algún grupo de referencia o si es influyente.

6. Política gubernamental

Una de las barreras de entrada con un rango de fuerza más influyente que las predecesoras; debido a que es el gobierno quién posee la libertad de regular el mercado de acuerdo a los intereses sociales que crea conveniente; puesto que, como señala Porter (1980) "el gobierno puede limitar y hasta prohibir el ingreso en industrias, aplicando controles como requisitos para conceder licencias y restringiendo el acceso a materias primas" (p. 53).

Una vez identificado aquellos elementos clave de la presente fuerza competitiva que impactan en la empresa; corresponde -como se muestra en la Tabla 3- evaluar a través de la matriz de atractividad, qué tan importante es la presencia de estos elementos para la empresa. Tabla 3

Matriz de Atractividad para la Entrada de Competidores Potenciales

\begin{tabular}{|c|c|c|c|c|c|}
\hline Elementos & 2 & 3 & 4 & 5 & Total \\
\hline Desventajas de costes independientes & & & $\mathrm{X}$ & & 4 \\
\hline Diferenciación del producto & & & $X$ & & 4 \\
\hline Necesidad de capital & & $\mathrm{X}$ & & & 3 \\
\hline Costes cambiantes & & & $X$ & & 4 \\
\hline Acceso a los canales de distribución & & $\mathrm{X}$ & & & 3 \\
\hline Política gubernamental & & $\mathrm{X}$ & & & 3 \\
\hline Calificación & & & & & 3.5 \\
\hline
\end{tabular}

Nota: Se asignó una escala de 1 a 5 para indicar qué tan atractivo es dicho elemento clave de la fuerza competitiva para la empresa, donde $1=$ no atractivo, $2=$ poco atractivo, $3=$ neutro, $4=$ atractivo y $5=$ muy atractivo. Adaptado de "Dirección de marketing", por Kotler, P. \& Keller, K. L, 2006, 12, México: Pearson: Prentice Hall. Copyright 2

La calificación obtenida en la Tabla 3 es de 3.5; esto significa que, si hay atractividad para la empresa en razón a esta fuerza competitiva.

\subsubsection{Rivalidad entre los competidores existentes}

Para David (2013) esta es la fuerza competitiva más poderosa de todo el modelo de las cinco fuerzas; debido a que, gracias a ella, el mercado se encuentra en constante circulación. Porter (1980) señala que "la rivalidad se debe a que uno o más competidores se sienten presionados o ven la oportunidad de mejorar su posición” (p. 58). Es aquí, donde se observa a las empresas ejecutar estrategias competitivas que influyen en sus competidores; generando, 
una respuesta tanto positiva para contrarrestar dicha estrategia como negativa en forma de represalias.

Todo mercado competitivo se rige bajo el principio de la libre competencia; la cual, determina ciertas reglas de juego para las empresas en el desarrollo de sus actividades dentro de la industria. Para INDECOPI (2013):

La competencia es un proceso dinámico a través del cual las empresas o agentes económicos rivalizan en el mercado por satisfacer mejor las necesidades y expectativas de los consumidores. En ese sentido, la competencia resulta un medio para lograr un fin superior, que es el bienestar del consumidor a través del funcionamiento del mercado (p. 214).

Como se aprecia, el bien común a salvaguardar es el bienestar del consumidor; por tanto, las empresas deberán tener una competencia donde, como denomina Porter (1980), no se intensifiquen sus ataques y contra ataques; puesto que, ello acarrearía consecuencias graves para el consumidor y la empresa en sí.

En la industria del fitness peruano, la competencia es amplia y variada; ocasionando, una lucha constante por capturar nuevos consumidores o conservar a los que ya poseen, mediante estrategias que fidelicen. En el modelo de negocio materia de la presente investigación, no es ajeno a una rivalidad entre competidores; tal como se muestra en la Tabla 3, en el Perú, existen 17 boxes de CrossFit afiliados; de los cuales, 3 cuentan con mejor posicionamiento; estos son: CrossFit Ramus, Marut CrossFit y CrossFit Perú; esto, en razón al número de boxes aperturados en Lima; no obstante, la intensión de expansión es latente en todos los demás boxes afiliados.

Es importante considerar que existen boxes de CrossFit no afiliados a CrossFit, Inc. -la razón principal de ello; evitar el pago anual de membresía de afiliación- lo cual, los convierte en boxes ilegales que aprovechan la denominación CrossFit para lucrar y captar consumidores; sin embargo, dadas las circunstancias que trasladan los conflictos legales con CrossFit, Inc., algunas de estas, han decidido cambiar su nombre comercial pero manteniendo los servicios del CrossFit; lo cual, sigue siendo un acto comercial desleal e ilegal. Un claro ejemplo de ello, se puede apreciar en las Figuras 2, 3, 4 y 5; donde las empresas Tuluka y Legado cambiaron la denominación CrossFit por Fitness en su nombre comercial. Por ello, se ha visto pertinente considerar aquellos boxes no afiliados como sustitutos del servicio. 


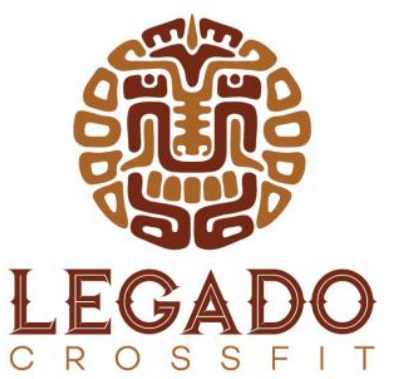

Figura 2. Logo de Legado CrossFit. Tomado de "Facebook Legado Fitness", 2018. Recuperado de https://www.facebook.com/legadocfitness/photos/a.107277163272037/120415871958166/?type=3\&theater

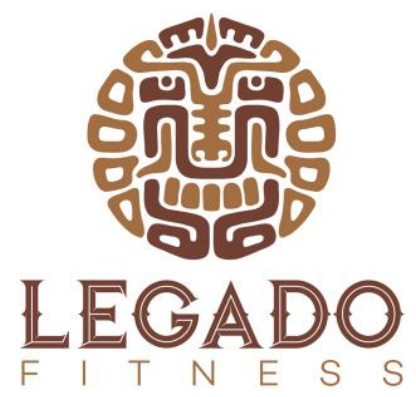

Figura 3. Logo de Legado Fitness. Tomado de "Facebook Legado Fitness", 2018. Recuperado de https://www.facebook.com/legadocfitness/photos/a.107277163272037/244637406202678/?type=3\&theater

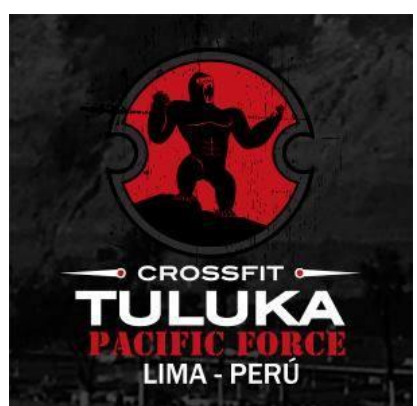

Figura 4. Logo de Tuluka CrossFit. Tomado de "Facebook Desafío CrossFit Perú", 2018. Recuperado de https://turnosweb.com/app/webroot/dominios/tulukaperu/img/logo_site.png

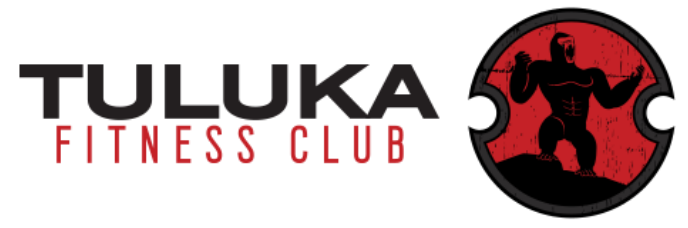

Figura 5. Logo de Tuluka Fitness Club. Tomado de "Web site Tuluka fitness", 2018. Recuperado de https://www.tulukafitness.com/tuluka-peru-2/ 
Contemplado el panorama actual de la industria en relación con la rivalidad entre empresas competidoras; corresponde identificar qué elementos clave de esta fuerza competitiva determinadas por Porter (1980) impactan en la empresa y posteriormente, definir el nivel de atractividad para evaluar qué tan fuerte es para la empresa.

1. Competidores numerosos o de igual fuerza

Baena et alt. (2013) señalan que para Porter (1980) este elemento clave "se trata de identificar si son pocas empresas las que dominan el mercado o si por el contrario se da un fenómeno de atomización" (p. 63); asimismo, ante la pluralidad de empresas que ofrezcan los mismos productos, servicios e incluso maneje los mismos recursos o posean el mismo tamaño; cada una ejecutará acciones que les otorgue el liderazgo del mercado; ocasionando, una lucha constante entre ellas.

En la mayoría de industrias, toda empresa que desee ingresar deberá determinar el número de competidores con quienes se enfrentará a diario; destacando a aquellas que poseen una mayor participación en el mercado, para posteriormente evaluar sus fortalezas y debilidades; y así, afrontarlos con mayor seguridad. La industria del fitness no es ajena a ello; más aún, que durante los últimos años, esta se ha convertido en un fenómeno. Según Mayer (2018):

El mercado fitness en el Perú avanza a pasos agigantados. No solo con la gran oferta de las cadenas de gimnasios, sino también con la tendencia de los centros de entrenamientos funcionales y crossfit, que desde hace tres años se hace más fuerte (p. 2).

2. Lento crecimiento de la industria

Baena et al. (2003) señala que "la competencia es más fuerte si la demanda del producto crece lentamente" (p.63); asimismo, Porter (1980) indica que "esto hace que las empresas que desean expandirse vean la competencia como un juego para alcanzar una mayor participación de mercado" (p. 59). En el caso de la industria Fitness, la demanda de los servicios que se ofertan -tanto diversas actividades físicas como centros de entrenamiento- han crecido rápidamente. Mayer (2018) advierte que según Klaus García Pacheco, gerente general del Inka Challenge Training -Centro de entrenamiento para las competencias nacionales peruanas denominadas como Inka Challenge- el boom fitness en el Perú, durante los últimos años, se debe a la competencia registrada entre los centros de entrenamientos tradicionalesgimnasios- frente al Crossfit y Functional training; indicando que, estos en comparación al impacto alcanzado en otros países es mínimo.

3. Altos costos fijos o de almacenamiento

Para comprender el presente elemento clave, se debe partir del concepto de costo fijo. Horngren, Datar y Rajan (2012) mencionan que "un costo fijo se mantiene estable en su 
totalidad durante cierto periodo de tiempo, a pesar de los amplios cambios en el nivel de la actividad o volumen total" (p. 30). Bajo esa premisa, Baena et al. (2003) apuntan que "si los costos fijos son elevados respecto al valor de los productos o servicios, las empresas se verán forzadas a mantener altas cifras de negocios" (p.63); evidenciándose que el valor del costo fijo será de suma importancia para cada actividad económica que se desarrolle. Ante ello, Porter (1980) indica que "las compañías sentirán la tentación de reducir un poco los precios con tal de asegurar las ventas" (p. 60); esto último, con el fin de obtener el presupuesto necesario para costear aquellos costos fijos. Esta medida, genera un desequilibrio en todas las empresas de la industria; a tal punto que, buscarán ejecutar medidas de reducción del costo fijo cuyo impacto puede ser positivo y competir en el mercado; así como, negativo y generar la inestabilidad empresarial con la salida del mercado.

\section{Ausencia de diferenciación o costes cambiantes}

Porter (1980) señala que en el desarrollo de la actividad económica de toda industria, el cliente basará su decisión de compra bajo dos premisas; esto es, el precio y servicio del producto; generando así, una rivalidad entre los competidores por alcanzar la mayor participación en el mercado. Ante ello, cada empresa busca estrategias que le permitan distinguirse; es por ello, que el factor de diferenciación del producto o servicio resulta valioso. Baena et al. (2003) indican que la diferenciación entre los productos "son las características del producto que lo hacen diferente, incluso hasta ser percibido como único en el mercado por su uso o aplicación. Puede ser por características propias del diseño, de la presentación, del servicio del cliente, etc” (p. 63). Asimismo, Porter (1980) señala que “...la diferenciación de productos proporciona capas de aislamiento frente a las guerras de competencia, pues los clientes muestran preferencia y lealtad por determinados proveedores" (p. 60). De otro lado, Baena et al. (2003) hacen referencia sobre los costes cambiantes a aquellos "cuando los costos de cambio de unos productos a otros, son bajos, se fomenta la lucha interna dentro del sector" (p. 60); es decir, que el coste de cambio que percibe el consumidor al momento de cambiar de producto, si es de menor costo en razón al producto que solía comprar, puede influenciar en sus compras a futuro; ocasionando en el mercado una guerra de precios entre las empresas del sector por poseer la preferencia del consumidor.

5. Aumento de la capacidad en grandes incrementos

Porter (1980) precisa que "cuando las economías de escala indican la necesidad de acrecentar la capacidad en gran proporción, estos incrementos desestabilizarán permanentemente el equilibrio de oferta/demanda en la industria, sobre todo cuando existe el riesgo de acumularlas" (p. 60); en ese mismo orden de ideas, Baena et al. (2003) precisan que 
debe existir un equilibrio entre la capacidad y producción, a tal punto que "cuando mayor sea el equilibrio entre la capacidad potencial de producción de un sector y su producción real, habrá más rivalidad" (p. 64). Lo anteriormente expuesto evidencia que un exceso en la capacidad ocasionaría serios problemas empresariales; las mismas que según Porter (1980) se han evidenciado en las industrias del papel, minerales, químicas y de construcción; ya sea por la demanda cíclica, la no diferenciación de los productos en razón a la orientación del consumidor basado en el precio del producto, factores tecnológicos, estructurales, competitivos, de información, administrativos y gubernamentales.

En cuanto a la industria del Fitness en razón al servicio proporcionado por las empresas que la integran, el efecto que del aumento de la capacidad se evidencia en: la demanda cíclica del servicio; esto es, la concurrencia de consumidores en las diversas estaciones del año, que por lo general, suelen acrecentarse en primavera y verano; siendo el primero de estas el de mayor registro. Del mismo modo, el efecto se configura cuando no hay diferenciación del servicio; esto último, se ve reflejado en la mayoría de gimnasios donde promueven la misma metodología de ejercicio basado en rutinas agobiantes y tradicionales. Caso contario ocurre con el CrossFit, donde la metodología es en base a movimientos funcionales de constante variación ejecutados a alta intensidad (CrossFit, Inc., 2017).

\section{Competidores diversos}

En toda industria, la presencia de competidores permite al consumidor tener una diversidad de opciones a elegir antes de la compra de su producto; para ello, evalúa previamente dichas opciones y determina cuál de estas ha de satisfacer en mayor proporción su necesidad. Porter (1980) indica al respecto que "los competidores con diferentes estrategias, origen, personalidad y relación con sus empresas matrices tienen metas y estrategias también diferentes para competir; a veces incluso chocan unos con otros" (p. 60). Por ello, las estrategias que toman cada uno de los competidores pueden ser opuestas entre sí, aún cuando experimenten los mismos eventos de su entorno. Esto se debe, a que no todas las empresas comparten el mismo objetivo empresarial; ya sea por el objeto de la sociedad o por el giro del negocio. De igual manera, Porter (1980) señala que "a menudo los competidores internacionales aportan gran diversidad a la industria porque viven en diversas situaciones y porque a veces persiguen metas diferentes" (p.60); asimismo, Baena et al. (2003) acotan que "la rivalidad aumenta cuando potentes grupos empresariales, compran empresas del sector para relanzarlas y entrar en ese mercado" (p.63). Al analizar estas evidencias, queda demostrado que las estrategias que cada empresa -ya sea nacional o extranjera- proporciona al mercado, generan la diversidad. 


\section{Importantes intereses estratégicos}

Para este elemento clave, Porter (1980) determina que "en una industria, la rivalidad se torna todavía mas inestable, si varias empresas buscan a toda costa el éxito en ella" (p. 61); es decir, si cualquier empresa desea alcanzar el éxito, ejecutará diversas estrategias que ocasionen un desequilibrio en el mercado, con el fin de lograr una sólida posición para posteriormente conquistar las demás industrias como afán expansionista; en muchos casos, dichas empresas son capaces de renunciar a una rentabilidad para lograr su meta deseada. En este mismo orden de ideas, Baena et al. (2003) identifican el presente elemento clave como los efectos de demostración de una empresa; definiéndola como "la necesidad de triunfar en los mercados más importantes, para poder introducirse con mayor facilidad en los demás” (p. 64)

8. Barreras sólidas de salida

Baena et al. (2003) señalan que el presente elemento clave se debe al costo elevado en la que incurriría la empresa en caso desee salir del mercado en vez de mantenerse y competir; así como, aquellas barreras que tendría que superar o que la limitan. Por su parte, Porter (1980) determina que dichas barreras "son factores de carácter económico, estratégico y emocional que permiten a las empresas competir en la industria, aunque obtengan rendimientos bajos y hasta negativos sobre la inversión" (p. 61); asimismo, las identifica en:

- Activos especializados

Como "los activos sumamente especializados de la industria o ubicación ofrecen bajos valores de liquidación o altos costes de transferencia o de conversión” (Porter, 1980, p. 61). En efecto, los activos especializados son difíciles de comercializar o liquidar en el mercado por parte de una empresa que ha decidido marcharse. Entendiéndose como activos aquellos inmuebles, maquinarias y equipos que posee la empresa saliente, cuya oferta a terceros se hace imposible; ya sea, por el sobrecosto que esta acarrea consigo el adquirir dicho activo o por el poco valor que ésta obtiene al salir de la industria.

- Costos fijos de la salida

Son los costes que toda empresa incurre al salir del mercado. Para Porter (1980) dichos costos fijos "son, entre otros, contratos colectivos de trabajo, costes de reubicación y capacidades de mantenimiento y de reparaciones" (p. 61). Dentro de este contexto, entra a detallar la pregunta: ¿Cuándo la empresa se somete a dichos costos fijos?; pues bien, partiendo de cualquiera de las premisas señaladas al inicio del presente elemento clave; toda empresa al querer salir del mercado, debe someterse a diversos procesos formales donde predomina el cumplimiento de sus deberes y obligaciones económicas frente a sus acreedores 
y socios. Para el ordenamiento jurídico, a dichos procesos les atribuye las denominaciones de disolución, liquidación y extinción de la sociedad.

- Interrelaciones estratégicas

Porter (1980) señala que "son las que se dan entre la unidad de negocio y otros departamentos de la empresa..."(p. 62); es decir, la comunicación entre cada uno de los elementos relacionados de la empresa; quienes en conjunto, buscan objetivos en común que se encuentran exteriorizadas en la misión y visión. Madero y Barboza (2015) argumentan que dichos elementos se enfocan “...en las estrategias que tienen que diseñar, desarrollar e implementar dentro de los equipos de trabajo de alto desempeño" (p. 740). Por lo tanto, cada estrategia tiene el propósito de unificar a cada uno de los elementos de la empresa para el cumplimiento de los objetivos.

\section{- Barreras emocionales}

Esta barrera se vincula con los sentimientos personales que perciben los socios, accionistas o directivos con la empresa; tal como señala Porter (1980) “...por su identificación con un negocio en particular, por su lealtad a los empleados, por el temor a arruinar su carrera y por orgullo" (p. 62).

- Restricciones gubernamentales y sociales

Son aquellas barreras que el gobierno impone a las empresas mucho antes de que se constituyan; su naturaleza se centra en salvaguardar los posibles efectos que causaría la salida de una empresa en el mercado. Porter (1980) al respecto indica que "el gobierno niega o alienta la salida de una empresa porque causaría la pérdida de empleos y efectos económicos a nivel regional..." (p. 62). Un claro ejemplo de ello, se aprecia en el marco normativo de la Ley General de Sociedades -Ley No 26887. Para que una empresa pueda salir del mercado, debe pasar por tres procesos importantes, las cuales han sido denominadas como disolución, liquidación y extinción de sociedades; esto último, con el único fin de proteger los intereses de los acreedores; sin embargo, en el artículo 411 de la mencionada ley, el Estado peruano puede ordenar la continuación forzosa de la sociedad siempre y cuando esta sea de seguridad nacional o de necesidad pública.

Una vez identificado aquellos elementos clave de la presente fuerza competitiva que impactan en la empresa; corresponde, tal y como se muestra en la Tabla 4, evaluar a través de la matriz de atractividad, qué tan importante es la presencia de estos elementos para la empresa. 
Tabla 4

Matriz de Atractividad para la Rivalidad entre los Competidores Existentes

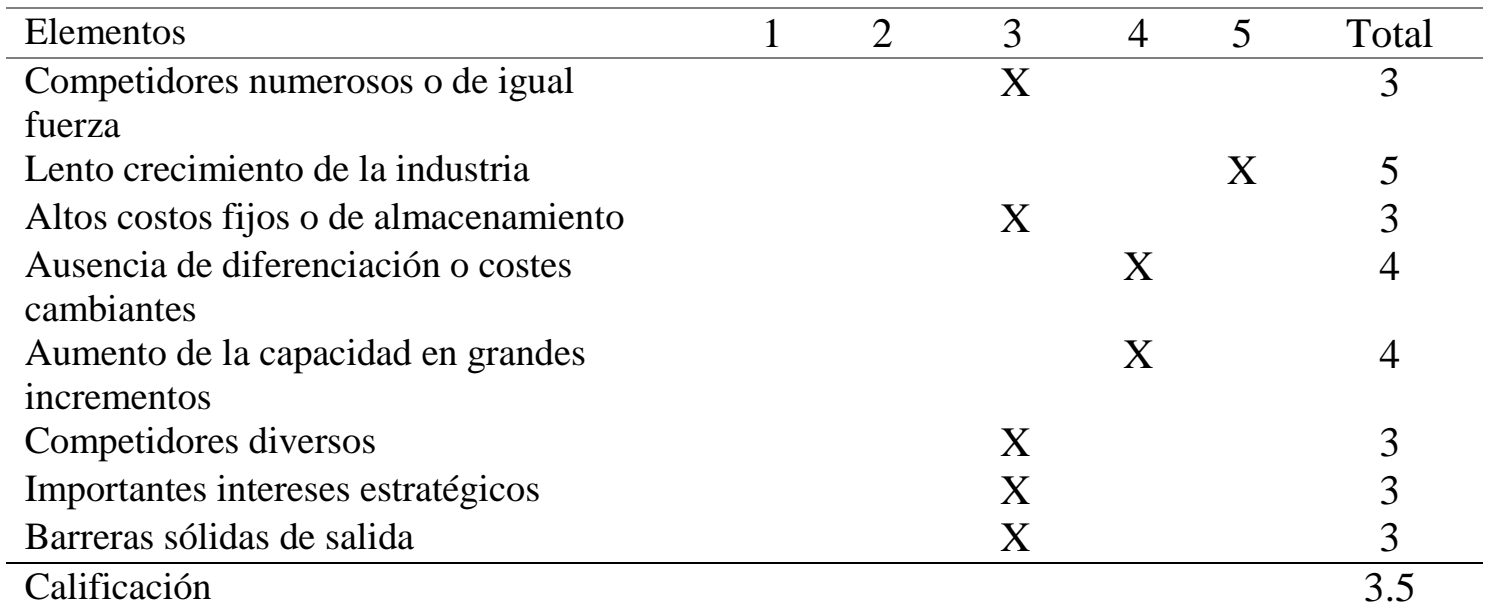

Nota: Se asignó una escala de 1 a 5 para indicar qué tan atractivo es dicho elemento clave de la fuerza competitiva para la empresa, donde $1=$ no atractivo, $2=$ poco atractivo, $3=$ neutro, $4=$ atractivo y $5=$ muy atractivo. Adaptado de "Dirección de marketing", por Kotler, P. \& Keller, K. L, 2006, 12, México: Pearson: Prentice Hall.

La calificación obtenida en la Tabla 4 es de 3.5; esto significa que, si hay atractividad para la empresa en razón a esta fuerza competitiva. Este resultado se debe a que en el Perú, la comunidad CrossFit recién ha tomado fuerza los últimos 5 años; a pesar que el primer box de CrossFit abrió sus puertas en el 2007 y que en el 2008, se celebró los primeros Regionales de CrossFit en Latinoamérica en nuestro país, donde estuvieron presentes los dos emblemas de esta actividad física: Greg Glassman, fundador de CrossFit, Inc.; y Dave Castro, director de los CrossFit Games.

\subsubsection{Productos sustitutos como amenaza}

Diversos autores (Porter, 1980; Baena et al., 2003; David, 2003) determinan que las empresas de una determinada industria compiten de manera directa con aquellas que pertenecen a industrias que elaboran productos sustitutos. Baena et al. (2003) define que "los bienes sustitutos son los productos que realizan las mismas funciones del producto en estudio..." (p. 64); asimismo, los citados autores determinan que los productos sustitutos son una amenaza siempre y cuando las necesidades cubiertas sean superiores a las del producto original. Sin embargo, algo beneficioso de la circulación de los productos sustitutos en el mercado, es que estos, tal y como lo señala Porter (1980) “...limitan los rendimientos potenciales de un sector industrial, pues imponen un techo a los precios que pueden cobrarse rentablemente en él” (p. 64). "Estos límites de precio determinan también la ganancia máxima y provocan una competencia más intensa entre rivales” (David, 2003, p. 77). 
Los productos y/o servicios sustitutos, sin excepción alguna, se encuentran en todos los mercados, con el único fin de hacerlos más competitivos; de esta manera, se busca satisfacer el deseo de los clientes aún no cubierto por el producto original; ya sea en el precio, rendimiento o calidad. En la industria Fitness, se puede encontrar un una gran variedad de productos sustitutos. Esto último, se debe a la evolución de las tendencias en razón a las necesidades de las personas en buscar actividades físicas distintas a las agobiantes rutinas de entrenamiento tradicional ofertados por los gimnasios. Como se ha señalado anteriormente, dichas actividades físicas llegan a convertirse en nuevas disciplinas o estilos de vida. Tal es el caso del modelo de negocio materia de la presente investigación, que surge de la experiencia de Greg Glassman; quién luego de una rutina de entrenamiento de gimnasia en la YWCA, se dio cuenta que con el paso del tiempo las rutinas de culturismo tradicional aburrían y no eran suficientes para mejorar la condición física de las personas y los atletas.

Partiendo de los supuestos anteriores, el CrossFit no es la excepción para tener sustitutos; debido a que, la base de su actividad se centra en el entrenamiento funcional y de alta intensidad. La primera, enfocada en ejercicios de progresión adaptados a cualquier deporte; y la segunda, basada en la calidad de repeticiones de un ejercicio ejecutadas con un peso promedio que permita la hipertrofia del cuerpo.

En la Tabla 5 se muestra los principales sustitutos del CrossFit en Lima; de los cuales, según Front Consulting (2017) quienes poseen el 70\% de participación del mercado Fitness son las cadenas de gimnasio Bodytech y Gold’s Gym; quienes de ese 70\%, Bodytech posee un $80 \%$, seguida de Gold’s Gym con un $20 \%$.

Tabla 5

Principales Sustitutos del CrossFit

\begin{tabular}{lcc}
\hline Gimnasios & Centros Fitness & Box de CrossFit no afiliado \\
\hline Bodytech & VO2 & Legado Fitness \\
Gold's Gym & JP Fitness Perú & Garage CrossFit \\
Sportlife & SmartFit Perú & Inca CrossFit \\
Mega Force & Tuluka Fitness & CrossFit Imperio \\
& Pulso Fitness & Iwia CrossFit \\
& Zumba Fitness & CrossFit Aukka \\
& Uno A1 & Ayax CrossFit \\
\hline
\end{tabular}

Contemplado el panorama actual de la industria en relación a los productos sustitutos como amenazada, corresponde identificar qué elementos clave de esta fuerza competitiva determinadas por Porter (1980) impactan en la empresa y posteriormente, definir el nivel de atractividad para evaluar qué tan fuerte es para la empresa. 


\section{Disponibilidad de sustitutos}

Porter (1980) señala que "para descubrir productos sustitutos es necesario buscar otros productos que realicen la misma función que el de la industria” (p. 65); es decir que, para este elemento es indispensable que se cumplan dos requisitos; el primero, la existencia del bien sustituto; y el segundo, que sea accesible para el cliente. Para efectos de la presente investigación, se detecta, según los resultados del cuestionario de opinión que los principales sustitutos que enfrenta el CrossFit en el distrito de Ate son: En primer lugar, los gimnasios; en segundo lugar, Functional Training; tercer lugar, los deportes; cuarto lugar, el baile; entre otros; tal y como se aprecia en el Apéndice 39. En cuanto a la accesibilidad de los pobladores hacia los productos sustitutos, el resultado del cuestionario de opinión que se muestra en el Apéndice 39 ha determinado que un 30,2\% es por la ubicación del centro de entrenamiento, un $22,1 \%$ por los horarios, un $11,4 \%$ por el precio, otros $16,9 \%$; mientras que, un $19,5 \%$ le pareció indiferente.

2. Precio relativo entre el producto ofrecido y el sustituto

Diversos autores (Porter, 1980; Baena et. al, 2003; Kotler \& Armstrong, 2013) han señalado que, en todas las industrias, los productos sustitutos instauran un límite a los precios; así como, el margen de utilidades que circulan en la industria. Las empresas que dominan el sector no podrán incrementar los precios a su favor; puesto que, los productos sustitutos se encargarán de frenar dicha capacidad que tenían; a tal punto de, influir en la disminución de la rentabilidad.

En el distrito de Ate, se ha determinado que en la industria Fitness existe una variabilidad de precios en los productos sustitutos; esto último, basado en el gasto promedio mensual que realizan los pobladores del distrito; tal y como se muestra en el Apéndice 39. Sin embargo, es preciso indicar que el precio varia en razón a la calidad del servicio que se ofrece; un claro ejemplo de ello se da al comparar el servicio que te ofrece las grandes cadenas de gimnasio como Bodytech y Gold’s Gym frente a los gimnasios de barrio, quienes por su gran infraestructura, pueden ofrecer mayores beneficios y servicios.

3. Rendimiento y calidad comparado entre el producto ofrecido y su sustituto

Baena et al. (2003) opinan que "los clientes se inclinaran por el producto sustituto si la calidad y el rendimiento son superiores al producto usado" (p. 64); más aún, si se oferta a un precio menor. En la industria del Fitness, los gimnasios han priorizado en brindar una mejor calidad de sus servicios a través de la infraestructura, mientras que los demás centros de entrenamiento han preferido personalizar su servicio. 
Por su parte, el CrossFit mezcla ambos conceptos para su servicio. Por un lado, la infraestructura debe ser la idónea para la realización de los ejercicios y la estadía de los clientes antes, durante y después de su entrenamiento; mientras que por el otro, la personalización debe ser en razón a las necesidades y capacidades físicas del cliente.

4. Costos de cambio para el cliente

Barroso y Picón (2004) han delimitado el concepto al señalar que los costos de cambio involucran aquellos costes que el cliente asume al desvincularse de proveedor; así como, aquellos que se originan como producto de la nueva relación con otro proveedor. El primero, suele suceder cuando se somete al cliente a una penalidad por la liberación del vínculo contractual; la segunda, acarrea consigo aquellos costes posteriores a la liberación; ya sean monetarios, de esfuerzo y tiempo en la búsqueda de la información del nuevo servicio.

En la industria fitness, cuando un cliente ha decidido desvincularse de su centro de entrenamiento tiene dos opciones: La primera, esperar la fecha de expiración de su membresía, aprovechando los servicios que le ofrecen hasta el final; y la segunda, abandonar en cualquier momento, dando por concluido su membresía y sometiéndose a una penalización de no reembolso y goce de los servicios. En cuanto a los costes en los que incurre el cliente por su nuevo vínculo con otro proveedor, está el pago por concepto de matrícula en la suscripción de su nueva membresía.

Una vez identificados aquellos elementos clave de la presente fuerza competitiva que impactan en la empresa; corresponde evaluar a través de la matriz de atractividad (ver Tabla 6), qué tan importante es la presencia de estos elementos para la empresa.

Tabla 6

Matriz de Atractividad de los Productos Sustitutos como Amenaza

\begin{tabular}{|c|c|c|c|c|c|c|}
\hline Elementos & 1 & 2 & 3 & 4 & 5 & Total \\
\hline Disponibilidad de sustitutos & & & $\mathrm{X}$ & & & 3 \\
\hline $\begin{array}{l}\text { Precio relativo entre el producto } \\
\text { ofrecido y el sustituto }\end{array}$ & & & & $\mathrm{X}$ & & 4 \\
\hline $\begin{array}{l}\text { Rendimiento y calidad comparado entre el } \\
\text { producto ofrecido y su sustituto }\end{array}$ & & & & $\mathrm{X}$ & & 4 \\
\hline Costos de cambio para el cliente & & & & $\mathrm{X}$ & & 4 \\
\hline Calificación & & & & & & 3.75 \\
\hline
\end{tabular}

Nota: Se asignó una escala de 1 a 5 para indicar qué tan atractivo es dicho elemento clave de la fuerza competitiva para la empresa, donde $1=$ no atractivo, $2=$ poco atractivo, $3=$ neutro, $4=$ atractivo y $5=$ muy atractivo. Adaptado de "Dirección de marketing", por Kotler, P. \& Keller, K. L, 2006, 12, México: Pearson: Prentice Hall. 
La calificación obtenida en la Tabla 6 es de 3.75; esto significa que, si hay atractividad para la empresa en razón a esta fuerza competitiva. Esto último, se debe a que el mercado peruano es muy cambiante en razón al ingreso de nuevas tendencias; mismas que son bien recibidas en respuesta a las necesidades no cubiertas por la industria.

\subsubsection{Poder de negociación de los compradores}

Porter (1980) al respecto señala que "los clientes compiten con la industria cuando la obligan a reducir los precios, cuando negocian una mejor calidad o más servicios y cuando enfrentan a los competidores entre sí” (p. 66); de otro lado, Kotler y Keller (2006) han identificado que "un segmento no es atractivo si los compradores tienen un poder de negociación fuerte o en crecimiento" (p. 232), en razón a los elementos claves que la identifican.

En la industria del Fitness, el panorama es distinto; puesto que, existe un equilibrio entre la demanda de personas que buscan un mejor estilo de vida, bajar de peso o mejorar la salud frente a la oferta de centros de entrenamiento y actividades físicas basadas en gustos, preferencias y necesidades.

Los elementos claves que se han identificado en esta fuerza y que impactan directamente en la empresa son:

\section{Concentración de clientes}

De acuerdo con Baena et al. (2003) en este elemento "se trata de identificar si existen pocos clientes que demandan la mayor parte de las ventas del sector o si existen muchos" (p. 64). La demanda del servicio fitness en los últimos años ha aumentado, a tal punto que, de 1,5\% a 2\% del total de habitantes en el Perú es población fitness (IHRSA, 2018).

Este fenómeno ha ocasionado que la oferta de centros de entrenamiento aumente. Un claro ejemplo de ello se encuentra en la propuesta del CrossFit y Functional Training, que según Klaus García (Mayer, 2018) han crecido gracias a la nueva cultura fitness que se ha instaurado. A pesar de ello, las tarifas del servicio fitness se ven influenciadas cuando el cliente tiene el poder de elegir frente a la saturada oferta del mercado. Sin embargo, dependerá de la empresa el poder diferenciarse para que el cliente no tenga tanto poder de negociación.

\section{Diferenciación}

Baena et al. (2003) consideran que " si los productos o servicios ofrecidos no están diferenciados los clientes tendrán más poder de negociación” (p. 64); puesto que, de acuerdo con Porter (1980), un mercado indiferenciado le da al cliente la convicción de localizar otra alternativa. En la industria Fitness podemos observar que los diversos centros de 
entrenamiento proponen beneficios adicionales a su servicio principal; tales como: uso de spa, sauna, nutrición, etc.

Hace unos años, las grandes cadenas de gimnasios como Bodytech y Gold’s Gym solían frenar el poder de negociación de los clientes, sometiéndolos a sus precios. Sin embargo, la tendencia del mercado ha cambiado; a tal punto que, hoy en día, los clientes del mercado Fitness buscan nuevas alternativas donde la obtención de resultados esté por encima de los servicios adicionales que le ofrezcan. Roncalla (2018) señala que "la diferencia es que las cadenas de gimnasios tradicionales ven más el mundo fitness por su rentabilidad y no les prestan atención a sus clientes ni a sus logros” (Mayer, 2018, p. 13). Dentro de este contexto, se ubica el CrossFit.

3. información acerca del proveedor

Desde el punto de vista de Porter (1980), "cuando el cliente conoce perfectamente la demanda, los precios de mercado e incluso los costes de proveedor, suele tener una mayor ventaja negociadora que cuando carece de estos datos" (p. 67). En la actualidad, los clientes pueden acceder, con mayor facilidad, a toda la información referente al producto o servicio brindado a través del internet, ya sea mediante las páginas web o redes sociales; por lo cual, su decisión de compra suele estar mejor sustentada. Sin embargo, los clientes suelen acceder a dicha información posteriormente; es decir, cuando ya se encuentran sumergidos en el mundo fitness.

4. Identificación de la marca

Citando a Baena et al. (2003) este elemento "es la asociación que hace el comprador con marcas existentes en el mercado, que lo puede llevar inclusive a identificar un producto con una marca..." (p. 65). En la industria Fitness, las grandes cadenas de gimnasio como Bodytech y Gold’s Gym se han posicionado en la mente de los consumidores; sin embargo, ambas asocian sus nombres comerciales al centro de entrenamiento, más no de la misma actividad física. Caso contrario ocurre con el CrossFit, que ha sabido posicionarse del mercado mundial gracias a su trademark; a tal punto que, los consumidores pueden identifican la actividad física con la marca.

\section{Productos sustitutos}

Como ya se ha señalado, la disponibilidad de sustitutos le permite al cliente tener un mayor poder de negociación. Sin embargo, es la diferenciación del producto o servicio lo que frena dicha potestad. 
Una vez identificado aquellos elementos clave de la presente fuerza competitiva que impactan en la empresa; corresponde evaluar a través de la matriz de atractividad, qué tan importante es la presencia de estos elementos para la empresa (ver Tabla 7).

Tabla 7

Matriz de Atractividad para el Poder de Negociación de los Compradores

\begin{tabular}{|c|c|c|c|c|c|c|}
\hline Elementos & 1 & 2 & 3 & 4 & 5 & Total \\
\hline Concentración de clientes & & & & $\mathrm{X}$ & & 4 \\
\hline Diferenciación & & & & $\mathrm{X}$ & & 4 \\
\hline Información acerca del proveedor & & & $\mathrm{X}$ & & & 3 \\
\hline Identificación de la marca & & & & $\mathrm{X}$ & & 4 \\
\hline Productos sustitutos & & & $\mathrm{X}$ & & & 3 \\
\hline Calificación & & & & & & 3.6 \\
\hline
\end{tabular}

Nota: Se asignó una escala de 1 a 5 para indicar qué tan atractivo es dicho elemento clave de la fuerza competitiva para la empresa, donde $1=$ no atractivo, $2=$ poco atractivo, $3=$ neutro, $4=$ atractivo y $5=$ muy atractivo. Adaptado de "Dirección de marketing", por Kotler, P. \& Keller, K. L, 2006, 12, México: Pearson: Prentice Hall.

La calificación obtenida en la Tabla 7 es de 3.6; esto significa que, si hay atractividad para la empresa en razón a esta fuerza competitiva. Este resultado se debe al equilibrio entre la oferta y demanda de la industria fitness; debido a que las empresas que compiten en ella, responden a la demanda de consumidores que desean mejorar su estilo de vida o salud a través de mejoras en los servicios para ganar su lealtad.

\subsubsection{Poder de negociación de los proveedores}

Los insumos para la elaboración de un producto o prestación de algún servicio son la base para el desarrollo de la actividad económica de toda empresa; para ello, es indispensable contar con uno o varios proveedores capaces de suministrar los insumos necesarios para la producción de productos o prestación de servicios. Es aquí donde, David (2013) señala que este poder “(...) afecta la intensidad de la competencia en una industria, sobre todo cuando hay un gran número de proveedores, cuando sólo existen unas cuantas materias primas sustituidas, o cuando el costo de cambiar a otras materias es especialmente alto" (p. 78).

En el caso de la industria del fitness, se puede apreciar que existe un sinfín de proveedores a nivel mundial; ya sea en marcas específicas de maquinarias de entrenamiento; así como, otros tipos de equipos que no necesariamente sean de una marca en específico; las cuales, se pueden apreciar en los gimnasios y centros de entrenamiento Functional. Por el contrario, el CrossFit cuenta con un número de proveedores limitados y autorizados; tales como: Rogue Fitness, como la principal y Concept, encargada de remos, bicicletas de aire y remos invertidos; de ahí, varios proveedores sustitutos, como alternativa más barata y accesible; 
ejemplo de ello, se puede apreciar con BullFit (ver Figura 6), Rudem (ver Figura 7) y Lycan (Ver Figura 8), que son las empresas encargadas de la distribución de equipos de CrossFit en el Perú:

1. BullFit

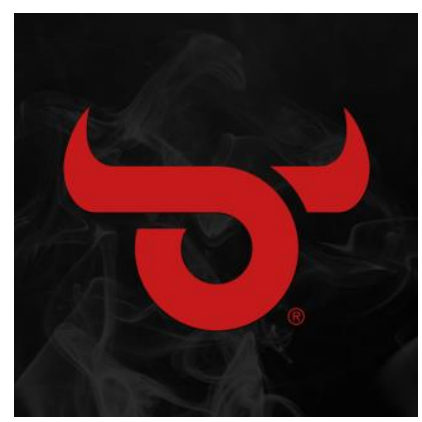

Figura 6. Logo de BullFit. Tomado de "Página de Facebook de BullFit", 2018. Recuperado de https://www.facebook.com/bullfitlatam/photos/a.1638330866436777/2002617686674758/?type=1\&theater

Año de Lanzamiento: 2015

Ubicación: Calle Daniel Alcides Carrión 223, Miraflores.

Teléfono: 987716981

Web: www.bullfitlatam.com

2. Rudem Fitness Equipment

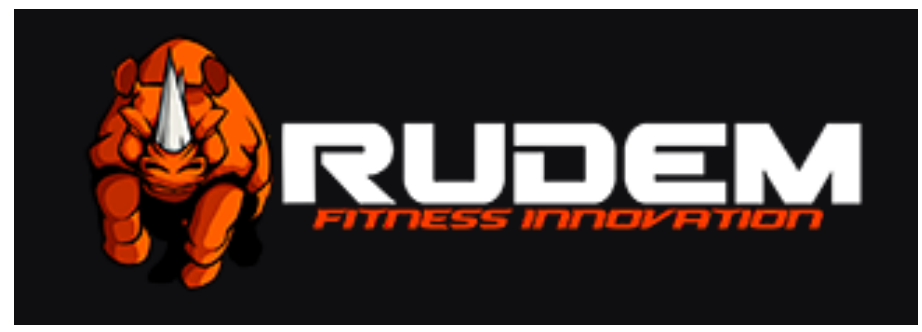

Figura 7. Logo de Rudem Fitness Equipment. Tomado de "Página web de Rudem Fitness Equipment", 2018. Recuperado de http://rudemfitness.com/

Año de Lanzamiento: 2013

Ubicación: Jirón Carlos Gonzales 239, San Miguel.

Teléfono: 989018212

Web: http://rudemfitness.com/

3. Lycan Fitness

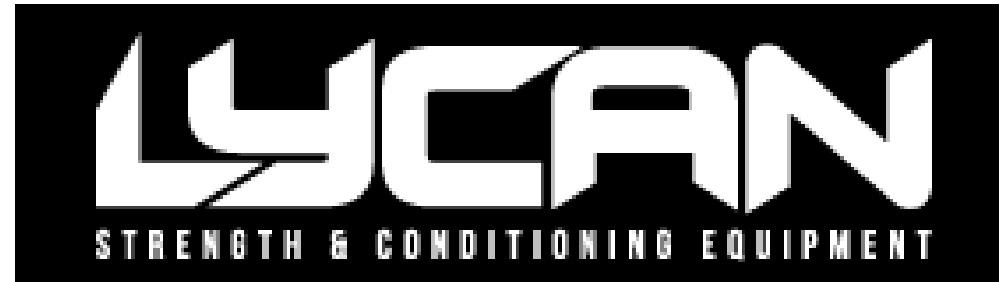

Figura 8. Logo de Lycan Fitness. Tomado de "Página web de Rudem Fitness Equipment", 2018. Recuperado de http://www.lycanfitness.pe 
Año de Lanzamiento: 2017

Teléfono: 999575817

Web: http://www.lycanfitness.pe

Los elementos claves identificados en esta fuerza que impactan a la empresa son:

1. Concentración de proveedores

Como señalan Baena et al. (2003) "se requiere identificar si la mayor parte de la provisión de insumos o recursos para las empresas del sector, las realizan pocas o compañías" (p. 65). En la industria Fitness, son pocas las empresas que se dediquen a la fabricación de equipos, muebles y enseres de este rubro; más aún del CrossFit; debido a que, la gran mayoría de empresas de equipamiento suelen ser distribuidoras autorizadas. El fabricante con mayor presencia en el mercado es Fitness Pro, que suele ofrecer maquinas y equipos para cualquier tipo de gimnasio; sin embargo, en el caso del CrossFit, sólo ofrecen: Racks, bancas para press y accesorios metálicos; por tanto, se debe adquirir los demás equipos de aquellos distribuidores especializados que se han señalado precedentemente.

\section{Diferenciación de insumos}

Al respecto Porter (1980) señala que la diferenciación de los insumos que ofertan los proveedores, puede impedir un enfrentamiento entre estos. De esta manera, los proveedores tendrían el poder de negociación. En la industria Fitness, se puede apreciar que la mayoría de equipos no suelen ser diferenciados; puesto que, en su mayoría suelen seguir los mismos diseños de equipamiento profesional ya establecidos para cada disciplina. Del mismo modo ocurre con el CrossFit, donde podemos apreciar, que la única diferenciación está en la trayectoria de la empresa, los detalles y presentación. Un caso que ilustra lo anterior es el de Rogue Fitness, que es la principal marca que fabrica los equipos de CrossFit; sin embargo, existen empresas que han diseñado los mismos equipos a un precio más bajo y más accesibles.

3. Costos de cambio

Este elemento "se refiere a los costos que incurre el comprador cuando cambia de proveedor..."(Baena et al., 2003, p. 65). En este caso, el proveedor puede incurrir en: (a) Costos por la liberación del vínculo contractual, y (b) Costos por nuevo vínculo con otro Proveedor.

4. Disponibilidad de insumos sustitutos

Baena et al. (2003) deducen que "es la existencia, disponibilidad y acceso a insumos sustitutos que por sus características pueden reemplazar a los tradicionales" (p. 65); en ese orden de ideas, Porter (1980) postula que la existencia de insumos sustitutos frena el control 
de negociación de los proveedores. En la industria Fitness, los principales sustitutos suelen ser otras maquinarias y equipos pero con diferente diseño. En el caso del CrossFit, el sustituto es adaptar los ejercicios con otros equipos o utilizar el peso corporal.

5. Impacto de los insumos

"se trata de identificar si los insumos ofrecidos mantienen, incrementan o mejoran la calidad del bien" (Baena et al., 2003, p. 65). El equipamiento de todo centro deportivo permite ofrecer a los clientes una variedad de rutinas para alcanzar sus objetivos. Por lo cual, el impacto de estos insumos en el servicio es el de incrementar la calidad de la misma.

Identificado los elementos clave de la presente fuerza competitiva, corresponde evaluar qué tan importante es la presencia de estas; y ello, lo conseguiremos mediante la elaboración de la matriz de atractividad; tal como se puede apreciar en la Tabla 8.

Tabla 8

Matriz de Atractividad para el Poder de Negociación de los Proveedores

\begin{tabular}{|c|c|c|c|c|c|c|}
\hline Elementos & $\begin{array}{c}\text { No } \\
\text { atractivo } \\
1\end{array}$ & $\begin{array}{c}\text { Poco } \\
\text { atractivo } \\
2\end{array}$ & $\begin{array}{c}\text { Neutro } \\
3\end{array}$ & Atractivo & $\begin{array}{c}\text { Muy } \\
\text { atractivo } \\
5\end{array}$ & Total \\
\hline $\begin{array}{l}\text { Concentración de } \\
\text { proveedores }\end{array}$ & & & $\mathrm{X}$ & & & 3 \\
\hline $\begin{array}{l}\text { Diferenciación de } \\
\text { insumos }\end{array}$ & & & & & $X$ & 5 \\
\hline Costos de cambio & & & & $X$ & & 4 \\
\hline $\begin{array}{l}\text { Disponibilidad de } \\
\text { insumos sustitutos }\end{array}$ & & & & $X$ & & 4 \\
\hline $\begin{array}{l}\text { Impacto de los } \\
\text { insumos }\end{array}$ & & & & $X$ & & 4 \\
\hline Calificación & & & & & & 4 \\
\hline
\end{tabular}

Nota: Se asignó una escala de 1 a 5 para indicar qué tan atractivo es dicho elemento clave de la fuerza competitiva para la empresa, donde $1=$ no atractivo, $2=$ poco atractivo, $3=$ neutro, $4=$ atractivo y $5=$ muy atractivo. Adaptado de "Dirección de marketing", por Kotler, P. \& Keller, K. L, 2006, 12, México: Pearson: Prentice Hall.

La calificación obtenida en el análisis de la matriz es de 4; esto significa, que la atractividad del mercado para el poder de negociación de los proveedores es atractiva. A pesar que en el mercado peruano no se cuenta con una variedad de proveedores oficiales de CrossFit y su alcance es poco accesibles; existe una fuerte presencia de algunos sustitutos que hacen que se tenga un mejor panorama para elegir la oferta más accesible. Asimismo, se puede observar que el elemento más relevante de este poder es: la diferenciación de insumos, debido a que el suministro de equipos deportivos de CrossFit, la comercializan varios proveedores, cuya diferenciación está en los detalles y presentación, más no en el precio y diseño. 
Una vez realizado y analizado el nivel de atractividad de cada una de las Fuerzas competitivas, se procede a elaborar la matriz resumen de atractividad (ver Tabla 9). El resultado obtenido es de 3.7, lo cual indica que el mercado es atractivo para la apertura de un box de CrossFit en el distrito de Ate.

Tabla 9

Matriz Resumen de Atractividad

\begin{tabular}{lccc}
\hline Fuerza Competitiva & Ponderación & $\begin{array}{c}\text { Nivel de } \\
\text { Atractividad }\end{array}$ & $\begin{array}{c}\text { Nivel de } \\
\text { Atractividad } \\
\text { ponderado }\end{array}$ \\
\hline $\begin{array}{l}\text { Amenaza de entradas de competidores } \\
\text { potenciales }\end{array}$ & 0.15 & 3.5 & 0.53 \\
Rivalidad entre competidores existentes & 0.20 & 3.5 & 0.7 \\
Productos sustitutos como amenaza & 0.30 & 3.75 & 1.13 \\
Poder de negociación de los compradores & 0.15 & 3.6 & 0.54 \\
Poder de negociación de los proveedores & 0.2 & 4 & 0.8 \\
Total & 1 & & 3.7 \\
\hline
\end{tabular}

\subsection{Análisis de la Competencia}

"Un análisis de la competencia actual o directa entraña manejar información precisa y confiable sobre su forma de trabajar, sus fortalezas y debilidades, su trato con los grupos de interés (stakeholders), su porcentaje de participación en el mercado, sus ventas o su aceptación por parte de los clientes" (Arbaiza, 2015, p. 59).

El presente plan de negocio se encuentra situado en el mercado fitness peruano, donde los últimos años ha crecido significativamente; a tal punto que, ha generado nuevas tendencias. Empleando las palabras de Llance (2017) "la tendencia del mercado apunta a los entrenamientos funcionales y, dentro de ellos, el CrossFit se vuelve una opción completa por la potencia y fuerza" (El Comercio, 2017, párr. 11).

\subsubsection{Empresas que of recen el mismo servicio}

En el Perú, el modelo de negocio CrossFit ha tenido un gran crecimiento; a tal punto que, hoy en día hay 17 boxes afiliados (ver Tabla 1); de los cuales, como ya lo hemos señalado, 15 se ubican en Lima y los restantes en provincia. Pero, ¿por qué un mismo modelo de negocio está desarrollándose tan rápido?; según Arbaiza (2015) esto se debe a que "cuando las empresas competidoras son muy similares en tamaño, en forma de operar o en las características de sus productos, no se genera una competencia muy intensa, ya que, probablemente, la industria presenta condiciones favorables para su crecimiento" (p. 61).

Para el contexto de la presente investigación, se determinó a los competidores directos de Ate CrossFit en razón a la clasificación propuesta por Arbaiza (2015) quién señala que "se 
debe identificar el elemento a partir del cual compiten las empresas rivales" (p. 61), dentro de estos destacan:

- La experiencia en el mercado, basado en los años que tiene de aperturado el box de CrossFit; dentro de este marco tenemos a CrossFit Ramus (ver Figura 9), CrossFit Marut (ver Figura 10) y CrossFit La Molina (ver Figura 11).

- El porcentaje de participación en el mercado, la cual se estudia en el punto 2.4.2 del presente capítulo; y cuyo análisis (ver figura 13) evidencia que CrossFit Ramus y CrossFit Marut son aquellas que, gracias a su poder adquisitivo, han podido expandirse con nuevas sedes.

- La ubicación que para efectos de la presente investigación se ha determinado que, dentro del distrito de Ate no hay competidores; es decir, hasta la fecha no existe un box de CrossFit afiliado. Sin embargo, existen competidores cercanos al distrito; estos son; CrossFit La Molina (ver Figura 11) y Legado CrossFit (ver Figura 12).

- La imagen posicionada, que de conformidad con Llance (2017) "hoy existe una oferta muy segmentada. Aún no hay una marca que sea el referente del crossfit actualmente en el país..." (párr. 12); es decir, que dentro del mercado Fitness peruano, no hay un box de CrossFit que sea el líder absoluto, por lo que diversas empresas dedicadas a esta actividad física están planteando expandirse a otros segmentos; tal es el caso de CrossFit Ramus y CrossFit Marut que en la actualidad se proyectan a aperturar más sedes.

1. CrossFit Ramus

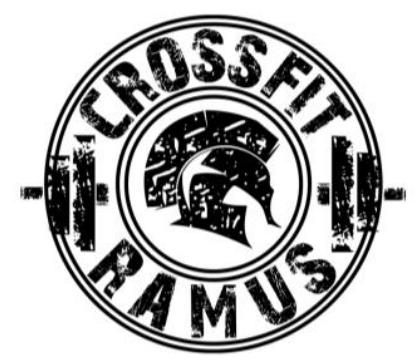

Figura 9. Crossfit Ramus. Tomado de "Página web de Crossfit Ramus", 2018. Recuperado de http://crossfitramus.com/

Año de lanzamiento: 2013

Sedes: 3 
Ubicación:

- Avenida Javier Prado № 4565, Urbanización Neptuno, Santiago de Surco.

- Pasaje Zodiaco № 459, Club Deportivo La Alborada, Surco.

- Jirón Carlos Gonzales № 239, San Miguel

Página web: www.crossfitramus.com

Membresías:

- $\quad$ Mensual: S/. 380.00

- Trimestral: S/. 1,050.00

- Semestral: S/. 1,900.00

- Anual: S/. 3,400.00

2. CrossFit Marut

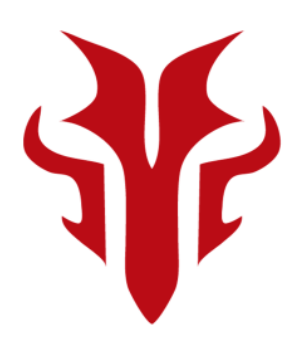

Figura 10. Crossfit Marut. Tomado de "Facebook Crossfit Marut", 2018. Recuperado de https://www.facebook.com/crossfitmarut/

Año de lanzamiento: 2014

Sedes: 2

Ubicación:

- Av. Angélica Gamarra № 653, Los Olivos

- Av. Leguía y Meléndez № 1068, ex Av. General Clemente, Pueblo Libre.

Página web: https://www.facebook.com/crossfitramus/

Membresías:

- $\quad$ Mensual: S/. 350.00

- Trimestral: S/.1,000.00

- Semestral: S/. 1,750.00

- Anual: S/. 3,000.00 


\section{CrossFit La Molina}

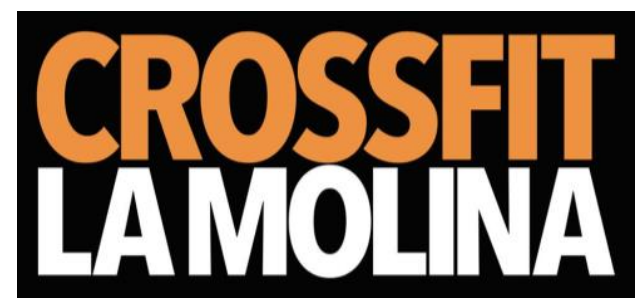

Figura 11. CrossFit La Molina. Tomado de "Página web de CrossFit La Molina", 2018. Recuperado de http://www.cflm.com.pe/

Año de lanzamiento: 2015

Sedes: 1

Ubicación: Calle el Grifo № 100, La Molina.

Página web: www.cflm.com.pe

Membresías:

- $\quad$ Mensual: S/. 380.00

- Trimestral: S/. 1,050.00

- Semestral: S/. 1,900.00

- Anual: S/. 3,200.00

4. Legado CrossFit (Legado Fitness)

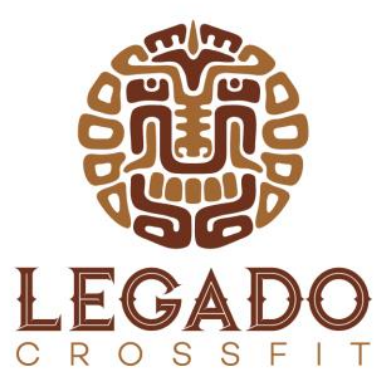

Figura 12. Legado crossfit. Tomado de "facebook de Legado Crossfit", 2018. Recuperado de https://www.facebook.com/legadocfitness/

Año de lanzamiento: 2017

Sedes: 1

Ubicación: Av. Javier Prado Este 5950, cruce con Av. La Molina.

Página web: https://www.facebook.com/legadocfitness/

Membresías:

- $\quad$ Mensual: S/. 350.00

- Trimestral: S/. 1,000.00

- Semestral: S/. 1,800.00

- $\quad$ Anual: S/. 3,000.00 


\title{
2.4.2 Participación de mercado de los competidores
}

En la Tabla 2 se detalla cada uno de los box de CrossFit que operan en Lima. Al tratarse de un modelo de negocio aún creciente y prácticamente nuevo para algunas empresas peruanas que estudian el mercado, no se cuenta con información detallada sobre el nivel de participación de cada uno de los box de CrossFit. Sin embargo, diversos expertos (Poppe, 2018; Andonayre, 2018; Baella, 2018) recomiendan estimar el nivel de participación de mercado (ver Apéndice 19) mediante el número de boxes que han aperturado cada una de las empresas afiliadas (ver Figura 13).

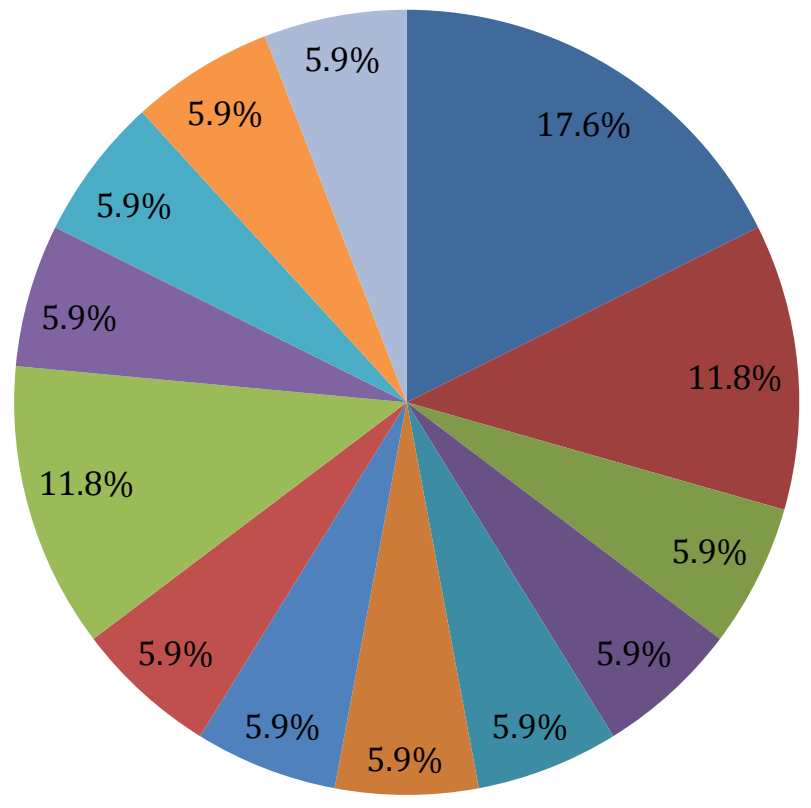

\author{
CrossFit Ramus \\ - CrossFit Marut \\ CrossFit Kronos \\ - CrossFit G300 \\ - Sinchi CrossFit \\ CrossFit Perú \\ - Barranco CrossFit \\ - CrossFit La Molina \\ Altair CrossFit \\ - Caution CrossFit \\ Atoq CrossFit \\ - Latido CrossFit \\ CrossFit La Parada
}

Figura 13. Nivel de Participación de los Boxes de CrossFit Afiliados en Lima. Adaptado de "CrossFit Affiliates", 2018. Recuperado de https://map.crossfit.com/

Como se indica previamente, en la presente investigación se toma en cuenta a: CrossFit La Molina, con un 6\% de participación en el mercado, por ubicarse en un distrito colindante al de Ate; CrossFit Ramus y Marut, con $17.6 \%$ y $11.8 \%$ de participación en el mercado respectivamente, por ser empresas con mayor participación en el mercado, y proyección a futuro; y finalmente, a Legado CrossFit, hoy Legado Fitness con un 6\% de participación, por ser un box de CrossFit en proceso de desafiliación y colindar al distrito de Ate. 


\subsubsection{Matriz del perfil competitivo}

David (2013) define a la Matriz de perfil competitivo (MPC) como aquella que "identifica a los principales competidores de la compañía, así como sus fortalezas y debilidades particulares en relación con la posición estratégica de una firma muestra” (p. 83); las cuales, serán calificadas y multiplicadas bajo una ponderación determinada de ciertos factores críticos para el éxito; dentro de las cuales, se incluyen tanto factores internos como externos de cada una. La calificación otorgada, será de uno a cuatro; siendo uno, debilidad principal; dos, debilidad menor; tres, fortaleza menor; y cuatro, fortaleza principal.

Para la elaboración del MPC de la presente investigación, se consideró dentro del grupo estratégico de competidores aquellos que han sido evaluados con los criterios de clasificación propuestos por Arbaiza (2015) descritos en el punto 2.4.1; estos son: CrossFit La Molina, Legado CrossFit, CrossFit Ramus y CrossFit Marut. En este mismo orden de ideas, tanto los factores críticos del éxito como la asignación del peso fueron determinados por el experto Julio Poppe, gerente general de CrossFit La Molina, a través de una entrevista a profundidad (Ver Apéndices 22, 26 y 27). Posteriormente, para la calificación respectiva de cada uno de los factores críticos del éxito en razón a cada competidor, se eligió a expertos que conozcan a profundidad el grupo estratégico seleccionado; por ende, se dispuso que tanto el Experto 1, dueño CrossFit La Molina, como los Expertos 2 y 3 (ver Apéndice 30 y 32), coaches a tiempo parcial de Legado CrossFit, CrossFit Marut, CrossFit Ramus y CrossFit La Molina, sean los encargados de realizar la calificación respectiva, basándose en su propia experiencia. (Ver Apéndices 28, 31 y 33). Una vez obtenidas las calificaciones respectivas, se procedió a realizar una síntesis de calificación de factores críticos (ver Apéndice 34) para que finalmente se obtenga el resultado de la calificación por expertos (ver Apéndice 35). Culminado dicho procedimiento, corresponde multiplicar el peso de cada factor crítico con la calificación respectiva; de esta manera, se obtiene la MPC (ver Tabla 10). 
Tabla 10

Matriz de Perfil Competitivo

\begin{tabular}{|c|c|c|c|c|c|c|c|c|c|}
\hline \multirow[t]{2}{*}{ Factores críticos } & \multirow[b]{2}{*}{ Peso } & \multicolumn{2}{|c|}{$\begin{array}{l}\text { CrossFit La } \\
\text { Molina }\end{array}$} & \multicolumn{2}{|c|}{$\begin{array}{l}\text { Legado } \\
\text { CrossFit }\end{array}$} & \multicolumn{2}{|c|}{$\begin{array}{c}\text { CrossFit } \\
\text { Ramus }\end{array}$} & \multicolumn{2}{|c|}{$\begin{array}{c}\text { CrossFit } \\
\text { Marut }\end{array}$} \\
\hline & & $(q)$ & $(r)$ & $(q)$ & $(r)$ & (q) & $(r)$ & $(q)$ & $(r)$ \\
\hline $\begin{array}{l}\text { Participación en el } \\
\text { mercado }\end{array}$ & 0.07 & 2 & 0.14 & 3 & 0.21 & 4 & 0.28 & 4 & 0.28 \\
\hline $\begin{array}{l}\text { Competitividad de } \\
\text { los precios }\end{array}$ & 0.07 & 1 & 0.07 & 3 & 0.21 & 3 & 0.21 & 3 & 0.21 \\
\hline Respaldo económico & 0.08 & 1 & 0.08 & 2 & 0.16 & 4 & 0.32 & 3 & 0.24 \\
\hline Calidad del servicio & 0.1 & 2 & 0.2 & 3 & 0.3 & 3 & 0.3 & 3 & 0.3 \\
\hline Lealtad del cliente & 0.06 & 1 & 0.06 & 2 & 0.12 & 2 & 0.12 & 2 & 0.12 \\
\hline Publicidad & 0.06 & 2 & 0.12 & 3 & 0.18 & 3 & 0.18 & 3 & 0.18 \\
\hline Imagen de la marca & 0.07 & 2 & 0.14 & 3 & 0.21 & 2 & 0.14 & 3 & 0.21 \\
\hline Red de contactos & 0.08 & 1 & 0.08 & 2 & 0.16 & 4 & 0.32 & 3 & 0.24 \\
\hline Red de ventas & 0.06 & 1 & 0.06 & 2 & 0.12 & 4 & 0.24 & 3 & 0.18 \\
\hline $\begin{array}{l}\text { Experiencia en el } \\
\text { sector }\end{array}$ & 0.07 & 3 & 0.21 & 1 & 0.07 & 4 & 0.28 & 4 & 0.28 \\
\hline Infraestructura & 0.08 & 1 & 0.08 & 3 & 0.24 & 4 & 0.32 & 3 & 0.24 \\
\hline Promociones & 0.07 & 1 & 0.07 & 3 & 0.21 & 3 & 0.21 & 2 & 0.14 \\
\hline Ubicación & 0.13 & 2 & 0.26 & 2 & 0.26 & 1 & 0.13 & 1 & 0.13 \\
\hline Total & 1 & & 1.57 & & 2.45 & & 3.05 & & 2.75 \\
\hline
\end{tabular}

Nota: (q) y (r) son las denominaciones a calificación y resultado, respectivamente. Matriz de perfil competitivo Adaptado de "Strategic Management: A Competitive Advantage Approach Concepts", por Fred R. David, 2013, Pearson Education, Inc., 14, p. 83. Copyright 213 por Pearson Educación de México S.A. de C.V.

Como se puede apreciar, en la Tabla 10; el resultado ponderado del factor crítico más fuerte en CrossFit La Molina es la ubicación; sin embargo, los más débiles son la lealtad del cliente y la red de ventas; esto último, en razón al nivel de desafiliación de miembros tras la apertura de Legado CrossFit en el 2017. En Legado CrossFit, hoy Legado Fitness, el resultado ponderado del factor crítico más fuerte es la calidad del servicio; sin embargo, el más débil es la experiencia en el sector; ello se debe a que recién lleva un año en el mercado. En el caso de CrossFit Ramus, el resultado ponderado del factor crítico más fuerte es: respaldo económico, red de contactos e infraestructura; de otro lado, los más débiles son la lealtad del cliente y ubicación, mismas que van de la mano al deseo de sus miembros, quienes buscan alternativas de entrenamiento más cercanas a su hogar, debilidad que a pesar de contar con tres sedes, no satisfacen la accesibilidad de sus miembros. Finalmente, en CrossFit Marut el resultado ponderado del factor crítico más fuerte es la calidad del servicio; no obstante, el más débil es la lealtad del cliente.

En conclusión, CrossFit Ramus resulta ser la empresa más fuerte en el sector, con un 3.05 en su puntuación ponderada; mientas que CrossFit La Molina es la más débil con 1.57. 


\subsection{Análisis del Contexto Actual y Esperado}

Para analizar los factores que afectan al entorno; emplearemos el método PESTEL que agrupa la información de los factores políticos, económicos, legales, culturales, tecnológicos y ecológicos.

\subsubsection{Análisis político - gubernamental}

La actual coyuntura política nacional tiene un componente constante en la gestión de los tres poderes del Estado. El Perú ha visto en el último año, la renuncia al cargo de Presidente de la República, además de un poder legislativo se ha mostrado más interesado en su papel fiscalizador al hacer denodados esfuerzos en investigaciones a casos de corrupción de gobiernos anteriores en lugar de priorizar su función legislativa para enfrentar los principales problemas de nuestra sociedad como combatir la pobreza, los problemas de salud, la seguridad ciudadana y la educación. Además nuestro Poder Judicial, Ministerio Público y algunos Gobiernos Municipales (La Victoria y el Callao, por poner ejemplos cercanos) se han visto expuestos en una investigación de una red de corrupción que ha hecho tambalear su veracidad e imparcialidad.

Según el último reporte de Transparencia Internacional (ver Tabla 11) publicado en febrero de 2018, nuestro país ubica la posición $N^{\circ} 96$ de un total de 180 países. El Perú obtiene una puntuación de 37 en el Índice de Percepción de Corrupción, mostrando una ligera mejora en comparación del resultado del 2016, mejorando en dos puntos su calificación y 5 subiendo puestos, sin embargo se cree que, en base a los sucesos acaecidos en el 2018 llevará a obtener un resultado negativo en la próxima edición anual.

Tabla 11

Perú: Índice de Percepción de la Corrupción 2012-2017

\begin{tabular}{lcc}
\hline Año & IPC & Puesto General \\
\hline 2012 & 38 & 83 \\
2013 & 38 & 83 \\
2014 & 38 & 85 \\
2015 & 36 & 88 \\
2016 & 35 & 101 \\
2017 & 37 & 96 \\
\hline
\end{tabular}

Nota: IPC es la denominación otorgada al Índice de Percepción de la Corrupción. Escala del IPC: 0 (malo) a 100 (bueno). A mayor valor del índice, menor percepción de corrupción. A mayor posición en la tabla, menor percepción de corrupción. Adaptado de “Transparency International, Corruption Perceptions Index 2017”, por Transparency International, 2018, Copyright 2017 por Transparency International. 
Es importante circunscribirnos en el Gobierno Local en el que se desarrollará el presente plan de negocio, el distrito de Ate, como todos los gobiernos municipales, cuenta con el Concejo Municipal como el máximo órgano de Gobierno de la Municipalidad, el cual es el encargado de aprobar las políticas, planes, presupuestos, proyectos, régimen de organización interna, ordenanzas, acuerdos y, otras atribuciones que están fijadas en el artículo $9^{\circ}$ de la Ley Orgánica de Municipalidades.

\subsubsection{Análisis económico}

\section{Crecimiento del Sector Fitness en el Perú}

Es una verdad innegable que la fama y la acogida de nuevos adeptos a practicar actividades como el CrossFit muestra un crecimiento interesante y prometedor en la ciudad. En marzo, la Cámara de Comercio de Lima publicó un informe especial donde resalta el crecimiento progresivo de los negocios ligados al Fitness y el CrossFit, vinculándolo a la concientización que la población va tomando respecto a cuidar su alimentación y asistiendo con cierta regularidad a lugares donde pueda realizar actividad física. Tradicionalmente esto último se ha centrado en la visita a gimnasios, pero estos negocios han empezado a perder clientela dado que se les asocia con un interés netamente comercial, manteniendo membresías y dejando a un segundo plano la evolución y mejora de sus clientes en relación a su propio bienestar. Por otro lado un negocio como el CrossFit basa su entrenamiento funcional fidelizando y haciéndole seguimiento a los logros de sus adeptos.

Según la Asociación Internacional de Clubes para la Salud, Juegos de Raqueta y de Deporte (IRHSA por sus siglas en inglés) hoy en día la población Fitness en el Perú bordea el 2\% de habitantes.

\section{Recuperación del Crecimiento Económico}

Si bien es cierto que la coyuntura política explicada líneas arriba tiene un impacto directo en el crecimiento económico del Perú, la conclusión a la que llegaron un total de 28 instituciones, entre bancos, gremios empresariales y consultoras tanto locales como extranjeras que fue recogido en el último Focus Economics Consensus Forecast, proyecta que el avance del PBI peruano está destinado a ganar un impulso considerable en los próximos año, gracias al fortalecimiento de la demanda interna. "Una postura monetaria complaciente, gasto de infraestructura pública en rápido crecimiento y altos precios de los productos básicos impulsará la inversión fija. Inflación moderada y creación de empleo saludable también debe apuntalar el gasto de los hogares" (Mayer, 2018, p. 14). Los panelistas encuestados preveían en el anterior reporte de julio un aumento del PBI de 3.6\% para el 2018. 


\section{Producto Bruto Interno}

En el primer trimestre del año 2018, el Producto Bruto Interno (PBI) registró un crecimiento de $3,2 \%$, explicado por la evolución favorable de la demanda interna (3,6\%), en un contexto de crecimiento de las principales economías desarrolladas, con repercusiones positivas en los precios de las materias primas en particular de los metales, principalmente en el sector minero (ver figura 14).

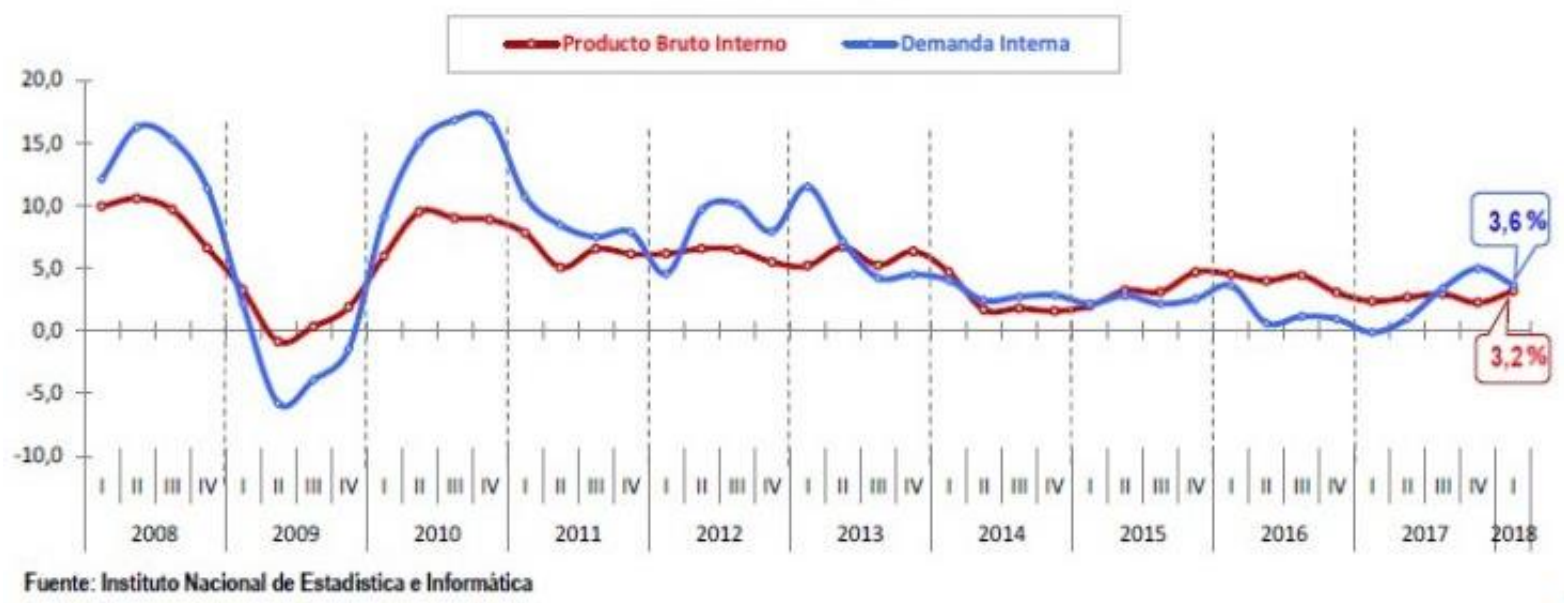

Figura 14. Producto Bruto Interno y Demanda Interna, 2008_I-2018_. Variación porcentual del Índice de volumen físico respecto al mismo período del año anterior, año base $2007=100$. Tomado de "Semana Económica”, por el Instituto Nacional de Estadística e Informática (INEI), 2018. Recuperado de http://semanaeconomica.com/article/economia/macroeconomia/291022-inei-consumo-e-inversion-impulsaronexpansion-de-3-2-del-pbi-en-el-primer-trimestre/

\section{Inflación}

Salvo el denominado bache del 2008, influenciado por factores externos, la inflación en el Perú se mantiene aún entre las menores de Latinoamérica, gracias a un manejo responsable tanto de parte del BCRP como del MEF. Este escenario, permite desarrollar proyectos a mediano y largo plazo, con estimaciones que, salvo algún factor externo que se presente, puedan ser muy cercanas a la realidad. Esta es una ventaja para los inversionistas que tengan al Perú como escenario (ver Figura 15). 


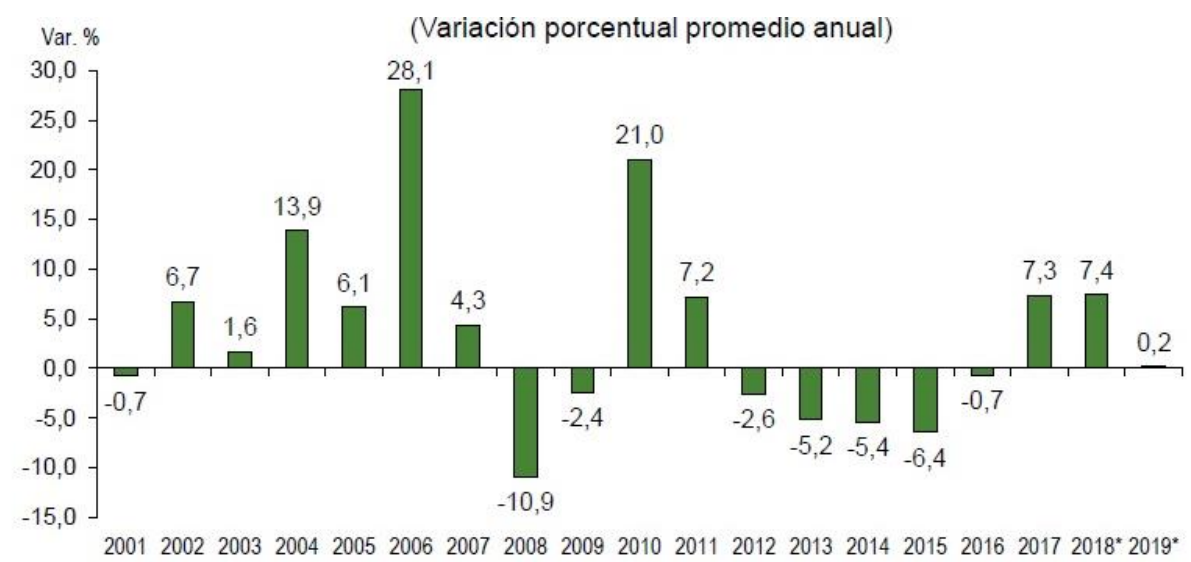

Figura 15. Términos de Intercambio. Variación porcentual promedio anual. Tomado de "Semana Económica", por el Banco Central de Reserva del Perú (BCRP), 2018. Recuperado de http://semanaeconomica.com/article/legal-y-politica/politica/273390-los-terminos-de-intercambioseguirian-creciendo-en-el-2018-y-llegarian-a-7-4/

\section{Tasa de Interés}

El Banco Central toma decisiones de política monetaria mediante el uso de un nivel de referencia para la tasa de interés del mercado interbancario. Dependiendo de las condiciones de la economía (presiones inflacionarias o deflacionarias), el Banco Central modifica la tasa de interés de referencia (hacia arriba o hacia abajo, respectivamente) de manera preventiva para mantener la inflación en el rango meta. Ello se debe a que las medidas que toma el Banco Central afectan a la tasa de inflación con rezagos.

En los últimos años el nivel y grado de variación de las tasas de interés del sistema financiero en moneda nacional muestran una mayor relación con la evolución de la tasa de interés de referencia, que es el instrumento de política monetaria desde 2002.

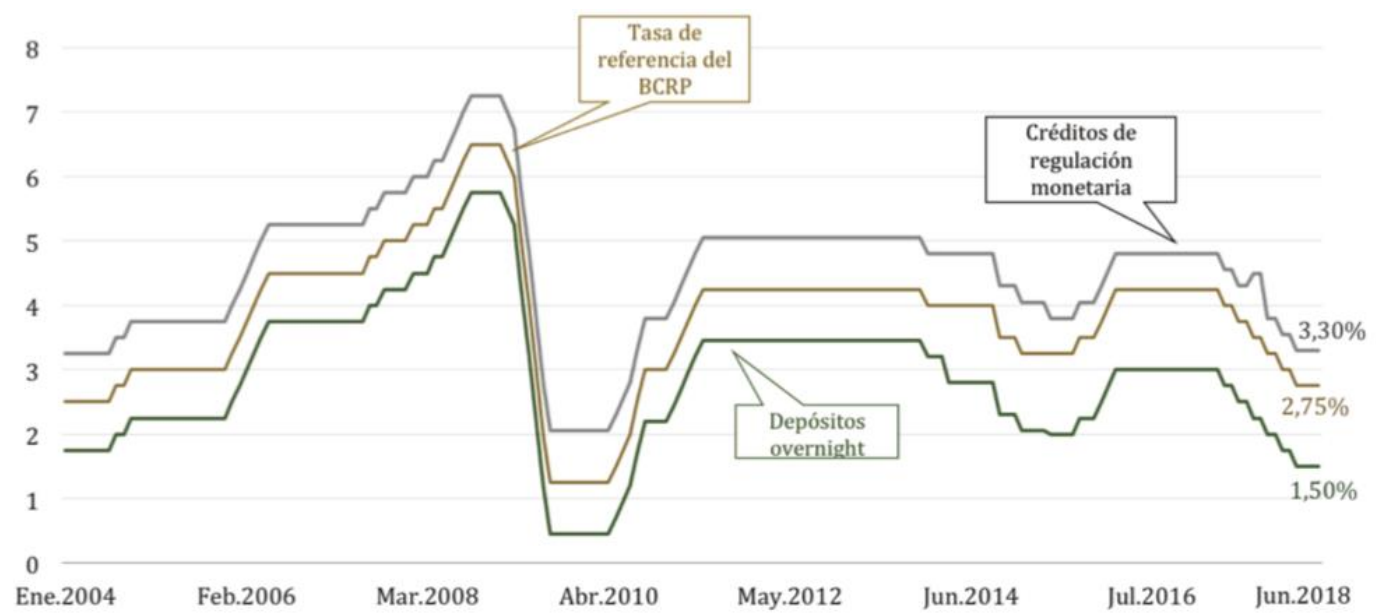

Figura 16. Tasa de Interés de Referencia del Banco Central. Cifras en Porcentajes. Tomado de "Estabilidad Monetaria: Diseño e Implementación de la Política Monetaria”, por el Banco Central de Reserva del Perú (BCRP), 2018. Recuperado de http://www.bcrp.gob.pe/docs/sobre-el-bcrp/folleto/folletoinstitucional.pdf 


\section{Tipo de Cambio}

La tendencia del tipo de cambio en los últimos meses es a la baja. En el caso de importadores y de aquellos que, como el proyecto, requieran de insumos importados, es una ventaja mantener un dólar a bajo precio, lo que sumado al crecimiento del consumo y de la economía en general, nos permiten mejorar los costos y generar mayores márgenes de ganancia (ver Figura 17).

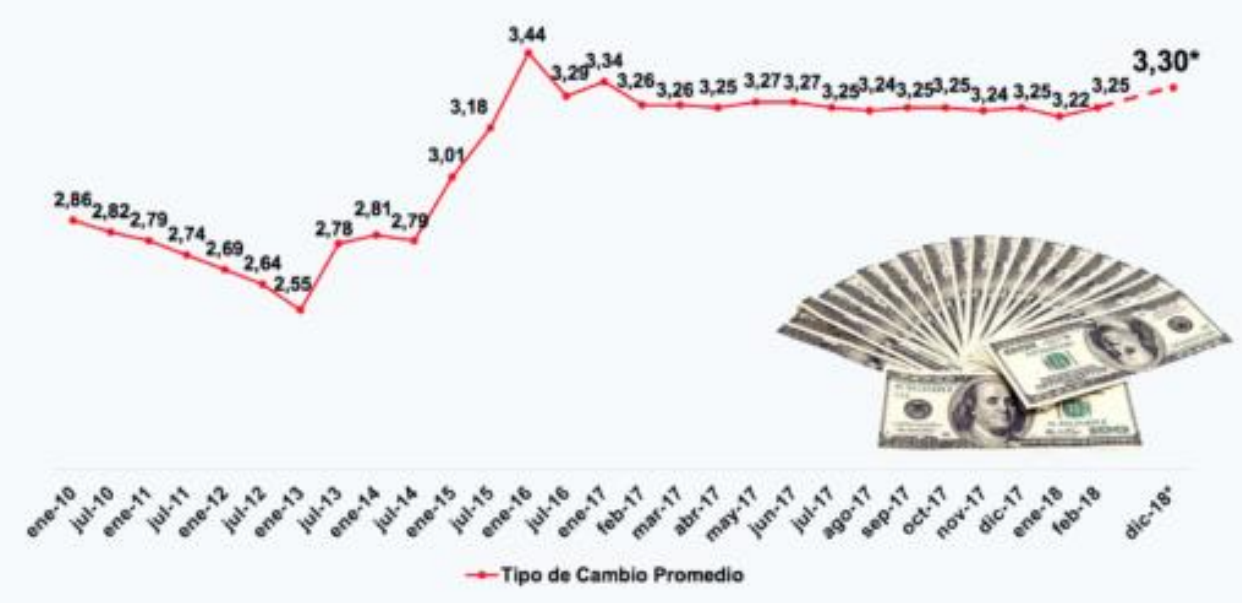

Figura 17. Evolución del Tipo de Cambio de Soles por Dólares. Tomado de "Evolución y Perspectiva de la Economía Peruana, para el mes de Marzo 2018”. Por Banco Central de Reserva del Perú (BCRP), 2018. Recuperado de https://www.panoramical.eu/columnas/evolucion-perspectivas-la-economia-peruana-mesmarzo-2018/

\section{Actividades Económicas de Ate}

El proceso de crecimiento y de consolidación de actividades comerciales y de servicios vienen ampliándose hacia los principales conos de Lima Metropolitana, donde se están configurando circuitos comerciales y de servicios sobre principales ejes viales, adquiriendo dinámicas propias, como es el caso del Cono Este donde se ubica el Distrito de Ate.

Dentro de este contexto las actividades económicas empresariales que se vienen realizando con mayor dinamismo en el Distrito de Ate son las comerciales y de servicios y en menor intensidad la actividad industrial. Las actividades económicas en el Distrito de Ate se desarrollan a través de medianas y grandes empresas, Pymes, y un sector de comercio informal. Empresas y unidades económicas que vienen soportando las consecuencias negativas de la libre importación de bienes y servicios. Asimismo, se ven afectadas por la falta de una articulación funcional y concertación entre medianas y grandes empresas y entre pymes, para posibilitar la organización de la oferta, mejorar la eficiencia, reducir costos y competir en el mercado metropolitano. 


\subsubsection{Análisis legal}

Para abrir un negocio como el que se propone, se debe cumplir con el procedimiento que el gobierno municipal ha definido. En tal sentido la Municipalidad de Ate pone a disposición un proceso abreviado y simplificado acorde con las normas vigentes, para la obtención de Licencia Municipal de Funcionamiento para el desarrollo de actividad comercial, industrial y/o de servicios en un establecimiento determinado. De conformidad con lo establecido por la Ley No 28976, Ley Marco de Licencia de Funcionamiento, Ordenanza No 159-MDA, están obligados a obtener dicha autorización, las personas naturales, jurídicas o entes colectivos, nacionales o extranjeros, de derecho privado o público, incluyendo empresas o entidades del estado, regionales o municipales, que desarrollen con o sin finalidad de lucro actividades de comercio, industriales, artesanales, de servicios y/o profesionales, en el ámbito de la Municipalidad de Ate. La Licencia de Funcionamiento tiene vigencia indeterminada de conformidad con lo establecido por el artículo 11 de la Ley N $^{\circ}$ 28976, Ley Marco de Licencia de Funcionamiento, artículo $36^{\circ}$ de la Ordenanza No $159-M D A$, sin embargo la Municipalidad puede expedir licencias TEMPORALES a solicitud expresa del usuario. En este caso no será necesaria la comunicación de cese al término de la actividad del establecimiento. Para el otorgamiento de la licencia de funcionamiento, la municipalidad evaluará los siguientes aspectos:

- Zonificación y compatibilidad de uso.

- Condiciones de seguridad en Defensa Civil,

Del mismo modo, es importante recalcar que, el modelo de negocio, encuentra una estrategia de diferenciación al utilizar la metodología CrossFit para el desarrollo del mismo. En tal sentido, la adquisición de la licencia correspondiente el cual tiene un costo equivalente al 3.65\% del valor de una UIT, esto es, S/ 129.58.

\subsubsection{Análisis cultural}

Actualmente Ate tiene 7,772 hectáreas, $20 \mathrm{Km}$. de extensión y una población de 646,9000 habitantes, producto del gran desplazamiento migratorio hacia el distrito, en busca de mejores ocasiones de empleo y mejores condiciones de vida, principalmente de los departamentos de Huancavelica, Ayacucho, Junín y de otros distritos de Lima.

Es el décimo distrito más grande de la provincia de Lima, el 6to más poblado de Lima Metropolitana y el 2do con mayor concentración de pobres, siendo el segundo distrito del Cono Este que cuenta con mayor número de hogares con las tres Necesidades Básicas Insatisfechas, después del distrito de San Juan de Lurigancho. 
La población es joven, el $57 \%$ es menor de 25 años, por otro lado la población femenina representa el $50.6 \%$ y la masculina el $49.4 \%$, indicando por lo tanto un mayor incremento de mujeres en el distrito y coincidentemente la importancia que va adquiriendo la mujer en diferentes roles en la familia y en las organizaciones sociales.

En el distrito se han constituidos diferentes grupos de organizaciones sociales para hacer frente a los problemas de alimentación de sus familias como: los Clubes de Madres, Comedores Populares, Comités de Vaso de Leche, entre otros. Además Ate cuenta con 3 hospitales, 7 Centros y 9 Puestos de Salud, es decir existe un déficit de infraestructura de instalaciones de Salud.

\section{Nueva clase media}

A pesar de los número y el tipo de habitante que cuenta Ate, nuevos estudios de Arellano Marketing indican que existe en el Perú una nueva clase media compuesta por alrededor de 9 millones de peruanos. Se trata pues de un grupo con actitudes y patrones de costumbres diferentes a los de la clase media tradicional. Sin embargo, es de vital importancia llegar a conocer a este segmento ya que concentra el $39 \%$ de la población total y es pues un mercado importante al cual apuntar.

Este grupo emergente se caracteriza por personas que construyen su propia historia, a diferencia de los tradicionales que suelen heredar las costumbres y hábitos de sus padres y generaciones anteriores. Además, en cuanto al trabajo también hay diferencias significativas entre esta nueva clase media con respecto a la tradicional. Mientras que el $60 \%$ de los tradicionales son trabajadores dependientes, el 60\% de los emergentes son dependientes.

\subsubsection{Análisis tecnológico}

En el Perú existe escaso desarrollo en tecnología e investigación al igual que la falta de estándares de calidad en productos elaborados lo cual es considerado un atraso para su desarrollo. El Perú ha invertido muy poco en ciencia, tecnología e investigación, el promedio de inversión realizada por el Perú es del $0.2 \%$ del PBI. El Fondo de Investigación y Desarrollo para la Competitividad (FIDECOM, 2011) es "liderado por el Ministerio de la Producción cuenta con 200 millones de soles para promover la investigación y desarrollo de proyectos de innovación productiva de utilización práctica en las empresas” (párr. 1). Financia dos tipos de proyectos:

(a) Proyectos de Innovación Productiva; son proyectos que apuntan al desarrollo de innovación en procesos, productos y servicios, la transferencia y difusión tecnológica para aplicación práctica e incremento de la productividad y competitividad empresarial. (b) Proyectos de Transferencia de Conocimientos para la Innovación Productiva y Gestión 
Empresarial; son proyectos que buscan la incorporación de conocimientos tecnológicos en procesos, productos, servicios y otros de las microempresas, a través del fortalecimiento de la capacidad de innovación, producción y gestión empresarial y la aplicación por parte de las microempresas de conocimientos tecnológicos (Fondo de Investigación y Desarrollo para la Competitividad [FIDECOM], 2011, párr. 11).

\section{Desarrollo de nuevas tecnologías Fitness}

El ejercicio y la tecnología siempre han mantenido una asociación muy interesante respecto a su crecimiento. Desde que aparecieron las máquinas para el ejercicio de la resistencia en la década de los 50, el movimiento fitness ha evolucionado para incluir videos de entrenamiento en los ochenta, el Tae Bo en los años noventa y el método Pilates a principios de 2000 .

Hoy en día, las populares rutinas de resistencia, estiramiento y entrenamiento se pueden medir mediante dispositivos de monitoreo sencillo, tales como los propios teléfonos inteligentes llegado incluso al uso de tecnologías vestibles (wearables), tales como las pulseras fitness y los relojes inteligentes. A ello se le suma que los entrenadores pueden interactuar con sus clientes en tiempo real a través de clases y/o seguimientos individuales o grupales por medios virtuales como Skype o FaceTime y de otros sitios de fitness como Wello y EMG Live Fitness

La posibilidad de medición siempre ha sido un importante activo para el ejercicio; después de todo, los objetivos del fitness suelen ser cuantificables: calorías quemadas, peso perdido, distancia recorrida o ritmo cardíaco alcanzado. Poder visualizar y registrar esta información supone una gran atracción tanto para la motivación como para llevar un control.

\subsubsection{Análisis ecológico}

\section{El CrossFit y la Ecología}

La filosofía de CrossFit define que para estar en forma no es necesario utilizar grandes aparatos eléctricos, televisores para entretenernos, máquinas expendedoras con bebidas energéticas o servicio de toallas calientes. Todos estos lujos innecesarios no son buenos para nuestro Planeta. En estos gimnasios ni siquiera hay aire acondicionado.

El CrossFit promueve un estilo de vida saludable en torno al deporte y a ejercicios funcionales que trabajan el cuerpo como un todo. No se utilizan máquinas para aislar los músculos. Lo que sí se encuentra en CrossFit son balones medicinales, muchas pesas, barras en las paredes, cuerdas para trepar, viejos neumáticos y otros instrumentos alimentados únicamente con la energía humana. La ausencia de máquinas electrónicas ayuda además a reducir los costes de reparación y mantenimiento que requieren. 
El tipo de ejercicios que se realizan en estos boxes ecológicos se centra sobre todo en levantamientos, gimnasia y actividades cardiovasculares (correr, remar, trepar, etc.). Desde ejercicios en anillos, saltos o sentadillas. El entrenamiento es muy efectivo, ya que los movimientos de CrossFit se utilizan en actividades de la vida cotidiana.

Otra ventaja de estos boxes es que suelen ocupar espacios relativamente pequeños. Es habitual encontrarlos en viejos edificios o garajes abandonados, lo que ayuda al desarrollo de una zona urbana desfavorecida. Las salas que utiliza CrossFit intentan aprovechar la ventilación natural y la luz del sol para acondicionar el lugar y eliminar la necesidad de electricidad durante los entrenamientos del día.

\subsection{Oportunidades y Amenazas}

Para el presente análisis, se elaboró la matriz de evaluación de factores externos (MEFE), la cual de muestra en la Tabla 12, que según David (2013) "permite que los estrategas resuman y evalúen información económica, social, cultural, demográfica, ambiental, política, gubernamental, legal, tecnológica y competitiva" (p. 80) de la industria. 
Tabla 12

Matriz de Evaluación de Factores Externos

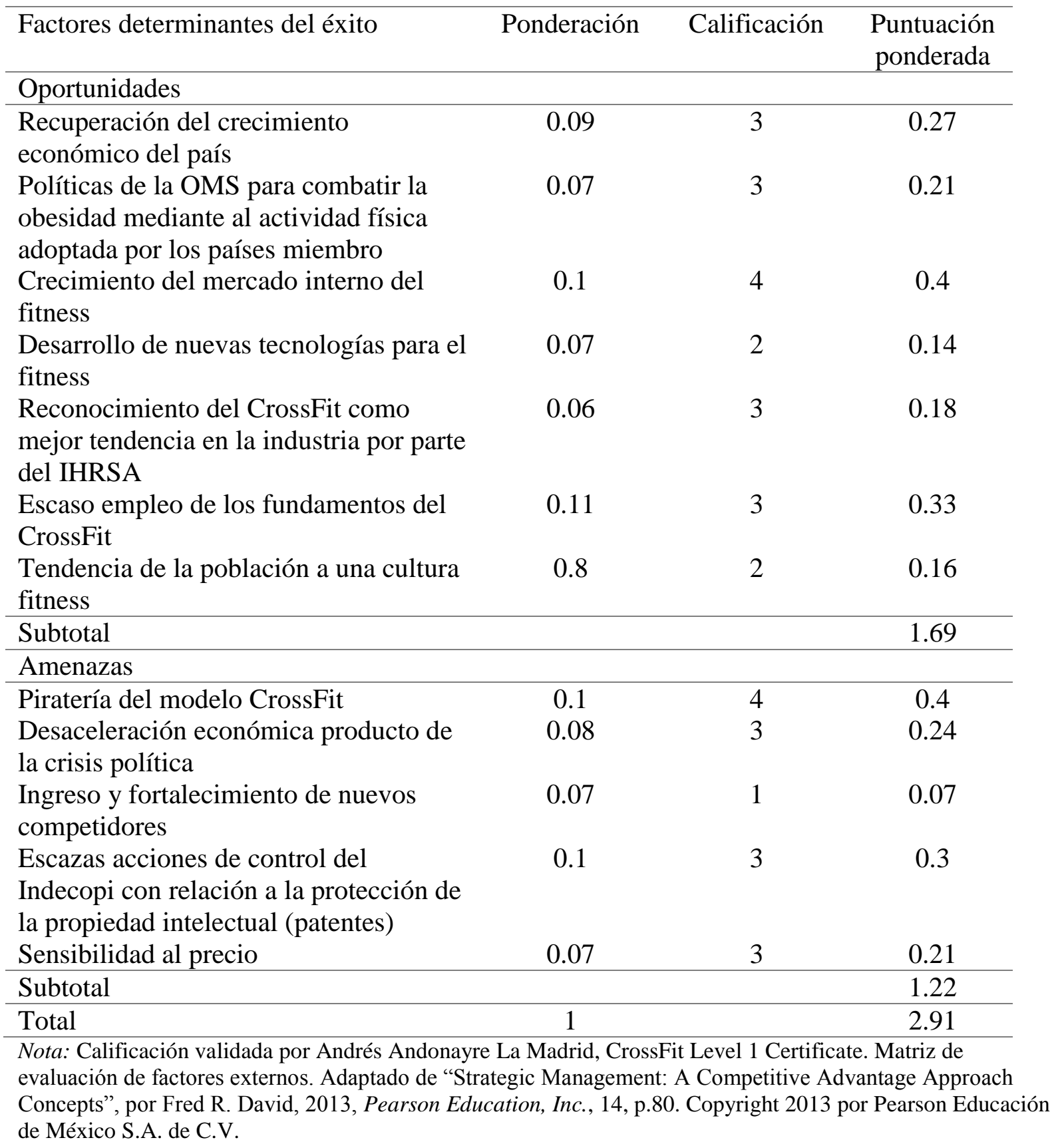

Del análisis de la Matriz EFE, se determina que la puntuación ponderada total es de 2.91; lo cual significa que, la idea de negocio va a responder a las oportunidades y amenazas del entorno. Es decir, tal como David (2013) señala, la empresa debe aprovechar las oportunidades que se le presentan y en la medida de lo posible, reducir las efectos que puedan impactar las amenazas del entorno. 


\section{Capítulo III: Estructura de Mercado}

Con el estudio de mercado realizado, se pretende conocer el comportamiento del público objetivo; ello, a través de estudios de mercado cualitativos y cuantitativos aplicados a la muestra utilizada. Gracias a este estudio, se conocerán las principales necesidades de las rutinas de ejercicio, hábitos, preferencias y otros.

Este capítulo es sumamente importante; debido a que, dará a conocer la viabilidad comercial de los servicios que se proyectan ofrecer.

\subsection{Descripción del Servicio}

El presente Plan de Negocios pretende ofrecer al mercado objetivo un lugar dónde realizar un régimen de ejercicios basado en movimientos funcionales con constante variación y ejecutados a alta intensidad -CrossFit-, el cual se encuentra diseñado para optimizar la competencia física en cada uno de los dominios reconocidos del fitness, mediante un acondicionamiento de los ejercicios en grado, pero no en tipo. Todo esto, con el fin de combatir la obesidad en uno de los distritos con mayor incidencia en Lima.

Greg Glassman, después de su primera sesión de gimnasia en la Asociación Cristiana de Hombres Jóvenes (YWCA, por sus siglas en inglés) se dio cuenta que con el paso del tiempo las rutinas agobiantes y muy tradicionales de culturismo no eran lo suficiente para mejorar la condición física de los atletas; esto, teniendo en consideración la cantidad de horas de entrenamiento ejecutadas por los atletas durante su formación deportiva en el área de su competencia. A causa de ello, en 1995 en la ciudad de Santa Cruz California, Greg Glassman apertura el primer sitio oficial de entrenamiento CrossFit, el cual se convertiría en el punto de partida de una gran compañía de entrenamiento. La idea inicial de Glassman, era usar las nuevas y alternadas rutinas de ejercicio para entrenar a policía de California; siendo esta misma utilizada para entrenar marinos, bomberos y militares norteamericanos, y que hoy en día es practicado por miles de personas en todo el mundo; contando inclusive con un campeonato mundial para elegir a la persona con el mejor estado físico de la tierra.

El CrossFit se desarrolla en un box, el cual es un gimnasio no convencional afiliado a CrossFit, Inc. cuya temática está ligada a un garaje de entrenamiento; ello debido a que, desde sus inicios, el CrossFit solo se practicaba en espacios reducidos con equipos básicos, que a lo largo de los años han ido evolucionando a tal punto que no sea un inconveniente para el atleta; sino que, le permita ejecutar en el menor tiempo posible la mayor cantidad de rondas y repeticiones con calidad.

Para aperturar un box de CrossFit, es necesario afiliarse. Para ello, CrossFit, Inc. (2017) ha determinado el proceso de afiliación, la cual consta de los siguientes pasos: a) solicitud en 
línea, adjuntando la información del nuevo box de CrossFit y un ensayo explicando el motivo por el cúal se desea aperturar; b) ubicación, croquis y lay out del lugar en donde se pretende aperturar el box; c) seguro contratado, en caso de que el box se apertura en Estados Unidos; d) pago de afiliación, mediante transferencia bancaria a una cuenta corriente de CrossFit, Inc.; e) firma del acuerdo de licencia, cuya vigencia y renovación es anual; y finalmente, f) envío de la licencia de funcionamiento de CrossFit. Sin embargo, no se podrá acceder al proceso de afiliación sin que el candidato haya cumplido con obtener los requerimientos previos, que según CrossFit, Inc (2017) son: a) certificado de entrenamiento de CrossFit Level One, b) prueba de seguro para afiliados en caso que el box se apertura en los Estados Unidos y, c) sitio web sin registro del dominio con la denominación CrossFit.

Pues bien, para fines de la presente investigación, cualquiera de los socios podría contar con el certificado de entrenamiento de CrossFit Level One; ya que, quién la obtenga, podrá desarrollar las funciones de Head Coach; mientas que el otro, desarrollará las funciones de administrador. Sin embargo, y a manera de salvaguardar la sociedad, los socios acuerdan en su estatuto de constitución, que ninguna de las partes podrá renunciar a la sociedad y mucho menos deslindarse de sus funciones por el período de 5 años; mismo tiempo de duración de la actividad económica de la empresa propuesta para fines académicos.

De otro lado, es pertinente indicar que existen riesgos derivados de la licencia CrossFit y que conllevan a su cancelación.; los cuales, a menudo, suelen ser el punto de quiebre de muchos boxes. De acuerdo con CrossFit, Inc. (2017) el quebrantamiento de las siguientes disposiciones, genera la cancelación de la licencia: a) acuerdo de licencia personalizado; es decir, que CrossFit, Inc. sólo autoriza tanto a la persona como a una sola sede de CrossFit; b) la licencia y nombre de la marca CrossFit en el nombre comercial del box no pueden utilizarse si en esa misma sede se imparten otras actividades físicas ajenas al CrossFit; c) el uso del logo y denominación 'CrossFit' en artículos de venta, queda totalmente prohibido; salvo que exista una previa autorización de CrossFit, Inc.; d) la realización de eventos externos sin el consentimiento de CrossFit, Inc.; e) la participación del box en eventos que no sean CrossFit; f) no permitir el control permanente de las actividades del box; y finalmente, g) dejar de ser sede para los cursos de especialidad y formación que imparta CrossFit, Inc.

En atención a los riesgos derivados de la licencia, Ate CrossFit plantea las siguientes estrategias para mitigarlas: primero, no aperturar más de una sede y que el Head Coach (Giancarlo Chávez, socio) será el encargado de todo el proceso de la obtención de la licencia de afiliación; segundo, Ate CrossFit tendrá como única actividad empresarial, el CrossFit; tercero, Ate CrossFit no plantea vender artículos de merchandising; cuarto, Ate CrossFit 
plantea realizar únicamente eventos internos para consolidar a su comunidad crossfitera; quinto, para la proliferación de su comunidad y demostración de resultados por evidencia, los miembros de Ate CrossFit podrán participar únicamente en las competiciones de CrossFit autorizadas; sexto, para garantizar el uso de la metodología adecuada y del cumplimiento de los estándares de calidad impuestos por CrossFit, Inc. en razón a la apertura de un box afiliado, Ate CrossFit enviará constantemente las evaluaciones de sus miembros, los eventos realizados; así como, acceder a la inspección esporádica de los fiscalizadores de CrossFit, Inc.; sétimo, en cumplimiento de las cláusulas del contrato de afiliación propuesto por CrossFit, Inc., en razón a ser sede para la difusión de programas de entrenamiento, Ate CrossFit se somete a las disposiciones contractuales.

Una sesión de entrenamiento CrossFit dura 60 minutos y su distribución consta de 4 etapas (ver Figura 18).

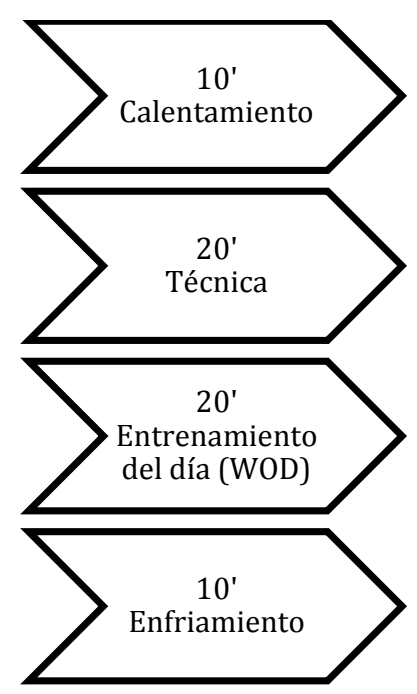

Figura 18. Etapas de una sesión de CrossFit Distribución del entrenamiento. Adaptado de "CrossFit Level 1 Course", 2018. Recuperado de https://crossfit.com/

\section{- Calentamiento o Warm up}

Etapa compuesta por estiramiento de las extremidades superiores e inferiores del cuerpo, mediante ciertos movimientos iniciados de manera pausada hasta convertirse en pequeños ejercicios de corta duración con pocas repeticiones; tales como: planchas, abdominales, carreras, flexiones, sentadillas, y coordinación; donde se evita obtener un resultado, procurando hacer cada ejercicio con calidad, y así evitar lesiones.

- Práctica de Técnica o Skills

Es la parte del entrenamiento donde se practica los movimientos funcionales que se han de utilizar en el entrenamiento del día o en el futuro. Es aquí, donde se inicia el acondicionamiento de los ejercicios de acuerdo con el perfil de la persona; con la finalidad de 
que este, pueda obtener una progresión de la técnica. Esta etapa está estructurada por acondicionamiento metabólico, levantamiento de pesas y gimnasia.

- Entrenamiento del día o Workout of the Day (WOD)

Momento más potente de la clase; donde se pone en práctica los Skills, la resistencia física, la coordinación y la estrategia. Esta etapa por lo general se base en ejecutar ejercicios compuestos por movimientos funcionales variados en corta duración con peso pesado o en larga duración con un peso liviano sin él. La estructura de cada WOD está basada en:

1. For Time: Ejecutar un número de rondas de ejercicios en el menor tiempo posible. Un ejemplo se aprecia en la Figura 19.

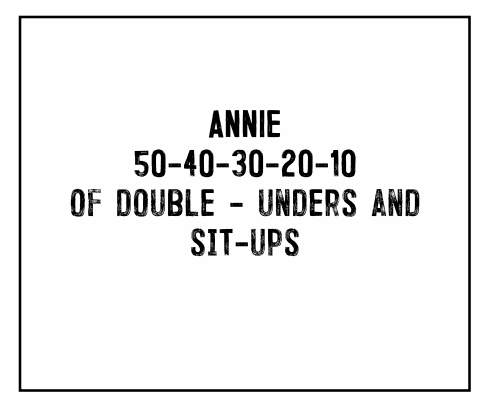

Figura 19. Annie Workout Adaptado de "First: What it takes to Win "(p. 275.), por Rich Froning, 2013, Illinois, Estados Unidos: Tyndale House Publishers, Inc. Copyright 2013 Rich Froning.

2. As many rounds or reps as possible (AMRAP): Consta en ejecutar la mayor cantidad de rondas o repeticiones posibles en un intervalo de tiempo determinado. Un ejemplo de ello se aprecia en la Figura 20.

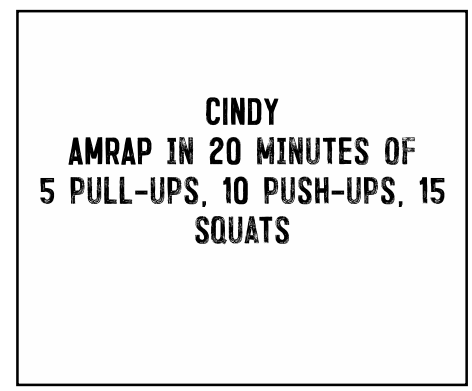

Figura 20. Cindy Workout Adaptado de "First: What it takes to Win "(p. 275.), por Rich Froning, 2013, Illinois, Estados Unidos: Tyndale House Publishers, Inc. Copyright 2013 Rich Froning.

3. Every minute on a minute (EMOM): Consiste en realizar un número determinado de ejercicios en un minuto durante varios minutos. Un ejemplo de ello se puede apreciar en la Figura 21. 


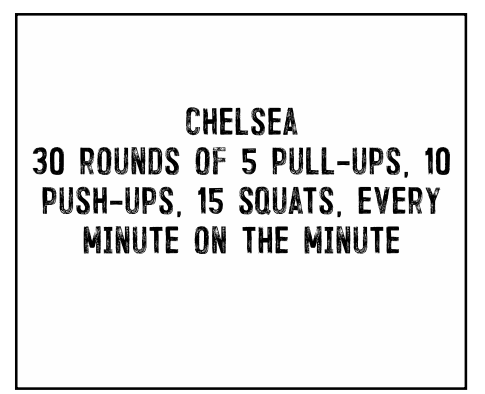

Figura 21. Chelsea Workout Adaptado de “First: What it takes to Win ”(p. 275.), por Rich Froning, 2013, Illinois, Estados Unidos: Tyndale House Publishers, Inc. Copyright 2013 Rich Froning.

4. TABATA: Ejecutar durante 4 minutos 8 rondas compuestas por 20 segundos de entrenamiento de cada ejercicio y 10 segundos de descanso. Un ejemplo de ello, se puede apreciar en la Figura 22.

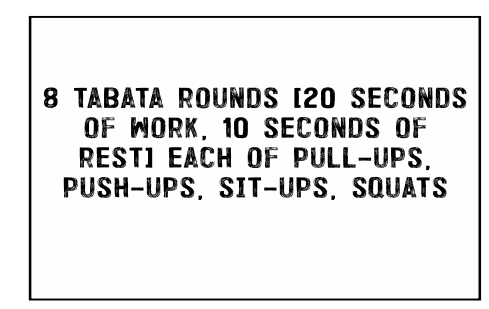

Figura 22. Tabata Workout Adaptado de "First: What it takes to Win "(p. 277.), por Rich Froning, 2013, Illinois, Estados Unidos: Tyndale House Publishers, Inc. Copyright 2013 Rich Froning.

En ese mismo orden de ideas, dentro de los WODS, existen algunos que ya cuentan con un nombre determinado, ya sea en honor a la memoria de soldados, policías, bomberos que fallecieron en el cumplimiento de sus funciones; las mismas que tienen un grado de dificultad intenso y, son denominados como HERO WOD; así también, aquellos que están basados en comparar su rendimiento frente a los demás, y que tienen el nombre de mujeres, haciendo referencia a los huracanes; puesto que el fin de estos, es valuar el estado en el que te encuentras después de ejercutarlos, y son denominados como THE GIRLS WOD.

- Enfriamiento o Cool Down

La parte más importante del entrenamiento; debido a que en ella, se busca volver al estado inicial el cuerpo mediante ejercicios de estiramiento (Mobility) que busca relajar las articulaciones y recuperar el estado físico del cuerpo sin dolor alguno.

Una vez descritas cada una de las etapas de una sesión de entrenamiento de CrossFit, corresponde proponer un modelo de la misma con cada uno de los ejercicios correspondientes (ver Figura 23). 


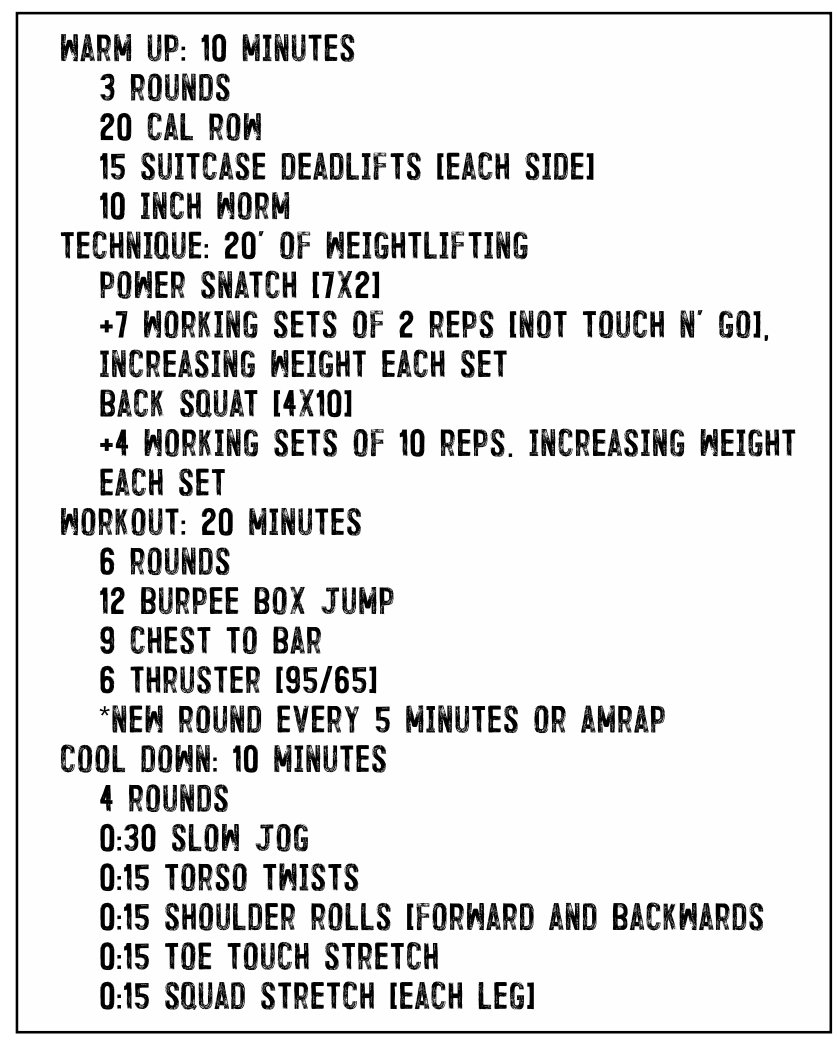

Figura 23. Sesión de entrenamiento. Adaptado de “Online Programming”. Por CrossFit Mayhem Freedom, 2018. Recuperado de https://www.crossfitmayhem.com/intro-page-online-programming/

El estudio de mercado, definirá el nivel de atracción hacia el CrossFit; así como, la frecuencia de los componentes del programa, costo y precio.

\subsection{Selección del Segmento de Mercado}

Kotler y Armstrong (2013) refieren que "a través de la segmentación del mercado, las empresas dividen los mercados grandes y heterogéneos en segmentos a los que pueden llegar de manera más eficiente y eficaz con productos y servicios que coinciden con sus necesidades únicas" (p. 165). Para la selección del segmento de mercado, se debe identificar a qué clientes Ate CrossFit se dirigirá y atenderá sus necesidades; para ello, se aplica lo que en diversos autores (Stanton, et al., 1999; Trout \& Rivkin, 1996; Kotler, 2001) han señalado como el proceso de segmentación.

1) Identificar el mercado relevante:

Para identificar el mercado al cual Ate CrossFit se va a dirigir; primero, se debe definir el mercado total y posteriormente identificar sus partes. Pues bien, el presente plan de negocio está enfocado en el mercado Fitness, en particular en aquellas actividades físicas no convencionales cuya metodología se basa en mejorar la condición física de las personas y la salud. 
2) Seleccionar las bases de segmentación:

También conocidas como las variables de segmentación que de acuerdo con Kotler y Armstrong (2013) permite dividir de manera idónea el mercado de acuerdo a las características descriptivas de los consumidores; por ejemplo: Geográfica, demográfica, psicográfica y conductual. Para ello, se ha empleado los resultados obtenidos en la ficha de reclutamiento del estudio de mercado realizado dentro del estudio cualitativo (ver Apéndices 1 y 2)

Del análisis obtenido en las fichas de reclutamiento, se ha seleccionado las bases de segmentación que se presentan en la Tabla 13

Tabla 13

Variables de Segmentación y Descriptores

\begin{tabular}{ll}
\hline Variables de segmentación & \multicolumn{1}{c}{ Descriptores } \\
\hline Geográfica & Distrito \\
& Población \\
Demográfica & Edad \\
& Sexo \\
& Nivel socio económico (NSE) \\
Psicográfica & Clase social \\
Conductual & Beneficios que buscan \\
\hline Nota: Adaptado de "Dirección de Marketing" (p. 248), por Philip Kotler y Kevin Lane Keller, 2006, México, \\
Pearson Education, Inc. Copyright 2006 por Pearson Educación de México S.A. de C.V.
\end{tabular}

3) Desarrollar el perfil de los segmentos

Una vez determinado las variables de segmentación con sus respectivos descriptores (ver Tabla 13); corresponde desarrollar perfiles (ver Tabla 14) que incluyan las características necesarias del segmento al cual Ate CrossFit se dirige; las cuales han sido obtenidas de la aplicación de fichas de reclutamiento para el estudio de mercado (Ver Apéndices 3,4,5,6,7,8 y 9) en el presente plan de negocio; y posteriormente, compete evaluarlas en la siguiente sección con el fin de seleccionar el mercado objetivo.

Para elaborar cada uno de perfiles que se presentan en la Tabla 14, se ha tomado en consideración los datos expuestos en el Apéndice 1, provenientes de los resultados de cada ficha de reclutamiento. 
Tabla 14

Matriz de perfil de los segmentos

\begin{tabular}{|c|c|c|c|c|}
\hline Descriptores & Perfil 1 & Perfil 2 & Perfil 3 & Perfil 4 \\
\hline \multicolumn{5}{|l|}{ Geográfica } \\
\hline Distrito & Ate & Ate & Ate & Ate \\
\hline Población & - & - & - & - \\
\hline \multicolumn{5}{|l|}{ Demográfica } \\
\hline Edad & 18 a 60 años & 18 a 60 años & - & 18 a 60 años \\
\hline Sexo & - & Indiferente & - & - \\
\hline NSE & - & - & A y $B$ & $\mathrm{~A}, \mathrm{~B}$ y $\mathrm{C}$ \\
\hline \multicolumn{5}{|l|}{ Psicográfica } \\
\hline Clase social & Media baja & - & Alta y media & - \\
\hline Conductual & - & - & - & - \\
\hline $\begin{array}{l}\text { Beneficios que } \\
\text { buscan }\end{array}$ & $\begin{array}{l}\text { Mejorar el } \\
\text { estado físico }\end{array}$ & Salud & Salud & $\begin{array}{l}\text { Mejorar el estado } \\
\text { físico y salud }\end{array}$ \\
\hline
\end{tabular}

4) Evaluación de los segmentos

Corresponde evaluar los perfiles desarrollados, con el fin de seleccionar el que más se adecue a los objetivos del presente plan de negocio. Para ello, se aplica algunos criterios elaborados por Kotler y Keller (2006) para la evaluación de segmentos y la determinación de su utilidad. Estos criterios son: (a) Medible, (b) sustancial, (c) accesible, (d) diferenciable y (e) procesable. En la Tabla 15 se muestra el análisis elaborado a cada uno de los perfiles.

Tabla 15

Matriz de Evaluación de Segmentos

\begin{tabular}{lcccccc}
\hline Descripción & Medible & Sustancial & Accesible & Diferenciable & Procesable & Total \\
\hline Perfil 1 & $\mathrm{Si}$ & $\mathrm{No}$ & $\mathrm{Si}$ & $\mathrm{No}$ & No & 2 \\
Perfil 2 & $\mathrm{Si}$ & $\mathrm{Si}$ & $\mathrm{Si}$ & $\mathrm{No}$ & No & 3 \\
Perfil 3 & $\mathrm{Si}$ & $\mathrm{No}$ & $\mathrm{Si}$ & $\mathrm{No}$ & $\mathrm{Si}$ & 3 \\
Perfil 4 & $\mathrm{Si}$ & $\mathrm{Si}$ & $\mathrm{Si}$ & $\mathrm{Si}$ & $\mathrm{Si}$ & 5 \\
\hline
\end{tabular}

Nota: Adaptado de "Dirección de Marketing" (p. 262), por Philip Kotler y Kevin Lane Keller, 2006, México, Pearson Education, Inc. Copyright 2006 por Pearson Educación de México S.A. de C.V.

5) Selección del mercado objetivo

Después del desarrollo de la evaluación de segmentos, se procede a seleccionar el mercado objetivo. Del análisis de la Tabla 15; se puede identificar que el perfil más adecuado es el Perfil 4; debido a que, cumple con la mayoría de criterios. Por ello se ha decidido por emplear el perfil 4 como mercado objetivo (ver Tabla 16). 
Tabla 16

Mercado Objetivo

\begin{tabular}{lc}
\hline Segmentación & Descripción \\
\hline Geográfica & Ate \\
$\quad$ Distrito & 18 a 60 años \\
Demográfica & A, B y C \\
$\quad$ Edad & \\
$\quad$ Nivel socio económico & Mejorar el estado físico \\
Conductual & Salud \\
Beneficios que buscan & \\
& Nota: Adaptado de "Dirección de Marketing" (p. 248), por Philip Kotler y Kevin Lane Keller, 2006, México, \\
Pearson Education, Inc. Copyright 2006 por Pearson Educación de México S.A. de C.V.
\end{tabular}

Como ya se ha señalado; el mercado objetivo descrito en el perfil 4, estará conformado por aquellos que cumplan los siguientes factores:

- Distrito con alto porcentaje de pobladores con obesidad y sobrepeso.

- Pobladores que pertenezcan al NSE A, B y C que residan en el distrito con alto porcentaje de obesidad.

- Pobladores de uno de los distritos con alto porcentaje de obesidad que deseen mejorar su estado físico y salud.

La presente investigación, se ha limitado al distrito de Ate, que de conformidad al ENDES (2016) es uno de los distritos con elevado porcentaje de pobladores con obesidad (11,7\%); cuyo número de habitantes, según el CENSO (2017) ascenderá a 630,086 (INEI, 2009); asimismo, de esta población, se considerará aquellos que se ubican en los NSE A, B y C, que representan aproximadamente el 67.04\% de habitantes en total (APEIM, 2017).

\subsection{Investigación Cualitativa}

Al Respecto Malhotra (2008) indica que "la investigación cualitativa proporciona conocimientos y comprensión del entorno del problema" (p. 143). Para el desarrollo de la presente investigación, se ha empleado la siguientes herramientas: (a) Focus Group, (b) entrevistas a profundidad, y (c) entrevistas a expertos.

Esto último, como medio para conocer de manera exploratoria las percepciones, opiniones y preferencias de las personas en cuanto al cuidado de su salud en razón a su peso corporal, práctica de alguna actividad física, nivel de satisfacción y preferencia de su centro de entrenamiento. 
1. Focus group

Objetivos generales

Conocer el comportamiento y los hábitos de consumo en razón a la actividad física del público objetivo.

Objetivos específicos

- Explorar el nivel de conocimiento acerca de la obesidad como problema de salud pública.

- Determinar el nivel de actividad física que realizan.

- Determinar el nivel de conocimiento acerca del CrossFit.

- Decidir el rango de precios dispuesto a pagar en un centro de entrenamiento.

- Determinar el nivel de satisfacción de los entrevistados en razón al servicio que ofrece su centro de entrenamiento.

- Determinar el grado de aceptación del CrossFit como alternativa para combatir la obesidad en el distrito de Ate.

2. Entrevistas a profundidad

Objetivos generales

Analizar el nivel de satisfacción y preferencia del CrossFit como actividad física.

Objetivos específicos

- Explorar el nivel de conocimiento acerca de la obesidad como problema de salud pública.

- Delimitar el nivel de conocimiento acerca del CrossFit.

- Determinar el nivel de satisfacción de los entrevistados en razón al servicio que ofrece su box de CrossFit.

- Determinar el nivel de influencia de la comunidad CrossFit.

- Determinar el grado de aceptación de la apertura de un Box de CrossFit como alternativa para combatir la obesidad en el distrito de Ate.

3. Entrevistas a expertos

Objetivos generales

Analizar la tendencia del CrossFit en el mercado fitness peruano.

Objetivos específicos

- Averiguar acerca de la obesidad como problema de salud pública.

- Analizar la influencia del CrossFit en el ejercicio de sus profesiones.

- Precisar si el CrossFit es una alternativa para combatir la obesidad. 
- Indagar la opinión respecto a la viabilidad de aperturar un box de CrossFit en el distrito de Ate.

- Determinar los criterios del éxito para la elaboración del MPC

- Obtener el peso y calificación para la MPC.

- Obtener el peso y calificación para matriz EFE.

- Determinar el nivel de participación de los box de CrossFit en el país.

\subsubsection{Proceso de muestreo}

\section{Focus Group}

Población objetivo

Se consideró, de acuerdo a la selección del mercado objetivo previsto en la Tabla 16 a aquellas personas que vivan en el distrito de Ate y que pertenezcan al NSE A, B y C (ver Apéndice 10); que realicen o no realicen actividad física de manera regular.

\section{Tamaño de la muestra}

El grupo estuvo integrado por siete personas entre los 20 y 40 años, de ambos sexos, de NSE A, B y C, y que viven en el distrito de Ate.

\section{Selección de la muestra}

Para la selección de la muestra, se empleó la ficha de reclutamiento (ver Apéndice 2) y de manera aleatoria, se procedió a invitar al Focus group aquellas personas que cumplan con las condiciones previstas en la población objetivo y en el tamaño de la muestra. En la Tabla 17 se encuentra la relación de personas seleccionadas.

Tabla 17

Relación de Participantes del Focus Group

\begin{tabular}{ll}
\hline Nombres y apellidos & Edad \\
\hline Yaniré Macalopú Cárdenas & 22 años \\
Sandra Parodi Medina & 21 años \\
Israel Gonzales & 29 años \\
Aaron Barrantes & 23 años \\
Brissa Atoche Lugo & 25 años \\
Jorge Pérez Pardave & 37 años \\
Joana Mallqui Rodriguez & 31 años \\
\hline
\end{tabular}

\section{Entrevistas a profundidad}

\section{Población Objetivo}

Se consideró, de acuerdo a la selección del mercado objetivo previsto en la Tabla 16, a las personas que pertenezcan al NSE A, B y C del distrito de Ate; que realicen CrossFit como actividad física. 


\section{Tamaño de la muestra}

El grupo estuvo integrado por cinco personas entre los 20 y 45 años, de ambos sexos, de NSE A, B y C, y que viven en el distrito de Ate.

\section{Selección de la muestra}

Para la selección de la muestra, se empleó la ficha de reclutamiento que se encuentra en el Apéndice 13; y se procedió a invitar aquellas personas que cumplan con las condiciones previstas en la población objetivo y en el tamaño de la muestra. En la Tabla 18 se encuentra la relación de personas seleccionadas.

Tabla 18

Relación de Participantes de las Entrevistas a Profundidad

\begin{tabular}{lll}
\hline Nombres y apellidos & Edad & Box de CrossFit \\
\hline Adolfo Uribe León & 29 años & Legado CrossFit \\
Pamela Chunga Seminario & 25 años & Legado CrossFit \\
Nicolay Patiño & 27 años & Legado CrossFit \\
Carlos Villalobos & 43 años & Legado CrossFit \\
Jesús Ramírez & 33 años & CrossFit Ramus \\
\hline
\end{tabular}

Nota: A fecha de la realización de las entrevistas a profundidad, la denominación de Legado CrossFit estaba habilitada; a la fecha, la empresa cambió su denominación a Legado Fitness.

\section{Entrevistas a expertos}

\section{Población Objetivo}

Se consideró, aquellos profesionales expertos en la materia de CrossFit y nutrición (ver Apéndice 19).

\section{Tamaño de la muestra}

El grupo estuvo integrado por cuatro personas que cuentan con años se experiencia en el área de estudio del CrossFit y nutrición.

\section{Selección de la muestra}

Para la selección de la muestra (ver Tabla 19), se consideró a un gerente general de un box de CrossFit, a dos Coaches y una nutricionista quienes poseen experiencia en el mundo del CrossFit; mismos que laboran a tiempo parcial en la competencia directa de Ate CrossFit determinadas en el 2.4.1 de la presente investigación. 
Tabla 19

Relación de Expertos que Participaron en la Entrevista

\begin{tabular}{|c|c|c|c|c|}
\hline Nombres y apellidos & Edad & Profesión & $\begin{array}{c}\text { Lugar de } \\
\text { trabajo }\end{array}$ & Puesto \\
\hline Julio Poppe & 30 años & Administrador & $\begin{array}{c}\text { CrossFit } \\
\text { La Molina }\end{array}$ & $\begin{array}{c}\text { Gerente general y } \\
\text { Head Coach }\end{array}$ \\
\hline $\begin{array}{l}\text { Andrés Andonayre } \\
\text { La Madrid }\end{array}$ & 26 años & Coach & $\begin{array}{l}\text { Legado } \\
\text { Fitness }\end{array}$ & $\begin{array}{l}\text { Coach de turno y } \\
\text { Atleta CrossFit }\end{array}$ \\
\hline Sergio Baella & 28 años & Coach & $\begin{array}{l}\text { CrossFit } \\
\text { La Molina }\end{array}$ & $\begin{array}{l}\text { Head Coach y } \\
\text { Atleta CrossFit }\end{array}$ \\
\hline Camen Quinteros & 28 años & Nutricionista & $\begin{array}{l}\text { Legado } \\
\text { Fitness }\end{array}$ & Nutricionista \\
\hline
\end{tabular}

\subsubsection{Diseño de instrumento}

\section{Focus group}

Objetivos de la investigación

El desarrollo del Focus group busca identificar los siguientes criterios:

- Perfil del participante

- Conocimiento acerca de la obesidad como problema de salud pública.

- Nivel de actividad física.

- Nivel de conocimiento sobre el CrossFit

- Satisfacción del servicio en su establecimiento deportivo

- Precios y formas de pago de los servicios

- De la apreciación del entorno de su establecimiento deportivo

- Grado de aceptación del CrossFit como actividad física para combatir la obesidad.

Guía de pautas

El Focus Group se basó en una guía de indagación; tal y como se muestra en el Apéndice 11; asimismo, se desarrolló en un tiempo de 53 minutos. Cada uno de los participantes iban respondiendo las preguntas en el orden de derecha a izquierda. Los integrantes del grupo intervinieron como moderadores, turnándose la participación en razón a las preguntas de cada sección.

\section{Entrevistas a profundidad}

Objetivos de la investigación

El desarrollo de las entrevistas a profundidad busca identificar los siguientes criterios:

- Perfil del entrevistado

- Nivel de conocimiento acerca de la obesidad como problema de salud pública 
- Perspectiva del CrossFit como deporte

- Nivel de satisfacción con el servicio en su establecimiento deportivo

- Influencia de la comunidad CrossFit

Guía de pautas

Las entrevistas a profundidad estuvieron basadas en una guía; tal y como se muestra en el Apéndice 14. Cada una de las entrevistas se desarrolló en un tiempo máximo de 15 minutos en una cafetería.

\section{Entrevistas a expertos}

Objetivos de la investigación

El desarrollo de las entrevistas a expertos busca identificar los siguientes criterios:

- Perfil del entrevistado

- Nivel de conocimiento de la obesidad como problema de salud pública

- Perspectiva del CrossFit como deporte

- Perspectiva del CrossFit como estilo de vida

- Perspectiva del CrossFit para combatir la obesidad

- Perspectiva del CrossFit basada en su experiencia profesional

- Tendencia del CrossFit en el mercado fitness peruano

- Expectativa de aperturar un box de CrossFit en Ate.

- Determinar los criterios del éxito para la elaboración del MPC.

- Obtener el peso y calificación para la MPC.

- Obtener el peso y calificación para matriz EFE.

- Determinar el nivel de participación de los box de CrossFit en el país.

Guía de pautas

Las entrevistas a expertos estuvieron basadas en tres guías; tal y como se muestran en los Apéndices 21, 29 y 36. Cada una de las entrevistas se desarrolló en un tiempo máximo de 30 minutos en una cafetería.

\subsubsection{Análisis y procesamiento de datos}

\section{Focus group}

\section{Procesamiento de datos}

Una vez realizado el Focus Group, se procedió a la visualización del video y transcripción del contenido (ver Apéndice 12). 


\section{Análisis de datos}

A continuación, se presenta los resultados del estudio cuantitativo provenientes del Focus Group:

Acerca del problema de salud pública

- Para los participantes, la obesidad es un problema endémico en la sociedad actual.

- Los principales factores que determinan la obesidad son la mala alimentación (comida chatarra) la falta de ejercicio físico a causa del tren de vida que llevan (estudiantes, ama de casa, empleados)

- El grupo considera que llevar una vida más sana conllevaría a combatir la obesidad, comiendo sano y a sus horas, además de realizar ejercicio físico

- La respuesta afirmativa es unánime respecto a considerar importante llevar una vida saludable y tener un buen estado físico.

Acerca de la actividad física

- Un buen estado físico es encontrarse en un peso ideal (se hace referencia al vínculo entre la estatura y el peso).

- Tener un buen estado físico es la mejor manera de sentirse vital, llenos de energía, renovados y alejar el estrés

- Las diversas ocupaciones y los tiempos que maneja cada participante imposibilitan la realización de alguna actividad física de manera habitual.

- Tener un soporte personal que los ayude o acompañe para realizar alguna actividad física, así como contar con un lugar adecuado dónde practicar de manera segura alguna actividad física son los principales factores que motivarían su realización.

- Las actividades físicas preferidas son correr y realizar ejercicios específicos para reducir peso o acumulación de grasa en zonas focalizadas.

- La frecuencia de práctica de actividad física para mantener un adecuado estado físico debería ser de entre 3 a 4 veces a la semana.

- Cada sesión de actividad física debería ser entre 45 a 60 minutos.

Acerca del nivel de satisfacción de los entrevistados en razón al servicio que le ofrecen en su centro de entrenamiento.

- Los participantes señalan que no se sienten satisfechos por el servicio.

Acerca del rango de precios dispuestos a pagar en un centro de entrenamiento.

- Los participantes concluyeron que el precio de pago dispuestos a pagar en un centro de entrenamiento oscila entre S/. 250.00 y S/. 300.00 nuevos soles. 


\section{Acerca del CrossFit}

- Los participantes indican que el método CrossFit es nuevo en el medio y que conocen algunos Box en algunos distritos ajenos a Ate y por ende lejanos a sus domicilios.

- La percepción que se tiene del CrossFit corresponde a un servicio distinto a los clásicos gimnasios, donde se busca una figura musculosa, pero que no se centra en mantener o combatir a la obesidad.

- Los participantes acuerdan que el CrossFit es una buena alternativa para combatir la obesidad en el distrito de Ate.

Acerca del nivel de intencionalidad de los participantes para probar el CrossFit.

- Los participantes muestran una alta intencionalidad de probar el servicio de CrossFit con una alta expectativa de ayuda a desarrollar un estado físico saludable.

- Los participantes manifiestan poder participar en una sesión de manera diaria siempre y cuando se realice en un horario que no interrumpa sus actividades y quehaceres diarios, además que no supere las 3 o 4 sesiones semanales.

- Se considera que contar con un lugar adecuado para realizar o practicar CrossFit marcaría una ventaja importante y un factor de motivación.

- Se reflexiona como un factor de diferenciación contar con un instructor que se encuentre certificado para darle mayor profesionalismo a la práctica del CrossFit

- Se determina como factor importante la cercanía del Box de CrossFit a su domicilio, incluso en comparación de cercanía a su centro laboral y/o de estudios.

\section{Entrevistas a profundidad}

Procesamiento de datos

Culminadas las entrevistas a profundidad, se procedió a escuchar las grabaciones de audio, y a realizar la transcripción respectiva.

Análisis de datos

A continuación, se presenta los resultados de las entrevistas a profundidad (ver Apéndice 13):

1. Perfil de los entrevistados

- Se determinó que todos los participantes realizan el CrossFit como un estilo de vida, para superar sus límites.

2. Nivel de conocimiento acerca de la obesidad como problema de salud pública

- Los participantes reconocen que la obesidad es un problema de salud pública nacional e internacional, y que deben tomarse medidas que promocionen la buena salud. 
3. Acerca Sobre la perspectiva del CrossFit como deporte

- Los entrevistado concluyen que el CrossFit es una actividad física que mejora las habilidades, rendimiento y capacidades físicas de las personas.

4. Del nivel de satisfacción con el servicio en su establecimiento deportivo

- Los participantes concluyen que si existe relación entre el precio y la calidad del servicio que le ofrecen; sin embargo, consideran que puede mejorarse. Asimismo, los inconvenientes que tuvieron fueron por el horario del servicio y las instalaciones.

5. Influencia de la comunidad CrossFit

- Los entrevistados consideran que la comunidad CrossFitera en su box es regular; puesto que no promocionan mucho la integración; asimismo, consideran que la comunidad es un elemento indispensable que influye en la práctica de dicha actividad física.

6. Determinar el grado de aceptación de la apertura de un Box de CrossFit como alternativa para combatir la obesidad en el distrito de Ate.

- Los participantes consideran que el CrossFit es una buena alternativa para combatir la obesidad y que la apertura de un box en su distrito ayudaría mucho.

\section{Entrevistas a expertos}

\section{Procesamiento de datos}

Culminadas las entrevistas, se procedió a escuchar las grabaciones de audio realizadas, y la transcripción respectiva.

\section{Análisis de datos}

A continuación, se presenta los resultados de las entrevistas a profundidad (ver Apéndice 19):

1. Del perfil del entrevistado

- Los entrevistados son especialistas en la materia del CrossFit como actividad física.

2. Acerca del nivel de conocimiento de la obesidad como problema de salud pública

- Los expertos han determinado que la obesidad es un problema de salud pública, cuya expansión es alarmante. Asimismo, consideran que se deben tomar medidas lo más pronto posible.

3. Análisis de la tendencia del CrossFit en el mercado fitness peruano.

- Los expertos consideran que el CrossFit es una tendencia que se mantendrá en el tiempo; esto, gracias a los eventos que se realizan a nivel mundial para promocionarlo; siendo el principal, los CrossFit Games. Asimismo, consideran que en el Perú aún no ha llegado a 
su máximo apogeo, por lo cual se espera que la comunidad CrossFit aumente en los próximos años.

4. Del CrossFit como alternativa para combatir la obesidad.

- Los expertos han concluido que el CrossFit es una actividad física que puede transformar la vida de las personas y combatir la obesidad.

5. De la experiencia del CrossFit en su experiencia profesional

- Los expertos han concluido que el CrossFit es una disciplina que les brinda un constante aprendizaje y les ha cambiado la vida de manera personal y profesional. Del mismo modo, el progreso tanto de sus alumnos como pacientes, los ha puesto un peldaño por encima de los demás profesionales en su rubro.

6. Respecto de la viabilidad de aperturar un box de CrossFit en Ate.

- Los expertos opinan que es necesario ampliar la comunidad CrossFit, más aún en aquellos distritos donde el nivel de obesidad es alto. Asimismo, opinan que al ser el primer box de CrossFit afiliado que funcione, lograría posicionarse del mercado inmediatamente.

7. De los criterios del éxito para la elaboración del MPC.

- El gerente general de CrossFit La Molina, definió los valores críticos del éxito que debe poseer todo box de CrossFit en el mercado.

8. Respecto al peso y calificación para la MPC

- El gerente general de CrossFit La Molina, consignó los pesos para la MPC. De otro lado, los Coaches asignaron la calificación correspondiente, debido a que cada uno tiene como experiencia, haber laborado en los box de CrossFit descritos como competidores para la presente investigación.

9. Respecto al peso y calificación para la matriz EFE.

- El gerente general de CrossFit La Molina, asignó el peso y calificación a cada uno de los factores del éxito de la Matriz de Evaluación de Factores externos. Esto último, en razón a su experiencia como dueño de un box de CrossFit. Asimismo, validó cada uno de los factores del éxito.

10. Determinar el nivel de participación de los box de CrossFit en el país.

- Los expertos han determinado que para medir el nivel de participación en el mercado de cada uno de los box de CrossFit en el Perú, se debe tener en consideración el número de sedes que cada Box afiliado posee. Esto último, debido a que en la actualidad no hay un estudio preciso que lo determine; así también, precisan que definir el nivel de participación por el número de miembros sería algo imposible, ya que dicha información es reservada. 


\subsection{Investigación Cuantitativa}

Al respecto Malhotra (2008) indica que "la investigación cuantitativa busca cuantificar los datos y, por lo general, aplica algún tipo de análisis estadístico” (p. 143); es decir, que a través de la investigación cuantitativa se busca que los supuestos planteados para este trabajo se confirman o rechacen en base a un análisis de datos numéricos loa objetivos planteados en la presente investigación.

\section{Objetivo general}

El objetivo general es ponderar y analizar de manera objetiva y directa, sobre la base de una muestra la información obtenida acerca de la valoración y comportamiento de una población hacia el modelo de negocio 'CrossFit'.

\section{Objetivos específicos}

- Conocer el perfil de la población de Ate encuestada (ver Figuras 24, 25 y 26).

- Conocer el motivo por el cual la población de ate realiza actividad Física (ver Figura 27).

- Conocer la estacionalidad para realizar la actividad física (ver Figura 28)

- Obtener el gasto promedio dispuesto a pagar por el servicio CrossFit (ver Figura 29).

- Conocer los factores más influyentes a la hora de elegir un centro de entrenamiento (ver Figura 30).

- Conocer la intención de asistencia al box de CrossFit (ver Figuras 31 y 32).

- Conocer el motivo por el cuál harían CrossFit (ver Figura 33).

- Conocer la frecuencia de asistencia al Box de CrossFit (ver Figura 34).

- Determinar el horario de asistencia al Box de CrossFit (ver Figura 35).

- Determinar la tendencia en la contratación de membresías (ver Figura 36).

- Conocer las promociones que debe contar el box de CrossFit (ver Figura 37).

- Conocer las preferencias en cuanto al uso de medios de comunicación (ver Figura 38).

\subsubsection{Proceso de muestreo}

En el presente plan de negocio, se empleó lo siguiente:

\section{Población objetivo}

El ámbito de aplicación para la puesta en marcha de un box de CrossFit es en el distrito de Ate, que de conformidad con el ENDES (2016) es uno de los distritos con mayor porcentaje de obesidad, cuya población proyectada (ver Figura 40 y Tabla 20) asciende a 613,517 habitantes. De los cuales, se tomó en cuenta a la población perteneciente a los NSE A, B y C; quienes conforman el $1 \%, 17 \%$ y $47 \%$ respectivamente, de la población del distrito de Ate (APEIM, 2017). 


\section{Tamaño de la muestra}

Con fines académicos y dadas las limitantes que presenta el plan de negocio, se ha empleado la técnica de muestreo no probabilístico por conveniencia. Malhotra (2008) señala que "el muestreo no probabilístico no se basa en el azar, sino en el juicio personal del investigador para seleccionar a los elementos de la muestra" (p. 340). Asimismo, el citado autor señala que "el muestreo por conveniencia busca obtener una muestra de elementos convenientes. La selección de las unidades de muestreo se deja principalmente al entrevistador" (Malhotra, 2008, p. 341).

Se empleó la fórmula estadística por muestras finitas, cuya fórmula es:

$$
\mathrm{n}=\frac{\mathrm{N} * \mathrm{Z}^{2 *} \mathrm{P} * \mathrm{Q}}{\mathrm{e}^{2 *}(\mathrm{~N}-1)+\mathrm{Z}^{2 *} \mathrm{P} * \mathrm{Q}}
$$

Donde:

$\mathrm{n}=$ tamaño de muestra buscado.

$\mathrm{N}=$ tamaño de población o universo.

$\mathrm{Z}=$ Nivel de confianza.

$\mathrm{e}=$ Margen de error.

$\mathrm{P}=$ probabilidad de éxito.

$\mathrm{Q}=$ probabilidad de fracaso.

Para la presente investigación, se empleó los siguientes valores:

Tamaño de muestra buscado:

$613,517 * 66 \%$ (NSE A, B y C de Ate).

$\mathrm{N}: 404,921$

Nivel de confianza

$\mathrm{Z}: 95 \%=(1.96)$

Margen de error:

e: $4.7 \%$

Probabilidad de éxito:

P: 0.5

Probabilidad de fracaso

$\mathrm{Q}=1-\mathrm{P}$

Q: 0.5 
Aplicando los datos a la fórmula:

$$
\begin{aligned}
& \mathrm{n}=\frac{404,921 *(1.96)^{2} * 0.5 * 0.5}{(4.7 \%)^{2 *}(404,921-1)+(1.96)^{2} * 0.5 * 0.5} \\
& \mathrm{n}=440
\end{aligned}
$$

El tamaño de muestra es de 440.

\subsubsection{Diseño de instrumento}

El instrumento utilizado fue un cuestionario de 39 preguntas (ver Apéndice 38), la mayor parte con preguntas cerradas y algunas abiertas. Este instrumento fue estructurado en cinco etapas las cuales se detallan a continuación:

1. La primera etapa, con siete preguntas filtro, para determinar si la persona vive en el distrito de Ate, realiza o no alguna actividad física, los motivos por la cual no lo realiza, y el lugar donde lo realiza.

2. La segunda etapa, con 15 preguntas sobre hábitos de consumo, para determinar qué tipo de actividad física realiza, el motivo por la cual lo realiza, la frecuencia, el tiempo que le toma realizar la actividad física, la estacionalidad, los factores que consideró importantes para la elección de su centro de entrenamiento, el gasto promedio por la membresía, la satisfacción de su centro de entrenamiento, los factores que influyen en su decisión al contratar un servicio de entrenamiento y los medios de comunicación por donde interactúa con su centro de entrenamiento.

3. La tercera etapa, consta de 11 preguntas sobre la evaluación del concepto del modelo de negocio propuesto, con la finalidad de determinar si la persona encuestada estaría dispuesto a practicar el CrossFit, las razones por la cual lo practicaría, la frecuencia, el horario, los aspecto por las cuales consideraría inscribirse en un Box de CrossFit, el rango de precios por el cual estaría dispuesto a pagar, el medio de pago, las promociones que loa atraerían y los medios de comunicación para interactuar.

4. La cuarta etapa, con cuatro preguntas filtro de nivel socio económico, con el fin de medir en que NSE se encuentra la población encuestada, y

5. La quinta etapa, con dos preguntas de datos personales, donde se mide el rango de edad de la población y el sexo.

\section{Aplicación del cuestionario}

La aplicación del cuestionario se hizo online, utilizando la plataforma google formularios; para ello, se empleó una base de datos de 2350 cuentas de clientes de una compañía peruana de seguro que clasifica a sus productos por tipo; mismas que han sido definidas por la compañía según la cantidad y el tipo de póliza de seguro, cuya prima supera el valor de US\$ 
750.00 (setecientos cincuenta y 00/100 dólares americanos) anuales que fueron adquiridos por personas que pertenecen a los NSE A, B y C y que provienen de las zonas 1, 2 y 3 (ver Figura 52) del distrito de ate.

De la base proporcionada, se realizaron cuatro filtros importantes: primero, se seleccionó aquellas cuentas de la compañía que hayan renovado su póliza de seguro durante el último año; segundo, que los clientes hayan interactuado con la aseguradora para la renovación de su contrato de seguros mediante el uso de correo electrónico; tercero, que dichos clientes tengan una cuenta en google (Gmail); y cuarto, que las cuentas sean personalísimas; es decir, no haber facilitado su correo para la filiación de otro cliente. Del procesamiento de los tres filtros, se obtuvo una base de 943 cuentas; acto seguido, se procedió al envío del formulario. Para hacer efectiva la muestra de 440, se le pusieron ciertas restricciones a la secuencia de comandos y configuración del formulario; tales como:

- $\quad$ Límite de fecha, con el fin de obtener los resultados a la brevedad posible.

- Límite de respuestas que aceptará el formulario; de esta manera, una vez obtenida la muestra de 440, el formulario se cerrará automáticamente y no aceptará más respuestas.

- Limitar a 1 respuesta por cuenta; con ello, se restringe el acceso al enlace para enviar otra respuesta. Para ello, el encuestado deberá iniciar sesión con su cuenta en google. Esto último, con el fin de no obtener dobles resultados y evitar que se reenvíe la encuesta a otros usuarios.

- Restringir la edición de respuestas después del envío.

- Acuse de recibo de respuestas a la cuenta principal para llevar un control del número de cuestionarios realizados; asimismo, se cierra automáticamente la opción de poder realizar el cuestionario.

- Condicionar el orden de las preguntas de manera estructurada.

\subsubsection{Análisis y procesamiento de datos}

\section{Procesamiento de datos}

Una vez realizada la toma de los cuestionarios, se procedió a revisar y seleccionar aquellos resultados de mayor relevancia e impacto para la presente investigación; asimismo, se procedió a la interpretación de los mismos.

\section{Análisis de datos}

Técnicas estadísticas

Frecuencia y elaboración de gráficos. 


\section{Resultados}

1. Perfil de la muestra:

Se obtuvo la siguiente información:

- Los encuestados viven en el distrito de Ate.

Total de respuestas: 440

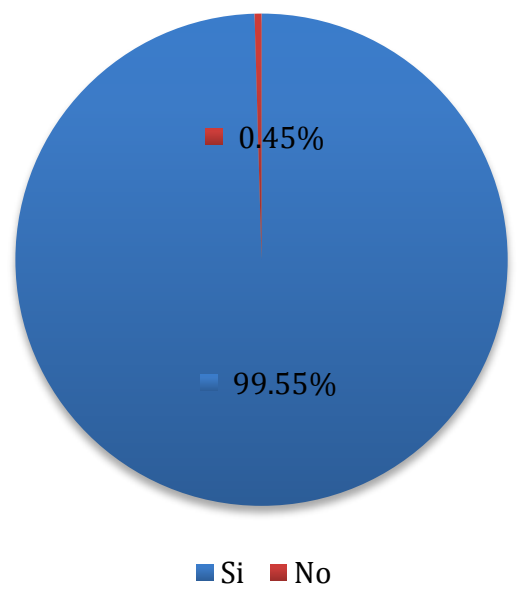

Figura 24. Porcentaje de personas que viven en el distrito de Ate. El $99.55 \%$ representa a 438 encuestados y el $0,5 \%$ a 2 .

- Proporción del género en la muestra

Total de respuestas: 254

El número de hombres es de 200 y el de mujeres 58

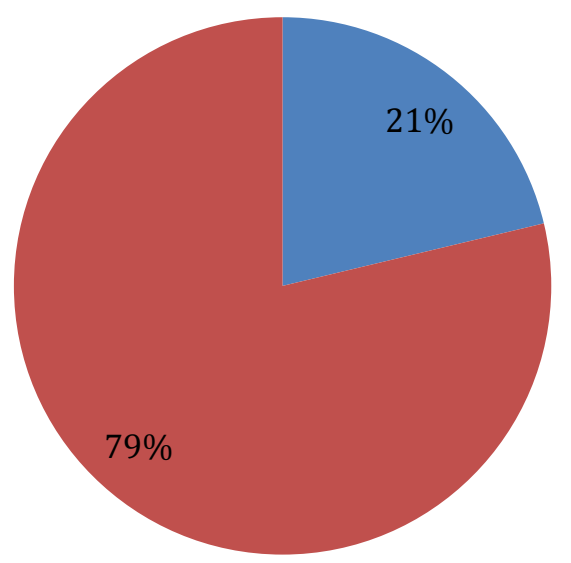

Mujer

Hombre

Figura 25. Género de la muestra 
- $\quad$ El rango de edad a la que pertenece la muestra.

Total de respuestas: 254

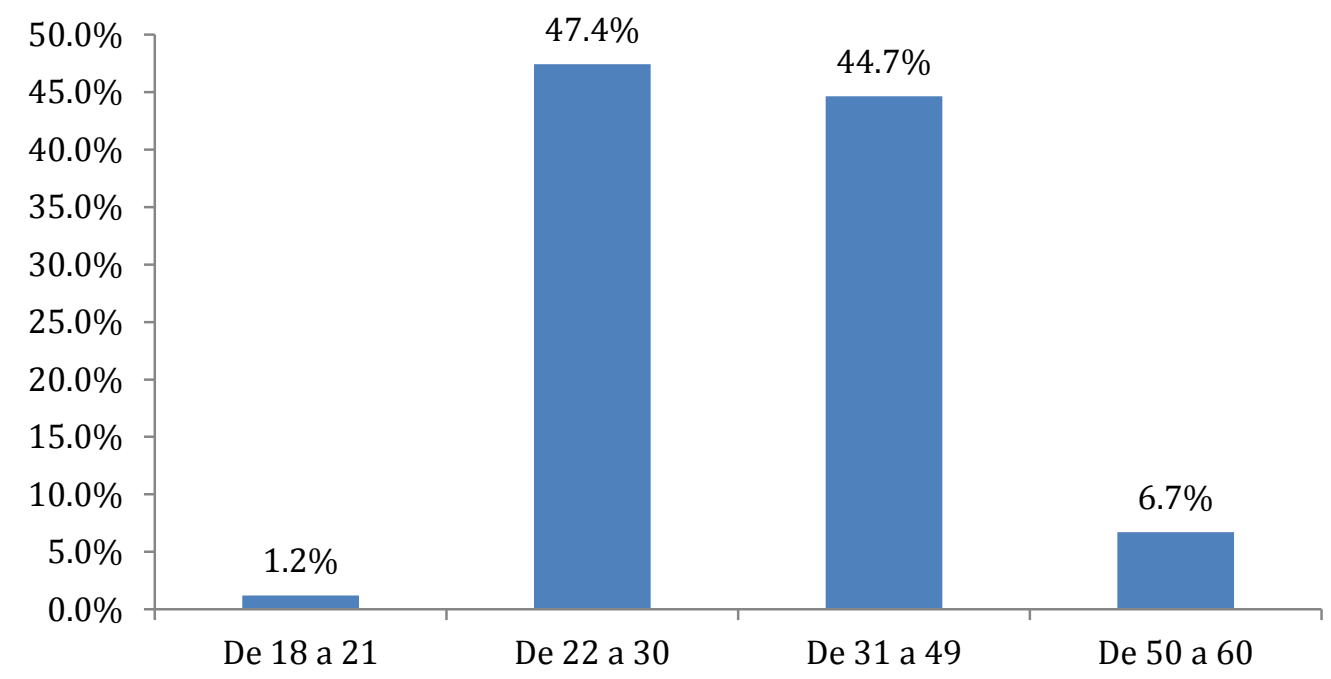

Figura 26. Rango de edad de la muestra

2. Resultados de los objetivos del estudio cuantitativo.

- Motivo por el cual realizan actividad física

El resultado del cuestionario determina que el mayor motivo por el cual las personas que realizan una actividad física dentro del distrito de Ate son para bajar de peso, seguidas de buen estado físico y salud (ver Figura 27). El total de respuestas fue de 149.

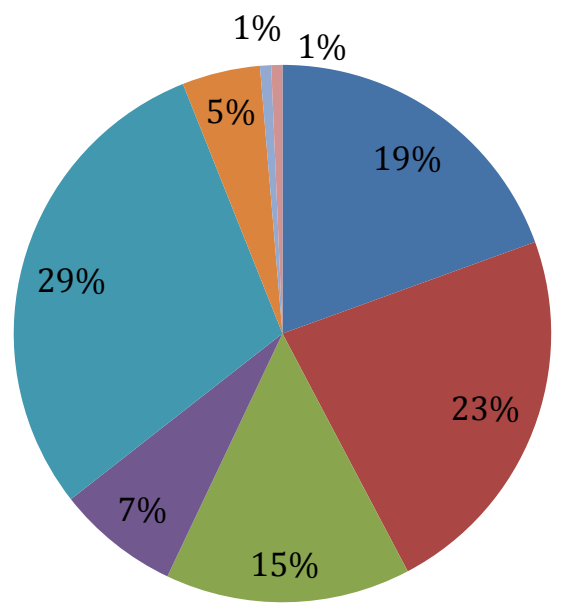

- Salud

- Buen estado físico

- Buena imagen

- Mejorar capacidades física

Bajar de peso

- Relajación

- Mantenerme en forma

Entretenerme

Figura 27. Motivo para realizar actividad física 
- Estacionalidad para realizar actividad física

De acuerdo a los resultados obtenidos del cuestionario (ver Apéndice 39), se ha determinado que la preferencia de estación del para realizar actividad física es en primavera; esto en razón a la cercanía del verano (ver Figura 28). El total de respuestas fue de 149.

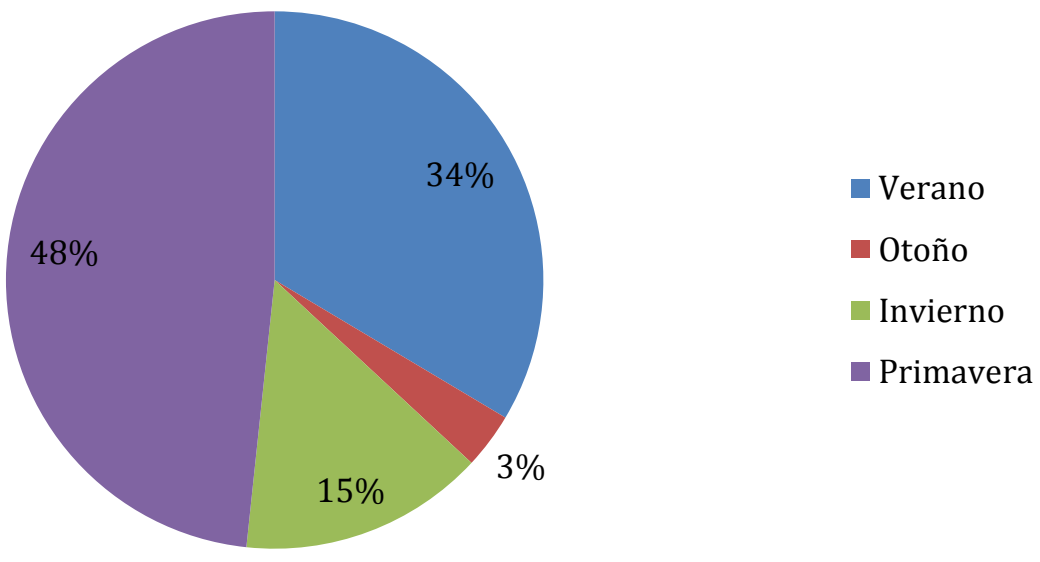

Figura 28. Preferencia de estacionalidad para hacer actividad física

- Gasto promedio dispuesto a pagar por el servicio CrossFit

De acuerdo a los resultados obtenidos del cuestionario (ver Apéndice 39), se ha determinado que el gasto promedio que las personas están dispuestas a pagar por el servicio CrossFit es del 201 a 300 soles (ver Figura 29). El total de respuestas fue de 254.

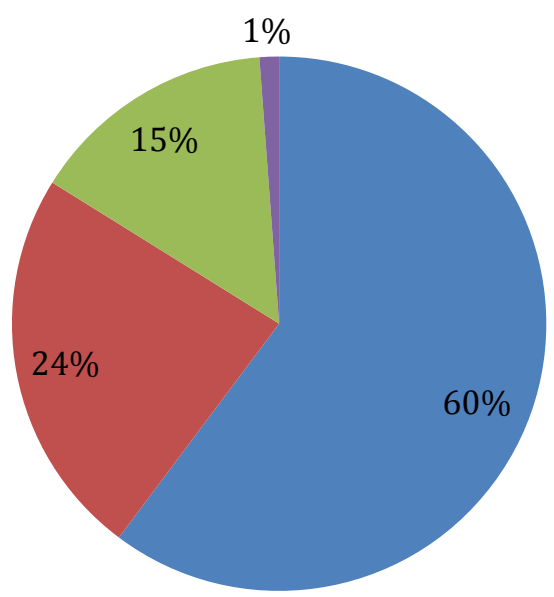

- De $S / 201.00$ a S/ 250.00

- De S/251.00 a S/ 280.00

- De S/281.00 a S/ 300.00

- De S/301.00 a S/ 350.00

Figura 29. Gasto promedio dispuesto a pagar por servicio CrossFit 
- Factores más influyentes a la hora de elegir un centro de entrenamiento

De acuerdo a los resultados obtenidos del cuestionario (ver Apéndice 39), se precisa que la ubicación es el factor más determinante de las personas del distrito de Ate para elegir un centro de entrenamiento(ver Figura 30). El total de respuestas fue de 149.

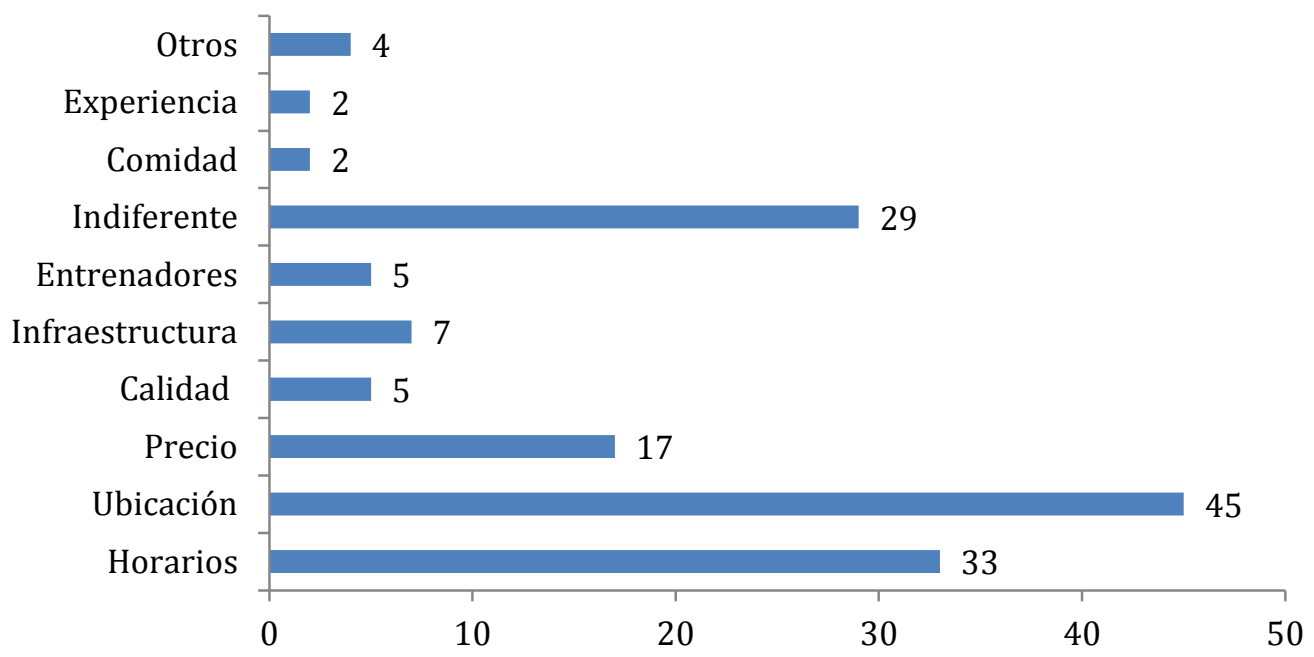

Figura 30. Factores para elegir un centro de entrenamiento

- Intención de asistencia al box de CrossFit

Para determinar la intención de asistencia al Box de CrossFit, se determinó si el participante estaría dispuesto a asistir a este tipo de entrenamiento (Ver Figura 31), para ello se explicó y mostró un video sobre el CrossFit. Total de respuestas 299.

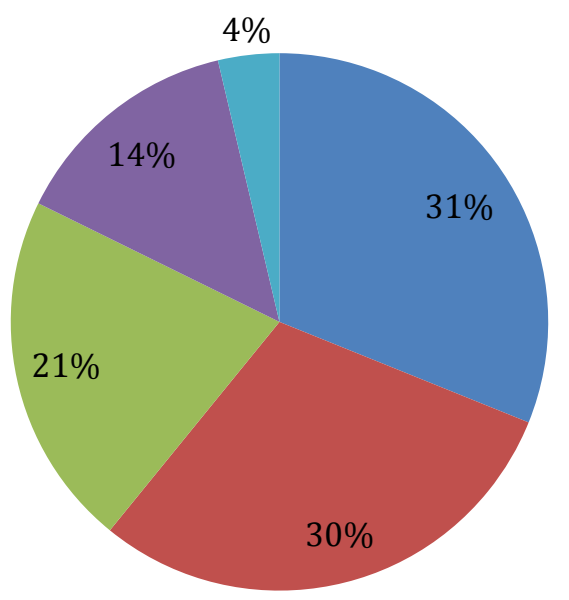

Definitivamente asistiría

- Probablemente asistiría

No sabe

- Probablemente no asistiría

Definitivamente no asistiría

Figura 31. Disposición de asistir al entrenamiento CrossFit 
Luego de exponer ciertas variables sobre el servicio que propone Ate CrossFit, se determinó si el participante se inscribiría en el servicio (ver Figura 32).

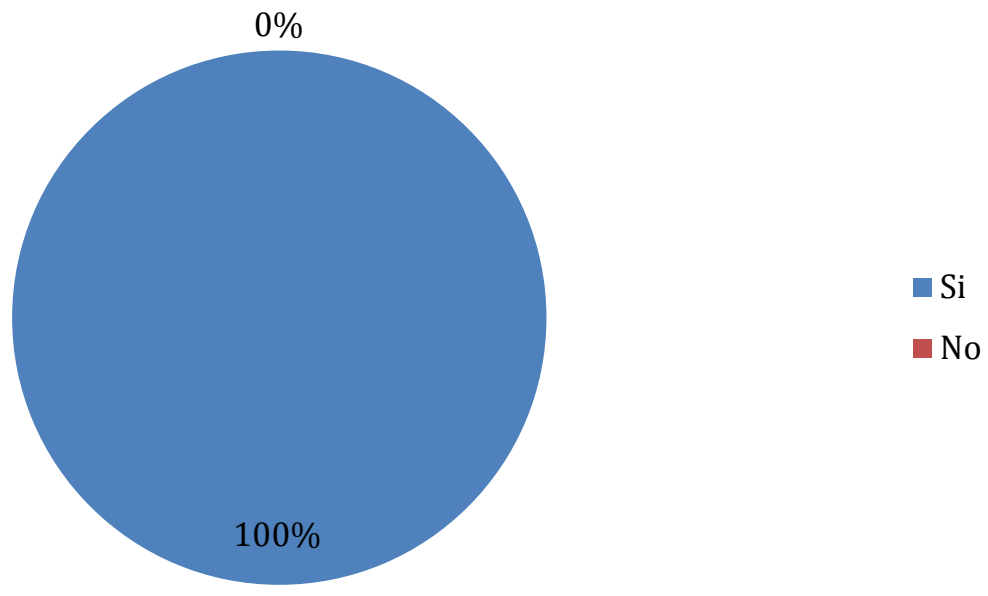

Figura 32. Intención de inscribirse en Ate CrossFit. Total de respuestas 254.

- Motivo por el cual harían CrossFit

De acuerdo a los resultados obtenidos del cuestionario (ver Apéndice 39), se precisa que los mayores motivos por los cuales los participantes harían CrossFit son: mejorar el estado físico y por salud (ver Figura 33). Total de respuestas 246.

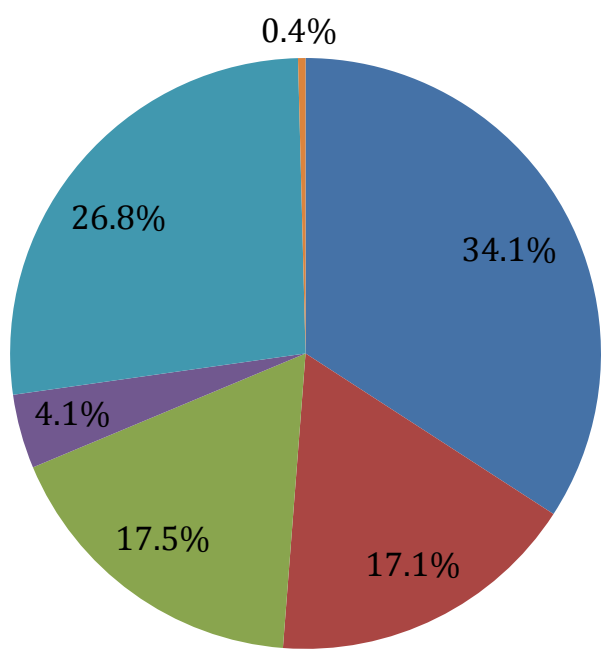

- Mejorar mi estado físico

- Mejorar mi imagen

- Rapidos Resultados

- Para ser atleta CrossFit

- Por salud

- Nuevo estilo deportivo

Figura 33. Motivo para hacer CrossFit 
- Frecuencia de asistencia al box de CrossFit

De conformidad con los resultados obtenidos del cuestionario (ver Apéndice 39), se precisa que los participantes prefieren asistir a entrenar de lunes a viernes (ver Figura 34). Total de respuestas: 254 .

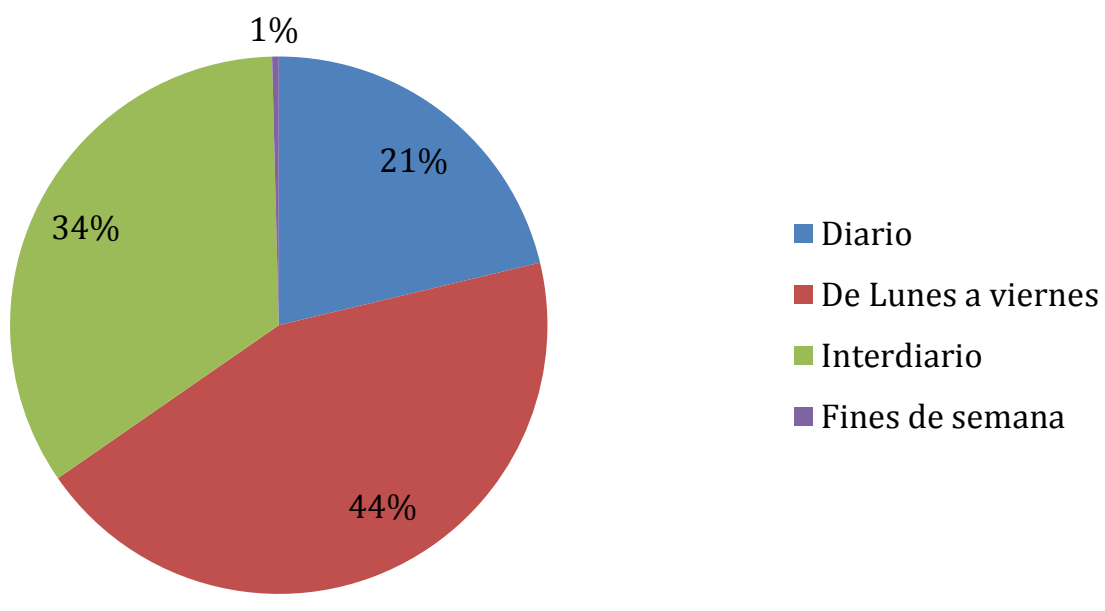

Figura 34. Frecuencia de asistencia al box de CrossFit

- Horario de asistencia al box de CrossFit

De conformidad con los resultados obtenidos del cuestionario (ver Apéndice 39), se precisa que los participantes prefieren asistir a entrenar en las mañanas y por las noches en los horarios que se establecen en la Figura 35. Total de respuestas: 254.

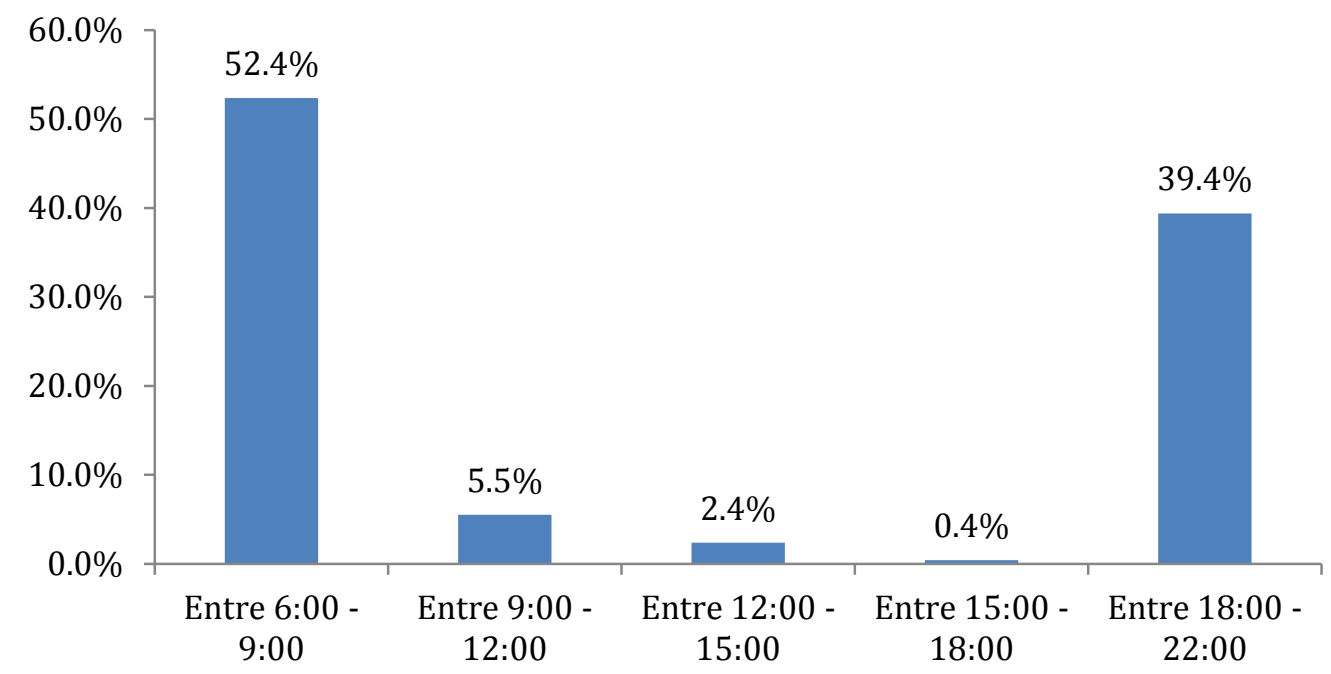

Figura 35. Horario de preferencia para acudir al box de CrossFit 
- Tendencia en la contratación de las membresías

En la figura 36, queda evidenciado que los participantes tienen mayor preferencia a contratar su membresía en un centro de entrenamiento por mensualidades. Total de respuestas: 149 .

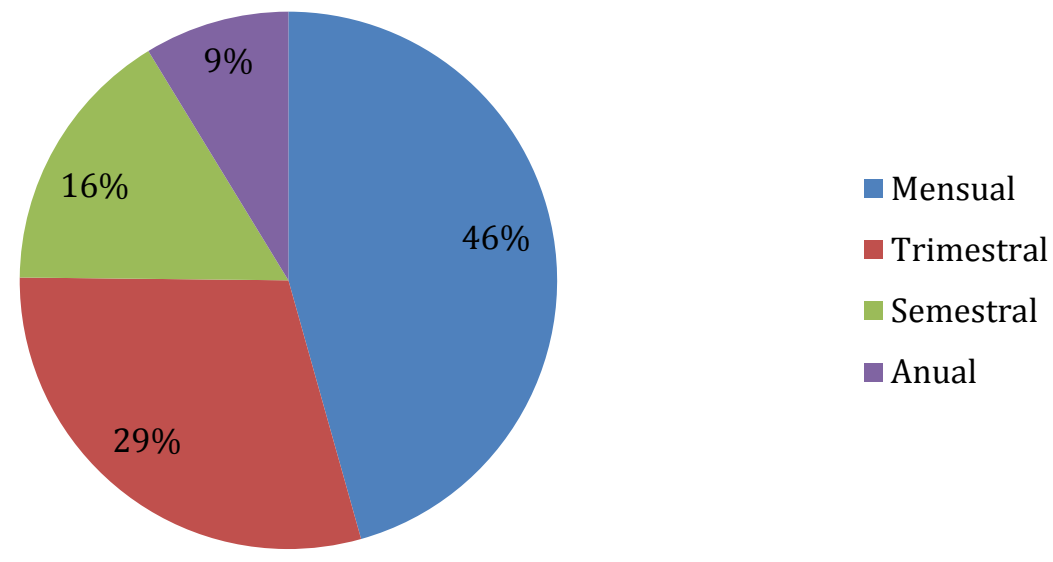

Figura 36. Modalidad de pago de membresía

\section{- Preferencia en promociones}

En la Figura 37, se determina la preferencia de los participantes en razón a las promociones que desean tener de Ate CrossFit. Total de respuestas: 254.

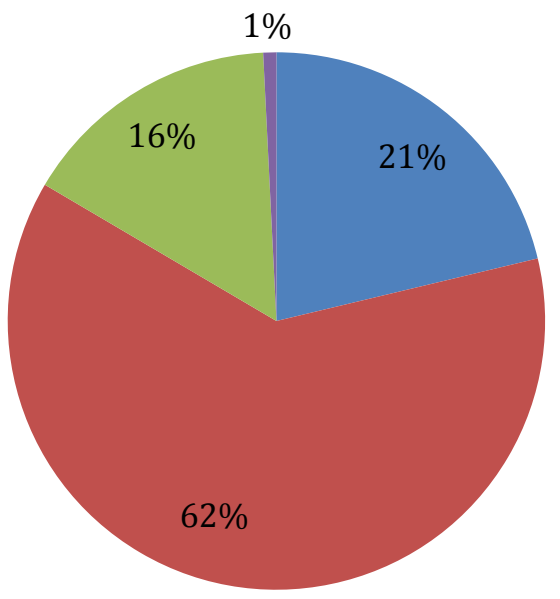

- Descuento

- Promociones

- Indumentaria de cortesia

andiferente

Figura 37. Preferencia en promociones de Ate CrossFit 
- Preferencia de uso de medios de comunicación.

En la Figura 38, se determina la preferencia de los participantes en razón a los medios de comunicación para informarse de las actividades de Ate CrossFit. Total de respuestas: 254.

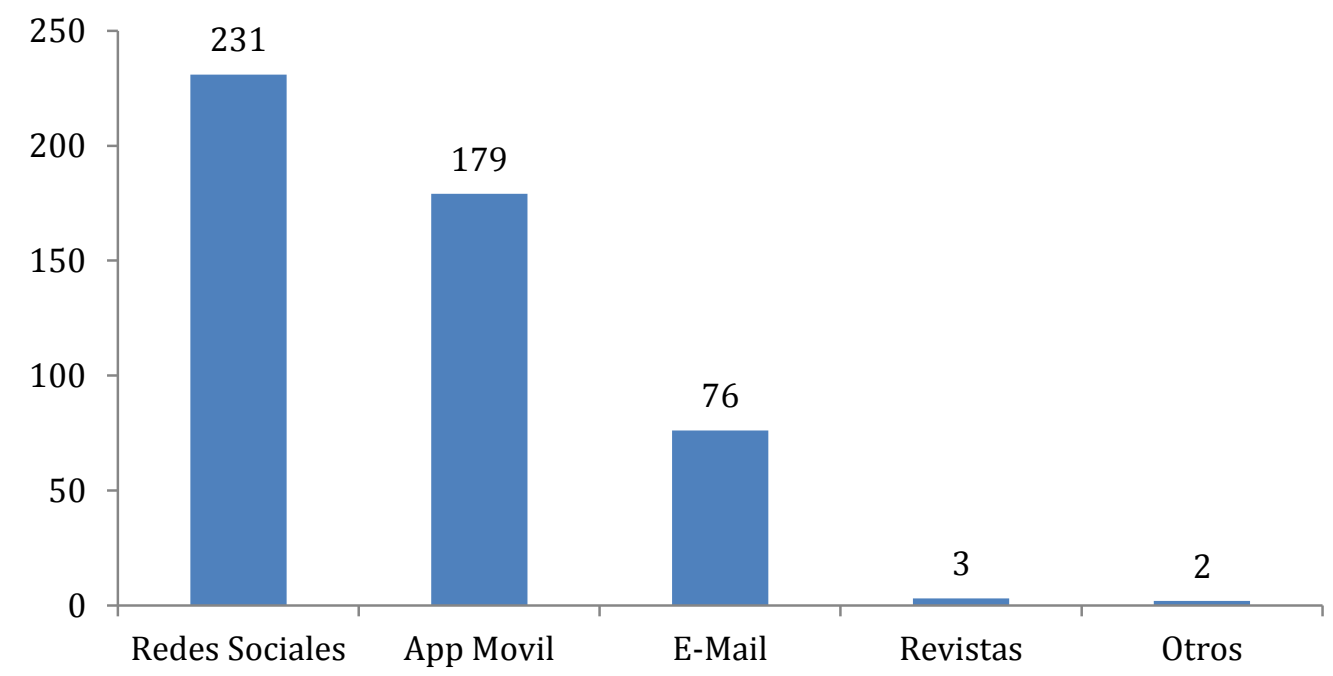

Figura 38. Preferencia de uso de medios de comunicación

Los resultados de cada pregunta del cuestionario se encuentran en el Apéndice 39.

\subsection{Conclusiones y Recomendaciones del Estudio Cualitativo y Cuantitativo}

\section{Estudio cualitativo}

\section{Focus Group}

Conclusiones

1. Los pobladores del distrito de Ate conocen de la problemática de la obesidad; tanto en los factores que la ocasionan como de las posibles consecuencias que esta puede derivar.

2. Asimismo, hay una tendencia fitness que se está cultivando de manera individual; pero que aún no llega a su máximo desarrollo debido a que no hay una conciencia saludable en razón a la práctica de alguna actividad física.

3. Se evidencia que el CrossFit es una actividad física que no ha sido inculcada en el sector.

4. La accesibilidad a un centro de entrenamiento es indispensable para el cliente; esto último, en razón a que uno de los 7 participantes había acudido a una clase de prueba, pero desistió en continuar; debido a que, el box de CrossFit se encontraba lejos de su zona de tránsito.

5. La percepción del CrossFit como una actividad física apta para toda persona aún no es clara; puesto que, se evidenció que los participantes tenían una noción distinta del 
deporte y lo asociaban únicamente a campeonatos o especial para los deportistas profesionales.

6. Queda evidenciado el un nivel de interés de los participantes en realizar una clase de CrossFit.

Recomendaciones

1. Aperturar el box de CrossFit en una zona accesible y de alto tránsito peatonal.

2. Invertir en un publicidad a través de redes sociales enfatizando el CrossFit como actividad física apta para todos.

3. Promocionar al CrossFit como la opción más viable para mejorar las capacidades física de la persona.

\section{Entrevistas a profundidad}

Conclusiones

1. Las personas que viven en Ate, no encuentran ofertas de box de CrossFit cercana a sus domicilios.

2. Se percibe que la proliferación de negocios como gimnasios tradicionales ha denotado un desinterés en el cliente, ya que se ha convertido en una guerra de precios, sin pensar en la satisfacción del cliente.

3. Hay poco seguimiento de los gimnasios tradicionales hacia sus clientes, solo se preocupan en el pago de sus membresías mas no de sus avances.

4. La ubicación de negocios similares al CrossFit se da en zonas comerciales o muy populares.

Recomendaciones

1. Hay un conocimiento superficial del CrossFit, por lo que es importantes ofrecer clases de prueba como estrategia de apertura.

2. Considerar la ubicación del negocio en una zona de fácil acceso y cercana al público objetivo.

3. Mostrar una real preocupación por el cliente.

\section{Entrevistas a expertos}

Conclusiones

1. Las personas entrevistadas son conscientes del desarrollo y progreso del CrossFit en Lima, esto debido al crecimiento de la cultura fitness, sumado a la orientación del mercado a tener cuidado de su salud a través de ejercicio y la sana alimentación. 
2. Se resalta que este tipo de negocio ofrece un valor distinto al que ofrecen los gimnasios tradicionales, ya que estos últimos no tienen un interés sobre el avance de sus clientes, solo en acumular membresías.

3. Las barreras de entrada para este tipo de negocio no son altas, ya que, a diferencia de los gimnasios, la inversión en los negocios tipo CrossFit requiere mucho menos inversión en equipamiento, lo cual se considera una ventaja.

4. Se considera la ubicación del negocio como un factor importante de éxito.

5. Los tiempos de implementación para la puesta en marcha de este tipo de negocios es corta, no superando los 4 o 5 meses.

6. El uso de redes sociales es un factor común con el mercado que concurre a los negocios Fitness, por lo que resulta un canal importante para el conocimiento del mismo.

7. Como segundo canal de difusión del negocio, se encuentra la recomendación, ya que el "correr la voz" de un buen negocio de este tipo puede ayudar, luego de las redes sociales.

8. Para lograr un resultado positivo en el negocio, es importante escuchar y conocer a los clientes con el fin de poder brindarle un servicio acorde a sus necesidades.

Recomendaciones

1. Definir correcta y específicamente el mercado objetivo del negocio.

2. Buscar una ubicación idónea y acorde a la definición del mercado objetivo.

3. Apalancar la diferenciación del negocio con la licencia CrossFit como metodología de entrenamiento.

4. Utilizar una estrategia de acercamiento a los clientes a través de canales como las redes sociales y la recomendación.

5. Contar con personal capacitado en habilidades blandas que permitan conocer y escuchar activamente a los clientes.

\section{Estudio cuantitativo}

Conclusiones

1. Existe un mercado desatendido en el distrito de Ate, que ofrece la viabilidad para la puesta en marcha de un modelo de negocio como el Box de CrossFit.

2. El primer trimestre de cada año son los meses que un negocio como el Box de CrossFit recibe mayor demanda.

3. El segundo trimestre de cada año son los meses que un negocio como el Box de CrossFit recibe menor demanda. 
4. El pago mensual que el público objetivo estaría dispuesto o actualmente paga en un negocio similar oscila entre S/ 150.00 a S/ 300.00 mensuales.

5. La ubicación y la disponibilidad de horarios son los principales factores para que el cliente potencial pueda inclinarse a decidir por asistir a un centro de entrenamiento.

6. La membresía mensual es la más preferida por los clientes potenciales, seguida por el tipo trimestral.

7. Se presenta un alto nivel de aceptación a la idea de negocio propuesta en el segmento de mercado definido.

8. La ubicación del negocio debe ser alejado de zonas populares del distrito y de fácil acceso.

9. La frecuencia de uso y visita al negocio propuesta es diaria, considerando visitas de lunes a viernes.

10. Se ha encontrado picos de afluencia de público en horarios diurnos, entre las 07:00 horas y las 09:00 horas, y nocturnos, entre las 18:00 y 22:00 horas.

11. Hay alta preferencia de uso de redes sociales para dar a conocer el negocio, así como para mantener informado de horarios y temas anexos a los clientes potenciales.

Recomendaciones

1. Implementar la idea de negocio dirigido al segmento A, B y C del distrito de Ate.

2. Definir estrategias de precios de acuerdo a la estacionalidad de asistencia de los clientes potenciales.

3. Definir una estrategia de diferenciación vinculada a ofrecer un servicio de alto valor a los clientes potenciales.

4. Encontrar una ubicación idónea para la implementación del negocio, considerando la cercanía a los segmentos de mercado definidos.

5. Aprovechar el tipo de membresía preferida por los clientes potenciales y utilizarlo en estrategias de precio y promoción.

6. Dimensionar el equipamiento para soportar la visita diaria de clientes en horarios pico, diurnos y nocturnos.

7. Explotar medios de difusión a través de redes sociales. 


\subsection{Perfil del Consumidor Tipo y sus Variantes}

Del análisis de la investigación, se ha podido determinar lo siguiente:

1. Ate CrossFit debe operar en un zona colindante a los distritos de Santa Anita y La Molina; debido a que son zonas de alto tránsito peatonal y accesible.

2. Las empresas del sector fitness, están enfocadas en brindar servicios complementarios; por tanto, el CrossFit debe enfocarse en una estrategia que permita diferenciarla de los demás centros de entrenamiento; en razón a las necesidades de los clientes, proponiéndoles un nuevo estilo de vida para combatir la obesidad mediante un fitness amplio, general e integral. 


\section{Capítulo IV: Proyección del Mercado Objetivo}

El estudio de mercado se define como una clase de investigación descriptiva (tipo de investigación incuestionable que tiene como objetivo cardinal la descripción de algo, generalmente las características o funciones del mercado), del mismo modo, son también: los estudios de participación, los estudios de análisis de ventas, los estudios de imagen, entre otros (Malhotra, 2008).

Igualmente, se consideró importante indicar que los términos estudio de mercado y estudio de marketing son utilizados de forma indistinta. Sin embargo, algunos autores intentan diferenciarlos; según ésta teoría, los estudios de mercado estudian propiamente los mercados y son un tipo de estudio de marketing, así como lo son los estudios de publicidad, de consumo.

Un estudio de mercado es una actividad de mercadotecnia que tiene la finalidad de ayudarle a tomar decisiones en situaciones de mercado específicas. Por ejemplo, para elaborar un pronóstico de ventas (para 1 año, 1 semestre o una temporada específica) el mercadólogo necesita conocer el tamaño actual del mercado meta, y para ello, necesita realizar un estudio de mercado que le permita obtener ese importante dato.

En este capítulo se proyectará el mercado objetivo al que se pretende dirigir los productos y servicios que se analizan en este plan de negocios. Esta información permitirá implementar dentro del plan de negocios una adecuada propuesta de valor realmente dirigida a estos consumidores. Esta proyección del mercado objetivo se realizará en base a información de la población del distrito de Ate.

Para la proyección del público objetivo se utilizó el método de proyección lineal. En los siguientes puntos del presente capítulo se han detallado los pasos para llegar a conocer el mercado objetivo. En cada uno de esos puntos se explicará cuál será el factor diferenciador y qué camino se consideró para lograr el éxito del negocio. Asimismo se ha establecido un plan de ingresos idóneo, el cual se enfoca en el objetivo de ventas. Para finalizar, es importante mencionar que todo negocio basado en el cliente debe tener una política de servicio y garantías que le brinde solidez a sus estrategias de marketing.

\subsection{El ámbito de la Proyección}

Para éste estudio, el ámbito de la Proyección se delimita al distrito de Ate, el cual actualmente tiene una población total de 599 mil 196 habitantes. En Ate la población económicamente activa representa un $58.5 \%$ lo cual es un buen signo de dinamismo económico y de mercado con buen potencial para poner un negocio, ya que hay poca población desempleada. 
El distrito de Ate fue definido para poder implementar el presente plan de negocio en base a los siguientes criterios:

- De conformidad con la Encuesta Demográfica y de Salud Familiar (ENDES, 2016) Ate es el tercer distrito de Lima, después de San Juan de Lurigancho y Comas con mayor índice de obesidad en su población.

- Hay poca oferta de servicios similares en la zona circunscrita para su implementación.

- Según el portal inmobiliario Urbania para el diario El Comercio (2018), el precio de alquiler por metro cuadrado en éste distrito se encuentra entre los más económicos de Lima Metropolitana.

- Como se observó en los resultados de la aplicación de nuestros cuestionario (ver Apéndice 39), existe un nicho de mercado de los NSE A, B y C que pueden acceder a asumir un pago relacionado al servicio que ofrecemos.

Habiendo explicado los criterios, en la Figura 39 se presenta la población proyectada al 2018 del distrito de Ate.

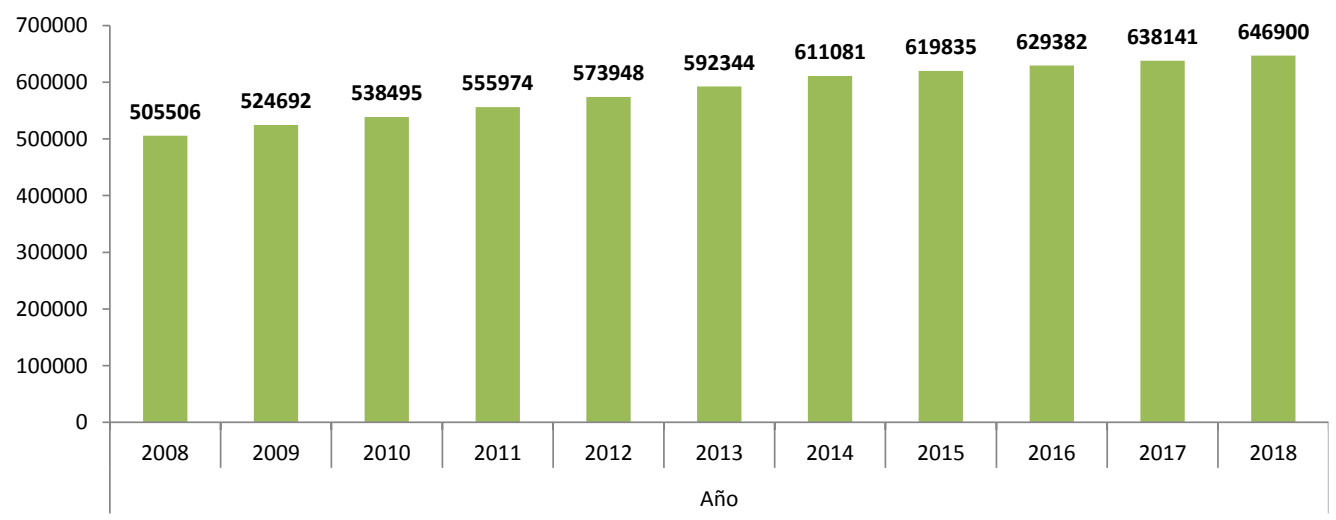

Figura 39. Proyección de la población del distrito de Ate. Tomado de "Boletín Estadístico Municipal de Ate 2011”. Por Municipalidad de Ate, 2011. Recuperado de http://www.muniate.gob.pe/mwginternal/de5fs23hu73ds/progress?id=MYFt7-AwnwgHd6q8DL4yERLueXEMpyilbXWYbhnEurs

\subsection{Selección del Método de Proyección}

El método de proyección empleado es el de la regresión lineal, el cual como su nombre indica, permite proyectar la población del distrito de Ate en base a una tendencia lineal según los datos históricos que se tienen de la población. Para reducir los niveles de error (probabilidad de que la función lineal no proyecte de manera adecuada a la población), se establece como parámetro que el coeficiente de determinación (R cuadrado) debe ser mayor o igual a 0.9 . 
La proyección de la población se realizó a partir del año 2018 (año 0 para efectos del estudio) y se prolongó hasta el año 2023, teniendo así que se está evaluando el proyecto por un periodo de 5 años (ver Figura 40). Asimismo, en la Tabla 20 se aprecia la proyección de la población de Ate en número de personas.

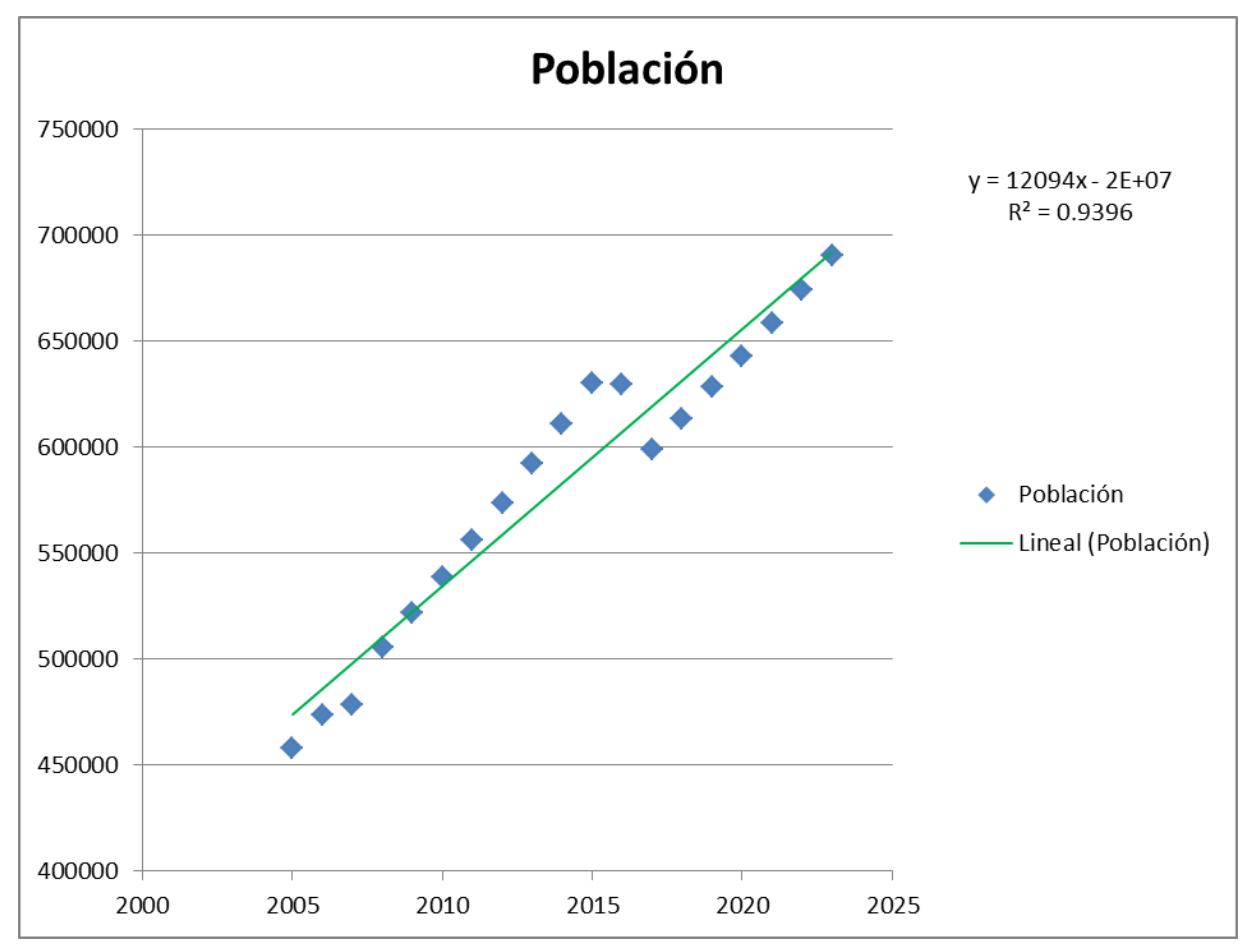

Figura 40. Regresión Lineal de la Población de Ate 2005-2022. Adaptado de "Boletín Estadístico Municipal de Ate 2011". Por Municipalidad de Ate, 2011. Recuperado de http://www.muniate.gob.pe/mwginternal/de5fs23hu73ds/progress?id=MYFt7-AwnwgHd6q8DL4yERLueXEMpyilbXWYbhnEurs

Tabla 20 Población Proyectada del año 2018 al 2022

\begin{tabular}{ll}
\hline Año $1=2018$ & 613,517 \\
Año 2 $=2019$ & 628,180 \\
Año 3 $=2020$ & 643,193 \\
Año 4 $=2021$ & 658,566 \\
Año 5 $=2022$ & 674,305 \\
\hline
\end{tabular}

\subsubsection{Mercado potencial}

"La segmentación de mercados divide un mercado en distintos grupos de compradores con diferentes necesidades, características o conductas, quienes podrían requerir productos o mezclas de marketing específicos" (Kotler y Keller, 2012, p. 217). El mercado potencial se refiere a aquella parte de la población que tiene una necesidad en el producto/servicio ofrecido y que tiene los recursos necesarios para adquirirlo. En este caso, como ya se definió, 
el mercado potencial (ver Tabla 24) se acota a la población del distrito de Ate pertenecientes a los NSE A, B y C y que oscilen en edades entre los 18 y 60 años. Para comenzar, se revisó el mercado total del Distrito de Ate 2018 al 2022 (ver Tabla 21).

Tabla 21

Proyección de la población total de Ate al 2022

\begin{tabular}{lccccc}
\hline Distrito & 2018 & 2019 & 2020 & 2021 & 2022 \\
\hline Ate & 613,517 & 628,180 & 643,193 & 658,566 & 674,305 \\
\hline
\end{tabular}

Luego de contar con ésta información, se requirió información de la representatividad de población que pertenezca a los Niveles Socio Económicos A, B y C, información que sirvió para ponderar su participación de acuerdo al estudio de APEIM (2018) NSE 2017 (Ver Tabla 22).

Tabla 22

Niveles Socioeconómicos de Ate 2017

\begin{tabular}{lccccc}
\hline Nivel A & Nivel B & Nivel C & Nivel D & Nivel F & A+B+C \\
\hline $1 \%$ & $18 \%$ & $47 \%$ & $27 \%$ & $7 \%$ & $66 \%$ \\
\hline
\end{tabular}

Del mismo modo, para deterinar la población únicamente entre las edades de 18 a 60 años, se investigó a la población según grupos quinquenales de edad y en función a la totalidad de población (ver Tabla 23), cifra proveniente del Boletón especial № 18 del INEI (2009).

Tabla 23

Porcentaje de Edades en el Distrito de Ate

\begin{tabular}{lllllllllll}
\hline Edad & $18-19$ & $20-24$ & $25-29$ & $30-34$ & $35-39$ & $40-44$ & $45-49$ & $50-54$ & $55-59$ & Total \\
\hline
\end{tabular}

$\begin{array}{lllllllllll}\text { Ate } & 2.9 \% & 7.6 \% & 8.3 \% & 9.7 \% & 7.4 \% & 6.6 \% & 1.4 \% & 1.8 \% & 1.4 \% & 47 \%\end{array}$

Nota: Adaptado de "Boletin especial $N^{\circ} 18$ ", por Instituto Nacional de Estadística e Informaática, 2009, Lima, INEI. Copyright 2015 por INEI, recuperado de http://proyectos.inei.gob.pe/web/biblioineipub/bancopub/Est/Lib0842/index.htm

Finalmente, para calcular el mercado potencial, se multiplicó la población de Ate estimada en la Tabla 21, por la sumatoria de porcentajes obtenidas de los NSE A, B Y C (ver Tabla 22) por el valor porcentual total de edades de la Tabla 23; cuyo resultado final se encuentra en Tabla 24. 
Tabla 24

Mercado Potencial de Ate al 2022

\begin{tabular}{|c|c|c|c|c|c|}
\hline Distrito & 2018 & 2019 & 2020 & 2021 & 2022 \\
\hline \multirow[t]{3}{*}{ Ate } & 613,517 & 628,180 & 643,193 & 658,566 & 674,305 \\
\hline & \multicolumn{5}{|c|}{ Población * 66\% (NSE A, B y C)* 47\% (Edad 18-60 años) } \\
\hline & 190,637 & 195,193 & 199,858 & 204,635 & 209,526 \\
\hline
\end{tabular}

Con fines académicos y dadas las limitantes que presenta el plan de negocio, se ha empleado la técnica de muestreo no probabilístico por conveniencia. Malhotra (2008) señala que "el muestreo no probabilístico no se basa en el azar, sino en el juicio personal del investigador para seleccionar a los elementos de la muestra" (p. 340)

\subsubsection{Mercado disponible}

De acuerdo con Kotler y Keller (2012) "es el conjunto de consumidores que tienen interés, ingresos y acceso a una oferta particular" (P. 85). En el presente caso, aquella población de ate que tiene interes en realizar alguna actividad física y cuenta con los recursos. Para hallar el mercado disponible (ver Tabla 25) se utilizó información propia de la aplicación del estudio de mercado cuantitativo, usando la pregunta filtro número dos (02) del cuestionario, ¿Usted realiza alguna actividad física? (ver Apéndice 38). Se obtuvo como resultado que el 35.8\% de la población encuestada sí realiza alguna actividad física (ver Apéndice 39).

Con lo indicado se procedió a realizar el cálculo para conocer el mercado disponible la cual se aprecia en la Tabla 25. Esto es, mercado disponible es igual a mercado potencial multiplicado por el $35.8 \% \%$ de personas que realiza alguna actividad física.

Tabla 25

Mercado Disponible Proyectado al 2022

\begin{tabular}{lccccc}
\hline Distrito & 2018 & 2019 & 2020 & 2021 & 2022 \\
\hline Ate & 190,637 & 195,193 & 199,858 & 204,635 & 209,526 \\
& & & $35,8 \%$ & & \\
& 68,248 & 69,879 & 71,549 & 73,259 & 75,010 \\
\hline
\end{tabular}

\subsubsection{Mercado efectivo}

El mercado efectivo es la proporción del mercado disponible que acepta la oferta de servicio que se está brindando, se encuentra en capacidad de adquirir esta propuesta y además muestra la mayor certeza de compra o consumo del producto. Para determinar este mercado se ha utilizado nuestro estudio cuantitativo de mercado (ver Figura 39). 
Se empleó el resultado proveniente de la pregunta 20 del cuestionario, ¿Estaría dispuesto a a asistir a este tipo de entrenamiento? en razón a la propuesta del CrossFit (ver Apéndice 38). Se obtuvo como resultado que el $31.1 \%$ de la población encuestada definitivamente asistiría a hacer crossfit (ver Apéndice 39); de esta manera, se evita caer en una sobreestimación del mercado efectivo. Asimismo, a ese porcentaje se le hace un ajuste de intención de compra; esto es, según Mc Daniel (2015) para hacer más real y conservador el cáculo de la intención de compra; por tal motivo, se le aplica un castigo del 65\%; misma que el citado autor detalla, en su libro Investigación de Mercados (p. 257). Por ende, el mercado efectivo es igual al mercado potencial multiplicado por el porcentaje de mayor certeza en la asistencia al local que se planea abrir y por el índice Mc Daniel. Dicho esto, el mercado efectivo proyectado se muestra en la Tabla 26.

Tabla 26

Mercado Efectivo Proyectado

\begin{tabular}{lccccc}
\hline Distrito & 2018 & 2019 & 2020 & 2021 & 2022 \\
\hline Ate & 68,248 & 69,879 & 71,549 & 73,259 & 75,010 \\
& & $31.1 \% * 0.65=0.20$ & & \\
& 13,796 & 14,126 & 14,464 & 14,809 & 15,163 \\
\hline
\end{tabular}

\subsubsection{Mercado objetivo}

El mercado objetivo se define como aquel grupo de consumidores al que se dirigirá directamente el proyecto; es decir, se refiere al alcance específico de un negocio, considerando las restricciones que tenga este como tamaño, disponibilidad de recursos, entre otros. Así pues, el mercado objetivo es la proporción del mercado efectivo al que atenderá "Ate CrossFit".

Considerando que se trata de un negocio nuevo se ha tomando una participación inicial del 1.04\% para el año base 2018 (ver Tabla 27). Para hallar el crecimiento de la participación de mercado del periodo de evaluación se tomó como referencia el promedio de crecimiento en los últimos 11 años del PBI del sector "Otros servicios” al cual pertenece el negocio evaluado, el cual es $6.5 \%$.

Tabla 27

Porcentaje de Participación Proyectado

\begin{tabular}{cccccc}
\hline Participación & 2018 & 2019 & 2020 & 2021 & 2022 \\
\cline { 2 - 6 } & $1.04 \%$ & $1.11 \%$ & $1.18 \%$ & $1.25 \%$ & $1.34 \%$ \\
\hline
\end{tabular}


Así pues, el mercado objetivo será igual a la participación de cada año multiplicada por el mercado efectivo de dicho año (ver Tabla 28).

Tabla 28

Participación de Mercado

\begin{tabular}{lccccc}
\hline Distrito & 2018 & 2019 & 2020 & 2021 & 2022 \\
\hline Ate & 13,796 & 14,126 & 14,464 & 14,809 & 15,163 \\
& $1.04 \%$ & $1.11 \%$ & $1.18 \%$ & $1.25 \%$ & $1.34 \%$ \\
& 143 & 156 & 170 & 186 & 203 \\
\hline
\end{tabular}




\section{Capítulo V: Plan de Marketing}

En este capítulo se revisarán las estrategias de marketing las cuales permitirán estructurar el ingreso correcto en el mercado objetivo al que apunta en el presente plan de negocios. Se realizará una evaluación del marketing mix: producto, precio, promoción y publicidad, personas, productividad, evidencia física y procesos.

Como Kotler (2008) lo indica, haciendo referencia a Porter (1980), existen estrategias básicas de posicionamiento, entre las que destacan:

- Liderazgo en costos,

- Enfoque

- Diferenciación.

Es justamente ésta última la que se consideró de mejor aplicación para el plan de negocio propuesto. En cada uno de los siguientes puntos se explica cuál será el factor diferenciador y qué camino se consideró para lograr el éxito del negocio. Asimismo se definió un plan de ventas idóneo, el cual consolida las estrategias anteriores enfocándose en el objetivo de ventas. Para finalizar, es importante mencionar que todo negocio basado en el cliente debe tener una política de servicio y garantías que le brinde solidez a sus estrategias de marketing.

\subsection{El ámbito de la Proyección}

\subsubsection{Estrategia de producto}

El nombre de la empresa es 'Ate CrossFit', éste nombre denota que se trata de un Box ubicado en un lugar del distrito de Ate, destinado a ser una nueva alternativa para realizar una rutina de ejercicios bajo el modelo CrossFit, lugar para encontrarse con un ambiente amigable, cálido y donde encontrará un servicio personalizado para lograr un mejor estilo de vida, combatiendo la obesidad en ésta zona de la capital.

Según la matriz de estrategias genéricas de Porter (1987), la que se usará es la de diferenciación, tal y como se aprecia en la Figura 41. La diferenciación que se quiere lograr está altamente relacionada a la excelencia en el servicio, lo cual permita ser considerado como Box de CrossFit más recordado en Ate. 
Ámbito competitivo

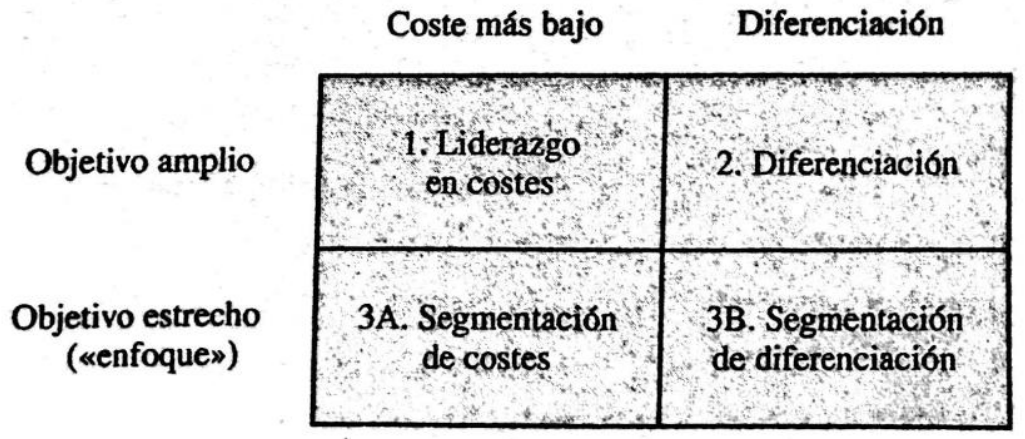

Figura 41. Matriz de estrategias genéricas. Tomado de Ventaja Competitiva: Creación y Sostenibilidad de un Rendimiento Superior (p. 40), por Michael Porter, 1987, Madrid: Ediciones Pirámide. Copyright 1987, 2002 por Michael Porter.

Con este plan de negocio, Ate CrossFit propone diferenciarse ofreciendo un servicio novedoso con el respaldo de una metodología patentada e invitando a nuestros clientes a llevar un estilo de vida fitness resaltando los beneficios de ello. Este grupo personas tendrán un régimen de ejercicio bajo la metodología CrossFit; puesto que, buscan mantener un estado físico, mental y biológico saludable. La oferta de "Ate CrossFit" estará principalmente conformada por el desarrollo del WOD, personalizándose en la intensidad de su ejecución en base al conocimiento del perfil y motivaciones del propio cliente. En la Figura 19 hay un ejemplo de sesión de entrenamiento CrossFit.

Respecto al diferencial de éste negocio, los aspectos considerados valiosos por los asistentes a éste Box de CrossFit son la capacitación del personal y los seguimientos respecto a los avances que los clientes puedan presentar en su constante asistencia al mismo.

Los coaches estarán capacitados en cuanto a la metodología para así absolver todas las dudas que pueda presentar el cliente. Se hace hincapié en este punto debido a la importancia que el público del focus group le dieron a este aspecto al momento de asistir a un establecimiento dónde ejercitar su físico; del mismo modo, prefieren que se trate de un servicio personalizado, cercano y que la persona que se encargue de su entrenamiento lo conozca y sea capaz de definir sus límites, motivándolos a superarlos. La capacitación se hará a manera de inducción inicialmente y luego se irán dando charlas mensuales con el head coach para que conozcan más acerca de la metodología utilizada en la rutina, información nutricional y las variantes que se puedan dar en la interacción con los clientes. Se buscará incentivarlos haciéndolos sentir parte de la organización, dándole importancia a sus aportes, y además, con reconocimientos dentro del negocio.

Si bien es cierto ya existen ofertas de negocios con similar core business; sin embargo, estos no son muy conocidos, ni están debidamente posicionados en el mercado. Asimismo, la 
cantidad de oferta es poca en comparación a una demanda creciente por este tipo de servicios.

Por otro lado, para optimizar la atención, se propondrá al coach conocer al cliente de forma que pueda identificar sus intereses y motivaciones por la nuestros clientes asisten a nuestro box de CrossFit, de ésta forma se podrán crear iniciativas que puedan satisfacer los diversos perfiles que acudirán. Asimismo, se utilizará elementos de marketing sensorial para lograr una identificación del cliente para con "Ate CrossFit" buscando vincular sus sentidos al negocio (olores, música, temperatura ambiental y colores de las distintas ubicaciones de nuestro negocio).

\subsubsection{Estrategia de precio}

Como señala Kotler (2008), las estrategias de fijación de precios suelen cambiar conforme el producto atraviesa su ciclo de vida. En tal sentido, el inicio de la operación puede resultar muy retador, para lo cual se considera dos estrategias generales: inicialmente definir un precio para penetrar en el mercado y posteriormente determinar un precio para el segmento más alto del mismo. El precio del servicio puesto a disposición del cliente incluye el IGV, para lo cual se han tomado en cuenta los siguientes aspectos:

\section{El Mercado}

Luego del análisis de nuestra investigación cuantitativa (mediante cuestionarios) y cualitativa (focus group, entrevistas de profundidad y entrevistas a expertos) se puede concluir que el mercado al que Ate CrossFit apunta atender está dispuesto a realizar un pago promedio mensual; tal y como se señala en la Figura 29.

\section{Los Competidores}

Los competidores ya presentes en el mercado, principalmente substitutos, ofertan un amplio y diverso rango de precios, tal como se pudo observar en el resultado de nuestro estudio de mercado.

\section{Costos}

Es importante para la determinación de la estrategia de precio, tener una detallada definición de todos los factores que intervienen para el ofreciendo del servicio ideal, incluyendo los costos tanto directos e indirectos que se necesitan para lograrlo. Todo éste detalle será debidamente explicado en el capítulo correspondiente.

\section{La Estrategia}

Se ha considerado que, dada la concepción de servicio y con los factores diferenciales que Ate CrossFit va ofrecer, la estrategia ideal es la de descreme (ver Tabla 29), que de conformidad con Goñi (2013) “este tipo de precio generalmente se utiliza en el caso de 
nuevos productos o cuando el mercado percibe ventajas que no son proporcionadas por otro producto" (p. 21).

Tabla 29

Estrategia de Descremes

\begin{tabular}{|c|c|c|c|}
\hline \multirow[b]{2}{*}{ Calidad del Servicio } & \multicolumn{3}{|c|}{ Precio } \\
\hline & Alto & Medio & Bajo \\
\hline Alta & Estrategia superior & $\begin{array}{l}\text { Estrategia de alto } \\
\text { valor }\end{array}$ & $\begin{array}{l}\text { Estrategia de valor } \\
\text { superior }\end{array}$ \\
\hline Media & $\begin{array}{l}\text { Estrategia de precio } \\
\text { excesivo }\end{array}$ & $\begin{array}{l}\text { Estrategia de valor } \\
\text { medio }\end{array}$ & $\begin{array}{c}\text { Estrategia de valor } \\
\text { bueno }\end{array}$ \\
\hline Baja & $\begin{array}{c}\text { Estrategia de } \\
\text { ganancia violenta }\end{array}$ & $\begin{array}{l}\text { Estrategia de } \\
\text { economía falsa }\end{array}$ & $\begin{array}{l}\text { Estrategia de } \\
\text { economía }\end{array}$ \\
\hline
\end{tabular}

Nota: Adaptado de "Fundamentos de Marketing" (p. 246), por Santon, 1995, México, The McGraw-Hill Interamericana. Copyright 1995 por The McGraw-Hill Interamericana.

\section{Formas de Pago}

El servicio podrá ser pagado de tres maneras: En efectivo, cargo en tarjeta de débito y/o cargo en tarjeta de crédito.

En consecuencia de lo explicado, la estrategia de precio propone definir el precio de mercado en un rango de entre S/ 250.00 y S/300.00 soles; esto para que permita manejar una estrategia de promoción que será explicanda más adelante.

\subsubsection{Estrategia de plaza y distribución}

Ate CrossFit es una empresa que distribuye servicios; por tanto, la importancia de la ubicación es indispensable para la rentabilidad de la misma. En este caso, son los clientes quienes acuden al establecimiento; por lo cual se empleará la estrategia de distribución directa sin la intervención de algún intermediario.

\section{Ubicación}

Para definir la estrategia de plaza y distribución, se ha considerado a la ubicación del negocio. Según la información del portal del Sistema de Información Geográfica para Emprendedores (SIGE) de INEI, se consideró como el lugar idóneo, aquella colindante a los distritos de Santa Anita y La Molina, dado que se verifica una aglomeración importante de aquellos segmentos poblacionales a los que trazó como objetivo (ver Figura 42). 


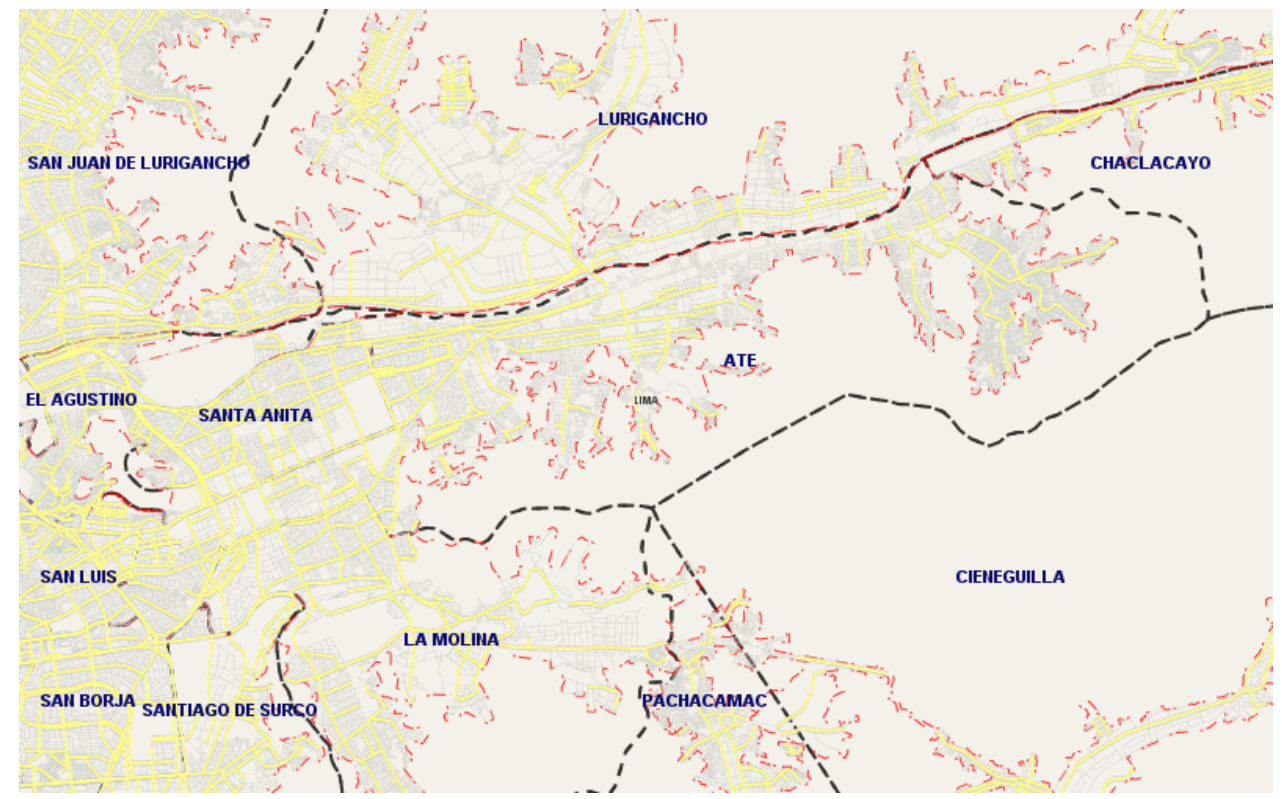

Figura 42. Mapa de ubicación geográfica de Ate. Tomado de "Sistema de Información Geográfica para Emprendedores", por el Instituto Nacional de Estadística e Informática (INEI), 2018, recuperado de http://sige.inei.gob.pe/sige/

Ate CrossFit se ubicará en la Calle Los Talladores $N^{\circ} 151$ - Distrito de Ate, el cual se encuentra a pocas cuadras del óvalo de Santa Anita; zona aledaña a centros comerciales tales como Wong y Promart; así como a empresas de servicios y centros de estudios con abundante afluencia de público; debido a la cercanía con la Avenida Separadora (ver Figura 43). En la Figura 44, se aprecia la fachada del local donde se aperturará Ate CrossFit, el cual cuenta con 10 metros de frento por 30 de fondo.

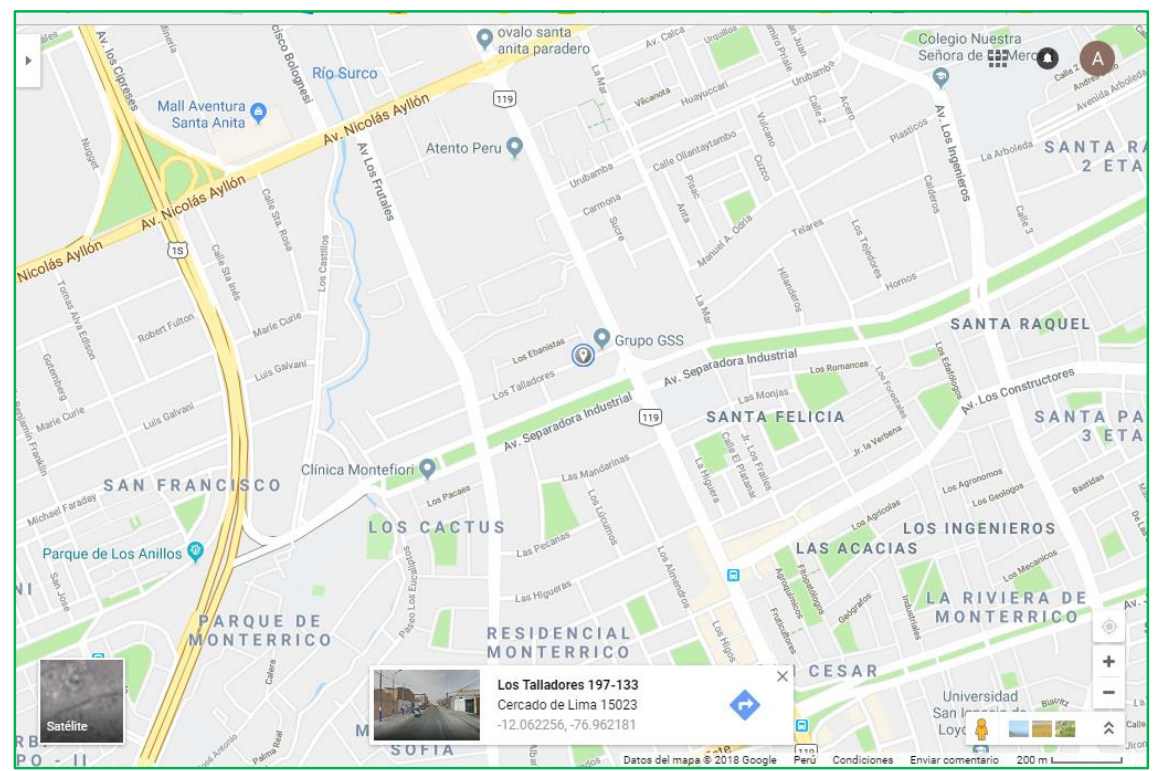

Figura 43. Mapa de ubicación geográfica de Ate Tomado de "Google Maps", por el Google, 2018, recuperado de https://www.google.com/maps 


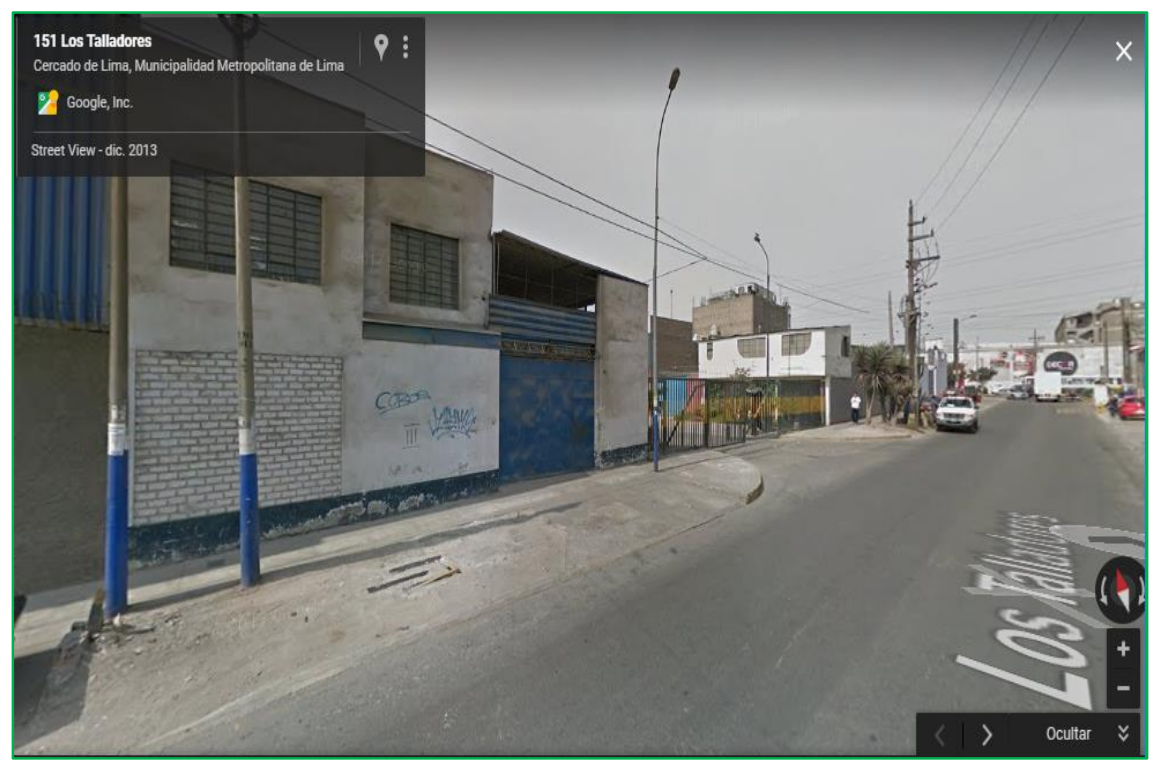

Figura 44. Street view frontis de local. Tomado de "Google Street View", por Google, 2018, recuperado de https://www.google.com/maps

\section{Características del Box}

El lugar manejará una distribución muy simple, acorde a la metodología CrossFit, con ambientes diseñados para la realización de las rutinas, descanso, vestidores y servicios higiénicos tanto para varones y mujeres (ver Figura LayOut). Se tomó la decisión de poner en marcha el negocio en éste lugar por ser considerada una zona céntrica dentro del distrito, así como el dinamismo y tránsito de público en la misma.

\subsubsection{Estrategia de promoción y publicidad}

Respecto a la publicidad, se considera necesario remitir la información que brinda el estudio de mercado; donde se muestra que, las redes sociales son el canal de promoción con mayor aceptación para los clientes (ver Figuras 45 y 46)

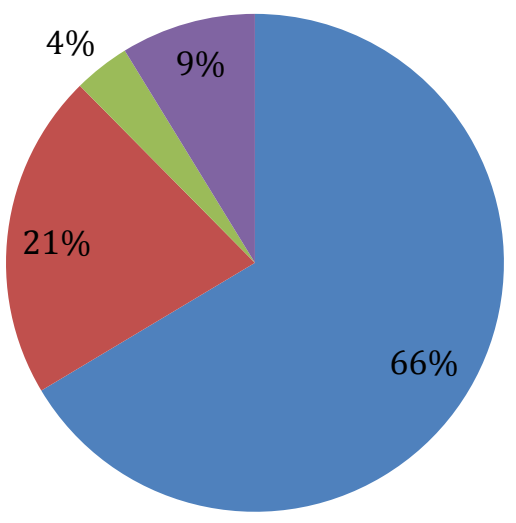

Redes Sociales

- Periodicos

E-mail

- Pagina web

Figura 45. Preferencia de canal de comunicación del centro de entrenamiento. 


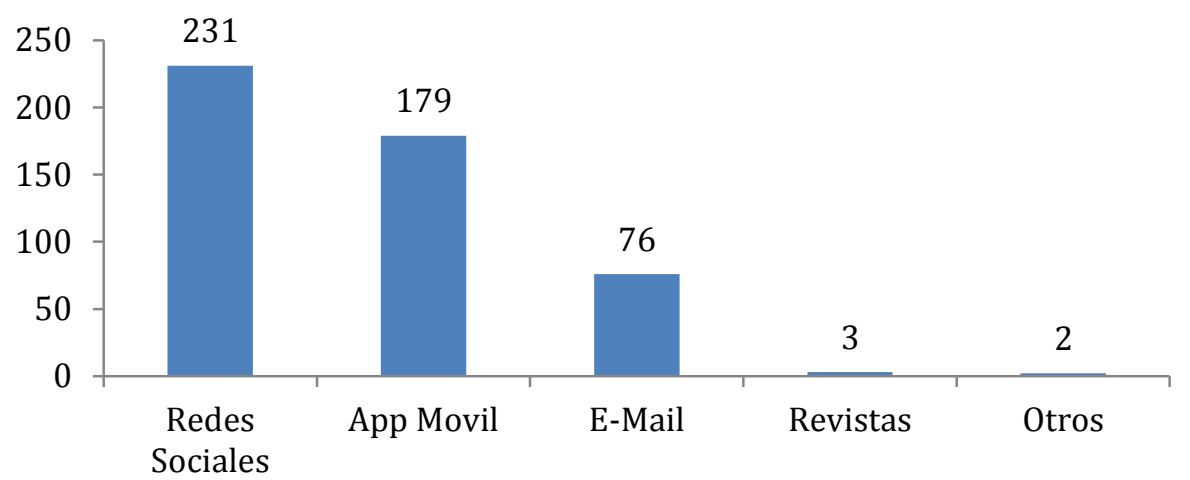

Figura 46. Preferencia de canal de comunicación para box de CrossFit. Pregunta 28 del cuestionario de indagación. Adaptado de 'recolección de datos del cuestionario'.

El segmento de mercado al cual se dirige Ate CrossFit se mantendrá informada de cualquier acto que esta misma realice a través de medios digitales; esto es, redes sociales como Facebook, Instagram y YouTube; asimismo, se empleará la aplicación móvil Wodifi, y el envío de correos electrónicos con el fin de mantener una interacción fluida con los clientes. Dado que, parte de la metodología del CrossFit está basado en un fitness por evidencia, es decir, la divulgación de la práctica de los ejercicios, resultados, eventos, ejecución de movimientos, Wod's, videos, programas de entrenamiento y artículos de investigación, mediante el internet y redes sociales, teniendo un gran protagonismo los colaboradores (entrenadores, atletas de élite, afiliados y clientes), es pertinente premiar con membresías gratuitas, descuentos en membresías y/o artículos deportivos de CrossFit a aquellos que logren promocionar y recomendar a Ate CrossFit; debido a que, este medio genera un gran margen de ventas. Para ello, se deberá cuantificar la promoción de videos por redes sociales, tomando en consideración el número de seguidores al que ha alcanzado dicha publicación. En ese mismo orden de ideas, se busca generar una relación con el cliente, motivándolo a llevar una vida saludable en su día a día; a través de consejos de cuidados nutricionales y físicos.

De otro lado, se elaborará una página web con características responsables para que sea un canal de captación de leads y generar una base de datos actualizada de clientes. La información básica a publicar en la página web será:

- Misión, visión y valores.

- Staff.

- Promociones

- Nuestro box

- Información y tips nutricionales

- Los Workouts 
- Información de contacto

- Galería de fotos

- Artículos de investigación relacionadas al impacto del CrossFit en la salud.

En cuanto a la promoción de venta, las principales elegidas por el público, según los resultados de la encuesta, son los descuentos en el precio. Para ello, Ate CrossFit ofrece descuentos vinculados al tiempo de afiliación de sus servicios; esto es, descuentos al obtener una membresía por la mayor cantidad de tiempo que contrate, siguiendo el formato que se establece en la Tabla 30.

Tabla 30

Precio de la membresía en Ate CrossFit

\begin{tabular}{ll}
\hline Tipo de membresía & Precio \\
\hline Mensual & S/. 300.00 \\
Trimestral & S/. 290.00 \\
Semestral & S/. 280.00 \\
Anual & S/. 270.00 \\
\hline
\end{tabular}

A manera de vivir la experiencia de la metodología CrossFit, Ate CrossFit contará con una promoción de dos sesiones de prueba gratuitas; para lo cual, se distribuirá invitaciones a quienes dejen sus datos en los canales virtuales, vecinos de la zona y empresas cercanas. Asimismo, la recomendación 'boca a boca' será premiada con membresías gratuitas, descuentos en la compra de cualquier membresía y obtención de artículos deportivos para CrossFit. La recomendación se cuantificará por el número de clientes nuevos que contraten una membresía. Por lo expuesto, en la Tabla 31 se proyecta el presupuesto de estrategias de promoción y publicidad.

Tabla 31

Costo por Concepto de Publicidad al Año

\begin{tabular}{lccc}
\hline Concepto & Frecuencia & Costo unitario & Precio final \\
\hline Material impreso & Trimestral & S/. 200.000 & S/. 800.00 \\
Mantenimiento Web & Mensual & S/. 120.00 & S/. $1,440.00$ \\
Facebook & Mensual & S/. 210.00 & S/. 2,520.00 \\
Participación en eventos & Mensual & & \\
Pago por espacio & Trimestral & S/. $1,000.00$ & S/. 4,000.00 \\
Personal & Trimestral & S/. 200.00 & S/. 800.00 \\
Total & & & S/. 9,560.00 \\
\hline
\end{tabular}




\subsubsection{Estrategia de personas}

Para otorgar una calidad en el servicio y superar las expectativas, Ate CrossFit contará con personal debidamente preparado. Los Coaches deben contar con el CrossFit Level One certificate cuya preparación está basada en temas metodológicos del fitness. Es importante resaltar que todo el personal contará con la indumentaria necesaria para atender correctamente a todos los clientes, debidamente uniformados y especial aseo personal.

Todos los colaboradores contarán con un gafete para que los clientes puedan familiarizarse con ellos sin ningún inconveniente. Asimismo, se establecerá un sistema para dar la bienvenida a todos clientes que acudan al box. El desarrollo de estos puntos es relevante debido a que de ello depende la fidelización de los clientes. De esta forma, el cliente tendrá una experiencia única cada vez que nos visite.

\subsubsection{Estrategia de procesos}

La estrategia de procesos estará enfocada en ofrecer la mejor experiencia al cliente en base a todo el proceso del servicio, el cual se detalla en el capítulo de Ingeniería del proyecto, desde su primer contacto con el Box de CrossFit, para lo cual se ha empleado la herramienta Customer Journey Map. Esto implica que se va a mapear todas las interacciones que tendrían los clientes. El tiempo de atención, espera, así como la satisfacción de cada contacto que tenga con el negocio serán establecidos en pro de ofrecer agilidad, simplicidad y transferencia en todos los procesos, tanto internos como de cara al cliente.

Por otro lado, se sabe que no se debe tener preferencias hacia un cliente en particular; el trato y servicio ofrecido debe ser el mismo hacia todos. Por tanto, la asesoría brindará deberá ser de la manera más exhaustiva, oportuna y óptima para el cliente. Finalmente, se deberá de tener un control continuo de la página web y la página de Facebook. La monitorización de la página web servirá para determinar una automatización para la obtención de datos, esto conlleva a implementar formularios de consultas, satisfacción, encuestas, datos que permita determinar en qué parte del proceso de atención se puede mejorar. Respecto a Facebook, se debe monitorizar las visitas de los clientes, analizar los comentarios para ver el grado de satisfacción, todos estos datos obtenidos ayudarán a procesarlos y a implementar nuevas acciones que generen fidelidad de los consumidores decantando en su recomendación.

\subsubsection{Estrategia de presencia física}

El local ubicado en Ate tendrá una decoración moderna y con muy buena iluminación (tanto natural como artificial), acompañada de materiales reciclados, se usará una paleta de colores relacionada a la vida sana como verdes, granates, cremas, (ver Figura 47); así como, las baldosas de color gris (Ver Figura 48). 


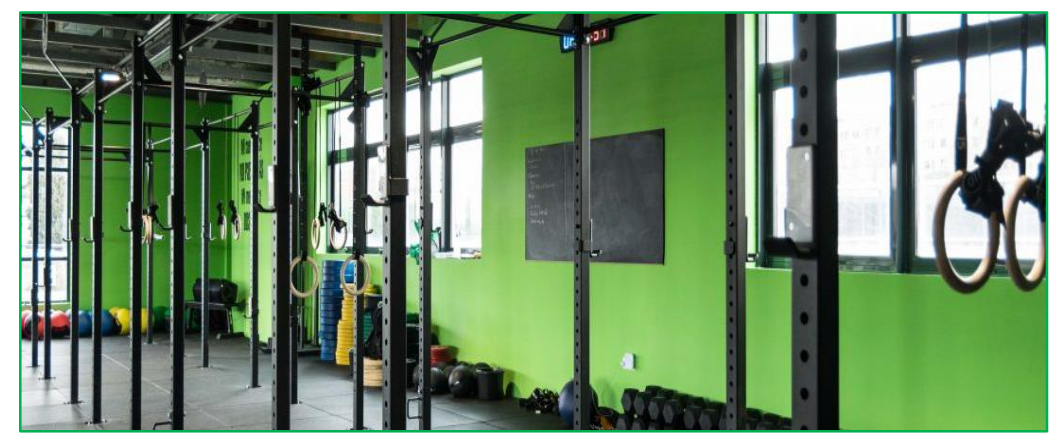

Figura 47. Decoración. Tomado de "CrossFit Affiliates", por CrossFit, Inc., 2018, recuperado de https://www.CrossFit.com

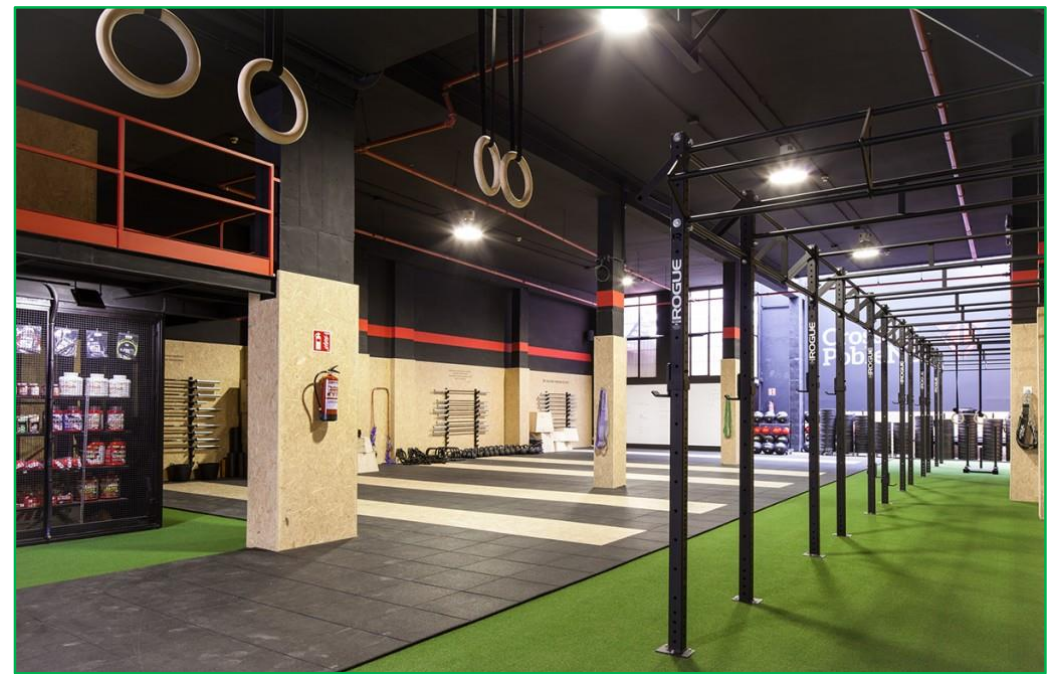

Figura 48. Decoración 2. Tomado de "CrossFit Affiliates", por CrossFit, Inc., 2018, recuperado de https://www.CrossFit.com

\subsection{Estrategia de Ventas}

\subsubsection{Plan de ventas}

Respecto al plan de ventas propuesto, se define tomando en cuenta las estrategias del marketing mix, producto, precio, plaza y promoción. Las ventas se van a impulsar a partir de la invitación a sesiones gratuitas para que los clientes potenciales puedan probar la metodología y engancharse con la calidad de servicio que se le ofrece. Del mismo modo, se tendrá en cuenta la estacionalidad que tienen los negocios de este tipo para manejar los precios a ofrecer; los mismos que se encuentran plasmados en la Tabla 32. 
Tabla 32

Variación de Precios por Estacionalidad

\begin{tabular}{ll}
\hline Mes & Variación \\
\hline Enero & \\
Febrero & $-10 \%$ \\
Marzo & \\
Abril & \\
Mayo & $-10 \%$ \\
Junio & \\
Julio & Sin variación \\
Agosto & \\
Septiembre & \\
Octubre & \\
Noviembre & Sin variación \\
Diciembre & \\
\hline
\end{tabular}

En cuanto a la publicidad, esta debe estar alineada a las promociones que Ate CrossFit ofrecerá a sus cliente; tales como las sesiones gratuitas de introducción y los precios por estacionalidad. Es menester, indicar que se busca utilizar técnicas de venta enfocadas en: revisión continua de las promociones vigentes, realización de campañas publicitarias, otorgar descuentos en fechas específicas, participación en eventos y brindar valor basado en el conocimiento de los clientes para la personalización de los entrenamientos.

Objetivo de venta

Incrementar la participación de mercado de Ate CrossFit en 6.5\% anual.

Estrategia

Se considera que, la personalización de los entrenamientos, como valor agregado, debe llevar a ofrecer descuentos adicionales, segmentar a los clientes, ofrecer planes sin variación por estacionalidad; así como, crear momentos memorables (celebraciones festivas, cumpleaños, días de integración y campeonatos) a través de la comunidad crossfitera que permita brindar un servicio de calidad y superar las expectativas de los clientes.

\section{Tácticas}

La recomendación es la mejor publicidad para el CrossFit; esto, sin quitar la relevancia de comunicar de manera interna y del mercado objetivo, las estrategias arriba mencionadas a través de los principales canales definidos por nuestros propios clientes: redes sociales y página web. 


\subsubsection{Políticas de servicios y garantías}

En Ate CrossFit, la preocupación principal es brindar a los clientes la mejor experiencia de entrenamiento que conlleve a mejorar su estilo de vida. Los principios de política de servicios y garantías de Ate CrossFit son los siguientes:

- Asegurar la fiabilidad de los servicios que se ofrecen. Esto, gracias al fiel cumplimiento de la metodología impuesta por CrossFit, Inc., la cual garantiza que los clientes reciban un entrenamiento acorde a sus motivaciones, y en una intensidad y seguimiento que los lleve a sentirse mejor con ellos mismos, propiciando un estilo de vida saludable.

- Los clientes son la razón de ser de la empresa; por tanto, se busca brindarles una calidad en el servicio que supere sus expectativas. Es por ello que, en Ate CrossFit, los Coaches deberán hacerles un seguimiento constante; así mismo, brindarles la información pertinente y oportuna en cualquier momento; de igual forma, estar en constante supervisión durante la sesión de entrenamiento para evitar lesiones que puedan interferir en su avance.

- Garantizar el orden, la seguridad, higiene y bien mantenimiento de los equipos e instalaciones, antes, durante y post entrenamiento.

- Diseñar los procesos internos de forma transparente y simple, para que los clientes sientan que se trabaja en la calidad del servicio, y que el enfoque de Ate CrossFit es llevar una vida saludable.

- Compromiso de evaluar todo impacto ambiental que pueda generar la empresa; así como fomentar la orientación ambiental. 


\section{Capítulo VI: Pronóstico de Ventas}

\subsection{Fundamentos y Supuestos}

Para obtener y medir la demanda que el presente plan de negocio pronostica, se utilizó el muestreo por juicio que de conformidad con Malhotra (2008) “...es una forma de muestreo por conveniencia, en el cual los elementos de la población se seleccionan con base en el juicio del investigador" (p. 343); todo ello, para conocer la frecuencia, segmentación y preferencia de asistencia que presenta el público objetivo al local de Ate CrossFit. Para ello se utilizó como base los resultados del cuestionario aplicado que responden a las siguientes consideraciones:

- La distribución de tipo membresía que ha de adquirir cada cliente,

- El crecimiento esperado en plazo de desarrollo del negocio hasta su liquidación tras 5 años de operación, y

- La capacidad instalada del negocio para dimensionar la clientela que se atiende.

\subsection{Justificación}

En la Tabla 33 se observa la proyección estimada del mercado objetivo de acuerdo a los resultados obtenidos obtenidos de la pregunta 15 del cuestionario realizado para la investigación de mercado (ver Apéndice 39).

Tabla 33

Proyección de Mercado Objetivo

\begin{tabular}{|c|c|c|c|c|c|c|}
\hline & & 2018 & 2019 & 2020 & 2021 & 2022 \\
\hline Mensual & $46 \%$ & 65 & 71 & 78 & 85 & 93 \\
\hline Trimestral & $30 \%$ & 42 & 46 & 50 & 55 & 60 \\
\hline Semestral & $17 \%$ & 24 & 26 & 29 & 31 & 34 \\
\hline Anual & $8 \%$ & 11 & 12 & 14 & 15 & 16 \\
\hline \multicolumn{2}{|c|}{ Total } & 143 & 156 & 170 & 186 & 203 \\
\hline
\end{tabular}

Una vez considerada la población, es pertinente desarrollar el pronóstico de la cantidad (q) de personas que van a acudir al box de CrossFit durante los próximos cinco años; en la Tabla 34 se vaticina un $65 \%$ de uso de capacidad instalada para el primer año de operación (la capacidad instalada es de 220 clientes de acuerdo a la maquinaria, equipo y aforo del local), al contar con 143 clientes asistentes. 
Tabla 34

Pronóstico de Cantidad de Clientes del Año 1

\begin{tabular}{|c|c|c|c|c|c|c|c|c|c|c|c|c|}
\hline \multirow{2}{*}{$\mathrm{q}$} & \multicolumn{12}{|c|}{ Año 1} \\
\hline & $\mathrm{E}$ & $\mathrm{F}$ & $\mathrm{M}$ & A & $\mathrm{M}$ & $\mathrm{J}$ & $\mathbf{J}$ & A & $\mathrm{S}$ & $\mathrm{O}$ & $\mathrm{N}$ & $\mathrm{D}$ \\
\hline Mensual & 19 & 21 & 22 & 21 & 23 & 24 & 30 & 32 & 34 & 58 & 61 & 65 \\
\hline Trimestral & 13 & 13 & 14 & 14 & 15 & 16 & 19 & 21 & 22 & 37 & 40 & 42 \\
\hline Semestral & 7 & 8 & 8 & 8 & 8 & 9 & 11 & 12 & 12 & 21 & 23 & 24 \\
\hline Anual & 3 & 4 & 4 & 4 & 4 & 4 & 5 & 6 & 6 & 10 & 11 & 11 \\
\hline Total & 42 & 45 & 48 & 47 & 50 & 53 & 65 & 70 & 74 & 126 & 135 & 143 \\
\hline
\end{tabular}

Nota: (q) es la denominación que se le da a la cantidad. Las letras que se ubican debajo del Año 1, corresponden a los meses del año.

En la Tabla 35 se pronostica un $71 \%$ de uso de capacidad instalada (la capacidad instalada es de 220 clientes) al terminar el segundo año con un total de 156 clientes activos. Para este caso y los posteriores se toma en consideración la estacionalidad de visita a este tipo de negocio que arroja el estudio de mercado aplicado.

Tabla 35

Pronóstico de Cantidad de Clientes del Año 2

\begin{tabular}{|c|c|c|c|c|c|c|c|c|c|c|c|c|}
\hline \multirow{2}{*}{$q$} & \multicolumn{12}{|c|}{ Año 2} \\
\hline & $\mathrm{E}$ & $\mathrm{F}$ & M & A & $\mathrm{M}$ & $\mathrm{J}$ & $\mathbf{J}$ & A & $S$ & $\mathrm{O}$ & $\mathrm{N}$ & $\mathrm{D}$ \\
\hline Mensual & 21 & 23 & 24 & 23 & 25 & 26 & 33 & 35 & 37 & 63 & 67 & 71 \\
\hline Trimestral & 14 & 15 & 15 & 15 & 16 & 17 & 21 & 22 & 24 & 41 & 43 & 46 \\
\hline Semestral & 8 & 8 & 9 & 9 & 9 & 10 & 12 & 13 & 14 & 23 & 25 & 26 \\
\hline Anual & 4 & 4 & 4 & 4 & 4 & 5 & 6 & 6 & 6 & 11 & 12 & 12 \\
\hline Total & 46 & 49 & 52 & 51 & 54 & 58 & 71 & 76 & 81 & 138 & 147 & 156 \\
\hline
\end{tabular}

En la Tabla 36 se prevé un $77 \%$ de uso de capacidad instalada (la capacidad instalada es de 220 clientes), al contar con 170 clientes asistentes al terminar el tercer año de operación. 
Tabla 36

Pronóstico de Cantidad de Clientes del Año 3

\begin{tabular}{|c|c|c|c|c|c|c|c|c|c|c|c|c|}
\hline \multirow{2}{*}{ q } & \multicolumn{12}{|c|}{ Año 3} \\
\hline & $\mathrm{E}$ & $\mathrm{F}$ & $\mathrm{M}$ & $\mathrm{A}$ & $\mathrm{M}$ & $\mathrm{J}$ & $\mathrm{J}$ & $\mathrm{A}$ & $\mathrm{S}$ & $\mathrm{O}$ & $\mathrm{N}$ & $\mathrm{D}$ \\
\hline Mensual & 23 & 25 & 26 & 25 & 27 & 29 & 36 & 38 & 40 & 69 & 73 & 78 \\
\hline Trimestral & 15 & 16 & 17 & 16 & 17 & 19 & 23 & 24 & 26 & 44 & 47 & 50 \\
\hline Semestral & 8 & 9 & 10 & 9 & 10 & 11 & 13 & 14 & 15 & 25 & 27 & 29 \\
\hline Anual & 4 & 4 & 5 & 4 & 5 & 5 & 6 & 7 & 7 & 12 & 13 & 14 \\
\hline Total & 50 & 54 & 57 & 56 & 59 & 63 & 78 & 83 & 88 & 150 & 160 & 170 \\
\hline
\end{tabular}

En la Tabla 37 se pronostica un $84 \%$ de uso de capacidad instalada (la capacidad instalada es de 220 clientes) al terminar el año con un total de 186 clientes activos. Para este caso y los posteriores se toma en consideración la estacionalidad de visita a este tipo de negocio que arroja el estudio de mercado aplicado.

Tabla 37

Pronóstico de Cantidad de Clientes del Año 4

\begin{tabular}{|c|c|c|c|c|c|c|c|c|c|c|c|c|}
\hline \multirow{2}{*}{$q$} & \multicolumn{12}{|c|}{ Año 4} \\
\hline & $\mathrm{E}$ & $\mathrm{F}$ & $\mathrm{M}$ & $\mathrm{A}$ & $\mathrm{M}$ & $\mathrm{J}$ & $\mathrm{J}$ & A & $\mathrm{S}$ & $\mathrm{O}$ & $\mathrm{N}$ & $\mathrm{D}$ \\
\hline Mensual & 16 & 17 & 18 & 28 & 29 & 31 & 39 & 41 & 44 & 75 & 80 & 85 \\
\hline Trimestral & 10 & 11 & 12 & 18 & 19 & 20 & 25 & 27 & 28 & 48 & 51 & 55 \\
\hline Semestral & 6 & 6 & 7 & 10 & 11 & 12 & 14 & 15 & 16 & 28 & 29 & 31 \\
\hline Anual & 3 & 3 & 3 & 5 & 5 & 5 & 7 & 7 & 8 & 13 & 14 & 15 \\
\hline Total & 35 & 38 & 40 & 61 & 65 & 69 & 85 & 90 & 96 & 164 & 174 & 186 \\
\hline
\end{tabular}

En la Tabla 38 se prevé un $92 \%$ de uso de capacidad instalada, lo cual considera un total de (la capacidad instalada es de 220 clientes), al contar con 203 clientes asistentes. 
Tabla 38

Pronóstico de Cantidad de Clientes del Año 5

\begin{tabular}{|c|c|c|c|c|c|c|c|c|c|c|c|c|}
\hline \multirow{2}{*}{ q } & \multicolumn{12}{|c|}{ Año 5} \\
\hline & $\mathrm{E}$ & $\mathrm{F}$ & $\mathrm{M}$ & A & $\mathrm{M}$ & $\mathrm{J}$ & $\mathrm{J}$ & $\mathrm{A}$ & $\mathrm{S}$ & $\mathrm{O}$ & $\mathrm{N}$ & $\mathrm{D}$ \\
\hline Mensual & 16 & 17 & 18 & 30 & 32 & 34 & 42 & 45 & 48 & 82 & 87 & 93 \\
\hline Trimestral & 10 & 11 & 12 & 19 & 21 & 22 & 27 & 29 & 31 & 53 & 56 & 60 \\
\hline Semestral & 6 & 6 & 7 & 11 & 12 & 13 & 16 & 17 & 18 & 30 & 32 & 34 \\
\hline Anual & 3 & 3 & 3 & 5 & 6 & 6 & 7 & 8 & 8 & 14 & 15 & 16 \\
\hline Total & 35 & 38 & 40 & 66 & 70 & 75 & 93 & 99 & 105 & 179 & 190 & 203 \\
\hline
\end{tabular}

Nota: (q) es la denominación que se le da a la cantidad. Las letras que se ubican debajo del Año 1, corresponden a los meses del año.

Acto seguido, corresponde determinar el precio que han de pagar las personas durante los cinco años proyectados; esto se establece claramente de acuerdo a la estrategia de precio explicada en el capítulo correspondiente.

Proyección del precio para el primer año:

Para el primer año, se considera un precio promocional o de introducción proyectando un descuento del $30 \%$ de descuento del precio normal durante el primer trimestre. Del mismo modo, se considera un descuento del $10 \%$ en el precio para el segundo trimestre siguiendo la estacionalidad de asistencia, como se muestra en la Tabla 39.

Tabla 39

Pronóstico de Precio Año 1

\begin{tabular}{|c|c|c|c|c|c|c|c|c|c|c|c|c|}
\hline \multirow{2}{*}{$\mathrm{p}$} & \multicolumn{12}{|c|}{ Año 1} \\
\hline & $E$ & $\mathrm{~F}$ & $\mathrm{M}$ & A & $\mathrm{M}$ & $\mathrm{J}$ & $\mathrm{J}$ & A & $\mathrm{S}$ & $\mathrm{O}$ & $\mathrm{N}$ & $\mathrm{D}$ \\
\hline Mensual & \multicolumn{3}{|c|}{ S/ 210.00} & \multicolumn{3}{|c|}{ S/ 270.00} & \multicolumn{3}{|c|}{ S/ 300.00} & \multicolumn{3}{|c|}{ S/ 300.00} \\
\hline Trimestral & \multicolumn{3}{|c|}{ S/ 203.00} & \multicolumn{3}{|c|}{ S/ 261.00} & \multicolumn{3}{|c|}{ S/ 290.00} & \multicolumn{3}{|c|}{ S/ 290.00} \\
\hline Semestral & \multicolumn{3}{|c|}{ S/ 196.00} & \multicolumn{3}{|c|}{ S/ 252.00} & \multicolumn{3}{|c|}{ S/ 280.00} & \multicolumn{3}{|c|}{ S/ 280.00} \\
\hline Anual & \multicolumn{3}{|c|}{ S/ 189.00} & \multicolumn{3}{|c|}{ S/ 243.00} & \multicolumn{3}{|c|}{ S/ 270.00} & \multicolumn{3}{|c|}{ S/ 270.00} \\
\hline
\end{tabular}

Nota: (p) es la denominación que se le da al precio. Las letras que se ubican debajo del Año 1, corresponden a los meses del año.

Proyección del precio para el segundo año:

Para el segundo año, se considera un precio normal sin proyectar aumento en el primer trimestre, y sí el descuento del 10\% en el precio para el segundo trimestre siguiendo la estacionalidad de asistencia, como se muestra en la Tabla 40. 
Tabla 40

Pronóstico de Precio Año 2

\begin{tabular}{|c|c|c|c|c|c|c|c|c|c|c|c|c|}
\hline \multirow{2}{*}{$\mathrm{p}$} & \multicolumn{12}{|c|}{ Año 2} \\
\hline & $\mathrm{E}$ & $\mathrm{F}$ & $\mathrm{M}$ & A & $\mathrm{M}$ & $\mathrm{J}$ & $\mathrm{J}$ & A & $\mathrm{S}$ & $\mathrm{O}$ & $\mathrm{N}$ & $\mathrm{D}$ \\
\hline Mensual & \multicolumn{3}{|c|}{ S/ 300.00} & \multicolumn{3}{|c|}{ S/ 270.00} & \multicolumn{3}{|c|}{ S/ 300.00} & \multicolumn{3}{|c|}{ S/ 300.00} \\
\hline Trimestral & \multicolumn{3}{|c|}{ S/ 290.00} & \multicolumn{3}{|c|}{ S/ 261.00} & \multicolumn{3}{|c|}{ S/ 290.00} & \multicolumn{3}{|c|}{ S/ 290.00} \\
\hline Semestral & \multicolumn{3}{|c|}{ S/ 280.00} & \multicolumn{3}{|c|}{ S/ 252.00} & \multicolumn{3}{|c|}{ S/ 280.00} & \multicolumn{3}{|c|}{ S/ 280.00} \\
\hline Anual & \multicolumn{3}{|c|}{ S/ 270.00} & \multicolumn{3}{|c|}{ S/ 243.00} & \multicolumn{3}{|c|}{$S / 270.00$} & \multicolumn{3}{|c|}{ S/ 270.00} \\
\hline
\end{tabular}

Nota: (p) es la denominación que se le da al precio. Las letras que se ubican debajo del Año 1, corresponden a los meses del año.

Proyección del precio para el tercer año:

Del mismo modo, la Tabla 41 muestra que a partir del 3 año se considera un incremento del $10 \%$ en el precio de todas las membresías, modificando así el precio base. Durante el primer trimestre entra en vigencia el nuevo precio, ya para el segundo se aplica un descuento del $10 \%$ por estacionalidad y ninguna variación en los dos últimos trimestres.

Tabla 41

Pronóstico de Precio Año 3

\begin{tabular}{|c|c|c|c|c|c|c|c|c|c|c|c|c|}
\hline \multirow{2}{*}{$\mathrm{p}$} & \multicolumn{12}{|c|}{ Año 3} \\
\hline & $\mathrm{E}$ & $\mathrm{F}$ & M & A & M & $\mathbf{J}$ & $\mathrm{J}$ & A & $\mathrm{S}$ & $\mathrm{O}$ & $\mathrm{N}$ & $\mathrm{D}$ \\
\hline Mensual & \multicolumn{3}{|c|}{ S/ 330.00} & \multicolumn{3}{|c|}{ S/ 297.00} & \multicolumn{3}{|c|}{ S/ 330.00} & \multicolumn{3}{|c|}{ S/ 330.00} \\
\hline Trimestral & \multicolumn{3}{|c|}{ S/ 319.00} & \multicolumn{3}{|c|}{ S/ 287.10} & \multicolumn{3}{|c|}{ S/ 319.00} & \multicolumn{3}{|c|}{ S/ 319.00} \\
\hline Semestral & \multicolumn{3}{|c|}{ S/ 308.00} & \multicolumn{3}{|c|}{ S/ 277.20} & \multicolumn{3}{|c|}{ S/ 308.00} & \multicolumn{3}{|c|}{ S/ 308.00} \\
\hline Anual & \multicolumn{3}{|c|}{ S/ 297.00} & \multicolumn{3}{|c|}{ S/ 267.30} & \multicolumn{3}{|c|}{ S/ 297.00} & \multicolumn{3}{|c|}{ S/ 297.00} \\
\hline
\end{tabular}

Nota: (p) es la denominación que se le da al precio. Las letras que se ubican debajo del Año 1, corresponden a los meses del año.

Proyección del precio para el cuarto año:

La Tabla 42 muestra que, en el cuarto año se considera un incremento del 10\% en el precio de todas las membresías durante el primer trimestre en relación al nuevo precio base, y un descuento del $10 \%$ en el segundo trimestre por la estacionalidad. Tanto el tercer como cuarto trimestre no presentan variación en el precio base establecido en el tercer año. 
Tabla 42

Pronóstico de Precio Año 4

\begin{tabular}{|c|c|c|c|c|c|c|c|c|c|c|c|c|}
\hline \multirow{2}{*}{$\mathrm{p}$} & \multicolumn{12}{|c|}{ Año 4} \\
\hline & $E$ & $\mathrm{~F}$ & $\mathrm{M}$ & A & $M$ & $\mathrm{~J}$ & $\mathrm{~J}$ & A & $S$ & $\mathrm{O}$ & $\mathrm{N}$ & $\mathrm{D}$ \\
\hline Mensual & \multicolumn{3}{|c|}{ S/ 363.00} & \multicolumn{3}{|c|}{ S/ 297.00} & \multicolumn{3}{|c|}{ S/ 330.00} & \multicolumn{3}{|c|}{ S/ 330.00} \\
\hline Trimestral & \multicolumn{3}{|c|}{ S/ 350.90} & \multicolumn{3}{|c|}{ S/ 287.10} & \multicolumn{3}{|c|}{ S/ 319.00} & \multicolumn{3}{|c|}{ S/ 319.00} \\
\hline Semestral & \multicolumn{3}{|c|}{ S/ 338.80} & \multicolumn{3}{|c|}{ S/ 277.20} & \multicolumn{3}{|c|}{ S/ 308.00} & \multicolumn{3}{|c|}{ S/ 308.00} \\
\hline Anual & \multicolumn{3}{|c|}{ S/ 326.70} & \multicolumn{3}{|c|}{ S/ 267.30} & \multicolumn{3}{|c|}{ S/ 297.00} & \multicolumn{3}{|c|}{ S/ 297.00} \\
\hline
\end{tabular}

Nota: (p) es la denominación que se le da al precio. Las letras que se ubican debajo del Año 1, corresponden a los meses del año.

Proyección del precio para el quinto año:

Para el quinto y último año de operación, no se considera variación al precio que se maneja en el cuarto año (ver Tabla 43).

Tabla 43

Pronóstico de Precio Año 5

\begin{tabular}{|c|c|c|c|c|c|c|c|c|c|c|c|c|}
\hline \multirow{2}{*}{$\mathrm{p}$} & \multicolumn{12}{|c|}{ Año 5} \\
\hline & $\mathrm{E}$ & $\mathrm{F}$ & $\mathrm{M}$ & A & $\mathrm{M}$ & $\mathrm{J}$ & $\mathrm{J}$ & A & $S$ & $\mathrm{O}$ & $\mathrm{N}$ & D \\
\hline Mensual & \multicolumn{3}{|c|}{ S/ 363.00} & \multicolumn{3}{|c|}{ S/ 297.00} & \multicolumn{3}{|c|}{ S/ 330.00} & \multicolumn{3}{|c|}{ S/ 330.00} \\
\hline Trimestral & \multicolumn{3}{|c|}{ S/ 350.90} & \multicolumn{3}{|c|}{ S/ 287.10} & \multicolumn{3}{|c|}{ S/ 319.00} & \multicolumn{3}{|c|}{ S/ 319.00} \\
\hline Semestral & \multicolumn{3}{|c|}{ S/ 338.80} & \multicolumn{3}{|c|}{ S/ 277.20} & \multicolumn{3}{|c|}{ S/ 308.00} & \multicolumn{3}{|c|}{ S/ 308.00} \\
\hline Anual & \multicolumn{3}{|c|}{ S/ 326.70} & \multicolumn{3}{|c|}{ S/ 267.30} & \multicolumn{3}{|c|}{ S/ 297.00} & \multicolumn{3}{|c|}{ S/ 297.00} \\
\hline
\end{tabular}

Nota: (p) es la denominación que se le da al precio. Las letras que se ubican debajo del Año 1, corresponden a los meses del año.

Ahora bien, una vez determinado el q y el p; corresponde multiplicar ambos elementos para obtener el pronóstico de ventas tanto mensual como anual.

Proyección del precio por cantidad del primer año:

Como se muestra en la Tabla 44, el primer año de operación y el precio definido para el mismo periodo, genera un ingreso que cubre los costos de inversión a partir del noveno mes. 
Tabla 44

Proyección del Precio por Cantidad del Año 1

\begin{tabular}{ccccccc}
\hline p*q & Mes & Mensual & Trimestral & Semestral & Anual & Total \\
\hline & Enero & $\mathrm{S} / 3,990.00$ & $\mathrm{~S} / 2,639.00$ & $\mathrm{~S} / 1,372.00$ & $\mathrm{~S} / 567.00$ & $\mathrm{~S} / 8,568.00$ \\
& Febrero & $\mathrm{S} / 4,410.00$ & $\mathrm{~S} / 2,639.00$ & $\mathrm{~S} / 1,568.00$ & $\mathrm{~S} / 756.00$ & $\mathrm{~S} / 9,373.00$ \\
& Marzo & $\mathrm{S} / 4,620.00$ & $\mathrm{~S} / 2,842.00$ & $\mathrm{~S} / 1,568.00$ & $\mathrm{~S} / 756.00$ & $\mathrm{~S} / 9,786.00$ \\
& Abril & $\mathrm{S} / 5,670.00$ & $\mathrm{~S} / 3,654.00$ & $\mathrm{~S} / 2,016.00$ & $\mathrm{~S} / 972.00$ & $\mathrm{~S} / 12,312.00$ \\
& Mayo & $\mathrm{S} / 6,210.00$ & $\mathrm{~S} / 3,915.00$ & $\mathrm{~S} / 2,016.00$ & $\mathrm{~S} / 972.00$ & $\mathrm{~S} / 13,113.00$ \\
Año 1 & Junio & $\mathrm{S} / 6,480.00$ & $\mathrm{~S} / 4,176.00$ & $\mathrm{~S} / 2,268.00$ & $\mathrm{~S} / 972.00$ & $\mathrm{~S} / 13,896.00$ \\
& Julio & $\mathrm{S} / 9,000.00$ & $\mathrm{~S} / 5,510.00$ & $\mathrm{~S} / 3,080.00$ & $\mathrm{~S} / 1,350.00$ & $\mathrm{~S} / 18,940.00$ \\
& Agosto & $\mathrm{S} / 9,600.00$ & $\mathrm{~S} / 6,090.00$ & $\mathrm{~S} / 3,360.00$ & $\mathrm{~S} / 1,620.00$ & $\mathrm{~S} / 20,670.00$ \\
& Setiembre & $\mathrm{S} / 10,200.00$ & $\mathrm{~S} / 6,380.00$ & $\mathrm{~S} / 3,360.00$ & $\mathrm{~S} / 1,620.00$ & $\mathrm{~S} / 21,560.00$ \\
& Octubre & $\mathrm{S} / 17,400.00$ & $\mathrm{~S} / 10,730.00$ & $\mathrm{~S} / 5,880.00$ & $\mathrm{~S} / 2,700.00$ & $\mathrm{~S} / 36,710.00$ \\
& Noviembre & $\mathrm{S} / 18,300.00$ & $\mathrm{~S} / 11,600.00$ & $\mathrm{~S} / 6,440.00$ & $\mathrm{~S} / 2,970.00$ & $\mathrm{~S} / 39,310.00$ \\
Total & Diciembre & $\mathrm{S} / 19,500.00$ & $\mathrm{~S} / 12,180.00$ & $\mathrm{~S} / 6,720.00$ & $\mathrm{~S} / 2,970.00$ & $\mathrm{~S} / 41,370.00$ \\
Nota: $(\mathrm{p})$ y (q) son las denominaciones que se le da al precio y cantidad respectivamente. &
\end{tabular}

Proyección del precio por cantidad del segundo año:

Como se muestra en la Tabla 45, el segundo año de operación genera un ingreso mayor que el primero que no solo cubre los costos de inversión, sino que empieza a generar rentabilidad al proyecto de negocio.

Tabla 45

Proyección del Precio por Cantidad del Año 2

\begin{tabular}{ccccccc}
\hline p*q & Mes & Mensual & Trimestral & Semestral & Anual & Total \\
\hline & Enero & $\mathrm{S} / 6,300.00$ & $\mathrm{~S} / 4,060.00$ & $\mathrm{~S} / 2,240.00$ & $\mathrm{~S} / 1,080.00$ & $\mathrm{~S} / 13,680.00$ \\
& Febrero & $\mathrm{S} / 6,900.00$ & $\mathrm{~S} / 4,350.00$ & $\mathrm{~S} / 2,240.00$ & $\mathrm{~S} / 1,080.00$ & $\mathrm{~S} / 14,570.00$ \\
& Marzo & $\mathrm{S} / 7,200.00$ & $\mathrm{~S} / 4,350.00$ & $\mathrm{~S} / 2,520.00$ & $\mathrm{~S} / 1,080.00$ & $\mathrm{~S} / 15,150.00$ \\
& Abril & $\mathrm{S} / 6,210.00$ & $\mathrm{~S} / 3,915.00$ & $\mathrm{~S} / 2,268.00$ & $\mathrm{~S} / 972.00$ & $\mathrm{~S} / 13,365.00$ \\
& Mayo & $\mathrm{S} / 6,750.00$ & $\mathrm{~S} / 4,176.00$ & $\mathrm{~S} / 2,268.00$ & $\mathrm{~S} / 972.00$ & $\mathrm{~S} / 14,166.00$ \\
Año 2 & Junio & $\mathrm{S} / 7,020.00$ & $\mathrm{~S} / 4,437.00$ & $\mathrm{~S} / 2,520.00$ & $\mathrm{~S} / 1,215.00$ & $\mathrm{~S} / 15,192.00$ \\
& Julio & $\mathrm{S} / 9,900.00$ & $\mathrm{~S} / 6,090.00$ & $\mathrm{~S} / 3,360.00$ & $\mathrm{~S} / 1,620.00$ & $\mathrm{~S} / 20,970.00$ \\
& Agosto & $\mathrm{S} / 10,500.00$ & $\mathrm{~S} / 6,380.00$ & $\mathrm{~S} / 3,640.00$ & $\mathrm{~S} / 1,620.00$ & $\mathrm{~S} / 22,140.00$ \\
& Setiembre & $\mathrm{S} / 11,100.00$ & $\mathrm{~S} / 6,960.00$ & $\mathrm{~S} / 3,920.00$ & $\mathrm{~S} / 1,620.00$ & $\mathrm{~S} / 23,600.00$ \\
& Octubre & $\mathrm{S} / 18,900.00$ & $\mathrm{~S} / 11,890.00$ & $\mathrm{~S} / 6,440.00$ & $\mathrm{~S} / 2,970.00$ & $\mathrm{~S} / 40,200.00$ \\
& Noviembre & $\mathrm{S} / 20,100.00$ & $\mathrm{~S} / 12,470.00$ & $\mathrm{~S} / 7,000.00$ & $\mathrm{~S} / 3,240.00$ & $\mathrm{~S} / 42,810.00$ \\
& Diciembre & $\mathrm{S} / 21,300.00$ & $\mathrm{~S} / 13,340.00$ & $\mathrm{~S} / 7,280.00$ & $\mathrm{~S} / 3,240.00$ & $\mathrm{~S} / 45,160.00$ \\
& & & & & & $\mathrm{~S} / 281,003.00$ \\
\hline
\end{tabular}

Nota: (p) y (q) son las denominaciones que se le da al precio y cantidad respectivamente. 
Proyección del precio por cantidad del tercer año:

El tercer año es mejor, considerando el reajuste del precio base en todas las membresías, que además provoca una culpabilidad operativa eficiente (ver Tabla 46).

Tabla 46

Proyección del Precio por Cantidad del Año 3

\begin{tabular}{ccccccc}
\hline p*q & Mes & Mensual & Trimestral & Semestral & Anual & Total \\
\hline & Enero & $\mathrm{S} / 7,590.00$ & $\mathrm{~S} / 4,785.00$ & $\mathrm{~S} / 2,464.00$ & $\mathrm{~S} / 1,188.00$ & $\mathrm{~S} / 16,027.00$ \\
& Febrero & $\mathrm{S} / 8,250.00$ & $\mathrm{~S} / 5,104.00$ & $\mathrm{~S} / 2,772.00$ & $\mathrm{~S} / 1,188.00$ & $\mathrm{~S} / 17,314.00$ \\
& Marzo & $\mathrm{S} / 8,580.00$ & $\mathrm{~S} / 5,423.00$ & $\mathrm{~S} / 3,080.00$ & $\mathrm{~S} / 1,485.00$ & $\mathrm{~S} / 18,568.00$ \\
& Abril & $\mathrm{S} / 7,425.00$ & $\mathrm{~S} / 4,593.60$ & $\mathrm{~S} / 2,494.80$ & $\mathrm{~S} / 1,069.20$ & $\mathrm{~S} / 15,582.60$ \\
& Mayo & $\mathrm{S} / 8,019.00$ & $\mathrm{~S} / 4,880.70$ & $\mathrm{~S} / 2,772.00$ & $\mathrm{~S} / 1,336.50$ & $\mathrm{~S} / 17,008.20$ \\
Año 3 & Junio & $\mathrm{S} / 8,613.00$ & $\mathrm{~S} / 5,454.90$ & $\mathrm{~S} / 3,049.20$ & $\mathrm{~S} / 1,336.50$ & $\mathrm{~S} / 18,453.60$ \\
& Julio & $\mathrm{S} / 11,880.00$ & $\mathrm{~S} / 7,337.00$ & $\mathrm{~S} / 4,004.00$ & $\mathrm{~S} / 1,782.00$ & $\mathrm{~S} / 25,003.00$ \\
& Agosto & $\mathrm{S} / 12,540.00$ & $\mathrm{~S} / 7,656.00$ & $\mathrm{~S} / 4,312.00$ & $\mathrm{~S} / 2,079.00$ & $\mathrm{~S} / 26,587.00$ \\
& Setiembre & $\mathrm{S} / 13,200.00$ & $\mathrm{~S} / 8,294.00$ & $\mathrm{~S} / 4,620.00$ & $\mathrm{~S} / 2,079.00$ & $\mathrm{~S} / 28,193.00$ \\
& Octubre & $\mathrm{S} / 22,770.00$ & $\mathrm{~S} / 14,036.00$ & $\mathrm{~S} / 7,700.00$ & $\mathrm{~S} / 3,564.00$ & $\mathrm{~S} / 48,070.00$ \\
& Noviembre & $\mathrm{S} / 24,090.00$ & $\mathrm{~S} / 14,993.00$ & $\mathrm{~S} / 7,392.00$ & $\mathrm{~S} / 3,861.00$ & $\mathrm{~S} / 50,336.00$ \\
& Diciembre & $\mathrm{S} / 25,740.00$ & $\mathrm{~S} / 15,950.00$ & $\mathrm{~S} / 8,932.00$ & $\mathrm{~S} / 4,158.00$ & $\mathrm{~S} / 54,780.00$ \\
Total & & & & & & $\mathrm{S} / 335,922.40$ \\
\hline
\end{tabular}

Nota: (p) y (q) son las denominaciones que se le da al precio y cantidad respectivamente.

Proyección del precio por cantidad del cuarto año:

El cuarto año de operación será similar al tercer año, con precios estables y variaciones acorde a la concepción inicial del plan de negocio ligados a la estacionalidad (ver Tabla 47). Tabla 47

Proyección del Precio por Cantidad del Año 4

\begin{tabular}{lcccccc}
\hline p*q & Mes & Mensual & Trimestral & Semestral & Anual & Total \\
\hline & Enero & $\mathrm{S} / 5,808.00$ & $\mathrm{~S} / 3,509.00$ & $\mathrm{~S} / 2,032.80$ & $\mathrm{~S} / 980.10$ & $\mathrm{~S} / 12,329.90$ \\
& Febrero & $\mathrm{S} / 6,171.00$ & $\mathrm{~S} / 3,859.90$ & $\mathrm{~S} / 2,032.80$ & $\mathrm{~S} / 980.10$ & $\mathrm{~S} / 13,043.80$ \\
& Marzo & $\mathrm{S} / 6,534.00$ & $\mathrm{~S} / 4,210.80$ & $\mathrm{~S} / 2,371.60$ & $\mathrm{~S} / 980.10$ & $\mathrm{~S} / 14,096.50$ \\
& Abril & $\mathrm{S} / 8,316.00$ & $\mathrm{~S} / 5,167.80$ & $\mathrm{~S} / 2,772.00$ & $\mathrm{~S} / 1,336.50$ & $\mathrm{~S} / 17,592.30$ \\
& Mayo & $\mathrm{S} / 8,613.00$ & $\mathrm{~S} / 5,454.90$ & $\mathrm{~S} / 3,049.20$ & $\mathrm{~S} / 1,336.50$ & $\mathrm{~S} / 18,453.60$ \\
Año 4 & Junio & $\mathrm{S} / 9,207.00$ & $\mathrm{~S} / 5,742.00$ & $\mathrm{~S} / 3,326.40$ & $\mathrm{~S} / 1,336.50$ & $\mathrm{~S} / 19,611.90$ \\
& Julio & $\mathrm{S} / 12,870.00$ & $\mathrm{~S} / 7,975.00$ & $\mathrm{~S} / 4,312.00$ & $\mathrm{~S} / 2,079.00$ & $\mathrm{~S} / 27,236.00$ \\
& Agosto & $\mathrm{S} / 13,530.00$ & $\mathrm{~S} / 8,613.00$ & $\mathrm{~S} / 4,620.00$ & $\mathrm{~S} / 2,079.00$ & $\mathrm{~S} / 28,842.00$ \\
& Setiembre & $\mathrm{S} / 14,520.00$ & $\mathrm{~S} / 8,932.00$ & $\mathrm{~S} / 4,928.00$ & $\mathrm{~S} / 2,376.00$ & $\mathrm{~S} / 30,756.00$ \\
& Octubre & $\mathrm{S} / 24,750.00$ & $\mathrm{~S} / 15,312.00$ & $\mathrm{~S} / 8,624.00$ & $\mathrm{~S} / 3,861.00$ & $\mathrm{~S} / 52,547.00$ \\
& Noviembre & $\mathrm{S} / 26,400.00$ & $\mathrm{~S} / 16,269.00$ & $\mathrm{~S} / 8,932.00$ & $\mathrm{~S} / 4,158.00$ & $\mathrm{~S} / 55,759.00$ \\
& Diciembre & $\mathrm{S} / 28,050.00$ & $\mathrm{~S} / 17,545.00$ & $\mathrm{~S} / 9,548.00$ & $\mathrm{~S} / 4,455.00$ & $\mathrm{~S} / 59,598.00$ \\
Total & & & & & & $\mathrm{S} / 349,866.00$ \\
\hline
\end{tabular}

Nota: (p) y (q) son las denominaciones que se le da al precio y cantidad respectivamente. 
Proyección del precio por cantidad del quinto año:

El último año de operación, previo a la liquidación del negocio, se tiene una capacidad operativa que supera el 90\%, lo cual permite cerrar la evaluación del proyecto con una holgura razonable de operación (ver Tabla 48).

Tabla 48

Proyección del Precio por Cantidad del Año 5

\begin{tabular}{lcccccc}
\hline p*q & Mes & Mensual & Trimestral & Semestral & Anual & Total \\
\hline \multirow{6}{*}{ Año 5 } & Enero & $\mathrm{S} / 5,808.00$ & $\mathrm{~S} / 3,509.00$ & $\mathrm{~S} / 2,032.80$ & $\mathrm{~S} / 980.10$ & $\mathrm{~S} / 12,329.90$ \\
& Febrero & $\mathrm{S} / 6,171.00$ & $\mathrm{~S} / 3,859.90$ & $\mathrm{~S} / 2,032.80$ & $\mathrm{~S} / 980.10$ & $\mathrm{~S} / 13,043.80$ \\
& Marzo & $\mathrm{S} / 6,534.00$ & $\mathrm{~S} / 4,210.80$ & $\mathrm{~S} / 2,371.60$ & $\mathrm{~S} / 980.10$ & $\mathrm{~S} / 14,096.50$ \\
& Abril & $\mathrm{S} / 8,910.00$ & $\mathrm{~S} / 5,454.90$ & $\mathrm{~S} / 3,049.20$ & $\mathrm{~S} / 1,336.50$ & $\mathrm{~S} / 18,750.60$ \\
& Mayo & $\mathrm{S} / 9,504.00$ & $\mathrm{~S} / 6,029.10$ & $\mathrm{~S} / 3,326.40$ & $\mathrm{~S} / 1,603.80$ & $\mathrm{~S} / 20,463.30$ \\
& Julio & $\mathrm{S} / 10,098.00$ & $\mathrm{~S} / 6,316.20$ & $\mathrm{~S} / 3,603.60$ & $\mathrm{~S} / 1,603.80$ & $\mathrm{~S} / 21,621.60$ \\
& Agosto $/ 13,860.00$ & $\mathrm{~S} / 8,613.00$ & $\mathrm{~S} / 4,928.00$ & $\mathrm{~S} / 2,079.00$ & $\mathrm{~S} / 29,480.00$ \\
& Setiembre & $\mathrm{S} / 14,850.00$ & $\mathrm{~S} / 9,251.00$ & $\mathrm{~S} / 5,236.00$ & $\mathrm{~S} / 2,376.00$ & $\mathrm{~S} / 31,713.00$ \\
& Octubre & $\mathrm{S} / 27,060.00$ & $\mathrm{~S} / 16,907.00$ & $\mathrm{~S} / 9,240.00$ & $\mathrm{~S} / 4,158.00$ & $\mathrm{~S} / 57,365.00$ \\
& Noviembre & $\mathrm{S} / 28,710.00$ & $\mathrm{~S} / 17,864.00$ & $\mathrm{~S} / 9,856.00$ & $\mathrm{~S} / 4,455.00$ & $\mathrm{~S} / 60,885.00$ \\
& Diciembre & $\mathrm{S} / 30,690.00$ & $\mathrm{~S} / 19,140.00$ & $\mathrm{~S} / 10,472.00$ & $\mathrm{~S} / 4,752.00$ & $\mathrm{~S} / 65,054.00$ \\
& & & & & & $\mathrm{~S} / 378,451.70$ \\
\hline
\end{tabular}

Nota: (p) y (q) son las denominaciones que se le da al precio y cantidad respectivamente.

\subsection{Análisis de los Riesgos y Aspectos Críticos que Impactan en el Pronóstico}

Para analizar el riesgo y aquellos factores cuyo cambio y/o transformación podrían afectar los escenarios de pronósticos de venta, es importante considerar el dinamismo que tiene el mercado actualmente, para ello se debe tomar en cuenta los factores tanto internos como externos que ameriten y en qué medida pueden impactar en el plan de negocio. Esto se ver-a mayor detalle en el capítulo $\mathrm{X}$ donde se evalúa financieramente los riesgos a los que el presente plan de negocio está expuesto.

La situación de riesgo se presenta cuando se encuentran factores que impactan en la disminución de las ventas pronosticadas, lo cual podría afectar de manera importante en la rentabilidad del negocio y por ende en su sostenibilidad.

Algunos factores críticos que pueden impactar en la gestión del plan de negocio son:

1. La situación económica general: en caso se presente una fuerte desaceleración económica que influya en el nivel de consumo privado ello mermaría el pronóstico de ventas que se tiene, al igual que un aumento importante en la inflación ya que haría que la población concentre sus ingresos en los aspectos que crea prioritarios como 
alimentación básica, salud, educación, vivienda. Sin embargo, al ser un negocio vinculado a la salud, el publico objetivo optaría por servicios substitutos al que se ofrece.

2. Nuevos competidores en la zona: este es otro aspecto bastante crítico que puede afectar negativamente el pronóstico de ventas. En el caso de que se abran otros negocios similares en la zona en la que se localiza Ate CrossFit, las personas que concurran en esta zona tendrán más alternativas para escoger y la demanda se racionaría entre el universo de establecimientos. Para disminuir este impacto de competencia directa en la zona, se está considerando las estrategias de diferenciación en el servicio que ser. explicada posteriormente.

3. Nivel de novedad del servicio: los servicios nuevos en el mercado son los más difíciles de proyecto dado que no se ha establecido una tendencia clara acerca de su consumo por el poco tiempo que tienen. En el caso de los Box de CrossFit, los negocios que se dedican únicamente a este tipo de servicios tienen mayor problema al momento de predecir las ventas ya que no se ha estimado un patrón de comportamiento sobre el consumidor de este tipo de servicios, ni tampoco se maneja con certeza el nivel de importancia que se le da al mismo.

4. Variaciones en el comportamiento del consumidor: es otro factor crítico ya que si la tendencia de estilo de vida saludable se vuelve más popular en el Perú, ello impactaría positivamente en las ventas ya que masificaría el modelo de negocio, haciendo que la disposición de la gente a asistir a este tipo de negocios crezca. En ello influyen los medios de comunicación y los programas del gobierno que buscan mejorar la calidad de vida de las personas.

5. Cambios en los servicios es un factor que puede ser generado de manera externa (como consecuencia de la evolución del mercado) o de manera interna (como estrategia del negocio en sí). Esto consiste en cambios que pueden incentivar la asistencia y hacerlo más llamativo para el público al cual se apunta.

6. Promociones de ventas: se considera un factor crítico inherente al mismo negocio con el fin de aumentar las ventas. Puede presentarse la situación en la que las promociones planeadas, las cuales son temporales, no solo contrarresten las bajas en las ventas en alguna mala temporada, sino que además tengan una mayor repercusión en las ventas, sobrepasando tal vez el pronóstico anual que se tendría en un entorno normal de venta. 


\section{Capítulo VII: Ingeniería del Proyecto}

Para la elaboración del presente capítulo, se ha tomado en consideración aquellos recursos y equipos necesarios para la implementación de Ate CrossFit; así como, la selección de los procesos productivos, la distribución de equipos y maquinarias. En ese mismo orden de ideas, se determinó el tamaño y estudio de localización. Todo esto con el fin de establecer procesos, definir operaciones y describir los recursos necesarios para la puesta en marcha de Ate CrossFit.

\subsection{Estudio de Ingeniería}

\subsubsection{Modelamiento y selección de procesos productivos}

Para que todo negocio pueda tener un buen resultado tanto del producto como del servicio que brinda, debe contar con un proceso productivo o varios, dependiendo de su capacidad que le permita tener un orden y secuencia de su interacción con el cliente. Todo ello, con el fin de cumplir con las necesidades del consumidor superando sus expectativas.

Hoy en día, es común ver que las micro y pequeñas empresas omitan la elaboración de procesos productivos, ocasionándoles diversos conflictos diarios que deben combatir entre las áreas estratégicas de la empresa. No obstante, la diferencia se resalta en aquellas empresas de mayor trayectoria, donde no sólo existe un proceso productivo; sino, diversos por cada área.

En el mundo del fitness, se puede encontrar que las grandes empresas como Gold's Gym y Bodytech cuentan con un sin fin de procesos; esto se debe, a que su objetivo principal está enfocado en la calidad de su servicio, que mientras más personalizado sea, mayor aproximación tendrá con la satisfacción de los requerimientos del cliente. Caso contario, lo encontramos en aquellos centros de entrenamiento caseros y no convencionales; cuya experiencia en el mercado es mínima y no reúnen los criterios mínimos indispensables para la elaboración de un proceso productivo.

En la Figura 49 se muestra el diagrama de procesos críticos tomados a consideración para Ate CrossFit, en razón al contacto del cliente con la empresa, la experiencia del servicio y la adquisición de la misma. 


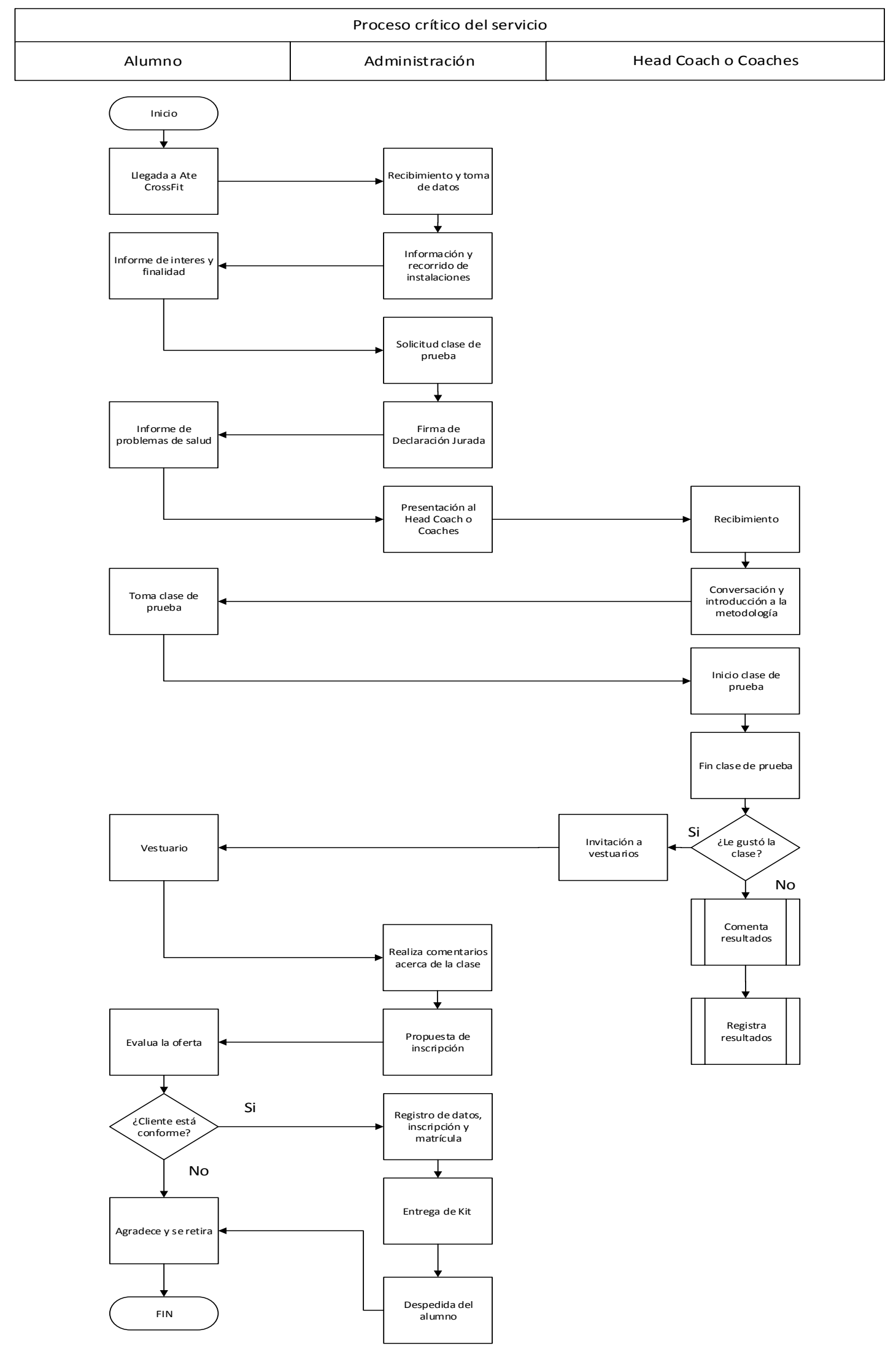

Figura 49. Proceso de servicio de Ate CrossFit 


\subsubsection{Selección del equipamiento}

Para la puesta en marcha de Ate CrossFit, es necesario contar con ciertos equipos, maquinarias y muebles. Por ser un modelo de negocio distinto a los ya tradicionales centros de entrenamiento, el CrossFit cuenta con sus propias características; basándose principalmente por la infraestructura y ambientación del local que, por lo general, se asemeja a un garaje; asimismo, las maquinas que se emplean son muy básicas y sobre todo, no ocupan mucho espacio en el local.

A continuación se detalla el equipo necesario para la operatividad de Ate CrossFit:

\section{Muebles y enseres.}

Para el buen funcionamiento de Ate CrossFit, se determinó que se debe contar con un área administrativa, de nutrición, de fisioterapia, área común de staff y área de espera. Por lo cual, es necesario el requerimiento de ciertos muebles y enseres; tales como, sillas, mesas, asientos, escritorios, televisores, laptops; etc. A continuación, se detallan cada uno de los requerimientos previstos para cada área propuesta.

En la Tabla 49 se detallan los muebles y enseres que se requieren para la operación de la oficina administrativa, donde se llevará a cabo la atención de los clientes, las inscripciones y aquellas operaciones de funcionamiento de Ate CrossFit a cargo del administrador.

Tabla 49

Muebles y Enseres de Oficina Administrativa

\begin{tabular}{|c|c|c|c|c|c|c|}
\hline Descripción & Proveedor & Cantidad & $\begin{array}{c}\text { Precio } \\
\text { unitario }\end{array}$ & $\begin{array}{l}\text { Costo sin } \\
\text { IGV }\end{array}$ & IGV & Costo total \\
\hline Sillas & SODIMAC & 2 & 100.00 & 169.49 & 30.51 & 200.00 \\
\hline Escritorio & SODIMAC & 1 & 500.00 & 423.73 & 76.27 & 500.00 \\
\hline Laptops & $\mathrm{HP}$ & 2 & $1,500.00$ & $2,542.37$ & 457.63 & $3,000.00$ \\
\hline $\begin{array}{l}\text { Impresora } \\
\text { multifuncional }\end{array}$ & EPSON & 1 & 900.00 & 762.71 & 137.29 & 900.00 \\
\hline $\begin{array}{l}\text { Estante de } \\
\text { archivos }\end{array}$ & SODIMAC & 1 & 500.00 & 423.73 & 76.27 & 500.00 \\
\hline Kit de seguridad & HIK VISION & 1 & $1,700.00$ & $1,440.68$ & 259.32 & $1,700.00$ \\
\hline Repisa & SODIMAC & 2 & 50.00 & 84.75 & 15.25 & 100.00 \\
\hline Colgador de ropa & SODIMAC & 1 & 20.00 & 16.95 & 3.05 & 20.00 \\
\hline $\begin{array}{l}\text { Ventilador } \\
\text { pequeño }\end{array}$ & HIRAOKA & 1 & 60.00 & 50.85 & 9.15 & 60.00 \\
\hline Total & & & & $5,915.25$ & $1,064.75$ & $6,980.00$ \\
\hline
\end{tabular}


En la Tabla 50 se detallan los muebles y enseres que se requieren para la operación de la oficina de nutrición, donde se llevará a cabo las asesorías nutricionales y control de peso a cargo del nutricionista.

Tabla 50

Muebles y Enseres de la Oficina de Nutrición

\begin{tabular}{lcccccc}
\hline Descripción & Proveedor & Cantidad & $\begin{array}{c}\text { Precio } \\
\text { unitario }\end{array}$ & $\begin{array}{c}\text { Costo sin } \\
\text { IGV }\end{array}$ & IGV & $\begin{array}{c}\text { Costo } \\
\text { total }\end{array}$ \\
\hline Sillas & SODIMAC & 2 & 100.00 & 169.49 & 30.51 & 200.00 \\
$\begin{array}{l}\text { Escritorio } \\
\text { Computadora }\end{array}$ & SODIMAC & 1 & 500.00 & 423.73 & 76.27 & 500.00 \\
$\begin{array}{l}\text { Repisa } \\
\text { Colgador de }\end{array}$ & SODIMAC & 3 & 50.00 & 127.12 & 22.88 & 150.00 \\
$\begin{array}{l}\text { ropa } \\
\text { Balanza }\end{array}$ & SODIMAC & 1 & 20.00 & 16.95 & 3.05 & 20.00 \\
$\begin{array}{l}\text { Ventilador } \\
\text { pequeño }\end{array}$ & SODIMAC & 1 & 100.00 & 84.75 & 15.25 & 100.00 \\
Total & HIRAOKA & 1 & 60.00 & 50.85 & 9.15 & 60.00 \\
\hline
\end{tabular}

En la Tabla 51 se detallan los muebles y enseres que se requieren para la operación de la oficina de fisioterapia, donde se llevará a cabo las sesiones de terapia física, rehabilitación y descarga muscular a cargo de la fisioterapeuta.

Tabla 51

Muebles y Enseres de la Oficina de Fisioterapia

\begin{tabular}{|c|c|c|c|c|c|c|}
\hline Descripción & Proveedor & Cantidad & $\begin{array}{c}\text { Precio } \\
\text { unitario }\end{array}$ & $\begin{array}{l}\text { Costo sin } \\
\text { IGV }\end{array}$ & IGV & $\begin{array}{c}\text { Costo } \\
\text { total }\end{array}$ \\
\hline Sillas & SODIMAC & 2 & 100.00 & 169.49 & 30.51 & 200.00 \\
\hline Escritorio & SODIMAC & 1 & 500.00 & 423.73 & 76.27 & 500.00 \\
\hline Computadora & COMPUCENTER & 1 & $1,200.00$ & $1,016.95$ & 183.05 & $1,200.00$ \\
\hline Repisa & SODIMAC & 3 & 50.00 & 127.12 & 22.88 & 150.00 \\
\hline $\begin{array}{l}\text { Colgador de } \\
\text { ropa }\end{array}$ & SODIMAC & 1 & 20.00 & 16.95 & 3.05 & 20.00 \\
\hline $\begin{array}{l}\text { Mesa de } \\
\text { Fisioterapia }\end{array}$ & & 1 & 500.00 & 423.73 & 76.27 & 500.00 \\
\hline $\begin{array}{l}\text { Ventilador } \\
\text { pequeño } \\
\text { Total }\end{array}$ & HIRAOKA & 1 & 60.00 & $\begin{array}{c}50.85 \\
2,228.81\end{array}$ & $\begin{array}{c}9.15 \\
401.19\end{array}$ & $\begin{array}{c}60.00 \\
2,630.00\end{array}$ \\
\hline
\end{tabular}


En la Tabla 52 se detallan los muebles y enseres que se requieren para la operación de el área común, donde los miembros del staff podrán comer sus alimentos, descansar, interactuar y/o reunirse para planificar la agenda semanal; esta área estará a cargo del Head Coach; quién deberá supervisar el cumplimiento de las normas de convivencia interna; así como, el estado idóneo del lugar para los miembros.

Tabla 52

Muebles y Enseres del Área Común

\begin{tabular}{|c|c|c|c|c|c|c|}
\hline Descripción & Proveedor & Cantidad & $\begin{array}{l}\text { Precio } \\
\text { unitario }\end{array}$ & $\begin{array}{l}\text { Costo sin } \\
\text { IGV }\end{array}$ & IGV & $\begin{array}{c}\text { Costo } \\
\text { total }\end{array}$ \\
\hline Sillas & SODIMAC & 3 & 100.00 & 254.24 & 45.76 & 300.00 \\
\hline Asientos & SODIMAC & 1 & 400.00 & 338.98 & 61.02 & 400.00 \\
\hline $\begin{array}{l}\text { Mesa de } \\
\text { plástico }\end{array}$ & SODIMAC & 1 & 200.00 & 169.49 & 30.51 & 200.00 \\
\hline $\begin{array}{l}\text { Televisor } 32^{\prime} \\
\text { AOC } \\
\text { Microondas }\end{array}$ & $\begin{array}{l}\text { HIRAOKA } \\
\text { SAGA }\end{array}$ & 1 & 900.00 & 762.71 & 137.29 & 900.00 \\
\hline LG & FALABELLA & 1 & 500.00 & 423.73 & 76.27 & 500.00 \\
\hline $\begin{array}{l}\text { Refrigeradora } \\
\text { LG }\end{array}$ & HIRAOKA & 1 & 800.00 & 677.97 & 122.03 & 800.00 \\
\hline $\begin{array}{l}\text { Hervidor } \\
\text { Eléctrico }\end{array}$ & HIRAOKA & 1 & 100.00 & 84.75 & 15.25 & 100.00 \\
\hline $\begin{array}{l}\text { Purificador de } \\
\text { agua }\end{array}$ & SODIMAC & 1 & 150.00 & 127.12 & 22.88 & 150.00 \\
\hline Repisa & SODIMAC & 2 & 50.00 & 84.75 & 15.25 & 100.00 \\
\hline $\begin{array}{l}\text { Lavadero de } \\
\text { cocina }\end{array}$ & SODIMAC & 1 & 300.00 & 254.24 & 45.76 & 300.00 \\
\hline Estante & SODIMAC & 1 & 300.00 & 254.24 & 45.76 & 300.00 \\
\hline Total & & & & $3,432.20$ & 617.80 & $4,050.00$ \\
\hline
\end{tabular}

En la Tabla 53 se detallan los muebles y enseres que se requieren para la zona de espera, donde los clientes podrán descansar, interactuar o reunirse antes o después de su sesión de entrenamiento. Esta área estará a cargo del Head Coach y del administrador; quiénes deberán supervisar el cumplimiento de las normas de funcionamiento; así como, el estado idóneo del lugar para los clientes. 
Tabla 53

Muebles y Enseres del Área de Espera

\begin{tabular}{lcccccc}
\hline Descripción & Proveedor & Cantidad & $\begin{array}{c}\text { Precio } \\
\text { unitario }\end{array}$ & $\begin{array}{c}\text { Costo sin } \\
\text { IGV }\end{array}$ & IGV & $\begin{array}{c}\text { Costo } \\
\text { total }\end{array}$ \\
\hline $\begin{array}{l}\text { Asientos } \\
\begin{array}{l}\text { Estante para } \\
\text { guardar ropa }\end{array}\end{array}$ & SODIMAC & 2 & 400.00 & 677.97 & 122.03 & 800.00 \\
Total & & 1 & 500.00 & 423.73 & 76.27 & 500.00 \\
\hline
\end{tabular}

En la Tabla 54 se detallan los muebles y enseres que se requieren para la operación del Área de entrenamiento o WOD ZONE, donde los clientes realizarán las sesiones de entrenamiento CrossFit; así como, los miembros del staff, quienes podrán utilizar el área para entrenar, en las horas que no esté destinado al uso de las sesiones; esto es, de 12 p.m. a 3 p.m.; esta área estará a cargo del Head Coach y del administrador; quiénes deberán supervisar el cumplimiento de las normas de funcionamiento; así como, el estado idóneo del lugar para los clientes y miembros.

Tabla 54

Muebles y Enseres del Área de Entrenamiento

\begin{tabular}{|c|c|c|c|c|c|c|}
\hline Descripción & Proveedor & Cantidad & $\begin{array}{l}\text { Precio } \\
\text { unitario }\end{array}$ & $\begin{array}{l}\text { Costo sin } \\
\text { IGV }\end{array}$ & IGV & Costo total \\
\hline Televisor 32' AOC & HIRAOKA & 1 & 900.00 & 762.71 & 137.29 & 900.00 \\
\hline $\begin{array}{l}\text { Minicomponente } \\
\text { Panasonic }\end{array}$ & $\begin{array}{c}\text { SAGA } \\
\text { FALABELLA }\end{array}$ & 1 & 800.00 & 677.97 & 122.03 & 800.00 \\
\hline Repisa & SODIMAC & 1 & 50.00 & 42.37 & 7.63 & 50.00 \\
\hline $\begin{array}{l}\text { Ventiladores } \\
\text { Grande }\end{array}$ & SODIMAC & 2 & 600.00 & $1,016.95$ & 183.05 & $1,200.00$ \\
\hline Chalk Stand & SODIMAC & 6 & 40.00 & 203.39 & 36.61 & 240.00 \\
\hline $\begin{array}{l}\text { Temporizador } \\
\text { Rogue }\end{array}$ & ROGUE & 1 & 900.00 & 762.71 & 137.29 & 900.00 \\
\hline Baldoza de goma & ROGUE & 1 & $8,500.00$ & $7,203.39$ & $1,296.61$ & $8,500.00$ \\
\hline Barbell storage & ROGUE & 5 & 250.00 & $1,059.32$ & 190.68 & $1,250.00$ \\
\hline $\begin{array}{l}\text { Dumbbell \& } \\
\text { Kettlebells Storage }\end{array}$ & ROGUE & 2 & $1,200.00$ & $2,033.90$ & 366.10 & $2,400.00$ \\
\hline Speed Rope Wall & ROGUE & 1 & 150.00 & 127.12 & 22.88 & 150.00 \\
\hline Total & & & & $13,889.83$ & $2,500.17$ & $16,390.00$ \\
\hline
\end{tabular}


En la Tabla 55 se detallan los muebles y enseres que se requieren para los baños, donde los clientes podrán asearse o cambiarse. Esta área estará a cargo del personal de limpieza, quién deberá informar al administrador sobre el funcionamiento abastecimiento del mismo; así como, el estado idóneo del lugar para los clientes.

Tabla 55

Muebles y Enseres de Baños

\begin{tabular}{|c|c|c|c|c|c|c|}
\hline Descripción & Proveedor & Cantidad & $\begin{array}{c}\text { Precio } \\
\text { unitario }\end{array}$ & $\begin{array}{l}\text { Costo sin } \\
\text { IGV }\end{array}$ & IGV & $\begin{array}{l}\text { Costo } \\
\text { total }\end{array}$ \\
\hline $\begin{array}{l}\text { Cortinas de } \\
\text { ducha }\end{array}$ & SODIMAC & 4 & 50.00 & 169.49 & 30.51 & 200.00 \\
\hline Repisa & SODIMAC & 2 & 50.00 & 84.75 & 15.25 & 100.00 \\
\hline Lavaderos & SODIMAC & 4 & 200.00 & 677.97 & 122.03 & 800.00 \\
\hline Inodoros & SODIMAC & 4 & 400.00 & $1,355.93$ & 244.07 & $1,600.00$ \\
\hline $\begin{array}{l}\text { Colgadores de } \\
\text { Ropa }\end{array}$ & SODIMAC & 6 & 20.00 & 101.69 & 18.31 & 120.00 \\
\hline $\begin{array}{l}\text { Dispensador de } \\
\text { papel higiénico }\end{array}$ & MAKRO & 4 & 50.00 & 169.49 & 30.51 & 200.00 \\
\hline $\begin{array}{l}\text { Dispensador de } \\
\text { papel Scott }\end{array}$ & MAKRO & 2 & 50.00 & 84.75 & 15.25 & 100.00 \\
\hline $\begin{array}{l}\text { Dispensador de } \\
\text { jabón }\end{array}$ & SODIMAC & 2 & 60.00 & 101.69 & 18.31 & 120.00 \\
\hline Espejo de baño & SODIMAC & 2 & 30.00 & 50.85 & 9.15 & 60.00 \\
\hline Total & & & & $2,796.61$ & 503.39 & $3,300.00$ \\
\hline
\end{tabular}

\section{Equipos}

Para la ejecución de los servicios, se deberá contar con ciertos equipos ya establecidos en la metodología de CrossFit, Inc. para la enseñanza del CrossFit; en caso de no contar con alguno, el head coach elaborará la adaptación y progresión respectiva. En el caso de Ate CrossFit, se va a emplear los equipos que se describen en la Tabla 56. 
Tabla 56

Equipos de Entrenamiento CrossFit

\begin{tabular}{|c|c|c|c|c|c|c|c|}
\hline Equipo & Descripción & Proveedor & Cantidad & $\begin{array}{c}\text { Precio } \\
\text { unitario } \\
\end{array}$ & $\begin{array}{c}\text { Costo sin } \\
\text { IGV }\end{array}$ & IGV & Costo Total \\
\hline Barbells Men & Barra olímpica de hombre. Peso $45 \mathrm{lbs}$ & BullFit & 10 & 700.00 & $5,932.20$ & $1,067.80$ & $7,000.00$ \\
\hline Barbells Girl & Barra olímpica de mujer. Peso $35 \mathrm{lbs}$ & BullFit & 6 & 600.00 & $3,050.85$ & 549.15 & $3,600.00$ \\
\hline Box Jump & Caja de salto & BullFit & 15 & 220.00 & $2,796.61$ & 503.39 & $3,300.00$ \\
\hline Rack & Jaula de CrossFit para 25 personas & - & 1 & $18,000.00$ & $15,254.24$ & $2,745.76$ & $18,000.00$ \\
\hline Med Balls & Pelota medicinal de $14,16,20,25$ y $30 \mathrm{lbs}$ & BullFit & 16 & 250.00 & $3,389.83$ & 610.17 & $4,000.00$ \\
\hline \multirow[t]{9}{*}{$\begin{array}{l}\text { Bumper } \\
\text { Plates }\end{array}$} & Discos olímpicos de carga. S/. $6.00 \times \mathrm{Lb}$ & BullFit & & & 0.00 & 0.00 & 0.00 \\
\hline & $2.5 \mathrm{lbs}$ & & 10 & 15.00 & 127.12 & 22.88 & 150.00 \\
\hline & $5 \mathrm{lbs}$ & & 10 & 30.00 & 254.24 & 45.76 & 300.00 \\
\hline & $10 \mathrm{lbs}$ & & 16 & 60.00 & 813.56 & 146.44 & 960.00 \\
\hline & $15 \mathrm{lbs}$ & & 16 & 90.00 & $1,220.34$ & 219.66 & $1,440.00$ \\
\hline & $25 \mathrm{lbs}$ & & 14 & 150.00 & $1,779.66$ & 320.34 & $2,100.00$ \\
\hline & $35 \mathrm{lbs}$ & & 10 & 210.00 & $1,779.66$ & 320.34 & $2,100.00$ \\
\hline & $45 \mathrm{lbs}$ & & 10 & 270.00 & $2,288.14$ & 411.86 & $2,700.00$ \\
\hline & $55 \mathrm{lbs}$ & & 10 & 330.00 & $2,796.61$ & 503.39 & $3,300.00$ \\
\hline \multicolumn{8}{|l|}{ Black } \\
\hline $\begin{array}{l}\text { Concept } 2 \\
\text { Model D } \\
\text { Rower }\end{array}$ & Remo. Marca Concept 2 & Concept 2 & 3 & $2,900.00$ & $7,372.88$ & $1,327.12$ & $8,700.00$ \\
\hline $\begin{array}{l}\text { Assault Air } \\
\text { Bike }\end{array}$ & Bicicleta de resitencia. Marca Concept 2 & Concept 2 & 3 & $2,500.00$ & $6,355.93$ & $1,144.07$ & $7,500.00$ \\
\hline $\begin{array}{l}\text { Climbing } \\
\text { Rope }\end{array}$ & Cuerda para escalar de $20^{\prime}$ x $1.5^{\prime \prime}$ & BullFit & 4 & 200.00 & 677.97 & 122.03 & 800.00 \\
\hline $\begin{array}{l}\text { Bandas } \\
\text { elásticas }\end{array}$ & Bandas elásticas para recuperación & BullFit & 12 & 50.00 & 508.47 & 91.53 & 600.00 \\
\hline $\mathrm{Ab}$ mat & Colchoneta & BullFit & 12 & 75.00 & 762.71 & 137.29 & 900.00 \\
\hline \multirow[t]{10}{*}{ Dumbbells } & Mancuerna $\mathrm{x}$ pair & Rudem & & & & & \\
\hline & 5 lbs - Pair & & 2 & 100.00 & 169.49 & 30.51 & 200.00 \\
\hline & $10 \mathrm{lbs}$ - pair & & 2 & 150.00 & 254.24 & 45.76 & 300.00 \\
\hline & $20 \mathrm{lbs}$ - pair & & 2 & 200.00 & 338.98 & 61.02 & 400.00 \\
\hline & $30 \mathrm{lbs}$ - pair & & 2 & 300.00 & 508.47 & 91.53 & 600.00 \\
\hline & $45 \mathrm{lbs}$ - pair & & 2 & 350.00 & 593.22 & 106.78 & 700.00 \\
\hline & $50 \mathrm{lbs}$ - pair & & 2 & 400.00 & 677.97 & 122.03 & 800.00 \\
\hline & $60 \mathrm{lbs}$ - pair & & 2 & 450.00 & 762.71 & 137.29 & 900.00 \\
\hline & $70 \mathrm{lbs}$ - pair & & 2 & 550.00 & 932.20 & 167.80 & $1,100.00$ \\
\hline & $80 \mathrm{lbs}$ - pair & & 2 & 600.00 & $1,016.95$ & 183.05 & $1,200.00$ \\
\hline \multirow[t]{7}{*}{ Kettlebells } & Pesas rusas & Rudem & & & & & \\
\hline & KB $9 \mathrm{lbs}$ & & 4 & 80.00 & 271.19 & 48.81 & 320.00 \\
\hline & KB $18 \mathrm{lbs}$ & & 4 & 100.00 & 338.98 & 61.02 & 400.00 \\
\hline & KB $26 \mathrm{lbs}$ & & 4 & 130.00 & 440.68 & 79.32 & 520.00 \\
\hline & KB $35 \mathrm{lbs}$ & & 3 & 150.00 & 381.36 & 68.64 & 450.00 \\
\hline & KB $53 \mathrm{lbs}$ & & 3 & 200.00 & 508.47 & 91.53 & 600.00 \\
\hline & KB $70 \mathrm{lbs}$ & & 2 & 260.00 & 440.68 & 79.32 & 520.00 \\
\hline Rings & Anillar - pair & BullFit & 10 & 200.00 & $1,694.92$ & 305.08 & $2,000.00$ \\
\hline Sled & Trineo de carga para deslizar & BullFit & 2 & 900.00 & $1,525.42$ & 274.58 & $1,800.00$ \\
\hline Yokes & Yugo de carga & Rudem & 2 & $1,500.00$ & $2,542.37$ & 457.63 & $3,000.00$ \\
\hline GHD & Glute Ham & Rudem & 2 & $1,200.00$ & $2,033.90$ & 366.10 & $2,400.00$ \\
\hline Parallettes & Paralelos & BullFit & 4 & 100.00 & 338.98 & 61.02 & 400.00 \\
\hline Speed Rope & Soga de salto & Huq & 12 & 50.00 & 508.47 & 91.53 & 600.00 \\
\hline Peg Board & Tablero de clavijas para escalar & Rogue & 4 & 500.00 & $1,694.92$ & 305.08 & $2,000.00$ \\
\hline Collars & Sujetadores de barra - par & BullFit & 14 & 60.00 & 711.86 & 128.14 & 840.00 \\
\hline $\begin{array}{l}\text { Accesorio de } \\
\text { Rack }\end{array}$ & Accesorio de Rack para levantamiento & BullFit & 13 & 150.00 & $1,652.54$ & 297.46 & $1,950.00$ \\
\hline Slam Ball & Pelotas de carga & BullFit & 3 & 150.00 & 381.36 & 68.64 & 450.00 \\
\hline Total & & & & & $77,881.36$ & $14,018.64$ & $91,900.00$ \\
\hline
\end{tabular}




\subsubsection{Lay out}

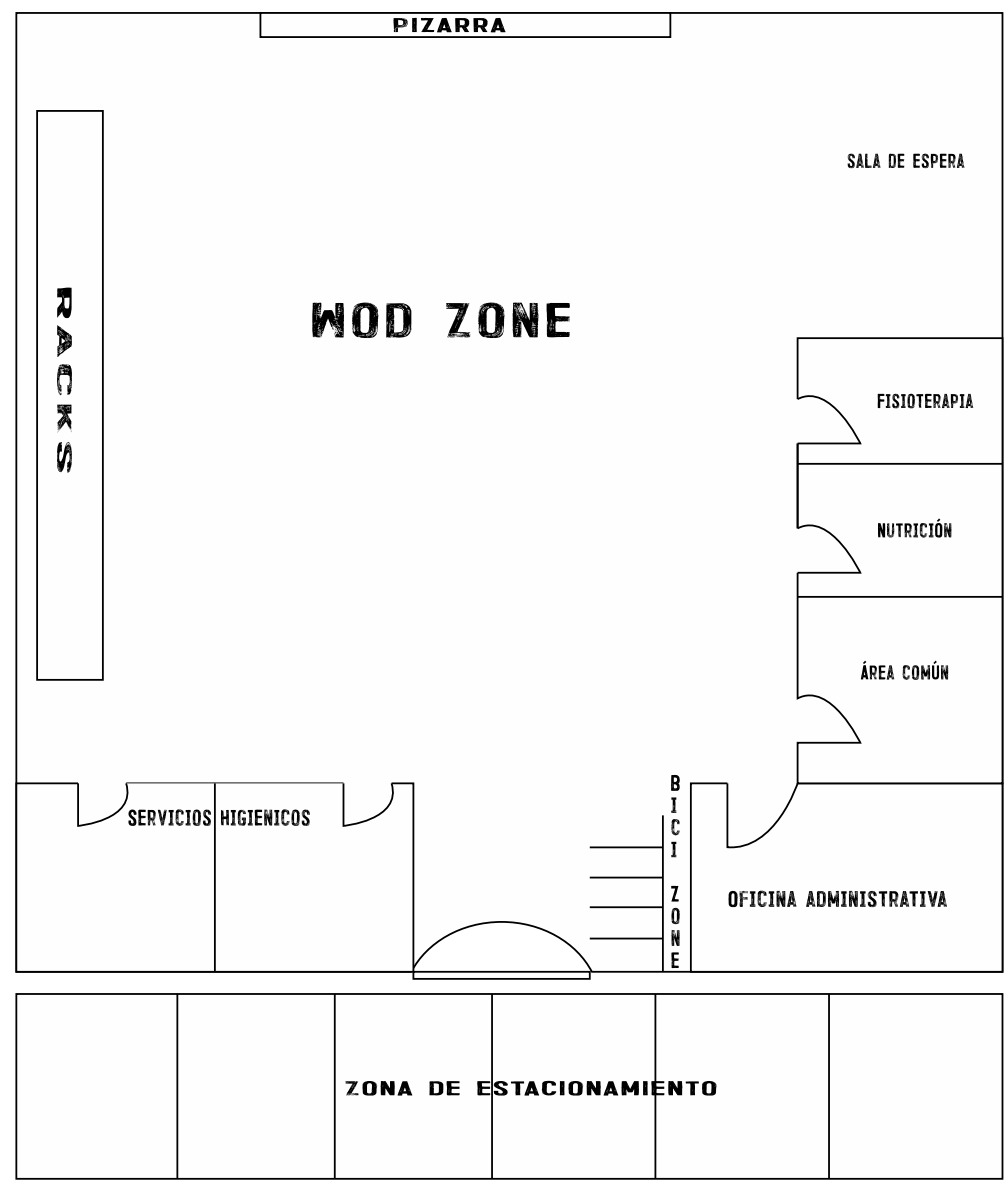

Figura 50. Layout Ate CrossFit

\subsubsection{Distribución de equipos y maquinarias}

Para maximizar la productividad y aprovechar al máximo los espacios del local, la distribución de equipos y muebles ha sido equitativa. En la Figura 51 se muestra los espacios donde los equipos y las maquinarias serán instaladas en cada área.

\subsection{Determinación del Tamaño}

La empresa se ubicará en un local de $300 \mathrm{~m}^{2}$ y se ha contemplado que se implementarán 7 áreas, las mismas que contarán con las dimensiones descritas en la Tabla 57; y estas son:

- Área de administración: espacio donde se ubicará el administrador y toda la información pertinente de la empresa.

- Área de espacios comunes: lugar donde los miembros del Staff podrán descansar, recrearse, consumir sus alimentos e interactuar entre si.

- Área de Fisioterapia: lugar donde se impartirá las sesiones de terapia física, rehabilitación y descarga muscular de los clientes.

- Área de nutrición: lugar donde se brindará las asesorías nutricionales a los clientes. 
- Área de entrenamiento: lugar donde se ejecutará los entrenamientos diarios. Este se dividirá en 3 espacios: WOD Zone, Weighlifting zone y Mobility zone.

- Área de servicios: lugar donde se ubicará los servicios higiénicos de la empresa.

- Área de espera: espacio donde los clientes podrán descansar o esperar su turno de atención o inicio de clase.

Tabla 57

Dimensiones de Áreas

\begin{tabular}{lc}
\hline Área & Dimensiones \\
\hline Administrativa & $20 \mathrm{~m}^{2}$ \\
Espacios comunes & $20 \mathrm{~m}^{2}$ \\
Fisioterapia & $20 \mathrm{~m}^{2}$ \\
Nutrición & $20 \mathrm{~m}^{2}$ \\
Entrenamiento & $180 \mathrm{~m}^{2}$ \\
Espera & $20 \mathrm{~m}^{2}$ \\
Servicios & $20 \mathrm{~m}^{2}$ \\
Total & $300 \mathrm{~m}^{2}$ \\
\hline Nota: $\mathrm{m}^{2}$ corresponde a la abreviación de metro cuadro.
\end{tabular}

\subsubsection{Proyección de crecimiento}

Ate CrossFit no contempla un crecimiento de sus instalaciones o cambio de local; esto, debido a que primero, la empresa deberá captar a clientes y fidelizarlos, reduciendo costos y generando ingresos; sin embargo, se prevé un crecimiento de la demanda del servicio a lo largo del tiempo; la misma que será satisfecha con la ampliación del horario de las sesiones de entrenamiento; así como del personal pertinente para el seguimiento y control de las mismas. El horario inicial será de 6 a.m. a 11 a.m. y de 4 p.m. a 9 p.m.; culminando el último turno a las 10 p.m. Esto último, debido a los resultados obtenidos de la investigación de mercado (ver Figura 51); donde se aprecia que el mayor porcentaje de personas que acudan al box de CrossFit, se dará en el turno de 6p.m a 10 p.m. y en segundo lugar el turno de 6 a.m. a 9 a.m.; cifras que permiten determinar las horas en las cuales deberán estar presentes 2 Coaches por clase, y que en el futuro, podría ampliarse la atención con un Coach adicional. 


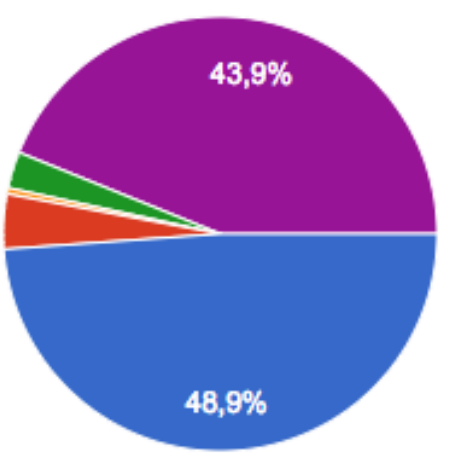

Figura 51. Preferencia de horario par asistir al Box de CrossFit Pregunta 23: ¿Qué horario prefiere para asistir al Box(Gimnasio) de CrossFit. Tomado de "Cuestionario de investigación de mercado", 2018. Recuperado de https://docs.google.com/forms/d/1__IAz6OKMpFN2uw8nA580A3v4jiYo9HZO6mGsveJSIg/edit\#responses

\subsubsection{Recursos}

Los recursos a emplearse en Ate CrossFit son:

Financieros

Para el presente plan de negocio, un $75 \%$ será por aporte de los socios, mientras que un $25 \%$ a través de un préstamo bancario del BBVA Continental

Humanos

Ate Crossfit estará conformada por: (a) Un administrador, (b) un contador, (c) un head coach, (d) tres Coaches, (e) una nutricionista, (f) una fisioterapeuta, y (g) un personal de limpieza.

Equipos

Los equipos, muebles y enseres que emplearemos están determinados en el encabezado

\subsection{2.}

\subsubsection{Tecnología}

Ate CrossFit utilizará la tecnología como medio tanto de comunicación como de seguimiento con sus clientes; para ello, se suscribirá a las siguientes a las siguientes plataformas:

- G Suite: plataforma de Google para optimizar el trabajo en las empresas. El paquete G Suite está conformado por las siguientes Google Apps: Drive, Gmail, Calendario, Documentos, Hangouts, etc.

- Microsoft Office: Software para el uso de herramientas de trabajo como Word, Power Point, Excel y Vicio. 
- Adobe: Software para el uso de herramientas de diseño y edición tales como: Adobe Premiere Pro CC, Ilustrator, Photoshop, InDesign, etc.

- Wodify: Plataforma de gestión de gimnasio; ya sea para la organización de las clases, seguimiento a los alumnos, asistencia, elaboración de los Wods, guía nutricional, etc.

\subsubsection{Flexibilidad}

En razón al horario de clases, el cliente podrá acudir a entrenar en cualquier momento del día dentro de los horarios establecidos. El cliente contará, dependiendo de su plan de membresía, días de congelamiento en caso de que este no pueda asistir al box y los podrá utilizar de la manera en las que este crea conveniente sin restricción alguna.

En el caso de las asesorías nutricionales, estas se darán 1 vez al mes y será de conformidad al cupo de reserva disponible; en caso que el alumno no pueda acudir, podrá reprogramarse a una siguiente cita sin necesidad de sustentarlo; siempre y cuando, de previo aviso de $6 \mathrm{hrs}$ mediante llamada telefónica, mensaje de texto, correo electrónico o WhatsApp; no es necesario la presencia física.

Las sesiones de fisioterapia se darán 1 vez al mes y será de conformidad al cupo de reserva disponible; en caso que el alumno no pueda acudir, se podrá programar a una siguiente cita sin necesidad de sustentarlo; siempre y cuando, de previo aviso de $24 \mathrm{hrs}$ mediante llamada telefónica, mensaje de texto, correo electrónico o WhatsApp; no es necesario la presencia física.

\subsubsection{Selección del tamaño ideal}

Para la distribución del todos los equipos, muebles y enseres; así como el cumplimiento de los servicios de Ate CrossFit; se ha determinado que el tamaño ideal para este box es de 300 $\mathrm{m} 2$.

\subsection{Estudio de Localización}

Al respecto Corrillo y Gutiérrez (2016) señalan que "el objetivo del estudio de la localización de un proyecto es analizar las diferentes alternativas de ubicación espacial del proyecto"; así mismo, indican que esta debe ofrecer los máximos beneficios y mejores costos para la empresa. Sapag (2014) indica que la localización es un factor decisivo para el éxito o fracaso de toda empresa.

\subsubsection{Definición de factores locacionales}

Para determinar los factores locacionales, se tomará en cuenta las fuerzas locacionales descritas por Sapag (2004); estas son: la macro localización y micro localización. 
Macro localización

Ate CrossFit estará ubicado en el distrito de Ate, provincia y departamento de Lima; exactamente en la Zona 2 (ver Figura 52) perteneciente a la Zona cinco de la distribución de niveles por APEIM. En la Tabla 58 se encuentra la descripción del Distrito.

Tabla 58

Información del Distrito de Ate

\begin{tabular}{lc}
\hline Información & \\
\hline Distrito & Ate \\
Año de Creación & 1821 \\
Altitud & $280 \mathrm{~m} . \mathrm{s.n.m}$. \\
Latitud sur & $12^{\circ} 01^{\prime} 18^{\prime \prime}$ \\
Longitud oeste & $76^{\circ} 54^{\prime} 57^{\prime}$, \\
Superficie & $77.72 \mathrm{~km} 2$ \\
Límites & \\
Norte & Río Rímac, distritos de Lurigancho-Chosica, \\
Sur & Santa Anita y El Agustino \\
& Distritos de Cieneguilla, La Molina y Santiago \\
Este & de Surco \\
Oeste & Distrito de Chaclacayo \\
\hline
\end{tabular}

Nota: Adaptado de "Boletín Estadístico N ${ }^{o} 1$ : Perfil Demográfico, Edad y Género a Nivel Distrital y Zonal" (pp. 3-4), por Municipalidad Distrital de Ate, 2011, Ate. Copyright 20115 por Municipalidad Distrital de Ate.

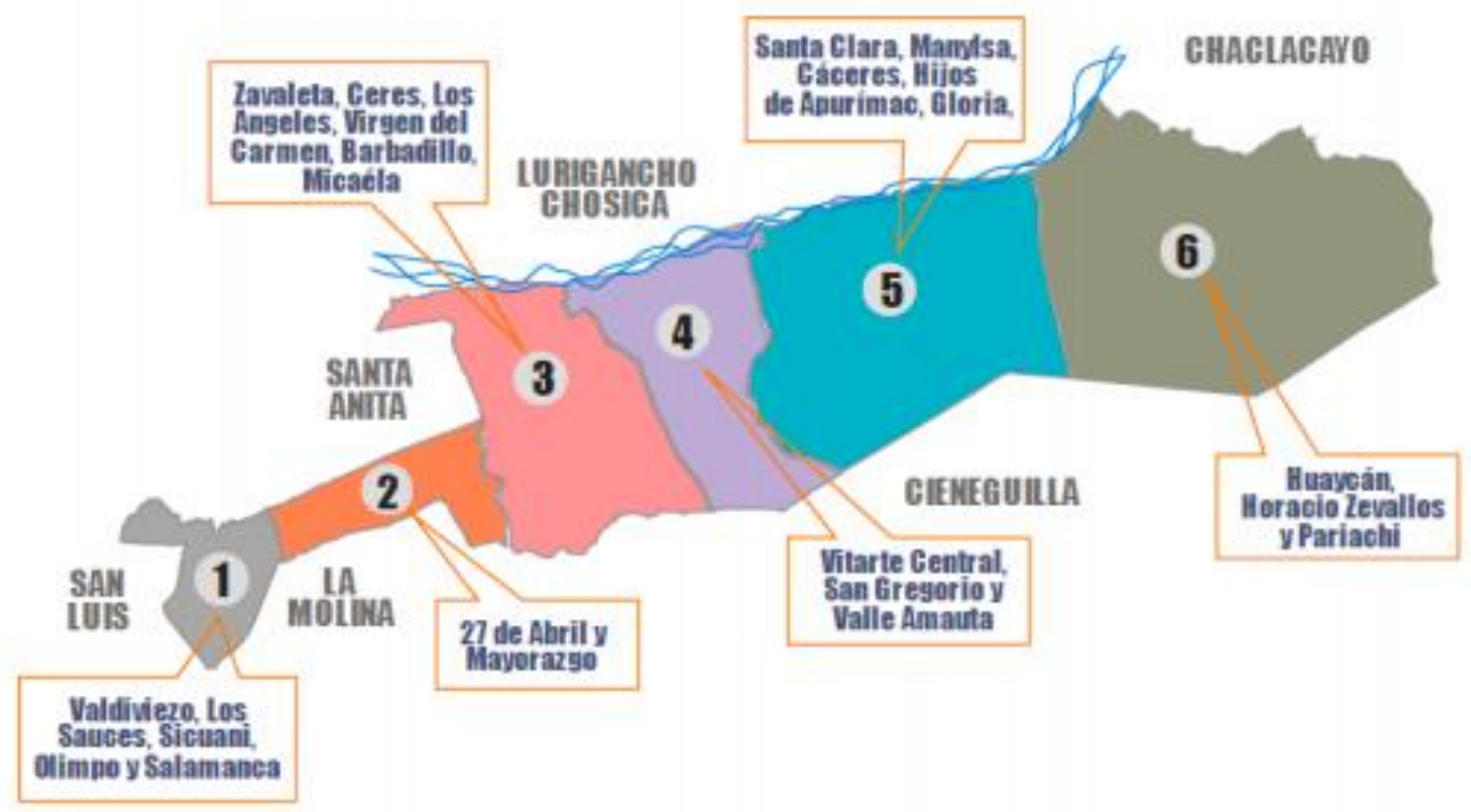

Figura 52. Zonas del distrito de Ate. Elaborado por Gerencia de Planificación-Sub Gerencia de Planes, Programas y Estadística, ordenanza No 35035-MDA Tomado de Plan de Manejo de Residuos 2014-2018 (p. 6), por Municipalidad Distrital de Ate, 2011, Ate. Copyright 2014 por Municipalidad Distrital de Ate. 
En las Figuras 53 y 54 se aprecia ubicación del Distrito de Ate en Lima Metropolitana y los limites de la misma.

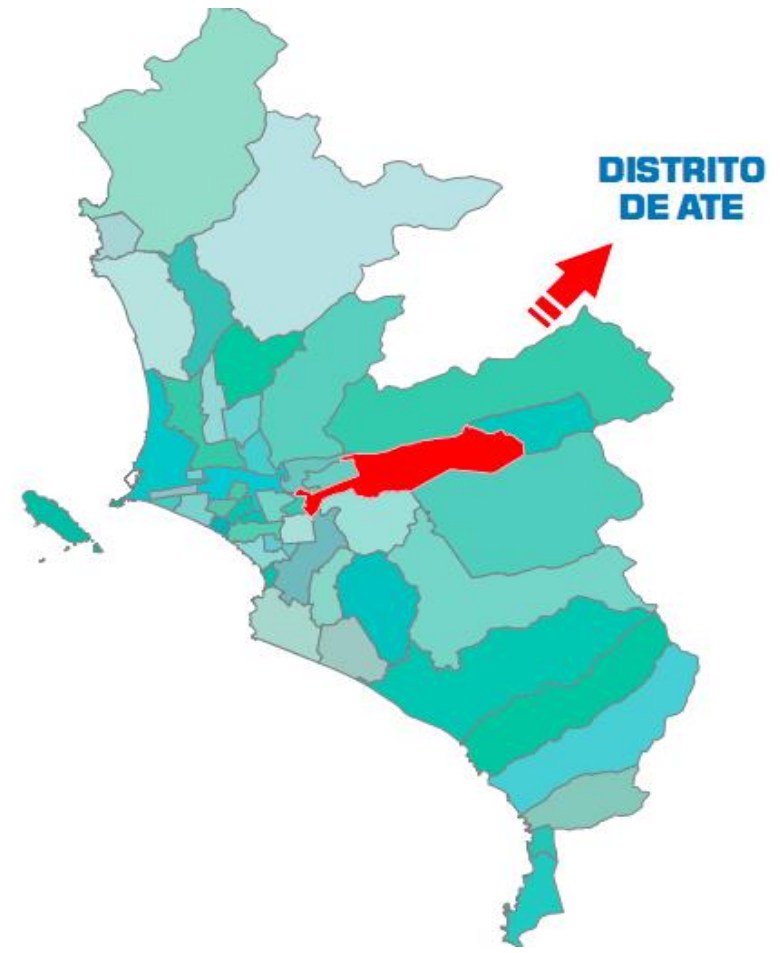

Figura 53. Distrito de Ate: ubicación del distrito en Lima Metropolitana. Elaborado por MDA- Gerencia de Planificación-Sub Gerencia de Planes, Programas y Estadística. Tomado de Boletín Estadístico No 1: Perfil Demográfico, Edad y Género a Nivel Distrital y Zonal (p. 3), por Municipalidad Distrital de Ate, 2011, Ate. Copyright 2011 por Municipalidad Distrital de Ate.

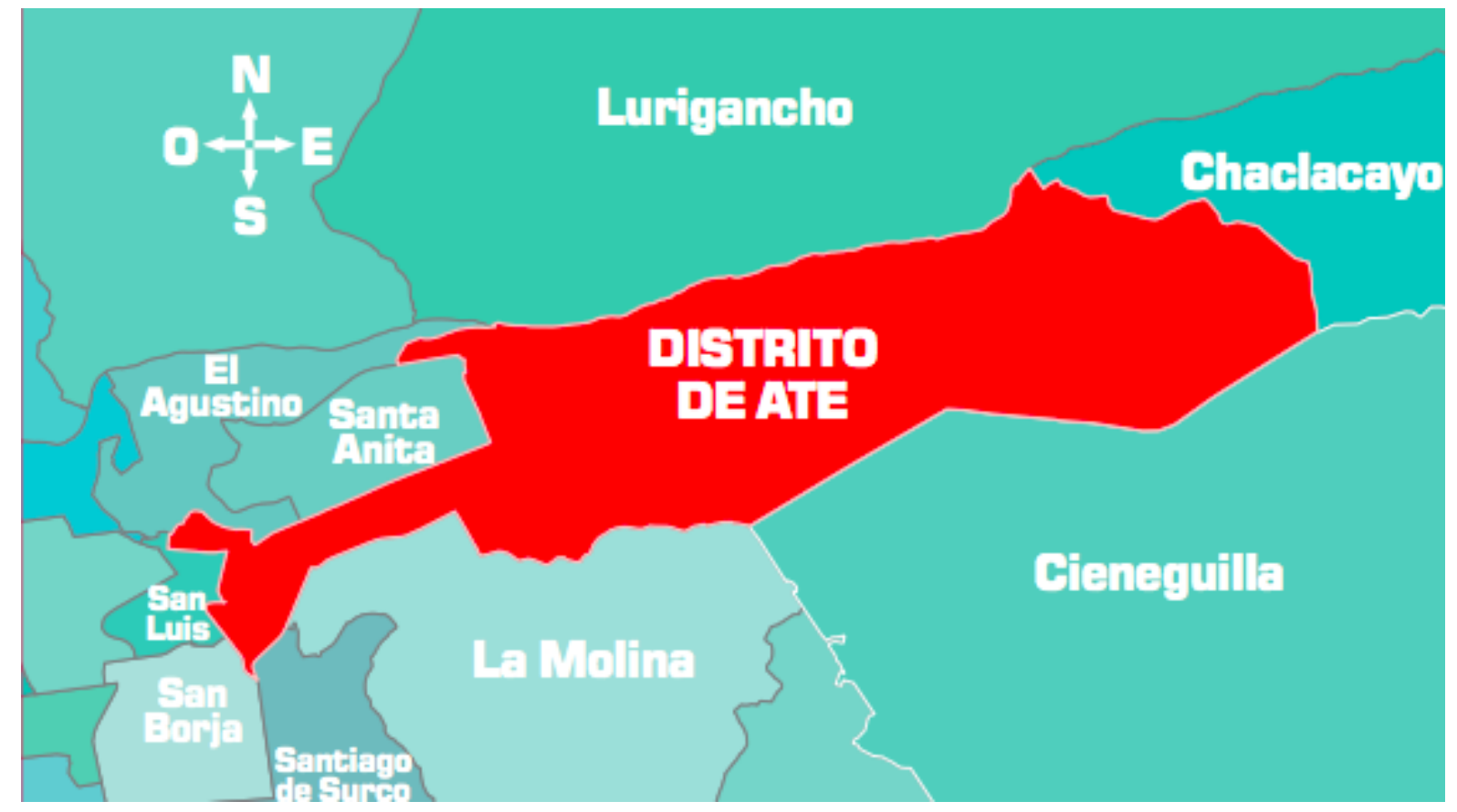

Figura 54. Distrito de Ate: Límites del distrito de Ate. Elaborado por MDA- Gerencia de Planificación-Sub Gerencia de Planes, Programas y Estadística. Tomado de Boletín Estadístico No 1: Perfil Demográfico, Edad y Género a Nivel Distrital y Zonal (p. 4), por Municipalidad Distrital de Ate, 2011, Ate. Copyright 2011 por Municipalidad Distrital de Ate. 


\section{Micro localización}

Se tomará en cuenta los factos establecidos por Sapag (2011):

1. Mercado de interés: La concentración de la población objetico para la presente investigación, tiene como finalidad la apertura de un box de CrossFit para combatir la obesidad en el distrito de Ate, que como ya se ha señalado, según ENDES (2016), es el tercer distrito con mayor porcentaje de obesidad en su población.

2. Transporte y accesibilidad: Es necesario que el box de CrossFit se encuentre cerca de las vías de comunicación y transporte más conexas del distrito de Ate, y que estas no sean de difícil acceso para la población. Por ende, se determinó que una zona accesible, de conformidad con lo observado en las Figuras 59 y 69, debe ser cerca de las avenidas que colinden con el distrito de La Molina como es el caso de la Av. Separadora Industrial, Av. Flora Tristán, Av. Ingenieros; así como de aquellas avenidas de alto tránsito de Ate, el óvalo de Santa Anita, zona aledaña a los centros comerciales de Wong y Promart; así como de empresas de servicios y centros de estudio. Asimismo, se debe tomar en cuenta que dichas zonas son las más seguras del distrito.

3. Regulaciones legales: La empresa estará sometida a los parámetros legales establecidos por la Ley General de Sociedades (Ley N²6887), las regulaciones tributarias dispuestas por la Superintendencia Nacional de Aduanas y de Administración Tributaria (SUNAT), las normas legales y ordenanzas que la Municipalidad Distrital de Ate disponga, Ley General de Trabajo, entre otros que corresponda al ámbito de fomento a la actividad económica del país.

4. Aspecto técnicos: Se ha considerado las condiciones climáticas y disponibilidad de agua. De conformidad con la Gerencia de Servicios a la Ciudad, Subgerencia de Limpieza Pública y Ornato de la Municipalidad Distrital de Ate (2014) el clima de del distrito es variado, lluvioso y templado, en el caso de las zonas ubicadas en la parte oeste (Salamanca de Monterrico y Olimpo) del distrito suele haber un clima húmedo en comparación al clima cálido y seco de la zona este (Santa Clara y Huaycán). En el caso del agua potable, la conexión facturada ha llegado a 69,137 al 2011; asimismo, la Gerencia de Servicios a la Ciudad, Subgerencia de Limpieza Pública y Ornato de la Municipalidad Distrital de Ate (2014) señala que se produjo "el consumo total de 18 mil 279 metros cúbicos y una producción subterránea de 42 mil 773 metros cúbicos de agua (p. 8).

5. Aspecto Ambiental: el distrito de Ate presenta ciertos problemas respecto al impacto ambiental que se general en el aire; esto, en razón al último informe emitido por la 
Gerencia de Servicios a la Ciudad, Subgerencia de Limpieza Pública y Ornato de la Municipalidad Distrital de Ate (2014) en el Plan de Manejo de Residuos Sólidos 20142018; donde se registra que según el último informe emitido por el Servicio Nacional de Meteorología e Hidrología (SENAMHI) 2015 la concentración promedio de polvo atmosférico sedimentable (PAS) en el 2011 se incrementó a 17.7 toneladas por kilómetro cuadrado y por mes en Ate; asimismo, en dicho plan se determinó que Ate tuvo menores índices de Dióxido de Azufre, con un 3.4 ppb; sin embargo esta es superior al mínimo permisible de 3 ppb, según OMS (2018). Finalmente, en razón a las partículas de PM10, al año 2014, el distrito de Ate registró una emisión de 130,7 ug/m3, cifra por debajo del límite máximo de $150 \mathrm{ug} / \mathrm{m} 3$ de acuerdo a los Estándares de Calidad para el Aire (ECA). Por ello, es indispensable que Ate CrossFit se somete a los lineamientos de mejora propuestos en el Plan de Manejo de Residuos Sólidos propuestos por la Gerencia de Servicios a la Ciudad, Subgerencia de Limpieza Pública y Ornato de la Municipalidad Distrital de Ate (2014); así como, al marco normativo nacional que se disponga, en razón a la reducción del impacto ambiental y orientación ambiental.

6. Costo y disponibilidad de terrenos: se considera que para la práctica del CrossFit, el tamaño ideal del box sea de $300 \mathrm{~m} 2$; a fin de que los equipos destinados, se encuentren en un espacio determinado sin que incomode el pase de las personas. Para ello, se realizó una investigación en las principales webs de venta y alquiler de viviendas; tales como: a donde vivir, urbania, etc. Determinándose que el precio del m2 en alquiler de Ate es cómodo; la cual oscila entre S/. 15 a S/. 25 nuevos soles.

En la Tabla 59 se muestra el análisis de los factores locacionales frente a las zonas de Ate; esto último con el fin de determinar la Zona (ver Figura 52), que se adapte mejor. Para ello, se efectuó el método cuantitativo por puntos. 
Tabla 59

Ponderación de las Zonas frente a los Factores Locacionales.

\begin{tabular}{|c|c|c|c|c|c|c|c|c|c|c|c|c|c|}
\hline & & $\begin{array}{c}\text { Zona } \\
1 \\
\end{array}$ & & $\begin{array}{c}\text { Zona } \\
2 \\
\end{array}$ & & $\begin{array}{c}\text { Zona } \\
3 \\
\end{array}$ & & $\begin{array}{c}\text { Zona } \\
4 \\
\end{array}$ & & $\begin{array}{c}\text { Zona } \\
5 \\
\end{array}$ & & $\begin{array}{c}\text { Zona } \\
6 \\
\end{array}$ & \\
\hline & Peso & C & $\mathrm{P}$ & C & $P$ & C & $\mathrm{P}$ & C & $P$ & C & $P$ & $\mathrm{C}$ & $P$ \\
\hline $\begin{array}{l}\text { Mercado de } \\
\text { Interés }\end{array}$ & 0.3 & 7 & 2.1 & 8 & 2.4 & 6 & 1.8 & 5 & 1.5 & 4 & 1.2 & 3 & 0.9 \\
\hline $\begin{array}{l}\text { Transporte y } \\
\text { accesibilidad }\end{array}$ & 0.15 & 6 & 0.9 & 7 & 1.05 & 5 & 0.75 & 3 & 0.45 & 3 & 0.45 & 2 & 0.3 \\
\hline $\begin{array}{l}\text { Reguaciones } \\
\text { legales }\end{array}$ & 0.15 & 6 & 0.9 & 8 & 1.2 & 4 & 0.6 & 3 & 0.45 & 3 & 0.45 & 2 & 0.3 \\
\hline $\begin{array}{l}\text { Aspectos } \\
\text { técnicos }\end{array}$ & 0.1 & 5 & 0.5 & 5 & 0.5 & 5 & 0.5 & 4 & 0.5 & 4 & 0.4 & 5 & 0.5 \\
\hline $\begin{array}{l}\text { Aspectos } \\
\text { ambientales }\end{array}$ & 0.1 & 4 & 0.4 & 7 & 0.7 & 3 & 0.3 & 3 & 0.3 & 3 & 0.3 & 1 & 0.1 \\
\hline $\begin{array}{l}\text { Costo y } \\
\text { disponibilidad } \\
\text { de terrenos }\end{array}$ & 0.2 & 3 & 0.6 & 5 & 1 & 5 & 1 & 6 & 1.2 & 7 & 1.4 & 8 & 1.6 \\
\hline Total & 1 & & 5.4 & & 6.85 & & 4.95 & & 4.3 & & 4.2 & & 3.7 \\
\hline
\end{tabular}

Nota: Las Zonas han sido determinadas por la Gerencia de Planificación-Sub Gerencia de Planes, Programas y Estadística, ordenanza N ${ }^{\circ} 35035-M D A$, asimismo, (c) y (p) pertenecen a la cantidad y puntaje, respectivamente Adaptado de "Estudio de localización de un proyecto", por Fabiola Corrillo Machicado y Maribel Gutiérrez Quiroga, 2016, Ventana Científica, 11, p. 32. Copyright 20116 por Ventana Científica.

Como ha de apreciarse, la Zona 2 es la que mayor puntuación ha obtenido; por lo cual, Ate CrossFit deberá situarse dentro de esta zona.

\subsubsection{Consideraciones legales}

Para la realización de cualquier actividad económica en el país, es necesario contar con una regularización que permita brindar la credibilidad de los servicios que se oferta. Así como, del aprovechamiento de ciertos incentivos empresariales que el estado otorga.

\subsubsection{Identificación del marco legal}

- Constitución de la sociedad: Para la constitución de una empresa se emplea como base legal la Ley General de Sociedades -Ley № 26887- la cual rige en todo el territorio peruano. Para el presente caso, el tipo de sociedad elegido es de una Sociedad Anónima Cerrada. Esto último, debido a que para la constitución de la misma, el capital proviene de la aportación que realicen los socios, que se representa en número de acciones, la cual limita la responsabilidad frente a terceros.

- Afectación tributaria: La empresa queda afecta a los siguientes tributos:

1. Régimen tributario: para el presente caso, se acoge el Régimen MYPE Tributario (RMT), la cual tiene por objetivo promover la actividad económica en el país. 
Asimismo, uno de los requisitos es que sus ingresos netos no superen las S/. 1700 UIT y cuyo pago de Renta será de forma proporcional a los ingresos netos anuales.

2. Rentas de tercera categoría: por la realización de cualquier actividad económica, el pago mensual mediante pagos a cuenta es de $30 \%$ de la utilidad neta.

3. Impuesto General a las Ventas: Este impuesto grava el valor agregado por cada transacción que se realiza en las ventas, la cual corresponde a una tasa de 16\% + 2\% del Impuesto de Promoción Municipal (IPM); de tal modo que a la operación gravada se le aplica un total de $18 \%$.

4. Prestaciones sociales: Según ley, estos tributos son deducciones que se le realizan al trabajador por concepto de Essalud y ONP o AFP, cuyas tasas varían entre 9\% y $13 \%$ respectivamente.

5. Impuesto predial: tributo municipal que grava la propiedad de predios urbanos.

6. Licencia municipal de funcionamiento de la Municipalidad de Ate: Autorización que otorga la Municipalidad a toda empresa para el desarrollo de su actividad comercial. Estas pueden ser, temporal e indeterminada. Para la obtención de dicho documento, se deben seguir los siguientes pasos: primero, presentar una Declaración Jurada de observancia de condiciones de seguridad de Defensa Civil; segundo, realizar el pago de derecho de trámite de S/. 100 soles en el año especificado

\subsubsection{Ordenamiento jurídico de la empresa}

Ate CrossFit será una persona jurídica formalmente constituida, cuyo tipo de sociedad será de una Sociedad Anónima Cerrada (S.A.C.). Los socios serán dos personas naturales cuyo aporte será:

1. Giancarlo Renán Chávez Suárez con el 50\% del total de acciones (Socio 1).

2. Arturo Palomino Mendioloza con el 50\% del total de acciones (Socio2).

Para efectos de que el registro de la sociedad se la idónea, a continuación se presentan los pasos a seguir para la constitución de la empresa:

1. Reserva de nombre: Para la verificación de que la razón social de la empresa no está en uso, se deberá realizar una búsqueda de la misma ante la Superintendencia Nacional de Registros Públicos (SUNARP); el costo será de S/. 5.00; acto seguido, si la razón social no está en uso, debemos de reservar el nombre por un período de 30 días y el costo de dicho trámite es de S/. 20.00. 
2. Minuta de constitución de la empresa: los socios deberán redactar y firmar la minuta de constitución de la empresa; donde deberá estipularse la descripción de la actividad económica, el aporte de los socios, el estatuto de la empresa, etc.

3. Capital de la empresa: Es el aporte dinerario con el cual se apertura una cuenta bancaria a nombre de la empresa o en su defecto, el aporte puede hacerse con maquinarias, equipos, mueves o enseres.

4. Elevación a registros públicos: Luego de haber elaborado la minuta y de tener el capital de la empresa, se acude a la notaría más cercana, con la finalidad de que el Notario de fe de dicho acto y convierta la minuta en una escritura pública y proceda a elevarla a registros públicos.

5. Inscripción de la empresa ante SUNAT: Antes de iniciar las operaciones de la empresa, se debe obtener el Registro Único de Contribuyentes (RUC). El trámite es gratuito y se debe llevar: Original y copia de DNI de los titulares o del representante legal; original y copia de recibo de luz o de agua o telefonía; original y copia de la partida electrónica con fecha cierta de la inscripción de la empresa ante SUNARP.

\subsection{Determinación de la Localización Óptima}

Se ha considerado como ubicación estratégica para "Ate CrossFit" en la Calle Los Talladores $N^{\circ} 151$ - Distrito de Ate, el cual se encuentra a pocas cuadras del óvalo de Santa Anita, zona aledaña a centros comerciales tales como Wong y Promart, así como cerca a empresas de servicios y estudios de mucha afluencia de público, al ser cercana a la Avenida Separadora Industrial lo cual lo ubica próxima a universidades. 


\section{Capítulo VIII: Aspectos Organizacionales}

En este capítulo se estudiará aquellas características esenciales que hay en cada cultura organizacional, y así poder decidir la nuestra. Se parte desde la creación de nuestra visión, misión y principios; del mismo modo, se formula las estrategias del negocio para determinar las ventajas competitivas. Se diseña una estructura organizacional deseable para la empresa acorde a los fundamentos de CrossFit, Inc. integrando los perfiles del puesto clave; pues, en la industria del fitness es indispensable contar con ésta; del mismo modo, se determina la remuneración, compensación e incentivos que cada trabajador tendrá por el desarrollo de sus funciones. Finalmente, se crea una política de recursos humanos que sirva de apoyo a todo lo contemplado en el presente capítulo.

\subsection{Caracterización de la Cultura Organizacional Deseada}

Kotler y Keller (2012) señalan que la cultura organizacional está basada en "las experiencias, historias, creencias y normas compartidas que caracterizan a una organización" (p. 45); las cuales, se van adaptando y desarrollando con el tiempo; siendo así, la base para el desarrollo de la empresa, que determina el éxito o fracaso de la misma en el corto o largo plazo.

\subsubsection{Visión}

El rumbo empresarial de toda organización está determinado en la declaración expresa de su visión; pues esta, orienta y motiva a todo colaborador de la empresa. David (2013) indica que la visión de toda organización responde a la pregunta ¿En qué queremos convertirnos?; la cual, exterioriza el anhelo del conjunto de personas que laboran a diario dentro de la organización y que "una visión compartida crea una comunión de intereses que puede sacar a los trabajadores de la monotonía del trabajo cotidiano, y llevarlos a un mundo nuevo de oportunidades y desafíos" (p. 47).

Para poder exteriorizar la declaración de visión; se debe cumplir con ciertos factores que determinen el objetivo de la empresa; ya sea a corto, mediano o largo plazo. Para ello, se ha empleado la matriz de visión propuesta; la cual, se aprecia en la Tabla 60; la misma que al ser confrontada con los elementos de análisis, brinden un resultado positivo y sustentable en resultados. 
Tabla 60

Matriz de Visión Propuesta

\begin{tabular}{|c|c|c|c|c|c|}
\hline \multirow[b]{3}{*}{ Preguntas } & \multirow[b]{3}{*}{ Respuesta } & \multicolumn{3}{|c|}{ Elementos de análisis } & \multirow[b]{3}{*}{ ¿Por que? } \\
\hline & & $\begin{array}{l}\text { Acorde a } \\
\text { misión }\end{array}$ & $\begin{array}{l}\text { Definida } \\
\text { en } \\
\text { tiempo }\end{array}$ & $\begin{array}{l}\text { Asociada } \\
\text { a los } \\
\text { valores }\end{array}$ & \\
\hline & & No & No & No & \\
\hline $\begin{array}{l}\text { ¿En qué } \\
\text { queremos } \\
\text { convertirnos? }\end{array}$ & $\begin{array}{c}\text { Box de CrossFit } \\
\text { líder }\end{array}$ & $X$ & $\mathrm{X}$ & $\mathrm{X}$ & $\begin{array}{c}\text { Nueva alternativa } \\
\text { de actividad física } \\
\text { en el mercado. }\end{array}$ \\
\hline $\begin{array}{l}\text { ¿Qué } \\
\text { resultados } \\
\text { queremos? }\end{array}$ & $\begin{array}{c}\text { Combatir la } \\
\text { obesidad }\end{array}$ & $X$ & $\mathrm{X}$ & $\mathrm{X}$ & $\begin{array}{l}\text { Alto índice de } \\
\text { obesidad en el } \\
\text { país. }\end{array}$ \\
\hline $\begin{array}{l}\text { ¿Cómo } \\
\text { queremos ser } \\
\text { reconocidos? }\end{array}$ & $\begin{array}{c}\text { Seguir los } \\
\text { fundamentos de } \\
\text { CrossFit, Inc. }\end{array}$ & $X$ & $\mathrm{X}$ & $\mathrm{X}$ & $\begin{array}{c}\text { Desarrollar un } \\
\text { nuevo estilo de } \\
\text { vida. }\end{array}$ \\
\hline
\end{tabular}

Desarrollada la matriz de visión propuesta, corresponde expresar la visión de nuestro negocio:

Ser el box de CrossFit líder en desarrollar un nuevo estilo de vida para combatir la obesidad mediante un fitness amplio, general e integral.

Tal como se puede apreciar, la visión expresa:

- Una nueva alternativa de actividad física en el mercado que adapta los fundamentos de CrossFit, Inc. como estrategia principal del negocio que influye en la cultura organizacional.

- El desarrollo de nuevas estrategias en el servicio del CrossFit distintas a otras actividades físicas del mercado, para combatir un problema de salud pública que viene en crecimiento.

- La competencia central basada en inculcar lo que realmente es el CrossFit, que es lograr un fitness amplio, general e integral: misma que se adapta a las tendencias del mercado, permitiéndonos innovar y ejecutar iniciativas que permitan generar un mayor valor; con la finalidad de ser sostenibles en el tiempo, convirtiéndola en la ventaja competitiva.

\subsubsection{Misión}

En el desarrollo de la actividad empresarial, es importante saber reconocerse frente a los demás; sobre todo, saber: ¿Quiénes somos?, ¿Qué hacemos?, ¿Qué ofrezco?; etc. David (2013) precisa que "la declaración de misión es más que un enunciado de detalles 
específicos; es un pronunciamiento de actitudes y perspectivas" (p. 49) que, de acuerdo con Peter Druker, es necesario para determinar objetivos y estrategias empresariales.

Bajo la premisa establecida, realizar la declaración de la misión, debe contemplar ciertos componentes que en su totalidad la hacen efectiva, idónea y perdurable. Fred R. David; ha establecido nueve componentes; las mismas que se han desarrollado en la Tabla 61.

Tabla 61

Matriz de Componentes de la Misión Propuesta

\begin{tabular}{|c|c|}
\hline Componentes & Respuesta \\
\hline Clientes & $\begin{array}{l}\text { Personas que deseen una mejor calidad de } \\
\text { vida y superar sus expectativas }\end{array}$ \\
\hline Productos o servicios & CrossFit (actividad física) \\
\hline Mercado & Peruano - Ate \\
\hline Tecnología & Wodify, SmartWod y Redes sociales. \\
\hline $\begin{array}{l}\text { Preocupación por la supervivencia, } \\
\text { crecimiento y la rentabilidad }\end{array}$ & Sostenibilidad económica \\
\hline Filosofía & Integrar la comunidad Crossfitera \\
\hline Autoconcepto & $\begin{array}{l}\text { Lograr un fitness amplio, general e } \\
\text { integral. }\end{array}$ \\
\hline Preocupación por la imagen pública & Combatir la obesidad \\
\hline Preocupación por los empleados & Integrar fundamentos de CrossFit Inc. \\
\hline
\end{tabular}

A continuación, corresponde realizar la declaración de la misión propuesta para el presente Plan de Negocios, indicando cada uno de los componentes establecidos en la Tabla 61:

Ofrecemos un servicio de entrenamiento CrossFit (2, 7 y 9) para combatir la obesidad (8) en Ate (3), empleando tecnologías (4) que integren a la comunidad crossfitera ( 1 y 6) como fuente de sostenibilidad del negocio (5).

\subsubsection{Principios}

En el desarrollo empresarial de hoy en día, es indispensable que toda empresa tenga sus principios basados en valores adaptadas a las tendencias actuales del mercado. Para ello, se debe determinar si cada valor propuesto cumple con los elementos base de valores; acto seguido, se analiza si cada valor se aplicará en cada uno de los niveles de la empresa, empezando por los socios, seguidos de los accionistas, colaboradores, proveedores y finalmente clientes.

Para la presente investigación; se ha determinado los siguientes elementos base de nuestros principios: 
- Ética. - Desde el panorama profesional, como la observancia de los derechos, deberes y obligaciones de los profesionales en el ejercicio de su profesión, y desde la perspectiva social, como la conducta del profesional frente a los demás a través de actos valiosos.

- Enfoque y perspectiva. - Asegurar en añadir valor y motivación hacia los clientes; debido a que, ellos acuden a la empresa por libre elección y por ende se debe dejar una experiencia inolvidable que supere sus expectativas bajo los fundamentos del CrossFit.

- Calidad e innovación. - La calidad del servicio debe ser incuestionable: por ello, se busca la manera de esforzarse para conseguir las mejores y apropiadas soluciones a los problemas que el cliente tenga; de igual forma, la innovación en el servicio será sofisticada y estará al alcance de todos.

- Disponibilidad al cambio. - Llevar a cabo una actividad empresarial, requiere de mucho temple y sobre todo, de tener por entendido que habrá la necesidad de hacer cambios cuando las cosas no salen como se planearon; donde, siempre se han de aplicar -de acuerdo al caso- cambios grandes o pequeños; las mismas que, harán un mejor camino económico.

Una vez establecido los elementos base, corresponde postularlos principios, para posteriormente, confrontarlas.

- Solidaridad. - Como imperativo de sentirse partícipes de las realidades y problemas ajenos, con la finalidad de participar de manera responsable en la solución de estas, velando más allá del interés del capital propio; esto es, ser solidarios con los intereses de los inversionistas, stakeholders, etc.

- Probidad. - Como parte de la unión de los principios de integridad y honestidad, en razón que los colaboradores sean incorruptibles en la ejecución de sus actos; así como, la propagación de estas, generando una confianza con los clientes como base de toda relación social y comercial.

- Balance. - Integrar a la cultura organizacional una figura que permita desarrollar y sostener en el tiempo un equilibrio entre vida y trabajo hacia los colaboradores en cualquiera de sus niveles laborales.

- Diversidad. - Respetar la heterogeneidad de identidades personales como riqueza cultural de la empresa, logrando una integración en función de un proyecto social común.

- Profesionalismo. - La exigencia del actuar con capacidad cualificada de los colaboradores en el ejercicio de sus funciones; con la finalidad de, lograr un servicio de calidad. 
Definido los principios, compete elaborar un análisis de éstos frente a los elementos base; las cuales se detallan en la Tabla 62.

Tabla 62

Matriz de Valores Propuestos

\begin{tabular}{lcccc}
\hline \multirow{2}{*}{ Valores } & Ética & $\begin{array}{c}\text { Enfoque y } \\
\text { perspectiva }\end{array}$ & $\begin{array}{c}\text { Clementos } \\
\text { Calidad e } \\
\text { innovación }\end{array}$ & $\begin{array}{c}\text { Disponibilidad al } \\
\text { cambio }\end{array}$ \\
\hline Solidaridad & $\mathrm{X}$ & $\mathrm{X}$ & $\mathrm{X}$ & $\mathrm{X}$ \\
Probidad & $\mathrm{X}$ & $\mathrm{X}$ & $\mathrm{X}$ & $\mathrm{X}$ \\
Balance & $\mathrm{X}$ & $\mathrm{X}$ & $\mathrm{X}$ & $\mathrm{X}$ \\
Diversidad & $\mathrm{X}$ & $\mathrm{X}$ & $\mathrm{X}$ & $\mathrm{X}$ \\
Profesionalismo & $\mathrm{X}$ & $\mathrm{X}$ & $\mathrm{X}$ & $\mathrm{X}$ \\
\hline
\end{tabular}

Con la elaboración de la matriz, se ha identificado que los principios satisfacen en su totalidad a los elementos base; siendo su implicancia idónea debido a que los valores han de ser integrados en Ate CrossFit.

\subsection{Formulación de Estrategias del Negocio}

Para la formulación de las estrategias del negocio, se debe enfocar en determinar las ventajas competitivas; para ello, emplearemos la matriz VRIO (ver Tabla 63), basada en el análisis de los recursos y capacidades tanto tangibles e intangibles de una empresa.

Tabla 63

Matriz VRIO

\begin{tabular}{|c|c|c|c|c|c|}
\hline Recursos & $\mathrm{V}$ & $\mathrm{R}$ & $\mathrm{I}$ & $\mathrm{O}$ & Implicancia competitiva \\
\hline \multicolumn{6}{|l|}{ Tangibles } \\
\hline Talento Humano & $X$ & & & $X$ & Ventaja competitiva temporal \\
\hline Estructura & $\mathrm{X}$ & & & $\mathrm{X}$ & Ventaja competitiva temporal \\
\hline Tecnología & $X$ & & & $X$ & Ventaja competitiva temporal \\
\hline Equipo & $\mathrm{X}$ & & & & Igualdad competitiva \\
\hline Cartera de clientes & $\mathrm{X}$ & & & & Igualdad competitiva \\
\hline Capacidad Financiera & $\mathrm{X}$ & & & $\mathrm{X}$ & Ventaja competitiva temporal \\
\hline \multicolumn{6}{|l|}{ Intangible } \\
\hline Marca & $\mathrm{X}$ & & & $\mathrm{X}$ & Ventaja competitiva temporal \\
\hline Patente & $\mathrm{X}$ & $\mathrm{X}$ & & $\mathrm{X}$ & Posible ventaja competitiva sostenible \\
\hline Fundamentos & $\mathrm{X}$ & $\mathrm{X}$ & & $\mathrm{X}$ & Posible ventaja competitiva sostenible \\
\hline Beneficio pre venta & $\mathrm{X}$ & $X$ & & $X$ & Posible ventaja competitiva sostenible \\
\hline
\end{tabular}

Nota: (V), (R), (I), (O) son las denominaciones de valor, raro, inimitable y organización, respectivamente.. Adaptado de "Gainining and Sustaining Competitive Advantage", por Jay Barney B., 2002, 2da, México, Pearson Education, Inc. Copyright 2002 por Pearson Educación de México S.A. de C.V. 
Antes del análisis de la Tabla 63, se debe precisar que, al ser un plan de negocio y aún no haberse puesto en marcha Ate CrossFit, no hay una ventaja competitiva como tal; sino, competencias centrales. Para generar una ventaja competitiva, Ate CrossFit debe generar una competencia en el mercado y posteriormente aplicar estrategias que le permitan ser sostenibles en el tiempo; mientras tanto, la competencia central será una competencia distintiva que con el paso del tiempo irá mejorando y posteriormente se acoplará al Core del negocio. En la Tabla 63, se puede identificar que hay recursos y capacidades imitables por la competencia, las cuales se encuentran reflejados en la paridad competitiva; asimismo, se observa que las posibles ventajas competitivas sostenibles se encuentran en la obtención de la patente de CrossFit, los fundamentos que CrossFit, Inc. ha elaborado para la ejecución de esta actividad física y el beneficio pre venta que Ate CrossFit ofrecerá, basándose en una atención personalizada donde se identifique las principales necesidades del cliente respecto a la progresión de la actividad física y nutrición.

\subsection{Determinación de las Ventajas Competitivas Críticas}

David (2013) señala que una ventaja competitiva es "cualquier cosa que una empresa haga especialmente bien en comparación con las empresas rivales" (p.8); pues bien, para que esta empresa se relacione con su entorno, debe aplicar ciertas estrategias competitivas que consiste, según Porter (1980), en “...tomar acciones defensivas y ofensivas para establecer una posición competitiva sostenible en una industria, para afrontar eficazmente las cinco fuerzas competitivas y con ello conseguir un excelente rendimiento sobre la inversión para la empresa" (p. 77). Para ello, el citado autor propone tres estrategias competitivas genéricas de gran efectividad que permite tomar ventaja frente a los rivales de la industria; estos son: primero, liderazgo global en costes; segundo, diferenciación; y tercero, segmentación.

Para efectos de la presente investigación, se ha considerado la estrategia de diferenciación; esto último, debido a que según Porter (2010) “en ella la compañía intenta distinguirse dentro de su sector industrial en algunos aspectos ampliamente apreciados por los compradores" ( $\mathrm{p}$. 42); esto debido a que, el juicio del cliente por lograr satisfacer su necesidad es sumamente importante. En el Caso de Ate CrossFit, esta ofrecerá Fitness amplio, general e integral a sus clientes bajo la metodología CrossFit; esto debido a que, existen personas que se encuentran desatendidas por los centros de entrenamiento convencionales en razón a la obtención de resultados sin éxito; así como, el no interés de esa población en la ejecución de actividades físicas por la monotonía de las rutinas de ejercicio; convirtiéndose en uno de los distritos con mayor porcentaje de obesidad. 


\subsection{Diseño de la Estructura Organizacional Deseada}

Para que una empresa tenga un orden en el ejercicio de sus actividades; es conveniente que ésta cuente con una estructura organizacional que divida las actividades de la empresa, del las áreas y las del personal. Para Ate CrossFit, se ha empleado una estructura funcional, que según David (2013) aparte de ser sencilla y de bajo costo, ésta “...promueve la especialización de las tareas, fomenta el uso eficiente de talento técnico y administrativo, minimiza la necesidad de un sistema de control elaborado y permite na rápida toma de decisiones" (p. 221).

En la Figura 55 se muestra la estructura organizativa propuesta para Ate CrossFit, la cual se define por persona en razón a sus funciones.

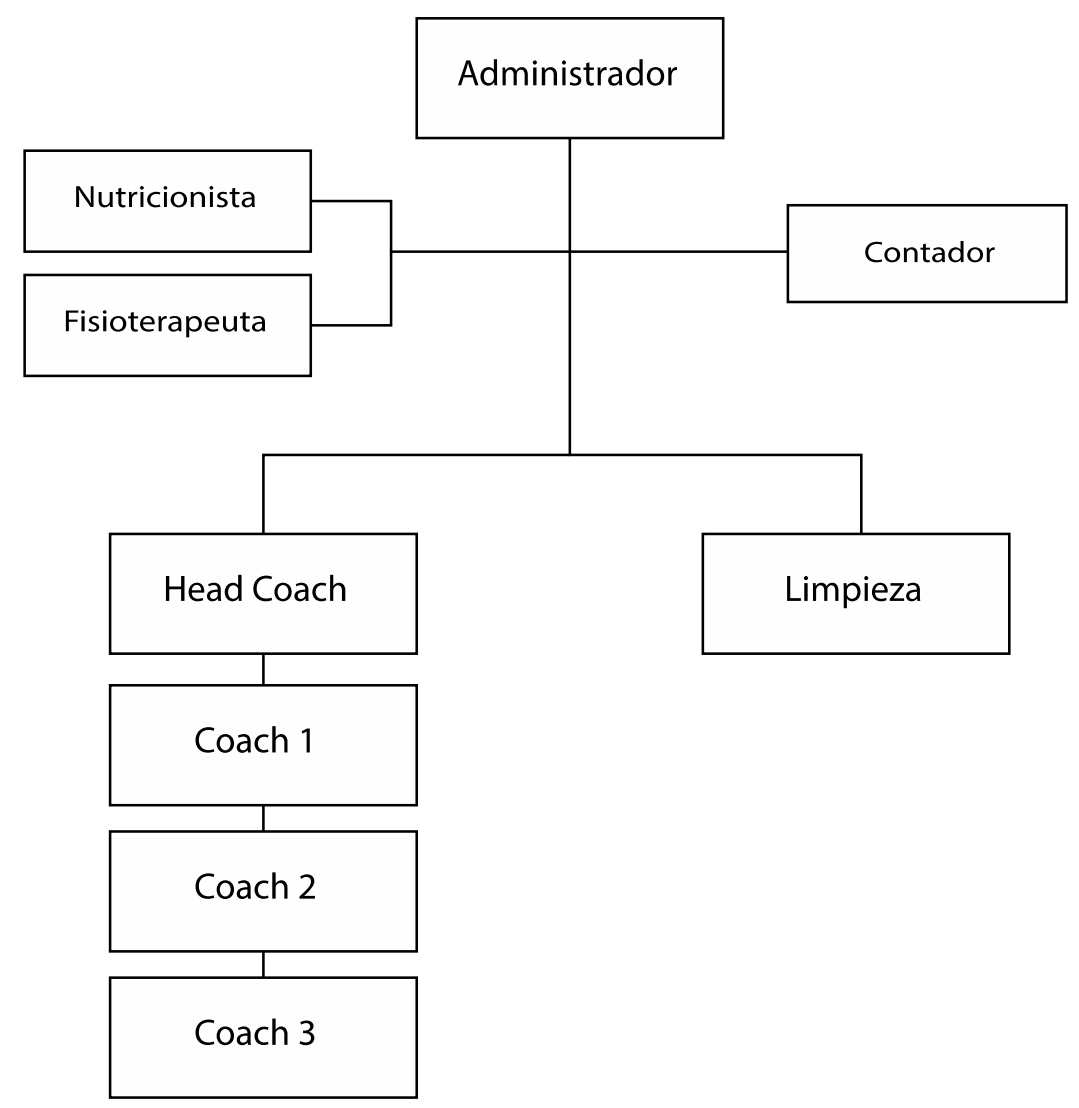

Figura 55. Organigrama de Ate CrossFit

\subsection{Diseño de los Perfiles de Puestos Clave}

Tal como se ha señalado anteriormente, Ate CrossFit contará dentro de su estructura organizacional con: administrador, contador, nutricionista, fisioterapeuta, Head Coach, 3 Coaches, y finalmente, con un personal de limpieza. Dichos puestos deberán cumplir con los requisitos que se detallan a continuación: 
Cargo: Administrador (socio $n^{\circ} 2$ ).

Sexo: Indiferente.

Edad: 23 a 35 años.

Función general: Gestionar y supervisar el funcionamiento de la empresa.

Funciones específicas:

- Supervisar y controlar el cumplimiento de los fundamentos CrossFit en el manejo de un box de CrossFit.

- Gestionar la membresía de los afiliados.

- Supervisar y controlar los procesos de pago a proveedores, costos, presupuestos y recursos humanos (planillas).

- Garantizar el cumplimiento de buenas prácticas laborales.

- Planificar la logística de la empresa.

- Definir, planificar y aplicar las campañas de publicidad.

- Ejercer funciones de Comunity Manager.

- Resolver los inconvenientes que presenten los afiliados

Requisitos de educación: Licenciado / Bachiller en administración, marketing o contabilidad.

Experiencia laboral: 2 años en puestos similares.

Competencias: Multitasker, proactivo, trabajo en equipo, liderazgo, comunicativo y empático.

Beneficios: Planilla desde el primer día, horarios establecidos de lunes a viernes en jornada laboral de 8 horas diarias, descanso fijo en sábados y domingos, membresía anual renovable y descuento de $15 \%$ en membresía para cualquier familiar.

\section{Cargo: Head Coach (Socio 1).}

Jefe inmediato: Administrador.

Sexo: Indistinto.

Edad: 23 a 25 años.

Función general: Desarrollar estrategias y las sesiones de entrenamiento semanal.

Funciones específicas:

- Seleccionar el personal competente de acuerdo a las necesidades y exigencias del mercado.

- Fijar las políticas y normas del Box.

- Supervisar el cumplimiento de los fundamentos de CrossFit, Inc.

- Analizar los resultados diarios de los participantes.

- Organizar eventos de confraternidad.

- Organizar competencias internas. 
- Elaborar el Wod diario y subirlo a las plataformas tecnológicas (redes y Wodify).

- Encargado de elaborar las clases de fundamentos para principiantes y la ensañanza de la misma.

- Encargado de desarrollar seminarios de atletas CrossFit

Requisitos de educación: CrossFit Level 1 Certificate Course, CrossFit Level 2 Certificate

Course, CrossFit Level 3 Certificate Course, CrossFit Level 4 Certificate Course y

Certificaciones de especialización.

Experiencia laboral: dos años en puestos similares y participación en competencias.

Competencias: Resilente, proactivo, trabajo en equipo, liderazgo, comunicativo y empático.

Beneficios: Planilla desde el primer día, horarios establecidos de 40 horas semanales, descanso fijo domingos, membresía anual renovable, descuento de $20 \%$ en membresía para cualquier familiar.

\section{Cargo: Coach}

Jefe inmediato: Head Coach.

Sexo: Indistinto.

Edad: 23 a 35 años.

Función general: Adecuar las rutinas conforme a las necesidades del usuario.

Funciones específicas:

- Diseñar programas de progresión.

- Enseñar el WOD mediante ejemplos.

- Diseñar programas de rutina de entrenamiento junto al Head coach.

- Revisar el desempeño de los atletas.

- Solicitar implementos para la ejecución de las rutinas.

- Supervisar la ejecución de los ejercicios en clase..

- Apoyo en los eventos que se organicen en el box

Requisitos: CrossFit Level 1 Certificate Course y Certificaciones de especialización.

Experiencia laboral: 2 años en puestos similares, participación en campeonatos.

Competencias: Resilente, proactivo, trabajo en equipo, comunicativo y empático.

Beneficios: Planilla desde el primer día, horarios establecidos de part-time (20 horas semanales), horario rotativo, turno mañana o noche, descanso fijo días de semana que no sean parte de su horario laboral, membresía anual renovable, descuento de $15 \%$ en membresía para cualquier familiar. 


\section{Cargo: Limpieza}

Jefe inmediato: Administrador.

Sexo: Indistinto.

Edad: Indistinto.

Función general: Mantener las instalaciones limpias y en orden.

Funciones específicas:

- Organizar y ordenar los implementos deportivos luego de cada clase.

- Mantener los servicios higiénicos limpios.

- Mantener el área deportiva limpia.

- Supervisar el uso de las instalaciones deportivas.

- Solicitar implementos de aseo

Requisitos: Indistinto

Experiencia laboral: 6 meses.

Competencias: Trabajo en equipo, comunicativo y empático.

Beneficios: Planilla desde el primer día, horarios establecidos de 40 horas semanales, descanso fijo sábados y domingos, membresía anual renovable y descuento del $15 \%$ en membresía para cualquier familiar.

\subsection{Remuneraciones, Compensaciones e Incentivos}

En lo concerniente al cumplimiento de las remuneraciones y demás beneficios que por ley correspondan a los trabajadores, Ate CrossFit se someterá al marco normativo nacional; esto es, al Decreto Legislativo No 728 , Ley de Productividad y Competitividad Laboral (D.S. N ${ }^{\circ}$ 003-97-TR) y su respectivo reglamento el D.S. No 001-96-TR. Asimismo, los contratos laborales deberán constar por escrito y presentados ante la Autoridad Administrativa de Trabajo en un plazo no mayor a 15 días de la suscripción de la misma.

En el caso de los contratos laborales a tiempo parcial; estos deberán contar con las siguientes características:

- Remuneración Mínima Vital (RMV) de S/. 850.00 nuevos soles.

- Jornada laboral de trabajo inferior a 4 horas diarias o 20 horas semanales.

- Beneficios laborales: gratificaciones legales, bonificación por gratificación, descanso semanal obligatorio, descanso en feriados, pago de horas extras, seguro social, seguro de vida, pensiones, asignación familiar, utilidades y sindicalización. Dentro de este contexto, no comprenden la compensación por tiempo de servicios (CTS), pago de vacaciones, indemnización por falta de descanso vacacional ni indemnización por despido arbitrario. 
En las Tablas 64, 65 y 66 se muestran las remuneraciones que percibirán los trabajadores de Ate CrossFit.

Tabla 64

Sueldos de Mano de Obra Directa

\begin{tabular}{lccccccccc}
\hline Descripción & Cantidad & Sueldo & Mensual & $\begin{array}{c}\text { Período } \\
\text { mensual }\end{array}$ & Sub total & $\begin{array}{c}\text { Gratificación } \\
\text { anual }\end{array}$ & CTS & Essalud & Total \\
\hline Head Coach & 1 & 850.00 & 850.00 & 12 & $10,200.00$ & $1,700.00$ & 991.67 & 918.00 & $13,809.67$ \\
Coach & 3 & 550.00 & $1,650.00$ & 12 & $19,800.00$ & $3,300.00$ & - & $1,782.00$ & $24,882.00$ \\
Fisioterapeuta & 1 & 400.00 & 400.00 & 12 & $4,800.00$ & 800.00 & - & 432.00 & $6,032.00$ \\
Nutricionista & 1 & 400.00 & 400.00 & 12 & $4,800.00$ & 800.00 & - & 432.00 & $6,032.00$ \\
Total & 6 & $2,200.00$ & $3,300.00$ & 12 & $39,600.00$ & $6,600.00$ & 991.67 & $3,564.00$ & $50,755.67$ \\
\hline
\end{tabular}

Tabla 65

Sueldo de Mano de Obra Indirecta

\begin{tabular}{lccccccccc}
\hline Descripción & Cantidad & Sueldo & Mensual & $\begin{array}{c}\text { Período } \\
\text { mensual }\end{array}$ & Sub total & $\begin{array}{c}\text { Gratificación } \\
\text { anual }\end{array}$ & CTS & Essalud & Total \\
\hline Limpieza & 1 & 850.00 & 850.00 & 12 & $10,200.00$ & $1,700.00$ & 991.67 & 918.00 & $13,809.67$ \\
Total & 1 & 850.00 & 850.00 & 12 & $10,200.00$ & $1,700.00$ & 991.67 & 918.00 & $13,809.67$ \\
\hline
\end{tabular}

Tabla 66

Sueldos de Personal Administrativo

\begin{tabular}{lccccccccc}
\hline Descripción & Cantidad & Sueldo & Mensual & $\begin{array}{c}\text { Período } \\
\text { mensual }\end{array}$ & Sub total & $\begin{array}{c}\text { Gratificación } \\
\text { anual }\end{array}$ & CTS & Essalud & Total \\
\hline Contador & 1 & 300.00 & 300.00 & 12 & $3,600.00$ & - & - & - & $3,600.00$ \\
Administrador & 1 & 900.00 & 900.00 & 12 & $10,800.00$ & $1,800.00$ & $1,050.00$ & 972.00 & $14,622.00$ \\
Total & 1 & $1,200.00$ & $1,200.00$ & 12 & $14,400.00$ & $1,800.00$ & $1,050.00$ & 972.00 & $18,222.00$ \\
\hline
\end{tabular}

\section{Incentivos}

Se propone realizar tres tipos de incentivos para los trabajadores por concepto de nivel de desempeño obtenido durante el año; estas son:

1. Capacitación

Los Coaches y parte del staff obtendrán una capacitación anual para la mejora en el cumplimiento de sus funciones. Dentro de este contexto, se encuentran las capacitaciones en materia de CrossFit y salud ocupacional.

\section{Descuentos familiares}

Los miembros del equipo obtendrán descuentos desde el 15\% hasta el 35\% para cada uno de sus familiares en cualquiera de las membresías. 


\section{Bono de reconocimiento}

Se dará en dos formas: El primero, mediante un sorteo, un bono a fin de año por valor de S/. 500.00 nuevos soles, mediante elección de los clientes; el segundo, un bono de S/. 400.00 nuevos soles mediante sorteo realizado a través de una rifa.

\subsection{Política de Recursos Humanos}

Para garantizar un buen ambiente laboral y desarrollo corporativo para alcanzar los objetivos de la empresa; se presenta la siguiente política de recursos humanos:

1. Definir objetivos de la empresa

Con el fin de determinar el rumbo empresarial y que todo el personal tenga conocimiento de la misma para que pueda desempeñar sus funciones sobre la base de las mismas.

2. Reclutamiento y selección de personal

Se seleccionará al personal cuyas competencias intrapersonales puedan acoplarse al plan de la empresa y se sienta identificado con los principios que se imparten en ella.

Para ello, en el proceso de selección se definirán bien los puestos, perfiles y competencias que el postulante deberá tener.

\section{Capacitación}

Dentro de esta política se tiene: inducción y profesionales.

4. Evaluación de desempeño

Que permita determinar el nivel de compromiso que tiene el personal con la empresa y los clientes; esto, se medirá con el número de quejas que los clientes presenten o con el incumplimiento de las funciones. Con el fin de ser partícipes de la mejora continúa.

\section{Clima organizacional}

Fomentar la integración, motivación y compromiso tanto de los miembros del staff como con los clientes.

6. Remuneración

La remuneración del personal está por encima del promedio del mercado; la cual se ha estipulado por el número de horas trabajadas y el puesto que ocupen; asimismo, se ha determinado dentro de esta política, los incentivos y beneficios laborales descritos anteriormente. 


\section{Capítulo IX: Planificación Financiera}

En este capítulo, se elaboró la planificación financiera de Ate Crossfit; con el fin de determinar: la inversión para la puesta en marcha del negocio, el financiamiento del proyecto donde se determinó el endeudamiento y las condiciones de la misma; los presupuesto base del negocio; así como, los presupuestos de resultados. Asimismo, se presentan el estado de ganancias y pérdidas, balance general y el flujo de caja proyectados.

\subsection{La Inversión}

De acuerdo con Moyano (2015) para determinar el monto total de la inversión del negocio se debe considerar dos tipos de inversión: La primera, denominada fija que involucra a los tangibles e intangibles; y la segunda, de capital de trabajo.

Bajo la metodología de CrossFit, Inc., se ha podido determinar que, para la apertura de un box de CrossFit se necesita una inversión basada en ciertos inmuebles, maquinarias, equipos y capital de trabajo específicos; las mismas que marcan la diferencia frente a sus competidores en razón a la infraestructura y servicio que se brinda.

\subsubsection{Inversión pre-operativa}

La inversión pre-operativa está compuesta por los activos fijos tangibles e intangibles que Ate CrossFit necesita para operar. Para el presente plan de negocio, el monto de la inversión pre - operativa asciende a S/. 179,300.00.

1. Activos Fijos tangibles

En este contexto se encuentran los equipos, muebles y enseres que utilizarán los clientes y miembros del negocio; mismos que justifican la infraestructura del local. El monto total de activos fijos tangibles que necesitará Ate CrossFit es de S/. 157,580.00.

\section{Equipos}

Como ya se ha mencionado, el CrossFit es la combinación de diversas disciplinas como: levantamiento de peso, mediante el uso de barras olímpicas, Dumbbells, Ketbells, etc; gimnasia, con anillas y barras; y finalmente, ejercicios aeróbicos con remos, sogas o uso del cuerpo. Por ende, para que Ate CrossFit funcione, deberá contar con los equipos que se muestran en la Tabla 56; cuyo monto de inversión asciende a S/. 91,900.00 nuevos soles.

\section{Muebles y enseres}

Un box es un gimnasio no convencional, cuya temática está ligada a un garaje de entrenamiento donde se practica el CrossFit; es por ello, que la ambientación del local juega un rol fundamental. En el encabezado 7.1.2 del presente trabajo de investigación se ha detallado el mobiliario que Ate CrossFit utilizará, cuyo monto de inversión asciende a S/. 36,880 nuevos soles (ver Tabla 67). 
Tabla 67

Inversión en Muebles y Enseres de Ate CrossFit

\begin{tabular}{lccc}
\hline Muebles y enseres & Costo sin IGV & IGV & Costo Total \\
\hline Oficina administrativa & S/. $5,915.25$ & S/. $1,064.75$ & S/. 6,980.00 \\
Oficina de nutrición & S/. $1,889.83$ & S/. 340.17 & S/. 2,230.00 \\
Oficina de fisioterapia & S/. $2,228.81$ & S/. 401.19 & S/. 2,630.00 \\
Área Común & S/. 3,432.20 & S/. 617.80 & S/. 4,050.00 \\
Zona WOD & S/. $13,889.83$ & S/. 2,500.17 & S/. 16,390.00 \\
Zona de espera & S/. $1,101.69$ & S/. 198.31 & S/. 1,300.00 \\
Baños & S/. 2,796.61 & S/. 503.39 & S/. 3,300.00 \\
Total & S/. 31,254.24 & S/. 5,625.76 & S/. 36,880.00 \\
\hline
\end{tabular}

2. Intangibles

En esta categoría se encuentran aquellas inversiones no medibles de manera física; pero, cuyo valor es esencial para la operación de la empresa. Para el presente plan de negocio, se ha considerado: la constitución de la empresa, trámites de licencia, garantía de alquiler, patente CrossFit, software y plataformas; entre otros, y cuyo monto de inversión es de S/. 21,720.00 nuevos soles (ver tabla 68).

Tabla 68

Inversión en Intangibles de Ate CrossFit

\begin{tabular}{lccc}
\hline Intangibles & Costo sin IGV & IGV & Costo con IGV \\
\hline Garantía de alquiler & S/. 10,169.49 & S/. 1,830.51 & S/. 12,000.00 \\
$\begin{array}{l}\text { Patente CrossFit } \\
\text { Formalización de } \\
\text { empresa }\end{array}$ & S/. $2,966.10$ & S/. $1,457.63 .90$ & S/. 3,500.00 \\
$\begin{array}{l}\text { Software y } \\
\text { plataformas }\end{array}$ & S/. $3,813.56$ & S/. 262.37 & S/. $1,720.00$ \\
Total & S/. 18,406.78 & S/. 3,313.22 & S/. 4,500.00 \\
\hline
\end{tabular}

\subsubsection{Inversión en capital de trabajo}

La inversión en el capital de trabajo de Ate CrossFit, ha sido calculado a través del método de Déficit Acumulado Máximo (DAM) a partir del flujo de caja mensual del primer año; tal como se aprecia en la Tabla 69; donde se observa que la empresa tendrá un flujo de caja negativo durante los primeros 9 meses; esto quiere decir, que se necesita colocar más dinero en la compañía para que funcione; a esto, se le denomina capital de trabajo.

El resultado obtenido en la aplicación del método DAM, identifica que el importe mayor se da en el mes de Julio con S/. 21,695.14 nuevos soles; a ello, se le adiciona un 20\% para cubrir algún imprevisto durante la proyección. De esta manera, el capital de trabajo será de 
S/. 26,034.16 nuevos soles. Asimismo, se observa que en el mes de octubre, la empresa obtendría resultados positivos de recuperación.

Tabla 69

\section{Capital de Trabajo}

\begin{tabular}{|c|c|c|c|c|c|c|c|c|c|c|c|c|c|}
\hline \multirow[t]{2}{*}{ Descripción } & \multicolumn{13}{|c|}{ Meses del año 1} \\
\hline & 0 & En & Feb & Mar & $\mathrm{Abr}$ & May & Jun & Jul & Ago & Set & Oct & Nov & Dic \\
\hline Ingresos x Cobranza & & $8,568.00$ & $9,373.00$ & $9,786.00$ & $12,312.00$ & $13,113.00$ & $13,896.00$ & $18,940.00$ & $20,670.00$ & $21,560.00$ & $36,710.00$ & $39,310.00$ & $41,370.00$ \\
\hline \multicolumn{14}{|l|}{ Egresos operativos } \\
\hline Mano de obra directa & & $-3,597.00$ & $-3,597.00$ & $-3,597.00$ & $-3,597.00$ & $-4,092.83$ & $-3,597.00$ & $-6,897.00$ & $-3,597.00$ & $-3,597.00$ & $-3,597.00$ & $-4,092.83$ & $-6,897.00$ \\
\hline Mano de obra indirecta & & -926.50 & -926.50 & -926.50 & -926.50 & $-1,422.33$ & -926.50 & $-1,776.50$ & -926.50 & -926.50 & -926.50 & $-1,422.33$ & $-1,776.50$ \\
\hline Sueldos administrativos & & $-1,281.00$ & $-1,281.00$ & $-1,281.00$ & $-1,281.00$ & $-1,806.00$ & $-1,281.00$ & $-2,181.00$ & $-1,281.00$ & $-1,281.00$ & $-1,281.00$ & $-1,806.00$ & $-2,181.00$ \\
\hline Gasto de ventas & & -750.00 & -750.00 & -750.00 & -750.00 & -750.00 & -750.00 & -750.00 & -750.00 & -750.00 & -750.00 & -750.00 & -750.00 \\
\hline Otros gastos administrativos & & $-6,653.88$ & $-6,653.88$ & $-6,653.88$ & $-6,653.88$ & $-6,653.88$ & $-6,653.88$ & $-6,653.88$ & $-6,653.88$ & $-6,653.88$ & $-6,653.88$ & $-6,653.88$ & $-6,653.88$ \\
\hline Pago de IGV & & 286.51 & 286.51 & 286.51 & 286.51 & 286.51 & 286.51 & 286.51 & 286.51 & 286.51 & 286.51 & 286.51 & 286.51 \\
\hline $\mathbb{R}$ & & -528.84 & -528.84 & -528.84 & -528.84 & -528.84 & -528.84 & -528.84 & -528.84 & -528.84 & -528.84 & -528.84 & -528.84 \\
\hline Flujo de caja operativo & & $-4,882.71$ & $-4,077.71$ & $-3,664.71$ & $-1,138.71$ & $-1,854.38$ & 445.29 & 439.29 & $7,219.29$ & $8,109.29$ & $23,259.29$ & $24,342.62$ & $22,869.29$ \\
\hline \multicolumn{14}{|l|}{ Inversiones } \\
\hline Activo Fijo & $-157,580.00$ & & & & & & & & & & & & \\
\hline Activo Intangible & $-21,720.00$ & & & & & & & & & & & & \\
\hline KW & 0.00 & 0.00 & 0.00 & 0.00 & 0.00 & 0.00 & 0.00 & 0.00 & 0.00 & 0.00 & 0.00 & 0.00 & 0.00 \\
\hline Flujo de caja economico & $-179,300.00$ & $-4,882.71$ & $-4,077.71$ & $-3,664.71$ & $-1,138.71$ & $-1,854.38$ & 445.29 & 439.29 & $7,219.29$ & $8,109.29$ & $23,259.29$ & $24,342.62$ & $22,869.29$ \\
\hline Préstamo/amortización & $52,000.00$ & -655.07 & -661.04 & -667.06 & -673.14 & -679.28 & -685.47 & -691.71 & -698.02 & -704.38 & -710.80 & -717.27 & -723.81 \\
\hline Intereses & & -473.85 & -467.88 & -461.86 & -455.78 & -449.64 & -443.45 & -437.21 & -430.90 & -424.54 & -418.12 & -411.65 & -405.11 \\
\hline Escudo fiscal & & 139.79 & 138.02 & 136.25 & 134.45 & 132.64 & 130.82 & 128.98 & 127.12 & 125.24 & 123.35 & 121.44 & 119.51 \\
\hline Financiamiento neto & $52,000.00$ & -989.13 & -990.90 & -992.67 & -994.47 & -996.28 & -998.10 & -999.94 & $-1,001.80$ & $-1,003.68$ & $-1,005.57$ & $-1,007.48$ & $-1,009.41$ \\
\hline Flujo de caja financiero & $-127,300.00$ & $-5,871.85$ & $-5,068.61$ & $-4,657.38$ & $-2,133.18$ & $-2,850.65$ & -552.81 & -560.66 & $6,217.49$ & $7,105.61$ & $22,253.72$ & $23,335.14$ & $21,859.88$ \\
\hline Déficit Acumulado & & $-5,871.85$ & $-10,940.45$ & $-15,597.84$ & $-17,731.01$ & $-20,581.67$ & $-21,134.48$ & $-21,695.14$ & $-15,477,65$ & $-8,372.04$ & $13,881.67$ & $37,216.81$ & $59,076.69$ \\
\hline Descripción & & & & & & & ses del año 1 & & & & & & \\
\hline Módulo IGV & 0 & En & Feb & Mar & $\mathrm{Abr}$ & May & Jun & Jul & Ago & Set & Oct & Nov & Dic \\
\hline IGV ventas & & $3,122.14$ & $3,122.14$ & $3,122.14$ & $3,122.14$ & $3,122.14$ & $3,122.14$ & $3,122.14$ & $3,122.14$ & $3,122.14$ & $3,122.14$ & $3,122.14$ & $3,122.14$ \\
\hline IGV compras & $27,350.85$ & $1,129.40$ & $1,129.40$ & $1,129.40$ & $1,129.40$ & $1,129.40$ & $1,129.40$ & $1,129.40$ & $1,129.40$ & $1,129.40$ & $1,129.40$ & $1,129.40$ & $1,129.40$ \\
\hline Diferencia & $-27,350.85$ & $1,992.73$ & $1,992.73$ & $1,992.73$ & $1,992.73$ & $1,992.73$ & $1,992.73$ & $1,992.73$ & $1,992.73$ & $1,992.73$ & $1,992.73$ & $1,992.73$ & $1,992.73$ \\
\hline Crédito Fiscal & $27,350.85$ & 0.00 & 0.00 & 0.00 & 0.00 & 0.00 & 0.00 & 0.00 & 0.00 & 0.00 & 0.00 & 0.00 & 0.00 \\
\hline Pago de IGV & 0 & $-25,358.12$ & $1,992.73$ & $1,992.73$ & $1,992.73$ & $1,992.73$ & $1,992.73$ & $1,992.73$ & $1,992.73$ & $1,992.73$ & $1,992.73$ & $1,992.73$ & $1,992.73$ \\
\hline
\end{tabular}

\subsubsection{Costo del proyecto}

Para la puesta en marcha de Ate CrossFit, se debe realizar una inversión ascendente a S/. 205,334.16 nuevos soles; tal y como se demuestra en la Tabla 70; las cuales provienen de la suma de los activos fijos, intangibles y capital de trabajo.

Tabla 70

\section{Inversión Total}

\begin{tabular}{lccc}
\hline Descripción & Valor de venta & IGV & Precio de inversión \\
\hline Activo fijo & $\mathrm{S} / .133,542.37$ & $\mathrm{~S} / .24,037.63$ & $\mathrm{~S} / .157,580.00$ \\
Intangibles & $\mathrm{S} / .18,406.78$ & $\mathrm{~S} / .3,313.22$ & $\mathrm{~S} / .21,720.00$ \\
Capital de trabajo & $\mathrm{S} / .26,034.16$ & & $\mathrm{~S} / .26,034.16$ \\
\hline Total & $\mathrm{S} / .177,983.31$ & $\mathrm{~S} / .27,350.85$ & $\mathrm{~S} / .205,334.16$ \\
\hline
\end{tabular}




\subsubsection{Inversiones futuras}

El presente plan de negocio no contempla hacer inversiones futuras; para ello, primero se evaluará la puesta en marcha y ejecución de los servicios del box de CrossFit.

\subsection{Financiamiento}

Moyano (2015) al respecto señala que "en esta sección se describe quién financia el negocio y cómo será porcentualmente ese financiamiento, a qué tasa, y cómo, y en cuánto tiempo se devolverá" (p. 139).

\subsubsection{Endeudamiento y condiciones}

Para la apertura del box de CrossFit; se ha tomado la decisión de ejecutar dicha inversión bajo la modalidad prevista en la Tabla 71; donde los socios aportarán un $75 \%$ y el resto mediante un préstamo bancario.

Tabla 71

Aportes de la Inversión

\begin{tabular}{lcc}
\hline Descripción & Aporte & Porcentaje de participación \\
\hline Capital de socios & S/. 153,334.16 & $75 \%$ \\
Deuda bancaria & S/. 52,000.00 & $25 \%$ \\
\hline Total & S/. 205,334.16 & $100 \%$ \\
\hline
\end{tabular}

Como se muestra en el índice xx, se prevé realizar un financiamiento con el banco BBVA Continental; adquiriendo un préstamo bancario bajo la modalidad de capital de trabajo ascendente a S/. 52,000 nuevos soles; esto es, un 25\% del total de la inversión. Este préstamo bancario cuenta con un Tasa de Costo Efectivo Anual (TCEA) de $11.50 \%$ y una Tasa Efectiva Mensual (TEM) de 0.91\%. El plazo del préstamo es de 60 meses.

\subsubsection{Capital y costo de oportunidad}

De acuerdo con Beltrán y Cueva (2014) “el costo de oportunidad del capital es una tasa de interés referencial que sirve para determinar los beneficios extraordinarios de un proyecto de inversión respecto de la mejor alternativa especulativa de igual riesgo" (p. 637). Para determinar el capital y costo de oportunidad (COK) se empleó el modelo Capital Asset Pricing Model (CAPM) a través de la formula:

$$
\mathrm{COK}=\mathrm{Rf}+\mathrm{BProy}(\mathrm{Rm}-\mathrm{Rf})
$$

Dadas las circunstancias del mercado peruano, no hay empresa fitness alguna que cotice en la bolsa de valores: por ende, para medir el riesgo se empleará el coeficiente Beta Unlevered $(\beta \mu)$ del mercado americano determinado por Aswath Damodaran (2018). En el 
presente caso, se ha empleado el $(\beta \mu)$ de la industria de entretenimiento. Acto seguido, se aplicó la ecuación de Hamada (1972) para determinar el Beta Levered ( $\beta \imath$ ); la misma que se aprecia en la Tabla 72.

Tabla 72

Estimación del Beta Levered

$$
\begin{aligned}
& \text { Ecuación de Hamada } \\
& \qquad(\beta \mu)=\frac{(\beta \mathrm{\imath})}{1+\mathrm{D} / \operatorname{Ex}(1-\mathrm{t})}
\end{aligned}
$$

Nota: $(\beta \mu),(\beta \mathrm{t}),(\mathrm{D}),(\mathrm{E})$ y $(\mathrm{t})$ son denominaciones otorgadas al beta desapalancado, beta apalancado, deuda, capital e impuesto país, respectivamente. Ecuación de Hamada. Adaptado de "The Effect of the Firm's Capital Structure on the Systematic Risk if Common Stocks", por R. Hamada, 1972, Journal of Finance,27, p.p. 423452.

Del desarrollo de la ecuación, se puede determinar que el Beta Levered $(\beta \imath)$ es de 1.14. Ahora, corresponde aplicar los datos obtenidos en la Tabla 73 en la fórmula del COK. Al no contar con una empresa fitness que cotice en bolsa, a dicha ecuación se le debe agregar la tasa de riesgo país peruana determinada por J.P Morgan (2018); así como, el Size Premium (riesgo adicional del mercado) determinado por Damodaran (2018) ascendente al 6.46\%.

Tabla 73

\section{Estimación del CAPM}

\begin{tabular}{lcc}
\hline Descripción & Abreviatura & Valor \\
\hline Beta unlevered & $(\beta \mu)$ & 0.92 \\
Tasa de rendimiento de mercado & $\mathrm{rm}$ & $11.53 \%$ \\
Tasa libre de riesgo & $\mathrm{rf}$ & $5.15 \%$ \\
Riesgo país peruano & $\mathrm{rp}$ & 0.0121 \\
Tasa de impuesto peruano & $\mathrm{Tperú}$ & $29.5 \%$ \\
Beta levered & $(\beta \mathrm{r})$ & 1.14 \\
Size Premium & $\mathrm{Sp}$ & $6.46 \%$ \\
\hline COK & Kproy=Rf+Bproy x $(\mathrm{Rm}-\mathrm{Rf})+\mathrm{Rp}+\mathrm{Sp}$ \\
\hline Total & \multicolumn{2}{c}{$20.09 \%$} \\
\hline
\end{tabular}

El costo de oportunidad obtenido es de $20.09 \%$; esto quiere decir, que el proyecto cuenta con un rendimiento como mínimo de $20.09 \%$ para que sea rentable en comparación al mercado.

\subsubsection{Costo de capital promedio ponderado}

Para determinar el Costo de Capital Promedio ponderado (CPPC), también denominado como Weighted Average Cost of Capital (WACC), se empleará el Cok y la deuda del proyecto obtenida a través del financiamiento bancario ascendente al 25\% de la inversión, valorizada en S/. 52,000 nuevos soles; para ello se utilizará la siguiente fórmula: 
WACC $=\underset{D+E}{D} \times \operatorname{rd} \times(1-T a x)+\underset{D+E}{E} \times$ re

Donde:

D: S/.52,000 nuevos soles por concepto de préstamo bancario

E: S/.153,334.16 nuevos soles como aporte de los socios a la inversión

Rd: $11.50 \%$ proveniente de la Tasa efectiva anual

Tax: $29.50 \%$ equivalente al Impuesto a la Renta peruano.

Re: $20.09 \%$ proveniente del COK

Aplicando la fórmula tenemos:

WACC $=\frac{52,000.00}{52,000+153,334.16} \times 11.50 \% \times(1-29.50 \%)+\frac{153,334.16}{52,000+} \times 20.09 \%$

El resultado obtenido del WACC es de $17.06 \%$; esto es, la empresa debe rendir no menos del $17.06 \%$. en comparación al Cok de $20.09 \%$; por lo tanto, la empresa si crea valor para los accionistas.

\subsection{Presupuestos Base}

\subsubsection{Presupuesto de ventas}

En la opinión de Moyano (2015) es la proyección de las ventas que tendrá el negocio en el tiempo. Para determinar el presupuesto de ventas, se ha tomado en consideración lo desarrollado en el estudio de mercado de la presente investigación; de donde extraeremos: el Precio (p) multiplicado por la Cantidad (q) proyectado a 5 años; tal y como se muestra en la Tabla 74; obteniendo en el primer año ingresos por S/. 245,608.00 y en el quinto año por S/. $377,731.70$.

Tabla 74

Presupuesto de Ingreso y Proyección de Ventas del Año 1 al 5

\begin{tabular}{lrrrrr}
\hline P*Q anual & \multicolumn{5}{c}{ Año } \\
\cline { 2 - 6 } & \multicolumn{1}{c}{1} & \multicolumn{1}{c}{3} & \multicolumn{1}{c}{4} & \multicolumn{1}{c}{5} \\
\hline Ventas & $208,142.37$ & $238,138.14$ & $284,156.78$ & $295,951.27$ & $320,111.61$ \\
IGV & $37,465.63$ & $42,864.86$ & $51,148.22$ & $53,271.23$ & $57,620.09$ \\
Ingreso total & $245,608.00$ & $281,003.00$ & $335,305.00$ & $349,222.50$ & $377,731.70$ \\
\hline
\end{tabular}




\subsubsection{Presupuesto de costos de producción}

Para la elaboración del presupuesto de costos de producción, se ha tomado en consideración el desembolso destinado a los costos directos e indirectos; mismos que, posteriormente, se dividirán con el número de ventas (q) para obtener el costo unitario promedio (ver Tabla 75).

Tabla 75

Presupuesto de Costos de Producción

\begin{tabular}{lrrrrr}
\hline Descripción & \multicolumn{5}{c}{ Año } \\
& \multicolumn{1}{c}{1} & \multicolumn{1}{c}{3} & \multicolumn{1}{c}{4} & \multicolumn{1}{c}{5} \\
\cline { 2 - 6 } Costo Directo & & & & & \\
$\quad$ Mano de obra directa & $50,755.67$ & $50,755.67$ & $50,755.67$ & $50,755.67$ & $50,755.67$ \\
Sub total & $50,755.67$ & $50,755.67$ & $50,755.67$ & $50,755.67$ & $50,755.67$ \\
\hline & & & & & \\
Costo Indirecto & & & & \\
$\quad$ Mano de obra indirecta & $13,809.67$ & $13,809.67$ & $13,809.67$ & $13,809.67$ & $13,809.67$ \\
$\quad$ Depreciación & $26,708.47$ & $26,708.47$ & $26,708.47$ & $26,708.47$ & $26,708.47$ \\
$\quad$ Sueldos administrativos & $18,222.00$ & $18,222.00$ & $18,222.00$ & $18,222.00$ & $18,222.00$ \\
$\quad$ Gasto de ventas & $7,627.12$ & $7,627.12$ & $7,627.12$ & $7,627.12$ & $7,627.12$ \\
$\quad$ Otros gastos administrativos & $67,666.53$ & $67,666.53$ & $67,666.53$ & $67,666.53$ & $67,666.53$ \\
$\quad$ Amortización & $1,840.68$ & $1,840.68$ & $1,840.68$ & $1,840.68$ & $1,840.68$ \\
Sub total & $135,874.46$ & $135,874.46$ & $135,874.46$ & $135,874.46$ & $135,874.46$ \\
\hline & & & & & \\
\hline Costo total & $186,630.13$ & $186,630.13$ & $186,630.13$ & $186,630.13$ & $186,630.13$ \\
\hline & & & & & \\
Numero de ventas & 143 & 156 & 170 & 186 & 202 \\
Costo unitario promedio & $1,305.11$ & $1,196.35$ & $1,097.82$ & $1,008.81$ & 923.91 \\
\hline
\end{tabular}

\subsubsection{Presupuesto de compras}

Se consideró los gastos a realizarse por la prestación del servicio; las mismas que han sido calculadas en base a una frecuencia anual. Para ello, se ha tomado en cuenta los gastos de utilería (ver Tabla 76) y los gastos de oficina (ver Tabla 77).

Tabla 76

Gastos de Utilería

\begin{tabular}{lccc}
\hline $\begin{array}{l}\text { Gastos de utilería } \\
\text { Iimpieza }\end{array}$ & $\begin{array}{c}\text { Costos sin } \\
\text { IGV }\end{array}$ & IGV & $\begin{array}{c}\text { Costo con } \\
\text { IGV }\end{array}$ \\
\hline Uniforme & $1,225.00$ & 220.50 & $1,445.50$ \\
Total & 296.61 & 53.39 & 350.00 \\
\hline
\end{tabular}


Tabla 77

Gastos de Oficina

\begin{tabular}{llccccc}
\hline Descripción & Proveedor & Cantidad & $\begin{array}{c}\text { Costo } \\
\text { unitario }\end{array}$ & $\begin{array}{c}\text { Costo sin } \\
\text { IGV }\end{array}$ & IGV & $\begin{array}{c}\text { Costo con } \\
\text { IGV }\end{array}$ \\
\hline Lapicros x Caja & Navarrete & 2 & 15.00 & 25.42 & 4.58 & 30.00 \\
Clips x caja & Navarrete & 3 & $\mathbf{1 . 5 0}$ & 3.81 & 0.69 & 4.50 \\
Papel Bond x 500 & Navarrete & 5 & 9.00 & 38.14 & 6.86 & 45.00 \\
Sobre manila paq. 20 & Navarrete & 2 & 4.50 & 7.63 & 1.37 & 9.00 \\
Cinta adhesiva & Navarrete & 5 & 1.50 & 6.36 & 1.14 & 7.50 \\
Cinta Mask & Navarrete & 3 & 2.00 & 5.08 & 0.92 & 6.00 \\
Engrapador & Navarrete & 3 & 7.00 & 17.80 & 3.20 & 21.00 \\
Perforador & Navarrete & 2 & 8.00 & 13.56 & 2.44 & 16.00 \\
Tijeras & Navarrete & 4 & 5.00 & 16.95 & 3.05 & 20.00 \\
Caja de plumones & Navarrete & 5 & 20.00 & 84.75 & 15.25 & 100.00 \\
Mota & Navarrete & 4 & 2.00 & 6.78 & 1.22 & 8.00 \\
Liquid paper & Navarrete & 5 & 5.00 & 21.19 & 3.81 & 25.00 \\
Tachuela & Navarrete & 3 & 3.00 & 7.63 & 1.37 & 9.00 \\
Pizarra grande & Navarrete & 1 & 250.00 & 211.86 & 38.14 & 250.00 \\
Pizarra pequeña & Navarrete & 2 & 60.00 & 101.69 & 18.31 & 120.00 \\
Pizarra de corcho & Navarrete & 2 & 50.00 & 84.75 & 15.25 & 100.00 \\
Total & & & & 653.39 & 117.61 & 771.00 \\
\hline
\end{tabular}

\subsubsection{Presupuesto de costo de ventas}

El costo de ventas está compuesto por la mano de obra directa (ver Apéndice 40), la mano de obra indirecta (ver Apéndice 41) y la depreciación (ver Apéndice 42), tal y como se muestra en la Tabla 78.

Tabla 78

Presupuesto de Costo de Ventas

\begin{tabular}{lccccc}
\hline Descripción & \multicolumn{5}{c}{ Año } \\
\cline { 2 - 6 } & 1 & 2 & 3 & 4 & 5 \\
\cline { 2 - 6 } Costo de ventas & $-91,273.81$ & $-91,273.81$ & $-91,273.81$ & $-91,273.81$ & $-91,273.81$ \\
Mano de obra directa & $-50,755.67$ & $-50,755.67$ & $-50,755.67$ & $-50,755.67$ & $-50,755.67$ \\
Mano de obra indirecta & $-13,809.67$ & $-13,809.67$ & $-13,809.67$ & $-13,809.67$ & $-13,809.67$ \\
Depreciación & $-26,708.47$ & $-26,708.47$ & $-26,708.47$ & $-26,708.47$ & $-26,708.47$ \\
\hline
\end{tabular}

\subsubsection{Presupuesto de gastos administrativos}

Para determinar el presupuesto de gastos administrativos, se ha considerado aquellos gastos que por su naturaleza no se vincula de manera directa con la prestación del servicio; pero que, sin embargo, forman parte de los gastos por ejercicio de la actividad económica de 
la empresa. Para ello, se ha tomado en cuenta los gastos de producción y los sueldos administrativos, como puede verse en las Tablas 79 y 80 respectivamente.

Tabla 79

Gastos de Producción

\begin{tabular}{lcccccc}
\hline Gastos de producción & Proveedor & Cantidad & $\begin{array}{c}\text { Costo } \\
\text { Unitario }\end{array}$ & $\begin{array}{c}\text { Costo sin } \\
\text { IGV }\end{array}$ & IGV & $\begin{array}{c}\text { Costo con } \\
\text { IGV }\end{array}$ \\
\hline $\begin{array}{lcccccc}\text { Alquiler Local } \\
\text { Comercial }\end{array}$ & mes & 12 & $6,000.00$ & $72,000.00$ & & $72,000.00$ \\
luz & Luz del Sur & 12 & 80.00 & 813.56 & 146.44 & 960.00 \\
Agua & Sedapal & 12 & 90.00 & 915.25 & 164.75 & $1,080.00$ \\
$\begin{array}{l}\text { Teléfono + Internet }+ \\
\text { Cable }\end{array}$ & Movistar & 12 & 150.00 & $1,525.42$ & 274.58 & $1,800.00$ \\
$\begin{array}{l}\text { FEE } \\
\text { Mantenimiento de }\end{array}$ & VISA & 12 & 50.00 & 508.47 & 91.53 & 600.00 \\
equipo & Bullfit & 12 & 70.00 & 711.86 & 128.14 & 840.00 \\
Total & & & & $65,491.53$ & $11,788.47$ & $77,280.00$ \\
\hline
\end{tabular}

Tabla 80

Sueldos de Personal Administrativo

\begin{tabular}{lrrrrrrrrr}
\hline \multicolumn{10}{c}{ Personal administrativo } \\
\hline Descripción & Cantidad & Sueldo & Mensual & $\begin{array}{r}\text { Período } \\
\text { mensual }\end{array}$ & Sub total & $\begin{array}{r}\text { Gratificación } \\
\text { anual }\end{array}$ & CTS & Essalud & Total \\
\hline Contador & 1 & 300.00 & 300.00 & 12 & $3,600.00$ & 0.00 & 0.00 & 0.00 & $3,600.00$ \\
Administrador & 1 & 900.00 & 900.00 & 12 & $10,800.00$ & $1,800.00$ & $1,050.00$ & 972.00 & $14,622.00$ \\
\hline Total & 1 & $1,200.00$ & $1,200.00$ & 12 & $14,400.00$ & $1,800.00$ & $1,050.00$ & 972.00 & $18,222.00$ \\
\hline
\end{tabular}

\subsubsection{Presupuesto de marketing y ventas}

El presupuesto de marketing y ventas está compuesto por aquellos gastos que la empresa generará por concepto de publicidad para atraer clientes y cuyo proveedor será la consultora Imagen S.A.C con una duración anual (ver Tabla 81). El servicio de la consultora descrita será en creación y mantenimiento de la página web, manejo de las redes sociales, volanteo por la zona, toma de fotos y elaboración de videos promocionales.

Tabla 81

Presupuesto de Marketing y Ventas

\begin{tabular}{llcccccr}
\hline Gastos de Ventas & Proveedor & Cantidad & $\begin{array}{c}\text { Costo } \\
\text { Unitario }\end{array}$ & $\begin{array}{c}\text { Costo sin } \\
\text { IGV }\end{array}$ & IGV & Costo total \\
\hline Publicidad & Imagen & 12 & 750.00 & $7,627.12$ & $1,372.88$ & $9,000.00$ \\
\hline Total & & & & $7,627.12$ & $1,372.88$ & $9,000.00$ \\
\hline
\end{tabular}




\subsubsection{Presupuesto de gastos financieros}

Por concepto de gastos financieros corresponden los intereses y amortizaciones del préstamo bancario solicitado al banco BBVA Continental para la inversión; la cual, como ya lo hemos señalado previamente, se cancelará en 5 años (60 meses). En la Tabla 82 se muestra la amortización de la deuda anual de la simulación del préstamo bancario.

Tabla 82

Presupuesto de Gastos Financieros

\begin{tabular}{cccccc}
\hline \multicolumn{5}{c}{ Amortización de la deuda anual } \\
\hline Año & Amortización & Intereses & Cuota & Saldo & Escudo Fiscal \\
\hline 0 & & & $52,000.00$ & \\
1 & $8,267.05$ & $5,279.99$ & $13,547.04$ & $43,732.95$ & $1,557.60$ \\
2 & $9,217.76$ & $4,329.28$ & $13,547.04$ & $34,515.18$ & $1,277.14$ \\
3 & $10,277.81$ & $3,269.24$ & $13,547.04$ & $24,237.38$ & 964.42 \\
4 & $11,459.75$ & $2,087.29$ & $13,547.04$ & $12,777.63$ & 615.75 \\
5 & $12,777.63$ & 769.42 & $13,547.04$ & 0.00 & 226.98 \\
\hline Total & $52,000.00$ & $15,735.21$ & $67,735.21$ & & $4,641.89$ \\
\hline
\end{tabular}

\subsection{Presupuestos de Resultados}

En este punto, se ha tomado en consideración los estados financieros mensuales del primer año; así como, los proyectados al quinto año; dentro de ellos se tiene: el estado de ganancias y perdidas, el balance general y el flujo de caja.

\subsubsection{Estado de ganancias y pérdidas proyectado}

De acuerdo con Moyano (2015) "los estados de ganancias y pérdidas son aquellos que muestran la utilidad en un periodo de tiempo determinado de un negocio" (p. 151). Dentro del estado de ganancias y pérdidas (EGyP) se considera la proyección de ventas, costo de ventas y aquellos gastos que se generan a lo largo del tiempo. En la Tabla 83 se muestra el EGyP proyectado al quinto año, donde se puede apreciar que desde el primer año, Ate CrossFit genera utilidades; y en la Tabla 84 el EGyP mensual del primer año, donde se determina que a partir del mes de agosto, la empresa genera utilidades. 
Tabla 83

Estado de Ganancias y Pérdidas Proyectado

\begin{tabular}{lccccc}
\hline Descripción & \multicolumn{5}{c}{ Año } \\
\hline \multirow{2}{*}{ Ventas } & $208,142.37$ & $238,138.14$ & $284,156.78$ & $295,951.27$ & $320,111.61$ \\
Costo de ventas & $-91,273.81$ & $-91,273.81$ & $-91,273.81$ & $-91,273.81$ & $-91,273.81$ \\
$\quad$ Mano de obra directa & $-50,755.67$ & $-50,755.67$ & $-50,755.67$ & $-50,755.67$ & $-50,755.67$ \\
$\quad$ Mano de obra indirecta & $-13,809.67$ & $-13,809.67$ & $-13,809.67$ & $-13,809.67$ & $-13,809.67$ \\
$\quad$ Depreciación & $-26,708.47$ & $-26,708.47$ & $-26,708.47$ & $-26,708.47$ & $-26,708.47$ \\
\hline Utilidad Bruta & $116,868.56$ & $146,864.33$ & $192,882.97$ & $204,677.46$ & $228,837.80$ \\
\hline Gastos de Operación & & & & & \\
$\quad$ Sueldos administrativos & $-18,222.00$ & $-18,222.00$ & $-18,222.00$ & $-18,222.00$ & $-18,222.00$ \\
$\quad$ Gastos de ventas & $-7,627.12$ & $-7,627.12$ & $-7,627.12$ & $-7,627.12$ & $-7,627.12$ \\
$\quad$ Otros Gastos & $-67,666.53$ & $-67,666.53$ & $-67,666.53$ & $-67,666.53$ & $-67,666.53$ \\
administrativos & $-1,840.68$ & $-1,840.68$ & $-1,840.68$ & $-1,840.68$ & $-1,840.68$ \\
$\quad$ Amortización & $-95,356.32$ & $-95,356.32$ & $-95,356.32$ & $-95,356.32$ & $-95,356.32$ \\
\hline Total Gastos de operación & $21,512.24$ & $51,508.01$ & $97,526.65$ & $109,321.14$ & $133,481.48$ \\
\hline Utilidad operativa & $-5,279.99$ & $-4,329.28$ & $-3,269.24$ & $-2,087.29$ & -769.42 \\
\hline$\quad$ Gastos financieros & $16,232.25$ & $47,178.73$ & $94,257.41$ & $107,233.85$ & $132,712.06$ \\
\hline Utilidad antes de impuestos & $4,788.51$ & $13,917.72$ & $27,805.94$ & $31,633.99$ & $39,150.06$ \\
\hline$\quad$ (-) IR 29.5\% & $11,443.74$ & $33,261.00$ & $66,451.48$ & $75,599.87$ & $93,562.01$ \\
\hline Utilidad Neta & $5 \%$ & $14 \%$ & $23 \%$ & $26 \%$ & $29 \%$ \\
\hline Margen Neto & & & & \\
\hline & & & & \\
\hline
\end{tabular}


Tabla 84

Estado de Ganancia y Pérdidas Mensual Primer Año

\begin{tabular}{|c|c|c|c|c|c|c|c|c|c|c|c|c|}
\hline \multirow[t]{2}{*}{ Descripción } & \multicolumn{12}{|c|}{ Meses del año 1} \\
\hline & En & Feb & Mar & Abr & May & Jun & Jul & Ago & Set & Oct & Nov & Dic \\
\hline Ventas & $7,261.02$ & $7,943.22$ & $8,293.22$ & $10,433.90$ & $11,112.71$ & $11,776.27$ & $16,050.85$ & $17,516.95$ & $18,271.19$ & $31,110.17$ & $33,313.56$ & $35,059.32$ \\
\hline Costo de ventas & $-6,749.21$ & $-6,749.21$ & $-6,749.21$ & $-6,749.21$ & $-7,740.87$ & $-6,749.21$ & $-10,899.21$ & $-6,749.21$ & $-6,749.21$ & $-6,749.21$ & $-7,740.87$ & $-10,899.21$ \\
\hline $\begin{array}{l}\text { Mano de obra } \\
\text { directa }\end{array}$ & $-3,597.00$ & $-3,597.00$ & $-3,597.00$ & $-3,597.00$ & $-4,092.83$ & $-3,597.00$ & $-6,897.00$ & $-3,597.00$ & $-3,597.00$ & $-3,597.00$ & $-4,092.83$ & $-6,897.00$ \\
\hline $\begin{array}{l}\text { Mano de obra } \\
\text { indirecta }\end{array}$ & -926.50 & -926.50 & -926.50 & -926.50 & $-1,422.33$ & -926.50 & $-1,776.50$ & -926.50 & -926.50 & -926.50 & $-1,422.33$ & $-1,776.50$ \\
\hline Depreciación & -2225.71 & -2225.71 & -2225.71 & -2225.71 & -2225.71 & -2225.71 & -2225.71 & -2225.71 & -2225.71 & -2225.71 & -2225.71 & -2225.71 \\
\hline Utilidad Bruta & 511.81 & $1,194.01$ & $1,544.01$ & $3,684.69$ & $3,371.84$ & $5,027.06$ & $5,151.64$ & $10,767.74$ & $11,521.98$ & $24,360.96$ & $25,572.69$ & $24,160.12$ \\
\hline \multicolumn{13}{|l|}{ Gastos de Operación } \\
\hline $\begin{array}{l}\text { Sueldos } \\
\text { administrativos }\end{array}$ & $-1,281.00$ & $-1,281.00$ & $-1,281.00$ & $-1,281.00$ & $-1,806.00$ & $-1,281.00$ & $-2,181.00$ & $-1,281.00$ & $-1,281.00$ & $-1,281.00$ & $-1,806.00$ & $-2,181.00$ \\
\hline Gastos de ventas & -635.593 & -635.593 & -635.593 & -635.593 & -635.593 & -635.593 & -635.593 & -635.593 & -635.593 & -635.593 & -635.593 & -635.593 \\
\hline $\begin{array}{l}\text { Otros Gastos } \\
\text { administrativos }\end{array}$ & -5638.88 & -5638.88 & -5638.88 & -5638.88 & -5638.88 & -5638.88 & -5638.88 & -5638.88 & -5638.88 & -5638.88 & -5638.88 & -5638.88 \\
\hline Amortización & -153.39 & -153.39 & -153.39 & -153.39 & -153.39 & -153.39 & -153.39 & -153.39 & -153.39 & -153.39 & -153.39 & -153.39 \\
\hline $\begin{array}{l}\text { Total Gastos de } \\
\text { operación }\end{array}$ & $-7,708.86$ & $-7,708.86$ & $-7,708.86$ & $-7,708.86$ & $-8,233.86$ & $-7,708.86$ & $-8,608.86$ & $-7,708.86$ & $-7,708.86$ & $-7,708.86$ & $-8,233.86$ & $-8,608.86$ \\
\hline Utilidad operativa & $-7,197.05$ & $-6,514.85$ & $-6,164.85$ & $-4,024.17$ & $-4,862.02$ & $-2,681.80$ & $-3,457.22$ & $3,058.88$ & $3,813.12$ & $16,652.10$ & $17,338.83$ & $15,551.26$ \\
\hline Gastos financieros & -473.85 & -467.88 & -461.86 & -455.78 & -449.64 & -443.45 & -437.21 & -430.90 & -424.54 & -418.12 & -411.65 & -405.11 \\
\hline $\begin{array}{l}\text { Utilidad antes de } \\
\text { impuestos }\end{array}$ & $-7,670.90$ & $-6,982.73$ & $-6,626.70$ & $-4,479.94$ & $-5,311.66$ & $-3,125.25$ & $-3,894.43$ & $2,627.98$ & $3,388.58$ & $16,233.98$ & $16,927.18$ & $15,146.14$ \\
\hline (-) IR $29.5 \%$ & -2262.91 & -2059.90 & -1954.88 & -1321.58 & -1566.94 & -921.95 & -1148.86 & 775.25 & 999.63 & 4789.02 & 4993.52 & 4468.11 \\
\hline Utilidad Neta & $-5,407.98$ & $-4,922.82$ & $-4,671.82$ & $-3,158.36$ & $-3,744.72$ & $-2,203.30$ & $-2,745.57$ & $1,852.73$ & $2,388.95$ & $11,444.96$ & $11,933.66$ & $10,678.03$ \\
\hline Margen Neto & $-74 \%$ & $-62 \%$ & $-56 \%$ & $-30 \%$ & $-34 \%$ & $-19 \%$ & $-17 \%$ & $11 \%$ & $13 \%$ & $37 \%$ & $36 \%$ & $30 \%$ \\
\hline
\end{tabular}




\subsubsection{Balance proyectado}

En la Tabla 85 se muestra el balance general proyecto a 5 años de Ate CrossFit.

Tabla 85

\section{Balance General Proyectado}

\begin{tabular}{lrrrrrr}
\hline Descripción & \multicolumn{7}{c}{ Año } \\
\hline & \multicolumn{1}{c}{0} & 1 & \multicolumn{1}{c}{2} & \multicolumn{1}{c}{3} & \multicolumn{1}{c}{4} & \multicolumn{1}{c}{5} \\
\cline { 2 - 7 } Caja & $26,034.16$ & $85,110.85$ & $137,703.24$ & $222,426.06$ & $315,115.33$ & $424,448.86$ \\
Activo Fijo & $157,580.00$ & $106,833.90$ & $80,125.42$ & $53,416.95$ & $26,708.47$ & 0.00 \\
Intangible & $21,720.00$ & $16,566.10$ & $14,725.42$ & $12,884.75$ & $11,044.07$ & $9,203.39$ \\
\hline Total Activo Fijo & $205,334.16$ & $208,510.85$ & $232,554.09$ & $288,727.76$ & $352,867.87$ & $433,652.25$ \\
\hline Préstamo Bancario & $52,000.00$ & $43,732.95$ & $34,515.18$ & $24,237.38$ & $12,777.63$ & 0.00 \\
\hline Total Pasivo & $52,000.00$ & $43,732.95$ & $34,515.18$ & $24,237.38$ & $12,777.63$ & 0.00 \\
\hline Capital Social & $153,334.16$ & $153,334.16$ & $153,334.16$ & $153,334.16$ & $153,334.16$ & $153,334.16$ \\
Resultados acumulados & & $11,443.74$ & $44,704.74$ & $111,156.22$ & $186,756.09$ & $280,318.09$ \\
\hline Total Patrimonio & $153,334.16$ & $164,777.90$ & $198,038.90$ & $264,490.38$ & $340,090.25$ & $433,652.25$ \\
\hline
\end{tabular}

\subsubsection{Flujo de caja proyectado}

Para analizar el saldo efectivo disponible al finalizar cada período y determinar las necesidades de fondos para cubrir las obligaciones del negocio, es necesario elaborar el flujo de caja mensual del primer año (ver Tabla 86) y el flujo de caja proyectado al quinto año (ver Tabla 87). 
Tabla 86

\section{Flujo de Caja Mensual Primer Año}

\begin{tabular}{|c|c|c|c|c|c|c|c|c|c|c|c|c|c|}
\hline Descripción & 0 & En & Feb & Mar & Abr & May & Jun & Jul & Ago & Set & Oct & Nov & Dic \\
\hline $\begin{array}{l}\text { Ingresos x } \\
\text { Cobranza }\end{array}$ & & $8,568.00$ & $9,373.00$ & $9,786.00$ & $12,312.00$ & $13,113.00$ & $13,896.00$ & $18,940.00$ & $20,670.00$ & $\begin{array}{c}21,560.0 \\
0\end{array}$ & $36,710.00$ & $39,310.00$ & $41,370.00$ \\
\hline \multicolumn{14}{|l|}{ Egresos operativos } \\
\hline $\begin{array}{l}\text { Mano de obra } \\
\text { directa }\end{array}$ & & $-3,597.00$ & $-3,597.00$ & $-3,597.00$ & $-3,597.00$ & $-4,092.83$ & $-3,597.00$ & $-6,897.00$ & $-3,597.00$ & $-3,597.00$ & $-3,597.00$ & $-4,092.83$ & $-6,897.00$ \\
\hline $\begin{array}{l}\text { Mano de obra } \\
\text { indirecta }\end{array}$ & & -926.50 & -926.50 & -926.50 & -926.50 & $-1,422.33$ & -926.50 & $-1,776.50$ & -926.50 & -926.50 & -926.50 & $-1,422.33$ & $-1,776.50$ \\
\hline $\begin{array}{l}\text { Sueldos } \\
\text { administrativos }\end{array}$ & & $-1,281.00$ & $-1,281.00$ & $-1,281.00$ & $-1,281.00$ & $-1,806.00$ & $-1,281.00$ & $-2,181.00$ & $-1,281.00$ & $-1,281.00$ & $-1,281.00$ & $-1,806.00$ & $-2,181.00$ \\
\hline Gasto de ventas & & -750.00 & -750.00 & -750.00 & -750.00 & -750.00 & -750.00 & -750.00 & -750.00 & -750.00 & -750.00 & -750.00 & -750.00 \\
\hline $\begin{array}{l}\text { Otros gastos } \\
\text { administrativos }\end{array}$ & & $-6,653.88$ & $-6,653.88$ & $-6,653.88$ & $-6,653.88$ & $-6,653.88$ & $-6,653.88$ & $-6,653.88$ & $-6,653.88$ & $-6,653.88$ & $-6,653.88$ & $-6,653.88$ & $-6,653.88$ \\
\hline Pago de IGV & & 286.51 & 286.51 & 286.51 & 286.51 & 286.51 & 286.51 & 286.51 & 286.51 & 286.51 & 286.51 & 286.51 & 286.51 \\
\hline IR & & -528.84 & -528.84 & -528.84 & -528.84 & -528.84 & -528.84 & -528.84 & -528.84 & -528.84 & -528.84 & -528.84 & -528.84 \\
\hline $\begin{array}{l}\text { Flujo de caja } \\
\text { operativo }\end{array}$ & & $-4,882.71$ & $-4,077.71$ & $-3,664.71$ & $-1,138.71$ & $-1,854.38$ & 445.29 & 439.29 & $7,219.29$ & $8,109.29$ & $23,259.29$ & $24,342.62$ & $22,869.29$ \\
\hline Activo Fijo & $-157,580.00$ & & & & & & & & & & & & \\
\hline Activo Intangible & $-21,720.00$ & & & & & & & & & & & & \\
\hline KW & $26,034.16$ & 0.00 & 0.00 & 0.00 & 0.00 & 0.00 & 0.00 & 0.00 & 0.00 & 0.00 & 0.00 & 0.00 & 0.00 \\
\hline $\begin{array}{l}\text { Flujo de caja } \\
\text { economico }\end{array}$ & $-153,265.84$ & $-4,882.71$ & $-4,077.71$ & $-3,664.71$ & $-1,138.71$ & $-1,854.38$ & 445.29 & 439.29 & $7,219.29$ & $8,109.29$ & $23,259.29$ & $24,342.62$ & $22,869.29$ \\
\hline $\begin{array}{l}\text { Préstamo } \\
\text { /amortización }\end{array}$ & $52,000.00$ & -655.07 & -661.04 & -667.06 & -673.14 & -679.28 & -685.47 & -691.71 & -698.02 & -704.38 & -710.80 & -717.27 & -723.81 \\
\hline Intereses & & -473.85 & -467.88 & -461.86 & -455.78 & -449.64 & -443.45 & -437.21 & -430.90 & -424.54 & -418.12 & -411.65 & -405.11 \\
\hline Escudo fiscal & & 139.79 & 138.02 & 136.25 & 134.45 & 132.64 & 130.82 & 128.98 & 127.12 & 125.24 & 123.35 & 121.44 & 119.51 \\
\hline $\begin{array}{l}\text { Financiamiento } \\
\text { neto }\end{array}$ & $52,000.00$ & -989.13 & -990.90 & -992.67 & -994.47 & -996.28 & -998.10 & -999.94 & $-1,001.80$ & $-1,003.68$ & $-1,005.57$ & $-1,007.48$ & $-1,009.41$ \\
\hline $\begin{array}{l}\text { Flujo de caja } \\
\text { financiero }\end{array}$ & $-101,265.84$ & $-5,871.85$ & $-5,068.61$ & $-4,657.38$ & $-2,133.18$ & $-2,850.65$ & -552.81 & -560.66 & $6,217.49$ & $7,105.61$ & $22,253.72$ & $23,335.14$ & $21,859.88$ \\
\hline Déficit Acumulado & & $-5,871.85$ & $-10,940.45$ & $-15,597.84$ & $-17,731.01$ & $-20,581.67$ & $-21,134.48$ & $-21,695.14$ & $-15,477.65$ & $-8,372.04$ & $13,881.67$ & $37,216.81$ & $59,076.69$ \\
\hline
\end{tabular}


Tabla 87

Flujo de Caja Proyectado

\begin{tabular}{|c|c|c|c|c|c|c|}
\hline Descripción & & & $\mathrm{Ai}$ & & & \\
\hline & 0 & 1 & 2 & 3 & 4 & 5 \\
\hline Ingresos x Cobranza & & $245,608.00$ & $281,003.00$ & $335,305.00$ & $349,222.50$ & $377,731.70$ \\
\hline Egresos operativos & & & & & & \\
\hline Mano de obra directa & & $-50,755.67$ & $-50,755.67$ & $-50,755.67$ & $-50,755.67$ & $-50,755.67$ \\
\hline Mano de obra indirecta & & $-13,809.67$ & $-13,809.67$ & $-13,809.67$ & $-13,809.67$ & $-13,809.67$ \\
\hline Sueldos administrativos & & $-18,222.00$ & $-18,222.00$ & $-18,222.00$ & $-18,222.00$ & $-18,222.00$ \\
\hline Gasto de ventas & & $-9,000.00$ & $-9,000.00$ & $-9,000.00$ & $-9,000.00$ & $-9,000.00$ \\
\hline $\begin{array}{l}\text { Otros gastos } \\
\text { administrativos }\end{array}$ & & $-79,846.50$ & $-79,846.50$ & $-79,846.50$ & $-79,846.50$ & $-79,846.50$ \\
\hline Pago de IGV & & $3,438.08$ & $-29,312.01$ & $-37,595.36$ & $-39,718.37$ & $-44,067.23$ \\
\hline IR & & $-6,346.11$ & $-15,194.86$ & $-28,770.36$ & $-32,249.74$ & $-39,377.04$ \\
\hline Flujo de caja operativo & & $71,066.13$ & $64,862.30$ & $97,305.44$ & $105,620.56$ & $122,653.60$ \\
\hline Inversiones & & & & & & \\
\hline Activo Fijo & $-157,580.00$ & & & & & \\
\hline Activo Intangible & $-21,720.00$ & & & & & \\
\hline KW & $-26,034.16$ & 0.00 & 0.00 & 0.00 & 0.00 & $26,034.16$ \\
\hline Flujo de caja económico & $-205,334.16$ & $71,066.13$ & $64,862.30$ & $97,305.44$ & $105,620.56$ & $148,687.76$ \\
\hline Préstamo /amortización & $52,000.00$ & $-8,267.05$ & $-9,217.76$ & $-10,277.81$ & $-11,459.75$ & $-12,777.63$ \\
\hline Intereses & & $-5,279.99$ & $-4,329.28$ & $-3,269.24$ & $-2,087.29$ & -769.42 \\
\hline Escudo fiscal & & $1,557.60$ & $1,277.14$ & 964.42 & 615.75 & 226.98 \\
\hline Financiamiento neto & $52,000.00$ & $-11,989.44$ & $-12,269.90$ & $-12,582.62$ & $-12,931.29$ & $-13,320.06$ \\
\hline Flujo de caja financiero & $-153,334.16$ & $59,076.69$ & $52,592.39$ & $84,722.82$ & $92,689.27$ & $135,367.69$ \\
\hline
\end{tabular}




\section{Capítulo X: Evaluación Económico Financiera}

Para determinar si la apertura de un box de CrossFit para combatir la obesidad en el distrito de Ate es viable o no; se empleó los siguientes indicadores de rentabilidad: TIR, VAN y Costo Beneficio; adicional a ello, el método de período de recuperación de la inversión (Payback). Asimismo, se elaboró el análisis de riesgo para determinar el punto de equilibrio, la sensibilidad y los posibles escenarios que pueden ocurrir en el tiempo.

\subsection{Evaluación Financiera}

\subsubsection{TIR}

Como señalan Beltrán y Cueva (2014) "la tasa interna de retorno es una tasa porcentual que indica la rentabilidad promedio por período que genera el capital que permanece invertido en el proyecto" (p. 388). En la presente investigación, se debe considerar el flujo de caja financiero inicial hasta el quinto año; tal y como se muestra en la Tabla 88. Esto último, debido a que se iniciará una actividad con deuda. Posteriormente, se aplica siguiente fórmula:

$$
I+\sum_{i=1}^{n} \frac{F C}{(1+d)^{\wedge} i}=\phi
$$

Tabla 88

Flujo de Caja Financiero Proyectado

\begin{tabular}{lcccccc}
\hline & \multicolumn{6}{c}{ Año } \\
\cline { 2 - 7 } & 0 & 1 & 2 & 3 & 4 & 5 \\
\hline Flujo de caja financiero & $-153,334.16$ & $59,076.69$ & $52,592.39$ & $84,722.82$ & $92,689.27$ & $135,367.69$ \\
\hline
\end{tabular}

El proyecto arroja una TIR de 39\%, mayor al Cok (20.09\%); es decir, la rentabilidad del proyecto en términos porcentuales promedio por año es más alta que la rentabilidad de una alternativa similar de riesgo. Por tanto, es recomendable que el proyecto se ejecute.

Asimismo, Ate CrossFit es rentable debido a que la TIR se encuentra por encima de la tasa de la prestación de la deuda.

\subsubsection{VAN}

Para determinar el Valor Actual Neto (VAN) o Valor Presente Neto (VPN) se debe considerar el flujo de caja financiero expuesto en la Tabla 88 y el Cok (20.09\%).

Posteriormente, se aplica la siguiente fórmula: 


$$
V P N=1+\sum_{i=1}^{n} \frac{F C i}{(1+d)^{\wedge} i}
$$

El VAN obtenido es de S/. 79,992.50, siendo mayor a 0, lo cual significa que el retorno ha sido más alto que el monto de la inversión. Por tanto, es recomendable ejecutar el proyecto; debido a que, se genera una ganancia, recuperando la inversión y se cumple con la rentabilidad mínima.

Período de recuperación de la inversión

De acuerdo con Beltrán y Cueva (2014) es el tiempo requerido para recuperar la inversión del proyecto. Para el desarrollo del cálculo del Período de recuperación de la inversión o Payback, se utiliza los datos del flujo de caja financiero proyectado (ver Tabla 89); tomándose en cuenta el método que considera el valor del dinero en el tiempo, aplicando la siguiente fórmula:

$\mathrm{PR}=\mathrm{a}+[(\mathrm{b}-\mathrm{c}) / \mathrm{d}]$

Donde:

$\mathrm{a}=$ año anterior a la recuperación de la inversión

$\mathrm{b}=$ Inversión inicial

c $=$ Suma de los flujos anteriores al año de recuperación de la inversión

d = Flujo del año en el que se satisface la inversión

Tabla 89

Flujo de Caja Financiero Proyectado y Déficit Acumulado

\begin{tabular}{|c|c|c|c|c|c|c|}
\hline Descripción & & & & Año & & \\
\hline & Inversión & 1 & 2 & 3 & 4 & 5 \\
\hline Flujo de caja financiero & $205,334.16$ & $59,076.69$ & $52,592.39$ & $84,722.82$ & $92,689.27$ & $135,367.69$ \\
\hline Déficit acumulado & $-205,334.16$ & $-146,257.47$ & $-93,665.08$ & $-8,942.26$ & $83,747.01$ & $219,114.70$ \\
\hline
\end{tabular}

Aplicando la fórmula tenemos:

$\mathrm{a}=$ año 3

$\mathrm{b}=205,334.16$

$c=196,391.9$

$d=92,689.27$ 
Entonces:

$\mathrm{PR}=3+[(205,334.16-196,391.9) / 92,689.27]$

$\mathrm{PR}=3+0.1$

Ahora, $0.1 * 12=1.2$

Luego $0.2 * 30=6$

Entonces, el período de recuperación de la inversión será en 3 años, 1 mes y 6 días.

Índice beneficio - costo

El índice beneficio - costo se determina a través de la suma de los ingresos descontados y traídos al presente divididos sobre la suma de los egresos descontados y traídos al presente; para ello, se debe consignar el flujo de caja proyectado con la acumulación; tal y como se muestra en la Tabla 90; y posteriormente, elaborar el Índice beneficio-costo como en la Tabla 91.

Tabla 90

Flujo de Caja Proyectado Acumulado

\begin{tabular}{llrrr}
\hline \multicolumn{5}{c}{ Flujos de caja } \\
\hline Años & Inversión & \multicolumn{1}{l}{ Ingresos } & \multicolumn{1}{l}{ Egresos } & \multicolumn{1}{c}{ FCA } \\
\hline 0 & $205,334.16$ & 0 & 0 & $-205,334.16$ \\
1 & & $245,608.00$ & $186,531.31$ & $59,076.69$ \\
2 & & $281,003.00$ & $228,410.61$ & $52,592.39$ \\
3 & & $335,305.00$ & $250,582.18$ & $84,722.82$ \\
4 & & $349,222.50$ & $256,533.23$ & $92,689.27$ \\
5 & & $403,765.86$ & $268,398.17$ & $135,367.69$ \\
\hline
\end{tabular}

Tabla 91

Índice Beneficio - Costo

Suma Ingresos $\mathrm{S} / 622,724.41$

Suma Egresos $\quad \mathrm{S} / 338,607.86$

Costo-Inversión S/543,942.02

$\mathrm{B} / \mathrm{C}$

1.145

El resultado obtenido del índice beneficio costo es de 1.145; lo cual significa que los ingresos han sido mayores que la inversión y los costos generados; por tanto, se acepta el proyecto. 


\subsubsection{ROE}

El cálculo del ROE se determinará al aplicar la fórmula presentada a continuación; donde, la utilidad neta proviene del Estado de ganancias y pérdidas proyectado, y el patrimonio del balance general proyectado; tal y como se muestra en la Tabla 92.

ROE $=$ Utilidad neta / Patrimonio

Tabla 92

Cálculo del ROE 1 a 5 años

\begin{tabular}{lrrrrr}
\hline Descripción & \multicolumn{6}{c}{ Año } \\
\cline { 2 - 6 } & \multicolumn{1}{c}{1} & \multicolumn{1}{c}{2} & \multicolumn{1}{c}{3} & \multicolumn{1}{c}{4} \\
\cline { 2 - 6 } Utilidad Neta & $11,443.74$ & $33,261.00$ & $66,451.48$ & $75,599.87$ & $93,562.01$ \\
Patrimonio & $164,777.90$ & $198,038.90$ & $264,490.38$ & $340,090.25$ & $433,652.25$ \\
ROE & $6.94 \%$ & $16.80 \%$ & $25.12 \%$ & $22.23 \%$ & $21.58 \%$ \\
\hline
\end{tabular}

Esto significa que, en el Año 1, por cada S/. 1.00 sol invertido por los accionistas en el patrimonio; este habrá producido un $6.94 \%$ en el resultado neto. La tendencia del ROE determina que al quinto año, por cada S/. 1.00 sol invertido, se producirá $21.58 \%$.

\subsubsection{Ratios}

Para el presente plan de negocio, se ha determinado que se evaluarán los ratios de liquidez, grado de solvencia y porcentajes de rentabilidad; los cuales se muestran en la Tabla 93.

Tabla 93

Análisis de Ratios

\begin{tabular}{|c|c|c|c|c|c|}
\hline Ratios Financieros & Año 1 & Año 2 & Año 3 & Año 4 & Año 5 \\
\hline \multicolumn{6}{|l|}{ Liquidez } \\
\hline Liquidez general & 1.95 & 3.99 & 9.18 & 24.66 & - \\
\hline $\begin{array}{l}\text { Ratios de solvencia } \\
\text { Capacidad de } \\
\text { endeudamiento }\end{array}$ & 0.27 & 0.17 & 0.09 & 0.04 & 0.00 \\
\hline \multicolumn{6}{|l|}{ Ratios de Rentabilidad } \\
\hline Margen Bruto & 0.56 & 0.62 & 0.68 & 0.69 & 0.71 \\
\hline ROA & 0.10 & 0.25 & 0.42 & 0.38 & 0.38 \\
\hline Productividad de ventas & 0.10 & 0.22 & 0.34 & 0.37 & 0.42 \\
\hline
\end{tabular}

Del análisis de los ratios se puede precisar que en razón a la Liquidez general que la empresa puede cubrir sus deudas a corto plazo, desde el primer año. En el caso del ratio de solvencia en razón a la capacidad de endeudamiento, significa que la empresa utiliza una pequeña cantidad de dinero de un tercero (Crédito Bancario BBVA); la misma que con el 
pasar de los años va disminuyendo. En los ratios de Rentabilidad, podemos precisar: primero, el margen bruto, en el primer año el $56 \%$ de las ventas resulta ser utilidad bruta, misma que va en aumento hacia el año 5; segundo, el ROA del primer año se interpreta que la empresa está obteniendo S/.0.10 de rentabilidad por cada unidad monetaria; y tercero, respecto a la productividad de ventas, un $10 \%$ de la utilidad operativa de Ate CrossFit proviene de las ventas de las membresías, siendo un valor bajo; dicha figura varia a lo largo del tiempo, puesto que existe un cambio favorable en las ventas y precio de la misma.

\subsection{Análisis de Riesgo}

Los métodos que se presentan a continuación, permiten considerar los riesgos que podrían afectar el presente proyecto.

\subsubsection{Análisis de punto de equilibrio}

El análisis de punto de equilibrio muestra la situación en la que el negocio no gana ni pierde, la misma que se ha determinado para conocer los niveles más bajos de ventas. Para ello, se empleó la ecuación que se muestra en la Tabla 94.

Tabla 94

Ecuación de Punto de Equilibrio

VP= Costo fijo total / [1-(Costo variable total / Ingreso por ventas)]

$\mathrm{Al}$ aplicar la fórmula planteada, se ha determinado que, para alcanzar el punto de equilibrio, la compañía necesita alcanzar y vender S/. 107,807.01 en el primer año.

\subsubsection{Análisis de sensibilidad}

Este método, permite identificar las variables más relevantes para el proyecto y su impacto sobre los indicadores de rentabilidad (VAN, TIR, Etc). Para efectos de la presente investigación, se ha realizado el análisis unidimensional y bidimensional; para ello, se ha considerado como variables: El porcentaje de la inversión a financiarse, el precio mensual, las ventas, el costo de ventas y la patente ( ver Tabla 95). 
Tabla 95

Análisis de Sensibilidad de la Inversión a Financiarse

\begin{tabular}{lc}
\hline & VAN \\
\cline { 2 - 2 } & $\mathrm{S} / 79,992.50$ \\
\hline $5 \%$ & $\mathrm{~S} / 86,880.16$ \\
$10 \%$ & $\mathrm{~S} / 85,156.89$ \\
$15 \%$ & $\mathrm{~S} / 83,452.63$ \\
$20 \%$ & $\mathrm{~S} / 81,767.11$ \\
$25 \%$ & $\mathrm{~S} / 79,992.50$ \\
$30 \%$ & $\mathrm{~S} / 78,451.29$ \\
$35 \%$ & $\mathrm{~S} / 76,820.46$ \\
$40 \%$ & $\mathrm{~S} / 75,207.35$ \\
$45 \%$ & $\mathrm{~S} / 73,611.73$ \\
\hline
\end{tabular}

En la Tabla 96 se aprecia el análisis de sensibilidad unidimensional del precio por membresía mensual.

Tabla 96

Sensibilidad por Precio Mensual de Membresía

\begin{tabular}{lrr} 
& \multicolumn{1}{c}{ VAN } & TIR \\
\cline { 2 - 3 } & $\mathrm{S} / 79,992.50$ & $39 \%$ \\
\hline 350 & $\mathrm{~S} / 135,157.86$ & $51 \%$ \\
340 & $\mathrm{~S} / 124,124.79$ & $49 \%$ \\
330 & $\mathrm{~S} / 113,091.72$ & $46 \%$ \\
320 & $\mathrm{~S} / 102,058.65$ & $44 \%$ \\
310 & $\mathrm{~S} / 91,025.57$ & $41 \%$ \\
300 & $\mathrm{~S} / 79,992.50$ & $39 \%$ \\
290 & $\mathrm{~S} / 68,959.43$ & $36 \%$ \\
280 & $\mathrm{~S} / 57,926.36$ & $34 \%$ \\
270 & $\mathrm{~S} / 46,893.29$ & $31 \%$ \\
260 & $\mathrm{~S} / 35,860.22$ & $28 \%$ \\
250 & $\mathrm{~S} / 24,827.15$ & $26 \%$ \\
\hline
\end{tabular}


En la Tabla 97 se muestra el análisis de sensibilidad unidimensional realizada a las ventas si es que esta disminuye o aumenta..

Tabla 97

Análisis de Sensibilidad a las Ventas

\begin{tabular}{lcc}
\hline & VAN & TIR \\
\cline { 2 - 3 } & $S / 79,992.50$ & $39 \%$ \\
\hline$S / 368,412.00$ & $S / 141,087.01$ & $59 \%$ \\
$S / 343,851.20$ & $S / 128,868.11$ & $54 \%$ \\
$S / 319,290.40$ & $S / 116,649.21$ & $50 \%$ \\
$S / 294,729.60$ & $S / 104,430.31$ & $46 \%$ \\
$S / 270,168.80$ & $S / 92,211.40$ & $42 \%$ \\
$S / 245,608.00$ & $S / 79,992.50$ & $39 \%$ \\
$S / 223,280.00$ & $S / 68,884.41$ & $36 \%$ \\
$S / 204,673.33$ & $S / 59,627.67$ & $33 \%$ \\
$S / 188,929.23$ & $S / 51,795.04$ & $31 \%$ \\
$S / 175,434.29$ & $S / 45,081.36$ & $30 \%$ \\
$S / 163,738.67$ & $S / 39,262.83$ & $28 \%$ \\
\hline
\end{tabular}

En la Tabla 98 se muestra el análisis de sensibilidad unidimensional realizada a la patente CrossFit; si es que esta disminuye o aumenta.

Tabla 98

Análisis de Sensibilidad por Patente CrossFit

\begin{tabular}{rrr}
\hline & \multicolumn{1}{c}{ VAN } & \multicolumn{1}{l}{ TIR } \\
\cline { 2 - 3 } & S/79,992.50 & $39 \%$ \\
\hline $\mathrm{S} / 2,500.00$ & $\mathrm{~S} / 80,735.82$ & $38.90 \%$ \\
$\mathrm{~S} / 3,000.00$ & $\mathrm{~S} / 80,364.24$ & $38.76 \%$ \\
$\mathrm{~S} / 3,500.00$ & $\mathrm{~S} / 79,992.50$ & $38.62 \%$ \\
$\mathrm{~S} / 4,000.00$ & $\mathrm{~S} / 79,620.60$ & $38.49 \%$ \\
$\mathrm{~S} / 4,500.00$ & $\mathrm{~S} / 79,248.54$ & $38.35 \%$ \\
$\mathrm{~S} / 5,000.00$ & $\mathrm{~S} / 78,876.32$ & $38.22 \%$ \\
$\mathrm{~S} / 5,500.00$ & $\mathrm{~S} / 78,503.94$ & $38.08 \%$ \\
\hline
\end{tabular}


En la Tabla 99 se muestra el análisis de sensibilidad unidimensional realizada al precio trimestral de la membresía CrossFit.; si es que esta disminuye o aumenta.

Tabla 99

Análisis de Sensibilidad al Precio Trimestral de Membresía

\begin{tabular}{lcc}
\hline & VAN & TIR \\
\cline { 2 - 3 } & $\mathrm{S} / 79,992.50$ & $39 \%$ \\
\hline $\mathrm{S} / 340.00$ & $\mathrm{~S} / 98,941.96$ & $42 \%$ \\
$\mathrm{~S} / 330.00$ & $\mathrm{~S} / 95,152.07$ & $42 \%$ \\
$\mathrm{~S} / 320.00$ & $\mathrm{~S} / 91,362.18$ & $41 \%$ \\
$\mathrm{~S} / 310.00$ & $\mathrm{~S} / 87,572.29$ & $40 \%$ \\
$\mathrm{~S} / 300.00$ & $\mathrm{~S} / 83,782.40$ & $39 \%$ \\
$\mathrm{~S} / 290.00$ & $\mathrm{~S} / 79,992.50$ & $39 \%$ \\
$\mathrm{~S} / 280.00$ & $\mathrm{~S} / 76,202.61$ & $38 \%$ \\
$\mathrm{~S} / 270.00$ & $\mathrm{~S} / 72,412.72$ & $37 \%$ \\
$\mathrm{~S} / 260.00$ & $\mathrm{~S} / 68,622.83$ & $36 \%$ \\
$\mathrm{~S} / 250.00$ & $\mathrm{~S} / 64,832.93$ & $36 \%$ \\
$\mathrm{~S} / 240.00$ & $\mathrm{~S} / 61,043.04$ & $35 \%$ \\
\hline
\end{tabular}

Análisis de sensibilidad bidimensional

Para efectos del análisis, se puso en comparación las ventas con el precio de mensual de membresía y las ventas con el porcentaje de endeudamiento; mismas que se presentan en las Tablas 100 y 101, respectivamente.

Tabla 100

Análisis de Sensibilidad Bidimensional Ventas sobre Precio Mensual de Membresía

\begin{tabular}{|c|c|c|c|c|c|c|c|c|}
\hline & VAN & & & & Ventas & & & \\
\hline \multirow{12}{*}{$\begin{array}{c}\text { Precio de } \\
\text { membresía } \\
\text { mensual }\end{array}$} & $\mathrm{S} / 79,992.50$ & $\mathrm{~S} / 319,290.40$ & $S / 294,729.60$ & $\mathrm{~S} / 270,168.80$ & $\mathrm{~S} / 245,608.00$ & $\mathrm{~S} / 223,280.00$ & $\mathrm{~S} / 204,673.30$ & $\mathrm{~S} / 188,929.23$ \\
\hline & $S / 350.00$ & $S / 153,964.40$ & $\mathrm{~S} / 141,745.50$ & $\mathrm{~S} / 129,526.60$ & $\mathrm{~S} / 117,307.70$ & S/106,199.61 & S/96,942.85 & S/89,110.23 \\
\hline & S/340.00 & $S / 146,501.36$ & $S / 134,282.46$ & $S / 122,063.56$ & $S / 109,844.66$ & S/98,736.57 & S/89,479.81 & $S / 81,647.20$ \\
\hline & $S / 330.00$ & $\mathrm{~S} / 139,038.32$ & $S / 126,819.42$ & $S / 114,600.52$ & $S / 102,381.62$ & S/91,273.53 & $S / 82,016.77$ & S/74,184.16 \\
\hline & $S / 320.00$ & $S / 131,575.29$ & $S / 119,356.38$ & $S / 107,137.48$ & S/94,918.58 & $\mathrm{S} / 83,810.49$ & $S / 74,553.73$ & $S / 66,721.12$ \\
\hline & $S / 310.00$ & $S / 124,112.25$ & S/111,893.35 & S/99,674.44 & $S / 87,455.54$ & S/76,347.45 & $S / 67,090.69$ & $\mathrm{~S} / 59,258.08$ \\
\hline & $S / 300.00$ & $S / 116,649.21$ & $S / 104,430.31$ & $\mathrm{~S} / 92,211.40$ & $\mathrm{~S} / 79,992.50$ & $\mathrm{~S} / 68,884.41$ & $S / 59,627.65$ & $\mathrm{~S} / 51,795.04$ \\
\hline & $S / 290.00$ & S/109,186.17 & S/96,967.27 & S/84,748.37 & $S / 72,529.46$ & S/61,421.37 & $S / 52,164.61$ & $S / 44,332.00$ \\
\hline & $\mathrm{S} / 280.00$ & $S / 101,723.13$ & S/89,504.23 & S/77,285.33 & $S / 65,066.43$ & $\mathrm{~S} / 53,958.33$ & S/44,701.57 & $S / 36,868.96$ \\
\hline & $S / 270.00$ & S/94,260.09 & $S / 82,041.19$ & S/69,822.29 & $S / 57,603.39$ & S/46,495.29 & $S / 37,238.53$ & S/29,405.92 \\
\hline & $S / 260.00$ & S/86,797.05 & $S / 74,578.15$ & S/62,359.25 & $\mathrm{S} / 50,140.35$ & $S / 39,032.26$ & $S / 29,775.50$ & $\mathrm{~S} / 21,942.88$ \\
\hline & $S / 250.00$ & S/79,334.01 & S/67,115.11 & S/54,896.21 & $S / 42,677.31$ & S/31,569.22 & $S / 22,312.46$ & $S / 14,479.84$ \\
\hline
\end{tabular}


Tabla 101

Análisis de Sensibilidad Bidimensional Ventas sobre Porcentaje de Endeudamiento

\begin{tabular}{|c|c|c|c|c|c|c|c|c|c|c|c|c|c|}
\hline VAN & & & & & & & Ventas & & & & & & \\
\hline $\mathrm{S} / 79,992.50$ & S/319,290.40 & S/ & $294,729.60$ & S/ & $270,168.80$ & S/ & $245,608.00$ & S/ & $223,280.00$ & S/ & $204,673.30$ & S/ & $188,929.23$ \\
\hline $10 \%$ & S/ $122,074.64$ & S/ & $109,768.72$ & S/ & $97,462.80$ & $\mathrm{~S} /$ & $85,156.89$ & S/ & $73,969.69$ & S/ & $64,647.01$ & S/ & $56,758.61$ \\
\hline $15 \%$ & S/ $120,284.80$ & S/ & $108,007.41$ & S/ & $95,730.02$ & $\mathrm{~S} /$ & $83,452.63$ & S/ & $72,291.36$ & S/ & $62,990.29$ & S/ & $55,120.18$ \\
\hline $20 \%$ & S/ $118,514.10$ & S/ & $106,265.10$ & S/ & $94,016.11$ & S/ & $81,767.11$ & S/ & $70,631.66$ & S/ & $61,352.10$ & S/ & $53,500.20$ \\
\hline $25 \%$ & S/ 116,649.21 & S/ & $104,430.31$ & S/ & $92,211.40$ & S/ & $79,992.50$ & S/ & $68,884.41$ & S/ & $59,627.65$ & S/ & $51,795.04$ \\
\hline $30 \%$ & S/ $115,029.08$ & S/ & $102,836.48$ & S/ & $90,643.88$ & S/ & $78,451.29$ & S/ & $67,367.11$ & S/ & $58,130.27$ & S/ & $50,314.52$ \\
\hline $35 \%$ & S/ $113,314.24$ & S/ & $101,149.64$ & S/ & $88,985.05$ & S/ & $76,820.46$ & S/ & $65,761.74$ & S/ & $56,546.12$ & S/ & $48,748.32$ \\
\hline $40 \%$ & S/ $111,617.50$ & S/ & $99,480.79$ & S/ & $87,344.07$ & S/ & $75,207.35$ & S/ & $64,173.98$ & S/ & $54,979.48$ & S/ & $47,199.55$ \\
\hline $45 \%$ & S/ 109,938.63 & S/ & $97,829.66$ & S/ & $85,720.70$ & $\mathrm{~S} /$ & $73,611.73$ & S/ & $62,603.58$ & S/ & $53,430.10$ & S/ & $45,667.96$ \\
\hline $50 \%$ & S/ 108,277.37 & S/ & $96,196.03$ & S/ & $84,114.68$ & S/ & $72,033.34$ & S/ & $61,050.30$ & S/ & $51,897.75$ & S/ & $44,153.31$ \\
\hline
\end{tabular}

\subsubsection{Análisis de escenarios}

Este método, permite analizar qué sucede con el VAN cuando se modifican el valor de algunas variables que se han considerado susceptibles a cambiar durante el período de evaluación (ver Tabla 102), el cual se plasma en dos escenarios: pesimista y optimista; las cuales se han detallado en la Tabla 103.

Tabla 102

Análisis de Sensibilidad por Escenarios

\begin{tabular}{lccc}
\hline Descripción & Moderado & Optimista & Pesimista \\
\hline Inversión & $\mathrm{S} / 205,334.16$ & $\mathrm{~S} / 180,000.00$ & $\mathrm{~S} / 250,000.00$ \\
\% de deuda & $25 \%$ & $10 \%$ & $46 \%$ \\
Precio mensual & $\mathrm{S} / 300.00$ & $\mathrm{~S} / 350.00$ & $\mathrm{~S} / 260.00$ \\
Ventas & $\mathrm{S} / 208,142.37$ & $\mathrm{~S} / 257,416.90$ & $\mathrm{~S} / 152,317.69$ \\
\hline
\end{tabular}

Tabla 103

Análisis de Escenarios

\begin{tabular}{ccccc}
\hline & Valores actuales & Moderado & Optimista & Pesimista \\
\hline Celdas cambiantes: & & & & \\
Inversión & $\mathrm{S} / 205,334.16$ & $\mathrm{~S} / 205,334.16$ & $\mathrm{~S} / 180,000.00$ & $\mathrm{~S} / 250,000.00$ \\
Deuda $\%$ & $25 \%$ & $25 \%$ & $10 \%$ & $40 \%$ \\
Precio mensual & $\mathrm{S} / 300.00$ & $\mathrm{~S} / 300.00$ & $\mathrm{~S} / 350.00$ & $\mathrm{~S} / 260.00$ \\
Ventas & $\mathrm{S} / 245,608.00$ & $\mathrm{~S} / 245,608.00$ & $\mathrm{~S} / 319,290.40$ & $\mathrm{~S} / 188,929.23$ \\
Celdas de resultado: & & & & \\
VAN & $\mathrm{S} / 79,992.5$ & $\mathrm{~S} / 79,992.5$ & $\mathrm{~S} / 175,706.2$ & $\mathrm{~S} / 6,272.2$ \\
TIR & $39 \%$ & $39 \%$ & $63 \%$ & $22 \%$ \\
\hline
\end{tabular}


El escenario moderado, es el escenario en el cual se sitúa el presente proyecto; donde la inversión es de S/. 205,334.16, el porcentaje de la deuda es de 25\%, el precio de la membresía mensual es de S/. 300 y las ventas de S/. 245,608.00. El VAN es de S/. S/ $79,992.5$ y la TIR de $39 \%$.

En el escenario optimista, se observa que la inversión fue reducida a S/.180,000, el porcentaje de la deuda es de 10\%, el precio mensual de la membresía se aumentó a S/. 350 y las ventas son de S/. 319,290.40. En este caso, el VAN aumentó a S/. 175,706.2 y la TIR a $63 \%$.

En el escenario pesimista, se observa que la inversión aumentó a S/. 250,000, el porcentaje de la deuda aumentó a un 40\%, el precio mensual de la membresía disminuyó a S/. 260 y las ventas se redujeron a S/. 188,929.23. En este caso, el VAN fue de S/. 6,272.2y la TIR disminuyó a $22 \%$. 


\section{Conclusiones y Recomendaciones}

\section{Conclusiones}

1. Se ha demostrado a través de la evaluación financiera que el proyecto de aperturar un box de Crossfit debe ser aceptado; debido a que, se determinó que el presente trabajo de investigaciónn es viable, factible y rentable.

2. Se ha corroborado que la mejor zona para aperturar Ate Crossfit es la zona 2 del distrito de Ate por su cercanía a los distritos de La Molina y Santa Anita.

3. Se determinó que la tendencia del mercado fitness en relación a los entrenamientos alternativos va en aumento.

4. La estrategia idónea para Ate Crossfit es la diferenciación en razón al fitness amplio, general e integral.

5. A través de los resultados obtenidos en la entrevista a expertos y las experiencias compartidas en Crossfit, inc. se ha confirmado que el Crossfit es una buena alternativa para combatir la obesidad.

6. El estudio de mercado determinó que la población de Ate haría Crossfit por mejorar su estado físico y salud.

7. En base a los resultados obtenidos por la entrevista a profundidad y expertos; se determina que en el Perú, la obesidad es un problema de salud pública.

8. Tanto la ubicación como los horarios accesibles, son los factores más importantes que considera la población de Ate para elegir su centro de entrenamiento.

9. Las redes sociales son los medios de comunicación más efectivos para la población de Ate.

10. Los días adicionales y de congelamiento son las promociones que más desean encontrar los pobladores de Ate.

11. El éxito de Ate CrossFit radica en la inclusión de un fitness amplio, general e integral desde la preventa hasta la postventa del servicio.

\section{Recomendaciones}

1. Considerar llevar a cabo la apertura del box de CrossFit en el distrito de Ate, de conformidad con el análisis y evaluación económico financiera que determinaron su viabilidad, factibilidad y rentabilidad.

2. Con la finalidad de combatir la obesidad, se recomienda ser partícipes del desarrollo de políticas públicas, actuando solidariamente en la promoción de una alimentación sana y de la actividad física como parte de la estrategia propuesta por la OMS para combatir la obesidad. Esto último, en razón a la naturaleza que refleja una política 
pública al evidenciarse un problema de salud público definido y demandado por la sociedad en su rol de participación ciudadana; asimismo, como parte de dicho rol, se puede participar en la formulación y ejecución de políticas públicas como actor no estatal.

3. Diseñar y ejecutar campañas de publicidad sobre los beneficios del CrossFit en la Salud.

4. Tomar en consideración los estudios elaborados por Crossfit, Inc. en razón al Crossfit como un estilo de vida.

5. Motivar a las consultoras de estudio de mercado a realizar un análisis del impacto del Crossfit en el mercado peruano, por ser la mayor tendencia fitness en el mundo.

6. Ejecutar campañas en cooperación con CrossFit, Inc. para salvaguardar la marca Crossfit en el mercado peruano ante Indecopi, a fin de evitar la competencia desleal de boxes no afiliados.

7. Tomar en consideración el presente plan de negocios para futuras investigaciones que deseen ahondar en el tema del Crossfit desde un panorama empresarial, actividad física o salud pública. 


\section{Referencias}

Arbaiza, L. (2015). Cómo elaborar un plan de negocio. Perú: Esan Ediciones.

Álvarez-Dongo, D., Sánchez-Abanto, J., Gómez-Guizado, G., \& Tarqui-Mamani, C. (2012). Sobrepeso y obesidad: prevalencia y determinantes sociales del exceso de peso en la población peruana (2009-2010). Rev Peru Med Exp Salud Publica, 29(3), 303-13.

Álvarez, E. (2014). El modelo económico de la constitución peruana. Revista Ius Et Veritas, 48, 256-269.

Asociación Peruana de Empresas de Investigación de Mercados. (2017). Niveles socioeconómicos 2017. Recuperado de http://www.apeim.com.pe/wpcontent/themes/apeim/docs/nse/APEIM-NSE-2017.pdf

Baena, E., Sánchez, J.J., Montoya, O. (2003). El entorno empresarial y la teoría de las cinco fuerzas competitivas. Scientia et Technica, 23, 61-66.

Barroso, M.C., \& Picón, A. (2004). La importancia de los costes de cambio en el comportamiento del cliente. Investigaciones Europeas de Dirección y Economía de la Empresa, 10(3), 209-232.

Beltran, A., \& Cueva, H. (2014). Evaluación privada de proyectos. Lima, Perú: Pearson.

Charles, D. (2014). Plan de empresa: crossfit equilibrio (Tesis de maestria, Universidad ICESI, Cali, Colombia). Recuperado de https://repository.icesi.edu.co/biblioteca_digital/bitstream/10906/77223/1/oberbeck_pl an_empresa_2014.pdf

Corrillo, F., \& Gutiérrez, M. (2016). Estudio de localización de un proyecto. Recuperado de http://www.revistasbolivianas.org.bo/pdf/rvc/v7n11/v7n11_a05.pdf

CrossFit, Inc. (2014). What is CrossFit? Recuperado el enero de 2018, de Crossfit.com: https://www.crossfit.com/what-is-crossfit

CrossFit, Inc. (2017). The CrossFit Level 1 Training Guide. CrossFit Level One Certificate Course. Estados Unidos de América.

CrossFit, Inc. (2018). CrossFit Affiliates. Recuperado el enero de 2018, de CrossFit: https://www.crossfit.com/affiliate-list

David, F. (2013). Conceptos de administración estratégica. Juárez, México: Pearson Education, inc.

Fidecom. (2011). ¿Qué es FIDECOM?. Ministerio de la producción. Recuperado de https://www.innovateperu.gob.pe/quienes-somos/nuestros-fondos/fidecom

Froning, R. (2013). First: what it takes to win.Illinois, Estados Unidos: Tyndale House Publisher.

Gerencia de Servicios a la Ciudad., Subgerencia de Limpieza Pública y Ornato., Municipalidad de Ate. (2014). Plan de manejo de residuos sólidos 2014-2018.

Recuperado de http://www.muniate.gob.pe/ate/files/documentosPlaneamientoOrganizacion/GESTIO N_RESIDUOS_SOLIDOS/2011/Plan\%20de\%20Manejo\%20de\%20Residuos\%20S\% C3\%B3lidos\%202014-2018.pdf

Gestión. (2017). Bodytech y Smart Fit ahora dominan mercado de gimnasio de US\$ 150 mlls. Gestión. Recuperado de https://gestion.pe/economia/empresas/bodytech-smart-fitdominan-mercado-gimnasio-us-150-mlls-143098

Glassman, G. (2012). ¿Qué es fitness?. Crossfit Journal. Recuperado de https://journal.crossfit.com/article/what-is-fitness-espanol

Goñi, A. (2013). El precio. Variable clave en el marketing. Lima, Perú: Pearson Educación.

Horngren, C., Datar, S., \& Rajan, M. (2012). Contabilidad de costos: un enfoque gerencial. México: Pearson Education, Inc.

IHRSA. (2017). The Ihrsa global report. Estados Unidos: IHRSA. 
Inga, C. (2107). Gimnasios CrossFit Marut quiere tener diez locales en el Perú. El Comercio. Recuperado de https://elcomercio.pe/economia/dia-1/gimnasios-crossfit-marut-quierediez-locales-peru-419785

Instituto Nacional de Defensa de la Competencia y de la Protección de la Propiedad Intelectual (2013). Libre competencia. Recuperado de

http://repositorio.indecopi.gob.pe/bitstream/handle/11724/5564/libre_competencia.pdf ?sequence $=1 \&$ is Allowed $=y$

Instituto Nacional de Estadística e Informática. (2009). Estimación y Proyecciones de población por grupos quinquenales de Edad 2005-2015. Recuperado de http://proyectos.inei.gob.pe/web/biblioineipub/bancopub/Est/Lib0842/libro.pdf.

Instituto Nacional de Estadística e Informática. (2016). Resultados de la encuesta demográfica y de salud familiar - ENDES 2016. Recuperado de https://proyectos.inei.gob.pe/endes/Investigaciones/Presentacion_del_Jefe_2016.pdf

Instituto Nacional de Estadística e Informática. (2018). Censos nacionales 2017 primeros resultados. Recuperado de https://www.inei.gob.pe/media/inei_en_los_medios/Conferencia_Prensa_CPV2017.p df

Instituto Nacional de Estadística e Informática. (2018). Perú - Encuesta nacional de hogares sobre condiciones de vida y pobreza 2017. Recuperado de https://webinei.inei.gob.pe/anda_inei/index.php/catalog/613

Kotler, P., \& Armstrong, G. (2013). Fundamentos de marketing. México: Pearson Education, Inc.

Kotler, P., \& Keller, K. (2006). Dirección de marketing. México: Pearson Education, Inc.

Kotler, P., \& Keller, K. (2012). Dirección de marketing. México: Pearson Education, Inc.

Madero Gómez, S. M., \& Barboza, G. A. (2015). Interrelación de la cultura, flexibilidad laboral, alineación estratégica, innovación y rendimiento empresarial. Contaduría y Administración, 60(4), 735-756. doi: 10.1016/j.cya.2014.08.001

Malhotra, N. (2008). Investigación de mercados. México: Pearson Education, Inc.

Mayer, S. (2018). Crossfit y Functional, los negocios fitness de moda. Camara de Comercio de Lima, Lima, Perú.

Mc Daniel, C. J., \& Gates, R. (2015). Investigación de mercados. México: Cengage Learning Editores.

Moyano, L. (2015). Plan de negocios. Lima, Perú: Editorial Macro.

Organización Mundial de la Salud. (2004). Estrategia mundial sobre régimen alimentario, actividad física y salud. Recuperado de

www.who.int/dietphysicalactivity/strategy/eb11344/strategy_spanish_web.pdf

Organización Mundial de la Salud. (2014). Plan de acción para la prevención y control de las ENT en las Américas 2013-2019. Recuperado de http://www.paho.org/hq/index.php?option=com_content $\&$ view=article\&id=11275\%3 Aplan-action-ncds-americas-2013$2019 \&$ catid $=7587 \% 3$ Ageneral $\&$ Itemid $=41590 \&$ lang $=$ es

Organización Mundial de la Salud. (2017). Obesidad y sobrepeso. Recuperado de http://www.who.int/mediacentre/factsheets/fs311/es

Ozanian, M. (2015). How crossfit became a $\$ 4$ billion brand. Forbes. Recuperado de https://www.forbes.com/sites/mikeozanian/2015/02/25/how-crossfit-became-a-4billion-brand/\#7ba991681f96

Porter, M. (1980). Estrategia competitiva: técnicas para el análisis de los sectores industriales y de la competencia. Madrid, España: Ediciones Pirámide.

Porter, M. (1987). Ventaja Competitiva: creación y sostenibilidad de un rendimiento superior. Madrid, España: Ediciones Pirámide. 
Sapag, N.C., \& Sapag, R.C. (2004). Preparación y evaluación de proyectos. México DF, México: Mc Granw-Hill.

Sapag, N.C. (2011). Proyectos de inversión: formulación y evaluación. Chile: Pearson Eduación.

Wang, C. (5 de abril de 2016). How health nut created the world's biggest fitness trend. Recuperado el enero de 2018, de CNB: https://www.cnbc.com/2016/04/05/howcrossfit-rode-a-single-issue-to-world-fitness-domination.html 


\section{Apéndice 1: Resumen de Ficha de Reclutamiento}

\begin{tabular}{lccc}
\hline Entrevista & Entrevistado & Profesión & Ubicación \\
\hline E 1 & Yaniré Macalopú & Estudiante & Apéndice 3 \\
E 2 & Sandra Parodi & Estudiante & Apéndice 4 \\
E 3 & Israel Huanri & Estudiante & Apéndice 5 \\
E 4 & Aaron Vargas & Estudiante & Apéndice 6 \\
E 5 & Brissa Atoche & Administradora & Apéndice 7 \\
E 6 & Jorge Pérez & Administrador & Apéndice 8 \\
E 7 & Joanna Mallqui & Administradora & Apéndice 9 \\
\hline
\end{tabular}

\begin{tabular}{lc}
\hline Objetivos & Preguntas \\
\hline Perfil del entrevistado & 1,2 y 3 \\
Condición física & 4 y 5 \\
Actividad física & 6 y 7 \\
Razón por la cual realiza actividad física & 8 \\
Frecuencia de realización de la actividad física & 9 \\
Tipo de actividad física & 10 \\
Establecimiento donde realiza actividad física & 11 y 12 \\
Razones para elegir un centro de entrenamiento & 13 \\
Motivo para adquirir una membresía & 14 \\
Rango de precios por membresía mensual & 15 \\
Medios sociales & 16 \\
Sobre el CrossFit & 17,18 y 19 \\
Nivel Socio Económico & $20,21,22$ Y 23 \\
\hline
\end{tabular}




\section{Apéndice 2: Ficha de Reclutamiento}

Presentación: Somos alumnos de la Escuela de Posgrado de la Universidad San Ignacio de Loyola - USIL y estamos organizando un Focus Group como parte de nuestro trabajo académico para graduarnos como magíster en Ciencias Empresariales; por ello, solicitamos su participación, y antes de iniciar la reunión le haremos unas preguntas de interés sólo para nosotros. Agradecemos que haya venido y le invitamos a compartir una mañana agradable.

- Marque con un aspa (X) la alternativa que usted considere como respuesta idónea.

- Complete la información que usted considere como respuesta idónea.

- Usted tiene un tiempo de 10 minutos para responder la presente ficha de reclutamiento.

- Valoramos la sinceridad de sus respuestas; asimismo, le recordamos que toda la información que nos proporcione será estrictamente confidencial y será utilizada sólo como objeto de estudio para la presente investigación. Muchas gracias.

1. ¿Usted vive en el distrito de Ate?

SI No

Si la respuesta es "No", culmina la ficha de reclutamiento, muchas gracias.

Si la respuesta es "Si", pasa a la pregunta 2.

2. ¿En qué Urbanización del distrito de Ate vive?

3. Seleccione el rango de edad donde se encuentra usted.
a. 14 a 17años
b. 18 a 21 años
c. 22 a 30 años
d. 31 a 49 años
e. 50 a 59 años
f. 60 a más años

4. Se considera usted una persona saludable

La OMS (2018) señala que una persona saludable, es aquella que lleva una alimentación sana y realiza actividad física constantemente.

SI No 
5. En cual de las siguientes categorías, considera usted que se encuentra.
a. Obeso
b. Sobrepeso
c. Normal (ni bajo en peso ni con sobrepeso)
d. Bajo en peso
e. Fitness (atlética)

6. ¿Realiza usted alguna actividad física?

$\mathrm{Si}$ No

Si la respuesta es "Si", pasar a la pregunta 8.

Si la respuesta es "No", pasar a la pregunta 7.

7. ¿Estaría dispuesto a realizar alguna actividad física?
a. SI
b. NO (por favor, especifique el motivo)

Si la respuesta es "No", la ficha de reclutamiento ha terminado, muchas gracias.

Si la respuesta es "Si", pasar a la pregunta 8.

8. ¿Cuál sería la razón por la que usted realiza o realizaría alguna actividad física?
a. Mejorar mi estado físico
b. Mejorar mi imagen
c. Rápidos resultados
d. Para ser un atleta.
e. Por salud (bajar de peso y reducir enfermedades)
f. Otros (por favor, especifique)

9. ¿Con qué frecuencia realiza o realizaría la actividad física?
a. Una vez a la semana
b. Fines de semana
c. Interdiario
d. De lunes a viernes
e. Diario 
10. ¿Qué actividad física realiza o realizaría usted?

11. La actividad física indicada, ¿Se realiza dentro de un centro de entrenamiento?

SI No

Si la respuesta es "No", pasar a la pregunta 12

$\mathrm{Si}$ la respuesta es "Si", pasar a la pregunta 13

12. ¿Estaría dispuesto a realizar la actividad física en un centro de entrenamiento?
a. SI
b. NO

Si la respuesta es "No", la ficha de reclutamiento ha terminado, muchas gracias.

Si la respuesta es "Si", pasar a la pregunta 13.

13. ¿Qué razones considera importantes para elegir un centro de entrenamiento?
a. Horarios accesibles
b. Ubicación accesible
c. Calidad del servicio
d. Precio
e. Infraestructura
f. Horario y ubicación accesible
g. Precio y calidad del servicio
h. Indiferente

14. ¿Qué es lo que más le motivaría al momento de adquirir una membresía en su centro fitness?
a. Descuentos en la membresía
b. Promoción de días adicionales
c. Promoción de días de congelamiento
d. Promoción de días adicionales y congelamiento
e. Indumentaria deportiva de cortesía
f. Descuentos en marca de ropa
g. Indiferente

15. ¿Cuál es el rango de precios que usted paga o estaría dispuesto a pagar por mensualidades en su centro fitness? 
16. ¿Por qué medio le es más factible enterarse de las noticias del centro fitness?
a. Redes sociales
b. Aplicaciones móviles
c. Revistas mensuales
d. Correos
e. Página web
f. Periódicos

17. ¿Ha practicado o practica el CrossFit?

$\mathrm{Si}$

No

si la respuesta es "no", pasar a la pregunta 19

si la respuesta es "si", pasar a la pregunta 18

18. Si la respuesta es $\mathrm{Si}$ ¿Cuál es la razón por la cual la practica?
a. Ser atleta CrossFit
b. Mejorar mi estado físico
c. Rápidos resultados
d. Porque otros lo practican
e. Por salud (bajar de peso y reducir enfermedades)

19. ¿Cuál es la razón por la cuál no practica CrossFit?
a. Desconozco del tema
b. Posibles lesiones
c. Considero que no es para mi
d. Disponibilidad de tiempo
e. No hay un box (gimnasio) de CrossFit cerca

20. ¿Cuál es su grado de estudio?
a. Primaria completa
b. Primaria incompleta
c. Secundaria completa
d. Secundaria incompleta
e. Superior técnica
f. Superior técnica incompleta
g. Universitaria
h. Universitaria incompleta
i. Post grado
j. Doctorado 
21. ¿Actualmente se encuentra trabajando?

$\mathrm{Si}$

No

22. ¿Cuál de estas comodidades posee usted en su hogar?
a. Televisor led
b. Laptop
c. Refrigeradora
d. Cocina
e. Lavadora
f. Play station

23. En caso de emergencia, ¿A dónde acudiría?
a. Hospital
b. Clínica
c. Posta
d. Doctor particular
e. Centro de salud municipal

Datos de control

Nombre:

Edad:

Distrito:

Urbanización:

Ocupación: 


\section{Apéndice 3: Ficha de Reclutamiento de Yaniré Macalopú}

Ficha De Reclutamiento

Presentación: Somos alumnos de la Escuela de Posgrado de la Universidad San Ignacio de Loyola - USIL y estamos organizando un Focus Group como parte de nuestro trabajo académico para graduarnos como magíster en Ciencias Empresariales; por ello, solicitamos su participación, y antes de iniciar la reunión le haremos unas preguntas de interés sólo para nosotros. Agradecemos que haya venido y le invitamos a compartir una mañana agradable.

- Marque con un aspa (X) la alternativa que usted considere como respuesta idónea.

- Complete la información que usted considere como respuesta idónea.

- Usted tiene un tiempo de 10 minutos para responder la presente ficha de reclutamiento.

- Valoramos la sinceridad de sus respuestas; asimismo, le recordamos que toda la información que nos proporcione será estrictamente confidencial y será utilizada sólo como objeto de estudio para la presente investigación. Muchas gracias.

1. ¿Usted vive en el distrito de Ate?

SI $X$ No

$\mathrm{Si}$ la respuesta es "No", culmina la ficha de reclutamiento, muchas gracias.

Si la respuesta es "Si", pasa a la pregunta 2.

2. ¿En qué Urbanización del distrito de Ate vive?

los Rauces

3. Seleccione el rango de edad donde se encuentra usted.
a. 14 a 17años
b. 18 a 21 años
2. 22 a 30 años
d. 31 a 49 años
e. 50 a 59 años
f. 60 a más años

4. Se considera usted una persona saludable

La OMS (2018) señala que una persona saludable, es aquella que lleva una alimentación sana y realiza actividad fisica constantemente.

SI No $x$ 
5. En cual de las siguientes categorías, considera usted que se encuentra.
a. Obeso
b. Sobrepeso
× Normal (ni bajo en peso ni con sobrepeso)
d. Bajo en peso
e. Fitness (atlética)

6. ¿Realiza usted alguna actividad física?

$\mathrm{Si} \times$ No

$\mathrm{Si}$ la respuesta es "Si", pasar a la pregunta 8.

Si la respuesta es "No", pasar a la pregunta 7.

7. ¿Estaría dispuesto a realizar alguna actividad física?
a. SI
b. NO (por favor, especifique el motivo)

Si la respuesta es "No", la ficha de reclutamiento ha terminado, muchas gracias. Si la respuesta es "Si", pasar a la pregunta 8.

8. ¿Cuál sería la razón por la que usted realiza o realizaría alguna actividad física?
a. Mejorar mi estado físico
. Mejorar mi imagen
c. Rápidos resultados
d. Para ser un atleta.
e.' Por salud (bajar de peso y reducir enfermedades)
f. Otros (por favor, especifique)

9. ¿Con qué frecuencia realiza o realizaría la actividad física?
a. Una vez a la semana
Y Fines de semana
c. Interdiario
d. De lunes a viernes
e. Diario 
10. ¿Qué actividad fisica realiza o realizaria usted?

baite

11. La actividad física indicada, ¿Se realiza dentro de un centro de entrenamiento? SI $\propto$ No

Si la respuesta es "No", pasar a la pregunta 12

$\mathrm{Si}$ la respuesta es "Si", pasar a la pregunta 13

12. ¿Estaría dispuesto a realizar la actividad física en un centro de entrenamiento?
a. SI
b. NO

Si la respuesta es "No", la ficha de reclutamiento ha terminado, muchas gracias.

$\mathrm{Si}$ la respuesta es "Si", pasar a la pregunta 13 .

13. ¿Qué razones considera importantes para elegir un centro de entrenamiento?
a. Horarios accesibles
b. Ubicación accesible
c. Calidad del servicio
d. Precio
e. Infraestructura
f. Horario y ubicación accesible
\&. Precio y calidad del servicio
h. Indiferente

14. ¿Qué es lo que más le motivaría al momento de adquirir una membresía en su centro fitness?
×. Descuentos en la membresía
b. Promoción de días adicionales
c. Promoción de días de congelamiento
d. Promoción de días adicionales y congelamiento
e. Indumentaria deportiva de cortesía
f. Descuentos en marca de ropa
g. Indiferente

15. ¿Cuál es el rango de precios que usted paga o estaría dispuesto a pagar por mensualidades en su centro fitness?

5. 200 
16. ¿Por qué medio le es más factible enterarse de las noticias del centro fitness?

\. Redes sociales

b. Aplicaciones móviles

c. Revistas mensuales

d. Correos

e. Página web

f. Periódicos

17. ¿Ha practicado o practica el CrossFit?

Si No $X$

Si la respuesta es "no", pasar a la pregunta 19

Si la respuesta es "si", pasar a la pregunta 18

18. Si la respuesta es $\mathrm{Si}$ ¿Cuál es la razón por la cual la practica?
a. Ser atleta CrossFit
b. Mejorar mi estado físico
c. Rápidos resultados
d. Porque otros lo practican
e. Por salud (bajar de peso y reducir enfermedades)

19. ¿Cuál es la razón por la cuál no practica CrossFit?

×. Desconozco del tema

b. Posibles lesiones

c. Considero que no es para mi

d. Disponibilidad de tiempo

e. No hay un box (gimnasio) de CrossFit cerca

20. ¿Cuál es su grado de estudio?
a. Primaria completa
b. Primaria incompleta
c. Secundaria completa
d. Secundaria incompleta
e. Superior técnica
f. Superior técnica incompleta
\&. Universitaria
h. Universitaria incompleta
i. Post grado
j. Doctorado 
21. ¿Actualmente se encuentra trabajando?
$\mathrm{Si} \times$
No

22. ¿Cuál de estas comodidades posee usted en su hogar?

2. Televisor Led

Laptop

e. Refrigeradora

×. Cocina

e. Lavadora

f. Play Station

23. En caso de emergencia, ¿A dónde acudiría?
×. Hospital
b. Clínica
c. Posta
d. Doctor particular
e. Centro de salud municipal

Datos de control

Nombre: Yauire Yacalopú Pordeuar

Edad: 22

Distrito: Ate

Urbanización: los saves

Ocupación: Uvivenitaria 


\section{Apéndice 4: Ficha de Reclutamiento Sandra Parodi}

Ficha De Reclutamiento

Presentación: Somos alumnos de la Escuela de Posgrado de la Universidad San Ignacio de Loyola - USIL y estamos organizando un Focus Group como parte de nuestro trabajo académico para graduarnos como magíster en Ciencias Empresariales; por ello, solicitamos su participación, y antes de iniciar la reunión le haremos unas preguntas de interés sólo para nosotros. Agradecemos que haya venido y le invitamos a compartir una mañana agradable.

- Marque con un aspa (X) la alternativa que usted considere como respuesta idónea.

- Complete la información que usted considere como respuesta idónea.

- Usted tiene un tiempo de 10 minutos para responder la presente ficha de reclutamiento.

- Valoramos la sinceridad de sus respuestas; asimismo, le recordamos que toda la información que nos proporcione será estrictamente confidencial y será utilizada sólo como objeto de estudio para la presente investigación. Muchas gracias.

1. ¿Usted vive en el distrito de Ate?

SI $\times$ No

Si la respuesta es "No", culmina la ficha de reclutamiento, muchas gracias.

$\mathrm{Si}$ la respuesta es "Si", pasa a la pregunta 2.

2. ¿En qué Urbanización del distrito de Ate vive?

Lor clavels

3. Seleccione el rango de edad donde se encuentra usted.
a. 14 a 17años
X. 18 a 21 años
c. 22 a 30 años
d. 31 a 49 años
e. 50 a 59 años
f. 60 a más años

4. Se considera usted una persona saludable

La OMS (2018) señala que una persona saludable, es aquella que lleva una alimentación sana y realiza actividad fisica constantemente.

SI No $x$ 
5. En cual de las siguientes categorías, considera usted que se encuentra.
a. Obeso
b. Sobrepeso
メ. Normal (ni bajo en peso ni con sobrepeso)
d. Bajo en peso
e. Fitness (atlética)

6. ¿Realiza usted alguna actividad física?

$\mathrm{Si} \times$ No

$\mathrm{Si}$ la respuesta es "Si", pasar a la pregunta 8.

Si la respuesta es "No", pasar a la pregunta 7.

7. ¿Estaría dispuesto a realizar alguna actividad física?
a. SI
b. NO (por favor, especifique el motivo)

Si la respuesta es "No", la ficha de reclutamiento ha terminado, muchas gracias. Si la respuesta es "Si", pasar a la pregunta 8 .

8. ¿Cuál sería la razón por la que usted realiza o realizaría alguna actividad física? a. Mejorar mi estado físico

b. Mejorar mi imagen

c. Rápidos resultados

d. Para ser un atleta.

e. Por salud (bajar de peso y reducir enfermedades)

f. Otros (por favor, especifique)

9. ¿Con qué frecuencia realiza o realizaría la actividad física?
a. Una vez a la semana
b. Fines de semana
2. Interdiario
d. De lunes a viernes
e. Diario 
10. ¿Qué actividad física realiza o realizaría usted?

$$
\text { baile }
$$

11. La actividad fisica indicada, ¿Se realiza dentro de un centro de entrenamiento? SI $\propto$ No

Si la respuesta es "No", pasar a la pregunta 12

Si la respuesta es "Si", pasar a la pregunta 13

12. ¿Estaría dispuesto a realizar la actividad física en un centro de entrenamiento? 2. SI

b. NO

Si la respuesta es "No", la ficha de reclutamiento ha terminado, muchas gracias. Si la respuesta es "Si", pasar a la pregunta 13.

13. ¿Qué razones considera importantes para elegir un centro de entrenamiento?
a. Horarios accesibles
b. Ubicación accesible
c. Calidad del servicio
d. Precio
e. Infraestructura
f. Horario y ubicación accesible
of Precio y calidad del servicio
h. Indiferente

14. ¿Qué es lo que más le motivaría al momento de adquirir una membresía en su centro fitness?
a. Descuentos en la membresía
b. Promoción de días adicionales
c. Promoción de días de congelamiento
d. Promoción de días adicionales y congelamiento
e. Indumentaria deportiva de cortesía
f. Descuentos en marca de ropa
\. Indiferente

15. ¿Cuál es el rango de precios que usted paga o estaría dispuesto a pagar por mensualidades en su centro fitness? 
16. ¿Por qué medio le es más factible enterarse de las noticias del centro fitness?

7a. Redes sociales

b. Aplicaciones móviles

c. Revistas mensuales

d. Correos

e. Página web

f. Periódicos

17. ¿Ha practicado o practica el CrossFit?

$\mathrm{Si}$

No $x$

Si la respuesta es "no", pasar a la pregunta 19

Si la respuesta es "si", pasar a la pregunta 18

18. Si la respuesta es $\mathrm{Si}$, ¿Cuál es la razón por la cual la practica?
a. Ser atleta CrossFit
b. Mejorar mi estado físico
c. Rápidos resultados
d. Porque otros lo practican
e. Por salud (bajar de peso y reducir enfermedades)

19. ¿Cuál es la razón por la cuál no practica CrossFit?

ঝ. Desconozco del tema

b. Posibles lesiones

c. Considero que no es para mi

d. Disponibilidad de tiempo

e. No hay un box (gimnasio) de CrossFit cerca

20. ¿Cuál es su grado de estudio?
a. Primaria completa
b. Primaria incompleta
c. Secundaria completa
d. Secundaria incompleta
e. Superior técnica
f. Superior técnica incompleta
\&. Universitaria
h. Universitaria incompleta
i. Post grado
j. Doctorado 
21. ¿Actualmente se encuentra trabajando?
$\mathrm{Si} \times$
No

22. ¿Cuál de estas comodidades posee usted en su hogar?

œ. Televisor Led

K. Laptop

¿.-Refrigeradora

Cocina

¿. Lavadora

f. Play Station

23. En caso de emergencia, ¿A dónde acudiría?

\. Hospital

b. Clínica

c. Posta

d. Doctor particular

e. Centro de salud municipal

Datos de control

Nombre: Sandra Poradi medina

Edad: 21

Distrito: ate

Urbanización: Los doveles

Ocupación: Eofudiennte 


\section{Apéndice 5: Ficha de Reclutamiento Israel Huanri}

Ficha De Reclutamiento

Presentación: Somos alumnos de la Escuela de Posgrado de la Universidad San Ignacio de Loyola - USIL y estamos organizando un Focus Group como parte de nuestro trabajo académico para graduarnos como magíster en Ciencias Empresariales; por ello, solicitamos su participación, y antes de iniciar la reunión le haremos unas preguntas de interés sólo para nosotros. Agradecemos que haya venido y le invitamos a compartir una mañana agradable.

- Marque con un aspa (X) la alternativa que usted considere como respuesta idónea.

- Complete la información que usted considere como respuesta idónea.

- Usted tiene un tiempo de 10 minutos para responder la presente ficha de reclutamiento.

- Valoramos la sinceridad de sus respuestas; asimismo, le recordamos que toda la información que nos proporcione será estrictamente confidencial y será utilizada sólo como objeto de estudio para la presente investigación. Muchas gracias.

1. ¿Usted vive en el distrito de Ate?

SI $x$ No

Si la respuesta es "No", culmina la ficha de reclutamiento, muchas gracias.

Si la respuesta es "Si", pasa a la pregunta 2.

2. ¿En qué Urbanización del distrito de Ate vive?

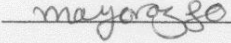

3. Seleccione el rango de edad donde se encuentra usted.
a. 14 a 17 años
b. 18 a 21 años
\. 22 a 30 años
d. 31 a 49 años
e. 50 a 59 años
f. 60 a más años

4. Se considera usted una persona saludable

La OMS (2018) señala que una persona saludable, es aquella que lleva una alimentación sana y realiza actividad fisica constantemente.

SI $x$ No 
5. En cual de las siguientes categorías, considera usted que se encuentra.
a. Obeso
\. Sobrepeso
c. Normal (ni bajo en peso ni con sobrepeso)
d. Bajo en peso
e. Fitness (atlética)

6. ¿Realiza usted alguna actividad física?

$\mathrm{Si} \times$ No

$\mathrm{Si}$ la respuesta es "Si", pasar a la pregunta 8.

Si la respuesta es "No", pasar a la pregunta 7.

7. ¿Estaría dispuesto a realizar alguna actividad física?
a. SI
b. NO (por favor, especifique el motivo)

Si la respuesta es "No", la ficha de reclutamiento ha terminado, muchas gracias.

$\mathrm{Si}$ la respuesta es "Si", pasar a la pregunta 8 .

8. ¿Cuál sería la razón por la que usted realiza o realizaría alguna actividad física?
a. Mejorar mi estado físico
b. Mejorar mi imagen
c. Rápidos resultados
d. Para ser un atleta.
¿.. Por salud (bajar de peso y reducir enfermedades)
f. Otros (por favor, especifique)

9. ¿Con qué frecuencia realiza o realizaría la actividad física?
a. Una vez a la semana
b. Fines de semana
re Interdiario
d. De lunes a viernes
e. Diario 
10. ¿Qué actividad fisica realiza o realizaría usted?

Gimnasio

11. La actividad física indicada, ¿Se realiza dentro de un centro de entrenamiento? $\mathrm{SI} \chi$ No

$\mathrm{Si}$ la respuesta es "No", pasar a la pregunta 12

$\mathrm{Si}$ la respuesta es "Si", pasar a la pregunta 13

12. ¿Estaría dispuesto a realizar la actividad física en un centro de entrenamiento?
a. SI
b. NO

Si la respuesta es "No", la ficha de reclutamiento ha terminado, muchas gracias.

Si la respuesta es "Si", pasar a la pregunta 13.

13. ¿Qué razones considera importantes para elegir un centro de entrenamiento?
a. Horarios accesibles
\ Ubicación accesible
c. Calidad del servicio
d. Precio
e. Infraestructura
f. Horario y ubicación accesible
g. Precio y calidad del servicio
h. Indiferente

14. ¿Qué es lo que más le motivaría al momento de adquirir una membresía en su centro fitness?
a. Descuentos en la membresía
b. Promoción de días adicionales
c. Promoción de días de congelamiento
đ. Promoción de días adicionales y congelamiento
e. Indumentaria deportiva de cortesía
f. Descuentos en marca de ropa
g. Indiferente

15. ¿Cuál es el rango de precios que usted paga o estaría dispuesto a pagar por mensualidades en su centro fitness? 
16. ¿Por qué medio le es más factible enterarse de las noticias del centro fitness?

\. Redes sociales

b. Aplicaciones móviles

c. Revistas mensuales

d. Correos

e. Página web

f. Periódicos

17. ¿Ha practicado o practica el CrossFit?

Si Not

Si la respuesta es "no", pasar a la pregunta 19

Si la respuesta es "si", pasar a la pregunta 18

18. Si la respuesta es $\mathrm{Si}$, ¿Cuál es la razón por la cual la practica?

a. Ser atleta CrossF it

b. Mejorar mi estado físico

c. Rápidos resultados

d. Porque otros lo practican

e. Por salud (bajar de peso y reducir enfermedades)

19. ¿Cuál es la razón por la cuál no practica CrossFit?

※. Desconozco del tema

b. Posibles lesiones

c. Considero que no es para mi

d. Disponibilidad de tiempo

e. No hay un box (gimnasio) de CrossFit cerca

20. ¿Cuál es su grado de estudio?
a. Primaria completa
b. Primaria incompleta
c. Secundaria completa
d. Secundaria incompleta
e. Superior técnica
f. Superior técnica incompleta
\$. Universitaria
h. Universitaria incompleta
i. Post grado
j. Doctorado 
21. ¿Actualmente se encuentra trabajando?
Si $x$
No

22. ¿Cuál de estas comodidades posee usted en su hogar?

׳. Televisor Led

D. Laptop

C. Refrigeradora

\& Cocina

e. Lavadora

f. Play Station

23. En caso de emergencia, ¿A dónde acudiría?

X. Hospital

b. Clínica

c. Posta

d. Doctor particular

e. Centro de salud municipal

Datos de control

Nombre: Inael Huani Pacotaype

Edad: 29

Distrito:

Urbanización:

Ocupación:

Ante

masoreazgo 


\section{Apéndice 6: Ficha de Reclutamiento Aaron Vargas}

Ficha De Reclutamiento

Presentación: Somos alumnos de la Escuela de Posgrado de la Universidad San Ignacio de Loyola - USIL y estamos organizando un Focus Group como parte de nuestro trabajo académico para graduarnos como magíster en Ciencias Empresariales; por ello, solicitamos su participación, y antes de iniciar la reunión le haremos unas preguntas de interés sólo para nosotros. Agradecemos que haya venido y le invitamos a compartir una mañana agradable.

- Marque con un aspa (X) la alternativa que usted considere como respuesta idónea.

- Complete la información que usted considere como respuesta idónea.

- Usted tiene un tiempo de 10 minutos para responder la presente ficha de reclutamiento.

- Valoramos la sinceridad de sus respuestas; asimismo, le recordamos que toda la información que nos proporcione será estrictamente confidencial y será utilizada sólo como objeto de estudio para la presente investigación. Muchas gracias.

1. ¿Usted vive en el distrito de Ate?

SI $\propto$ No

Si la respuesta es "No", culmina la ficha de reclutamiento, muchas gracias.

$\mathrm{Si}$ la respuesta es "Si", pasa a la pregunta 2.

2. ¿En qué Urbanización del distrito de Ate vive?

3. Seleccione el rango de edad donde se encuentra usted.
a. 14 a 17 años
b. 18 a 21 años
Q 22 a 30 años
d. 31 a 49 años
e. 50 a 59 años
f. 60 a más años

4. Se considera usted una persona saludable

La OMS (2018) señala que una persona saludable, es aquella que lleva una alimentación sana y realiza actividad fisica constantemente.

SI $\times$ No 
5. En cual de las siguientes categorías, considera usted que se encuentra.

a. Obeso

\%. Sobrepeso

c. Normal (ni bajo en peso ni con sobrepeso)

d. Bajo en peso

e. Fitness (atlética)

6. ¿Realiza usted alguna actividad física?

$\mathrm{Si} \times$ No

Si la respuesta es "Si", pasar a la pregunta 8.

Si la respuesta es "No", pasar a la pregunta 7.

7. ¿Estaría dispuesto a realizar alguna actividad física?

a. SI

b. NO (por favor, especifique el motivo)

Si la respuesta es "No", la ficha de reclutamiento ha terminado, muchas gracias.

$\mathrm{Si}$ la respuesta es "Si", pasar a la pregunta 8 .

8. ¿Cuál sería la razón por la que usted realiza o realizaría alguna actividad física?
a. Mejorar mi estado físico
b. Mejorar mi imagen
c. Rápidos resultados
d. Para ser un atleta.
C. Por salud (bajar de peso y reducir enfermedades)
f. Otros (por favor, especifique)

9. ¿Con qué frecuencia realiza o realizaría la actividad física?
a. Una vez a la semana
b. Fines de semana
c. Interdiario
e. De lunes a viernes
e. Diario 
10. ¿Qué actividad física realiza o realizaría usted?

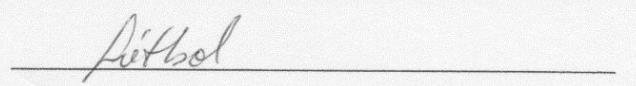

11. La actividad física indicada, ¿Se realiza dentro de un centro de entrenamiento? SI No $x$

Si la respuesta es "No", pasar a la pregunta 12

Si la respuesta es "Si", pasar a la pregunta 13

12. ¿Estaría dispuesto a realizar la actividad física en un centro de entrenamiento? ج.XS

b. NO

Si la respuesta es "No", la ficha de reclutamiento ha terminado, muchas gracias. Si la respuesta es "Si", pasar a la pregunta 13.

13. ¿Qué razones considera importantes para elegir un centro de entrenamiento?
a. Horarios accesibles
b. Ubicación accesible
c. Calidad del servicio
d. Precio
e. Infraestructura
* Horario y ubicación accesible
g. Precio y calidad del servicio
h. Indiferente

14. ¿Qué es lo que más le motivaría al momento de adquirir una membresía en su centro fitness?

2. Descuentos en la membresía

b. Promoción de días adicionales

c. Promoción de días de congelamiento

d. Promoción de días adicionales y congelamiento

e. Indumentaria deportiva de cortesía

f. Descuentos en marca de ropa

g. Indiferente

15. ¿Cuál es el rango de precios que usted paga o estaría dispuesto a pagar por mensualidades en su centro fitness? s: 200 
16. ¿Por qué medio le es más factible enterarse de las noticias del centro fitness? 2. Redes sociales

b. Aplicaciones móviles

c. Revistas mensuales

d. Correos

e. Página web

f. Periódicos

17. ¿Ha practicado o practica el CrossFit? $\mathrm{Si} \quad$ No $X$

Si la respuesta es "no", pasar a la pregunta 19

Si la respuesta es "si", pasar a la pregunta 18

18. Si la respuesta es $\mathrm{Si}$ ¿ ¿Cuál es la razón por la cual la practica?
a. Ser atleta CrossFit
b. Mejorar mi estado físico
c. Rápidos resultados
d. Porque otros lo practican
e. Por salud (bajar de peso y reducir enfermedades)

19. ¿Cuál es la razón por la cuál no practica CrossFit?
a. Desconozco del tema
b. Posibles lesiones
c. Considero que no es para mi
d. Disponibilidad de tiempo
\& No hay un box (gimnasio) de CrossFit cerca

20. ¿Cuál es su grado de estudio?
a. Primaria completa
b. Primaria incompleta
c. Secundaria completa
d. Secundaria incompleta
e. Superior técnica
f. Superior técnica incompleta
g. Universitaria
h. Universitaria incompleta
i. Post grado
j. Doctorado 
21. ¿Actualmente se encuentra trabajando?
$\mathrm{Si} \times$
No

22. ¿Cuál de estas comodidades posee usted en su hogar?

2. Televisor Led

b. Laptop

क. Refrigeradora

\%. Cocina

o. Lavadora

f. Play Station

23. En caso de emergencia, ¿A dónde acudiría?
*. Hospital
b. Clínica
c. Posta
d. Doctor particular
e. Centro de salud municipal

Datos de control

Nombre: Jarou ztorgose
Edad: 23
Distrito: Ate
Urbanización: La Merced
Ocupación: Etucliaute




\section{Apéndice 7: Ficha de Reclutamiento Brissa Atoche}

Ficha De Reclutamiento

Presentación: Somos alumnos de la Escuela de Posgrado de la Universidad San Ignacio de Loyola - USIL y estamos organizando un Focus Group como parte de nuestro trabajo académico para graduarnos como magíster en Ciencias Empresariales; por ello, solicitamos su participación, y antes de iniciar la reunión le haremos unas preguntas de interés sólo para nosotros. Agradecemos que haya venido y le invitamos a compartir una mañana agradable

- Marque con un aspa (X) la alternativa que usted considere como respuesta idónea.

- Complete la información que usted considere como respuesta idónea.

- Usted tiene un tiempo de 10 minutos para responder la presente ficha de reclutamiento.

- Valoramos la sinceridad de sus respuestas; asimismo, le recordamos que toda la información que nos proporcione será estrictamente confidencial y será utilizada sólo como objeto de estudio para la presente investigación. Muchas gracias.

1. ¿Usted vive en el distrito de Ate?

$\mathrm{SI} \times$ No

Si la respuesta es "No", culmina la ficha de reclutamiento, muchas gracias.

$\mathrm{Si}$ la respuesta es "Si", pasa a la pregunta 2.

2. ¿En qué Urbanización del distrito de Ate vive?

$$
27 \text { de abril }
$$

3. Seleccione el rango de edad donde se encuentra usted.
a. 14 a 17 años
b. 18 a 21 años
2. 22 a 30 años
d. 31 a 49 años
e. 50 a 59 años
f. 60 a más años

4. Se considera usted una persona saludable

La OMS (2018) señala que una persona saludable, es aquella que lleva una alimentación sana y realiza actividad física constantemente.

SI No $x$ 
5. En cual de las siguientes categorías, considera usted que se encuentra.
a. Obeso
b. Sobrepeso
(c.) Normal (ni bajo en peso ni con sobrepeso)
d. Bajo en peso
e. Fitness (atlética)

6. ¿Realiza usted alguna actividad física?

$\mathrm{Si}$ No $\chi$

Si la respuesta es "Si", pasar a la pregunta 8 .

Si la respuesta es "No", pasar a la pregunta 7.

7. ¿Estaría dispuesto a realizar alguna actividad física?
(a) SI
b. NO (por favor, especifique el motivo)

Si la respuesta es "No", la ficha de reclutamiento ha terminado, muchas gracias. $\mathrm{Si}$ la respuesta es "Si", pasar a la pregunta 8.

8. ¿Cuál sería la razón por la que usted realiza o realizaría alguna actividad física?
a. Mejorar mi estado físico
b. Mejorar mi imagen
c. Rápidos resultados
d. Para ser un atleta.
(e. Por salud (bajar de peso y reducir enfermedades)
f. Otros (por favor, especifique)

9. ¿Con qué frecuencia realiza o realizaría la actividad física?
a. Una vez a la semana
b. Fines de semana
c. Interdiario
d. De lunes a viernes
(e) Diario 
10. ¿Qué actividad fisica realiza o realizaría usted?

Gimnasio

11. La actividad física indicada, ¿Se realiza dentro de un centro de entrenamiento?

SI $X$ No

Si la respuesta es "No", pasar a la pregunta 12

$\mathrm{Si}$ la respuesta es "Si", pasar a la pregunta 13

12. ¿Estaría dispuesto a realizar la actividad física en un centro de entrenamiento?

a. SI

b. NO

Si la respuesta es "No", la ficha de reclutamiento ha terminado, muchas gracias.

Si la respuesta es "Si", pasar a la pregunta 13 .

13. ¿Qué razones considera importantes para elegir un centro de entrenamiento?
a. Horarios accesibles
b. Ubicación accesible
c. Calidad del servicio
d. Precio
(e.) Infraestructura
f. Horario y ubicación accesible
g. Precio y calidad del servicio
h. Indiferente

14. ¿Qué es lo que más le motivaría al momento de adquirir una membresía en su centro fitness?
(a) Descuentos en la membresía
b. Promoción de días adicionales
c. Promoción de días de congelamiento
d. Promoción de días adicionales y congelamiento
e. Indumentaria deportiva de cortesía
f. Descuentos en marca de ropa
g. Indiferente

15. ¿Cuál es el rango de precios que usted paga o estaría dispuesto a pagar por mensualidades en su centro fitness?

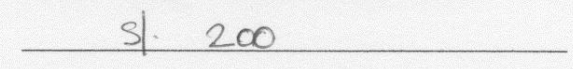


16. ¿Por qué medio le es más factible enterarse de las noticias del centro fitness?
a. Redes sociales
(b) Aplicaciones móviles
c. Revistas mensuales
d. Correos
e. Página web
f. Periódicos

17. ¿Ha practicado o practica el CrossFit?

Si

No $x$

Si la respuesta es "no", pasar a la pregunta 19

Si la respuesta es "si", pasar a la pregunta 18

18. Si la respuesta es $\mathrm{Si}$ ¿Cuál es la razón por la cual la practica?
a. Ser atleta CrossF it
b. Mejorar mi estado físico
c. Rápidos resultados
d. Porque otros lo practican
e. Por salud (bajar de peso y reducir enfermedades)

19. ¿Cuál es la razón por la cuál no practica CrossFit?
(a.) Desconozco del tema
b. Posibles lesiones
c. Considero que no es para mi
d. Disponibilidad de tiempo
e. No hay un box (gimnasio) de CrossFit cerca

20. ¿Cuál es su grado de estudio?
a. Primaria completa
b. Primaria incompleta
c. Secundaria completa
d. Secundaria incompleta
e. Superior técnica
f. Superior técnica incompleta
(g.) Universitaria
h. Universitaria incompleta
i. Post grado
j. Doctorado 
21. ¿Actualmente se encuentra trabajando?

$$
\mathrm{Si} x \quad \text { No }
$$

22. ¿Cuál de estas comodidades posee usted en su hogar?
(a) Televisor Led
(b.) Laptop
(c) Refrigeradora
(d.) Cocina
(e) Lavadora
(C.) Play Station

23. En caso de emergencia, ¿A dónde acudiría?
(a.) Hospital
b. Clínica
c. Posta
d. Doctor particular
e. Centro de salud municipal

Datos de control

Nombre: Brissa Atoche

Edad: 25

Distrito: Ate

Urbanización: 27 de abril

Ocupación: Administradora 


\section{Apéndice 8: Ficha de Reclutamiento Jorge Pérez}

Ficha De Reclutamiento

Presentación: Somos alumnos de la Escuela de Posgrado de la Universidad San Ignacio de Loyola - USIL y estamos organizando un Focus Group como parte de nuestro trabajo académico para graduarnos como magíster en Ciencias Empresariales; por ello, solicitamos su participación, y antes de iniciar la reunión le haremos unas preguntas de interés sólo para nosotros. Agradecemos que haya venido y le invitamos a compartir una mañana agradable.

- Marque con un aspa (X) la alternativa que usted considere como respuesta idónea

- Complete la información que usted considere como respuesta idónea.

- Usted tiene un tiempo de 10 minutos para responder la presente ficha de reclutamiento.

- Valoramos la sinceridad de sus respuestas; asimismo, le recordamos que toda la información que nos proporcione será estrictamente confidencial y será utilizada sólo como objeto de estudio para la presente investigación. Muchas gracias

1. ¿Usted vive en el distrito de Ate?

$\mathrm{SI} \times$ No

$\mathrm{Si}$ la respuesta es "No", culmina la ficha de reclutamiento, muchas gracias.

$\mathrm{Si}$ la respuesta es "Si", pasa a la pregunta 2.

2. ¿En qué Urbanización del distrito de Ate vive?

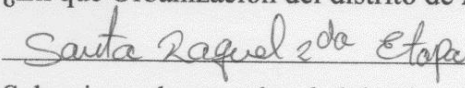

3. Seleccione el rango de edad donde se encuentra usted.
a. 14 a 17 años
b. 18 a 21 años
c. 22 a 30 años
D. 31 a 49 años
e. 50 a 59 años
f. 60 a más años

4. Se considera usted una persona saludable

La OMS (2018) señala que una persona saludable, es aquella que lleva una alimentación sana y realiza actividad fisica constantemente.

SI

No $x$ 
5. En cual de las siguientes categorías, considera usted que se encuentra.
a. Obeso
\&. Sobrepeso
c. Normal (ni bajo en peso ni con sobrepeso)
d. Bajo en peso
e. Fitness (atlética)

6. ¿Realiza usted alguna actividad física?

Si No $x$

$\mathrm{Si}$ la respuesta es "Si", pasar a la pregunta 8.

Si la respuesta es "No", pasar a la pregunta 7.

7. ¿Estaría dispuesto a realizar alguna actividad física?

a SI

b. NO (por favor, especifique el motivo)

Si la respuesta es "No", la ficha de reclutamiento ha terminado, muchas gracias.

Si la respuesta es "Si", pasar a la pregunta 8 .

8. ¿Cuál sería la razón por la que usted realiza o realizaría alguna actividad física? 2. Mejorar mi estado físico
b. Mejorar mi imagen
c. Rápidos resultados
d. Para ser un atleta.
e. Por salud (bajar de peso y reducir enfermedades)
f. Otros (por favor, especifique)

9. ¿Con qué frecuencia realiza o realizaría la actividad física?
a. Una vez a la semana
b. Fines de semana
c. Interdiario
d. De lunes a viernes
Diario 
10. ¿Qué actividad física realiza o realizaría usted?

\section{Sumosic}

11. La actividad física indicada, ¿Se realiza dentro de un centro de entrenamiento? SI No

Si la respuesta es "No", pasar a la pregunta 12

Si la respuesta es "Si", pasar a la pregunta 13

12. ¿Estaría dispuesto a realizar la actividad física en un centro de entrenamiento?

a. SI

b. $\mathrm{NO}$

Si la respuesta es "No", la ficha de reclutamiento ha terminado, muchas gracias.

Si la respuesta es "Si", pasar a la pregunta 13.

13. ¿Qué razones considera importantes para elegir un centro de entrenamiento?
a. Horarios accesibles
b. Ubicación accesible
c. Calidad del servicio
d. Precio
e. Infraestructura
* Horario y ubicación accesible
g. Precio y calidad del servicio
h. Indiferente

14. ¿Qué es lo que más le motivaría al momento de adquirir una membresía en su centro fitness?
a. Descuentos en la membresía
b. Promoción de días adicionales
c. Promoción de días de congelamiento
A. Promoción de días adicionales y congelamiento
e. Indumentaria deportiva de cortesía
f. Descuentos en marca de ropa
g. Indiferente

15. ¿Cuál es el rango de precios que usted paga o estaría dispuesto a pagar por mensualidades en su centro fitness? 
16. ¿Por qué medio le es más factible enterarse de las noticias del centro fitness?
a. Redes sociales
b. Aplicaciones móviles
c. Revistas mensuales
a. Correos
e. Página web
f. Periódicos

17. ¿Ha practicado o practica el CrossFit?

$\mathrm{Si}$ No $\chi$

Si la respuesta es "no", pasar a la pregunta 19

Si la respuesta es "si", pasar a la pregunta 18

18. Si la respuesta es $\mathrm{Si}$, ¿Cuál es la razón por la cual la practica?
a. Ser atleta CrossFit
b. Mejorar mi estado físico
c. Rápidos resultados
d. Porque otros lo practican
e. Por salud (bajar de peso y reducir enfermedades)

19. ¿Cuál es la razón por la cuál no practica CrossFit?

a Desconozco del tema

b. Posibles lesiones

c. Considero que no es para mi

d. Disponibilidad de tiempo

e. No hay un box (gimnasio) de CrossFit cerca

20. ¿Cuál es su grado de estudio?
a. Primaria completa
b. Primaria incompleta
c. Secundaria completa
d. Secundaria incompleta
e. Superior técnica
f. Superior técnica incompleta
(2) Universitaria
h. Universitaria incompleta
i. Post grado
j. Doctorado 
21. ¿Actualmente se encuentra trabajando?
$\mathrm{Si} \chi$
No

22. ¿Cuál de estas comodidades posee usted en su hogar?

ж. Televisor Led

Laptop

\&. Refrigeradora

d. Cocina

o. Lavadora

A. Play Station

23. En caso de emergencia, ¿A dónde acudiría?

a. Hospital

b. Clínica

c. Posta

d. Doctor particular

e. Centro de salud municipal

\section{Datos de control}

Nombre:_orge Po'rz

Edad: 37

Distrito: Ate

Urbanización: Sauta Raquel 2cla Etapa

Ocupación: Idministrador 


\section{Apéndice 9: Ficha de Reclutamiento Joanna Mallqui}

Ficha De Reclutamiento

Presentación: Somos alumnos de la Escuela de Posgrado de la Universidad San Ignacio de Loyola - USIL y estamos organizando un Focus Group como parte de nuestro trabajo académico para graduarnos como magíster en Ciencias Empresariales; por ello, solicitamos su participación, y antes de iniciar la reunión le haremos unas preguntas de interés sólo para nosotros. Agradecemos que haya venido y le invitamos a compartir una mañana agradable.

- Marque con un aspa (X) la alternativa que usted considere como respuesta idónea.

- Complete la información que usted considere como respuesta idónea.

- Usted tiene un tiempo de 10 minutos para responder la presente ficha de reclutamiento.

- Valoramos la sinceridad de sus respuestas; asimismo, le recordamos que toda la información que nos proporcione será estrictamente confidencial y será utilizada sólo como objeto de estudio para la presente investigación. Muchas gracias.

1. ¿Usted vive en el distrito de Ate?

SI $\times$ No

Si la respuesta es "No", culmina la ficha de reclutamiento, muchas gracias.

Si la respuesta es "Si", pasa a la pregunta 2.

2. ¿En qué Urbanización del distrito de Ate vive?

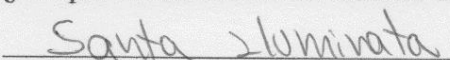

3. Seleccione el rango de edad donde se encuentra usted.
a. 14 a 17años
b. 18 a 21 años
c. 22 a 30 años
※. 31 a 49 años
e. 50 a 59 años
f. 60 a más años

4. Se considera usted una persona saludable

La OMS (2018) señala que una persona saludable, es aquella que lleva una alimentación sana y realiza actividad fisica constantemente.

SI No 
5. En cual de las siguientes categorías, considera usted que se encuentra.
a. Obeso
b. Sobrepeso
屯. Normal (ni bajo en peso ni con sobrepeso)
d. Bajo en peso
e. Fitness (atlética)

6. ¿Realiza usted alguna actividad física?

$\mathrm{Si} \times$ No

$\mathrm{Si}$ la respuesta es "Si", pasar a la pregunta 8 .

Si la respuesta es "No", pasar a la pregunta 7.

7. ¿Estaría dispuesto a realizar alguna actividad física?
a. SI
b. NO (por favor, especifique el motivo)

Si la respuesta es "No", la ficha de reclutamiento ha terminado, muchas gracias.

$\mathrm{Si}$ la respuesta es "Si", pasar a la pregunta 8.

8. ¿Cuál sería la razón por la que usted realiza o realizaría alguna actividad física?
a. Mejorar mi estado físico
b. Mejorar mi imagen
c. Rápidos resultados
d. Para ser un atleta.
Q. Por salud (bajar de peso y reducir enfermedades)
f. Otros (por favor, especifique)

9. ¿Con qué frecuencia realiza o realizaría la actividad física?
a. Una vez a la semana
b. Fines de semana
c. Interdiario
d. De lunes a viernes
e. Diario 
10. ¿Qué actividad física realiza o realizaría usted?

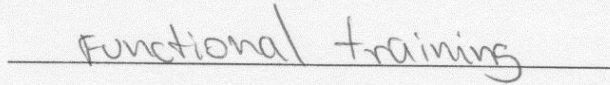

11. La actividad física indicada, ¿Se realiza dentro de un centro de entrenamiento? SI $X$ No

Si la respuesta es "No", pasar a la pregunta 12

$\mathrm{Si}$ la respuesta es "Si", pasar a la pregunta 13

12. ¿Estaría dispuesto a realizar la actividad física en un centro de entrenamiento?
a. SI
b. NO

Si la respuesta es "No", la ficha de reclutamiento ha terminado, muchas gracias. Si la respuesta es "Si", pasar a la pregunta 13.

13. ¿Qué razones considera importantes para elegir un centro de entrenamiento?
a. Horarios accesibles
b. Ubicación accesible
c. Calidad del servicio
d. Precio
e. Infraestructura
※. Horario y ubicación accesible
g. Precio y calidad del servicio
h. Indiferente

14. ¿Qué es lo que más le motivaría al momento de adquirir una membresía en su centro fitness?
a. Descuentos en la membresía
b. Promoción de días adicionales
c. Promoción de días de congelamiento
d. Promoción de días adicionales y congelamiento
e. Indumentaria deportiva de cortesía
f. Descuentos en marca de ropa
g. Indiferente

15. ¿Cuál es el rango de precios que usted paga o estaría dispuesto a pagar por mensualidades en su centro fitness? 
16. ¿Por qué medio le es más factible enterarse de las noticias del centro fitness?

a. Redes sociales

b. Aplicaciones móviles

c. Revistas mensuales

d. Correos

\& Página web

f. Periódicos

17. ¿Ha practicado o practica el CrossFit?

$\mathrm{Si} \_$No

Si la respuesta es "no", pasar a la pregunta 19

Si la respuesta es "si", pasar a la pregunta 18

18. Si la respuesta es $\mathrm{Si}$, ¿Cuál es la razón por la cual la practica?

a. Ser atleta CrossFit

b. Mejorar mi estado físico

c. Rápidos resultados

d. Porque otros lo practican

e. Por salud (bajar de peso y reducir enfermedades)

19. ¿Cuál es la razón por la cuál no practica CrossFit?

a. Desconozco del tema

b. Posibles lesiones

c. Considero que no es para mi

d. Disponibilidad de tiempo

e. No hay un box (gimnasio) de CrossFit cerca

20. ¿Cuál es su grado de estudio?

a. Primaria completa

b. Primaria incompleta

c. Secundaria completa

d. Secundaria incompleta

e. Superior técnica

f. Superior técnica incompleta

S. Universitaria

h. Universitaria incompleta

i. Post grado

j. Doctorado 
21. ¿Actualmente se encuentra trabajando?

$$
\mathrm{Si} X \text { No }
$$

22. ¿Cuál de estas comodidades posee usted en su hogar?

$$
\begin{aligned}
& \text { Televisor Led } \\
& \text { b. Laptop } \\
& \text { e. Refrigeradora } \\
& \text { Cocina } \\
& \text { f. Lavadora } \\
& \text {. Play Station }
\end{aligned}
$$

23. En caso de emergencia, ¿A dónde acudiría?
a. Hospital
b. Clínica
c. Posta
d. Doctor particular
e. Centro de salud municipal

\section{Datos de control}

Nombre: Joanna Mallqui
Edad: 31
Distrito: Oute
Urbanización: Sata sluminata
Ocupación: administradora


Apéndice 10: Resumen de Focus Group

\begin{tabular}{lccc}
\hline Entrevistado & Entrevistado & Profesión & Ubicación \\
\hline E 1 & Yaniré Macalopú & Estudiante & \\
E 2 & Sandra Parodi & Estudiante & \\
E 3 & Israel Huanri & Estudiante & Apéndice 12 \\
E 4 & Aaron Vargas & Estudiante & \\
E 5 & Brissa Atoche & Administradora & \\
E 6 & Jorge Pérez & Administrador & \\
E 7 & Joanna Mallqui & Administradora & \\
\hline
\end{tabular}

\begin{tabular}{lc}
\hline Objetivos & Preguntas \\
\hline Obesidad como problema de salud pública & $1,2,3,4$ y 5 \\
Acerca del nivel de la actividad física que realizan & $7,8,9$, \\
$\begin{array}{l}\text { Nivel de satisfacción del servicio que le ofrecen en su centro } \\
\text { de entrenamiento }\end{array}$ & 17 y 18 \\
$\begin{array}{l}\text { Precios y formas de pago de los servicios que le ofrece su } \\
\text { centro de entrenamiento }\end{array}$ & 22,24 y 25 \\
$\begin{array}{l}\text { Nivel de conocimiento acerca del CrossFit } \\
\text { Grado de aceptación del CrossFit } \\
\text { Nivel de aceptación del rango de precios a pagar por un } \\
\text { servicio CrossFit }\end{array}$ & 31 y 32 \\
\hline
\end{tabular}




\section{Apéndice 11: Guía de indagación para Focus Group}

Introducción

Muy buenos días, somos un grupo de estudiantes de la maestría en Ciencias Empresariales de la USIL, que estamos realizando una investigación de mercados con el objetivo de elaborar un trabajo de investigación para la obtención del grado de magister. Por tal motivo, el día de hoy nos encontramos reunidos en esta sala con el fin de conversar con Uds. acerca de un modelo de negocio para combatir la obesidad en el distrito de Ate. Le pedimos de su tiempo para conversar acerca de este tema tan importante y por favor siéntanse con la libertad de dar su opinión sin ninguna restricción, ya que todo lo que Uds. nos digan será tratado de manera confidencial. No hay respuestas buenas ni malas, solo buscamos sus respuestas. Les damos las gracias por su participación.

Reglas de juego: Relajarse, no tema estar en desacuerdo, grabación y audio.

Calentamiento: Breve presentación de los participantes.

Descripción del problema de salud pública (20 minutos)

Hablemos de la obesidad

1. Para ustedes, ¿Qué es la obesidad?

2. ¿Qué factores creen que influyen en la obesidad?

3. ¿Consideran que la obesidad es un problema de salud pública? ¿Porqué?

4. ¿Cómo combatirían la obesidad?

5. ¿A ustedes les importa estar en un buen estado de salud física? ¿Porqué?

Acerca de la actividad física

6. ¿Para ti, qué es estar en un buen estado físico?

7. ¿Practican alguna actividad física? ¿Cuál?

8. ¿Hace cuanto tiempo realizan dicha actividad física?

9. ¿Por qué practican aquella actividad física?

10. ¿Qué factores consideraron atractivos al momento de elegir la actividad física? ¿Por qué?

11. ¿Dónde realizan la actividad física? Y ¿’Por qué eligieron dicho establecimiento?

12. ¿Con qué frecuencia acudes al establecimiento donde realizas la actividad física?

13. ¿En qué momentos del día acudes al establecimiento donde realizas la actividad física?

14. ¿Cuánto tiempo te toma realizar toda la actividad física?

Hablemos acerca del servicio del establecimiento deportivo

15. ¿Cuál es su antigüedad como cliente?

16. ¿Qué factores consideró atractivos al momento de elegir dicho establecimiento? ¿Por qué?

17. ¿Qué opinión tiene sobre el servicio que le brindan en su establecimiento deportivo?

18. ¿El servicio que reciben está acorde a la proporción del precio y calidad?

19. ¿Alguna vez ha realizado algún reclamo o queja por un mal servicio? ¿Cuáles fueron? 
20. ¿Qué acciones ejecutó la empresa en relación con su reclamo o queja?

21. ¿Se sintió satisfecho con la solución a su reclamo o queja?

Acerca de los precios y forma de pago de los servicios

22. ¿A cuánto asciende su gasto promedio mensual por el servicio que le ofrecen?

23. ¿Qué opinión le merece el precio del servicio?

24. ¿Usted contrata el servicio de manera mensual, trimestral, medio año o anual?

25. ¿Ustedes pagan al contado, con tarjeta de crédito, débito u otra forma? ¿Porqué?

Analizando el entorno del servicio

26. A parte de la actividad física que usted realiza, ¿Qué otros servicios conocen? Y ¿Cómo te enteraste de su existencia?

27. ¿Por qué no eligieron dichos servicios?

28. ¿Cuáles creen que sean las desventajas de dichos servicios?

29. ¿Qué ventajas ofrece tu actividad deportiva, frente a los otros servicios que mencionaste?

30. ¿Cuál de esas actividades físicas intentarías probar? Y ¿Cuál descartarías por completo?

Acerca del CrossFit y de los servicios de un Box de CrossFit

A los participantes se les informa que el CrossFit es un régimen de ejercicios que consiste en movimientos funcionales con constante variación -desde corta duración con peso pesado, hasta larga duración con poco peso o sin este- y ejecutados a alta intensidad; optimizando sus capacidades físicas y logrando superar sus expectativas. Donde hay una combinación de diversas disciplinas como levantamiento de peso con barras olímpicas, Dumbbells, Ketbells, etc, gimnasia y ejercicios aeróbicos. (se reproduce un video corto). Luego de ello, se les pregunta:

31. ¿Qué opinas del CrossFit?

32. ¿Qué diferencias crees que tiene el CrossFit frente a la actividad física que realizas?

33. ¿Qué tan dispuesto estarías en probar una clase de prueba de CrossFit? Y ¿Porqué?

34. ¿Intentarían hacer el CrossFit si esta se desarrolla en 1 hora de clase diaria?

35. ¿Influiría mucho elegir el CrossFit como tu actividad física, si esta se desarrolla en un ambiente amplio?

36. ¿Influiría en tu elección de hacer el CrossFit, si el personal de entrenamiento está debidamente certificado?

37. ¿Influiría en tu elección de hacer el CrossFit, si el Box de CrossFit se encuentra ubicado en tu distrito?

38. ¿Estarías dispuesto a pagar entre 280 a 320 soles por una membresía mensual? Fundamenta tu respuesta. 


\section{Apéndice 12: Transcripción de Focus Group}

Arturo Palomino (AP): Buenos días agradecerles a todos la presencia, que nos acompañen hoy, bueno nosotros, el Señor Giancarlo Chávez (GC) y yo Arturo, estamos culminando nuestro maestría en ciencias empresariales en USIL así que, dentro del proyecto de negocio que estamos formulando para poder optar por el grado de magíster, los hemos convocados para levantar información respecto a una idea de negocio que estamos proyectando hacer, en ese sentido Ustedes han pasado ya una guía de reclutamiento y selección, tiene alguna característica similar entre todos, así que vamos a comenzar, los voy a dejar con el Sr. Giancarlo Chávez para que un poco pueda moderar el Focus y bueno sí les agradecemos que nos permitan grabar la sesión y bueno siéntanse en libertad de expresar las ideas que quieran comentar, con total soltura.

Giancarlo Chavez (GC): Les damos las gracias por la participación, la información que salga aquí es estrictamente confidencial y como dijo mi compañero, no hay respuestas buenas ni respuestas malas siéntese con toda libertad, el modo que vamos empezar es de derecha hacia la izquierda, se van presentando primero, en qué Distrito vive y procederemos finalmente a pasar con las preguntas.

Yaniré Macalupú Cárdenas (YM): Buenos días ante todo al grupo, mi nombre es yaniré Macalupu, tengo 22 años de edad y soy del distrito de Ate.

Sandra Parodi Medina (SP): Mi nombre es Sandra Xiomara Parodi Medina tengo 21 años de edad y soy del distrito de Ate

Israel Huanri (IH): Buenos días, mi nombre es Israel Huanri, tengo 29 años y vivo en el distrito de Ate

Aaron Barrantes (AB): Buenos días ante todo, mi nombre es Aaron Barrantes Montalva, tengo 23 años y vengo del distrito de Ate

Brissa Atoche Lugo (BA): Buenos días, mi nombre es Brissa Atoche, tengo 25 años y vivo en el distrito de Ate

Jorge Perez Pardave (JP): Mi nombre es Jorge Perez, tengo 37 años y actualmente vivo en Ate

Joanna Mallqui Rodriguez (JM): Hola, mi nombre es Joanna Mallqui, tengo 31 años y vivo en Ate

GC: Vamos a iniciar, con la descripción del problema de salud pública que concierne un poco a nuestra idea de negocio, hablemos de la obesidad, para Uds ¿qué es la obesidad? 
YM: La obesidad es una enfermedad en sí, se podría decir que conlleva con la alimentación que las personas llevamos de acuerdo a como va su nutrición desde pequeños, e inclusive lo que vendría a ser éste tipo de enfermedad.

SP: Como dice mi compañera, la obesidad es una enfermedad que puede ser producto del stress, por problemas, ansiedad de comer y cosas así

IH: Como comentan, dicen la que la obesidad es la enfermedad el siglo XXI, es una enfermedad que toda persona está propensa, a la obesidad que tiene como consecuencia a la diabetes, la celulitis, como así, se debe a la mala alimentación, mala educación, el estilo de vida, calidad, falta de ejercicios.

AB: Mi opinión, yo creo que más es un estilo de vida, ya que las personas se acostumbran a comer determinados alimentos, que no son en sí alimentos, sino cosas que por el ajetreo del día a día necesitamos algo rápido, algo que nos ayude a alimentarnos y seguir con nuestras labores.

BA: es una enfermedad que se da por la costumbre, el día a día, la facilidad de comer lo primero que encontramos es comida chatarra, y la poca costumbre de hacer ejercicio y desde chiquitos creo que no nos inculcan eso.

JP: Para mi es la consecuencia de un estilo de vida poco activo y una mala alimentación

JM: Bueno, para terminar con la pregunta, en mi caso pienso que es un tema de estilo de vida, como dice el joven, es ahora porque ya las personas tienen una vida muy agitada, muy rápida entonces solamente comen lo que se les presenta en la calle y aparte de eso la falta de ejercicio que casi nadie lo realiza

JP: El sedentarismo no?

JM: Exacto

GC: Bien, ¿Cómo combatirían la obesidad?

YM: Combatiríamos primero se tendría que tomar en cuenta, o poder realizar campañas, charlas sobre todo a los padres de familia porque ellos tienen a sus hijos, de acuerdo como van ensañandoles van a ir creciando, y también podríamos implementar o motivar a los niños para que puedan hacer ejercicios desde chiquios,

SP: Yo creo que se puede combatir también tomando consciencia uno mismo de lo que está comiendo, porque como siempre mayormente las comidas son grasa, siempre darse un tiempo para cuidarse, hacer ejercicios, comer sano, por lo menos un tiempo del dia.

IH: Como comentan yo creo que pasa por la educación, los hábitos alimenticios y el estilo de vida que lleva cada uno 
AB: Por mi parte opino que desde la casa, ya que si los padres enseñan a los hijos a alimentarse bien y no caer en la comida chatarra, entonces si a eso lo sumamos que los padres les inculquen a los hijos a hacer algún deporte, entonces ya estaríamos encaminados hacia una solución

BA: Yo creo que primero es tomando conciencia, luego haciendo campañas, por ejemplo en las universidades e institutos lo que encuentras es comida chatarra afuera, es bien difícil encontrar frutas y verduras, haciendo campañas para que estas personas que venden también vendan tipos de comida saludable

JP: Pienso que deberían promoverse el apoyo, la asesoría de profesionales, nutricionistas, entrenadores físicos, porque no todos los casos no son iguales, lo que te funciona a ti no te funciona a ti. Pero debe promoverse más, yo pienso que ahora se ve como un tema muy costoso, entonces la gente no opta por eso, pero para mí la mejor opción es tener el apoyo de un profesional.

JM: Efectivamente, de todas maneras el apoyo de alguien y poder hacer eso más de conocimiento público porque la gente no sabe mucho de ése tema y lo toma muy simple y tiene que tener mucho que ver con lo que piensa uno mismo. Primero tomar conciencia una persona que está mal o no y después de eso qué puede hacer de acuerdo a las opciones que le dan en el mercado que son varias

GC: Para terminar esta primera parte de salud pública que es la obesidad, la última pregunta es: ¿a Uds les importa estar en un buen estado de salud física? ¿por qué?

YM: Sí, lo considerable es que a todos nos debería importar tener una buena salud física, no quiere decir que todos tenemos conciencia a ello, incluso mi persona, podría decir que soy parte de no digerir alimentos súper saludables, verduras, hay algunas cosas que no suelo comer

AP: No te gustan las verduras

YM: No me gustan las verduras, sobre todo por eso, esta enfermedad puede conllevar inclusive hasta la muerte, tiene consecuencias bien graves, sería bueno tomar conciencia por ello.

SP: Lo que es yo sí tengo un poco de conciencia, de todas maneras suelo comer bastante grasa, hago actividad física como bailar y caminar para poder manterme

IH: la consecuencia de un estilo de vida, es poder sentirse más ágil, poder dejar el sedentarismo y poder hacer cosas más, porque si estamos en un estilo de vida de estar solamente sentado y comer, comer y voy al mercado o voy a la tienda, como una papita y no tengo un estilo de vida de comer una verdura o una fruta que es mismo nutriente, pero es el 
campo de subir la obesidad. Honestamente donde yo trabajo, salgo y lo primero que veo es una tienda, en la tienda tiene fruta, tiene snack, luego fruta o snack, y eligo el snack, chapo la papita, el tortees, lo mas sencillo.

AB: ¿me puede repetir la pregunta?

GC: ¿a Uds les importa estar en un buen estado de salud física? ¿por qué?

AB: En mi caso soy futbolista amateur, juego en una liga, y la verdad es muy importante ya que las personas que trabajan conmigo en la parte física, podemos ver que se merma el rendimiento de las personas que no hacen deporte, entonces nos recomiendan una dieta y nos recomiendan hacer determinados ejercicios de acuerdo a la posición donde jugamos, en éste caso a mí me han dicho que tengo sobrepeso, solo unos cuantos kilos, que son reducibles ¿no? De acuerdo a la actividad física que tenemos y la verdad es que es bastante importante porque se ve que merma el rendimiento de cada personas

BA: Creo que es muy importante, porque no solamente implica en cómo te ves, sino como te sientes, en tu estado de ánimo, en tu día a día, en hablar de cuantos años vas a vivir, porque mas adelante esto te va a pasar la factura.

JP: Para mí también es muy importante, recientemente porque como lo mencionó aquí la señorita, de repente en la juventud no sentimos los efectos de los abusos que hacemos, no solo con la alimentación, con las bebidas, pero a medida que van pasando los años vamos a ver las consecuencias, los temas cardiovasculares son graves en gente muy joven que fallece por éstos temas, por no cuidarse, por darle la importancia debida, porque tu te puedes ver muy bien, o tienes sobrepeso, pero puede ser que la alimentación no sea la correcta, el estado físico el correcto, y bueno, puedes tener alguna enfermedad sin saberlo y bueno, vas a sufrir las consecuencias, para mí es muy importante.

JM: Creo que recién ahora, y hablo por mi persona, recién se toma conciencia cuando uno pasa los 30, cuanto tenía 20 o en la base 2 , no tomaba conciencia y comía lo que se me presentaba, y ahora también no?, hay tiendas donde todo está cerquita o delivery, pero trato de ser mas conciente, si quieres lo haces, depende de uno, pero sabes que está mal porque a la larga se te va a venir todo encima y mas aun si tienes familiares o antecedentes que pueden sufrir de ése tipo de enfermedades.

AP: Bueno, a manera de conclusión de ésta parte, se ha hablado mucho de la alimentación, actividad física, la conciencia frente a estos problemas. Queremos centrarnos en el tema de la actividad física, en ése plano quisiéramos que nos comenten de manera libre, cual es para uds la actividad la física que practican, con qué frecuencia, cuanto tiempo o no 
hcen ninguna actividad física para que pueda conllevar al tema del estado físico que estamos conversando ahorita

YM: en mi persona asisto a un taller de danza, de repente no asisto a un gimnasio, pero realizo ese tipo de actividad.

AP: Con qué frecuencia, cuánto dura cada sesión

GM: Dos veces por semana, y un aproximado de 2 horas cada sesión

SP: Lo que es yo también pertenezco a un taller de danza, voy con ella dos veces por semana estamos en el mismo horario y aparte de eso mi rutina de trabajo es caminar, caminar y caminar y como que ahí hago ejercicio.

IH: En mi caso solo practico una vez a la semana, los domingos salgo corro con mis hermanas, cerca a mi casa hay un complejo que tiene una pista reglamentaria de maratón, de atletismo alrededor de la cancha de futbol y terminamos y luego juego con los patas que están por ahí

AP: y mas o menos cuánto dura ésa sesión

IH: cada vez que voy me doy 5 vueltas ( 2 mil metros) y plan de 9 de la mañana.

AB: Bueno en mi caso es el futbol no, y en ciertas ocasiones el vóley, en este caso lo practico martes, jueves, sábado y domingo, cuatro veces por semana regularmente y es mayormente entre 1 y 3 horas. De acuerdo al entrenador, a veces es ejercicio físico meramente que es una hora u hora veinte y después pasamos a balón. En promedio entre hora y media y dos horas.

BA: En mi caso no hago ninguna actividad física

JP: Yo juego fulbito una vez por semana, dos horas

AP: solo una vez a la semana

JP: Ahorita sí, antes jugaba mas, pero tengo un problema en la rodilla que mas el sobrepeso me ha limitado a eso.

JM: No no hago ninguna actividad física.

AP: Y al momento que Uds. eligen la actividad física, han hablado de temas de danza, de jugar pelota, de correr, en el caso de Uds. ¿cuál sería ese factor que los motiva a hacer la actividad física hoy en día? ¿por qué correr por ejemplo en tu caso?

IH: Mas que todo en la semana estoy sentado, de lunes a viernes y sábado a veces me quedo en mi caso, el único día que puedo hacer deporte es ése día. Toda la semana desde las 8 am hasta las 5 pm estoy sentado, entonces para compensar. Mejorar el estilo de vida y reducir el estrés también.

AP: ¿y en su caso chicas? 
YM: yo para reducir el estrés

SP: La verdad que a mí me encanta, me gusta bailar desde chiquita, lo hago porque me nace, me encanta.

AB: En mi caso, desestresarme, divertirme y porque desde muy pequeño estuve en la academia de futbol, no lo veo como un deporte, es como un hobby pero ya me apasiona.

JP: Yo también voy para reducir el estrés, corro grito, me peleo, todo ahí, así es.

AP: En tu caso Brissa qué te motivaría a realizar una actividad física. Qué factor te llevar

BA: Tener un gimnasio, un lugar cerca a mi domicilio

JM: A mí me falta mas disciplina, porque yo ya he estado en gimnasios, CrossFit, por ahí, pero no iba, porque no me llamaba la atención, entonces me matriculaba

AP: Era flor de un día, te emocionabas un día y luego no iba mas

JM: Así es

GC: Bien, quienes practican alguna actividad física, queremos saber más o menos algunas cosas acerca del establecimiento donde realizan, y quienes no acuden a un establecimiento, quisiéramos saber más o menos qué es lo que gustaría que tenga un un establecimiento para que ustedes puedan ir a ése establecimiento a practicar. Quisiéramos saber ¿qué factores consideran atractivos al momento de elegir un lugar fitness para entrenar? En su caso chicas, qué les motivo ese lugar para hacer danza.

YM: Ah bueno, yo creo que sobretodo para poder practicar danza, para poder desenvolverte, tiene que haber un espacio determinado, grandecito para poder bailar,

GC: $Y$ en cuanto al servicio que te ofrece ¿qué te parece?

YM: Bueno sobretodo por la calidad de los profesores, creo que eso también tiene que ver mucho, la calidad y el monto que uno tiene que pagar.

SP: Como dice ella, el espacio a donde vamos es grande, los profesores son buenos, y también es el monto de que pagamos que a veces nos gustaría que sea un poquito menos

GC: Entonces la calidad de servicio con el precio está asociada

SP: Yo creo que está un poquito alto

GC: En tu caso Israel, que te motivaría en acudir a un centro fitness, ¿Qué factor o factores considerarías tú atractivos para acudir a un lugar fitness para que entrenes?.

IH: Estaba en un gimnasio antes cuando estaba en el otro trabajo, estuve un gimnasio que tenía en el lugar donde trabajaba, íbamos con mi Jefe a determinadas horas, pero luego cuando me cambiaron de lugar, dejamos de ir por la distancia, y sí nos gustó el ambiente, porque tenía duchas, entrenador personal, nos ayudaban, muchachos vamos a hacer esto, sí fue un buen lugar, fue mi primera experiencia en un gimnasio y con mi jefe iba a sobrepasar 
nuestros límites como se dice, un día hicimos lo que es la caminadora hicimos media hora, una semana, terminamos muertos, la otra semana hicimos una hora, competencia, quien aguantaba más. Por mi casa hay lugares pero lo que pasa es que es muy lejos para mí, poder bajar, aparte la hora que llego de estudiar de la universidad ya no alcanza el tiempo.

GC: Que bien. En tu caso Aaron que factores consideraste para estar dentro del centro deportivo donde practicas futbol

AB: No es tanto un centro deportivo, es un campo de futbol reglamentario, pero el típico de Lima, que es pura tierra, entonces en ese caso, es muy parecido a un gimnasio solo que nosotros trabajamos ciertos músculos, lo que es potencia, elasticidad, velocidad, para poder desempeñarnos en el campo de juego. En este caso, sería una maravilla que sea de pasto natural, pero la mayoría de campos de nuestra zona son tierra, arena, bastante descuidados.

GC: ¿Qué factor o factores considerarías importantes para acudir a un lugar fitness para que entrenes?.

BA: El principal factor sería el entrenador que tienes, porque en alguna ocasión me matriculé en clases de baile, y fui solamente una semana, porque los primeros días estaba detrás mío, como que más personalizada la atención, pero pasaron los días y ya era distinto, como que te dejaban de lado no estaban constantemente contigo, y adicional a eso no solo actividad física apoyarte, sino darte consejos de nutrición sobre que podrias comer para que pueda complementar

GC: En tu caso?

JP: En mi caso la cercanía, la comodidad, la limpieza, el seguimiento a los socios a los asistentes y seguridad también

GC: Y en cuanto al precio y calidad de servicio?

JP: Yo pienso que sí deben ir de la mano

GC: En tu caso... qué factores...

JM: Que buscaría, cerca a mi casa definitivamente uno, y dos yo pienso que si quieres algo bueno de hecho tienes que invertir en algo, porque definitivamente hay lugares donde sí te pueden dar el mismo servicio pero no necesariamente con la misma calidad y obviamente te van a cobrar mucho menos, entonces debe ir de la mano a mi parecer. Y obviamente que si estas pagando por algo más, que sea pues algo bueno, con una atención personalizada y algún plus que te puedan adicionar.

GC: Perfecto, ahora vamos a ver un poco más a profundidad el tema del centro deportivo, quienes están en un centro deportivo, quisiéramos saber si alguna vez han realizado alguna queja por el mal servicio de éste. 
IH: Cuando he estado en la cancha donde ahora practico, antes era tierra, la pista reglamentaria era pura tierra, la gente iba, tenía huecos, algunos se caían, algunos se tropezaban, hicimos la queja a la municipalidad y la municipalidad mandó su requerimiento al IPD y el IPD a los dos meses vino e hizo todo, hizo pista, puso cancha de grass sintético, cercó, puso duchas, puso también para jugar lo que es tenis, canchita de tenis.

GC: En pocas palabras te sentiste satisfecho con ésta implementación?

IH: En realidad fue una motivación para que toda la sociedad pueda bajar ahí y practicar el deporte que quiera.

GC: ¿En tu caso Aaron?

AB: Como le digo como es una cancha así al aire libre y de tierra, por supuesto que no, y bueno, nos tenemos que cambiar a la intemperie, a veces pasan chicas.

GC: Has llegado a quejarte de eso?.

AB: Las chicas se han quejado.

GC: Entonces hasta el momento no hicieron ninguna... no han implementado, te sentirías insatisfecho por...

AB: no hay un espacio donde alistarnos de manera menos impúdica

GC: En tu caso?

JP: Bueno, yo te puedo hablar más del futbol no?, alguna vez hemos tenido problemas con la iluminación, con los tiempos, y sí nos hemos quejado, hemos llamado, mira estamos a oscuras, y como que siempre han tratado de quedar bien con nosotros creo yo, para no perdernos como clientes, siempre nos han dado tiempo extra o un día programar la próxima fecha que jugamos, nos cobraban la mitad o cosas así, pero sí satisfecho con la atención.

AP: Buenísimo, con respecto a éste tema de la actividad física quisiéramos un poco aterrizar un poco el concepto a nivel de gasto, a nivel de economía. Quisiéramos saber en general, ¿cuál es el gasto promedio mensual que Uds, invierten para practicar la actividad física que practican hoy en día, y en el caso de que no practiquen, ¿cuánto estarían dispuestos a invertir, de manera mensual, trimestral, semestral, anual, dependiendo de la forma de la que a Uds, les parece más cómoda, y si tienen alguna forma de pago preferida, no sé, cupones, tarjeta de crédito, efectivo tal vez, lo dejo picando ahí a nivel de economía.

GC: El monto que yo pago mensual es un aproximado S/250 a S/ 300., AP: Sandra, qué te parece ése precio, es muy alto, siempre le estamos buscando pagar un poquito más abajo

YM: 250 podría ser un poquito menos

AP: En tu caso Sandra? 
SP: Pago lo mismo que ella, porque practicamos igual, pero en el caso de nosotros, en nuestro caso, somos muy buenas bailarinas, entonces siempre hay como un poco de preferencia, unos cuantos descuentos y a otras chicas que también bailan muy bien.

GC: Y el método de pago que realizan es efectivo?

SP: Efectivo, mensual pagamos en efectivo.

AP: Y si les dieran una chance de un descuento digamos a nivel de pagar por un trimestre y les rebajen algo... estarían en la posibilidad de hacerlo

SP: Sí claro

AP: Sería locazo dice Sandrita, muy bien, ¿en tu caso Israel?

IH: Estuve viendo por ahí por mi casa los gimnasios y tienen promociones, por ejemplo, pagos mensuales, dos por uno y parece más interesante el dos por uno

AP: Estas buscando tu partner, quien te acompañe?

IH: Claro porque a veces ir solo a entrenar, no hay quien te diga vamos, no hay quien te motive, estoy buscando, y ya tengo una persona ahí,

AP: Ya tienes ya

IH: Ya encontré el lugar a donde vamos a ir, y el precio es de 320 soles los dos primeros meses

AP: 320 por los dos los dos primeros meses

IH: Sí, 320320 y después de ahí individual sería 280

AB: Bueno en mi caso, como participamos en una liga distrital el entrenador no pagamos nada, lo único es el transporte hasta el campo de futbol

AP: Por derechos de árbitros, de cancha, de indumentaria, algo

AB: Son donaciones que reciben

AP: A ustedes les pagan.

AB: No. En éste caso también intenté ir a un gimnasio como dice mi compañero, la verdad es que falta fuerza de voluntad. Éramos tres, un trío, entonces, pagamos bastante menos de las personas que pagan uno, pero en este caso, faltaba uno y el otro se desanimaba. Pagamos un mes, dos meses y ya lo dejamos.

BA: Yo creo las promociones son muy buenas, dos por uno, si llevas a un referido, te bajan un poco y también el medio de pago, Visa, MasterCard, tarjetas de crédito, débito creo que es lo principal

AP: y cuanto estaría el rango de ticket de pago que tú podrías manejar para poder participar

BA: 250 así, mensuales 
AP: Jorge, ¿en tu caso?

JP: Con esto del fulbito la verdad no sé cuánto gasto,.

AP: Cuánto gastas en el fulbito cada semana?

JP: Depende no, depende de dónde juegue, ponle que por la cancha gaste 20 soles, en movilidad, 20 soles más, y en los refrescos como 60, pero... lo que no me gusta es la estrategia de los gimnasios, estoy a punto de entrar a un gimnasio entonces yo voy y me encuentro con un fortachón al frente y me dice oye sí que bien, que esto, que lo otro, que mira. Ya mira ok ok, está bien, los precios no me los quieren mostrar por ningún lado y yo mentalizado en el precio porque obviamente no me gusta mucho el deporte, todo esto lo estoy haciendo por un tema de salud y me dice, si tú quieres un mes te cuesta como 300 soles y yo ya me quiero ir, y me dice no espérate, pero mira qué quieres tú, en cuánto tiempo, entonces 3 meses ya estaba cerca de 50\%, 6 meses ya estaba por debajo del 50\%, entonces es una estrategia que no me gusta porque tampoco no me gustaría meterme 6 meses, de repente va a pasar lo de siempre, voy a ir una vez y de ahí no regreso más, y voy a estar pagando los 6 meses porque obviamente lo voy a pagar con tarjeta de crédito y bueno como estrategia para el público no me gusta, pero de alguna manera te beneficia, ahorita estoy viendo propuestas, tengo un Golds Gym cerca y me va a costar como 105 soles el mes, y hay un gimnasio más cerca que es mucho más pequeño que tiene menos cosas, pero me quiere cobrar como 180 con la misma estrategia, métete 3 meses, métete 6 meses, obviamente me voy a ir con la opción que me da mejores beneficios. Pero no pienso pagar más de 150 soles

AP: Pero te gastas como 100 soles semanales en las sesiones de fulbito

JP: Ah pero eso es sagrado.

AP: Pero son como 400 soles mensuales

JP: No que va, 250 al mes, no no era una broma lo de los refrescos, no es siempre, pero que me gaste pues unos 250 al mes.

AP: Por una sesión a la semana

JP: Digamos una vez a la semana el fulbito y ahí el gimnasio libre

JM: Igual, pagaría un aprox de eso, porque de hecho todos te van a dar promociones o te van dar las membresías de 6 a un año y obviamente te va a salir mucho menor, asi pagues un mes y de alguna forma te ayuda a que vayas, porque si ya estas pagando tienes que ir pues no obligatorio.

AP: Buenísimo, a ver. Ya habíamos hablado de las formas de pago, cierto, que en su caso es en efectivo, Brissa nos había dicho que sería con tarjeta de crédito, ¿en tu caso Jorge?

JP: Tarjeta también 
AP: Johanna?

JM: Tarjeta también

AP: Ok, y Uds. nos han hablado de algunos lugares que han frecuentado, no es cierto, se han ido alguna a un gimnasio, han tenido alguna una experiencia que duraste una vez y ya no fuiste, tu en el caso de CrossFit un par de veces y ya no más. ¿qué otros servicios de los que nos han comentado conocen? A parte de un gimnasio, en su caso taller de danza probablemente, en su caso también, gimnasio, hay alguna otra alternativa que hayan encontrado para hacer o practicar alguna actividad física.

SP: Yo practicaba fútbol

AP: Jugabas futbol

SP: Claro antes,

GC: ¿Y por qué no elegiste ése servicio en lugar de danza?

SP: Es el tema del tiempo, mi trabajo, luego la universidad, salgo noche, al día siguiente es lo mismo, siempre he sido desde el colegio muy apasionada, yo siempre he sido muy disciplinada en lo que era cuidarme, porque he modelado ropa desde muy pequeña, desde los 10 años hasta los 17, entonces he tenido 7 años cuidándome, yendo al gimnasio, o sea me cuidaba tal como me decían, y me gustaba mucho jugar partido, para mí el futbol era no sé lo máximo, incluso mucho más que el vóley el vóley yo sentía que era para débiles. Yo me sentía así, entonces en el momento que entré a la universidad, avanzaba los ciclos, el tema del horario, el trabajo, me alejé mucho de lo que era el gimnasio, me aleje mucho del futbol, cosas que a mí me apasionaba, me puse a bailar break dance, que es algo que también me encanta, participaba en concursos, pero como te digo el tema es mi universidad y mi trabajo, me tienen así desde la mañana hasta la noche, entonces dejé cosas que yo amaba los dejé al lado y tuve que priorizar lo que era mis estudios y mi trabajo, y ahora que con mi mejor amiga vamos a un taller de danza, como que me siento libre, me encanta, no sé, siento que es mi pasión bailar.

AP: Te gusta más que el futbol?

SP: Los dos me encantan de verdad, pero el tema del futbol no lo puedo hacer, porque no voy a ir una vez a la semana. A veces salgo los domingos con los de mi barrio, con las chicas de mi barrio, pero a veces los domingos digo no, es el único día que descanso, entonces con todo el tema del tiempo no voy más que a bailar con mi mejor amiga

YM: A veces también en el tema del tiempo, que no te ayuda mucho

SP: Vamos lejos, bajo como 20 cuadras para jugar partido, llego cansada

GC: En tu caso Yaniré?, Qué otros servicios de actividad física te gustaría?. 
YM: Actividad física, natación

GC: Por qué?

YM: Podría decir que hasta ahora no sé nadar, entro así solo hasta donde llega mi tamaño. A veces me gustaría hasta más allá, o cuando voy a la playa con mi familia, mi papá y mi hermano si saben nadar, y me tienen que llevar de la manito, sobre todo por eso

AP: En su caso señores. Uds. Además el futbol y del vóley que eventualmente practicaron, qué otra actividad te interesaría digamos

BA: En mi caso, antes de practicar, a mí siempre desde que estaba en el colegio me gustaba correr, después el deporte de contacto, karata tae kon do,

AP: El box

BA: El box también llegue a practicar cierto tiempo

AP: ¿y te noqueraon?

BA: y ahí le quitaron las ganas, pero ya cuando terminó la universidad meterme otra vez al box, pero por la edad ya es más difícil y el rendimiento físico

AP: ¿Aaron en tu caso? Tú lo noqueaste a...

AB: También hice box, pero el entrenador dijo que no era muy compatible con el futbol, ya que para el box se necesita agilidad, flexibilidad, potencia, en cambio en el box te vuelves duro, es más contextura física y cuánto puedas aguantar, osea en por ese caso no pude entrar al box, también he visto que cerca de mi casa han abierto un centro de alto rendimiento, que serían no se si habrá visto concursos donde suben sogas con los brazos

GC: Ah functional

AB: Ejercicios de alta intensidad, pero en éste caso es para mantenerse en forma, pero no me he atrevido a ingresar, porque parece que no va mucha gente.

AP: Brissa en tu caso

BA: A mí me gustaría creo que natación, porque es uno de los deportes más completos, trabajan de pies a cabeza.

GC: ¿Y por qué no lo practicas?

BA: Porque por mi casa no hay un lugar donde pueda practicar, creo que son pocos los lugares.

GC: En tu caso Jorge.

JP: A mí siempre me gustó el tae kon do, de niño lo practiqué, lo dejé, y ahora lo retomé, pero tuve problemas con la rodilla, con el tobillo, por el sobrepeso, y otras cosas más, así que vengo con un programa primero para bajar de peso y luego voy a meterme al gimnasio a trabajar más lo que es el cardio y todo eso, y sí pensaría retomarlo de todas maneras. 
JM: En mi caso, de los dos sitios donde he estado que ha sido el gimnasio y crossfit, el gimnasio de alguno u otra forma lo dejé porque para mí era muy duro, el hecho de levantar pesas, el peso en sí es muy fuerte, y el crossfit sí le agarré un poquito más de cariño, pero que pasaba, que eran muy estrictos los entrenadores, entonces si tu no hacías en el ritmo que los demás hacían, ya te decían oye avanza o que haces acá pues no.

GC: Entonces te han tocado coaches que no tienen la mentalidad del CrossFit

JM: Exacto, si, creo que sí, porque me gustaba el hecho de que saltas soga, corres, este habían muchos ejercicios buenos que te mantenían en forma. Pero de verdad más me estresaba el entrenador que lo que yo me podría sentir bien, creo que por ese dejé también

GC: Bien, ahora vamos a hablar de lo que es nuestra idea de negocio, que es aperturar justo un Box de CrossFit en el distrito de Ate. Para los que no conocen en sí qué es el Cross Fit, es un régimen de ejercicios que consiste en movimientos funcionales con constante variación, puede ser mediante un peso intenso con una corta duración o durante larga duración con poco peso o casi sin éste mismo, y ejecutado sobre todo a alta intensidad con la finalidad de optimizar la salud de cada una de las personas y tratando de superar las expectativas de las mismas. El Crossfit es una combinación de ciertos ejercicios como el levantamiento olímpico de pesas, gimnasia y ejercicios aeróbicos sobre todo. El CrossFit también tiene una distinción larguísima frente a los que es functional y otros similares debido a que el CrossFit en esencia en sí es un ejercicio en el cual tú vas a ir, en éste caso, vas a ir pausadamente, no vas a ir de frente a levantar un peso olímpico sino que vas a ir progresivamente avanzando en esto. Entonces bajo ésa premisa, qué opinan Uds, de éste deporte llamado CrossFit, ¿les interesaría probarlo?

YM: Sería bueno no, yo considero que todas las personas que no han tomado consciencia de su salud, de la vida saludable que tienen, entonces pueden ir de repente a un CrossFit, más que todo para poder mejorar la vida saludable

SP: He escuchado cosas así, como levantar pesas, pero te digo que no es lo mismo, pero de ahí si como escuché al Doctor Giancarlo diciendo que salta, aeróbicos, entonces digo, me gustaría ir para conocer en verdad cómo es, y sí me gusta saltar, correr y todo, pero el tema de cargar peso no es lo mismo, pero sí me gustaría para ver algo nuevo en mi vida y cambiar de rutina, cosas asi, pero no he visto que haya uno por mi casa, he escuchado, pero nunca he ido a uno, tampoco he visto un local.

IH: En mi caso he visto ahí letreros que dicen CrossFit, Fitness, pero nunca supe qué era, pero lo que comenta Ud. creo que es un deporte que me gustaría practicar, tanto que fusiona la parte de levantar peso, lo que a los hombres nos gusta, hacer crecer músculo, resistencia y 
todas esas cosas, sí motiva, eso como movimientos dinámicos que son cambiante sí me gustaría

AB: Se parece bastante al futbol, porque hay una progresión, ingresas y nunca habías jugado futbol, te enseñan desde lo básico y va subiendo la intensidad, y llega un punto que ya es tu limite y te toca mantener ése límite, y por eso digo que es bastante parecido, y si pudiera llegar a mejorar las habilidades que tuviera dentro del futbol sería interesante.

BA: En mi caso me parece muy interesante por lo que has mencionado, son varias actividades que realiza, sería poco probable que me aburra, por la variedad.

JP: Sí lo he visto, no eres la primera persona que se estresa con la rutina, también me gustaría probarlo, una mejor condición física, pero sí pienso que sería importante que tengan algo para principiantes y algo para los que son pro. Por lo que he visto, he tenido oportunidad de ver un par de sesiones por ahí, las que he visto, a todo el mundo le dan rl mismo ritmo y no todos van por igual, y he visto también por temas laborales que he tenido que ir por varias partes bien temprano o ya en la noche, gente que se está juntando en parques, en placitas, 3, 4 o 5 personas, las veo que están haciendo así, no sé si será CrossFit porque he pasado no más, pero sí he visto pequeños grupos y veo que se está proliferando, como que está en pleno apogeo.

JM: Sí, como les comentaba, es bueno, a mí me gustó, hecho yo lo había visto antes de matricularme, había visto, había chequeado cómo eran las clases, y me parecería divertido, entonces por eso yo de alguna u otra forma decidí matricularme, pero ya cuando estaba ahí era otra cosa, sí me estresé, de hecho un coach era como más paciente y el otro dale vamos, no puedo me duele, entonces me sentaba, debería probar otro de repente.

GC: Lo concerniente al CrossFit, quiero resaltarles que el CrossFit es un entrenamiento que es progresivo de por sí, no vas a empezar levantando el peso que todos tus compañeros, la primera vez que uno va al CrossFit, empiezas con entrenamientos funcionales, y los primeros skills o técnicas de principiantes, es cierto que existen ciertos Boxes o Gimnasios que pretenden sacar el tema del CrossFit como nombre pero terminan ejecutando otras actividades, como el caso del entrenamiento de los parques, que dicen que es CrossFit pero no es CrossFit, pero la ventaja que tiene en general frente a sus demás competencias es que el CrossFit se desarrolla en una hora, entonces tienen 5 minutos de calentamiento, luego tienes unos 15 a 20 minutos de técnica, de ahí tienes aproximadamente 20 minutos, 25 minutos en los cuales tú vas ejecutando el WOD, que es un entrenamiento del día que es una serie de ejercicios funcionales con peso o sin peso, con una variación de tiempo diferente, nunca se repite la misma rutina y sobre todo y lo más curioso de éste entrenamiento es que al finalizar 
tienes unos 10 o 15 minutos de lo que se llama MOBILITY, es decir el estiramiento, que es la parte fundamental, mucha gente ejecuta diversas actividades, pero se olvida siempre del enfriamiento corporal y entonces ahí vienen las lesiones y todo ello. Otra de las cosas importantes que hace el CrossFit para tratar de atraer a sus consumidores es que te brindan clases de prueba, entonces bajo ésta premisa ¿estarían dispuestos de probar el CrossFit con una o dos clases de prueba? Y ¿qué les parece el tema que se desarrolle en una hora?

YM: Yo considero que sí sería una bonita idea si te van a dar dos días de prueba. Asistir y dependiendo de ello si te gusta, y ver también el tema del entrenador, la persona que va a estar ahí, detrás tuyo, tiene que haber una persona que te esté motivando, más que todo el tema disciplinario.

SP: Sí, si te van a dar una o dos clases está bien, mucho mejor si es una hora, los que tenemos el tiempo es corto para poder hacer cosas que nos gusta, y dedicar una hora para hacer algo que te pueda llegar a gustar, sí lo haría.

IH: Mas por el tiempo, de lo que es una hora, más me parece que es un deporte de resistencia, porque en una hora, porque como le dije, me iba al gimnasio con mi Jefe íbamos 3 horas para hacer solamente 4 máquinas, bicicleta, caminata, un poco de pesas, un poco de barra, en cambio sí me comenta que el CrossFit es un deporte muy dinámico y todo se hace en una hora, creo que dos sesiones de prueba, para ver nuestro rendimiento físico, estamos aptos o no para éste deporte.

AB: En mi caso, de acuerdo a la explicación de Ud. dio, quizá ya haya probado el CrossFit, hubo una vez que me fui a probar a un equipo, exactamente lo que Ud. dijo lo hizo el entrenador, y así seleccionaba a los jugadores que le podían servir.

GC: Claro, sí, el CrossFit también sirve para medir y también es utilizado en muchos deportes,

AB: En cambio hubo otro equipo donde de frente nos mandaba dos horas a correr, y al día siguiente iba la mitad, y nos tenía una hora corriendo más, y eran tres días seguidos, tanto para que solos nos enseñara el dribleo

BA: Yo creo que el caso de una hora está perfecto para las personas que nos estamos acostumbradas a realizar alguna actividad física, y eso del día de prueba también en cuanto a rutina, pero creo que en cuanto a servicio y atención no, porque para que gane el cliente ése día te pueda atender perfectamente, pero nada te garantiza que más adelante te siga atendiendo igual. 
JP: Bueno, sí, de todas maneras, como ya lo dije, me gustaría probarlo, creo que una hora está bien, puedes disponer de ésa hora en el momento que te convenga, no de todas maneras lo haría.

GC: En el caso de Joanna que ya tiene la experiencia.

JM: Si, bueno iría a otro para probar, pero que tengan ésas etapas, principiantes.

GC: Y sobre todo el servicio en tu caso no?

JM: Claro yo ya pasé una experiencia y por eso lo haría.

GC: Nosotros proponemos que éste CrossFit realmente cumpla con los estándares establecidos por la misma compañía CrossFit Inc que es americana, en la cual nosotros buscamos emplear en sí, algo que no tiene todo CrossFit acá, es decir un ambiente amplio, los coaches que estén capacitados y que tengan la certificación misma de CrossFit Inc para éste ejercicio, y sobre todo que esté ubicado en Ate, Uds. qué piensan ¿influiría mucho en ustedes, poder elegir éste Box de CrossFit si cumple con un ambiente amplio, con coaches certificados y que esté en Ate?

YM: Claro sí, implicaría mucho que este en Ate por el tema de que esté cerca a tu casa, casi la mayoría, en cuanto al ambiente, si es como usted dice que es amplio y te ofrence los servicios que acaba de mencionar, no habría ningún problema.

SP: Si el ambiente es amplio y los profesores son buenos, creo que si ah, estoy segura que sí iría.

IH: Claro si está cerca de nuestra casa porque está en el mismo distrito, otro es lo que comenta nuestro compañero Jorge, de que va a haber la progresión de principiantes, intermedios y avanzados y ambiente amplio para cada uno de nosotros.

AB: Yo creo que debería ser un lugar céntrico para atraer más personas, porque si estamos en un límite va a ser imposible venir hasta aca, porque se va a tomar una hora más hasta acá.

GC: En éste caso, sí influiría que esté en Ate.

AB: Si está cerca de mi distrito yo sí estoy de acuerdo, pero si lo que se quiere es atraer gente, se daría para la gente.

BA: Creo que lo principal que esté cerca a tu domicilio, pero también yo elegiría uno que tenga otros locales, porque de repente en alguna ocasión yo estoy en otro distrito por algún motivo y no pierdo mi clase si no puedo ir.

GC: Una especie de convenio con otros CrossFit, digamos que tu trabajo está en Miraflores.

BA: Si sales tarde, ya no llegas 
JP: Ya lo había mencionado que la cercanía es importante, la comodidad la limpieza creo que son requisitos mínimos que deben brindarse.

JM: Si definitivamente cerca a tu casa.

AP: Más que cerca a tu trabajo probablemente

JM: No, tiene que ser cerca a mi casa, es más cómodo, llegas a tu casa, sales con tranquilidad, no sales corriendo y llegas también a tu casa a descansar.

GC: Bien, hemos concluido con éste focus group, les agradecemos su participación y por las respuestas tan sinceras y claras y mi compañero

AP: Solamente aunarme a tu agradecimiento y nada más. Gracias! 


\section{Apéndice 13: Resumen de Entrevistas a Profundidad}

\begin{tabular}{lccc}
\hline Entrevista & Entrevistado & Profesión & Ubicación \\
\hline E 1 & Alfonso Uribe & Médico & Apéndice 15 \\
E2 & Pamela Chunga & Estudiante universitaria & Apéndice 16 \\
E3 & Nicolay Patiño & Médico & Apéndice 17 \\
E4 & Carlos Villalobos & Administrador & Apéndice 18 \\
\hline
\end{tabular}

\begin{tabular}{lc}
\hline Objetivos & Preguntas \\
\hline Perfil del entrevistado & $1,2,3$ y 4 \\
Obesidad como problema de salud pública & $5,6,7,8,9$ y 10 \\
Conocimiento del CrossFit & 11 y 12 \\
Motivos por el cual practican CrossFit & 14 y 15 \\
Experiencia practicando CrossFit & 16,17 y 18, \\
CrossFit para combatir la obesidad & 25 \\
Nivel de satisfacción del servicio de su box de CrossFit & $27,32,33$ y 34 \\
Pago del servicio & 28 y 29 \\
Influencia de la comunidad CrossFit & $37,38,39$ y 40 \\
Aceptación de aperturar un box de CrossFit en Ate & 42 \\
\hline
\end{tabular}




\section{Apéndice 14: Esquema de Entrevista a Profundidad}

Entrevistador:

Fecha:

Entrevistado:

Introducción

Buenos días/tardes, mi nombre es Giancarlo Renán Chávez Suárez y junto a mi compañero Arturo Palomino Mendiolaza, estamos realizando un estudio sobre un plan de Negocio para combatir la obesidad en el distrito de Ate mediante un modelo de negocio "CrossFit" para obtener nuestro Grado de Magister en Ciencias Empresariales de la USIL.

Por tal motivo, el día de hoy le realizamos esta entrevista a profundidad y quiero agradecerle por el tiempo que nos está brindando- En este sentido, siéntase libre de compartir sus ideas. Aquí no hay respuestas correctas o incorrectas, lo que importa es su opinión sincera, ya que la información que usted nos otorgue será únicamente materia para la presente investigación, al igual que otras opiniones.

Para agilizar la toma de la información, resulta de mucha utilidad grabar la conversación. Tomar notas a mano, demoraría y se podría perder cuestiones importantes. Asimismo, le recordamos que la información es estrictamente confidencial.

Ante ello, ¿Existe algún inconveniente en que grabemos la conversación?

¡Desde ya muchas gracias!

\section{OBJETIVO DEL ESTUDIO}

Investigar si el CrossFit es una alternativa idónea para combatir la obesidad.

\section{PREGUNTAS}

A. Conociendo al entrevistado (5 min.)

1. Cuéntanos un poco de ti, ¿Cómo te llamas?, ¿Cuántos años tienes? ¿a qué te dedicas? ¿En qué distrito vives?

2. Actualmente, ¿Cuál es tu centro de labores?

3. ¿Cuánto tiempo llevas ahí?

4. ¿Y cómo te nació la vocación por servir a la sociedad?

\section{B. Conocimiento sobre la obesidad}

5. Situándonos en el objetivo de estudio que planteamos; hablemos un poco de la obesidad, ¿Qué opinas sobre el crecimiento de la obesidad en los últimos años a nivel mundial?

6. Y en cuanto al Perú, ¿Cómo ves el panorama de nuestro país ante dicha enfermedad?

7. ¿Consideras que la obesidad es un problema de Salud Pública en nuestro país? ¿Por qué crees ello?

8. A criterio personal ¿Qué factores consideras que influyen en la obesidad?

9. Si tuvieras que pensar en alguna solución para contrarrestar esta enfermedad, ¿Cómo combatirías la obesidad?

10. Consideras que estás en un buen estado físico? ¿Por qué?

\section{Del CrossFit}

11. Si yo le digo CrossFit ¿Qué es lo primero que se le viene a la mente?

12. ¿Cuánto tiempo llevas practicando el CrossFit? Y ¿Cómo lo descubriste?

13. ¿Dónde practicas el CrossFit?

14. ¿Por qué decidiste practicar el CrossFit?

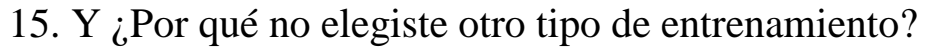


16. Ahora, cuéntanos un poco sobre tu experiencia con el CrossFit ¿Qué es lo que más te gusta del CrossFit?

17. Y ¿Lo que más odias?

18. ¿Qué opinas de la estructura del entrenamiento?

19. ¿Cómo te sentiste luego de tu primera clase de prueba?

20. Hasta la actualidad, ¿Qué tal ha sido tu progreso?

21. ¿Qué deseas lograr con el CrossFit?

22. ¿Has participado en alguna competencia?

Si la respuesta es no preguntar: ¿Te animarías más adelante a participar?

23. A parte del entrenamiento, ¿sigues una dieta?

24. En comparación a otros tipos de entrenamiento, ¿consideras que el CrossFit es mejor que estas? ¿Por qué?

25. Y en cuanto a la obesidad, ¿Consideras que el CrossFit es un buen mecanismo para combatirla?

\section{Del servicio}

26. ¿Qué factores consideraste como atractivos al momento de elegir el Box de CrossFit donde entrenas?

27. ¿Qué tal es el servicio? ¿consideras que hay relación entre el precio y la calidad?

28. ¿A cuanto asciende el precio que pagaste por la membresía?

29. ¿Tuviste alguna promoción?

30. ¿Has presentado algún inconveniente?

31. Si la respuesta fue si, ¿Qué tipo de reclamo hiciste?,¿Qué acciones ejecutaron como solución a tu reclamo?

32. ¿Qué tan satisfecho te encuentras con el servicio brindado?

33. ¿Qué cambiarias del box de CrossFit?

34. A nivel personal ¿Qué recomendaciones darías para mejorar el servicio que te ofrecen?

35. ¿Qué medio de comunicación utilizan en el Box para dar a conocer las noticias, eventos, promociones y programación de los WODS?

36. ¿Te parece muy bueno ese medio de comunicación? o ¿te gustaría que hubiera otro? ¿Cuál?

E. De la Comunidad CrossFit

37. ¿Qué te parece la comunidad Crossfitera?

38. En tu Box de CrossFit, ¿impulsan dicha comunidad?

39. ¿Consideras importante la confraternidad de la comunidad CrossFit para tomar la decisión de practicar el CrossFit?

40. ¿Te gustaría que tu box, proponga eventos de integración para la comunidad Crossfitera? ¿Por qué?

F. Cierre

41. Ahora bien, para terminar ¿Recomendarías el CrossFit a aquellas personas que no lo han probado?

42. ¿Qué opinas de la apertura de un Box de CrossFit en un distrito que cuenta con un porcentaje alto de obesidad y sobrepeso?

43. Finalmente, ¿Algún otro comentario que desees agregar?

Firma del entrevistado 


\section{Apéndice 15: Entrevista a Profundidad Alfonso Uribe León}

Entrevistador: Giancarlo Renán Chávez Suárez

Fecha: $19 / 4 / 2018$

Entrevistado: Alfonso Uribe León

Introducción

Buenos días/tardes, mi nombre es Giancarlo Renán Chávez Suárez y junto a mi compañero Arturo Palomino Mendiolaza, estamos realizando un estudio sobre un plan de Negocio para combatir la obesidad en el distrito de Ate mediante un modelo de negocio "CrossFit" para obtener nuestro Grado de Magister en Ciencias Empresariales de la USIL.

Por tal motivo, el día de hoy le realizamos esta entrevista a profundidad y quiero agradecerle por el tiempo que nos está brindando- En este sentido, siéntase libre de compartir sus ideas. Aquí no hay respuestas correctas o incorrectas, lo que importa es su opinión sincera, ya que la información que usted nos otorgue será únicamente materia para la presente investigación, al igual que otras opiniones.

Para agilizar la toma de la información, resulta de mucha utilidad grabar la conversación. Tomar notas a mano, demoraría y se podría perder cuestiones importantes. Asimismo, le recordamos que la información es estrictamente confidencial.

Ante ello, ¿Existe algún inconveniente en que grabemos la conversación?

Entrevistado: No, ninguna

¡Desde ya muchas gracias!

OBJETIVO DEL ESTUDIO

Investigar si el CrossFit es una alternativa idónea para combatir la obesidad.

\section{PREGUNTAS}

A. Conociendo al entrevistado (5 min.)

1. Cuéntanos un poco de ti, ¿Cómo te llamas?, ¿Cuántos años tienes? ¿a qué te dedicas? ¿En qué distrito vives?

Bueno, mi nombre es Alfonso Enrique Uribe León, tengo 25 años de edad y vivo en el distrito de Ate, soy médico y bombero voluntario de profesión, también tengo una pequeña empresa.

2. Actualmente, ¿Cuál es tu centro de labores?

Tengo una empresa propia.

3. ¿Cuánto tiempo llevas ahí?

Unos 5 años.

4. ¿Y cómo te nació la vocación por servir a la sociedad?

Eh, bueno si, la verdad es algo que he mantenido desde muy pequeño de repente por el mismo hecho de que mi familia está dedicada al área de la salud; entonces derrepente algunos valores han ido calando en mi desde muy pequeño.

\section{B. Conocimiento sobre la obesidad}

5. Situándonos en el objetivo de estudio que planteamos; hablemos un poco de la obesidad, ¿Qué opinas sobre el crecimiento de la obesidad en los últimos años a nivel mundial?

Sinceramente es algo alarmante porque va en aumento y no solo es la obesidad en si; sino lo que conlleva. Lo cual puede llevar a enfermedades cardiovacuslares y diabetes; es por ello que, es importante tratarlo.

6. Y en cuanto al Perú, ¿Cómo ves el panorama de nuestro país ante dicha enfermedad? 
Sí, sin duda el Perú no escapa de las estadísticas mundiales. Es por ello que debe tratarse a tiempo.

7. ¿Consideras que la obesidad es un problema de Salud Pública en nuestro país? ¿Por qué crees ello?

Si Claro que si es un problema de salud pública. Y como lo había mencionado, es importante ver los riesgos que puede ocasionar la obesidad.

8. A criterio personal ¿Qué factores consideras que influyen en la obesidad?

Básicamente, el sedentarismo, la vida cotidiana que lleva cada persona, en la cual no se encuentra mucho el ejercicio y creo que es eso básicamente.

9. Si tuvieras que pensar en alguna solución para contrarrestar esta enfermedad, ¿Cómo combatirías la obesidad?

Básicamente, el ejercicio físico y unos buenos hábitos alimenticios.

10. Consideras que estás en un buen estado físico? ¿Por qué?

Actualmente, sí. Si me considero que estoy en un buen estado físico.

\section{Del CrossFit}

11. Si yo le digo CrossFit ¿Qué es lo primero que se le viene a la mente? Disciplina.

12. ¿Cuánto tiempo llevas practicando el CrossFit? Y ¿Cómo lo descubriste?

Tres meses. Eh, me lo recomendaron. Si fue algo como que, divertido, misterioso, siempre cuando uno inicia algo nuevo, se pone un poco nervioso; pero, una vez que lo conoces, te acostumbras, entonces tienes una nueva disciplina, te haces un nuevo ritmo de vida y sinceramente te ayuda bastante.

13. ¿Dónde practicas el CrossFit?

En Legado CrossFit.

14. ¿Por qué decidiste practicar el CrossFit?

Sí, básicamente lo hice por dos cosas. Una cosa fue, poder desarrollar mejor mi trabajo como bombero, porque sé que me va ayudar bastante en el aspecto físico y rendimiento ante una emergencia, y otra cosa por la cual lo hice fue por salud.

15. Y ¿Por qué no elegiste otro tipo de entrenamiento?

Creo que el CrossFit es un poco más intenso a diferencia de otros entrenamientos. Creo que también hay bastante motivación de los coaches y el mismo equipo que trabaja contigo, y eso sin duda es algo diferente que no se ve en un gimnasio ni en otros tipos de actividades.

16. Ahora, cuéntanos un poco sobre tu experiencia con el CrossFit ¿Qué es lo que más te gusta del CrossFit?

Eh, me gusta como te había mencionado hace rato, la motivación; porque, te ayuda a dar lo máximo de ti. Cuando alguien te está motivando, no solamente tu coach, sino también amigos, te puede ayudar a dar lo mejor de ti.

17. Y ¿Lo que más odias?

Lo cansado que te deja, cuando ya puedes más debes de continuar; ósea, es lo mas fregado pero a su vez lo más bonito también.

18. ¿Qué opinas de la estructura del entrenamiento?

Me parece que está bien desarrollada, porque al principio siempre se preocupan por calentar y al final estirar, y ello previene las lesiones. También te enseñan la técnica de los ejercicios que es básico y fundamental, para que uno pueda desarrollarlos bien y no lesionarse, y después ya viene la parte intensa, la parte del WOD; por ello, me parece que la estructura está bien hecha.

19. ¿Cómo te sentiste luego de tu primera clase de prueba? 
Destrozado totalmente; pero, si como que te dices, no puedo con esto; pero, tienes que seguir nomás adelante.

20. Hasta la actualidad, ¿Qué tal ha sido tu progreso?

La verdad que me sorprende bastante porque uno va notando que va cargando más peso, que va teniendo más resistencia, que puede correr un poco más y eso también lo motiva a uno mismo, porque dices que sí, si está funcionando y siguen adelante.

21. ¿Qué deseas lograr con el CrossFit?

Superar mis límites y mejorar mis capacidades físicas.

22. ¿Has participado en alguna competencia?

No aún no he tenido la oportunidad pero si me gustaría participar en una.

Si la respuesta es no preguntar: ¿Te animarías más adelante a participar?

23. A parte del entrenamiento, ¿sigues una dieta?

No, mi dieta no es muy estricta. Si de todas maneras influye tener una alimentación sana para ayudarte a tener más energía tanto en el momento en que haces el ejercicio físico como durante el día. Mi dieta no es muy exigente, básicamente hay una restricción de carbohidratos, eh y si consumo un poco más de proteínas y vitaminas, tengo un suplemento energético que consumo, pero no es tan estricta.

24. En comparación a otros tipos de entrenamiento, ¿consideras que el CrossFit es mejor que estas? ¿Por qué?

$\mathrm{Si}$, claro. En los aspectos en cargar peso el CrossFit es más exigente.

25. Y en cuanto a la obesidad, ¿Consideras que el CrossFit es un buen mecanismo para combatirla?

Claro que si, porque uno que emplea bastante el cardio, nos va ayudar bastante en el progreso; asimismo los ejercicios localizados.

\section{Del servicio}

26. ¿Qué factores consideraste como atractivos al momento de elegir el Box de CrossFit donde entrenas?

Básicamente la cercanía a donde vivo.

27. ¿Qué tal es el servicio? ¿consideras que hay relación entre el precio y la calidad?

La calidad es muy buena y la atención que tienen los coach y todas las personas que trabajan en el lugar es muy amable.

28. ¿A cuanto asciende el precio que pagaste por la membresía?

Bueno, al ser bombero no pagamos.

29. ¿Tuviste alguna promoción?

Si la que viene por ser bombero; lo cual, es sinceramente un apoyo muy grande al cuerpo general de bomberos y definitivamente es algo que influencio en mi decisión de elegir este box.

30. ¿Has presentado algún inconveniente?

Por el momento no.

31. Si la respuesta fue si, ¿Qué tipo de reclamo hiciste?,¿Qué acciones ejecutaron como solución a tu reclamo?

Se pasó a la pregunta 32.

32. ¿Qué tan satisfecho te encuentras con el servicio brindado?

Satisfecho.

33. ¿Qué cambiarias del box de CrossFit?

No le haría muchos cambios. Creo que los equipos son los necesarios.

34. A nivel personal ¿Qué recomendaciones darías para mejorar el servicio que te ofrecen?

La verdad que ninguno por el momento. 
35. ¿Qué medio de comunicación utilizan en el Box para dar a conocer las noticias, eventos, promociones y programación de los WODS?

Básicamente las redes sociales, a través de grupos internos.

36. ¿Te parece muy bueno ese medio de comunicación? o ¿te gustaría que hubiera otro? ¿Cuál?

Me parece perfecto, porque es algo que nosotros estamos en constante uso, es algo práctico y la comunicación es mucho más rápida y efectiva.

E. De la Comunidad CrossFit

37. ¿Qué te parece la comunidad Crossfitera?

Me parece muy amigable, muy buena onda, con muchas buena vibras, con mucha gente que quiere hacer bastante cosas en su vida y bien disciplinados.

38. En tu Box de CrossFit, ¿impulsan dicha comunidad?

Sí, claro que si.

39. ¿Consideras importante la confraternidad de la comunidad CrossFit para tomar la decisión de practicar el CrossFit?

Es básico, es básico que ellos estén siempre en constante comunicación con uno, obteniendo un feedback para mejorar.

40. ¿Te gustaría que tu box, proponga eventos de integración para la comunidad Crossfitera? ¿Por qué?

Sí, me parecería interesante como para mantener en unión al grupo. Ehh, tengo entendido que participan en campeonatos, de repente no son tan continuos, pero si los hacen.

F. Cierre

41. Ahora bien, para terminar ¿Recomendarías el CrossFit a aquellas personas que no lo han probado?

Sin duda alguna lo recomendaría, va ayudar bastante, no solo en el aspecto físico; sino también, en la salud y lo va ayudar en la vida porque el CrossFit es una disciplina que te ayuda estar más ordenado y te va ayudar en todo sentido.

42. ¿Qué opinas de la apertura de un Box de CrossFit en un distrito que cuenta con un porcentaje alto de obesidad y sobrepeso como Ate?

Me parece perfecta la idea. Mientras más se pueda distribuir este gran deporte, esta gran disciplina que es el CrossFit, va servir de mucha ayuda a las personas con obesidad.

43. Finalmente, ¿Algún otro comentario que desees agregar?

No, más que todo agradecer la entrevista y por ayudar a que se cumpla este proyecto de investigación y que se siga difundiendo mucho más el CrossFit, porque es de gran ayuda para combatir la obesidad.

Muchas gracias. 


\section{Apéndice 16: Entrevista a Profundidad Pamela Chunga Seminario}

Entrevistador: Giancarlo Renán Chávez Suárez

Fecha: 19/4/2018

Entrevistado: Pamela Chunga Seminario

Introducción

Buenos días/tardes, mi nombre es Giancarlo Renán Chávez Suárez y junto a mi compañero Arturo Palomino Mendiolaza, estamos realizando un estudio sobre un plan de Negocio para combatir la obesidad en el distrito de Ate mediante un modelo de negocio "CrossFit" para obtener nuestro Grado de Magister en Ciencias Empresariales de la USIL.

Por tal motivo, el día de hoy le realizamos esta entrevista a profundidad y quiero agradecerle por el tiempo que nos está brindando- En este sentido, siéntase libre de compartir sus ideas. Aquí no hay respuestas correctas o incorrectas, lo que importa es su opinión sincera, ya que la información que usted nos otorgue será únicamente materia para la presente investigación, al igual que otras opiniones.

Para agilizar la toma de la información, resulta de mucha utilidad grabar la conversación. Tomar notas a mano, demoraría y se podría perder cuestiones importantes. Asimismo, le recordamos que la información es estrictamente confidencial.

Ante ello, ¿Existe algún inconveniente en que grabemos la conversación?

Entrevistada: No, no tengo ningún problema.

¡Desde ya muchas gracias!

OBJETIVO DEL ESTUDIO

Investigar si el CrossFit es una alternativa idónea para combatir la obesidad.

\section{PREGUNTAS}

A. Conociendo al entrevistado ( $5 \mathrm{~min}$.)

1. Cuéntanos un poco de ti, ¿Cómo te llamas?, ¿Cuántos años tienes? ¿a qué te dedicas? ¿En qué distrito vives?

Me llamo Pamela Chunga Seminario, tengo 24 años, estudio psicología y trabajo en una ONG y vivo en Ate.

2. Actualmente, ¿Cuál es tu centro de labores?

En la casa Ronald Mc Donald.

3. ¿Cuánto tiempo llevas ahí?

Un año y dos meses.

4. ¿Y cómo te nació la vocación por servir a la sociedad?

La vocación de servicio, me nació desde muy pequeño. En realidad siempre me ha gustado hacer obras sociales. Incluso postulé a la compañía de bomberos de La Molina y en realidad en mi trabajo veo ahora mucho el tema de labor social porque comparto con muchas familias de extrema pobreza; ellas vienen a Lima y se hospedan en la casa Ronald Mc Donald porque sus hijos tienen enfermedades complejas y reciben tratamiento médico en Lima.

B. Conocimiento sobre la obesidad

5. Situándonos en el objetivo de estudio que planteamos; hablemos un poco de la obesidad, ¿Qué opinas sobre el crecimiento de la obesidad en los últimos años a nivel mundial?

EH, bueno hace dos años viaje a Estados Unidos y obviamente comparando nuestro país con Estados Unidos, hay mucha diferencia porque allá la comida chatarra abunda y es más barata. El tiempo que tienen de trabajo a casa es muy 
reducido; entonces, tienen que parar en comidas rápidas para poder alimentarse más rápido que de hecho es mucho más económico.

6. Y en cuanto al Perú, ¿Cómo ves el panorama de nuestro país ante dicha enfermedad? En los últimos años, si veo casos de personas que no cuidan su alimentación.

7. ¿Consideras que la obesidad es un problema de Salud Pública en nuestro país? ¿Por qué crees ello?

Sí, debido a que no hay participación del estado para el control de ello.

8. A criterio personal ¿Qué factores consideras que influyen en la obesidad?

Falta de ejercicio, la comida chatarra y los medios televisivos.

9. Si tuvieras que pensar en alguna solución para contrarrestar esta enfermedad, ¿Cómo combatirías la obesidad?

Podría realizar campañas gratuitas en parques o ambientes amplios y que sean gratuitos para aquellas personas que realmente quieran cambiar su estilo de vida y aumentaría la cantidad de restaurantes.

10. Consideras que estás en un buen estado físico? ¿Por qué?

$\mathrm{Si}$, ya que entreno todos los días y llevo una dieta equilibrada.

C. Del CrossFit

11. Si yo le digo CrossFit ¿Qué es lo primero que se le viene a la mente? Competencia.

12. ¿Cuánto tiempo llevas practicando el CrossFit? Y ¿Cómo lo descubriste? Llevo practicando CrossFit un año y lo descubrí cuando estaba entrenando para ser bombero, unos bomberos voluntarios practicaban CrossFit y llevaron a la bomba este deporte y nos enseñaron técnicas sobre como poder cargar a las personas haciendo peso muerto.

13. ¿Dónde practicas el CrossFit?

En Legado CrossFit.

14. ¿Por qué decidiste practicar el CrossFit?

Porque me parece divertido y porque se acomoda muy bien a mis horarios de trabajo y universidad.

15. Y ¿Por qué no elegiste otro tipo de entrenamiento?

Porque no me parecían completos.

16. Ahora, cuéntanos un poco sobre tu experiencia con el CrossFit ¿Qué es lo que más te gusta del CrossFit?

Me gusta porque no hay límites .

17. Y ¿Lo que más odias?

Las pesas.

18. ¿Qué opinas de la estructura del entrenamiento?

Me parece que está bien organizado porque si no estiras, te puedes lesionar. Si no sigues cada una de las pautas indicadas, puede que generes un problema en los WOD.

19. ¿Cómo te sentiste luego de tu primera clase de prueba?

Bien, en sí la primera clase que hice en Legado, no era mi primera clase de prueba; sino que ya antes en la compañía de bomberos habíamos realizado un WOD. En si, mi primera clase me pareció muy buena.

20. Hasta la actualidad, ¿Qué tal ha sido tu progreso?

He cambiado mi estilo de vida.

21. ¿Qué deseas lograr con el CrossFit?

Quisiera competir.

22. ¿Has participado en alguna competencia?

Si la respuesta es no preguntar: ¿Te animarías más adelante a participar?

No he participado, pero me gustaría mucho entrar a una competencia interna primero. 
23. A parte del entrenamiento, ¿sigues una dieta?

No en realidad. Solamente sigo mi alimentación normal.

24. En comparación a otros tipos de entrenamiento, ¿consideras que el CrossFit es mejor que estas? ¿Por qué?

Sería difícil determinarlo, todo depende de intentarlo; en mi caso, la experiencia de haber intentado antes el CrossFit, me sirvió para elegirlo como entrenamiento.

25. Y en cuanto a la obesidad, ¿Consideras que el CrossFit es un buen mecanismo para combatirla?

Sí porque de hecho no solo es entrenamiento; sino también es el ambiente dentro del cuál se realiza dicha actividad que más que nada puedes compartir con otras personas con quienes puedes tener ideas similares.

\section{Del servicio}

26. ¿Qué factores consideraste como atractivos al momento de elegir el Box de CrossFit donde entrenas?

El ambiente y la ubicación a la universidad.

27. ¿Qué tal es el servicio? ¿consideras que hay relación entre el precio y la calidad? Si todo es bastante similar.

28. ¿A cuanto asciende el precio que pagaste por la membresía?

300 soles por promoción y tiempo.

29. ¿Tuviste alguna promoción?

Si la de estudiante

30. ¿Has presentado algún inconveniente?

Si.

31. Si la respuesta fue si, ¿Qué tipo de reclamo hiciste?,¿Qué acciones ejecutaron como solución a tu reclamo?

El coach llegó demasiado tarde, es decir, yo sólo puedo entrenar de 6 a.m. a 7 a.m. y el Coach llegó 6:40 a.m. y obviamente no pude entrenar, y luego también los baños que no estaban tan limpios. Legado CrossFit dio como solución otorgarme días gratis de membresía.

32. ¿Qué tan satisfecho te encuentras con el servicio brindado?

Bien.

33. ¿Qué cambiarias del box de CrossFit?

Crearía o añadiría áreas verdes.

34. A nivel personal ¿Qué recomendaciones darías para mejorar el servicio que te ofrecen?

Mejorar los temas de puntualidad y aseo.

35. ¿Qué medio de comunicación utilizan en el Box para dar a conocer las noticias, eventos, promociones y programación de los WODS?

Por Facebook.

36. ¿Te parece muy bueno ese medio de comunicación? o ¿te gustaría que hubiera otro? ¿Cuál?

Ehmmm, creo que ahora más que Facebook, se utiliza mucho Instagram y ahí podrían promocionar más cosas del box.

E. De la Comunidad CrossFit

37. ¿Qué te parece la comunidad Crossfitera?

Es regular, de hecho llega mucha gente y ahí recién se conocen. No es que hagan un grupo aparte, sino que siento que no hacen muchos programas de integración.

38. En tu Box de CrossFit, ¿impulsan dicha comunidad?

No. 
39. ¿Consideras importante la confraternidad de la comunidad CrossFit para tomar la decisión de practicar el CrossFit?

$\mathrm{Si}$.

40. ¿Te gustaría que tu box, proponga eventos de integración para la comunidad Crossfitera? ¿Por qué?

Sí sería bueno.

\section{F. Cierre}

41. Ahora bien, para terminar ¿Recomendarías el CrossFit a aquellas personas que no lo han probado?

Sí al cien porciento.

42. ¿Qué opinas de la apertura de un Box de CrossFit en un distrito que cuenta con un porcentaje alto de obesidad y sobrepeso?

Ayudaría mucho en reducir este problema social.

43. Finalmente, ¿Algún otro comentario que desees agregar?

Eh sí, que la gente se anime a probar el CrossFit y que cambien su estilo de vida; de hecho, eso les va ayudar a sentirse mejor cuando se levantan, cuando se acuestan, y de repente si tienen algún problema de autoestima, el CrossFit les va ayudar mucho.

Entrevistador: Muchas gracias.

Entrevistada: De Nada.

Firma del entrevistado 


\section{Apéndice 17: Entrevista a Profundidad Nicolay Patiño}

Entrevistador: Giancarlo Renán Chávez Suárez

Fecha: $20 / 4 / 2018$

Entrevistado: Nicolay Patiño Sedano

Introducción

Buenos días/tardes, mi nombre es Giancarlo Renán Chávez Suárez y junto a mi compañero Arturo Palomino Mendiolaza, estamos realizando un estudio sobre un plan de Negocio para combatir la obesidad en el distrito de Ate mediante un modelo de negocio "CrossFit" para obtener nuestro Grado de Magister en Ciencias Empresariales de la USIL.

Por tal motivo, el día de hoy le realizamos esta entrevista a profundidad y quiero agradecerle por el tiempo que nos está brindando- En este sentido, siéntase libre de compartir sus ideas. Aquí no hay respuestas correctas o incorrectas, lo que importa es su opinión sincera, ya que la información que usted nos otorgue será únicamente materia para la presente investigación, al igual que otras opiniones.

Para agilizar la toma de la información, resulta de mucha utilidad grabar la conversación. Tomar notas a mano, demoraría y se podría perder cuestiones importantes. Asimismo, le recordamos que la información es estrictamente confidencial.

Ante ello, ¿Existe algún inconveniente en que grabemos la conversación?

¡Desde ya muchas gracias!

\section{OBJETIVO DEL ESTUDIO}

Investigar si el CrossFit es una alternativa idónea para combatir la obesidad.

\section{PREGUNTAS}

A. Conociendo al entrevistado (5 min.)

1. Cuéntanos un poco de ti, ¿Cómo te llamas?, ¿Cuántos años tienes? ¿a qué te dedicas? ¿En qué distrito vives?

Hola, soy Nicolay Patiño, tengo 27 años, soy médico y bombero voluntario, y vivo en el distrito de Ate.

2. Actualmente, ¿Cuál es tu centro de labores?

Como médico en el hospital Centro Médico Naval y como bombero en la compañía de La Molina.

3. ¿Cuánto tiempo llevas ahí?

En el hospital llevo 3 años y en la compañía unos 5 .

4. ¿Y cómo te nació la vocación por servir a la sociedad?

Bueno, en sí fue porque la misma carrera de medicina te exigía el contacto humano; entonces, poco a poco me fui dando cuenta que el grupo de bomberos necesita muchas manos para los grandes incendios y es por ello que contribuyo con un granito de arena.

\section{B. Conocimiento sobre la obesidad}

5. Situándonos en el objetivo de estudio que planteamos; hablemos un poco de la obesidad, ¿Qué opinas sobre el crecimiento de la obesidad en los últimos años a nivel mundial?

Es impresionante. Las cifras se han elevado demasiado. Hoy en día es común ver a niños con obesidad mórbida.

6. Y en cuanto al Perú, ¿Cómo ves el panorama de nuestro país ante dicha enfermedad? 
Está impactando muy fuerte. Si no se toman las medidas del caso correspondientes, en pocos años seremos como Estados Unidos, un país con mucha gente con sobrepeso y obesidad a temprana edad.

7. ¿Consideras que la obesidad es un problema de Salud Pública en nuestro país? ¿Por qué crees ello?

Sí, debido a que las entidades que forman parte del cuidado y bienestar social no están ejecutando políticas públicas pertinentes para el cuidado de la misma.

8. A criterio personal ¿Qué factores consideras que influyen en la obesidad?

Bueno, podemos iniciar con la mala alimentación, la escaza regulación sobre la comida chatarra, el sedentarismo, la sobrecarga laboral, entre otros.

9. Si tuvieras que pensar en alguna solución para contrarrestar esta enfermedad, ¿Cómo combatirías la obesidad?

Impulsaría el control de la comida chatarra.

10. Consideras que estás en un buen estado físico? ¿Por qué?

No, aún no lo estoy. Yo he sido una persona con sobrepeso y me está costando bajar.

\section{Del CrossFit}

11. Si yo le digo CrossFit ¿Qué es lo primero que se le viene a la mente? Estado fitness.

12. ¿Cuánto tiempo llevas practicando el CrossFit? Y ¿Cómo lo descubriste? Recién voy un año. Lo descubrí por un amigo, quién me había hablado del CrossFit y de cómo había sido su evolución.

13. ¿Dónde practicas el CrossFit?

En Legado CrossFit.

14. ¿Por qué decidiste practicar el CrossFit?

Para mejorar mi estado físico y la salud.

15. Y ¿Por qué no elegiste otro tipo de entrenamiento?

El CrossFit es mucho más completo. Además, posee una metodología que otros entrenamientos no cuentan.

16. Ahora, cuéntanos un poco sobre tu experiencia con el CrossFit ¿Qué es lo que más te gusta del CrossFit?

La práctica con peso muerto.

17. Y ¿Lo que más odias?

Cuando hacemos cardio y burpees.

18. ¿Qué opinas de la estructura del entrenamiento?

Esta bien estructurada. Iniciar con un pequeño calentamiento, seguido de las técnicas y luego pasar al entrenamiento duro es muy agradable. A ello, le sumas los minutos de estiramiento y quedas como nuevo.

19. ¿Cómo te sentiste luego de tu primera clase de prueba? Sin fuerzas para seguir.

20. Hasta la actualidad, ¿Qué tal ha sido tu progreso?

Ha sido muy bueno, he disminuido mi porcentaje de grasa y he aumentado mis capacidades físicas.

21. ¿Qué deseas lograr con el CrossFit?

Mejorar mi estado física y alcanzar un nivel fitness.

22. ¿Has participado en alguna competencia?

Si la respuesta es no preguntar: ¿Te animarías más adelante a participar?

No, aún no he tenido la oportunidad de participar en una competencia. Pero si me gustaría competir pronto.

23. A parte del entrenamiento, ¿sigues una dieta? 
Sí. La nutricionista del Box de CrossFit, nos hace una dieta personalizada.

24. En comparación a otros tipos de entrenamiento, ¿consideras que el CrossFit es mejor que estas? ¿Por qué?

Por supuesto, el CrossFit es más completo que otros tipos de entrenamiento.

25. Y en cuanto a la obesidad, ¿Consideras que el CrossFit es un buen mecanismo para combatirla?

Sí, si yo he perdido muchos kilos de grasa, imagínate una persona que sufra de obesidad.

D. Del servicio

26. ¿Qué factores consideraste como atractivos al momento de elegir el Box de CrossFit donde entrenas?

La promoción para bomberos y la infraestructura.

27. ¿Qué tal es el servicio? ¿consideras que hay relación entre el precio y la calidad? Sí, a decir verdad, he visto que los Coach buscan hacer un buen trabajo con cada alumno.

28. ¿A cuanto asciende el precio que pagaste por la membresía?

En mi caso, por ser bombero voluntario, no realizo pago alguno. Sin embargo, la tarifa oscila entre 320 a 340 mensual.

29. ¿Tuviste alguna promoción?

Sí la Promoción Bomberos.

30. ¿Has presentado algún inconveniente?

Por el momento no.

31. Si la respuesta fue si, ¿Qué tipo de reclamo hiciste?,¿Qué acciones ejecutaron como solución a tu reclamo?

32. ¿Qué tan satisfecho te encuentras con el servicio brindado?

Satisfecho.

33. ¿Qué cambiarias del box de CrossFit?

Bueno, cambiaría un poco el espacio para los entrenamientos; puesto que, suelen ocuparse por alumnos que sólo hacen técnica.

34. A nivel personal ¿Qué recomendaciones darías para mejorar el servicio que te ofrecen?

Que inviertan en organizadores de equipos.

35. ¿Qué medio de comunicación utilizan en el Box para dar a conocer las noticias, eventos, promociones y programación de los WODS?

Utilizan mucho el Facebook.

36. ¿Te parece muy bueno ese medio de comunicación? o ¿te gustaría que hubiera otro? ¿Cuál?

La verdad si me gustaría que hubiese otro. Uno donde puedas abastecerte de la información del Wod, así como del control progresivo de tus objetivos.

E. De la Comunidad CrossFit

37. ¿Qué te parece la comunidad Crossfitera?

Es buena si se le da el impulso correspondiente.

38. En tu Box de CrossFit, ¿impulsan dicha comunidad?

No tanto, sólo para ciertos eventos. Por lo general, se reúne la gente de un par de turnos o que son muy amigos con los Coach

39. ¿Consideras importante la confraternidad de la comunidad CrossFit para tomar la decisión de practicar el CrossFit?

Por supuesto, sin comunidad todo sería muy aburrido. Sería como ir a un gimnasio.

40. ¿Te gustaría que tu box, proponga eventos de integración para la comunidad Crossfitera? ¿Por qué? 
Sí, debido a que hay muchas personas que estamos en el mismo horario, pero que sólo nos saludamos por el simple hecho de vernos. Más allá, no hay un intercambio de palabras.

F. Cierre

41. Ahora bien, para terminar ¿Recomendarías el CrossFit a aquellas personas que no lo han probado?

Por supuesto, siempre es bueno probar algo nuevo. Más aún este deporte. Una vez que le coges el gusto, es muy difícil de parar.

42. ¿Qué opinas de la apertura de un Box de CrossFit en un distrito que cuenta con un porcentaje alto de obesidad y sobrepeso?

A decir verdad, sería un buen negocio; ya que, el CrossFit siempre pega. Vayas a donde vayas, ya hay gente que habla de él, pero aún no lo han probado. En mi caso, cuando escuché de él, no podía asistir a un box que estuviese cerca de mi casa, porque no lo hay. Si vengo a Legado es porque está en la ruta hacia la compañía de bomberos. A Ate le falta un buen box de CrossFit.

43. Finalmente, ¿Algún otro comentario que desees agregar?

Bueno, sólo agradecerte por haberme invitado a esta entrevista y espero que puedan aperturar un box de CrossFit por Ate.

Entrevistador: Muchas gracias

Entrevistado: De nada.

Firma del entrevistado 


\section{Apéndice 18: Entrevista a Profundidad Carlos Villalobos}

Entrevista a profundidad Carlos Villalobos

Entrevistador: Giancarlo Renán Chávez Suárez

Fecha: 20/4/2018

Entrevistado: Carlos Villalobos

Introducción

Buenos días/tardes, mi nombre es Giancarlo Renán Chávez Suárez y junto a mi compañero Arturo Palomino Mendiolaza, estamos realizando un estudio sobre un plan de Negocio para combatir la obesidad en el distrito de Ate mediante un modelo de negocio "CrossFit" para obtener nuestro Grado de Magister en Ciencias Empresariales de la USIL.

Por tal motivo, el día de hoy le realizamos esta entrevista a profundidad y quiero agradecerle por el tiempo que nos está brindando- En este sentido, siéntase libre de compartir sus ideas. Aquí no hay respuestas correctas o incorrectas, lo que importa es su opinión sincera, ya que la información que usted nos otorgue será únicamente materia para la presente investigación, al igual que otras opiniones.

Para agilizar la toma de la información, resulta de mucha utilidad grabar la conversación. Tomar notas a mano, demoraría y se podría perder cuestiones importantes. Asimismo, le recordamos que la información es estrictamente confidencial.

Ante ello, ¿Existe algún inconveniente en que grabemos la conversación?

¡Desde ya muchas gracias!

\section{OBJETIVO DEL ESTUDIO}

Investigar si el CrossFit es una alternativa idónea para combatir la obesidad.

\section{PREGUNTAS}

A. Conociendo al entrevistado (5 min.)

1. Cuéntanos un poco de ti, ¿Cómo te llamas?, ¿Cuántos años tienes? ¿a qué te dedicas? ¿En qué distrito vives?

Mi nombre es Carlos Villalobos, tengo 44 años de edad, soy Gerente de Grupo En alta del área Banca Afluente del BCP y vivo en Ate.

2. Actualmente, ¿Cuál es tu centro de labores?

$\mathrm{BCP}$

3. ¿Cuánto tiempo llevas ahí?

Más de 20 años.

\section{B. Conocimiento sobre la obesidad}

4. Situándonos en el objetivo de estudio que planteamos; hablemos un poco de la obesidad, ¿Qué opinas sobre el crecimiento de la obesidad en los últimos años a nivel mundial?

Bueno, te puedo decir que es muy impresionante. Hace menos de 10 años, la gente no se preocupaba mucho de si llegar a ser obeso podría ser una enfermedad agresiva, y hoy en día se ha vuelto una pandemia.

5. Y en cuanto al Perú, ¿Cómo ves el panorama de nuestro país ante dicha enfermedad? Está creciendo demasiado. Las autoridades deben preocuparse más en este tema.

6. ¿Consideras que la obesidad es un problema de Salud Pública en nuestro país? ¿Por qué crees ello?

$\mathrm{Si}$, ya que la problemática ha abarcado gran parte del país y deben desarrollarse políticas para contrarrestarlas.

7. A criterio personal ¿Qué factores consideras que influyen en la obesidad? 
La falta de tiempo para ir a un centro de entrenamiento, la mala alimentación y el estrés laboral.

8. Si tuvieras que pensar en alguna solución para contrarrestar esta enfermedad, ¿Cómo combatirías la obesidad?

Haciendo campañas de sensibilidad en el tema.

9. Consideras que estás en un buen estado físico? ¿Por qué?

No, aún me falta mucho para llegar a un buen estado físico. Debido a que, recién he tomado conciencia de mi salud.

\section{Del CrossFit}

10. Si yo le digo CrossFit ¿Qué es lo primero que se le viene a la mente?

Estilo de vida y salud.

11. ¿Cuánto tiempo llevas practicando el CrossFit? Y ¿Cómo lo descubriste?

Cerca de un año, lo descubrí por una amiga de mi trabajo que venía a este lugar a entrenar y vi sus resultados.

12. ¿Dónde practicas el CrossFit?

En CrossFit La Molina

13. ¿Por qué decidiste practicar el CrossFit?

Para mejorar mi salud.

14. Y ¿Por qué no elegiste otro tipo de entrenamiento?

Debido a que vi resultados en otras personas.

15. Ahora, cuéntanos un poco sobre tu experiencia con el CrossFit ¿Qué es lo que más te gusta del CrossFit?

La exigencia en los entrenamientos.

16. Y ¿Lo que más odias?

Hacer las sentadillas con barra encima.

17. ¿Qué opinas de la estructura del entrenamiento?

Es muy detallada y precisa. Además se acomoda muy bien a la estructura de cada entrenamiento diario.

18. ¿Cómo te sentiste luego de tu primera clase de prueba?

Agotado, no me obedecían las piernas y el cansancio era enorme. Creo que jamás había entrenado a tan alta intensidad.

19. Hasta la actualidad, ¿Qué tal ha sido tu progreso?

Pues bien, sobre todo para una persona de mi edad. Antes cargaba sólo 75 libras en barra y me parecía demasiado peso. Ahora cargo $185 \mathrm{lbs}$ y quiero ir aumentado. Mi estado físico ha cambiado y mi salud también.

20. ¿Qué deseas lograr con el CrossFit?

Mejorar mi salud, debido a que yo he tenido sobrepeso.

21. ¿Has participado en alguna competencia?

Sí. Competí el año pasado en un WOD Navideño y me sentí muy motivado por mis amigos. Si bien no gané nada, el solo hecho de haber participado, fue mi mayor recompensa.

Si la respuesta es no preguntar: ¿Te animarías más adelante a participar?

22. A parte del entrenamiento, ¿sigues una dieta?

$\mathrm{Si}$, la nutricionista ha sido muy puntual en ello. Sigo todas las indicaciones que ella prescribe en sus planes de nutrición.

23. En comparación a otros tipos de entrenamiento, ¿consideras que el CrossFit es mejor que estas? ¿Por qué?

Sí; debido a que, es mucho más completo y sobre todo que se utiliza poco tiempo para poder realizar un entrenamiento. 
24. Y en cuanto a la obesidad, ¿Consideras que el CrossFit es un buen mecanismo para combatirla?

Claro, la práctica de todo entrenamiento es buena para combatir la obesidad. En el caso del CrossFit, esta reúne muchas de ellas en un solo WOD.

\section{Del servicio}

25. ¿Qué factores consideraste como atractivos al momento de elegir el Box de CrossFit donde entrenas?

La cercanía a mi trabajo.

26. ¿Qué tal es el servicio? ¿consideras que hay relación entre el precio y la calidad? El servicio es bueno, y la relación precio vs calidad es relativo, ya que, el espacio suele llenarse en horas de la noche.

27. ¿A cuanto asciende el precio que pagaste por la membresía?

A 330 por mes en un paquete por 6 meses.

28. ¿Tuviste alguna promoción? No.

29. ¿Has presentado algún inconveniente? A veces, cuando los baños no han sido limpiados.

30. Si la respuesta fue si, ¿Qué tipo de reclamo hiciste?,¿Qué acciones ejecutaron como solución a tu reclamo?

Bueno, reclame al joven que hace la limpieza y me dijo que son los mismos alumnos del turno anterior quienes habían llenado el baño de agua. Sólo atinó a decir eso y no pasó a limpiarlo.

31. ¿Qué tan satisfecho te encuentras con el servicio brindado?

Regularmente satisfecho.

32. ¿Qué cambiarias del box de CrossFit?

Sin duda el ambiente, suele llenarse muy rápido.

33. A nivel personal ¿Qué recomendaciones darías para mejorar el servicio que te ofrecen?

Optaría por eliminar la zona de yoga y colocar ciertas barras en otros lados.

34. ¿Qué medio de comunicación utilizan en el Box para dar a conocer las noticias, eventos, promociones y programación de los WODS?

Usan mucho Wodifi y Facebook.

35. ¿Te parece muy bueno ese medio de comunicación? o ¿te gustaría que hubiera otro? ¿Cuál?

Bueno, por Wodifi, sólo tenemos un acceso nivel usuario para ver los wods del día y uno que otro artículo fitness. En cuanto al uso de Facebook, a veces suelen colocar otro tipo de anuncios.

E. De la Comunidad CrossFit

36. ¿Qué te parece la comunidad Crossfitera?

Es muy buena.

37. En tu Box de CrossFit, ¿impulsan dicha comunidad?

Si al $100 \%$ -

38. ¿Consideras importante la confraternidad de la comunidad CrossFit para tomar la decisión de practicar el CrossFit?

Claro, si tienes un buen grupo de amigos y buscan los mismos fines, una comunidad ayudaría mucho en impulsarnos a mejorar.

39. ¿Te gustaría que tu box, proponga eventos de integración para la comunidad Crossfitera? ¿Por qué?

Claro, ello sería muy bueno para confraternizar entre amigos y coaches. 


\section{F. Cierre}

40. Ahora bien, para terminar ¿Recomendarías el CrossFit a aquellas personas que no lo han probado?

$\mathrm{Si}$, porque hay resultados muy buenos.

41. ¿Qué opinas de la apertura de un Box de CrossFit en un distrito que cuenta con un porcentaje alto de obesidad y sobrepeso?

Excelente.

42. Finalmente, ¿Algún otro comentario que desees agregar? No, ninguno.

Entrevistador: Muchas gracias Carlos.

Entrevistado: De nada.

Firma del entrevistado 
Apéndice 19: Resumen de Entrevista a Expertos

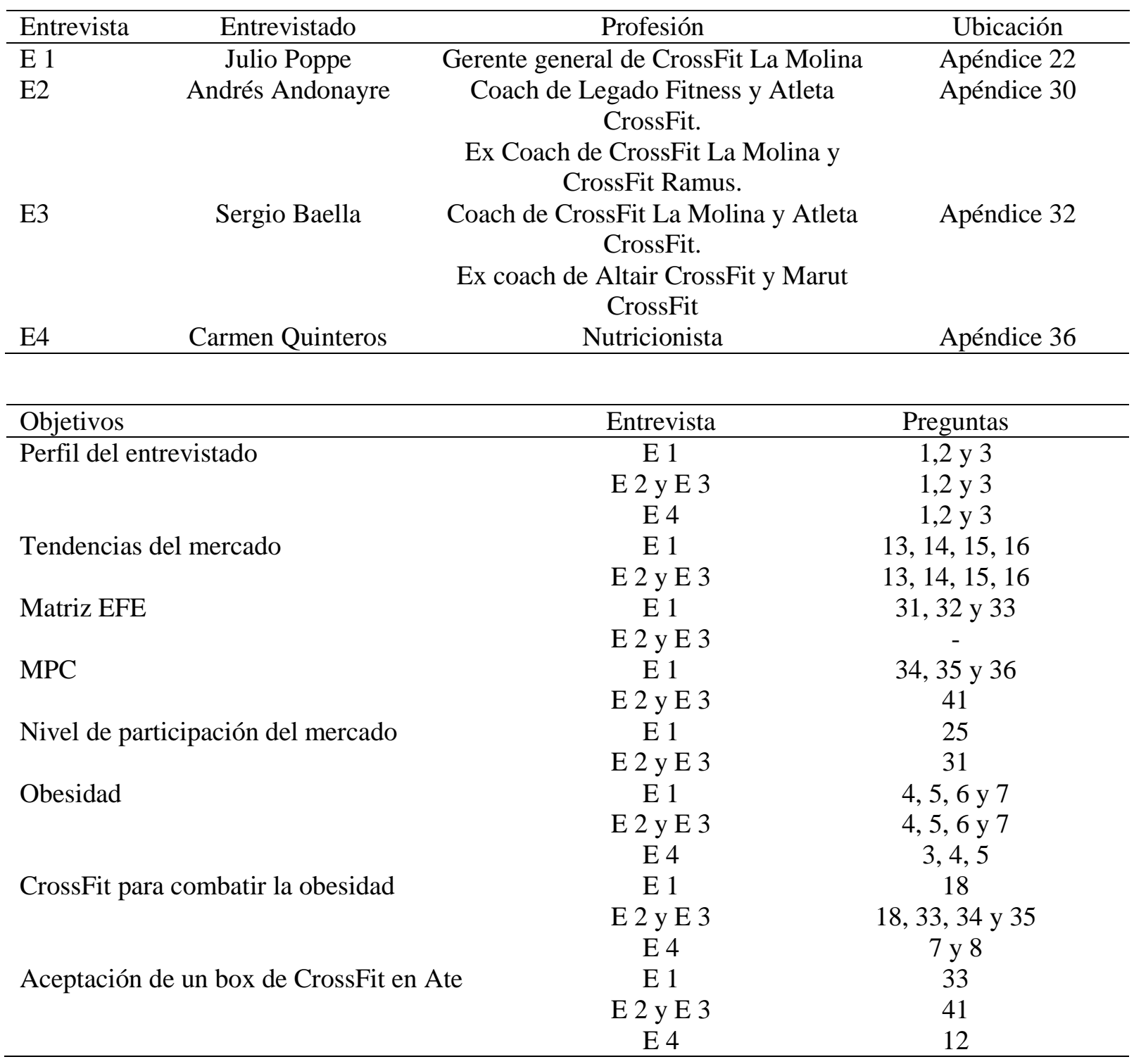


Apéndice 20: Resumen de Tablas de Validación

\begin{tabular}{|c|c|c|c|}
\hline Tablas & Expertos & Nombre & Ubicación \\
\hline $\begin{array}{l}\text { Validación de factores externos } \\
\text { claves }\end{array}$ & E 1 & Julio Poppe & Apéndice 23 \\
\hline $\begin{array}{l}\text { Ponderación de factores externos } \\
\text { claves }\end{array}$ & E 1 & Julio Poppe & Apéndice 24 \\
\hline $\begin{array}{l}\text { Calificación de factores externos } \\
\text { claves }\end{array}$ & E 1 & Julio Poppe & Apéndice 25 \\
\hline $\begin{array}{l}\text { Validación de factores críticos para } \\
\text { el éxito }\end{array}$ & E 1 & Julio Poppe & Apéndice 26 \\
\hline $\begin{array}{l}\text { Ponderación de factores críticos } \\
\text { para el éxito }\end{array}$ & E 1 & Julio Poppe & Apéndice 27 \\
\hline $\begin{array}{l}\text { Calificación de factores críticos por } \\
\text { dueño de CrossFit }\end{array}$ & E 1 & Julio Poppe & Apéndice 28 \\
\hline $\begin{array}{l}\text { Calificación de factores críticos por } \\
\text { Coach } 1\end{array}$ & E 2 & Andres Andonayre & Apéndice 31 \\
\hline $\begin{array}{l}\text { Calificación de factores críticos por } \\
\text { Coach } 2\end{array}$ & E 3 & Sergio Baella & Apéndice 33 \\
\hline $\begin{array}{l}\text { Síntesis de calificación por } \\
\text { expertos de factores críticos }\end{array}$ & E 1 , E 2 y E 3 & Todos & Apéndice 34 \\
\hline $\begin{array}{l}\text { Resultados de calificación por } \\
\text { expertos con aproximación decimal } \\
\text { a la unidad }\end{array}$ & E 1, E 2 y E 3 & Todos & Apéndice 35 \\
\hline
\end{tabular}




\section{Apéndice 21: Esquema de Entrevista a Experto 1}

Entrevistador:

Fecha:

Entrevistado:

Introducción

Buenos días/tardes, mi nombre es . Quiero agradecerle por el tiempo que nos está brindando y quisiera pedirle por favor responder con toda confianza las preguntas, ya que la información que usted nos otorgue será estrictamente confidencial.

Objetivo de estudio

Investigar si el CrossFit es una alternativa idónea para combatir la obesidad.

\section{PREGUNTAS}

A. Conociendo al entrevistado (5 min.)

1. Cuéntanos un poco de ti ¿Cuántos años tienes?

2. ¿A que te dedicas?

3. Actualmente, ¿Cuál es tu centro de labores?

\section{B. Conocimiento de la obesidad (10 min)}

4. Hablemos un poco de la obesidad; ¿Qué opinas sobre el crecimiento de la obesidad en los últimos años a nivel mundial? y ¿En el Perú?

5. ¿Consideras que la Obesidad es un problema de salud pública?

6. ¿Qué factores consideras que influyen en la obesidad?

7. ¿Cómo combatirias la obesidad?

\section{Conociendo un poco del CrossFit (25 min)}

8. Podrías describirnos brevemente ¿Qué es el CrossFit?

9. ¿Qué disciplinas componen el CrossFit?

10. ¿Quiénes pueden hacer CrossFit?

11. Explicanos, ¿A que se llama un Box de CrossFit?

12. Ahora, apuntando un poco al lado empresarial, ¿Qué opinas del modelo de negocio CrossFit?

13. ¿Qué te parece el crecimiento del CrossFit a nivel mundial? y ¿En el Perú?

14. ¿A qué crees que se deba el éxito de este crecimiento?

15. ¿Piensas que el CrossFit en el Perú es sólo una tendencia que desaparecerá pronto?

16. ¿Cómo ves el panorama de crecimiento del CrossFit en el Perú en los próximos años?

17. En relación a otros tipos de entrenamiento que existen en el mercado fitness peruano, ¿Consideras que el CrossFit es mejor que estas?, ¿Porqué?

18. Cambiando de tema, ¿Consideras que el CrossFit, es un buen mecanismo para combatir la obesidad? ¿Por qué?

\section{E. CrossFit como un estilo de vida ( 25 min)}

14. ¿Cuánto tiempo llevas practicando el CrossFit y cómo lo descubriste?

15. ¿Por qué te animaste a probar el CrossFit?

16. ¿Qué es lo que más te gusta del CrossFit

17. ¿Cómo te sentiste, luego de tu primera clase de Prueba?

18. ¿Qué tal ha sido tu progreso desde que iniciaste en el mundo del CrossFit?

19. ¿Has participado en alguna competencia? ¿Cúal(es)? y ¿Cómo te fue?

20. ¿Has participado en las clasificatorias de los CrossFit Games? ¿En que años? 


\section{E. CrossFit bajo la perspectiva del dueño de un box (25 min)}

21. ¿Cómo surgió la idea de aperturar CrossFit La Molina?

22. ¿Cuántos años de fundado tiene tu box?

23. ¿Cómo ha sido tu experiencia como dueño de un box de CrossFit?

24. ¿Cuál crees que sea el valor agregado de tu Box de CrossFit?

25. ¿Cúal es el nivel de participación en el mercado de cada uno de los boxes de CrossFit en Lima?

26. ¿Qué ventajas se obtienen al afiliarse a CrossFit, Inc.?

27. ¿Qué opinas de aquellos Box de CrossFit que no están afiliados?

28. ¿Cuál es el error más grave que incurren los demás boxes CrossFit?

29. ¿Qué recomendación darías a una persona que aún no ha intentado el CrossFit?

30. ¿Qué opinas de la apertura de un box de CrossFit en uno de los distritos con elevado porcentaje de obesidad como Ate?

31. A continuación se presentan los siguientes factores externos claves; según tu experiencia, ¿Podrías validar aquellas que afectan a la industria del fitness y a un box de CrossFit en el mercado peruano? siendo aceptable aquel factor que influye e inaceptable aquel que no influye.

32. Pues bien, ¿Podrías asignarle una ponderación a cada uno de los factores externos claves?, teniendo en cuenta que la suma total debe ser igual a 1.0.

33. Ahora, dada tu experiencia como dueño de un box de CrossFit, queremos determinar qué tan eficaz responden los box de CrossFit ante los factores externos claves; para ello, ¿Podrías asignar una calificación del 1 al 4 a cada uno de los factores externos claves?, teniendo en cuenta que cuatro (4), es superior; tres (3), es por encima del promedio; dos (2), es promedio; y, uno (1), es deficiente.

34. A continuación se presentan los siguientes factores críticos para el éxito; según tu experiencia, ¿Podrías validar aquellos factores críticos para el éxito que deben afrontar cada box de CrossFit en el mercado peruano? siendo aceptable aquel factor que influye e inaceptable aquel que no influye.

35. Ahora, ¿podrías asignarle una ponderación a cada uno de los factores críticos para el éxito?, teniendo en cuenta que la suma total debe ser igual a 1.0

36. Finalmente, dada tu experiencia en el rubro como dueño de un box de CrossFit, queremos identificar los fortalezas y debilidades de los principales competidores del CrossFit en razón a los factores críticos de éxito; para ello, ¿Podrías asignar una calificación del 1 al 4 a cada uno de los competidores en razón a cada factor crítico?, teniendo en cuenta que cuatro (4), es fortaleza principal; tres (3), es fortaleza menor; dos (2), debilidad menor; y, uno (1), es debilidad principal.

Cierre y agradecimiento al especialista.

\section{Datos Básicos}

Nombre de la Empresa:

Ubicación:

Cargo del entrevistado:

Número de trabajadores en la compañía. 


\section{Apéndice 22: Transcripción de Entrevista a Experto 1}

Entrevistadores:

Fecha: $10 / 04 / 2018$

Giancarlo Renán Chávez Suárez

Arturo Palomino Mendiolaza

Entrevistado:

Julio Poppe

Dueño de CrossFit La Molina

Introducción

Buenos días. Queremos agradecerle por el tiempo que nos está brindando y quisiera pedirle por favor responder con toda confianza las preguntas, ya que la información que usted nos otorgue será estrictamente confidencial.

Objetivo de estudio

Investigar si el CrossFit es una alternativa idónea para combatir la obesidad.

\section{PREGUNTAS}

A. Conociendo al entrevistado (5 min.)

1. Cuéntanos un poco de ti ¿Cuántos años tienes? Tengo 32 años.

2. ¿A que te dedicas?

Soy dueño de CrossFit La Molina y Head Coach.

3. Actualmente, ¿Cuál es tu centro de labores?

CrossFit La Molina.

\section{B. Conocimiento de la obesidad (10 $\mathrm{min})$}

4. Hablemos un poco de la obesidad; ¿Qué opinas sobre el crecimiento de la obesidad en los últimos años a nivel mundial? y ¿En el Perú?

Es preocupante. A pesar de los esfuerzos y campañas que la OMS viene realizando, el crecimiento de la obesidad va en ascenso. Este factor, se debe a las escazas políticas públicas y poco interés de los países. En el Perú, la obesidad

venta de fast food y mala regulación de los productos chatarra, generan

5. ¿Consideras que la Obesidad es un problema de salud pública?

Claro, el poco interés y control del estado, ha generado una proliferación de dicha enfermedad.

6. ¿Qué factores consideras que influyen en la obesidad?

Una mala alimentación, el sedentarismo, y la flojera de las personas para ocupar algunas horas de entrenamiento en su ritmo de vida.

7. ¿Cómo combatirias la obesidad?

Mediante la actividad física y control nutricional.

\section{Conociendo un poco del CrossFit (25 min)}

8. Podrías describirnos brevemente ¿Qué es el CrossFit?

Claro. El Crossfit viene a ser un programa de fuerza y funcionamiento que mejora tu fitness si o si, basándose en 3 pilares: Levantamiento de pesas, gimnasia y cardio; los cuales tanto individualmente como en conjunto, se crean programas para sacar lo mejor de uno mismo.

9. ¿Qué disciplinas componen el CrossFit?

El levantamiento olímpico, gimnasia y cardio. 
10. ¿Quiénes pueden hacer CrossFit?

Todos, no hay restricción de edad, peso o género.

11. Explicanos, ¿A que se llama un Box de CrossFit?

Un box de CrossFit es un gimnasio donde se practica el CrossFit, cuyo diseño está

basado en un garage de entrenamiento que usaban los militares.

12. Ahora, apuntando un poco al lado empresarial, ¿Qué opinas del modelo de negocio CrossFit?

Es un modelo de negocio muy bueno, lo considero, en comparación al resto de programas deportivos, como el mejor del mercado. No sólo por su innovación, buenos resultados y rentabilidad; si no tambien, por la inversión no exagerada.

13. ¿Qué te parece el crecimiento del CrossFit a nivel mundial? y ¿En el Perú?

Extraordinario, en los últimos 3 años, según las cifras de CrossFit, Inc. el número de afiliados crecio al doble. Asimismo, la cantidad de personas que se inscriben a los CrossFit Games es impresionante, cada año se suman más y más personas. En el Perú, el CrossFit va agarrando fuerza, hace 3 años cuando iniciamos, terminamos el año con 100 alumnos; hoy somos más de 300 miembros.

14. ¿A qué crees que se deba el éxito de este crecimiento?

Al mismo fin de su creación, buscar un estado fitness, buenos resultados y, a superarse día a día.

15. ¿Piensas que el CrossFit en el Perú es sólo una tendencia que desaparecerá pronto? No, el CrossFit es ya una disciplina. Y su comunidad va creciendo día a día.

16. ¿Cómo ves el panorama de crecimiento del CrossFit en el Perú en los próximos años? Muy alentadora, cada día se va haciendo más conocida. Se estima que el próximo año, los regionales de latinoamérica de los CrossFit Games se realicen en Perú. Ello, favorecería a gran escala el mercado.

17. En relación a otros tipos de entrenamiento que existen en el mercado fitness peruano, ¿Consideras que el CrossFit es mejor que estas?, ¿Porqué?

$\mathrm{Si}$, debido a que el CrossFit no sólo se enfoca en una sola área, sino que, buscar mejorar tu capacidad física llevándote al extremo.

18. Cambiando de tema, ¿Consideras que el CrossFit, es un buen mecanismo para combatir la obesidad? ¿Por qué?

Por supuesto, el CrossFit ha dado gramdes resultados. La combinación de las disciplinas permite que el trabajo se enfoque en todo el cuerpo y la quema de calorías mucho mayor.

\section{E. CrossFit como un estilo de vida (25 min)}

19. ¿Cuánto tiempo llevas practicando el CrossFit y cómo lo descubriste?

Alrededor de 6 años, el CrossFit llego a mi. Un primo me había hablado de un nuevo entrenamiento y viendo un video en Youtube, decidimos empezar a entrenar.

Terminamos agotados, pero valió la pena todo el esfuerzo y desde ahí, no lo he dejado.

20. ¿Por qué te animaste a probar el CrossFit?

Porque me pareció algo novedoso y difícil de hacer.

21. ¿Qué es lo que más te gusta del CrossFit?

La gran intensidad de los WOD y la variedad de los mismos.

22. ¿Cómo te sentiste, luego de tu primera clase de Prueba?

Agotado al máximo, no podía moverme por unos 10 minutos. Sentí que me había atropellado un camión.

23. ¿Qué tal ha sido tu progreso desde que iniciaste en el mundo del CrossFit? 
Ha sido grande, a inicios sólo podía hacer buenas barras y el levantamiento de pesas era muy bajo. Hoy en día cargo $225 \mathrm{lbs}$ y hacer anillas.

24. ¿Has participado en alguna competencia? ¿Cúal(es)? y ¿Cómo te fue?

Sí, he participado en el Ramus Challenge del 2017, no me fue tan bien, debido a que no venía bien prepado; sin embargo, alcance el puesto 12 de 50 competidores.

25. ¿Has participado en las clasificatorias de los CrossFit Games? ¿En que años?

Si, todos los años. Desde el 2015 que abrimos CrossFit La Molina. Esto nos sirve para medir nuestro avance.

\section{E. CrossFit bajo la perspectiva del dueño de un box (25 min)}

26. ¿Cómo surgió la idea de aperturar CrossFit La Molina?

Basicamente, yo tenía muchos amigos aquí en la Molina y les prácticaba sobre el CrossFit, y ellos me decían, yo hago functional training; pero siempre les resaltaba que no era lo mismo, osea, el CrossFit hace movimientos funcionales pero a gran intensidad. Entonces, vi la necesitad de abrir un box de CrossFit en el distrito.

27. ¿Cuántos años de fundado tiene tu box?

Iniciamos en el 2015, en la actualidad vamos por el cuarto año.

28. ¿Cómo ha sido tu experiencia como dueño de un box de CrossFit?

Ha sido gratificante. Mi aventura como empresario ha sido de altas y bajas. Al inicio yo abría el box a las 6 a.m y cerraba a las 10 p.m de lunes a viernes y los sábados de 7 a.m a 12 p.m. la he sudado bien. Ahora ya puedo dormir más horas y entrenar más con el crew.

29. ¿Cuál crees que sea el valor agregado de tu Box de CrossFit?

La calidad del servicio que ofrecemos. Puesto que, mientras otros box de CrossFit se sitúan más en hacer un WOD fuerte y una buena clase; nosotros vamos más allá, invertimos el tiempo en una buena técnica, esta no sólo debe desarrollarse dentro de la clase; sino también incentivamos a los alumnos a que se queden después de la hora de clase y practiquen sus técnicas para perfeccionarlas. Donde, un coach se encarga exclusivamente de esa preparación. Asimismo, realizamos rutinas post entrenamiento, donde enfocamos mucho la progresión tanto en levantamiento de pesas con las técnicas y aumento de peso; así como, al hacer una simple barra, para pasar hacer un kipping pull up, hasta llegar a dorminarla con el butterfly pull up.

30. ¿Cúal es el nivel de participación en el mercado de cada uno de los boxes de CrossFit en Lima?

Estimar ello es un poco imposible, ya que cada box de CrossFit guarda para sí sus cifras de afiialiados. Lo que podríamos hacer es calcular del total de Box de CrossFit afiliados cuantos son de cada empresa.

31. ¿Qué ventajas se obtienen al afiliarse a CrossFit, Inc.?

Muchas, por ejemplo, tu box puede ser elegido como nueva sede de los Cursos de CrossFit en Perú, asimismo, la aceptación de tus alumnos a participar en los CrossFit Games, la validación de resultados de los WOD de clasificación para los CrossFit Games, formar parte del staff de voluntarios para los CrossFit Games; salir en la revista de CrossFit, Inc; entre otros. Pero más allá de ello, la gran ventaja es que tú eres marca CrossFit Oficial, y todo lo que enseñas es lo que CrossFit, Inc, estipula en su metodología.

32. ¿Qué opinas de aquellos Box de CrossFit que no están afiliados?

Sinceramente, son la competencia desleal más preocupante. Tú puedes tener un gimnasio o dictar clases de functional y yoga; pero la metodología de CrossFit ya sea desde el levantamiento de barras, gimnasia, hasta la práctica del core, no puede ser copiada a simple vista. Nosotros, para obtener el Level One Certificate, debemos 
viajar hasta EEUU, llevar los cursos ahí, la estancia de 4 días, clases teóricas y prácticas y tomar una evaluación. Sin duda, la competencia desleal de estos Box no afiliados desprestigian a la marca.

33. ¿Cuál es el error más grave que incurren los demás boxes CrossFit?

No hacer un seguimiento constante a sus miembros. El CrossFit no es un simple deporte, es un estilo de vida que debes seguir y asegurarte que, quién lo está haciendo no tenga problemas más adelante. Para ello, la metodología de CrossFit, Inc debe seguirse.

34. ¿Qué recomendación darías a una persona que aún no ha intentado el CrossFit? Que lo intente. Van a ver que la vida les va a cambier. Tu personalidad, autoestima y estilo de vida serán envidiables.

35. ¿Qué opinas de la apertura de un box de CrossFit en uno de los distritos con elevado porcentaje de obesidad como Ate?

Sería maravilloso. Llegar a Ate y combatir la obesidad a través del CrossFit es sin duda algo que los vecinos del distrito van a querer hacer si o si. Más aún si les enseñas un nuevo estilo de vida, donde sus límites serán superados.

36. A continuación se presentan los siguientes factores externos claves; según tu experiencia, ¿Podrías validar aquellas que afectan a la industria del fitness y a un box de CrossFit en el mercado peruano? siendo aceptable aquel factor que influye e inaceptable aquel que no influye.

Claro. se le entregó al entevistado una ficha (ver apéndice 23), donde realizó la validación de los factores.

37. Pues bien, ¿Podrías asignarle una ponderación a cada uno de los factores externos claves?, teniendo en cuenta que la suma total debe ser igual a 1.0.

Ok.

De la validación realizada en el apéndice 23, se descartó aquellos factores que el experto consideró inaceptables; luego realizó la ponderación correspondiente (Ver apéndice 24).

38. Ahora, dada tu experiencia como dueño de un box de CrossFit, queremos determinar qué tan eficaz responden los box de CrossFit ante los factores externos claves; para ello, ¿Podrías asignar una calificación del 1 al 4 a cada uno de los factores externos claves?, teniendo en cuenta que cuatro (4), es superior; tres (3), es por encima del promedio; dos (2), es promedio; y, uno (1), es deficiente.

Ok.

En el apéndice 25, el entrevistado consignó la calificación respectiva.

39. A continuación se presentan los siguientes factores críticos para el éxito; según tu experiencia, ¿Podrías validar aquellos factores críticos para el éxito que deben afrontar cada box de CrossFit en el mercado peruano? siendo aceptable aquel factor que influye e inaceptable aquel que no influye.

De acuerdo.

Se le entregó al entevistado una ficha (ver apéndice 26), donde realizó la validación de los factores críticos para el éxito.

40. Ahora, ¿podrías asignarle una ponderación a cada uno de los factores críticos para el éxito?, teniendo en cuenta que la suma total debe ser igual a 1.0

Ya, es algo igual con la anterior ficha, no?

Si.

Ok.

De la validación realizada en el apéndice 26, se descartó aquellos factores críticos para el éxito que el experto consideró inaceptables; luego, realizó la ponderación correspondiente (Ver apéndice 27). 
41. Finalmente, dada tu experiencia en el rubro como dueño de un box de CrossFit, queremos identificar los fortalezas y debilidades de los principales competidores del CrossFit en razón a los factores críticos de éxito; para ello, ¿Podrías asignar una calificación del 1 al 4 a cada uno de los competidores en razón a cada factor crítico?, teniendo en cuenta que cuatro (4), es fortaleza principal; tres (3), es fortaleza menor; dos (2), debilidad menor; y, uno (1), es debilidad principal.

Ok, ok.

En el apéndice 28, el entrevistado consignó la calificación respectiva. Luego, se le reiteró el agradecimiento por el tiempo prestado.

\section{Datos Básicos}

Nombre de la Empresa: CrossFit La Molina

Ubicación: Calle el Grifo 100, La Molina.

Cargo del entrevistado: Dueño y Head Coach

Número de trabajadores en la compañía 8

\section{Muchas Gracias por su participación}


Apéndice 23: Validación de Factores Externos Claves por Experto 1

\begin{tabular}{|c|c|c|}
\hline \multirow[t]{2}{*}{ Factores externos claves } & \multicolumn{2}{|c|}{ Valoración de los factores } \\
\hline & Aceptable & Inaceptable \\
\hline \multicolumn{3}{|l|}{ Oportunidades } \\
\hline 1. Lucha contra la corrupción & & $\mathrm{X}$ \\
\hline 2. Recuperación del crecimiento económico del país & $\mathrm{X}$ & \\
\hline $\begin{array}{l}\text { 3. Políticas de la OMS para combater la obesidad } \\
\text { mediante la actividad física adoptada por los países } \\
\text { miembros }\end{array}$ & $\mathrm{X}$ & \\
\hline 4.Crecimiento del Mercado interno fitness & $\mathrm{X}$ & \\
\hline $\begin{array}{l}\text { 5. Desarrollo de medidas de impulse económico en favor } \\
\text { de Pymes y Mypes }\end{array}$ & & $\mathrm{X}$ \\
\hline $\begin{array}{l}\text { 6.Desarrollo de nuevas tecnologías fitness para el } \\
\text { CrossFit }\end{array}$ & $\mathrm{X}$ & \\
\hline $\begin{array}{l}\text { 7.Reconocimiento del CrossFit como mejor tendencia en } \\
\text { la industria por parte del IHRSA }\end{array}$ & $\mathrm{X}$ & \\
\hline 8. Escaso empleo de los fundamentos del CrossFit & $\mathrm{X}$ & \\
\hline 9. Tendencia de la población a una cultura fitness & $X$ & \\
\hline \multicolumn{3}{|l|}{ Amenazas } \\
\hline $\begin{array}{l}\text { 1. Corrupción en las municipalidades para la obtención } \\
\text { de licencias de funcionamiento }\end{array}$ & & $\mathrm{X}$ \\
\hline 2. Piratería del modelo CrossFit & $\mathrm{X}$ & \\
\hline $\begin{array}{l}\text { 3. Desaceleración económica producto de la crisis } \\
\text { política }\end{array}$ & $\mathrm{X}$ & \\
\hline 4. Ingreso y fortalecimiento de nuevos competidores & $\mathrm{X}$ & \\
\hline 5. Variación del tipo de cambio a la alza & & $\mathrm{X}$ \\
\hline $\begin{array}{l}\text { 6. Escazas acciones de control del Indecopi con relación } \\
\text { a la protección de la propiedad intelectual (patentes) }\end{array}$ & $\mathrm{X}$ & \\
\hline 7. Sensibilidad al precio & $\mathrm{X}$ & \\
\hline 8. Desarrollo de apps de entrenamiento de paga & & $\mathrm{X}$ \\
\hline
\end{tabular}


Apéndice 24: Ponderación de Factores Externos Claves por Experto 1

\begin{tabular}{lc}
\hline Factores externos claves & Ponderación \\
\hline Oportunidades & 0.09 \\
1. Recuperación del crecimiento económico del país & 0.07 \\
2. Políticas de la OMS para combater la obesidad mediante la & \\
actividad física adoptada por los países miembros & 0.1 \\
3.Crecimiento del Mercado interno fitness & 0.07 \\
4.Desarrollo de nuevas tecnologías fitness para el CrossFit & 0.06 \\
5.Reconocimiento del CrossFit como mejor tendencia en la & \\
industria por parte del IHRSA & 0.11 \\
6. Escaso empleo de los fundamentos del CrossFit & 0.08 \\
7. Tendencia de la población a una cultura fitness & \\
Amenazas & 0.1 \\
1. Piratería del modelo CrossFit & 0.08 \\
2. Desaceleración económica producto de la crisis política & 0.07 \\
3. Ingreso y fortalecimiento de nuevos competidores & 0.1 \\
4. Escazas acciones de control del Indecopi con relación a la & \\
protección de la propiedad intelectual (patentes) & 0.07 \\
5. Sensibilidad al precio & 1 \\
Total & \\
\hline Nota: La ponderación fue adaptada de valor porcentual a decimal. &
\end{tabular}

Nota: La ponderación fue adaptada de valor porcentual a decimal. 
Apéndice 25: Calificación de Factores Externos Claves por Experto 1

\begin{tabular}{|c|c|c|}
\hline Factores externos claves & Ponderación & Calificación \\
\hline \multicolumn{3}{|l|}{ Oportunidades } \\
\hline $\begin{array}{l}\text { 1. Recuperación del crecimiento económico del } \\
\text { país }\end{array}$ & 0.09 & 3 \\
\hline $\begin{array}{l}\text { 2. Políticas de la OMS para combater la obesidad } \\
\text { mediante la actividad física adoptada por los países } \\
\text { miembros }\end{array}$ & 0.07 & 3 \\
\hline 3.Crecimiento del Mercado interno fitness & 0.1 & 4 \\
\hline $\begin{array}{l}\text { 4.Desarrollo de nuevas tecnologías fitness para el } \\
\text { CrossFit }\end{array}$ & 0.07 & 2 \\
\hline $\begin{array}{l}\text { 5.Reconocimiento del CrossFit como mejor } \\
\text { tendencia en la industria por parte del IHRSA }\end{array}$ & 0.06 & 3 \\
\hline 6. Escaso empleo de los fundamentos del CrossFit & 0.11 & 3 \\
\hline 7. Tendencia de la población a una cultura fitness & 0.08 & 2 \\
\hline \multicolumn{3}{|l|}{ Amenazas } \\
\hline 1. Piratería del modelo CrossFit & 0.1 & 4 \\
\hline $\begin{array}{l}\text { 2. Desaceleración económica producto de la crisis } \\
\text { política }\end{array}$ & 0.08 & 3 \\
\hline $\begin{array}{l}\text { 3. Ingreso y fortalecimiento de nuevos } \\
\text { competidores }\end{array}$ & 0.07 & 1 \\
\hline $\begin{array}{l}\text { 4. Escazas acciones de control del Indecopi con } \\
\text { relación a la protección de la propiedad intelectual } \\
\text { (patentes) }\end{array}$ & 0.1 & 3 \\
\hline 5. Sensibilidad al precio & 0.07 & 3 \\
\hline Total & 1 & \\
\hline
\end{tabular}


Apéndice 26: Factores Críticos por Experto 1

\begin{tabular}{lcc}
\hline Factores críticos & \multicolumn{2}{c}{ Valoración de los factores } \\
\cline { 2 - 3 } & Aceptable & Inaceptable \\
\hline Participación en el mercado & $\mathrm{X}$ & \\
Administración & $\mathrm{X}$ & \\
Competitividad de los precios & $\mathrm{X}$ & \\
Respaldo económico & & $\mathrm{X}$ \\
Expansión global & & $\mathrm{X}$ \\
Distribución de ventas & $\mathrm{X}$ & \\
Calidad del servicio & $\mathrm{X}$ & $\mathrm{X}$ \\
Lealtad del cliente & & \\
Estructura de la organización & $\mathrm{X}$ & $\mathrm{X}$ \\
Publicidad & $\mathrm{X}$ & \\
Imagen de la marca & & \\
Comercio electrónico & $\mathrm{X}$ & \\
Red de contactos & $\mathrm{X}$ & $\mathrm{X}$ \\
Red de ventas & $\mathrm{X}$ & \\
Experiencia en el sector & $\mathrm{X}$ & \\
Infraestructura & & \\
Compromiso de los colaboradores & $\mathrm{X}$ & \\
Promociones & $\mathrm{X}$ & \\
Ubicación & & \\
\hline
\end{tabular}




\section{Apéndice 27: Ponderación de Factores Críticos por Experto 1}

\begin{tabular}{lc}
\hline Factores críticos & Ponderación \\
\hline Participación en el mercado & 0.07 \\
Competitividad de los precios & 0.07 \\
Respaldo económico & 0.08 \\
Calidad del servicio & 0.1 \\
Lealtad del cliente & 0.06 \\
Publicidad & 0.06 \\
Imagen de la marca & 0.07 \\
Red de contactos & 0.08 \\
Red de ventas & 0.06 \\
Experiencia en el sector & 0.07 \\
Infraestructura & 0.08 \\
Promociones & 0.07 \\
Ubicación & 0.13 \\
Total & 1
\end{tabular}

Nota: La ponderación fue adaptada de valor porcentual a decimal. 
Apéndice 28: Calificación Factores Críticos por Experto 1

\begin{tabular}{|c|c|c|c|c|c|}
\hline Factores críticos & Peso & $\begin{array}{c}\text { CrossFit } \\
\text { La Molina }\end{array}$ & $\begin{array}{l}\text { Legado } \\
\text { CrossFit }\end{array}$ & $\begin{array}{c}\text { CrossFit } \\
\text { Ramus }\end{array}$ & $\begin{array}{c}\text { CrossFit } \\
\text { Marut }\end{array}$ \\
\hline & & (q) & (q) & (q) & (q) \\
\hline Participación en el Mercado & 0.07 & 3 & 3 & 4 & 4 \\
\hline Competitividad de los precios & 0.07 & 1 & 2 & 3 & 3 \\
\hline Respaldo Ecónomico & 0.08 & 2 & 2 & 4 & 4 \\
\hline Calidad del servicio & 0.1 & 3 & 2 & 3 & 3 \\
\hline Lealtad del cliente & 0.06 & 2 & 2 & 2 & 2 \\
\hline Publicidad & 0.06 & 2 & 2 & 3 & 3 \\
\hline Imagen de la marca & 0.07 & 2 & 2 & 3 & 2 \\
\hline Red de contactos & 0.08 & 1 & 2 & 4 & 4 \\
\hline Red de ventas & 0.06 & 1 & 1 & 4 & 3 \\
\hline Experiencia en el sector & 0.07 & 3 & 1 & 3 & 3 \\
\hline Infraestructura & 0.08 & 2 & 2 & 3 & 3 \\
\hline Promociones & 0.07 & 2 & 3 & 1 & 2 \\
\hline Ubicación & 0.13 & 2 & 2 & 1 & 1 \\
\hline Total & 1 & & & & \\
\hline
\end{tabular}


Apéndice 29: Esquema de Entrevista a Coach

Entrevistador:

Fecha:

Entrevistado:

Introducción

Buenos días/tardes, mi nombre es Quiero agradecerle por el tiempo que nos está brindando y quisiera pedirle por favor responder con toda confianza las preguntas, ya que la información que usted nos otorgue será estrictamente confidencial.

OBJETIVO DEL ESTUDIO

Investigar si el CrossFit es una alternativa idónea para combatir la obesidad.

\section{PREGUNTAS}

\section{A. Conociendo al entrevistado (5 min.)}

1. Cuéntanos un poco de ti ¿Cuántos años tienes?

2. ¿A que te dedicas?

3. Actualmente, ¿Cuál es tu centro de labores?

\section{B. Conocimiento de la obesidad (10 min)}

4. Hablemos un poco de la obesidad; ¿Qué opinas sobre el crecimiento de la obesidad en los últimos años a nivel mundial? y ¿En el Perú?

5. ¿Consideras que la Obesidad es un problema de salud pública?

6. ¿Qué factores consideras que influyen en la obesidad?

7. ¿Cómo combatirias la obesidad?

\section{Conociendo un poco del CrossFit (25 min)}

8. Podrías describirnos brevemente ¿Qué es el CrossFit?

9. ¿Qué disciplinas componen el CrossFit?

10. ¿Quiénes pueden hacer CrossFit?

11. Explicanos, ¿A que se llama un Box de CrossFit?

12. Ahora, apuntando un poco al lado empresarial, ¿Qué opinas del modelo de negocio CrossFit?

13. ¿Qué te parece el crecimiento del CrossFit a nivel mundial? y ¿En el Perú?

14. ¿A qué crees que se deba el éxito de este crecimiento?

15. ¿Piensas que el CrossFit en el Perú es sólo una tendencia que desaparecerá pronto?

16. ¿Cómo ves el panorama de crecimiento del CrossFit en el Perú en los próximos años?

17. En relación a otros tipos de entrenamiento que existen en el mercado fitness peruano, ¿Consideras que el CrossFit es mejor que estas?, ¿Porqué?

18. Cambiando de tema, ¿Consideras que el CrossFit, es un buen mecanismo para combatir la obesidad? ¿Por qué?

\section{E. CrossFit como un estilo de vida (25 min)}

19. ¿Cuánto tiempo llevas practicando el CrossFit y cómo lo descubriste?

20. ¿Por qué te animaste a probar el CrossFit?

21. ¿Qué es lo que más te gusta del CrossFit

22. ¿Cómo te sentiste, luego de tu primera clase de Prueba? 
23. ¿Qué tal ha sido tu progreso desde que iniciaste en el mundo del CrossFit?

24. ¿Has participado en alguna competencia? ¿Cúal(es)? y ¿Cómo te fue?

25. ¿Has participado en las clasificatorias de los CrossFit Games? ¿En que años?

\section{E. CrossFit bajo la perspectiva de un Coach (25 min)}

26. ¿Cuántos años llevas como Coach?

27. ¿Cómo ha sido tu experiencia como Coach de CrossFit?

28. ¿Cómo estructuras una clase de CrossFit?

29. ¿Qué es el CrossFit Level 1 certificate?

30. ¿Qué opinas de aquellos Box de CrossFit que no están afiliados?

31. ¿Conoces el nivel de participación en el mercado de cada uno de los CrossFit de Lima?

32. ¿Haz tenido alumnos que han sufrido de obesidad o sobrepeso?

33. ¿Cuál ha sido el caso de obesidad más alarmante que hayas atendido como Coach?

34. ¿Cómo es el entrenamiento para las personas con obesidad o sobrepeso?

35. A parte de realizar el entrenamiento ¿Los alumnos llevan una dieta?

36. ¿Consideras que una persona normal que practica CrossFit, debe alimentarse al igual que un atléta de élite?

37. ¿Qué tan propenso es una persona a quedar lastimada al practicar el CrossFit?

38. ¿Cuál es el error más grave en la que incurren las personas que practican el CrossFit?

39. ¿Qué recomendación darías a una persona que aún no ha intentado el CrossFit?

40. ¿Qué opinas de la apertura de un box de CrossFit en uno de los distritos con elevado porcentaje de obesidad como Ate?

41. Finalmente, dada tu experiencia como coach en diversos box de CrossFit, te presentamos los siguientes factores críticos del éxito; así como, los principales competidores que se ha considerado en la presente investigación, con el fin de identificar las fortalezas y debilidades de cada uno de ellos; ante ello, ¿Qué calificación le darías a los competidores en razón a cada uno de los factores criticos? teniendo en cuenta que cuatro (4), es fortaleza principal; tres (3), es fortaleza menor; dos (2), debilidad menor; y, uno (1), es debilidad principal.

\section{Datos Básicos}

Nombre de la Empresa:

Ubicación:

Cargo del entrevistado:

Número de trabajadores en la compañía 


\section{Apéndice 30: Transcripción de Entrevista a Experto 2}

Fecha: $16 / 4 / 2018$

Entrevistado: Andrés Andonayre La Madrid

Introducción

Buenos días/tardes, mi nombre es Giancarlo Renán Chávez Suárez y quiero agradecerle por el tiempo que nos está brindando y quisiera pedirle por favor responder con toda confianza las preguntas, ya que la información que usted nos otorgue será estrictamente confidencial.

OBJETIVO DEL ESTUDIO

Investigar si el CrossFit es una alternativa idónea para combatir la obesidad.

\section{PREGUNTAS}

\section{A. Conociendo al entrevistado (5 min.)}

1. Cuéntanos un poco de ti ¿Cuántos años tienes? Tengo 27 años.

2. ¿A que te dedicas? Actualment, estudio administración de empresas y soy Coach de CrossFit.

3. Actualmente, ¿Cuál es tu centro de labores?

Como Coach me desenvuelvo a tiempo parcial en Legado CrossFit y anteriormente en CrossFit La Molina.

\section{B. Conocimiento de la obesidad (10 min)}

4. Hablemos un poco de la obesidad; ¿Qué opinas sobre el crecimiento de la obesidad en los últimos años a nivel mundial? y ¿En el Perú?

Alarmante, la obesidad está creciendo de manera abrumadora en todo el mundo. Hoy en día, ya no es novedad ver a personas subidas de peso. Y en el Perú, podemos observar que el incremento se viene dando de manera alarmante en los niños y jóvenes; quienes han dejado de hacer actividades físicas por estar sentados en la computadora o frente al televisor jugando videojuegos.

5. ¿Consideras que la Obesidad es un problema de salud pública?

Por supuesto, existe un problema social que no es tocado en ningún foro parlamentario. Hoy en día, estamos entre los tres (03) primeros países de latinoamérica con mayor porcentaje de obesidad; lamentablemente las entidades encargadas para la regulación de alimentos chatarra y la salud, han dejado de hacer campañas para poder concientizar a la población. Al parecer, nuestros funcionarios públicos sólo velan por intereses ajenos y no por la salud de la población.

6. ¿Qué factores consideras que influyen en la obesidad?

Eh bueno; tenemos la vida sedentaria, la mala alimentación, la falta de tiempo para poder hacer ejercicios y el estrés por sobrecarga laboral o académica.

7. ¿Cómo combatirias la obesidad?

Bueno, para empezar realizaría más campañas de concientización social, donde no sólo se les critique a las personas por tener obesidad o sobrepeso y sólo brindarles una dieta; sino también, incentivar la actividad física como tal, para que puedan tomarlo como parte de un estilo de vida, la cual, si bien es difícil de seguir, no es imposible de poder hacerla. Asimismo, exhortaría a las insituciones del estado que cumplan su función de entes regularizadores, respecto a la comida chatarra; pues esta, de por sí ya genera serios problemas en la alimentación. Finalmente, impulsaría actividades físicas 
novedosas; ya no las tradicionales, porque a la gente le gusta la innovación; y ello, es el factor clave para poder combatir esta enfermedad.

\section{Conociendo un poco del CrossFit (25 min)}

8. Podrías describirnos brevemente ¿Qué es el CrossFit?

El CrossFit es un entrenamiento funcional realizado en períodos de corta duración a alta intensidad o en larga duración con poca intensidad pero con más variaciones; donde combinas diversas disciplinas y superas tus límites.

9. ¿Qué disciplinas componen el CrossFit?

El CrossFit puede abarcar desde lo más básico del fitness como una plancha o sentadilla hasta subir una cuerda de 30 metros o caminar con las manos o levantar una barra olímpica con 250 libras. Por ello, el CrossFit involucra muchas actividades que por lo general las personas no hacen o han dejado de hacer; tales como, gimnasia, levantamiento olímpico, ejercicios aeróbicos y anabólicos.

10. ¿Quiénes pueden hacer CrossFit?

El CrossFit no discrimina a nadie. Puede hacerlo una niña o niño de 5 años hasta un adulto mayor de 81 años, inculso una persona con discapacidad física. Si puedes ver diversos videos de publicidad del Los CrossFit Games del 2017, se puede apreciar que la edad no es indispensable. Muchos se suelen llevar por las redes sociales y dicen que el CrossFit es muy intenso y que nunca lo intentarían; ya sea porque se levanta mucho peso, porque jamás le saldría una caminata de manos o una sentadilla con una pierna; asimismo, no quieren tener el bull body (cuerpo de toro) ó lesionarse. Cuando es todo lo contrario, el CrossFit es un sistema de adaptación donde sólo varía el grado de intensidad más no el ejercicio.

11. Explicanos, ¿A que se llama un Box de CrossFit?

Es un gimnasio no convencional donde se practica el CrossFit; el cual debe estar afiliado a CrossFit, Inc.

12. Ahora, apuntando un poco al lado empresarial, ¿Qué opinas del modelo de negocio CrossFit?

Es muy atractivo, pero la inversión es fuerte. Si no cuentas con un buen capital que te permita abastecerte de las indumentarias y del ambiente, pues prácticamente no tienes un Box. Sin embargo, la ganancia es buena.

13. ¿Qué te parece el crecimiento del CrossFit a nivel mundial? y ¿En el Perú?

Impresionante, el CrossFit ha crecido de manera rápida en los últimos 5 años. En Estados Unidos hay prácticamente un Box de CrossFit en cada ciudad, y en todo el mundo hay al menos 2 Box de CrossFit en cada país. En el Perú este crecimiento se viene dando de manera alentadora; hoy existen 15 box den Lima y 2 en provincia; sin embargo, el aforo en cada una de estas ya está sobrepasando; a tal punto que hay varias empresas que ya están insetando una sede más en otros distritos. Cada vez, hay más gente que desea probar el CrossFit y la oferta de este servicio se está viendo muy reducida.

14. ¿A qué crees que se deba el éxito de este crecimiento?

Podríamos decir en primera instancia, la obtención de buenos resultados físicos y el buen manejo de la marca, pero eso no es todo. El crecimiento del CrossFit se debe también, a la enorme comunidad que tiene; donde muchos de sus miembros comparten sus resultados, se incentivan a lograr objetivos, comparten actividades como: ver los CrossFit Games, almuerzos, salidas a la playa, etc; lo cual incentiva al nuevo miembro a integrarse; a ello, se le suma la variación constante de los ejercicios 
que es distinta a otros centros de entrenamiento donde suelen repetirlos; en cambio, el CrossFit es mucho más dinámico, divertido, competitivo y confraternal.

15. ¿Piensas que el CrossFit en el Perú es sólo una tendencia que desaparecerá pronto? No, dudo mucho que el CrossFit desaparezca pronto. Es más, me arriesgo a decir que el CrossFit no va a desaparecer; debido a que ésta, se ha establecido como un deporte que cuenta con sus propias olimpiadas; lo cual, lo hace más atractivo. El CrossFit, si es una tendencia que ha llegado para quedarse.

16. ¿Cómo ves el panorama de crecimiento del CrossFit en el Perú en los próximos años? Con buena expectativa. El CrossFit sigue atrayendo a más miembros a su comunidad que buscan un estado fitness y la necesidadde satisfacer dicha demanda genera nuevas oportunidades para los empresarios o emprendedores, que decidan apostar por abrir un Box de CrossFit. Además, Gleg Glassman, el creador del CrossFit y Dave Castro, el director de los CrossFit Games, están recompensando el crecimiento de la comunidad, llevando a cabo los Open y Regionales en nuevas sedes en diversos países; tal como fue en el 2008, cuando celebraron los primeros Regionales de Latinoamérica en Perú.

17. En relación a otros tipos de entrenamiento que existen en el mercado fitness peruano, ¿Consideras que el CrossFit es mejor que estas?, ¿Porqué?

Sí; definitivamente el CrossFit es mucho mejor que otras alternativas de entrenamiento; debido a que, su estructura es en menor tiempo, es personalizada, donde no necesitas esperar por una maquina o alternar con alguien para usarla; asimismo, es variada, con mejores resultados tanto físicos como personales; y sobre todo, no busca venderte más servicios, sólo lograr que rompas tus límites y entres a un nuevo estilo de vida.

18. Cambiando de tema, ¿Consideras que el CrossFit, es un buen mecanismo para combatir la obesidad? ¿Por qué?

Sí, el CrossFit ha dado grandiosos resultados. Por ejemplo, el caso más emblemático de CrossFit a nivel mundial es de Ivan García, un joven de 28 de años quién sufría de sobrepeso y por ello no podía ingresar a la policía norteamericana. En menos de 2 años, Ivan ha logrado reducir 70 kilos y logró ingresar a la policía. Esto demuesta que el CrossFit, es un entrenamiento con grandiosos resultados; no obstante, toda disciplina debe ir acompañada de una buena alimentación. Sin embargo, romper los límites que nuestra mente nos pone, sin duda, el CrossFit lo logra. De otro lado, debemos recordar que el CrossFit no solo es una herramienta para perder peso; sino también, para mejorar la calidad de vida de cualquier persona, a cualquier edad, con cualquier enfermedad y con cualquier discapacidad física.

\section{E. CrossFit como un estilo de vida (25 min)}

19. ¿Cuánto tiempo llevas practicando el CrossFit y cómo lo descubriste? Llevo 7 años en el CrossFit, de los cuales 4 son como Coach. Lo descubrí por recomendación de un amigo quién practicaba conmigo levantamiento olímpico. Un día me llevó a una clase de prueba y desde ahí no dejé el CrossFit.

20. ¿Por qué te animaste a probar el CrossFit?

Porque el levantamiento olímpico no era un deporte suficiente para mi; es decir, no quemaba las calorías necesarias y no tenía un estado fitness completo, solo aumentaba masa muscular, pero no mejoraba mi condición física. Cuando entrené por primera vez, me di cuenta que la combinación de todas las disciplinas eran perfectas para alcanzar mis objetivos.

21. ¿Qué es lo que más te gusta del CrossFit?. 
Lo agotado que te puede dejar un WOD, y lo bien que te sientes luego de entrenar. Además, la integración del levantamiento olímpico como parte de algún WOD, lo cual no me aleja de mis principios en la Halterofilia. Si me dieras a escoger un WODf favorito, sería Heavy Fran.

22. ¿Cómo te sentiste, luego de tu primera clase de Prueba?

Me sentí muy feliz y cómodo a la vez. Obviamente que el primer entrenamiento me dejó muy agotado, al punto de colapsar; pero valió la pena. Sentí una conexión única con el CrossFit, algo que no había conseguido con el gimnasio y otros deportes; a tal punto que, el CrossFit se ha vuelto un estilo de vida.

23. ¿Qué tal ha sido tu progreso desde que iniciaste en el mundo del CrossFit? Ha sido bastante bueno, he logrado bajar 15 kilos, disminuir mi nivel de grasa corporal. He aumentado masa corporal y sobre todo he podido realizar movimientos que jamás en mi vida había pensado que podía hacer.

24. ¿Has participado en alguna competencia? ¿Cúal(es)? y ¿Cómo te fue?

Si he participado en las diversas versiones del Ramus United Challenge, Reto Imperio y desafío CrossFit Perú; sólo llegue al podio en 2do lugar en el Ramus United Challenge del 2006; en las demás llegué a estar entre los 10 mejores.

25. ¿Has participado en las clasificatorias de los CrossFit Games? ¿En que años?

Sí, es prácticamente un requisito que te superes cada año y mejores. Por ello, desde el 2012 participo en las clasificatorias de los CrossFit Games, y cada año voy escalando. Mi mejor año fue en el 2016, donde por poco ingreso a los Regionales.

\section{E. CrossFit bajo la perspectiva de un Coach (25 min)}

26. ¿Cuántos años llevas como Coach?

Llevo 4 años como Coach. 3 en CrossFit La Molina, y 1 en Legado CrossFit.

27. ¿Cómo ha sido tu experiencia como Coach de CrossFit?

Maravillosa, siempre hay un constante aprendizaje con tus alumnos; puesto que, al ser un entrenamiento donde muchas veces debes adaptar los ejercicios y crear la variación precisa para cada alumno; pues no todos pueden llegar al mismo grado y muchas veces debes crear una nueva variante.

28. ¿Cómo estructuras una clase de CrossFit?

Por lo general, la estructuro en 4 etapas: la primera, un warm up de 5 minutos con un Wod simple para que se pueda entrar en ritmo y en calor; la segunda, es la práctica de Skills, la cual debe ser muy cuidadosa, puesto que, de esta, el atleta podrá realizar el ejercicio en un mejor rango, por ello utilizo 15 a 20 minutos; la tercera, es el WOD, la cual suelo combinar la mayor parte de los fundamentos del CrossFit en un tiempo no mayor a 20 minutos; y, finalmente, el estiramiento, donde trato que los alumnos no queden con lesiones y no les duela el cuerpo.

29. ¿Qué es el CrossFit Level 1 certificate?

Es el requisito base para todo aquel que quiere abrir un Box de CrossFit o ser entrenador de CrossFit; la cual se obtiene, previa a una capacitación y rendición de exámen tanto teórico como práctico. Sin esta certificación, no puedes enseñar el CrossFit.

30. ¿Qué opinas de aquellos Box de CrossFit que no están afiliados?

Es una competencia desleal; puesto que, estas empresas no pagan los US\$1,000 (mil dólares) de membresía afiliada de CrossFit, Inc. y aprovechan en lucrar con la marca. Es muy fácil atraer a la gente utilizando la marca CrossFit; sin embargo, tarde o temprano atrae problemas legales. Hoy en día CrossFit, Inc. está detectando a nivel mundial aquellos Box que usan su marca sin haberse afiliado y los está demandando. 
Adicional a ello, el no contar con la afiliación, te limita el acceso a participar en competencias, a recibir capacitaciones y sobre todo, a no participar en eventos especiales que organiza la compañía en distintas partes del mundo, con los atletas de élite.

31. ¿Conoces el nivel de participación en el mercado de cada uno de los CrossFit de Lima?

Bueno, es difícil determinar dicho nivel de participación; puesto que el CrossFit es un modelo de negocio que recién está siendo observado por las agencias de estudio. Considero que una manera de medir el nivel de participación de estas es por el número de boxes de CrossFit que han aperturado como el caso de CrossFit Ramus y Marut. Esos son factores que pueden darte una aproximación cercana.

32. ¿Haz tenido alumnos que han sufrido de obesidad o sobrepeso?

Sí, he tenido unos 5 alumnos con obesidad, y que en la actualidad han podido lograr sus objetivos. A pesar que el camino es largo, la motivación que te da el CrossFit, ya sea, por querer superar tus propios límites, así como la integración e impulso de su comunidad; pueden generar un cambio piscológico en la persona en querer cumplir sus objetivos.

33. ¿Cuál ha sido el caso de obesidad más alarmante que hayas atendido como Coach? Fue el de una señora de 55 años. Ella es americana e ingresó al CrossFit con un peso de 135 kilos; de los cuales, a la actualidad ha podido reducir 40.

34. ¿Cómo es el entrenamiento para las personas con obesidad o sobrepeso?

El entrenamiento es el mismo, en cuanto al tipo. Lo único que varía es el nivel de intensidad; ello no quiere decir, que el entrenamiento sea más fácil; todo lo contrario, es igual de intenso. Por ejemplo, en el caso de la señora de 55 años con obesidad; ella no podía realizar una sentadilla, puesto que su peso corporal la perjudicaba; sin embargo, se le hacía la variación a sentarse en un box jump (caja de salto) y que se pare lo más rápido posible. De igual forma, sucedia con las planchas, donde ella se apoyaba en la caja y hacia una pequeña flexión; sin embargo, sucedia todo lo contrario, cuando ella levantaba peso; su nivel corporal, le permitía levantar un peso mayor que a otras señoras e incluso le iba mucho mejor que hacer sentadillas. Hoy en día, ella ya puede hacer varias sentadillas libres y planchas con normalidad; incluso, su capacidad para hacer levantamiento de pesas ha mejorado mucho más.

35. A parte de realizar el entrenamiento ¿Los alumnos llevan una dieta?

Sí. Para obtener mejores resultados, es bueno que se siga una dieta adecuada y adaptada al ritmo de vida de cada persona. En toda disciplina, la dieta es un $70 \%$ y el entrenamiento un 30\%. Por lo general, en el CrossFit usamos la dieta Paleolítica y la dieta de la zona.

36. ¿Consideras que una persona normal que practica CrossFit, debe alimentarse al igual que un atléta de élite?

No. Cada persona tiene un estilo de vida distinto. Los atletas de élite consumen muchas más calorias que una persona promedio; ello debido a que, entrenan entre 5 a 6 horas al día. Además, su grado de entrenamiento es mucho más fuerte. Si una persona se alimenta igual que un atleta de élite, ello podría no ser beneficioso para su salud; puesto que, estaría asimilando muchas más calorias.

37. ¿Qué tan propenso es una persona a quedar lastimada al practicar el CrossFit? Como en todo deporte, una persona es propensa a lesionarse. Muchas personas afirman que el CrossFit es el deporte que puede causar severas lesiones; y esto no es así, debido a que, si haces un buen calentamiento, ejecutas los entrenamientos por calidad y haces un buen estiramiento, es muy difícil que te lesiones. Por ello los 
Coaches, debemos siempre estar atentos a cada alumno para corregir las posturas, mejorar sus skills y determinar si puede o no aumentar el peso.

38. ¿Cuál es el error más grave en la que incurren las personas que practican el CrossFit? Por lo general, en tratar de llegar a la categoría Rx lo más pronto posible, con la finalidad de querer competir en los CrossFit Games; y ello no debe ser así. El CrossFit no se trata de ir a los Games; sino, de estar en un buen estado fitness, aprender de a pocos y sobre todo seguir las indicaciones de los Coaches. Además de ello, las personas no siguen una buena alimentación; creen que entrenando fuerte van a compensar las calorías consumidas

39. ¿Qué recomendación darías a una persona que aún no ha intentado el CrossFit? Que se arriesguen y lo intenten. Que no se dejen llevar por las redes sociales que afirman que el CrossFit lesiona. Una vez que pruebas el CrossFit, no hay marcha atrás a querer formar parte de esta comunidad.

40. ¿Qué opinas de la apertura de un box de CrossFit en uno de los distritos con elevado porcentaje de obesidad como Ate?

Una verdadera oportunidad; debido a que, aún no hay un Box de CrossFit Afiliado en la zona. Además, se contibuiría con la reducción de la obesidad y sobre todo, con ampliar esta bonita comunidad CrossFittera.

41. Finalmente, dada tu experiencia como coach en diversos box de CrossFit, te presentamos los siguientes factores críticos del éxito; así como, los principales competidores que se ha considerado en la presente investigación, con el fin de identificar las fortalezas y debilidades de cada uno de ellos; ante ello, ¿Qué calificación le darías a los competidores en razón a cada uno de los factores criticos? teniendo en cuenta que cuatro (4), es fortaleza principal; tres (3), es fortaleza menor; dos (2), debilidad menor; y, uno (1), es debilidad principal.

(*) se le entregó al entevistado una ficha (ver apéndice 31), donde consignó la calificación respectiva. Posteriormente, se agradeció la entrevista.

\section{Datos Básicos}

Nombre de la Empresa: Legado CrossFit

Ubicación: Av. Javier Prado Este 5950, La Molina.

Cargo del entrevistado: Coach

Número de trabajadores en la compañía: 10 
Apéndice 31: Calificación de Factores Críticos por Experto 2

\begin{tabular}{lccccc}
\hline Factores críticos & Peso & $\begin{array}{c}\text { CrossFit } \\
\text { La Molina }\end{array}$ & $\begin{array}{c}\text { Legado } \\
\text { CrossFit }\end{array}$ & $\begin{array}{c}\text { CrossFit } \\
\text { Ramus }\end{array}$ & $\begin{array}{c}\text { CrossFit } \\
\text { Marut }\end{array}$ \\
\hline & & $(\mathrm{q})$ & $(\mathrm{q})$ & $(\mathrm{q})$ & $(\mathrm{q})$ \\
\hline Participación en el Mercado & 0.07 & 2 & 3 & 4 & 4 \\
Competitividad de los precios & 0.07 & 2 & 3 & 3 & 3 \\
Respaldo Ecónomico & 0.08 & 1 & 1 & 4 & 3 \\
Calidad del servicio & 0.1 & 1 & 3 & 4 & 3 \\
Lealtad del cliente & 0.06 & 1 & 3 & 2 & 2 \\
Publicidad & 0.06 & 2 & 3 & 4 & 3 \\
Imagen de la marca & 0.07 & 1 & 3 & 2 & 3 \\
Red de contactos & 0.08 & 1 & 2 & 4 & 3 \\
Red de ventas & 0.06 & 1 & 3 & 4 & 3 \\
Experiencia en el sector & 0.07 & 2 & 1 & 4 & 4 \\
Infraestructura & 0.08 & 1 & 3 & 4 & 2 \\
Promociones & 0.07 & 1 & 3 & 3 & 2 \\
Ubicación & 0.13 & 3 & 2 & 1 & 2 \\
\hline
\end{tabular}




\section{Apéndice 32: Transcripción de Entrevista a Experto 3}

Entrevistado: Sergio Baella

Fecha: $11 / 04 / 2018$

Introducción

Buenos días/tardes. Quiero agradecerle por el tiempo que nos está brindando y quisiera pedirle por favor responder con toda confianza las preguntas, ya que la información que usted nos otorgue será estrictamente confidencial.

OBJETIVO DEL ESTUDIO

Investigar si el CrossFit es una alternativa idónea para combatir la obesidad.

\section{PREGUNTAS}

A. Conociendo al entrevistado (5 min.)

1. Cuéntanos un poco de ti ¿Cuántos años tienes? Tengo 28 años.

2. ¿A que te dedicas? Actualmente soy coach, estudiante universitario y atleta deportivo.

3. Actualmente, ¿Cuál es tu centro de labores? CrossFit La Molina.

\section{B. Conocimiento de la obesidad (10 $\mathrm{min})$}

4. Hablemos un poco de la obesidad; ¿Qué opinas sobre el crecimiento de la obesidad en los últimos años a nivel mundial? y ¿En el Perú?

Es preocupante. Durante los últimos años el sedentarismo y las malas prácticas alimenticias han desarrollado un pésimo estilo de vida en las personas. A ello, debemos agregar que hoy en día son pocas las personas que realizan una actividad física por estilo de vida, solamente buscan compensar su mala alimentación con el deporte. El Perú no escapa de esta enfermedad, más aún que nuestro país es un destino gastronómico, y las políticas de control sobre los alimentos chatarra no ayudan.

5. ¿Consideras que la Obesidad es un problema de salud pública?

$\mathrm{Si}$, debido a que se ha transformado en una enfermedad a nivel nacional y el estado debe tomar las medidas del caso correspondientes.

6. ¿Qué factores consideras que influyen en la obesidad?

La vida sedentaria, las malas prácticas alimenticias, inactividad deportiva, estrés y la sobrecarga laboral.

7. ¿Cómo combatirias la obesidad?

A través de un paquete completo que incluya una buena alimentación y actividad deportiva. Esta debe ser impulsada desde el colegio, hogar, intituciones del estado y centros clinicos; sólo así, podremos acostumbrar a las personas a tomar nuevos estilos de vida.

\section{Conociendo un poco del CrossFit (25 min)}

8. Podrías describirnos brevemente ¿Qué es el CrossFit?

$\mathrm{El}$ CrossFit es un entrenamiento que combina las mejores disciplinas de entrenamiento con movimientos funcionales ejecutados a alta intensidad en períodos de corto tiempo.

9. ¿Qué disciplinas componen el CrossFit?

Tenemos la halterofilia, gimnasia, atletismo y el yoga. 
10. ¿Quiénes pueden hacer CrossFit?

En si, el CrossFit está diseñado para cuaquier persona, sin restricción ni límite de edad.

11. Explicanos, ¿A que se llama un Box de CrossFit?

Es la denominación designada por CrossFit, Inc. al gimnasio de CrossFit, cuya similitud es a un garaje deportivo.

12. Ahora, apuntando un poco al lado empresarial, ¿Qué opinas del modelo de negocio CrossFit?

Es un éxito. Si nos enfocamos a los resultados en razón a cuantos boxes de CrossFit han aperturado en los últimos 3 años es impresionante. Asimismo, la cantidad de alumnos que tienen los box ha sobrepasado las expectativas.

13. ¿Qué te parece el crecimiento del CrossFit a nivel mundial? y ¿En el Perú?

El CrossFit, más que un deporte, se está convirtiendo en un estilo de vida; a tal punto que, pasando las primeras semanas desde que inicias, ya te vas contagiando de su mundo; y ello, te lleva a expandirlo hacia tus amigos y familiares. Tener un estado fit, en el CrossFit, ha permitido que este destierre de su primer lugar a los gimnasios. En el Perú, se espera que el incremento de la comunidad sea mayor en los próximos años. Esto se debe a que muchas personas creen que es un deporte exclusivo para personas fitness.

14. ¿A qué crees que se deba el éxito de este crecimiento?

A la estructura del programa, la cual no es una rutina; asimismo, el tiempo de duración de una clase, permite adaptarse a cualquier horario.

15. ¿Piensas que el CrossFit en el Perú es sólo una tendencia que desaparecerá pronto? No, el CrossFit ha llegado para quedarse.

16. ¿Cómo ves el panorama de crecimiento del CrossFit en el Perú en los próximos años? Muy alentador, ya que hoy en día la gente no sólo está buscando verse y sentirse bien; sino también, un equilibrio en su salud.

17. En relación a otros tipos de entrenamiento que existen en el mercado fitness peruano, ¿Consideras que el CrossFit es mejor que estas?, ¿Porqué?

Definitivamente el CrossFit es mucho mejor que otras; no solo por el grado de intensidad o la varidad de disciplinas que se aplican; sino también por el grado de competitividad y superación personal.

18. Cambiando de tema, ¿Consideras que el CrossFit, es un buen mecanismo para combatir la obesidad? ¿Por qué?

Sí, debido a que CrossFit, Inc. ha demostrado grandes casos como el de Ivan García quién bajo 70 kilos en dos años, convirtiendo el CrossFit en un estilo de vida.

\section{E. CrossFit como un estilo de vida (25 min)}

19. ¿Cuánto tiempo llevas practicando el CrossFit y cómo lo descubriste?

Lo práctico desde el 2012, gracias a un amigo quién me reto a finalizar una clase completa. Desde ahí, el CrossFit ha sido fundamental en mi vida.

20. ¿Por qué te animaste a probar el CrossFit?

Porque, como atleta de natación, necesitaba completar mis rutinas con un deporte que también me diera la posibilidad de superar mis límites y no se centrara sólo en ganar masa muscular o adelgazarme. El CrossFit, era mi paquete completo.

21. ¿Qué es lo que más te gusta del CrossFit?

La variación de la rutina del día; así como, la constante creación de rutinas más difíciles que permiten poner al límite tus capacidades físicas.

22. ¿Cómo te sentiste, luego de tu primera clase de Prueba? 
Me sentí destruido, pero a la vez muy contento de haber superado mis límites en aquel WOD. Era un Hero Wod llamado MURPH, el cual por lo general, no es apto para aquellos que recién inician.

23. ¿Qué tal ha sido tu progreso desde que iniciaste en el mundo del CrossFit?

Ha sido bastante bueno, cuando inicié pesaba 70 kilos y ahora estoy en 80 pero con masa muscular y bien proporcionada. Asimismo, mis capacidades físicas han mejorado y han sido un gran aporte para la natación.

24. ¿Has participado en alguna competencia? ¿Cúal(es)? y ¿Cómo te fue?

Sí, todos los años participo en el Ramus Challenge y en los CrossFit Games. En las últimas tres ediciones del Ramus Challenge he alcanzado el podio; lamentablemente en los CrossFit Games, no he tenido un buen desempeño.

25. ¿Has participado en las clasificatorias de los CrossFit Games? ¿En que años?

Sí, como te decía, todos los años participo en los CrossFit Games, con el fin de ver mi progreso y poder medirme con otros atletas a nivel mundial.

\section{E. CrossFit bajo la perspectiva de un Coach ( 25 min)}

26. ¿Cuántos años llevas como Coach?

Unos 5 años, inicie como apoyo de Coach y luego con la certificación Level 1, pude tomar clases completas.

27. ¿Cómo ha sido tu experiencia como Coach de CrossFit?

Ha sido bastante enriquecedora. Cada día uno puedo ir aprendiendo e innovando con las progresiones que incluso las puedes practicar tu mismo por diversión.

28. ¿Cómo estructuras una clase de CrossFit?

Primero, inicio con un calentamiento enfocado en las articulaciones enfocados en la ciática, rodillas, hombros y muñecas; luego hago un mini workout sin usar mucho peso orientado a calentar los músculos. De ahí, viene la práctica de técnica, donde se se enseña al alumno cómo realizar un ejercicio y determinar si debe o no hacerse una adaptación; posteriormente, se hace el WOD, la cual dependerá del head coach, y finalmente, el estiramiento; el cual abarca unos 10 minutos.

29. ¿Qué es el CrossFit Level 1 certificate?

Es la certificación que debe obtener todo coach para la enseñanza del CrossFit; así como todo dueño de CrossFit para poder aperturar un box.

30. ¿Qué opinas de aquellos Box de CrossFit que no están afiliados?

Son un peligro para este negocio; debido a que, al no contar con las condiciones mínimas de afiliación, producen una mala reputación al CrossFit. Esto, en razón al uso indebido de la denominación, la mala enseñanza y pésima infraestructura.

31. ¿Conoces el nivel de participación en el mercado de cada uno de los CrossFit de Lima?

Es un poco difícil determinar el nivel de participación de cada box de CrossFit en el mercado peruano; ya que, no existe un estudio que haya determinado dichas cifras. Lo que podemos hacer es dividir el mercado de boxes de CrossFit afiliados aperturados hasta la fecha y cuantas sedes tiene cada uno de estos.

32. ¿Haz tenido alumnos que han sufrido de obesidad o sobrepeso?

Claro, es normal encontrar a muchas personas que van a los centros de entrenamiento para bajar de peso y mejorar su salud.

33. ¿Cuál ha sido el caso de obesidad más alarmante que hayas atendido como Coach?

Fue el de una señora de 55 años, quién pesaba 95 kilos, sufría de las rodillas y era asmática. Se le realizó muchas adaptaciones en los entrenamientos para que progresivamente mejore. Por ejemplo, ella no podía hacer una sentadilla completa, iniciamos con sentarse en una silla y que se pare, lo cual compensaba el ejercicio. Se 
le hizo un seguimiento diario. Hoy en día, la señora pesa 65 y ya puede hacer sentadillas completas e incluso puede pararse de manos.

34. ¿Cómo es el entrenamiento para las personas con obesidad o sobrepeso?

Debe medirse su capacidad física y hacer una evaluación completa, si sufre de algún problema de salud o tiene alguna lesión. Luego se pasa a enseñarle las técnicas de rutina del día; y si no puede ejecutarlas, se realiza las progresiones y adaptaciones respectivas.

35. A parte de realizar el entrenamiento ¿Los alumnos llevan una dieta?

Por supuesto, el ejercicio se complementa con una buena alimentación.

36. ¿Consideras que una persona normal que practica CrossFit, debe alimentarse al igual que un atléta de élite?

No, un atleta CrossFit o de cualquier deporte, entrena entre 5 a 8 horas diarias, el consumo de calorías en proporción a los carbohidratos y proteínas son mayores; además, ellos ya se encuentran en un estado fitness, por lo tanto, a veces suelen darse su día de comida chatarra en cantidades grandiosas. Si una persona que inicia, come igual que ellos, pero solo entrena 1 hora al día; sin duda, los resultados no serán los deseados.

37. ¿Qué tan propenso es una persona a quedar lastimada al practicar el CrossFit? Dependiento de que tán preparado sea el Coach, por lo general si el alumno sigue las indicaciones y el Coach está al pendiente de este, las probabilidades son mínimas.

38. ¿Cuál es el error más grave en la que incurren las personas que practican el CrossFit? El no seguir un ritmo constante y querer aumentar peso a las barras rápido, sin haber dominado la técnica.

39. ¿Qué recomendación darías a una persona que aún no ha intentado el CrossFit? Que lo intente sin pensarlo dos veces. Si quieren superar sus límites tener una mejor salud y mejorar sus capacidades físicas, el CrossFit será su mejor aliado.

40. ¿Qué opinas de la apertura de un box de CrossFit en uno de los distritos con elevado porcentaje de obesidad como Ate?

Sería un golazo. Expandir la comunidad CrossFit en zonas donde la obesidad se ha apoderado ayudaría en gran parte a combatirla. Ya que el CrossFit se adecua a cualquier persona, estilo de vida y horario.

41. Finalmente, dada tu experiencia como coach en diversos box de CrossFit, te presentamos los siguientes factores críticos del éxito; así como, los principales competidores que se ha considerado en la presente investigación, con el fin de identificar las fortalezas y debilidades de cada uno de ellos; ante ello, ¿Qué calificación le darías a los competidores en razón a cada uno de los factores criticos? teniendo en cuenta que cuatro (4), es fortaleza principal; tres (3), es fortaleza menor; dos (2), debilidad menor; y, uno (1), es debilidad principal.

(*) se le entregó al entevistado una ficha (ver apéndice 33), donde consignó la calificación respectiva. Posteriormente, se agradeció la entrevista.

\section{Datos Básicos}

Nombre de la Empresa: CrossFit La Molina

Ubicación: Calle el grifo 100, La Molina.

Cargo del entrevistado: Coach

Número de trabajadores en la compañía 8 
Apéndice 33: Calificación de Factores Críticos por Experto 3

\begin{tabular}{lccccc}
\hline Factores críticos & Peso & $\begin{array}{c}\text { CrossFit } \\
\text { La Molina }\end{array}$ & $\begin{array}{c}\text { Legado } \\
\text { CrossFit }\end{array}$ & $\begin{array}{c}\text { CrossFit } \\
\text { Ramus }\end{array}$ & $\begin{array}{c}\text { CrossFit } \\
\text { Marut }\end{array}$ \\
\hline Participación en el Mercado & 0.07 & 2 & 3 & 4 & $(\mathrm{q})$ \\
Competitividad de los precios & 0.07 & 1 & 3 & 4 & 3 \\
Respaldo Ecónomico & 0.08 & 1 & 2 & 4 & 3 \\
Calidad del servicio & 0.1 & 1 & 3 & 2 & 3 \\
Lealtad del cliente & 0.06 & 1 & 2 & 2 & 2 \\
Publicidad & 0.06 & 2 & 3 & 3 & 3 \\
Imagen de la marca & 0.07 & 3 & 3 & 2 & 4 \\
Red de contactos & 0.08 & 1 & 1 & 4 & 3 \\
Red de ventas & 0.06 & 2 & 2 & 4 & 3 \\
Experiencia en el sector & 0.07 & 3 & 1 & 4 & 3 \\
Infraestructura & 0.08 & 1 & 3 & 4 & 3 \\
Promociones & 0.07 & 1 & 3 & 4 & 1 \\
Ubicación & 0.13 & 1 & 2 & 2 & 1 \\
\hline
\end{tabular}




\section{Apéndice 34: Síntesis de Calificación de Factores Críticos}

\begin{tabular}{|c|c|c|c|c|c|c|c|c|c|c|c|c|c|c|c|c|c|}
\hline \multirow[t]{3}{*}{ Factores criticos } & & \multicolumn{4}{|c|}{ CrossFit La Molina } & \multicolumn{4}{|c|}{ Legado CrossFit } & \multicolumn{4}{|c|}{ CrossFit Ramus } & \multicolumn{4}{|c|}{ CrossFit Marut } \\
\hline & & E1 & E2 & E3 & Total & E1 & E2 & E3 & Total & E1 & E2 & E3 & Total & E1 & E2 & E3 & Total \\
\hline & Peso & & $(q)$ & & & & $(q)$ & & & & $(q)$ & & & & $(q)$ & & \\
\hline Participación en el mercado & 0.07 & 3 & 2 & 2 & 2.3 & 3 & 3 & 3 & 3 & 4 & 4 & 4 & 4 & 4 & 4 & 4 & 4 \\
\hline Competitividad de los precios & 0.07 & 1 & 2 & 1 & 1.3 & 2 & 3 & 3 & 2.7 & 3 & 3 & 4 & 3.3 & 3 & 3 & 3 & 3 \\
\hline Respaldo económico & 0.08 & 2 & 1 & 1 & 1.3 & 2 & 1 & 2 & 1.7 & 4 & 4 & 4 & 4 & 4 & 3 & 3 & 3.3 \\
\hline Calidad del servicio & 0.1 & 3 & 1 & 1 & 1.7 & 2 & 3 & 3 & 2.7 & 3 & 4 & 2 & 3 & 3 & 3 & 3 & 3 \\
\hline Lealtad del cliente & 0.06 & 2 & 1 & 1 & 1.3 & 2 & 3 & 2 & 2.3 & 2 & 2 & 2 & 2 & 2 & 2 & 2 & 2 \\
\hline Publicidad & 0.06 & 2 & 2 & 2 & 2 & 2 & 3 & 3 & 2.7 & 3 & 4 & 3 & 3.3 & 3 & 3 & 3 & 3 \\
\hline Imagen de la marca & 0.07 & 2 & 1 & 3 & 2 & 2 & 3 & 3 & 2.7 & 3 & 2 & 2 & 2.3 & 2 & 3 & 4 & 3 \\
\hline Red de contactos & 0.08 & 1 & 1 & 1 & 1 & 2 & 2 & 1 & 1.7 & 4 & 4 & 4 & 4 & 4 & 3 & 3 & 3.3 \\
\hline Red de ventas & 0.06 & 1 & 1 & 2 & 1.3 & 1 & 3 & 2 & 2 & 4 & 4 & 4 & 4 & 3 & 3 & 3 & 3 \\
\hline Experiencia en el sector & 0.07 & 3 & 2 & 3 & 2.7 & 1 & 1 & 1 & 1 & 3 & 4 & 4 & 3.7 & 3 & 4 & 3 & 3.3 \\
\hline Infraestructura & 0.08 & 2 & 1 & 1 & 1.3 & 2 & 3 & 3 & 2.7 & 3 & 4 & 4 & 3.7 & 3 & 2 & 3 & 2.7 \\
\hline Promociones & 0.07 & 2 & 1 & 1 & 1.3 & 3 & 3 & 3 & 3 & 1 & 3 & 4 & 2.7 & 2 & 2 & 1 & 1.7 \\
\hline Ubicación & 0.13 & 2 & 3 & 1 & 2 & 2 & 2 & 2 & 2 & 1 & 1 & 2 & 1.3 & 1 & 2 & 1 & 1.3 \\
\hline
\end{tabular}

Nota: (q) y (r) son las denominaciones a calificación y resultado, respectivamente. E1, E2 y E3 son las denominaciones a experto 1, experto 2 y experto 3 ,

respectivamente. Matriz de perfil competitivo Adaptado de "Strategic Management: A Competitive Advantage Approach Concepts", por Fred R. David, 2013, Pearson Education, Inc., 14, p. 83. Copyright 213 por Pearson Educación de México S.A. de C.V 


\section{Apéndice 35: Resultados de Calificación por Expertos}

\begin{tabular}{lccccc}
\hline Factores criticos & & $\begin{array}{c}\text { CrossFit } \\
\text { La Molina }\end{array}$ & $\begin{array}{c}\text { Legado } \\
\text { CrossFit }\end{array}$ & $\begin{array}{c}\text { CrossFit } \\
\text { Ramus }\end{array}$ & $\begin{array}{c}\text { CrossFit } \\
\text { Marut }\end{array}$ \\
\hline & Peso & $(q)$ & $(q)$ & $(q)$ & $(q)$ \\
\hline Participación en el mercado & 0.07 & 2 & 3 & 4 & 4 \\
Competitividad de los precios & 0.07 & 1 & 3 & 3 & 3 \\
Respaldo económico & 0.08 & 1 & 2 & 4 & 3 \\
Calidad del servicio & 0.1 & 2 & 3 & 3 & 3 \\
Lealtad del cliente & 0.06 & 1 & 2 & 2 & 2 \\
Publicidad & 0.06 & 2 & 3 & 3 & 3 \\
Imagen de la marca & 0.07 & 2 & 3 & 2 & 3 \\
Red de contactos & 0.08 & 1 & 2 & 4 & 3 \\
Red de ventas & 0.06 & 1 & 2 & 4 & 3 \\
Experiencia en el sector & 0.07 & 3 & 1 & 4 & 4 \\
Infraestructura & 0.08 & 1 & 3 & 4 & 3 \\
Promociones & 0.07 & 1 & 3 & 3 & 2 \\
Ubicación & 0.13 & 2 & 2 & 1 & 1 \\
\hline
\end{tabular}

Nota: (q) es la denominación a calificación, misma que deriva del resultado final de cada factor crítico por parte de los expertos. 


\section{Apéndice 36: Transcripción de Entrevista a Experto 4}

Entrevistada: Carmen Quinteros Reyes

Fecha: 17/04/2018

Introducción

Buenas tardes, somos alumnos de la Maestría en Ciencias Empresariales de la Universidad

San Ignacio de Loyola y queremos agradecerle por el tiempo que nos está brindando y quisiera pedirle por favor responder con toda confianza las preguntas, ya que la información que usted nos otorgue será estrictamente confidencial y único uso para la presente investigación.

\section{OBJETIVO DEL ESTUDIO}

Investigar si el CrossFit es una alternativa idónea para combatir la obesidad.

\section{PREGUNTAS}

\section{A. Conociendo al entrevistado (5 min.)}

1. Cuéntanos un poco de ti, ¿Cuántos años tienes?

Tengo 27 años

2. Cuál es tu profesión?

Soy Nutricionista deportiva.

3. ¿En qué Universidad estudiaste?

En la UPC. Actualmente soy candidata a la Maestría en Nutrición, Actividad Física y Salud Pública en la Universidad de Bristol en Reino Unido.

\section{B. Conocimiento de la obesidad (10 min)}

4. ¿Cómo ves el crecimiento de la obesidad en los últimos años?

Sin duda alguna, es muy alarmante. Las últimas cifras de la OMS indican que el incremento tanto de la obesidad como el sobrepeso se ha triplicado, más en los países no desarrollados. Asimismo, se ha determinado que la obesidad está atacando a los niños a gran escala. Esto último, se debe a que en países como en el Perú, las instituciones del estado no regulan el contenido de algunos productos, así como la venta de la misma en los niños. Esta enfermedad, tiende a aumentar en los próximos años, la vida sedentaria y los malos hábitos alimenticios seguiran en constante expansión.

5. ¿Cuál es el balance perfecto para poder combatir la obesidad?

Podríamos decir que un $20 \%$ es la actividad física constante y un $80 \%$ es la buena alimentación. Por más que entrenes 2 a 4 horas al día y tu alimentación no sea idónea, los resultados no van aparecer.

6. Dentro de tu carrera profesional, ¿Cuál ha sido el caso de obesidad más alarmante que hayas atendido?

El de un joven de 24 años, quién padecía de obesidad grado 3 o como comunmente llamamos obesidad mórbida. Este joven sufría de dicha enfermedad desde los 10 años y conforme iba creciendo, su peso aumentaba; a tal punto que llego a pesar 150 kilos. Hoy en día pesa 85, pero la pérdida de peso ha sido larga. Su plan nutricional se enfocó en reducir los carbohidratos y reemplazar los azúcares.

\section{Conocimiento del CrossFit (25 min)}

7. ¿Cómo ha sido tu experiencia al practicar CrossFit?

Muy gratificante. Bueno, al principio me llamo la atención este tipo de entrenamiento por no tener una rutina de ejercicio constante, la cual se da en los gimnasios; 
asimismo, el nivel de exigencia y uso de equipos menos costosos. Luego de practicarlo, me ofrecieron ser la nutricionista de Legado CrossFit, la cual acepté, puesto que vi un nuevo mercado al cual enfocarme como nutricionista deportiva para personas quebuscan un nuevo estilo de vida y un estado fitness.

8. ¿Cómo ha sido tu experiencia como nutricionista en un box de CrossFit? Muy enriquecedora, puesto que me ha ayudado mucho en mi especialización como nutricionista deportiva y gracias a ello, pude candidatear a la maestría.

9. ¿Consideras que el CrossFit es un estilo de vida? ¿Por qué?

$\mathrm{Si}$, el CrossFit al inicio es un deporte nuevo que vas experimentando y conforme van avanzando los días, el reto de superarte a ti mismo y encontrar un lado deportivo que desconocías, te hace formar parte de una comunidad. Además, te pegas mucho con los eventos que tiene como los CrossFit Games, las competencias internas y con el estilo que llevan los atletas de élite. Además, te permite ser más competitivo, mejora tus habilidades físicas, psicomotriz, coordinación y autoestima. En si, el CrossFit es un paquete completo para todo.

10. En relación a otros tipos de entrenamiento, ¿Consideras que el CrossFit es una buena alternativa para combatir la obesidad? ¿Por qué?

$\mathrm{Si}$, debido a que tiene una mejor progresión enfocado en las necesidades del consumidor. En los gimnasios, por lo general, utilizan siempre el mismo esquema, cardio, y peso; en el CrossFit, te enseñan a mejorar tu agilidad, a que domines tu cuerpo y mente de manera progresiva. Si hoy no puedes hacer un pull up, créeme que cuando menos lo pienses podrás hacer 10 a 15. Asimismo, ejecutar movimientos funcionales con alta intesidad en períodos de tiempo breves, hacen que puedas quemar muchas más calorias que correr por una hora.

11. ¿Cuál es el error más grave que tienen las personas que practican el CrossFit en relación a sus hábitos alimenticios?

Si bien, luego de una clase de CrossFit terminas con mucha hambre, debes buscar alimentos que compensen el desgaste físico que has realizado como por ejemplo, comer una pechuga de pollo con palta en trozos y beber agua, te ayudarán a retribuir las calorias gastadas y le devolverá a tu cuerpo las energias necesarias. Pero lamentablemente, las personas hacen las cosas diferente, en vez de comer sano, salen y comen una hamburguesa con papas fritas y gaseosa, o van a comer parrilla o pizza, alegando que las calorías que consumen, ya las quemaron. Esto último debe corregirse y enseñarles que de nada sirve matarse entrenando para que luego no haga efecto en los resultados.

12. ¿Consideras que una persona normal que practica CrossFit, debe alimentarse al igual que un atléta de élite?

No, todas las personas tenemos un organismo distinto del otro. Por lo tanto, si igualamos la dieta de un atleta CrossFit en vez de conseguir resultados, estaremos empeorando nuestro organismo. La alimentación debe ser concordante al peso de cada persona y a su estado de salud. No puedes darle el mismo esquema de nutrición a una persona con obesidad grado 3 que a una que tiene diabetes o que es celiática.

13. Entonces ¿Cómo debe de alimentarse una persona que practica el CrossFit?

$\mathrm{Su}$ alimentación debe ser de acuerdo a sus objetivos, peso, salud y estado en el que se encuentra la persona. Luego de ello, su plan de nutrición será enfocado a cada objetivo; pero siempre se empieza por una dieta para limpiar el organismo y que ayude a quemar grasa.

14. ¿Qué opinas de la apertura de un box de CrossFit en uno de los distritos con elevado porcentaje de obesidad como Ate? 
Me parece excelente, la actividad física debe propagarse en aquellos distritos con elevado porcentaje de obesidad. Aperturar un box de CrossFit, sin duda ayudaría mucho a combatirla; ya que es una propuesta distinta a las tradicionales. Además, se asegura la reducción de peso y la mejora en la salud.

15. ¿Qué recomendación darías a una persona que aún no ha intentado el CrossFit? Que se atreva a realizar una clase de prueba, y verá que el CrossFit es completo en razón a otras actividades físicas. No se van arrepentir.

\section{Datos Básicos}

Nombre de la Empresa: Legado CrossFit

Ubicación: Av. Javier Prado Este 5950, La Molina.

Cargo del entrevistado: Nutricionista

Número de trabajadores en la compañía 10

Muchas Gracias por su participación 
Apéndice 37: Resumen de Cuestionario

\begin{tabular}{lc}
\hline Objetivos & Preguntas \\
\hline Perfil de población & 1,35 y 36 \\
Motivo por el cual realiza actividad física & 9 \\
Estacionalidad para realizar actividad física & 12 \\
Factores que influyen para elegir un centro de entrenamiento & 13 \\
Intención de asistencia a un box de CrossFit & 20 y 29 \\
Gasto promedio dispuesto a pagar por membresía CrossFit & 25 \\
Motivo por el cuál harían CrossFit & 21 \\
Frecuencia con la que acudirían al Box de CrossFit & 22 \\
Horario de asistencia al Box de CrossFit & 23 \\
Tendencia en la adquisición de membresía & 15 \\
Promociones con las que debe contar el box de CrossFit & 27 \\
Preferencia en uso de medios de comunicación & 28 \\
\hline
\end{tabular}




\section{Apéndice 38: Esquema de Cuestionario de Opinión}

Buenos días/tardes, somos alumnos de la maestría en Ciencias Empresariales de la Universidad San Ignacio de Loyola y estamos realizando una investigación acerca de un modelo de negocio para combatir la obesidad en uno de los distritos con mayor porcentaje de obesidad. Para ello, le agradecemos nos conceda unos minutos de su tiempo para contestar el presente cuestionario. Por favor, le pedimos responda las siguientes preguntas, cuyas respuestas serán tratadas de manera confidencial y será utilizada como objeto de estudio. Agradecemos su participación.

\section{FILTRO}

1. ¿Usted vive en el distrito de Ate?

$\mathrm{Si}$

Si la respuesta es "no", ha concluido la encuesta; muchas gracias.

2. ¿Usted realiza alguna actividad física?

$\mathrm{Si}$

Si la respuesta es "si" pasar a la pregunta 4; si la respuesta es "no", pasar a la pregunta 3

3. ¿Por qué motivos no realiza actividad física?
a. Indisponibilidad de tiempo
b. Lesión
c. No me gusta hacer ejercicio
d. No encuentro un deporte que me motive
e. Me aburren las rutinas de ejercicio
f. Otro (por favor especifique)

Si las respuestas son "a" o "b" o "c", ha concluido la encuesta; muchas gracias.

Si las respuestas son "d", "e" o "f" pasar a explicación pregunta 20

4. ¿Usted realiza la actividad física en su distrito (Ate)?

$\mathrm{Si}$

No

\section{HÁBITOS DE CONSUMO}

5. ¿Cuál de las siguientes actividades físicas usted realiza?
a. Gimnasio
b. Functional Training
c. Baile
d. Deportes
e. CrossFit
f. Otro (por favor especifique)

Si la respuesta es "a", "b", "c", "d" y "f" pasar a la pregunta 9 
6. Por favor indíquenos a qué Box (gimnasio) de CrossFit acude:

7. Por favor indíquenos a qué distrito pertenece su Box (gimnasio) de CrossFit:

8. ¿Estaría dispuesto a cambiar su Box (gimnasio) de CrossFit, por uno que esté en su distrito?

$\mathrm{Si}$

Si la respuesta es "no", ha concluido la encuesta; muchas gracias. Se llena los datos del encuestado.

Si la respuesta es "si", pasar a la pregunta 22

9. ¿Qué le motiva a realizar la actividad física?
a. Salud
b. Buen estado físico
c. Buena imagen
d. Mejorar mis capacidades físicas
e. Bajar de peso
f. Otro (por favor especifique)

10. ¿Con qué frecuencia realiza la actividad física?
a. Diario
b. Interdiario
c. Tres veces por semana
d. Dos veces por semana
e. Una vez por semana
f. Otro (por favor especifique)

11. Por favor indíquenos ¿Cuánto tiempo le dedica a la actividad física dentro de su centro de entrenamiento? horas

12. En qué estación del año suele realizar mayor actividad física
a. Verano (22 diciembre - 21 marzo)
b. Otoño (22 marzo - 21 junio)
c. Invierno (22 julio - 22 setiembre)
d. Primavera ( 23 setiembre -11 diciembre) 
13. ¿Qué factor consideró importante para elegir su centro de entrenamiento?
a. Horarios accesibles
b. Ubicación accesible
c. Precio
d. Calidad del servicio
e. Infraestructura
f. Buenos entrenadores
g. Indiferente
h. Otro (por favor especifique)

14. Indique usted ¿A cuanto asciende su gasto promedio mensual por el servicio que le ofrecen en su centro de entrenamiento? soles

15. ¿Cómo suele contratar su membresía en un centro de entrenamiento?
a. Mensual
b. Trimestral
c. Semestral
d. Anual

16. ¿Cómo es su sistema de pago al contratar una membresía en un centro de entrenamiento?
a. Tarjeta de Crédito
b. Tarjeta de débito
c. En efectivo
d. Transacción bancaria
e. Otro (por favor especifique)

17. Por favor califique del 1 al 5, siendo 1 muy malo y 5 muy bueno, los aspectos clave de su centro de entrenamiento

\begin{tabular}{|l|c|c|c|c|c|}
\hline & $\begin{array}{c}1 \\
\text { Muy malo }\end{array}$ & $\begin{array}{c}2 \\
\text { Malo }\end{array}$ & $\begin{array}{c}3 \\
\text { Regular }\end{array}$ & $\begin{array}{c}4 \\
\text { Bueno }\end{array}$ & $\begin{array}{c}5 \\
\text { Muy Bueno }\end{array}$ \\
\hline Infraestructura & & & & & \\
\hline Equipamiento & & & & & \\
\hline Entrenadores & & & & & \\
\hline Grupo social & & & & & \\
\hline Limpieza & & & & & \\
\hline Seguridad & & & & & \\
\hline Servicio al cliente & & & & & \\
\hline
\end{tabular}


18. ¿Cuál de los siguientes factores influirían al momento de adquirir una membresía en un centro de entrenamiento?
a. Descuentos
b. Promoción de días adicionales
c. Promoción de días de congelamiento de membresía
d. Promoción de días adicionales y de congelamiento de membresía
e. Indumentaria deportiva de cortesía
f. Descuentos en ropa deportiva
g. Indiferente
h. Otro (por favor especifique)

19. ¿Por qué medio de comunicación se enteró de la información de su centro de entrenamiento?
a. Redes sociales
b. Radio
c. Televisión
d. Periódicos y/o Revistas
e. Correos electrónicos
f. Página web
g. Otros (por favor especifique)

\section{Evaluación Del Concepto Del Modelo De Negocio Propuesto}

EXPLICACIÓN: Si usted supiese que existe un centro de entrenamiento "CrossFit" basado en movimientos funcionales de constante variación y ejecutados a alta intensidad, que combina las diversas disciplinas del fitness como: levantamiento de peso, gimnasia y ejercicios aeróbicos con progresión en cada persona a cualquier edad, optimizando las capacidades físicas; así como, la obtención de resultados en corto tiempo; cuya duración por clase es de 1 hora, divididas en: calentamiento, práctica de técnica, entrenamiento y estiramiento.

20. ¿Estaría dispuesto a asistir a este tipo de entrenamiento?
a. Definitivamente asistiría.
b. Probablemente asistiría
c. No sabe
d. Probablemente no asistiría
e. Definitivamente no asistiría.

Si la respuesta es "d" o "e" ha concluido la encuesta; muchas gracias.

Se llena los datos del encuestado 
21. ¿Cuál sería la razón por la cual practicaría?
a. Mejorar mi estado físico
b. Mejorar mi imagen
c. Rápidos resultados
d. Para ser un atleta CrossFit
e. Por salud
f. Otro (por favor especifique)

22. Bajo la premisa indicada, en razón al tiempo de cada clase de CrossFit (1 hora); indíquenos ¿Con que frecuencia que acudiría a entrenar?
a. Diario
b. Lunes a viernes
c. Interdiario
d. Fines de semana
e. Otro (por favor especifique)

23. ¿Qué horario prefiere para asistir al Box (gimnasio) de CrossFit? Puede indicar más de una opción

\begin{tabular}{|l|l|}
\hline Entre 6 a.m. y 9 a.m. & \\
\hline Entre 9 a.m. y 12 a.m. & \\
\hline Entre 12 p.m. y 3 p.m. & \\
\hline Entre 3 p.m. y 6 p.m. & \\
\hline Entre 6 p.m. y10 p.m. & \\
\hline
\end{tabular}

24. Por favor califique del 1 al 5 qué tan importante sería para usted los aspectos clave que un Box (gimnasio) de CrossFit debería considerar para su inscripción; siendo 1, nada importante; 2 , ligeramente importante; 3 , un poco importante; 4 , muy importante y 5 , extremadamente importante.

\begin{tabular}{|l|l|l|l|l|l|}
\hline & 1 & 2 & 3 & 4 & 5 \\
\hline Entrenadores certificados & & & & & \\
\hline Ambiente amplio & & & & & \\
\hline Equipos en buen estado & & & & & \\
\hline Grupo social activo & & & & & \\
\hline Promociones & & & & & \\
\hline Limpieza & & & & & \\
\hline Seguridad & & & & & \\
\hline Precio & & & & & \\
\hline
\end{tabular}


25. ¿Cuál sería el rango de precios que usted estaría dispuesto a pagar por una membresía mensual de CrossFit?
a. Entre S/. 200 a S/. 250 nuevos soles
b. Entre S/. 251 a S/. 280 nuevos soles
c. Entre S/. 281 a S/. 300 nuevos soles
d. Entre S/. 301 a S/. 350 nuevos soles

26. Bajo que manera le gustaría efectuar el pago de su membresía
a. Efectivo
b. Tarjeta de crédito
c. Tarjeta de débito
d. Transferencia bancaria
e. Otro (por favor especifique)

27. ¿Qué tipo de promociones le gustaría encontrar?
a. Descuentos
b. Promoción de días adicionales
c. Promoción de días de congelamiento de membresía
d. Promoción de días adicionales y de congelamiento de membresía
e. Indumentaria deportiva de cortesía
f. Descuentos en ropa deportiva
g. Indiferente
h. Otro (por favor especifique)

28. ¿Mediante qué medios le gustaría estar informado de las noticias, entrenamientos y eventos del Box (gimnasio) de CrossFit?

Puede elegir hasta 3 opciones

\begin{tabular}{|l|l|}
\hline & Marque con una X \\
\hline Redes sociales & \\
\hline Aplicación móvil & \\
\hline Correos electrónicos & \\
\hline Revistas semanales & \\
\hline Periódicos semanales & \\
\hline Volantes (flyers) & \\
\hline Radio & \\
\hline
\end{tabular}




\section{Interés De Compra Y Nivel Satisfacción}

29. Si el Box (gimnasio) de CrossFit, cumpliese con las expectativas de compra que ha indicado; ¿Usted se inscribiría en este servicio?

$\mathrm{Si}$

No

\section{Filtro De Nivel Socio Económico}

30. ¿Cuál es su grado de instrucción?
a. Primaria completa
b. Primaria incompleta
c. Secundaria completa
d. Secundaria incompleta
e. Superior técnica
f. Superior técnica incompleta
g. Universitaria
h. Universitaria incompleta
i. Post grado
j. Doctorado

31. ¿Actualmente se encuentra trabajando?

$\mathrm{Si}$

No

32. ¿Cuál de estas comodidades posee en su hogar?

Puede señalar hasta 3 opciones
a. Televisor led
b. Laptop
c. Refrigeradora
d. Cocina
e. Lavadora
f. Play station

33. En caso de emergencia, ¿A dónde acudiría?
a. Hospital
b. Clínica
c. Posta
d. Doctor particular
e. Centro de salud municipal 


\section{Datos Personales}

34. En razón a su peso corporal, en qué situación se considera usted:
a. Falto de peso
b. Sobrepeso mínimo
c. Sobrepeso excesivo
d. Peso ideal

35. Seleccione el rango de edad a la que usted pertenece

\begin{tabular}{|c|c|}
\hline $\begin{array}{llll}\text { Entre } & 14 & \text { a } & 17 \\
\text { años } & & & \end{array}$ & \\
\hline $\begin{array}{llll}\text { Entre } & 18 & \text { a } & 21 \\
\text { años } & & & \\
\end{array}$ & \\
\hline $\begin{array}{llll}\text { Entre } & 22 & \text { a } & 30 \\
\text { años } & & & \end{array}$ & \\
\hline $\begin{array}{llll}\text { Entre } & 31 & \text { a } & 49 \\
\text { años } & & & \end{array}$ & \\
\hline $\begin{array}{llll}\text { Entre } & 50 & \text { a } & 59 \\
\text { años } & & & \end{array}$ & \\
\hline $\begin{array}{llll}\text { Entre } & 60 & \text { a } & 67 \\
\text { años } & & & \end{array}$ & \\
\hline Entre 68 a más & \\
\hline
\end{tabular}

36. Sexo

Masculino Femenino

Nombre y apellido:

Email:

Ocupación: 


\section{Apéndice 39: Resultados de Cuestionario de Opinión}

Buenos días/tardes, somos alumnos de la maestría en Ciencias Empresariales de la Universidad San Ignacio de Loyola y estamos realizando una investigación acerca de un modelo de negocio para combatir la obesidad en uno de los distritos con mayor porcentaje de obesidad. Para ello, le agradecemos nos conceda unos minutos de su tiempo para contestar el presente cuestionario. Por favor, le pedimos responda las siguientes preguntas, cuyas respuestas serán tratadas de manera confidencial y será utilizada como objeto de estudio. Agradecemos su participación.

Dirección de correo Electrónico:

\section{FILTRO}

1. ¿Usted vive en el distrito de Ate?

Total de respuestas: 440.

Si $(438,99.5 \%) \quad$ No $(2,0.5 \%)$

Si la respuesta es "no", ha concluido la encuesta; muchas gracias.

2. ¿Usted realiza alguna actividad física?

Total de respuestas: 438 .

Si $(157,35.8 \%) \quad$ No $(281,64.2 \%)$

Si la respuesta es "si" pasar a la pregunta 4; si la respuesta es "no", pasar a la pregunta 3

3. ¿Por qué motivos no realiza actividad física?

Total de respuestas: 281 .

a. Indisponibilidad de tiempo $(26.7 \%)$

b. Lesión $(7.8 \%)$

c. No me gusta hacer ejercicio $(12.1 \%)$

d. No encuentro un deporte que me motive $(19.6 \%)$

e. Me aburren las rutinas de ejercicio (12.1\%)

f. Otro (por favor especifique)

Falta de interés deportivo (12.8\%), mala experiencia (1.8\%), falta de interés $(1.8 \%)$, pereza $(1.1 \%)$, insatisfacción con el servicio $(0.7 \%)$, mala experiencia $(0.11 \%)$, desinterés en el tema $(0.14 \%)$, no hay un gimnasio cerca $(0.8 \%)$, y no hay un centro de entrenamiento cerca $(0.4 \%)$.

Si las respuestas son "a" o "b" o "c", ha concluido la encuesta; muchas gracias.

Si las respuestas son "d", "e" o "f" pasar a explicación pregunta 20.

4. ¿Usted realiza la actividad física en su distrito (Ate)?

Total de respuestas: 157 .

$\mathrm{Si}(69.4 \%) \quad$ No $(30.6 \%)$ 


\section{HÁBITOS DE CONSUMO}

5. ¿Cuál de las siguientes actividades físicas usted realiza?

Total de respuestas: 157.

a. Gimnasio (43.9\%)

b. Functional Training (18.5\%)

c. Baile $(12.7 \%)$

d. Deportes $(17.8 \%)$

e. CrossFit $(5.1 \%)$

f. Otro (por favor especifique)

Correr (1.9\%)

Si la respuesta es “a”, “b”, “c”, "d” y "f” pasar a la pregunta 9

6. Por favor indíquenos a qué Box (gimnasio) de CrossFit acude:

Total de respuestas: 8 .

CrossFit Ramus (2), Legado CrossFit (2), CrossFit La Molina (2), Latido CrossFit (2).

7. Por favor indíquenos a qué distrito pertenece su Box (gimnasio) de CrossFit:

Total de respuestas: 8 .

La Molina (4), Miraflores (1) y Surco (3).

8. ¿Estaría dispuesto a cambiar su Box (gimnasio) de CrossFit, por uno que esté en su distrito?

Total de respuestas: 8

Si $(100 \%) \quad$ No (-)

Si la respuesta es "no", ha concluido la encuesta; muchas gracias. Se llena los datos del encuestado.

Si la respuesta es "si", pasar a la pregunta 22

9. ¿Qué le motiva a realizar la actividad física?

Total de respuestas: 149.

a. Salud $(19.5 \%)$

b. Buen estado físico $(22.8 \%)$

c. Buena imagen $(14.8 \%)$

d. Mejorar mis capacidades físicas (7.4\%)

e. Bajar de peso $(29.5 \%)$

f. Otro (por favor especifique)

Relajarme $(4.7 \%)$, mantenerme en forma $(0.7 \%)$ y entretenimiento $(0.7 \%)$ 
10. ¿Con qué frecuencia realiza la actividad física?

Total de respuestas: 149.
a. Diario $(25.5 \%)$
b. Interdiario $(22.1 \%)$
c. Tres veces por semana $(36.2 \%)$
d. Dos veces por semana $(11.4 \%)$
e. Una vez por semana $(4.7 \%)$
f. Otro (por favor especifique)

11. Por favor indíquenos ¿Cuánto tiempo le dedica a la actividad física dentro de su centro de entrenamiento?

Total de respuestas: 149.

45 minutos (2\%), 50 minutos (1\%), 1 hora (34\%), 1 hora 15 minutos (1\%), 1 hora 20 minutos (4\%), 1 hora 30 minutos (26\%), 1 hora 45 minutos (1\%), 1 hora 50 minutos (1\%), y 2 horas $(31 \%)$.

12. En qué estación del año suele realizar mayor actividad física

Total de respuestas: 149.
a. Verano (22 diciembre - 21 marzo) $(33.6 \%)$
b. Otoño (22 marzo - 21 junio) (3.4\%)
c. Invierno (22 julio - 22 setiembre) $(14.8 \%)$
d. Primavera (23 setiembre -11 diciembre) $(48.3 \%)$

13. ¿Qué factor consideró importante para elegir su centro de entrenamiento?

Total de respuestas: 149.
a. Horarios accesibles $(22.1 \%)$
b. Ubicación accesible (30.2\%)
c. Precio $(11.4 \%)$
d. Calidad del servicio $(3.4 \%)$
e. Infraestructura $(4.7 \%)$
f. Buenos entrenadores $(3.4 \%)$
g. Indiferente $(19.5 \%)$
h. Otro (por favor especifique)

Comodidad (1.3\%), experiencia (1.3\%), reuniones de amistad $(0.7 \%)$, años de experiencia en el mercado $(0.7 \%)$, nombre de la empresa $(0.7 \%)$, y años en el mercado $(0.7 \%)$.

14. Indique usted ¿A cuanto asciende su gasto promedio mensual por el servicio que le ofrecen en su centro de entrenamiento?

Total de respuestas: 149.

De S/. 0.00 a S/. $150.00 \quad(12 \%)$

De S/. 151.00 a S/. $200.00(32 \%)$

De S/. 201.00 a S/. 250.00 (32\%)

De S/. 251.00 a S/. 300.00 (21\%)

De S/. 301.00 a S/. $350.00 \quad(3 \%)$ 
15. ¿Cómo suele contratar su membresía en un centro de entrenamiento?

Total de respuestas: 149.
a. Mensual (43.6\%)
b. Trimestral $(27.5 \%)$
c. Semestral $(14.8 \%)$
d. Anual $(6 \%)$
e. Ninguna $(8.1 \%)$

16. ¿Cómo es su sistema de pago al contratar una membresía en un centro de entrenamiento?

Total de respuestas: 137.
a. Tarjeta de Crédito $(10.2 \%)$
b. Tarjeta de débito $(38 \%)$
c. En efectivo
d. Transacción bancaria $(0 \%)$
e. Otro (por favor especifique) $(0 \%)$

17. Por favor califique del 1 al 5, siendo 1 muy malo y 5 muy bueno, los aspectos clave de su centro de entrenamiento

Total de respuestas: 137.

\begin{tabular}{|l|c|c|c|c|c|}
\hline & $\begin{array}{c}1 \\
\text { Muy malo }\end{array}$ & $\begin{array}{c}2 \\
\text { Malo }\end{array}$ & $\begin{array}{c}3 \\
\text { Regular }\end{array}$ & $\begin{array}{c}4 \\
\text { Bueno }\end{array}$ & $\begin{array}{c}5 \\
\text { Muy Bueno }\end{array}$ \\
\hline Infraestructura & - & - & 36 & 88 & 14 \\
\hline Equipamiento & - & 5 & 74 & 56 & 3 \\
\hline Entrenadores & 3 & 9 & 68 & 46 & 11 \\
\hline Grupo social & 8 & 36 & 57 & 35 & 1 \\
\hline Limpieza & 10 & 26 & 53 & 45 & 3 \\
\hline Seguridad & 5 & 9 & 55 & 64 & 4 \\
\hline Servicio al cliente & 11 & 29 & 69 & 25 & 3 \\
\hline
\end{tabular}

Nota: las cantidades representan al número de personas que seleccionaron los aspectos clave de su centro de entrenamiento

18. ¿Cuál de los siguientes factores influirían al momento de adquirir una membresía en un centro de entrenamiento?

Total de respuestas: 137.
a. Descuentos $(23.4 \%)$
b. Promoción de días adicionales (10.2\%)
c. Promoción de días de congelamiento de membresía (22.6\%)
d. Promoción de días adicionales y de congelamiento de membresía (13.9\%)
e. Indumentaria deportiva de cortesía (19.7\%)
f. Descuentos en ropa deportiva $(2.9 \%)$
g. Indiferente $(7.3 \%)$
h. Otro (por favor especifique) 
19. ¿Por qué medio de comunicación se enteró de la información de su centro de entrenamiento?

Total de respuestas: 137.
a. Redes sociales $(66.4 \%)$
b. Radio (0\%)
c. Televisión $(0 \%)$
d. Periódicos y/o Revistas $(21.2 \%)$
e. Correos electrónicos $(3.6 \%)$
f. Página web $(8.8 \%)$
g. Otros (por favor especifique)

\section{Evaluación Del Concepto Del Modelo De Negocio Propuesto}

Explicación: Si usted supiese que existe un centro de entrenamiento "CrossFit" basado en movimientos funcionales de constante variación y ejecutados a alta intensidad, que combina las diversas disciplinas del fitness como: levantamiento de peso, gimnasia y ejercicios aeróbicos con progresión en cada persona a cualquier edad, optimizando las capacidades físicas; así como, la obtención de resultados en corto tiempo; cuya duración por clase es de 1 hora, divididas en: calentamiento, práctica de técnica, entrenamiento y estiramiento.

20. ¿Estaría dispuesto a asistir a este tipo de entrenamiento?

Total de respuestas: 299.

a. Definitivamente asistiría. (31.1\%)

b. Probablemente asistiría $(29.8 \%)$

c. No sabe $(21.4 \%)$

d. Probablemente no asistiría (14\%)

e. Definitivamente no asistiría. (3.7\%)

Si la respuesta es "d" o "e" ha concluido la encuesta; muchas gracias.

Se llena los datos del encuestado

21. ¿Cuál sería la razón por la cual practicaría?

Total de respuestas: 246.

a. Mejorar mi estado físico $(34.1 \%)$

b. Mejorar mi imagen $(17.1 \%)$

c. Rápidos resultados $(17.5 \%)$

d. Para ser un atleta CrossFit (4.1\%)

e. Por salud $(26.8 \%)$

f. Otro (por favor especifique)

22. Bajo la premisa indicada, en razón al tiempo de cada clase de CrossFit (1 hora); indíquenos ¿Con que frecuencia que acudiría a entrenar?

Total de respuestas: 254.
a. Diario $(21.3 \%)$
b. Lunes a viernes $(44.1 \%)$
c. Interdiario $(34.3 \%)$ 
d. Fines de semana $(0.4 \%)$

e. Otro (por favor especifique)

23. ¿Qué horario prefiere para asistir al Box (gimnasio) de CrossFit?

Puede indicar más de una opción

Total de respuestas: 254 .

\begin{tabular}{|l|c|}
\hline Entre 6 a.m. y 9 a.m. & $52.4 \%$ \\
\hline Entre 9 a.m. y 12 a.m. & $5.5 \%$ \\
\hline Entre 12 p.m. y 3 p.m. & $0.4 \%$ \\
\hline Entre 3 p.m. y 6 p.m. & $2.4 \%$ \\
\hline Entre 6 p.m. y10 p.m. & $39.4 \%$ \\
\hline
\end{tabular}

24. Por favor califique del 1 al 5 qué tan importante sería para usted los aspectos clave que un Box (gimnasio) de CrossFit debería considerar para su inscripción; siendo 1, nada importante; 2 , ligeramente importante; 3 , un poco importante; 4, muy importante y 5 , extremadamente importante.

Total de respuestas: 254 .

\begin{tabular}{|l|c|c|c|c|c|}
\hline & $\mathbf{1}$ & $\mathbf{2}$ & $\mathbf{3}$ & $\mathbf{4}$ & $\mathbf{5}$ \\
\hline Entrenadores certificados & - & - & - & $26 \%$ & $74 \%$ \\
\hline Ambiente amplio & - & - & - & $46 \%$ & $54 \%$ \\
\hline Equipos en buen estado & - & - & - & $37 \%$ & $63 \%$ \\
\hline Grupo social activo & $1 \%$ & $5 \%$ & $17 \%$ & $36 \%$ & $42 \%$ \\
\hline Promociones & - & - & $9 \%$ & $44 \%$ & $48 \%$ \\
\hline Limpieza & - & - & - & $10 \%$ & $90 \%$ \\
\hline Seguridad & - & - & - & $9 \%$ & $91 \%$ \\
\hline Precio & - & - & $10 \%$ & $39 \%$ & $51 \%$ \\
\hline
\end{tabular}

25. ¿Cuál sería el rango de precios que usted estaría dispuesto a pagar por una membresía mensual de CrossFit?

Total de respuestas: 254.
a. Entre S/. 200 a S/. 250 nuevos soles $(60.2 \%)$
b. Entre S/. 251 a S/. 280 nuevos soles $(23.6 \%)$
c. Entre S/. 281 a S/. 300 nuevos soles (15\%)
d. Entre S/. 301 a S/. 350 nuevos soles (1.2\%)

26. Bajo que manera le gustaría efectuar el pago de su membresía

Total de respuestas: 254 .
a. Efectivo (48.4\%)
b. Tarjeta de crédito $(8.3 \%)$
c. Tarjeta de débito $(43.3 \%)$
d. Transferencia bancaria $(0 \%)$
e. Otro (por favor especifique) 
27. ¿Qué tipo de promociones le gustaría encontrar?

Total de respuestas: 254.

a. Descuentos $(17.3 \%)$

b. Promoción de días adicionales $(4.7 \%)$

c. Promoción de días de congelamiento de membresía (2\%)

d. Promoción de días adicionales y de congelamiento de membresía $(55.5 \%)$

e. Indumentaria deportiva de cortesía $(15.7 \%)$

f. Descuentos en ropa deportiva $(3.9 \%)$

g. Indiferente $(0.4 \%)$

h. Otro (por favor especifique)

Majases $(0.4 \%)$

28. ¿Mediante qué medios le gustaría estar informado de las noticias, entrenamientos y eventos del Box (gimnasio) de CrossFit?

Puede elegir hasta 3 opciones

Total de respuestas: 254 .

\begin{tabular}{|l|c|}
\hline & Marque con una X \\
\hline Redes sociales & 231 \\
\hline Aplicación móvil & 179 \\
\hline Correos electrónicos & 76 \\
\hline Revistas semanales & 3 \\
\hline Periódicos semanales & \\
\hline Volantes (flyers) & \\
\hline Radio & 2 \\
\hline
\end{tabular}

Nota: las cantidades representan al número de personas que seleccionaron los aspectos clave de su centro de entrenamiento

\section{Interés De Compra Y Nivel Satisfacción}

29. Si el Box (gimnasio) de CrossFit, cumpliese con las expectativas de compra que ha indicado; ¿Usted se inscribiría en este servicio?

Total de respuestas: 254 .

Si $(100 \%) \quad$ No $(0 \%)$

\section{Filtro De Nivel Socio Económico}

30. ¿Cuál es su grado de instrucción?

Total de respuestas: 254 .

a. Primaria completa $(0 \%)$

b. Primaria incompleta $(0 \%)$

c. Secundaria completa $(5.1 \%)$

d. Secundaria incompleta

e. Superior técnica $(27.6 \%)$

f. Superior técnica incompleta $(2.4 \%)$

g. Universitaria $(54.3 \%)$ 
h. Universitaria incompleta $(5.9 \%)$

i. Post grado $(4.7 \%)$

j. Doctorado $(0 \%)$

31. ¿Actualmente se encuentra trabajando?

Total de respuestas: 254 .

Si $(94.1 \%)$ No $(5.9 \%)$

32. ¿Cuál de estas comodidades posee en su hogar?

Puede señalar hasta 3 opciones

Total de respuestas: 254 .
a. Televisor led $(88 \%)$
b. Laptop (75\%)
c. Refrigeradora (96\%)
d. Cocina $(88 \%)$
e. Lavadora (54\%)
f. Play station $(15 \%)$

33. En caso de emergencia, ¿A dónde acudiría?

Total de respuestas: 254 .
a. Hospital $(77.2 \%)$
b. Clínica $(18.1 \%)$
c. Posta $(1.6 \%)$
d. Doctor particular $(0.4 \%)$
e. Centro de salud municipal $(2.8 \%)$

\section{Datos Personales}

34. En razón a su peso corporal, en qué situación se considera usted:

Total de respuestas: 254 .
a. Falto de peso (3.1\%)
b. Sobrepeso mínimo (52.8\%)
c. Sobrepeso excesivo (20.9\%)
d. Peso ideal $(23.2 \%)$

35. Seleccione el rango de edad a la que usted pertenece Total de respuestas: 254 .

\begin{tabular}{|l|c|}
\hline Entre 14 a 17 años & $0.04 \%$ \\
\hline Entre 18 a 21 años & $1.2 \%$ \\
\hline Entre 22 a 30 años & $47.2 \%$ \\
\hline Entre 31 a 49 años & $44.5 \%$ \\
\hline Entre 50 a 59 años & $6.7 \%$ \\
\hline Entre 60 a 67 años & \\
\hline Entre 68 a más & \\
\hline
\end{tabular}


36. Sexo

Total de respuestas: 254

Masculino (78.7\%) Femenino (21.3\%)

Nombre y apellido:

Email:

Ocupación: 
Apéndice 40: Costo de Mano de Obra Directa

\begin{tabular}{lccccccccc}
\hline \multicolumn{7}{c}{ Mano de obra directa } \\
\hline Descripción & Cantidad & Sueldo & Mensual & $\begin{array}{c}\text { Período } \\
\text { mensual }\end{array}$ & Sub total & $\begin{array}{c}\text { Gratificación } \\
\text { anual }\end{array}$ & CTS & Essalud & Total \\
\hline Head Coach & 1 & 850.00 & 850.00 & 12 & $10,200.00$ & $1,700.00$ & 991.67 & 918.00 & $13,809.67$ \\
Coach & 3 & 550.00 & $1,650.00$ & 12 & $19,800.00$ & $3,300.00$ & 0.00 & $1,782.00$ & $24,882.00$ \\
Fisioterapeuta & 1 & 400.00 & 400.00 & 12 & $4,800.00$ & 800.00 & 0.00 & 432.00 & $6,032.00$ \\
Nutricionista & 1 & 400.00 & 400.00 & 12 & $4,800.00$ & 800.00 & 0.00 & 432.00 & $6,032.00$ \\
\hline Total & 6 & $2,200.00$ & $3,300.00$ & 12 & $39,600.00$ & $6,600.00$ & 991.67 & $3,564.00$ & $50,755.67$ \\
\hline
\end{tabular}

Mano de obra directa mensual

\begin{tabular}{lccc}
\hline \multicolumn{1}{c}{ Descripción } & Sueldo & CTS & $\begin{array}{c}\text { Gratificación } \\
\text { Jul - Dic }\end{array}$ \\
\hline Head Coach & 926.50 & $1,422.33$ & $1,776.50$ \\
Coach & $1,798.50$ & $1,798.50$ & $3,448.50$ \\
Fisioterapeuta & 436.00 & 436.00 & 836.00 \\
Nutricionista & 436.00 & 436.00 & 836.00 \\
\hline Total & $3,597.00$ & $4,092.83$ & $6,897.00$ \\
\hline
\end{tabular}


Apéndice 41: Costo de Mano de Obra Indirecta

\begin{tabular}{|c|c|c|c|c|c|c|c|c|c|}
\hline \multicolumn{10}{|c|}{ Mano de obra indirecta } \\
\hline Descripción & Cantidad & Sueldo & Mensual & $\begin{array}{l}\text { Período } \\
\text { mensual }\end{array}$ & Sub total & $\begin{array}{c}\text { Gratificación } \\
\text { anual }\end{array}$ & CTS & Essalud & Total \\
\hline Limpieza & 1 & 850.00 & 850.00 & 12 & $10,200.00$ & $1,700.00$ & 991.67 & 918.00 & $13,809.67$ \\
\hline
\end{tabular}

Mano de obra indirecta mensual

\begin{tabular}{lccc}
\multicolumn{4}{c}{ Mano de obra indirecta mensual } \\
\hline Descripción & Sueldo & CTS & $\begin{array}{c}\text { Gratificación } \\
\text { Jul - Dic }\end{array}$ \\
\hline Limpeza & 926.50 & $1,422.33$ & $1,776.50$ \\
\hline Total & 926.50 & $1,422.33$ & $1,776.50$ \\
\hline
\end{tabular}




\section{Apéndice 42: Depreciación}

\begin{tabular}{lccc}
\hline \multicolumn{4}{c}{ Depreciación anual $(5$ años) - Activos Fijos Equipos } \\
\hline Año & Activo inicial & Depreciación & Activo Final \\
\hline 1 & $77,881.36$ & $15,576.27$ & $62,305.08$ \\
2 & $62,305.08$ & $15,576.27$ & $46,728.81$ \\
3 & $46,728.81$ & $15,576.27$ & $31,152.54$ \\
4 & $31,152.54$ & $15,576.27$ & $15,576.27$ \\
5 & $15,576.27$ & $15,576.27$ & 0.00 \\
\hline
\end{tabular}

\begin{tabular}{lccc}
\hline \multicolumn{4}{c}{ Depreciación anual (5 años) - Activos Fijos - Muebles y enseres } \\
\hline Año & Activo inicial & Depreciación & Activo final \\
\hline 1 & $31,254.24$ & $6,250.85$ & $25,003.39$ \\
2 & $25,003.39$ & $6,250.85$ & $18,752.54$ \\
3 & $18,752.54$ & $6,250.85$ & $12,501.69$ \\
4 & $12,501.69$ & $6,250.85$ & $6,250.85$ \\
5 & $6,250.85$ & $6,250.85$ & 0.00 \\
\hline \multicolumn{5}{c}{} \\
\hline Año & Activo Inicial & Depreciación anual (5 años) - Ob. Civ. \\
\hline 1 & $24,406.78$ & $4,881.36$ & Activo final \\
2 & $19,525.42$ & $4,881.36$ & $19,525.42$ \\
3 & $14,644.07$ & $4,881.36$ & $14,644.07$ \\
4 & $9,762.71$ & $4,881.36$ & $9,762.71$ \\
5 & $4,881.36$ & $4,881.36$ & $4,881.36$ \\
\end{tabular}

\begin{tabular}{lc}
\hline \multicolumn{2}{l}{ Inversiones en } \\
\hline Monto & Depreciación \\
\hline $133,542.37$ & $26,708.47$ \\
$106,833.90$ & $26,708.47$ \\
$80,125.42$ & $26,708.47$ \\
$53,416.95$ & $26,708.47$ \\
$26,708.47$ & $26,708.47$ \\
\hline
\end{tabular}

